Peter Mendler

\title{
Zur ökonomischen und politischinstitutionellen Analyse öffentlicher Kredithilfen
}




\section{Zur ökonomischen und politischinstitutionellen Analyse öffentlicher Kredithilfen}

Die staatliche Subventionsgewährung erfolgt vielfach in der Form öffentlicher Kredithilfen, die häufig von außerbudgetären Einrichtungen vergeben und finanziert werden. Im Rahmen einer positiven Wirkungsanalyse wird untersucht, wie sich die Individuen an gegebene Kredithilfeprogramme anpassen und welche allokativen und distributiven Konsequenzen daraus resultieren. Um die Entscheidung zugunsten öffentlicher Kredithilfen als Subventionsform und deren verbreitete Realisierung außerhalb des Budgets zu erklären, wird der politische Prozeß in die weitere Analyse einbezogen. Dabei wird insbesondere diskutiert, inwieweit einzelne Gruppen von Subventionsnachfragern und -anbietern durch Kredithilfen und die Einschaltung außerbudgetärer Einrichtungen Verteilungsvorteile zu Lasten der Allgemeinheit erzielen können. Schließlich wird analysiert, wie durch konstitutionelle Regeln mögliche Schäden für die Allgemeinheit aufgrund von Kredithilfen und außerbudgetären Einrichtungen begrenzt werden können.

Peter Mendler wurde 1957 in Kirchheim/Teck geboren. Nach dem Studium der Volkswirtschaftslehre und der Rechtswissenschaft von 1976 bis 1983 an den Universitäten Mainz und Tübingen war er von 1983 bis 1986 Verwaltungsreferendar beim Land Baden-Württemberg. Von 1986 bis 1991 war er als Wissenschaftlicher Mitarbeiter bei Prof. Dr. C. Folkers am Lehrstuhl für Finanzwissenschaft der Universität Hohenheim tätig. Seit März 1991 ist er Mitarbeiter im Wirtschaftsministerium Baden-Württemberg. 
Zur OKonomischen und politisch-Institutionellen Analyse offentlicher Kredithilfen 


\section{Hohenheimer Volkswirtschaftlicheschriften}

\section{Herausgegebenvon}

Prof. Dr. Cay Folkers, Prof.Dr. Harald Hagemann,

Prof.Dr. Klaus Herdzina, Prof.Dr. Renate Ohr, Prof. Dr. Walter Piesch, Prof. Dr.Ingo Schmidt, Prof.Dr. Helmut Walter, Prof.Dr. JosuaWerner $†$

Band 14

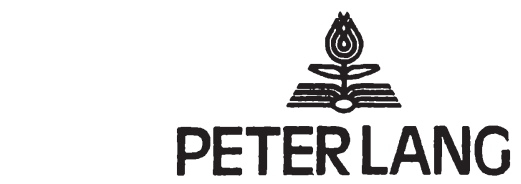

Frankfurt am Main - Bern - New York - Paris 


\section{Peter Mendler}

\section{Zur ökonomischen und politisch- institutionellen Analyse öffentlicher Kredithilfen}

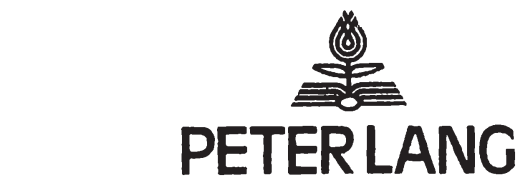

Frankfurt am Main - Bern - New York - Paris 
Die Deutsche Bibliothek - CIP-Einheitsautnahme

Mendler, Peter:

Zur ókonomischen und politisch-institutionellen Analyse

óffentlicher Kredithilfen / Peter Mendler. - Frankfurt am Main ;

Bem ; New York ; Paris : Lang, 1992

(Hohenheimer volkswirtschaftliche Schriften ; Bd. 14)

Zugl.: Hohenheim, Univ., Diss., 1991

ISBN 3-631-44394-3

Open Access: The online version of this publication is published on www.peterlang.com and www.econstor.eu under the international Creative Commons License CC-BY 4.0. Learn more on how you can use and share this work: http://creativecommons. org/licenses/by/4.0.

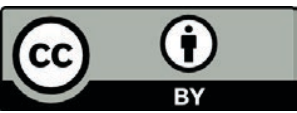

This book is available Open Access thanks to the kind support of ZBW - Leibniz-Informationszentrum Wirtschaft.

NE: GT

\author{
D 100 \\ ISSN 0721-3085 \\ ISBN 3-631-44394-3 \\ ISBN 978-3-631-75549-5 (eBook) \\ (c) Verlag Peter Lang GmbH, Frankfurt am Main 1992 \\ Alle Rechte vorbehalten.
}

Das Werk einschlieBlich aller seiner Teile ist urheberrechtlich geschützt. Jede Verwertung auBerhalb der engen Grenzen des Urheberrechtsgesetzes ist ohne Zustimmung des Verlages unzulāssig und strafbar. Das gilt insbesondere fūr Vervielfältigungen, Übersetzungen, Mikroverfilmungen und die Einspeicherung und Verarbeitung in elektronischen Systemen.

Printed in Germany 134567 


\section{Geleitwort}

Offentliche Kredithilfen stellen eine bedeutsame Form staatlicher Subventionsgewăhrung dar. Waren sie zunăchst primăr zum Ausgleich von Kriegsfolgelasten und zur Beseitigung von Kriegsschăden gedacht, so haben sie sich in der Folgezeit zu wesentlichen Instrumenten der allgemeinen Subventionspraxis entwickelt. Die zu ihrer Begrindung angeführten normativen Argumente können allerdings in den meisten Fällen - wie auch bei anderen Subventionsformen - kaum überzeugen. Vielmehr sind bei realistischer Betrachtung überwiegend Wohlfahrtsverluste, Verfehlungen der intendierten Anreizeffekte und unsystematische Verschiebungen der Verteilungsvorteile von den formal Begünstigten zu anderen Gruppen zu erwarten. Während Kredithilfen unter okonomischen Gesichtspunkten somit als eine wenig vorteilhafte Subventionsform anzusehen sind, bestehen jedoch unter politisch-institutionellen Gesichtspunkten starke Anreize zu ihrem Einsatz. Dabei spielen die Möglichkeiten zur Einschaltung außerbudgetärer Vergabeeinheiten eine nicht zu übersehende Rolle.

Die vorliegende Arbeit enthält neben einer systematischen Darstellung der öffentlichen Kredithilfeaktivităten in der Bundesrepublik Deutschland eine umfassende ökonomische Wirkungsanalyse der allokativen und distributiven Effekte von Kredithilfen und einen geschlossenen Beitrag zur politisch-ökonomischen Frage nach den Bestimmungsgründen für die Wahl dieser Subventionsform und für ihre Realsierung auBerhalb des Budgets. Schließlich widmet sich die Studie der normativ-konstitutionellen Frage, durch welche Vorkehrungen ein Einsatz dieser Subventionsform zu Lasten der Allgemeinheit eingeschränkt und eine mißbräuchliche Verwendung außerbudgetärer Vergabeeinheiten verhindert werden kann. Damit werden sowohl für die wissenschaftliche als auch für die politische Grundsatzdiskussion bemerkenswerte Aspekte aufgezeigt.

Die Arbeit entstand wăhrend der Tătigkeit des Verfassers als Wissenschaftlicher Mitarbeiter am Lehrstuhl für Finanzwissenschaft der Universität Hohenheim. Sie ist Teil eines längerfristigen Forschungsprogramms, das künftig an anderer Stelle fortgeführt wird. Der vorliegende Beitrag legt ein kohärentes Konzept zur Würdigung eines wesentlichen Bereichs öffentlicher Subventionstätigkeit und zur Begründung notwendiger Korrekturmaßnahmen vor. Ich wünsche der Untersuchung, daß sie die Resonanz finden möge, die der ökonomischen und politischen Bedeutung der behandelten Fragen entspricht.

Bochum, im Juli 1991

Cay Folkers 
Peter Mendler - 978-3-631-75549-5

Downloaded from PubFactory at 01/11/2019 03:40:17AM

via free access 


\section{VORWORT}

Die vorliegende Arbeit entstand im Rahmen meiner Tätigkeit als Wissenschaftlicher Angestellter am Lehrstuhl für Finanzwissenschaft der Universität Hohenheim. Mein erster Dank gilt meinem Doktorvater, Herrn Prof. Dr. Cay Folkers, der den Anstoß zu dieser Untersuchung gab und in den schwierigsten Phasen mit wertvollen Anregungen und kritischen Hinweisen wesentlich zum Gelingen der Arbeit beitrug.

Danken möchte ich auch meinen ehemaligen Kollegen Dr. Thomas Märtz, Dipl.oec. Karin Beckmann, Dr. Friedhelm Herb, Dipl.oec. Bernhard Neumärker, Dipl.-Volkswirt Hannes Wirth und Dipl.-Volkswirt Stefan ElBer, die mir stets mit hilfreichen Diskussionen und aufmunternden Worten zur Seite gestanden sind. Für die umfassende technische Hilfe und das gute Betriebsklima danke ich stellvertretend für andere Silke Dahlke, cand.oec. Brigitte Butz, cand.oec. Esther Höhl und Dipl.oec. Frank Ziegele.

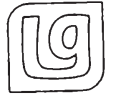

stiftung

Dank gebührt außerdem der LG-Stiftung: Ausbildung, Fort- und WeiterLZB bildung, einer Stiftung der Landesgirokasse Stuttgart, sowie der Landeszentralbank Baden-Württemberg, die mit großzügigen Druckkostenzuschüssen die Veröffentlichung dieser Arbeit gefördert haben.

Gleichfalls danke ich meinen Eltern, die mir im Laufe meiner Ausbildung in vielfältiger Weise geholfen haben. Leider durfte meine Mutter die Fertigstellung dieser Arbeit nicht mehr erleben. Besonderen Dank schulde ich meiner Frau Eva, die mir jahrelang zahlreiche Pflichten abnahm und mich bei der Bewältigung der promotionstypischen Höhen und Tiefen nach Kräften unterstützte. Nur dadurch konnte mein Vorhaben gelingen. Schließlich danke ich meinen Kindern Daniel und Lea, die für das Zustandekommen meiner Dissertation vielleicht die größten Opfer bringen mußten. Ihnen sei diese Arbeit gewidmet. 
Peter Mendler - 978-3-631-75549-5

Downloaded from PubFactory at 01/11/2019 03:40:17AM

via free access 


\section{GLIEDERUNG}

Seite

A. EINLEITUNG 1

I. Problemstellung 1

II. Abgrenzung des Untersuchungsgegenstandes 4

III. Gang der Untersuchung $\quad 6$

B. ÖFFENTLICHE KREDITHILFEN IN DER BUNDESREPUBLIK DEUTSCHLAND

I. Formen öffentlicher Kredithilfen $\quad 8$

1. Schuldendiensthilfen 10

2. Öffentliche Direktdarlehen 11

3. Kreditgewährleistungen 14

a. Kreditbürgschaften 14

b. Kreditgarantien 15

c. Gemeinsamkeiten von Kreditbürgschaften und
-garantien

4. Zahlungswirksamkeit öffentlicher Kredithilfen 19

II. Finanzierungsquellen für öffentliche Kredithilfen 22

1. Die öffentlichen Haushalte $\quad 22$

a. Finanzierung aus allgemeinen Haushaltsmitteln 23

b. Finanzierung aus zweckgebundenen Haushaltsmitteln 23

c. Gemeinschaftsfinanzierung aus Haushaltsmitteln
verschiedener staatlicher Ebenen

2. Außerbudgetäre Sondervermögen 25

a. Sondervermögen des Bundes $\quad 27$

aa. Das ERP-Sondervermögen 27

bb. Der Lastenausgleichsfonds 28

cc. Der Ausgleichsfonds für überregionale Maßnahmen zur Ein$\begin{array}{ll}\text { gliederung Schwerbehinderter in Arbeit, Beruf und Gesellschaft } & 29 \\ \text { Landwirtschaftliche Sondervermögen } & 30\end{array}$

$\begin{array}{ll}\text { dd. Landwirtschaftliche Sondervermögen } & 30 \\ \text { ee. Das Treuhandvermögen für den Bergarbeiterwohnungsbau } & 31\end{array}$

b. Sondervermögen der Länder $\quad 32$

aa. Wohnungsbauvermögen der Länder 32

bb. Sonstige Sondervermögen der Länder 34

3. Außerbudgetäre Kredithilfe-Einrichtungen 35

a. Sonderkreditinstitute $\quad 35$

b. Sonderkreditinstitute des Bundes $\quad 37$

aa. Die Kreditanstalt für Wiederaufbau $\quad 37$

bb. Die Deutsche Ausgleichsbank $\quad 40$

cc. Die Berliner Industriebank AG 41 
c. Sonderkreditinstitute der Länder

aa. Die Landeskreditbank Baden-Württemberg 42

bb. Die Bayerische Landesanstalt für Aufbaufinanzierung 44

cc. Weitere Sonderkreditinstitute der Länder 46

$\begin{array}{ll}\text { d. Träger der Sozialversicherung } & 47\end{array}$

III. Die Bedeutung außerbudgetärer Einheiten bei der Vergabe
öffentlicher Kredithilfen

1. Funktionen der Sondervermögen $\quad 48$

a. Finanzierung eigener Programme 48

b. Bereitstellung liquider Mittel für Zusatzprogramme der
Gebietskörperschaften

2. Funktionen der Sonderkreditinstitute $\quad 50$

a. Durchführung von Kredithilfeprogrammen der
Gebietskörperschaften

b. Finanzierungsbeteiligung bei öffentlichen Kredithilfen 52

c. Eigenfinanzierung öffentlicher Kredithilfen 54

d. Einnahmenerzielung für die Gebietskörperschaften 56

aa. Gewinnabführung an die Gebietskörperschaften 56

bb. Liquidation von Forderungen der
Gebietskörperschaften

3. Funktionen der Sozialversicherungsträger 58

IV. Institutioneller Rahmen für öffentliche Kredithilfen 59

1. Rechtsstaatliche Grundsätze $\quad 59$

2. Begrenzung öffentlicher Kredithilfen durch die
Finanzverfassungen der Gebietskörperschaften

a. Allgemeine Haushaltsgrundsätze $\quad 61$

b. Staatliche Verschuldungsvorschriften $\quad 62$

c. Zuwendungs- und Gewährleistungsvorschriften
der Haushaltsordnungen

3. Spezialregelungen für Sondervermögen 66

4. Spezialregelungen für Sonderkreditinstitute 67

a. Rechtmäßigkeitsvoraussetzungen für die Errichtung
von Sonderkreditinstituten

b. Beschränkungen der Kredithilfevergabe durch
die Errichtungsgesetze der Sonderkreditinstitute

5. Publizitätspflichten in bezug auf öffentliche
Kredithilfen

a. Haushalts- und Wirtschaftspläne als
Publizitätsinstrument

b. Geschäftsberichte der Sonderkreditinstitute
als Publizitätsinstrument

c. Subventionsberichterstattung als Publizitäts-
instrument 
6. Beschränkungen für öffentliche Kredithilfen durch supranationale Regeln

a. EG-rechtliche Beschränkungen für öffentliche Kredithilfen

aa. Beihilfebegriff und Verfahrensrecht

bb. Materielle Beihilferegelungen

75

b. Weitere Beschränkungen öffentlicher Kredithilfen

V. Höhe und Förderzwecke offentlicher Kredithilfen in der Bundesrepublik Deutschland

1. Öffentliche Kredithilfen der Gebietskörperschaften und Sondervermögen

a. Schuldendiensthilfen

aa. Höhe der Ausgaben für Schuldendiensthilfen

bb. Förderzwecke der Schuldendiensthilfen

b. Darlehen

aa. Höhe der Darlehensausgaben

bb. Einnahmen aufgrund von öffentlichen Darlehen

cc. Zinsverbilligungskosten öffentlicher Darlehen

88

dd. Bestand an Darlehensforderungen

91

ee. Förderzwecke öffentlicher Darlehen

c. Gewährleistungen

aa. Das Haftungsvolumen aus öffentlichen Gewährleistungen

bb. Einnahmen und Ausgaben aufgrund von Gewährleistungen

cc. Das Gewährleistungsrisiko

dd. Forderungsbestand aufgrund der Inanspruchnahme aus Gewährleistungen

ee. Förderzwecke der Gewährleistungen

2. Kredithilfen der außerbudgetären Einrichtungen 97

a. Kredithilfen der Sonderkreditinstitute 97

aa. Darlehens-Eigenprogramme 98

bb. Gewährleistungen 100

b. Kredithilfen der Bundesanstalt für Arbeit 101

$\begin{array}{ll}\text { VI. Zusammenfassung } & 102\end{array}$

C. ÖKONOMISCHE ANALYSE ÖFFENTLICHER KREDITHILFEN BEI GEGEBENEN INSTITUTIONELLEN BEDINGUNGEN

I. Der Kreditmarkt als analytischer Ausgangspunkt 107

1. Das Grundmodell des Kreditmarkts 107

a. Der Kreditmarkt ohne Investitionen 108

b. Der Kreditmarkt unter Berücksichtigung von Investitionen 110

2. Kreditmarkt und Kreditversicherungsmarkt bei Unsicherheit 112

a. Das Kreditausfallrisiko 113

aa. Der Kreditmarkt ohne Kreditversicherung 113

bb. Der Kreditversicherungsmarkt 115

b. Das Zinsänderungs- und Liquiditätsrisiko 118 
3. Der Kreditmarkt bei Existenz von Transaktionskosten

4. Kredit- und Kreditversicherungsmarkt bei Informationsunvollkommenheiten

a. Adverse Selektion $\quad 120$

b. Moral hazard $\quad 123$

II. Normative Begründungen öffentlicher Kredithilfen 127

1. Korrektur von allokativem Marktversagen 127

a. Kapitalmarktunvollkommenheiten 128

aa. Monopolistische Tendenzen auf den Kreditmärkten 129

bb. Staatliche Regulierung der Kreditmärkte 130

cc. Fehlende Kreditsicherheiten für einzelne Gruppen
von Kreditnachfragern

dd. Fehlendes Kreditversicherungsangebot 131

ee. Fehleinschätzung von Kreditrisiken 133

ff. Liquiditätsbeschränkungen für bestimmte Kreditnachfrager 135

b. Allokatives Marktversagen auf Gütermärkten 138

aa. Externe Effekte 139

bb. Sinkende Durchschnittskosten 141

cc. Sonstige Marktstörungen 142

2. Reduzierung von Einkommensdisparitäten und Absicherung
sozialer Härtefälle

3. Behebung gesamtwirtschaftlicher Ungleichgewichte 146

4. Kritik: Die Kosten öffentlicher Kredithilfen 147

III. Anreizwirkungen öffentlicher Kredithilfen 149

1. Anstoßwirkungen öffentlicher Kredithilfen $\quad 150$

2. Wirkungen öffentlicher Kredithilfen auf die
Konsumkreditnachfrage

3. Wirkungen öffentlicher Kredithilfen auf die Investitionshöhe 155

a. Wirkungen öffentlicher Kredithilfen bei sicheren
Investitionen

b. Wirkungen öffentlicher Kredithilfen bei riskanten
Investitionen

aa. Risikoneutralität des Investors 157

bb. Risikoaversion des Investors 159

c. Die Bedeutung der institutionellen Bedingungen 159

$\begin{array}{lr}\text { d. Die Berücksichtigung von ökonomischen } & 161 \\ \text { Anpassungsreaktionen } & 162\end{array}$

e. Das Problem der Mitnahmeeffekte 162

4. Wirkungen öffentlicher Kredithilfen auf die Arbeitsnachfrage 168

5. Wirkungen öffentlicher Kredithilfen auf die Risikoübernahme 171

a. Das Investitionsrisiko bei vollständiger Information 171

aa. Risikoneutralität des Investors 171

bb. Risikoaversion des Investors 172 
b. Das Investitionsrisiko bei unvollständiger Information 179

aa. Risikoneutralität des Investors

bb. Risikoaversion des Investors

cc. Einbeziehung von Subventionsmittlern 182

$\begin{array}{ll}\text { dd. Konsequenzen } & 184\end{array}$

6. Kapitalstruktureffekte öffentlicher Kredithilfen 185

a. Kapitalstruktureffekte nach der traditionellen Finanzierungstheorie $\quad 185$

b. Kapitalstruktureffekte bei vollkommenen Kapitalmärkten

c. Kapitalstruktureffekte nach der Agency-Theorie 188

IV. Distributive Wirkungen öffentlicher Kredithilfen 192

1. Der Subventionswert öffentlicher Kredithilfen 192

a. Das Grundkonzept der Subventionswertermittlung 193

b. Praktische Probleme bei der Subventionswertermittlung 194

c. Das Inzidenzkonzept der Subventionswertermittlung 195

2. Die materielle Inzidenz öffentlicher Kredithilfen im Partialmodell 196

a. Die Inzidenz öffentlicher Kredithilfen auf dem Kreditmarkt 196

b. Die Inzidenz öffentlicher Kredihilfen auf dem Kapitalgütersektor $\quad 202$

c. Grenzen der Partialanalyse

3. Differentialinzidenz öffentlicher Kredithilfen im Partialmodell

4. Die materielle Inzidenz öffentlicher Kredithilfen in einem allgemeinen Gleichgewichtsmodell

5. Intertemporale Verteilungswirkungen öffentlicher Kredithilfen 215

V. Zusammenfassung

D. POLITISCH-INSTITUTIONELLE ANALYSE ÖFFENTLICHER KREDITHILFEN

I. Positive Erklärungsansätze für öffentliche Kredithilfen 225

1. Nachfrageseitige Erklärungsansätze für öffentliche Kredithilfen 226

a. Minimierung der Subventionsausgaben durch öffentliche Kredithilfen 228

b. Erzielung von Verteilungsvorteilen durch Kredithilfen bei gegebenem Subventionsvolumen

aa. Entscheidung zwischen Kredithilfen und Investitionszuschüssen $\quad 233$

bb. Entscheidung zwischen Kredithilfen, Investitionszuschüssen und Steuervergünstigungen

cc. Fälligkeit der Subventionsausgaben verschiedener

Subventionsformen zu unterschiedlichen Zeitpunkten

c. Erzielung von Verteilungsvorteilen durch Erhöhung der

Subventionsausgaben bei öffentlichen Kredithilfen

aa. Rationale Ignoranz

bb. Fiskalillusion

d. Erzielung von Verteilungsvorteilen durch öffentliche Kredithilfen

bei dynamischer Betrachtung 
2. Angebotsseitige Erklärungsansätze für öffentliche Kredithilfen 253

a. Anreize der Politiker zur Vergabe von Kredithilfen 254

aa. Kredithilfen als ausgabenminimale Subventionsform $\quad 254$

$\mathrm{bb}$. Begünstigung spezieller Interessengruppen bei gegebenen Subventionsausgaben

cc. Ausdehnung von Kredithilfen aufgrund der Falschwahrnehmung ihrer Kosten

dd. Umgehung fiskalischer Restriktionen

aaa. Umgehung des Gebots eines materiellen Haushaltsausgleichs 260

bbb. Umgehung des Gebots zur Subventionierung mit der ausgabenminimalen Subventionsform

ccc. Umgehung eines Verbots zur Bildung staatlichen

Finanzvermögens

ddd. Umgehung von Restriktionen für die maximale

Subventionsintensität

b. Anreize der Bürokraten zur Vergabe von Kredithilfen 265

aa. Das Angebot von Kredithilfen als ausgabenminimale Subventionsform

bb. Erhöhung der Subventionsausgaben und Administrationskosten durch Kredithilfen

cc. Bestehende Kredithilfe-Einrichtungen

3. Die Synthese nachfrage- und angebotsseitiger Erklärungsansätze für öffentliche Kredithilfen

II. Normative Analyse öffentlicher Kredithilfen aus konstitutioneller Perspektive 269

1. Das Grundkonzept der konstitutionellen Wirtschaftstheorie 271

2. Das Interesse der Allgemeinheit bei Entscheidungen über die Subventionsform

3. Staatliche Verhaltensmuster im konstitutionellen Kalkül der Individuen 274

a. Der Staat als wohlwollender Alleinherrscher 275

b. Der Staat als überschußmaximierender Leviathan 276

c. Der Vergünstigungsstaat 280

d. Die Relevanz alternativer staatlicher Verhaltensmuster
im konstitutionellen Kalkül der Bürger

4. Arten fiskalischer Restriktionen 285

5. Fiskalische Restriktionen für die Vergabe öffentlicher Kredithilfen 286

a. Kredithilfe-Regeln für den Leviathan 287

aa. Verbot der zeitlichen Verschiebung von Subventionsausgaben durch Kredithilfen

bb. Zweckbindung von Kredithilfeeinnahmen 293

b. Regeln für den Vergünstigungsstaat 297

aa. Gebot der ausgabenminimalen Subventionsform 298

bb. Grundsätze für die Abfolge von Subventionsentscheidungen

cc. Beschränkungen für den Erlaß von Kredithilfe-Forderungen $\quad 300$

dd. Beschränkungen für die entgeltliche Veräußerung von Kredithilfe-Forderungen

ee. Anreizmechanismen zur korrekten Abschätzung von Kredithilfe-Risiken

ff. Beschränkungen für Zinsverbilligungen nach der "Methode auf" 304 
gg. Umfassende Publizitätspflicht für Kredithilfen

hh. Bemessung maximaler Subventionsintensitäten an den Subventionsausgaben

ii. Verbot einer Festlegung außerbudgetärer Subventionseinrichtungen auf Kredithilfen

ij. Ergebnisbezogene Restriktionen

III. Positive Erklärungsansätze für außerbudgetäre Einheiten

1. Exkurs: Außerbudgetäre Einheiten aus der Sicht der Gemeinwirtschaftslehre

2. Analytische Grundlagen politisch-ökonomischer Erklärungsansätze für außerbudgetäre Einheiten

3. Die Errichtung außerbudgetärer Einheiten als Strategie zur Erzielung nichtmarktlicher Verteilungsvorteile

a. Erzielung von Verteilungsvorteilen durch die Errichtung von Sondervermögen

aa. Beeinflussung der Wahrnehmung der Kosten beim Aufbau eines staatlichen Forderungsvermögens

bb. Beeinflussung der Wahrnehmung der Bruttoausgaben für öffentliche Kredithilfen

cc. Beeinflussung der Wahrnehmung der Förderintensität öffentlicher Darlehen

dd. Umgehung staatlicher Verschuldungsvorschriften

ee. Schaffung allgemeiner politischer Handlungsspielräume

b. Erzielung von Verteilungsvorteilen durch die Errichtung von

Sonderkreditinstituten

aa. Vorteile aufgrund der Durchführung budgetärer Kredithilfen

bb. Vorteile aufgrund der Finanzierung der Darlehensausgaben staatlicher Kredithilfen durch Sonderkreditinstitute

cc. Vorteile aufgrund von Eigenprogrammen der Sonderkreditinstitute 327

dd. Vorteile aus der Abtretung von budgetären Darlehensforderungen an die Sonderkreditinstitute

ee. Vorteile aus der Schaffung politischer Handlungsspielräume

c. Erzielung von Verteilungsvorteilen durch die Verwendung der Mittel sonstiger außerbudgetärer Einrichtungen zur Finanzierung öffentlicher Kredithilfen

4. Die Errichtung außerbudgetärer Einheiten als konstitutionelle Entscheidung

a. Die Errichtung von Sondervermögen als konstitutionelle Entscheidung

aa. Effizientere Erfüllung staatlicher Aufgaben durch Sondervermögen 333

bb. Sondervermögen als fiskalische Restriktionen

b. Die Errichtung von Sonderkreditinstituten als konstitutionelle Entscheidung

aa. Effizientere Erfüllung staatlicher Aufgaben durch Sonderkreditinstitute

bb. Sonderkreditinstitute als fiskalische Restriktionen

5. Bestehende außerbudgetäre Einheiten - Ergebnis strategischen

Verhaltens oder konstitutionellen Kalküls? 
IV. Normative Analyse außerbudgetärer Einheiten aus konstitutioneller Perspektive

1. Restriktionen für Sondervermögen

a. Beschrănkungen für die Kreditaufnahme von Sondervermögen 352

b. Zeitliche Befristung von Sondervermögen 354

c. Beschrănkungen für die Förderintensităt von Darlehen der Sondervermögen

d. Gebot einer umfassenden Information über Kredithilfen der Sondervermögen

e. Darlegungslast bei der Errichtung von Sondervermögen 358

2. Restriktionen für Sonderkreditinstitute

a. Verbot der Verbilligung von Kredithilfen aus Ertrăgen der Sonderkreditinstitute

b. Informationspflichten bezüglich der Kredithilfeaktivitäten der Sonderkreditinstitute

c. Darlegungs- und Begründungspflichten bei Durchführung staatlicher Kredithilfeprogramme durch Sonderkreditinstitute

d. Regeln zur Stärkung der Eigenstăndigkeit von Sonderkreditinstituten

e. Sonstige Beschränkungen

3. Beschränkungen für die Verwendung der Mittel sonstiger außerbudgetärer Einrichtungen

a. Definition von Eigentumsrechten der Versichertengemeinschaft 365

b. Verbot der nichtmarktlichen Anlage von Rücklagemitteln 365

V. Zusammenfassung 366

E. SCHLUSSBEMERKUNGEN 370

ANHANG 375

LITERATURVERZEICHNIS 393 


\begin{tabular}{|c|c|}
\hline a.A. & anderer Ansicht \\
\hline ABl. & Amtsblatt \\
\hline AFG & Arbeitsförderungsgesetz \\
\hline Anm. & Anmerkung \\
\hline BAFöG & Bundesausbildungsförderungsgesetz \\
\hline $\mathrm{BfA}$ & Bundesanstalt für Arbeit \\
\hline BGBl. & Bundesgesetzblatt \\
\hline $\mathrm{BHO}$ & Bundeshaushaltsordnung \\
\hline BIB & Berliner Industriebank ĂG \\
\hline DAB & Deutsche Ausgleichsbank \\
\hline DEG & $\begin{array}{l}\text { Deutsche Finanzierungsgesellschaft für Beteiligungen in } \\
\text { Entwicklungsländern mbH }\end{array}$ \\
\hline DSLB & Deutsche Siedlungs- und Landesrentenbank \\
\hline EG & Europäische Gemeinschaften \\
\hline EGKSV & $\begin{array}{l}\text { Vertrag über die Gründung der Europäischen Gemeinschaft } \\
\text { für Kohle und Stahl }\end{array}$ \\
\hline EPl. & Einzelplan \\
\hline ERP & European Recovery Programme \\
\hline EuGH & Europäischer Gerichtshof \\
\hline EWGV & $\begin{array}{l}\text { Vertrag zur Gründung der Europäischen Wirtschafts- } \\
\text { gemeinschaft }\end{array}$ \\
\hline Fn. & Fußnote \\
\hline GA & Gemeinschaftsaufgabe \\
\hline GATT & General Agreement on Tariffs and Trade \\
\hline GemHVO/BW & Gemeindehaushaltsverordnung Baden-Württemberg \\
\hline GemO/BW & Gemeindeordnung Baden-Württemberg \\
\hline GVBl. & $\begin{array}{l}\text { Grundgesetz } \\
\text { Gesetz- und Verordnungsblatt }\end{array}$ \\
\hline GVOBl. & Gesetz- und Verordnungsblatt \\
\hline h.M. & herrschende Meinung \\
\hline HGrG & Haushaltsgrundsätzegesetz \\
\hline Hrsg. & Herausgeber \\
\hline i.V.m. & in Verbindung mit \\
\hline Kap. & Kapitel \\
\hline KfW & Kreditanstalt für Wiederaufbau \\
\hline KStG & Körperschaftsteuergesetz \\
\hline LAF & Lastenausgleichsfonds \\
\hline LAG & Lastenausgleichsgesetz \\
\hline LfA & Bayerische Landesanstalt für Aufbaufinanzierung \\
\hline LHO & Landeshaushaltsordnung \\
\hline LKB & Landeskreditbank Baden-Württemberg \\
\hline LKB-FA & Landeskreditbank Baden-Württemberg-Förderungsanstalt \\
\hline LRB & Landwirtschaftliche Rentenbank \\
\hline LTS & Landestreuhandstelle \\
\hline LV & Landesverfassung \\
\hline m.w.N. & mit weiteren Nachweisen \\
\hline NordLB & Norddeutsche Landesbank Girozentrale \\
\hline OECD & Organisation for Economic Co-operation and Development \\
\hline p.a. & per annum \\
\hline $\mathbf{R}$ & ner \\
\hline
\end{tabular}


Rz.

SchwbG

StabWG

u.a.O.

v.H.

v.T.

VV-BHO

VV-LHO
Randziffer

Schwerbehindertengesetz

Gesetz zur Förderung der Stabilität und des Wachstums der Wirtschaft

und andere Orte

vom Hundert

vom Tausend

Vorläufige Allgemeine Verwaltungsvorschriften zur

Bundeshaushaltsordnung

Vorläufige Allgemeine Verwaltungsvorschriften zur 


\section{A. EINLEITUNG}

\section{PROBLEMSTELLUNG}

Subventionen als staatliche Maßnahmen zur Förderung spezieller ökonomischer Aktivitäten besitzen eine lange Tradition, die sich bis in die Zeit des Merkantilismus zurückverfolgen läßt ${ }^{1}$. Im Rahmen einer marktwirtschaftlichen Ordnung sind diese "Instrumente des finanzwirtschaftlichen Interventionismus" ${ }^{2}$ seit jeher stark umstritten. Dies belegen nicht zuletzt die verbreiteten Forderungen nach einem Subventionsabbau, ${ }^{3}$, die in Zeiten offenkundiger Finanznöte des Staates, wie zuletzt im Zusammenhang mit der Finanzierung der deutschen Einheit, in politischen Absichtserklärungen besondere Konjunktur haben ${ }^{4}$. Andererseits ist festzustellen, daß zumindest die absolute Höhe der Subventionsausgaben im Zeitablauf kontinuierlich zunimmt. Daher kann es nicht überraschen, daß das finanzwissenschaftliche Schrifttum zur allgemeinen Subventionsproblematik mittlerweile einen beträchtlichen Umfang erreicht hat ${ }^{5}$.

Neben der allgemeinen Subventionsliteratur gibt es auch zahlreiche Studien, die sich mit speziellen Subventionsformen befassen. Dabei fällt auf, daß öffentliche Kredithilfen, nämlich Schuldendiensthilfen, Darlehen und Gewährleistungen, die allesamt über eine Verbilligung der Fremdkapitalfinanzierung die geförderten Aktivitäten anreizen sollen ${ }^{6}$, im wirtschaftswissenschaftlichen ${ }^{7}$ und im juristischen ${ }^{8}$ Schrifttum eine besondere Resonanz gefunden haben.

Vgl. WEILEPP (1982), S.329; JOOSS (1987), S.286.

ANDEL (1970).

3 Vgl. WEILEPP (1982); FOX/ZEITEL (1984); ALBRECHT/THORMÄLEN (1985), S.73 ff.; V.ARNIM (1986). Siehe auch § 12 Abs.4 StabWG, der den gesetzlichen Auftrag an die Exekutive enthält, periodische Übersichten über den Umfang der Subventionen zu erstellen, ihre Voraussetzungen zu überprüfen und einen Zeitplan für ihren Abbau vorzulegen.

4 Vgl. FOX/ZEITEL (1984), S.865 f.

5 Vgl. z.B. ANDEL (1970); GRÖBNER (1983).

6 In der finanzwissenschaftlichen Literatur wird der Begriff "öffentliche Finanzierungshilfen" teilweise als synonym zum Begriff "öffentlicher Kredithilfen" betrachtet. Vgl. z.B. DICKERTMANN (1980). Dies erscheint jedoch wenig sinnvoll, weil letztlich sämtliche Subventionen einschließlich der Steuervergünstigungen auf eine Erleichterung der Finanzierung der geförderten Aktivitäten gerichtet sind. Vgl. GOLDSCHMIDT (1987), S.17.

7 Vgl. z.B. SAULNIER/HALCROW/JACOBY (1958); BREAK (1961); v.WYSOCKI (1961); FEDERAL CREDIT PROGRAMS (1963); BREAK (1965); CONRAD (1967); RICHTER (1970); SMEKAL (1971); LARKINS (1972); KRAJEWSKI (1975); ZEITEL (1977); DICKERTMANN (1980); CONGRESSIONAL BUDGET OFFICE (1981b); IPPOLITO (1984); DICKERTMANN/HANSMEYER (1987); GOLDSCHMIDT (1987); KLEMP (1990).

8 Vgl. z.B. KRUMING (1955), ROSER (1965), QUELLMALZ (1963), HUISMANS (1971). 
Die vorliegenden ökonomischen Untersuchungen über öffentliche Kredithilfen beschäftigen sich zum einen mit den verschiedenen Varianten der technischen Ausgestaltung von Kredithilfen. Daneben werden schwerpunktmäßig normative und wirkungsanalytische Fragestellungen diskutiert. Allerdings ist erstaunlich, daß trotz der Literaturfülle ein systematischer Überblick zu den positiven Wirkungen öffentlicher Kredithilfen, der auch neuere theoretische Entwicklungen, z.B. in den Bereichen der Informationsökonomie und der Risikotheorie, berücksichtigt, bislang nicht vorhanden ist.

Darüber hinaus ist festzustellen, daß kaum untersucht wird, unter welchen Bedingungen Kredithilfen gegenüber alternativen Subventionsformen vorgezogen werden. Stattdessen wird bisweilen einfach angenommen, daß die "Entscheidung über eine zu wählende Subventionsform (...) durch die Qualität der ökonomischen Schwäche geprägt"1 wird, die nach den Vorstellungen des Subventionsgebers überwunden werden soll. D.h. daß die Erklärung der gewählten Subventionsform auf das objektive Problem ihrer instrumentellen Eignung zur Erfüllung bestimmter Subventionsziele reduziert wird. Diese Argumentation ist jedoch wenig überzeugend, wenn man sich vergegenwärtigt, daß dieselben ökonomischen Aktivitäten in zeitlicher ${ }^{2}$ und räumlicher ${ }^{3}$ Hinsicht mit unterschiedlichen Subventionsformen gefördert werden.

Weiterhin fällt im Zusammenhang mit öffentlichen Kredithilfen auf, daß in ihre Vergabe häufig staatliche Organisationseinheiten eingeschaltet werden, die keinen direkten Bezug zu den Budgets der Gebietskörperschaften aufweisen und daher als außerbudgetäre Einheiten bezeichnet werden können. Zur Erklärung der Beteiligung solcher außerbudgetärer Einheiten bei der Kredithilfevergabe reicht es nicht aus, da $B$ undifferenziert auf Zweckmäßigkeitserwägungen verwiesen wird ${ }^{4}$. Abgesehen davon, daß mit diesem Argument positive und normative Aussagen in unzulässiger Weise vermengt werden, kann damit nicht erklärt werden, weshalb außerbudgetäre Einheiten bei den einzelnen Programmen in unterschiedlichem Ausmaß an der Vergabe öffentlicher Kredithilfen beteiligt sind.

1 DICKERTMANN/DILLER (1989), S.171. Siehe auch DICKERTMANN/DILLER (1986a).

2 Beispielhaft sei erwähnt, daß die Ausbildungsförderung in der Bundesrepublik Deutschland bis Anfang der achtziger Jahre zu einem größeren Teil als Zuschuß, der Rest dagegen als Darlehen gewährt wurde. Danach wurde die Förderung auf Volldarlehen umgestellt.

3 So werden die im Rahmen der Gemeinschaftsaufgabe "Verbesserung der regionalen Wirtschaftsstruktur" verfügbaren Mittel grundsätzlich nur in Form von Investitionszuschüssen vergeben. Das Land Baden-Württemberg nimmt dagegen für sich in Anspruch, im Rahmen seines technischen Ermessensspielraums unter bestimmten Bedingungen statt Zuschüssen zinsverbilligte Darlehen zu vergeben. Vgl. GOLDSCHMIDT (1987), S.165.

4 So aber DEUTSCHER BUNDESTAG (1968), S.104; siehe auch DICKERTMANN (1985), S.170. 
Die positive Erklärung der Wahl von Kredithilfen als Subventionsinstitution und der Beteiligung außerbudgetärer Einheiten an der Kredithilfevergabe gehört damit zu den fehlenden Bausteinen einer umfassenden Subventionstheorie ${ }^{1}$. Diese Lücke ist jedoch zu schließen, weil die Subventionsstruktur ohne die Untersuchung spezieller Subventionsinstitutionen nicht erklärbar ist. Dies ist insoweit problematisch, als erwartet werden kann, daß die Wirkungen und das Ausmaß der Subventionierung ebenso von der Subventionsstruktur abhängen, wie die Steuerstruktur für die Steuerwirkungen und die Höhe des staatlichen Steueraufkommens relevant ist ${ }^{2}$.

Die genannten Fragestellungen zeigen, daß eine umfassende Analyse öffentlicher Kredithilfen der institutionenökonomischen Forschungsrichtung zuzuordnen ist. Dabei kann im Rahmen institutionenökonomischer Analysen generell danach unterschieden werden, ob Institutionen entweder als exogene oder endogene Variablen betrachtet werden ${ }^{3}$. Zum einen ist zu analysieren, wie sich Individuen mit ihrem Verhalten an gegebene Institutionen anpassen. D.h. es ist zu untersuchen, welche Wirkungen zu erwarten sind, wenn der Staat öffentliche Kredithilfen als gegebenes Subventionsinstrument anbietet. Andererseits kann analysiert werden, inwieweit die Entstehung von Institutionen durch individuelle Handlungen beeinflußt wird. Kredithilfen sind danach gegenüber anderen Subventionsformen als alternative Subventionsinstitutionen zu betrachten, die aufgrund individueller Interaktionen gewählt werden. Dabei ist zu berücksichtigen, daß sich die Entscheidungen über Subventionsinstitutionen im Rahmen gegebener, allgemeiner politisch-institutioneller Bedingungen vollziehen, welche den Ablauf von politischen Entscheidungsprozessen wesentlich bestimmen. In entsprechender Weise läßt sich die Errichtung außerbudgetärer Einheiten als institutionelle Entscheidung interpretieren, die Rückwirkungen auf die Art der Finanzierung und Durchführung von Kredithilfeprogrammen besitzt.

Ausgehend von einer positiven Erklärung der Vergabe öffentlicher Kredithilfen ist die Frage zu stellen, ob und unter welchen Bedingungen Entscheidungen für Kredithilfen als Subventionsform und organisatorische Entscheidungen zugunsten außerbudgetärer Einheiten unerwünschte Ergebnisse implizieren können. Unmittelbar damit verknüpft ist das Problem, welche Vorkehrungen aus der Sicht der Bürger und Steuerzahler erforderlich sind, damit solche unerwünschten ökonomischen Ergebnisse vermieden werden können.

1 Dagegen wurden positive Erklärungsansätze für Subventionen allgemein in jüngerer Zeit im Rahmen des Rent-seeking-Ansatzes ausführlich diskutiert. Vgl. z.B. HARTWIG (1990); MÄRTZ (1990) m.w.N.

2 Vgl. dazu BRENNAN/BUCHANAN (1980/1988).

$3 \mathrm{Zu}$ den im Rahmen des institutionenökonomischen Ansatzes zu diskutierenden Fragestellungen vgl. BUCHANAN (1967), S.213 ff. 
Von entscheidender Bedeutung für eine theoretisch konsistente Analyse der institutionenökonomischen Fragestellungen ist die Verwendung eines einheitlichen methodischen Ansatzes. Dabei wird in dieser Arbeit auf den methodologischen Individualismus ${ }^{1}$ zurückgegriffen. Nach diesem Ansatz ist der Mensch als homo oeconomicus zu modellieren, d.h. als ein rationales Wesen, das darauf aus ist, seinen individuellen Vorteil zu maximieren. Dabei wird angenommen, daß sich die Menschen in privaten und öffentlichen Entscheidungssituationen nicht in ihren Motivationen, sondern allein durch die Restriktionen unterscheiden, denen sie bei der Verfolgung ihrer individuellen Ziele jeweils unterworfen $\operatorname{sind}^{2}$. Es kann und soll jedoch nicht behauptet werden, daß dieses Modell zu allen Zeiten und unter allen Umständen menschliches Verhalten zutreffend beschreibt. Aber "the relevant question to ask about the 'assumptions' of a theory is not whether they are descriptively 'realistic', for they never are, but whether they are sufficiently good approximations for the purpose in hand"3. Die Rechtfertigung der Verwendung des Modells des homo oeconomicus ist demnach darin zu sehen, daß es sich zur Erklärung der verschiedensten Phänomene menschlichen Verhaltens als besonders brauchbar erwiesen hat ${ }^{4}$. Dies gilt unabhängig davon, ob ein Individuum als Privatperson oder im Rahmen staatlicher Aktivitäten handelt.

\section{ABGRENZUNG DES UNTERSUCHUNGSGEGENSTANDES}

Den öffentlichen Kredithilfen werden in dieser Arbeit alle Schuldendiensthilfen, Darlehen und Kreditgewährleistungen zugerechnet, die sich unter den Begriff der Subventionen subsumieren lassen. Allerdings besteht trotz ausführlicher Diskussion keine Einigkeit über den geeigneten Subventionsbegriff. Um den Untersuchungsgegenstand nicht unnötig einzuengen, wird die Begriffsabgrenzung hier in extensiver Form vorgenommen. Danach soll von einer Subvention dann gesprochen werden, wenn eine öffentliche Stelle unmittelbar an den privaten Sektor eine nichtmarktliche Leistung vergibt, die den Preis bestimmter Aktivitäten der rechtlichen Leistungsempfänger verbilligt ${ }^{6}$.

\footnotetext{
Vgl. dazu BUCHANAN/TULLOCK (1962), S.11 ff.

2 Vgl. FOLKERS (1986d), S.5.

3 FRIEDMAN (1953), S.15.

4 Vgl. BRENNAN/BUCHANAN (1980/1988), S.19 f.
}

5 Zur Diskussion um den Subventionsbegriff aus ökonomischer und rechtlicher Sicht vgl. z.B. GRÖBNER (1983), S.10 ff.; FOX/ZEITEL (1984), S.866 ff.; JOOSS (1987), S.291 ff. Einer Feststellung von ANDEL (1970), S.4 zufolge tendiert jedoch der Grenzertrag der Diskussion über den Subventionsbegriff gegen Null und ist nicht selten negativ.

$6 \mathrm{Zu}$ einer ähnlichen Definition siehe JOOSS (1987), S.291 ff., der allerdings den Begriff der Leistung nicht im ökonomischen Sinn, sondern in einem engeren juristischen Sinn interpretiert. 
Nach dieser Definition werden hier alle Kredithilfen erfaßt, die von Bund, Ländern und Gemeinden oder sonstigen öffentlichen Einrichtungen an Einzelpersonen oder eine Mehrheit privater Wirtschaftssubjekte vergeben werden. Dabei werden nur solche Schuldendiensthilfen, Darlehen und Kreditgewährleistungen den Kredithilfen zugerechnet, denen keine marktliche Gegenleistung der Empfänger gegenübersteht. D.h. daß beispielsweise Darlehen einer Gebietskörperschaft, die vom Empfänger marktüblich zu verzinsen sind, nicht als Kredithilfen betrachtet werden.

Nichtmarktliche Leistungen werden als Kredithilfen berücksichtigt, wenn sie Unternehmen oder Privatpersonen gewährt werden. Dabei soll es hier nicht darauf ankommen, $o b$ an der Kredithilfevergabe eine oder mehrere öffentliche Stellen finanziell beteiligt sind. Dagegen bleiben Kredithilfen ausgeklammert, die eine staatliche Ebene von einer anderen Ebene erhält, um damit eigene Realausgaben zu finanzieren. Dabei wird es im gegebenen Zusammenhang als unerheblich angesehen, da $B$ die mit Kredithilfen finanzierten Realausgaben einer Gebietskörperschaft mittelbar ihren Bürgern zugute kommen, weil auf diese Weise der Preis für die Bereitstellung öffentlicher Leistungen gesenkt werden kann. Denn solche Finanzbeziehungen zwischen Gebietskörperschaften sind primär ein Problem des fiskalischen Föderalismus, der nicht Gegenstand dieser Arbeit ist. Gleichwohl ist nicht auszuschließen, daß bestimmte Untersuchungsergebnisse dieser Arbeit in gewissen Umfang auf entsprechende Finanzbeziehungen zwischen Gebietskörperschaften übertragen werden könnten.

Aus ökonomischer Sicht entstehen Kreditbeziehungen auch dann, wenn der Gläubiger einer Leistung dem Schuldner die Erfüllung stundet. Werden von der öffentlichen Hand fällige Zahlungsansprüche gegenüber privaten Wirtschaftssubjekten, insbesondere Steueransprüche, unentgeltlich gestundet, könnte man darin ebenfalls eine Kredithilfe sehen $^{1}$. Aufgrund der damit verbundenen rechtlichen Besonderheiten wird jedoch auf eine Diskussion dieser Fallgruppen verzichtet, sofern die Zahlungsansprüche der öffentlichen Hand nicht auf der Vergabe von Kredithilfen beruhen.

Schließlich werden in dieser Arbeit Kredithilfen supranationaler Einrichtungen, wie des Internationalen Währungsfonds, der Weltbank und der Europäischen Investitionsbank, nicht explizit berücksichtigt ${ }^{2}$. Dementsprechend muß offen bleiben, in welcher Weise die folgenden Analysen im Hinblick auf diese supranationalen Einrichtungen zu modifizieren wären.

So z.B. DICKERTMANN (1980), S.52.

Vgl. dazu DICKERTMANN (1980), S.375 ff., 414 ff.; VAUBEL (1990). 


\section{GANG DER UNTERSUCHUNG}

Die vorliegende Untersuchung ist in drei Teile gegliedert. In Kapitel B. wird eine Bestandsaufnahme der Kredithilfeaktivitäten in der Bundesrepublik Deutschland vorgenommen. Anschließend wird in Kapitel C. eine ökonomische Analyse öffentlicher Kredithilfen bei gegebenen institutionellen Bedingungen durchgeführt. In Kapitel D. werden öffentliche Kredithilfen aus politisch-institutioneller Perspektive untersucht.

In Kapitel B. werden zunächst die einzelnen Kredithilfeformen näher betrachtet. Dabei wird auf ihre rechtlichen Merkmale, die technischen Gestaltungsmöglichkeiten sowie ihre Konsequenzen für staatliche Ausgaben und Einnahmen bzw. das staatliche Vermögen eingegangen. Daran anschließend wird dargestellt, welche Quellen zur Finanzierung öffentlicher Kredithilfen bereitstehen. In diesem Zusammenhang wird eine Unterscheidung zwischen budgetären und außerbudgetären Finanzierungsquellen vorgenommen. In einem nächsten Schritt werden die Funktionen außerbudgetärer Einheiten bei der Vergabe öffentlicher Kredithilfen betrachtet. Weiterhin wird der institutionelle Rahmen für öffentliche Kredithilfen untersucht. Dabei geht es vor allem darum, inwieweit bestehende institutionelle Regeln die Möglichkeit zur Vergabe öffentlicher Kredithilfen beschränken. Zum Abschluß von Kapitel B. werden Umfang und Förderzwecke öffentlicher Kredithilfen betrachtet.

In Kapitel C. wird zur Schaffung eines Analyserahmens zunächst ein Modell des Kreditmarkts entwickelt. Dabei werden die Auswirkungen von Unsicherheit, Transaktionskosten und Informationsunvollkommenheiten auf die Kreditzinssätze bzw. die gleichgewichtige Kreditmenge berücksichtigt. In einem nächsten Schritt werden normative Begründungen für öffentliche Kredithilfen analysiert. Daran anschließend wird der Frage nachgegangen, wie sich die Individuen an Kredithilfen als gegebene Subventionsinstitutionen anpassen und welche ökonomischen Wirkungen daraus resultieren. Dabei wird zunächst die Anstoßwirkung von Kredithilfen untersucht. Darüber hinaus wird analysiert, wie Konsum-Kredithilfen die individuellen Konsumentscheidungen beeinflussen. Außerdem werden die Effekte von Kredithilfen auf Investitionsentscheidungen, die Arbeitsnachfrage, die Risikoübernahme und die Kapitalstruktur betrachtet. Daran anschließend werden die Verteilungswirkungen öffentlicher Kredithilfen unter verschiedenen Modellannahmen untersucht.

In Kapitel D. wird die Annahme gegebener institutioneller Bedingungen aufgehoben. Es werden zunächst positive Erklärungsansätze für die Wahl von Kredithilfen als Subventionsform untersucht. Dabei wird angenommen, daß sich die Entscheidungen über die 
Subventionierung bestimmter Aktivitäten und die Entscheidungen über die Form der Subventionierung analytisch trennen lassen. Als wesentliche Bestimmungsfaktoren für die Wahl der Subventionsinstitution der Kredithilfen werden die Interessen verschiedener Gruppen von Nachfragern und Anbietern öffentlicher Leistungen diskutiert. In einem weiteren Schritt wird analysiert, wie der politisch-institutionelle Rahmen gestaltet werden sollte, um zu verhindern, daß Entscheidungen über die Subventionsform im Widerspruch zu kollektiven Interessen getroffen werden. Danach wird untersucht, wie die Einschaltung außerbudgetärer Einheiten in die Kredithilfevergabe zu erklären ist. Abschließend werden verschiedene Regeln diskutiert, die verhindern sollen, daß sich einzelne Gruppen durch die Existenz außerbudgetärer Einheiten auf Kosten der Allgemeinheit Vorteile verschaffen, ohne daß dadurch wünschenswerte Effekte außerbudgetärer Einheiten beeinträchtigt werden. 


\section{B. ÖFFENTLICHE KREDITHILFEN IN DER BUNDESREPUBLIK DEUTSCHLAND}

Öffentliche Kredithilfen spielen seit Beginn der deutschen Nachkriegsgeschichte eine bedeutsame Rolle. Einen wesentlichen Markstein bildet dabei die Schaffung des ERPSondervermögens, das von Anfang an für die Vergabe zinsverbilligter öffentlicher Darlehen zur Förderung der deutschen Wirtschaft verwendet wurde. Öffentliche Kredithilfen größeren Ausmaßes wurden frühzeitig auch zum Ausgleich von Kriegsfolgelasten und zur Förderung des Wohnungsbaus vergeben. Darüber hinaus gab es in den fünfziger Jahren zahlreiche weitere öffentliche Kredithilfeprogramme ${ }^{1}$. Die Gesamtzahl solcher Programme wird für 1958 mit weit über 500 angegeben ${ }^{2}$. Öffentliche Kredithilfen haben indes in den darauffolgenden Jahrzehnten offenkundig nichts von ihrer Attraktivität eingebüßt, wie Übersichten der existierenden Subventionsprogramme in der Bundesrepublik zeigen ${ }^{3}$.

Ziel dieses Kapitels ist es, die öffentlichen Kredithilfeaktivitäten in der Bundesrepublik Deutschland systematisch zu erfassen. Dabei ist zunächst zu klären, welche Arten öffentlicher Kredithilfen in der Bundesrepublik Deutschland gewährt werden. In einem nächsten Schritt wird dargestellt, welche Finanzierungsquellen für öffentliche Kredithilfen vorhanden sind. Danach werden die Funktionen außerbudgetärer Einheiten bei der Vergabe öffentlicher Kredithilfen aufgezeigt. Im darauffolgenden Abschnitt wird der institutionelle Rahmen für öffentliche Kredithilfen dargelegt. Zum Abschluß dieses Kapitels werden Umfang und Förderzwecke öffentlicher Kredithilfen betrachtet.

\section{FORMEN ÖFFENTLICHER KREDITHILFEN}

Als öffentliche Kredithilfen werden in dieser Arbeit alle Maßnahmen öffentlicher Stellen bezeichnet, die auf eine Begünstigung der Kreditfinanzierung des privaten Konsums oder privater Investitionen abzielen.

Im juristischen Schrifttum besteht weitgehende Einigkeit darüber, daß Kredithilfen - wie andere Subventionen auch - nur vergeben werden dürfen, wenn sie der Erfüllung eines bestimmten Zwecks dienen ${ }^{4}$, weil es sich verbiete, "zwangsweise eingezogene Abgaben

$1 \mathrm{Zu}$ den bedeutendsten öffentlichen Kredithilfemaßnahmen in den ersten Nachkriegsjahren vgl. ausführlich KRUMING (1955), S.4 ff.

2 Vgl. SCHNEIDER-GÄDICKE (1963), S.16 ff.

3 Vgl. DITTES (1989).

4 Eine eindeutige Begriffsabgrenzung des relevanten Subventionszwecks steht allerdings aus. Zur Diskussion um die verschiedenen Abstufungen des Subventionszweck-Begriffs vgl. SCHETTING (1973), S.9 ff.; VOGEL (1977); HENKE (1979), S.71 ff. Diese oftmals wenig ver- 
beliebig zu verschenken"1. Dabei wird zwischen einem Endzweck und einem Primärzweck unterschieden, wobei ersterer dem angestrebten öffentlichen Erfolg entspricht, wohingegen der Primärzweck als "Nahziel (...) auf dem Weg zum Endzweck"2 betrachtet wird, der vom Leistungsempfänger, dem im rechtlichen Sinn Begünstigten, zu erfüllen ist. Wenn dies geschehen ist, fehlt danach "zur Verwirklichung des Endzwecks nur noch der Ablouf, so wie er den tatsächlichen oder mutmaßlichen Sachgesetzlichkeiten entspricht" ${ }^{3}$. Allerdings mangelt es an juristischen Kriterien zur Beurteilung, inwieweit die Erfüllung des Primärzwecks zur Erreichung des Endzwecks geeignet ist ${ }^{4}$. Gleichwohl ist eine dem Primärzweck entsprechende Verwendung der Kredithilfe eine der Hauptpflichten jedes Empfängers ${ }^{5}$. Zur Sicherung des Primärzwecks enthält die Vergabeentscheidung in der Regel verschiedene "Auflagen"6. Besondere Bedeutung haben dabei die Verwendungsauflagen, die bei Investitions-Kredithilfen überwiegend in Form von Investitionsauflagen auftreten ${ }^{7}$. Weiter sind Auskunfts- und Aufklärungspflichten sowie die Pflicht zur Duldung von Kontrollen einer zweckgerichteten Mittelverwendung als übliche Auflagearten zu nennen ${ }^{8}$.

Ein Rechtsanspruch auf eine Kredithilfe besteht nur, wenn dies ausdrücklich gesetzlich bestimmt ist. In der ganz überwiegenden Mehrzahl der Fälle gibt es hingegen lediglich einen Anspruch auf ermessensfehlerfreie Entscheidung des Kredithilfegebers ${ }^{9}$. Dabei kann eine ablehnende Entscheidung des Kredithilfegebers z.B. ermessensfehlerfrei auf die Erschöpfung der für das entsprechende Programm bereitstehenden Haushaltsmittel gestützt werden, sofern die Verteilung der Mittel dem Gleichheitssatz genügt ${ }^{10}$.

ständliche Diskussion legt nahe, daß die Einschätzung von ZACHER (1967), S.318, daß nämlich der öffentliche Zweck das "Geheimnis der Subventionierung" darstelle, gerade auch aus juristischer Sicht heute noch aktuell ist.

IPSEN (1967), S.293. Zum Schenkungsverbot für den Staat siehe auch JOOSS (1987), S.298 m.w.N.

2 SCHETTING (1973), S.13.

3 SCHETTING (1973), S.13.

4 Dieser ungeklärte Zusammenhang scheint in der juristischen Literatur bisweilen einfach unterstellt zu werden, wenn beispielsweise argumentiert wird, daß die "Summe aller (realisierten) Primärzweckelemente (...) den (realisierten) Endzweck" ergäbe. Siehe SCHETTING (1973), S.8.

5 Vgl. dazu grundlegend SCHETTING (1973), S.129 ff.

6 Dabei handelt es sich um Auflagen im rechtstechnischen Sinn nur, wenn die Vergabeentscheidung durch Verwaltungsakt getroffen wird.

7 Vgl. HANSMEYER (1977), S.969.

8 Vgl. HENKE (1979), S.256 ff.; JOOSS (1987), S.290; DICKERTMANN/DILLER (1989), S.169. Zahlreiche Einzelbeispiele enthält SCHNEIDER-GÄDICKE (1963), S.100 ff.

9 Vgl. HENKE (1979), S.138 ff.; STOBER (1987), S.120 f.

10 Ein rechtlich zulässiges Vergabeverfahren beschränkter Haushaltsmittel ist u.a. das sog. Windhundverfahren, nach dem die Vergabe der verfügbaren Mittel gemäß der Reihenfolge des Antragseingangs erfolgt. Vgl. IPSEN (1967), S.283; HENKE (1979), S.107 f.; siehe dazu auch DICKERTMANN/DILLER (1989), S.169. 
Die Gewährung von öffentlichen Kredithilfen setzt, wie im Bereich der Leistungsverwaltung üblich, eine Mitwirkung des Leistungsempfängers voraus ${ }^{1}$. Dies gilt beim Gebrauch öffentlichrechtlicher Handlungsformen, also eines Verwaltungsaktes bzw. eines öffentlichrechtlichen Vertrages ${ }^{2}$, und privatrechtlicher Verträge gleichermaßen ${ }^{3}$.

Aus der Sicht der Leistungsempfänger lassen sich drei Grundformen öffentlicher Kredithilfen unterscheiden: Schuldendiensthilfen, öffentliche Direktdarlehen sowie Kreditgewährleistungen ${ }^{4}$. Diese Formen sollen im folgenden näher betrachtet werden. In einem gesonderten Abschnitt wird auf die Zahlungswirksamkeit öffentlicher Kredithilfen und die damit verbundenen Nettoausgaben eingegangen.

\section{Schuldendiensthilfen}

Schuldendiensthilfen in Form von Zins- bzw. Tilgungszuschüssen zeichnen sich dadurch aus, daß der Zuschußgeber dem Empfänger über mehrere Perioden hinweg oder bei kapitalisierten Zuschüssen einmalig einen bestimmten Geldbetrag endgültig gewährt, um ihn von den aufgrund eines privaten Kreditverhältnisses zu leistenden Schuldendienstzahlungen zu entlasten. Der private Kredit wird vom Kreditgeber zu marktüblichen Bedingungen vergeben ${ }^{5}$. Dabei werden grundsätzlich nur Kredite von Kreditinstituten bezuschußt ${ }^{6}$.

1 Es gilt der Grundsatz: "Omnis subventio est voluntaria." D.h. daß eine Zwangssubventionierung rechtlich nicht zugelassen ist. Siehe IPSEN (1967), S.293; HENKE (1979), S.160.

2 Dabei geht die h.M. davon aus, daß die Vergabe von Kredithilfen grundsätzlich mittels Verwaltungsakt erfolgt. Vgl. EHLERS (1983), S.112 ff.; JARASS (1984b), S.198; OLDIGES (1984), S.1932; MAURER (1986), S.357. A.A. SCHETTING (1973), 313 ff.; HENKE (1979), S.44, die darauf abstellen, daß bei öffentlichen Kredithilfen die Konstellation eher so sei, wie sie für Verträge typisch ist.

3 Die h.M. in Lehre und Rechtsprechung anerkennt ein Wahlrecht der subventionierenden Stelle zwischen privat- und öffentlichrechtlichen Handlungsformen, vgl. KNIRSCH (1984), S.496; STOBER (1987), S.126; BUNDESVERFASSSUNGSGERICHT (1964), S.97; BUNDESVERFASSSUNGSGERICHT (1975), S.284 f. Kritisch bezüglich der privatrechtlichen Handlungsalternative sind demgegenüber EHLERS (1983), S.114. m.w.N. und MAURER (1986), S.355.

4 Dabei ist zu beachten, daß beispielsweise nicht alle in den öffentlichen Haushalten ausgewiesenen Schuldendiensthilfen den Leistungsempfänger auch in dieser Form erreichen, weil sie vielfach an Dritte gewährt werden, die in die Kredithilfevergabe eingeschaltet werden und die die Schuldendiensthilfen zur Zinsverbilligung für Darlehen an die Leistungsempfänger einsetzen. Auf diesen Zusammenhang wird an anderer Stelle näher eingegangen.

5 Dies schließt jedoch nicht aus, da $\beta$ die privaten Kreditanbieter unter sonst gleichen Bedingungen für die subventionierten Kredite einen höheren Bruttozinssatz durchsetzen können als bei nichtsubventionierten Krediten. Vgl. TSCHEBULL (1988), S.22 f.

6 Vgl. SCHETTING (1973), S.53. 
Bei Zinszuschüssen, dem Regelfall der Schuldendiensthilfen, lassen sich hinsichtlich der Zuschußhöhe zwei verschiedene Methoden unterscheiden. Nach der ersten wird der Zuschuß so festgesetzt, daß sich der Kreditzinssatz um eine bestimmte Anzahl von Prozentpunkten reduziert. Nach der anderen Methode wird ein Prozentsatz festgelegt, auf den der Zinssatz verbilligt wird ${ }^{1}$.

Der zuschußfähige Kredit und damit auch die absolute Höhe des Zuschusses ist bei Schuldendiensthilfen häufig betragsmäßig begrenzt. Außerdem ist in manchen Fällen die Zuschußperiode kürzer als die Kreditlaufzeit ${ }^{2}$. Vielfach werden Schuldendiensthilfen nicht direkt an den Empfänger, sondern an die kreditgebende Hausbank ${ }^{3}$ ausbezahlt. Die als Subventionsmittler ${ }^{4}$ tätige Hausbank rechnet den ausbezahlten Zuschuß gegen ihre Darlehensforderungen auf, so daß sich die Verpflichtungen des Schuldners entsprechend reduzieren. Um die "Weitergabe" der Schuldendiensthilfe auf diesem Weg sicherzustellen, ist in diesen Fällen zusätzlich eine direkte Rechtsbeziehung zwischen dem Zuschußgeber und der Hausbank notwendig, die regelmäßig privatrechtlich ausgestaltet ist ${ }^{5}$.

\section{2. Öffentliche Direktdarlehen}

Bei Direktdarlehen wird der Kreditbetrag nicht durch einen privaten Kreditgeber, sondern durch eine öffentliche Stelle selbst zur Verfügung gestellt. Dadurch entstehen für den Empfänger des Kredits Zahlungsverbindlichkeiten gegenüber dem öffentlichen Kreditgeber ${ }^{6}$. Sie bestehen einmal in der Verpflichtung, den Darlehensbetrag zurückzuzahlen. Zum anderen sind an den Kreditgeber regelmäßig Zinsen zu entrichten.

Typischerweise ist der Zinssatz bei öffentlichen Darlehen niedriger als der Marktzinssatz für Kredite zur Finanzierung entsprechender Aktivitäten bei sonst gleichen Kreditkonditionen. Die Höhe dieser "Zinsverbilligung" reduziert sich zum Teil während der Kreditlaufzeit ${ }^{7}$. Teilweise entfällt die Zinszahlungspflicht auch ganz. Eine besondere Form

\footnotetext{
1 Vgl. SCHETTING (1973), S.117; DICKERTMANN/HANSMEYER (1987), S.41 f.
}

2 Vgl. SCHETTING (1973), S.118 f.

3 Zum Begriff der Hausbank grundlegend MENZEL (1960), S.23 ff.

4 Als Subventionsmittler werden alle an der Begründung und Abwicklung von Subventionsverhältnissen mit eigenen Rechten und Pflichten beteiligte Dritte bezeichnet, die nicht Partei des Subventionsverhältnisses sind. Zur Begriffsabgrenzung und den verschiedenen Ausprägungen der Subventionsvermittlung siehe HENKE (1979), S.85 ff.

5 Vgl. SCHETTING (1973), S.56; JOOSS (1987), S.300 f.

6 Dies gilt allgemein bei wirtschaftlicher Betrachtungsweise, nicht aber zwangsläufig im rechtlichen Sinn, weil bei Direktdarlehen häufig Dritte zur Weiterleitung der Darlehen an den Kredithilfenehmer eingeschaltet werden.

7 So sehen die Landeswohnungsbauprogramme in Baden-Württemberg regelmäBig Förderdarlehen mit zehn- bis zwölfjähriger Laufzeit vor, für die im ersten Jahr eine Zinsverbilligung 
der Zinsverbilligung liegt vor, wenn bei Eintritt bestimmter Bedingungen lediglich ein Bruchteil der Darlehenssumme zurückzuzahlen ist. Sofern das Darlehen nominal zinslos vergeben wird, ist eine derartige Umwandlung eines Teils des Darlehens in einen sogenannten verlorenen Zuschuß einer Negativverzinsung des Darlehens äquivalent ${ }^{1}$.

Bei der Gestaltung der sonstigen Kreditkonditionen läßt sich bei öffentlichen Darlehen eine ähnliche Vielfalt wie bei privaten Kreditverträgen beobachten. Hier wie dort ist die Vereinbarung von Kreditnebenkosten wie Disagios, Verwaltungskostenbeiträgen und Bearbeitungsgebühren verbreitet. Die Laufzeiten öffentlicher Darlehen sind in der Regel länger als für vergleichbare private Darlehen. Darüber hinaus sind die Tilgungsregelungen für den Kreditnehmer meist relativ günstig. So werden häufig Tilgungsfreijahre eingeräumt. Außerdem ist in vielen Fällen eine vorzeitige Darlehenstilgung möglich².

An die Besicherung öffentlicher Darlehen werden meist geringere Anforderungen gestellt als bei einem entsprechenden privaten Kredit. So werden vielfach vergleichsweise riskante Besicherungsformen, wie Gehaltsabtretungen, akzeptiert. Teilweise wird auf jede Form der Besicherung verzichtet. In anderen Fällen ist hingegen eine bankübliche Absicherung vorgeschrieben, die insbesondere über dingliche Sicherheiten, aber auch über öffentliche Bürgschaften erfolgen kann ${ }^{3}$.

Die Höhe öffentlicher Darlehen ist auf eine Teilfinanzierung des damit geförderten Vorhabens beschränkt, sofern es sich dabei um Zuwendungen im Sinne des § 44 BHO/ LHO $^{4}$ handelt ${ }^{5}$. Danach hat sich der Kreditnehmer in angemessenem Umfang mit Eigenmitteln und anderen Fremdfinanzierungsmitteln an der Gesamtfinanzierung des Vorhabens zu beteiligen ${ }^{6}$. Um sicherzustellen, daß zur Finanzierung des Vorhabens über das öffentliche Darlehen hinaus auch andere Mittel eingesetzt werden, enthalten die Vergabebedingungen regelmäßig Bestimmungen über den maximalen Betrag und/oder den maximalen Finanzierungsanteil des öffentlichen Darlehens ${ }^{7}$.

um 5 Prozentpunkte gewährt wird, die dann schrittweise auf 0,5 bis 1 Prozentpunkt im letzten Jahr der Kreditlaufzeit zurückgeführt wird. Vgl. INNENMINISTERIUM BADENWÜRTTEMBERG (1989), S.56 f.

1 Dies gilt beispielsweise für die zinslosen BAFöG-Darlehen, wo unter der Bedingung eines vorzeitigen und überdurchschnittlich guten Studienabschlusses ein teilweiser Darlehenserlaß gewährt wird. Vgl. § $18 \mathrm{~b}$ BAFöG.

2 Vgl. ZEITEL (1977), S.1005. Eine Auflistung der Kreditkonditionen verschiedener öffentlichen Darlehen enthält DICKERTMANN (1980), S.260 ff.

3 Vgl. ZEITEL (1977), S.1005; DICKERTMANN (1980), S. 264.

4 Zum haushaltsrechtlichen Zuwendungsbegriff vgl. GÜNDISCH (1984), S.489 f.

5 Vgl. Nr. 2 VV-LHO zu \& 44 Abs.1.

6 Vgl. MENZEL (1960), S.111; v.WYSOCKI (1961), S.52 f.

7 Vgl. HENKE (1979), S.230; DICKERTMANN (1980), S.259. 
Sofern öffentliche Darlehen über die Hausbanken an die Endkreditnehmer ausgereicht werden, sind erstere Darlehensschuldner des öffentlichen Kreditgebers und haben unter voller oder teilweiser Primärhaftung dem Endkreditnehmer einen zweckgebundenen Kredit zu gewähren, ohne da $\beta$ ihnen jedoch die positive Kreditauswahl zusteht ${ }^{1}$. Da die Hausbanken für die Kredite haften müssen, können sie Förderanträge aus Risikogründen

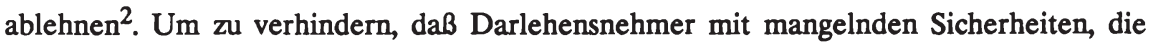
jedoch gefördert werden sollen, bei der Kreditwürdigkeitsprüfung der Hausbank scheitern, werden die Risiken der Hausbanken häufig durch öffentliche Bürgschaften abgesichert, die in der Regel bis zu $90 \%$ eines möglichen Ausfalls decken ${ }^{3}$. Als Entgelt für die Kreditabwicklung und die Risikoübernahme werden den Hausbanken vom öffentlichen Kredithilfegeber Zinsmargen eingeräumt, die sich üblicherweise zwischen $0,5 \%$ und $1 \%$ p.a. bewegen ${ }^{4}$.

Die Vergabe von Darlehen erfolgt in unterschiedlichen rechtlichen Formen. Die BAFöG-Darlehen werden beispielsweise durch Verwaltungsakt gewährt, der mit einer Rückzahlungsauflage verbunden ist ${ }^{5}$. Andererseits ist teilweise gesetzlich vorgeschrieben, daß der Vergabe öffentlicher Darlehen ein zweistufiges Verfahren zugrundeliegt. Dabei wird auf der ersten Stufe mittels Verwaltungsaktes eine Entscheidung über das $O b$ der Leistung getroffen, während auf der zweiten Stufe durch privatrechtlichen Vertrag das Wie der Leistung geregelt wird ${ }^{6}$. In anderen Fällen ist die Handlungsform bei der Darlehensvergabe von der kreditgebenden Stelle nach pflichtgemäßem Ermessen zu bestimmen. Wenn Banken als Subventionsmittler dazwischengeschaltet sind, entsteht ein rechtliches Dreiecksverhältnis, in dem die Beziehungen zwischen Kreditgeber und Endkreditnehmer in aller Regel durch einen Verwaltungsakt gestaltet werden, während die Beziehungen des

1 Vgl. SCHETTING (1973) S.81.

2 Vgl. MENZEL (1960), S. 98 ff., S.140 ff.; SCHNEIDER-GÄDICKE (1963), S.94 ff; DICKERTMANN (1980) S.276 f.

3 Empirische Untersuchungen zeigen, daß bei Existenzgründungsdarlehen ein Drittel der Endkreditnehmer zusätzlich eine öffentliche Bürgschaft in Anspruch nehmen muB, da andernfalls die Kreditvergabe durch die Hausbank aus Bonitätsgründen scheitern würde. Vgl. GOLDSCHMIDT (1987), S.67.

Vgl. GOLDSCHMIDT (1987), S.207. Etwas höhere Zahlen nennt MENZEL (1960), S.194.

5 Vgl. § 39 Abs.2 BAFöG i.V.m. § 10 Darlehensverordnung.

6 Vgl. hierzu $\S 102$ Zweites Wohnungsbaugesetz und Nr. 2.4 VV-LHO zu $\$ 44$ Abs.1. Ein solches zweistufiges Vergabeverfahren wird von den Vertretern der sogenannten Zweistufentheorie auch beim Fehlen entsprechender gesetzlicher Vorschriften gefordert. Diese Position wird jedoch zunehmend angegriffen, weil öffentlichrechtliche Bindungen der staatlichen Stellen bei der Vergabe von Darlehen auch ohne diese komplizierte Konstruktion gewährleistet sind. Zur Diskussion um die Zweistufentheorie vgl. ROSER (1965), S.39 ff.; EHLERS (1983), S 116 ff.; JARASS (1984b), S.200; MAURER (1986), S.350 ff. m.w.N. 
Subventionsmittlers mit dem Kreditgeber und dem Endkreditnehmer privatrechtlicher Natur sind ${ }^{1}$.

\section{Kreditgewährleistungen}

Der Begriff der Gewährleistungen wird als Sammelbegriff für verschiedene Arten öffentlicher Haftungszusagen verwendet. Das gemeinsame Kennzeichen der Kreditgewährleistungen ist die öffentliche Risikoübernahme im Zusammenhang mit Kreditverhältnissen ${ }^{2}$, indem der Gewährleistungsübernehmer gegenüber dem -gläubiger eine bedingte Verpflichtung übernimmt. Damit sind Kreditgewährleistungen Formen der Kreditversicherung ${ }^{3}$. Die wichtigsten Kategorien sind die Bürgschaft und die Garantie. Zu den sonstigen Gewährleistungen gehört der Kreditauftrag, bei dem der Auftraggeber dem Beauftragten für die Erfüllung der Verbindlichkeiten des Kreditschuldners haftet ${ }^{4}$. Wegen seiner relativ geringen Bedeutung soll der Kreditauftrag im folgenden unberücksichtigt bleiben. Dies gilt aufgrund der Thematik dieser Arbeit prinzipiell auch für Gewährleistungen, die keine Kreditrisiken abdecken ${ }^{5}$, wenngleich eine scharfe Abgrenzung gegenüber Kreditgewährleistungen nicht immer möglich ist.

\section{a. Kreditbürgschaften}

Durch eine Kreditbürgschaft verpflichtet sich der öffentliche Bürge entprechend der Regelung des $§ 765$ Abs.1 BGB gegenüber dem Gläubiger eines Kreditschuldners für die Erfüllung von dessen Verbindlichkeiten aus einem Kreditverhältnis einzustehen. Im Schadensfall ist der Bürge damit zur Leistung gegenüber dem Kreditgläubiger verpflichtet.

Wesentliches Merkmal der Bürgschaft ist die Akzessorietät zur abgesicherten Darlehensforderung. Damit ist die Bürgschaft von Bestehen und Umfang der Darlehensforderung dauernd abhängig und geht mit deren Erfüllung unter ${ }^{6}$. Die Kreditbürgschaft setzt außer der meist öffentlichrechtlichen Rechtsbeziehung zwischen Bürge und Kreditschuldner, der im rechtlichen Sinn Leistungsempfänger ist, zwei weitere Rechtsgeschäfte voraus. Einmal muß ein privater Kreditvertrag vorliegen, wobei nur Kredite von

\footnotetext{
Vgl. EHLERS (1983), S.118; JARASS (1984b), S.200 f.; MAURER (1986), S.356.

Vgl. PIDUCH (1990), Anm. 21 zu Art.115 GG.

Vgl. EISEN (1979), S.24 f.

4 Vgl. PIDUCH (1990), Anm. 21 zu Art.115 GG.

5 Beispiele dafür sind insbesondere bestimmte Arten von Garantien, wie Fabrikationsrisiko-, Preis- oder Währungsgarantien. Vgl. hierzu SCHETTING (1973), S.45 ff.

6 Vgl. THOMAS (1989), Einführung vor $\$ 765$, Anm.1 e).
} 
Kreditinstituten verbürgt werden ${ }^{1}$. Zum anderen muß der Bürge mit dem Gläubiger des Hauptschuldners, regelmäßig der Hausbank, einen Bürgschaftsvertrag abschließen, welcher in aller Regel privatrechtlicher Natur ist.

Eine Sonderform der öffentlichen Kreditbürgschaft ist bei der Rückverbürgung von Kreditbürgschaften privater Einrichtungen durch öffentliche Stellen gegeben. Hier kommt zu den drei genannten Rechtsverhältnissen ein weiteres zwischen dem Bürgen und dem Rückbürgen hinzu. Eine direkte Rechtsbeziehung des Rückbürgen zu den beiden Seiten des privaten Kreditvertrags existiert dabei nicht ${ }^{2}$.

Kreditbürgschaften werden in der Regel als modifizierte Ausfallbürgschaften vergeben. Gegenüber der reinen Ausfallbürgschaft zeichnen sie sich dadurch aus, daß ein Ausfall, der die Leistungspflicht des Bürgen aufleben läßt, nicht erst nach Erhebung der Vorausklage gegen den Hauptschuldner und fruchtloser Vollstreckung in dessen Vermögen, sondern bereits dann angenommen wird, wenn der Hauptschuldner die Zahlungen eingestellt hat und Eingänge aus der Verwertung von Kreditsicherheiten oder sonstigen Vermögens nicht mehr zu erwarten sind ${ }^{3}$.

\section{b. Kreditgarantien}

Bei der Kreditgarantie wird durch den Garanten das Risiko eines Kreditschuldners, der Garantienehmer ist, abgesichert. Dabei verpflichtet sich der Garant, für einen bestimmten Erfolg einzustehen. Der Garantienehmer hat im Schadensfall Zahlungsansprüche gegenüber dem Garanten. Der Garantie fehlt demnach das bürgschaftstypische Dreiecksverhältnis ${ }^{4}$. Dementsprechend erfolgt die Übernahme von Garantien in der Regel durch einen einheitlichen Rechtsakt, sei es nun ein Verwaltungsakt oder ein öffentlichrechtlicher Vertrag ${ }^{5,6}$. Weiterhin ist es, ebenfalls anders als bei Kreditbürgschaften,

1 Vgl. SCHETTING (1973), S.58.

2 Diese Konstellation ist in der Bundesrepublik vor allem bei Bürgschaften der Kreditgarantiegemeinschaften von Bedeutung. Vgl. dazu SCHULZ (1970); REINERMANN (1976); DICKERTMANN (1980), S.283 ff.; BECKER, H. (1980); GOLDSCHMIDT (1987), S.101 ff; JOOSS (1987), S.304. Siehe auch unten Abschnitt B.II.3.

3 Vgl. SCHETTING (1973), S.126.

4 Vgl. CONRAD (1967), S. 85; HENKE (1979), S.218 f., 236.

5 Vgl. EHLERS (1983), S.119; JARASS (1984b), S.201; MAURER (1986), S.357 f.

6 Bei Ausfuhrgarantien ist allerdings eine der Übernahmeentscheidung vorgelagerte "grundsätzliche Stellungnahme" des Bundes üblich, die die rechtlich verbindliche Zusicherung enthält, bei unveränderter Sach- und Rechtslage positiv über die beantragte Gewährleistung zu entscheiden. Vgl. v.SPIEGEL (1984), S.2007 f. 
grundsätzlich möglich, daß der Garant seine Haftung auf bestimmte Teilrisiken beschränkt und die restlichen Risiken beim Garantienehmer verbleiben ${ }^{1}$.

Obwohl es der öffentlichen Garantie an der Akzessorietät zu einer Darlehensforderung fehlt, steht sie doch häufig in direktem Zusammenhang mit einem Kreditvertrag, indem sie diesen erst ermöglicht. Dies gilt insbesondere im Bereich von Exportgeschäften, wo die Einräumung von Zahlungszielen für den ausländischen Importeur, die eine Kreditaufnahme des Exporteurs notwendig machen, häufig Bestandteil des Kontrakts ist ${ }^{2}$. Öffentliche Ausfuhrgarantien ${ }^{3}$ dienen dabei vielfach als Sicherheit für die kreditgebende Bank. Die AKA Ausfuhr-Kreditgesellschaft $\mathrm{mbH}$, ein privates Kreditinstitut, das von einem Bankenkonsortium 1952 als Spezialinstitut für die mittel- und langfristige Exportfinanzierung gegründet wurde, macht beispielsweise eine öffentliche Ausfuhrgarantie, die sogenannte HERMES-Deckung ${ }^{4}$, zur Voraussetzung für die Vergabe von Ausfuhrkrediten mit einer Laufzeit von über 2 Jahren $^{5}$.

Bei öffentlichen Garantien, die in erster Linie zur Absicherung von Exportgeschäften übernommen werden, sind unterschiedliche Deckungsformen zu verzeichnen. Lange Zeit dominierend war die Einzeldeckung, mit der lediglich ein bestimmtes Geschäft abgesichert wird. Bei der revolvierenden Deckung wird ein Deckungshöchstbetrag eingeräumt, in dessen Rahmen bei Erfüllung abgesicherter Geschäfte des Garantienehmers neue Forderungen gegen denselben Kunden oder einen vertraglich abgegrenzten Kundenkreis gedeckt werden können. Die Pauschaldeckung erlaubt demgegenüber die Absicherung von

1 Vgl. SCHETTING (1973), S.119 ff.

2 Vgl. HICHERT (1986), S.104 f.

3 Im Bereich der Ausfuhrgewährleistungen werden Bürgschaften und Garantien danach abgegrenzt, ob der ausländische Vertragspartner des einheimischen Deckungsnehmers ein Staat, eine Gebietskörperschaft bzw. eine vergleichbare Institution ist. Wenn dies der Fall ist, wird generell von Ausfuhrbürgschaften, in allen anderen Fällen von Ausfuhrgarantien gesprochen. Vgl. HICHERT (1986), S.49, 252; PIDUCH (1990), Anm. 2 zu § 39 BHO. Abgesehen von Zuordnungsschwierigkeiten, wenn im Importland sowohl privatrechtliche als auch öffentlichrechtliche Einrichtungen am abgesicherten Geschäft beteiligt sind, fehlen den Ausfuhrbürgschaften die bürgschaftstypischen Merkmale, wie die Akzessorietät, so daß insoweit die zivilrechtliche Begriffsbildung geeigneter erscheint. Vgl. hierzu SCHETTING (1973), S.45 f., Fn. 145 .

4 Diese Bezeichnung für öffentliche Ausfuhrgarantien rührt daher, daß die Übernahme von Ausfuhrgewährleistungen des Bundes über ein Mandatarkonsortium bestehend aus der bundeseigenen TREUARBEIT AG und der federführenden HERMES Kreditversicherungs-AG erfolgt. Dabei ist allerdings zu beachten, daB dieses Konsortium im Namen und auf Rechnung der Bundesrepublik Deutschland tätig wird und somit im Schadensfall eine Leistungspflicht des Bundes entsteht. Außer diesen Mandatargeschäften ist die HERMES AG aber auch als privater Kreditversicherer tätig, wobei beide Sparten vollkommen getrennt voneinander arbeiten. Vgl. dazu HICHERT (1986), S.47 f., 65.

5 Vgl. SCHETTING (1973), S.59 f.; SCHRÖDER (1973), S.667 f.; ELBRECHT (1976), Sp.1186. 
Geschäften mit einer großen Zahl wechselnder Kunden ${ }^{1}$. Dabei wird ebenfalls ein Garantiehöchstbetrag festgelegt, wobei das einzelne im Rahmen der Pauschaldeckung abgesicherte Geschäft in der Regel bestimmte Höchstgrenzen nicht überschreiten darf ${ }^{2}$.

Mit Ausfuhrgarantien können sowohl wirtschaftliche als auch politische Risiken abgesichert werden. Zu den wirtschaftlichen Risiken gehören die Zahlungsunfähigkeit sowie der Zahlungsverzug ("protracted default") des Kunden des Garantienehmers. Politische Risiken resultieren demgegenüber aus der Gefahr schädigender staatlicher Maßnahmen wie Zahlungsverbote oder Enteignung bzw. schädigender politischer Ereignisse, z.B. Krieg, Revolution oder Aufruhr, in den Importländern. Die HERMES-Deckung umfaßt üblicherweise beide Arten von Risiken. Im Gegensatz zu einigen anderen Industrieländern werden durch die staatlichen Ausfuhrgewährleistungen sonstige Risiken, wie z.B. das Katastrophenrisiko, nicht gedeckt ${ }^{3}$.

\section{c. Gemeinsamkeiten von Kreditbürgschaften und -garantien}

Bei Kreditgewährleistungen gehen die Ansprüche des Inhabers der besicherten Forderung im Schadensfall auf den öffentlichen Gewährleistungsübernehmer über ${ }^{4}$. Daher lassen sich im Falle einer staatlichen Inanspruchnahme mit gewisser Wahrscheinlichkeit künftige Einnahmen aufgrund der fortbestehenden Forderungen erwarten ${ }^{5}$.

Für die beiden angesprochenen Arten öffentlicher Gewährleistungen gilt gleichermaßen, daß sie die abgesicherten Risiken regelmäßig nicht vollständig, sondern lediglich anteilig decken ${ }^{6}$, so daß dem Gläubiger der besicherten Forderung eine Selbstbeteili-

1 Vgl. SCHETTING (1973), S.48 ff.; HICHERT (1986), S.49 ff.

2 Vgl. BUNDESMINISTER FÜR WIRTSCHAFT (1989), S.10.

3 Vgl. SCHRÖDER (1973), S.666; HICHERT (1986), S.53 ff., 129 ff.

4 So ist in Nr.1 VV-BHO zu $\S 39$ bestimmt, daß sich Bürgschaften nach $\S 8765 \mathrm{ff}$. BGB regeln, wobei $\S 774$ BGB einen Forderungsübergang vom Gläubiger auf den Bürgen bei dessen Inanspruchnahme vorsieht. In § 11 der Allgemeinen Bedingungen für die Übernahme von Ausfuhrgarantien (abgedruckt in HICHERT (1986), S.258 ff.) ist ein Übergang der besicherten Forderungen des Garantienehmers auf den Bund im Fall einer Entschädigungsleistung vorgesehen.

5 Bei den Ausfuhrgewährleistungen zur Deckung wirtschaftlicher Risiken des Bundes standen im Zeitraum von 1979 bis 1988 Auszahlungen des Bundes in Höhe von 639,6 Mio. DM Rückflüsse von 107,6 Mio. DM gegenüber. Bei Gewährleistungen für politische Risiken betrugen die Auszahlungen des Bundes im entsprechenden Zeitraum 13,66 Mrd. DM und die Rückflüsse 3,01 Mrd. DM. (Eigene Berechnungen aufgrund der Angaben in BUNDESMINISTER FÜR WIRTSCHAFT (1989), S.15 f.).

6 Bei Ausfuhrgarantien des Bundes wird das wirtschaftliche Risiko zu 85 und das politische Risiko zu 90 Prozent übernommen, vgl. HICHERT (1986), S.130. Gewährleistungen des ERPSondervermögens sollen beispielsweise 80 Prozent des etwaigen Ausfalls eines Kreditgebers nicht übersteigen, vgl. BUNDESMINISTERIUM FÜR WIRTSCHAFT (1988), S.69. Die durch Bund und Länder rückverbürgten Kreditbürgschaften der Kreditgarantiegemeinschaften sind 
gung bleibt. Dabei ist eine anderweitige Zusatzabsicherung insbesondere bei Garantien in aller Regel verboten ${ }^{1}$.

Außerdem werden für alle Gewährleistungsmaßnahmen üblicherweise bestimmte Entgelte erhoben, die als Prämie oder Provision bezeichnet werden. Dieses Entgelt besteht oftmals aus einer Grundgebühr zur Deckung der Bearbeitungskosten und einer periodisch anfallenden Provision, die über die gesamte Laufzeit der Deckung zu entrichten ist. Allerdings gibt es auch bedeutende Beispiele für entgeltlose öffentliche Gewährleistungen. Dazu gehören die Rückbürgschaften von Bund und Ländern für die Kreditgarantiegemeinschaften $^{2}$.

Nach der relativen Höhe dieser Prämienverpflichtung ${ }^{3}$ lassen sich drei Typen öffentlicher Kreditgewährleistungen unterscheiden. Der erste Typus ist dadurch gekennzeichnet, daß für eine große Anzahl von gleichartigen Einzelfällen Gewährleistungen übernommen werden, die ein Risiko-Pooling erlauben. Die Prämie ist dabei nach versicherungsmathematischen Grundsätzen festgelegt. D.h. daß die Prämienhöhe so bestimmt wird, daß die erwarteten Einnahmen des entsprechenden Programms zur Deckung der erwarteten Ausgaben ausreichen ${ }^{4}$. Das Entgelt für die Gewährleistungsübernahme entspricht daher zumindest näherungsweise dem Preis auf privaten Kreditversicherungsmärkten ${ }^{5}$. Diesem Typus lassen sich am ehesten die vom Bund übernommenen Ausfuhrgewährleistungen zuordnen, wenngleich das damit verbundene Prä-

auf ebenfalls 80 Prozent des Kreditbetrages begrenzt, vgl. DICKERTMANN (1980), S.283. Jedoch gibt es auch hier Ausnahmen von der Regel. So wurden in der Vergangenheit insbesondere bei Sanierungsbürgschaften Kredite zu 100 Prozent abgesichert; vgl. SCHLECHT (1982), S.423.

1 Vgl. SCHETTING (1973), S.123, 125.

$2 \mathrm{Zu}$ den Konditionen für öffentliche Kreditgewährleistungen vgl. ausführlich DICKERTMANN (1980), S.270 f.

3 Die absolute Entgelthöhe ist als Maßstab zur Unterscheidung verschiedener Kategorien öffentlicher Gewährleistungen ungeeignet, da beispielsweise ein unterdurchschnittliches Entgelt sowohl auf geringen Schadenswahrscheinlichkeiten als auch auf einer vergleichsweise intensiven Subventionierung beruhen kann.

4 BOSWORTH/CARRON/RHYNE (1987), S.37. Damit lassen ex post feststellbare periodische Defizite eines Gewährleistungsprogramms noch nicht zwingend den SchluB zu, daß die Prämienhöhe nicht nach versicherungsmathematischen Grundsätzen bestimmt ist. Denn periodische Verluste können durch Gewinne in anderen Perioden kompensiert werden. Andererseits können Ex-post-Defizite auch darauf hindeuten, da $\beta$ die der Prämienberechnung zugrundeliegenden Schadenswahrscheinlichkeiten bewußt zu niedrig kalkuliert waren, so daß eine Durchbrechung versicherungsmathematischer Grundsätze zu konstatieren wäre; vgl. dazu CONRAD (1967), S.87 ff.

5 Von Risikokosten wird hier zunächst abstrahiert. Zur Problematik privater Kreditversicherungsmärkte vgl. unten Abschnitt C.I.2.a.bb. 
mienaufkommen in den zurückliegenden Jahren zur Deckung der Schadensleistungen des Bundes nicht ausreichte ${ }^{1}$.

Zum zweiten Typus gehören Gewährleistungsprogramme mit vielen Einzelfällen, bei denen aber die Entgelte so festgelegt sind, daß die Einnahmen ex ante zur Deckung der Ausgaben nicht ausreichen. Diese Programme enthalten somit eine eindeutige und geplante Prämienvergünstigung ${ }^{2}$. Ein Beispiel hierfür sind die mittelbar öffentlichen Kreditbürgschaften der Kreditgarantiegemeinschaften ${ }^{3}$.

Der dritte Typus öffentlicher Kreditgewährleistungen bezieht sich auf Einzelfallrisiken, bei denen eine Risikoreduktion durch ein diversifiziertes Gewährleistungsportfolio kaum möglich ist ${ }^{4}$. In diesen Fällen wird regelmäßig kein auf die Ausfallwahrscheinlichkeit bezogenes Entgelt erhoben, das andererseits angesichts der erheblichen Schadenswahrscheinlichkeit von Einzelgewährleistungen vergleichsweise hoch sein müßte. Als Beispiele für solche Einzelgewährleistungen können zahlreiche staatliche "Rettungsbürgschaften", wie sie etwa zugunsten der AEG-Telefunken übernommen wurden, genannt werden ${ }^{5}$.

\section{Zahlungswirksamkeit öffentlicher Kredithilfen}

Im Gegensatz zu den meisten anderen öffentlichen Ausgaben sind öffentliche Kredithilfen dadurch gekennzeichnet, $\mathrm{da} B$ die damit verbundenen Nettoausgaben, also die Finanzierungskosten öffentlicher Kredithilfen, nicht ohne weiteres erkennbar sind ${ }^{6}$. Dies beruht darauf, daß öffentliche Kredithilfen, abgesehen von kapitalisierten Zinszuschüssen, nicht oder nicht nur in der Vergabeperiode, sondern (auch) in künftigen Perioden zu Ausgaben führen. Umgekehrt resultieren aus der Vergabe von Kredithilfen wiederum Einnahmen, die mit den Ausgaben saldiert werden müssen, um die damit verbundenen Nettoausgaben zu ermitteln. Die Kenntnis der Nettoausgaben ist aber notwendige Voraussetzung für eine umfassende Kosten-Nutzen-Analyse öffentlicher Kredithilfen bzw. einer Analyse sozial optimaler Programmniveaus und -strukturen ${ }^{7}$. Im diesem Abschnitt soll auf-

1 Vgl. BUNDESMINISTER FÜR WIRTSCHAFT (1989), S.15.

2 Vgl. BOSWORTH/CARRON/RHYNE (1987), S.37

3 Hier sind die Provisionen so niedrig festgesetzt, daß nur durch öffentliche entgeltlose Haftungsübernahme das Fortbestehen dieser Einrichtungen gesichert werden kann. Vgl. DICKERTMANN (1980), S.284.

4 Vgl. BOSWORTH/CARRON/RHYNE (1987), S.38.

5 Vgl. SCHLECHT (1982), S.423 ff. mit einem Überblick über die zwischen 1972 und 1982 übernommenen öffentlichen "Rettungsbürgschaften" und die damit verbundenen Schadensleistungen des Bundes.

6 Vgl. BOSKIN/BARHAM/CONE/OZLER (1987), S.14.

7 Vgl. BOSKIN/BARHAM/CONE/OZLER (1987), S.15. 
gezeigt werden, welche Zahlungsströme durch die Vergabe öffentlicher Kredithilfen verursacht werden. Dabei sollen die durch Kredithilfen verursachten Verwaltungskosten unberücksichtigt bleiben. Außerdem wird an dieser Stelle aus Vereinfachungsgründen von marktlichen Preisreaktionen abgesehen, die durch Kredithilfen induziert werden können und gegebenenfalls Rückwirkungen auf die Höhe der Nettoausgaben öffentlicher Kredithilfen haben können. Schließlich bleiben die mit der Finanzierung dieser Nettoausgaben verbundenen sozialen Kosten unberücksichtigt.

Die Nettoausgaben öffentlicher Kredithilfen werden definiert als Differenz des (erwarteten) Gegenwartswerts der Ausgaben und des (erwarteten) Gegenwartswerts der Einnahmen ${ }^{1}$. Die Abdiskontierung künftiger Zahlungsströme erfolgt dabei mit der Opportunitätskostenrate, die zumindest näherungsweise durch den Marktzinssatz für Kredite entsprechender Laufzeit zu erfassen ist ${ }^{2}$. Soweit öffentliche Kredithilfen Ausgabenüberschüsse implizieren, ziehen sie einen Finanzierungsbedarf nach sich.

Bei Schuldendiensthilfen ist der Finanzierungsbedarf vergleichsweise einfach zu erfassen, da sie ausschließlich zu Ausgaben führen ${ }^{3}$. Allerdings hängt die zeitliche Verteilung der erforderlichen Einnahmen davon ab, ob die Schuldendiensthilfe in kapitalisierter oder laufender Form vergeben wird. Im ersteren Fall müssen die Ausgaben für Schuldendiensthilfen vollständig in der Vergabeperiode finanziert werden. Im anderen Fall verteilen sich die Ausgaben über mehrere Perioden, wobei aber bereits in der Vergabeperiode Verbindlichkeiten in Höhe des Gegenwartswerts der künftigen Zahlungen entstehen.

Dagegen verursacht ein Darlehen in der Vergabeperiode Ausgaben in Höhe der Darlehenssumme. Durch diese Ausgaben kommt es jedoch zu einem Forderungserwerb des Darlehensgebers; das öffentliche Nominalvermögen erhöht sich um die Darlehenssumme ${ }^{4,5}$. Die Erhöhung des nominalen Finanzvermögens, d.h. der Ausgabenüberschuß der Vergabeperiode, muß durch Einnahmen in der Vergabeperiode finanziert werden, wobei die "Umwandlung" liquider Mittel in eine Forderung einen Aktivtausch darstellt ${ }^{6}$. Erfolgt dieser Vorgang mittels Steuerfinanzierung, ist die Darlehensvergabe mit künftigen Einnahmenüberschüssen in Form von Tilgungs- und ggf. auch Zinszahlungen verbunden.

1 Von Risikokosten wird hier abgesehen.

2 Zum vergleichbaren Problem der Bestimmung von Diskontierungsraten in Kosten-NutzenAnalysen vgl. ausführlich BOADWAY/WILDASIN (1984), S.203 ff., 213 ff. m.w.N. Siehe auch FOLKERS (1981), S.25.

3 Dabei wird davon abgesehen, daß Einnahmen bei Schuldendiensthilfen aus der Rückabwicklung des Subventionsverhältnisses analog den zivilrechtlichen Regeln über die ungerechtfertigte Bereicherung entstehen können.

4 Vgl. DICKERTMANN (1980), S.240.

5 Das Umgekehrte gilt bei Erfüllungsleistungen auf solche Forderungen.

6 Vgl. ZEITEL (1977), S.1000. 
Der Bestand steuerfinanzierter Darlehensforderungen bildet somit einen "Reservefonds"1, der künftig zur Deckung laufender staatlicher Ausgaben verwendet werden kann. Wird der Forderungserwerb dagegen kreditfinanziert, so leuchtet unmittelbar ein, daß die Darlehensvergabe Zinsverbilligungskosten verursacht ${ }^{2}$. Sie steigen mit zunehmender Kreditausfallwahrscheinlichkeit, die bei marktlichen Krediten zu einer Erhöhung des nominalen Zinssatzes führt ${ }^{3}$. Diese Zinsverbilligungskosten erzeugen einen Finanzierungsbedarf in den Folgeperioden. Darüber hinaus reduziert die Vergabe zinsverbilligter Darlehen, die durch eine Kreditaufnahme am Kapitalmarkt refinanziert werden, gegenüber der Vergabe von Darlehen mit marktlicher Verzinsung das öffentliche Nettovermögen. Da der Nettogegenwartswert der künftigen Zahlungssalden ökonomisch dem Nettovermögen entspricht ${ }^{4}$, ergibt sich hier aufgrund der Zinsverbilligung ein negativer Wert, der genau dem Gegenwartswert der Nettoausgaben öffentlicher Darlehen entspricht. Denn die Zinseinnahmen stellen insoweit lediglich Teilkostenersätze für die Zinsaufwendungen dar $^{5}$. Ein Nettovermögensverlust gleicher Höhe ergibt sich jedoch auch bei Steuerfinanzierung des Forderungserwerbs, sofern die Opportunitätskostenrate von der Finanzierung des Forderungserwerbs unabhängig ist ${ }^{6}$. Dies kommt darin zum Ausdruck, daß der (potentielle) Marktwert der Darlehensforderung wegen der Zinsverbilligung unterhalb des Nominalbetrags liegen muB ${ }^{7}$. Da der Marktwert der Forderungen bereits im Zeitpunkt der Darlehensvergabe unter seinem Nominalwert liegt, realisieren sich die Nettoausgaben des öffentlichen Darlehens in kapitalisierter Höhe in diesem Zeitpunkt.

Kreditgewährleistungen führen als Eventualverbindlichkeiten nur im Schadensfall zu Ausgaben. Sofern dafür Prämien zu entrichten sind, werden die Ausgaben zumindest teilweise durch Einnahmen ausgeglichen. Ein über die Prämieneinnahmen hinausgehender

1 ZEITEL (1967), S.211.

2 Dies gilt nur dann nicht, wenn die Zinshöhe des öffentlichen Darlehens und des Refinanzierungskredits übereinstimmen.

3 Vgl. DICKERTMANN (1980), S.50.

4 Zum Vermögensbegriff vgl. FOLKERS (1980).

5 Vgl. SMEKAL (1971), S.76.

6 Unterstellt man einen vollkommenen Kapitalmarkt, so stimmen im Gleichgewicht die soziale Zeitpräferenz- und Opportunitätskostenrate überein. Die staatliche Diskontierungsrate ist daher unabhängig davon, ob die Darlehensfinanzierung durch Entzug finanzieller Ressourcen zur Finanzierung privater Investitionen oder privaten Konsums erfolgt. Berücksichtigt man dagegen, daß die Opportunitätskostenrate die Zeitpräferenzrate wegen der Besteuerung von Kapitaleinkünften übersteigt, können sich bei der Kredit- gegenüber der Steuerfinanzierung unterschiedliche soziale Opportunitätskosten ergeben, wenn beide Finanzierungsinstrumente in unterschiedlicher Weise zu einer Verdrängung privater Investitionen führen. Zu einem Überblick hierzu siehe BOADWAY/WILDASIN (1984), S.203 ff.

7 Vgl. DICKERTMANN (1980), S.241. Diese Überlegung basiert auf dem einfachen Zusammenhang, daB der Kurs einer künftig fälligen Forderung kleiner ist als der Nominalbetrag, wenn der Marktzinssatz den Nominalzinssatz übersteigt. 
Finanzierungsbedarf entsteht dabei in den Perioden, in denen die Ausgaben die Einnahmen übersteigen. Da die Inanspruchnahme aus Gewährleistungen zu einem Forderungserwerb führt, können auch nach dem Ende des Gewährleistungszeitraums Einnahmenüberschüsse entstehen. Allerdings ist der Marktwert der aufgrund einer Inanspruchnahme aus Gewährleistungen erworbenen Forderungen wegen der teilweise sehr geringen Erfüllungswahrscheinlichkeit regelmäßig deutlich niedriger als bei Forderungen aus öffentlichen Darlehen. Die Nettoausgaben eines Kreditgewährleistungs-Programms bestimmen sich jedoch wiederum allein nach dem Gegenwartswert der Differenz von Ausgaben und Einnahmen über den gesamten Zeitraum, in dem die Gewährleistungen zahlungswirksam werden.

\section{FINANZIERUNGSQUELLEN FÜR ÖFFENTLICHE KREDITHILFEN}

Die Finanzierung von periodischen Ausgabenüberschüssen aufgrund öffentlicher Kredithilfen erfolgt sowohl durch den Einsatz budgetärer Mittel der Gebietskörperschaften als auch aus Mitteln außerbudgetärer Einheiten. Die Bezeichnung "außerbudgetäre Einheiten" wird als Oberbegriff für staatliche Organisationseinheiten verwendet, die in ihrer laufenden Wirtschaftsführung von den Haushalten der Gebietskörperschaften formal unabhängig sind und bei denen somit die einzelnen Ausgabenzwecke außerhalb des Budgetierungsverfahrens der Gebietskörperschaften festgelegt wird. Bei den außerbudgetären Einheiten ist zwischen speziellen Vermögensmassen der Gebietskörperschaften, den Sondervermögen, und außerbudgetären Kredithilfe-Einrichtungen zu unterscheiden. In diesem Abschnitt sollen nun die bedeutendsten Finanzierungsquellen für öffentliche Kredithilfen dargestellt und ihre wesentlichen Merkmale herausgearbeitet werden.

\section{Die öffentlichen Haushalte}

Bei der Finanzierung öffentlicher Kredithilfen aus Haushaltsmitteln kann danach unterschieden werden, ob dafür allgemeine oder zweckgebundene Haushaltsmittel eingesetzt werden. Weiterhin sind an der Finanzierung budgetärer Kredithilfen häufig verschiedene staatliche Ebenen beteiligt. 
a. Finanzierung aus allgemeinen Haushaltsmitteln

Allgemeine Haushaltsmittel sind alle Haushaltseinnahmen einschließlich der Kreditaufnahme, für die eine spezielle Zweckbindung nicht besteht. Sofern die Vergabe von aus allgemeinen Haushaltsmitteln finanzierten Kredithilfen mit Einnahmen verbunden ist, können diese zur Finanzierung aller Ausgaben eingesetzt werden ${ }^{1}$. Diese Finanzierungsform entspricht dem durch die Finanzreform 1969 zum haushaltswirtschaftlichen Regelfall erhobenen Budgetgrundsatz der Gesamtdeckung ${ }^{2}$, der unabhängig davon gilt, ob staatliche Ausgaben als Investitionen oder Konsum eingeordnet werden.

\section{b. Finanzierung aus zweckgebundenen Haushaltsmitteln}

Insbesondere bei Bund und Ländern stehen auch zweckgebundene Haushaltsmittel zur budgetären Finanzierung von Kredithilfen zur Verfügung. Solche zweckgebundenen Einnahmen resultieren aus den Rückflüssen des Forderungsvermögens, das im Zusammenhang mit der Vergabe von Wohnungsbaudarlehen akkumuliert wurde ${ }^{3}$. Durch die Zweckbindung erhalten die Wohnungsbauvermögen von Bund und Ländern die Gestalt revolvierender Darlehensfonds ${ }^{4}$, wenngleich sie beim Bund und einigen Ländern ${ }^{5}$ vollständig in deren Haushaltswirtschaft integriert sind.

Solche zweckgebundenen Einnahmen sind von den klassischen Fällen der Zweckbindung von Einnahmen zu unterscheiden, sofern der Forderungsbestand nicht ausschließlich durch Verwendung zweckgebundener Einnahmen akkumuliert wurde. Da zur Wohnungsbauförderung ursprünglich keinerlei spezielle Steuern oder Abgaben zur Verfügung

1 Allerdings gilt für die im Zusammenhang mit Gewährleistungen anfallenden Einnahmen die sogenannte "unechte" Deckungsfähigkeit, wonach Mehreinnahmen zur Deckung von Mehrausgaben verwendet werden. Vgl. Kap. 3214 der Bundeshaushaltspläne.

2 Siehe $\$ 8 \mathrm{BHO} / \mathrm{LHO}$. In den Gemeinden gilt das Gesamtdeckungsprinzip sowohl im Verwaltungs- als auch im Vermögenshaushalt, vgl. exemplarisch § $16 \mathrm{GemHVO} / \mathrm{BW}$. Siehe auch HEDTKAMP (1977), S.82 ff.

3 Für den Bund ist in $\S 17$ Erstes Wohnungsbaugesetz und $\S 20$ Zweites Wohnungsbaugesetz bestimmt, daß Rückflüsse aus Wohnungsbaudarlehen zweckgebunden wiederum für denselben Förderzweck einzusetzen sind. Bei den Ländern sind die Rückflüsse aufgrund der Wohnungsbauförderdarlehen ebenfalls zweckgebunden einzusetzen. Allerdings sind die entsprechenden Landeswohnungsbauvermögen teilweise aus dem Budget herausgelöst. FECHER (1963), S.27 spricht hier von "Zweckbindung nichtsteuerlicher Einnahmen".

4 Vgl. EHRENFORTH (1965), S.53.

5 Dies gilt z.B. für Baden-Württemberg, wo nach dem Gesetz über die Bindung von Rückflüssen aus Darlehen zur Förderung des Wohnungsbaus in der Fassung vom 12.03.1968 (GBl. BadenWürttemberg, S.77) die Rückflüsse aus den Landesdarlehen zur Wohnungsbauförderung wieder zur Förderung von Maßnahmen zugunsten des sozialen Wohnungsbaus zu verwenden sind. Entsprechende Vorschriften gelten u.a. auch in Bayern; vgl. dazu das entsprechende Gesetz vom 23.03.1962 (GVBl. S.30). 
standen, mußten allgemeine Haushaltsmittel aufgewendet werden, die dann durch die Art ihrer Verausgabung mit einer Zweckbindung versehen wurden ${ }^{1}$.

Es gibt jedoch in der Geschichte der Bundesrepublik Deutschland eine Reihe originär zweckgebundener, für öffentliche Kredithilfen verwendbarer Einnahmen der Gebietskörperschaften. Da diese jedoch ganz überwiegend verschiedenen Sondervermögen zufließen oder zugeflossen sind, soll darauf weiter unten eingegangen werden.

\section{c. Gemeinschaftsfinanzierung aus Haushaltsmitteln verschiedener staatlicher Ebenen}

Während bisher nur die Finanzierung von Kredithilfen aus Mitteln eines öffentlichen Haushalts betrachtet wurden, ist die Kredithilfepraxis häufig durch Gemeinschaftsfinanzierungen aus Mitteln verschiedener öffentlicher Haushalte gekennzeichnet. Solche Gemeinschaftsfinanzierungen nehmen unterschiedliche Formen $a^{2}$. Die wichtigsten sind dabei die Darlehensgewährung sowie Erstattungen und Zuweisungen des Bundes an die Länder. Außerdem werden in bestimmten Fällen die Kosten der Inanspruchnahme aus Gewährleistungen von Bund und Ländern gemeinsam getragen.

In einigen Fällen gewährt der Bund den Ländern Darlehen, die dann von letzteren unter Verwendung zusätzlicher eigener Mittel an die Empfänger ausgereicht werden. Dabei wird nur zum Teil ein formalrechtlicher Darlehensvertrag zwischen dem Bund und dem jeweiligen Land abgeschlossen ${ }^{3}$. In anderen Fällen wird ein Darlehensverhältnis zwischen Bund und dem jeweiligen Land lediglich haushaltsrechtlich fingiert, ohne formalrechtlich entsprechend gestaltet zu sein ${ }^{4}$.

Darüber hinaus gewährt der Bund den Ländern Zuschüsse oder Erstattungen zur Finanzierung von Kredithilfen. Zuschüsse werden den Ländern vom Bund endgültig überlassen. Sie bilden dann mit Landesmitteln die Finanzmasse, die für einen bestimmten Zweck zur Verfügung steht ${ }^{5}$.

1 Vgl. FECHER (1963), S.27.

2 Die Gemeinschaftsfinanzierung von Kredithilfen unter Einschluß der kommunalen Ebene bleibt hier wegen ihres geringeren Umfangs außer acht.

3 Die Wohnungsbaufördermittel des Bundes werden den Ländern als Globaldarlehen gegen Schuldschein, die in der Regel nach Maßgabe des § 19 Abs.3 S.2 Zweites Wohnungsbaugesetz zu verzinsen und mit mindestens $1 \mathrm{v} . \mathrm{H}$. jährlich zu tilgen sind.

4 So tragen Bund und Länder die Ausgaben nach dem BAFöG in einem gesetzlich vorgesehenen Verhältnis. Umgekehrt werden die Darlehensrückflüsse diesem Verhältnis entsprechend auf Bund und Länder aufgeteilt. Vgl. § 56 BAFöG. Die Ausgaben des Bundes werden im Bundeshaushaltsplan als Darlehen des Bundes an die Länder veranschlagt. Vgl. Epl. 32, Titel 85212.

5 Ein Beispiel hierfür ist das Bund-Länder-Programm für Aussiedler in den Jahren 1989 und 1990. In Baden-Württemberg werden die Bundeszuschüsse zusammen mit komplementären 
Bei den Gemeinschaftsaufgaben "Verbesserung der regionalen Wirtschaftsstruktur" und "Verbesserung der Agrarstruktur und des Küstenschutzes" wird den Ländern der festgelegte Bundesanteil an den Gesamtausgaben erstattet, deren Höhe in jährlich fortgeschriebenen Rahmenplänen festgelegt wird. Sofern die im Rahmen der Gemeinschaftsaufgaben bereitgestellten Mittel als Darlehen gewährt werden, sind Zinseinnahmen und Darlehensrückflüsse an den Bund entsprechend seinem Finanzierungsanteil abzuführen ${ }^{1}$.

Eine Gemeinschaftsfinanzierung der Schadensleistungen aufgrund von Gewährleistungen durch Bund und Länder erfolgt insbesondere im Falle der Kreditgarantiegemeinschaften ${ }^{2}$. Dabei handelt es sich um gemeinnützige "Selbsthilfeeinrichtungen der Wirtschaft" zur Förderung kleinerer Betriebe, die nicht über ausreichende eigene Kreditsicherheiten verfügen. Die Kreditgarantiegemeinschaften sind nach Wirtschaftsbereichen gegliedert und werden von den berufsständischen Verbänden und der Kreditwirtschaft getragen. Der Sicherstellung ihrer dauerhaften Zahlungsfähigkeit dienen zum einen die haftenden Einlagen ihrer Gesellschafter. Zum anderen werden dafür in erheblichem Umfang öffentliche Mittel verwendet. So gewähren Bund und Länder sogenannte Haftungsfondsdarlehen, die mit einem vertraglich fixierten Prozentsatz an allen von den Kreditgarantiegemeinschaften zu tragenden Kreditausfällen teilnehmen. Bedeutender sind die Rückbürgschaften von Bund und Ländern für die von den Kreditgarantiegemeinschaften verbürgten Kredite. Die prozentuale Deckungshöhe der durch Rückbürgschaften abgesicherten Bürgschaften wird alle fünf Jahre neu ausgehandelt. Sie betrug anfänglich 80 Prozent und wurde schrittweise auf 62,5 Prozent zurückgeführt, wobei der Bund daran in der Regel zu drei Fünfteln und das Land, in dem die Kreditgarantiegemeinschaft ansässig ist, zu zwei Fünfteln beteiligt sind ${ }^{3}$.

\section{Außerbudgetäre Sondervermögen}

Als Finanzierungsalternative für öffentliche Kredithilfen stehen dem Bund und den Ländern eine Reihe spezieller Vermögensmassen zur Verfügung, die als Sondervermögen vom übrigen Vermögen der Gebietskörperschaften abgesondert sind und die für ihre eige-

Landesmitteln zur Zinsverbilligung von Darlehen eingesetzt. Vgl. BADEN-WÜRTTEMBERG (1990), EP1.03, Kap.0309, S.137.

1 BADEN-WÜRTTEMBERG (1990), Epl.08, Kap.0802, S.23.

2 Vgl. dazu SCHULZ (1970); REINERMANN (1976); DICKERTMANN (1980), S. 285 ff.; BECKER, H. (1980); JOOSS (1987), S. 304.

3 Vgl. SCHULZ (1970), S.336; BECKER, H. (1980), S.23 ff.; DICKERTMANN (1980), S.284; DICKERTMANN/HANSMEYER (1987), S.105 ff.; GOLDSCHMIDT (1987), S.101 ff. 
nen Verbindlichkeiten selbst, nicht jedoch für die übrigen Verbindlichkeiten der Gebietskörperschaft haften ${ }^{1}$. Entsprechend der obigen Begriffsabgrenzung werden sie in dieser Arbeit den außerbudgetären Einheiten zugerechnet.

Zur Errichtung der Sondervermögen werden primär Haushaltsmittel der Gebietskörperschaften eingesetzt, die entweder aus allgemeinen oder speziellen Einnahmen stammen. In nachfolgenden Perioden finanzieren sich diese Sondervermögen teilweise durch zusätzliche Haushaltsmittel, durch Zufluß spezieller zweckgebundener Einnahmen sowie durch Verschuldung auf dem Kreditmarkt. Darüber hinaus ist für sie wesentlich, daß Erträge, Tilgungen und sonstige Rückflüsse vergebener Kredithilfen in aller Regel bei den Sondervermögen verbleiben und von ihnen wiederum zweckgebunden verwendet werden ${ }^{2}$. Daher handelt es sich bei den Sondervermögen um revolvierende Fonds, deren nominale Höhe im Zeitablauf von der Anfangsausstattung, vom Ausmaß originärer Einnahmequellen, der Höhe der Erträge aus den vergebenen Mitteln sowie den zu tragenden Aufwendungen abhängt ${ }^{3}$.

Die für die Vergabe von Kredithilfen eingesetzten Sondervermögen verfügen regelmäßig nicht über Personal- und Sachmittel ${ }^{4}$. Sie haben keine eigene Rechtspersönlichkeit und stehen rechtlich vollständig im Eigentum einer Gebietskörperschaft. Im Haushalt der Gebietskörperschaft treten die Sondervermögen nur in Erscheinung, wenn Zuführungen oder Ablieferungen angezeigt sind ${ }^{5}$. Zumindest beim Bund ist der Bestand an Sondervermögen gemäß $\S 86$ BHO auch in der Vermögensrechnung nachzuweisen ${ }^{6}$. Ansonsten sind diese Vermögensmassen aber vollständig aus der Haushaltswirtschaft der Gebietskörperschaft herausgelöst und unterliegen einer gesonderten Wirtschaftsführung, die sich jedoch nicht in allen Fällen in einem formalen Wirtschaftsplan niederschlägt ${ }^{7}$. Teilweise werden diese Vermögensmassen durch ihre Eigentümerin, die jeweilige Gebietskörperschaft, verwaltet, während in anderen Fällen diese Aufgabe durch Stellen außerhalb der Verwaltung der Gebietskörperschaft wahrgenommen wird. Regelmäßig unterliegen die Sondervermögen der Rechnungshofkontrolle.

1 Allerdings ist davon auszugehen, daß die Gebietskörperschaften ihre Sondervermögen faktisch nicht notleidend werden lassen können. Vgl. PIDUCH (1990), Anm.2 zu § 113 BHO.

2 Vgl. PIDUCH (1990), Anm.4 zu § 8 BHO.

3 Allgemein zu revolvierenden Fonds vgl. HANSMEYER/DICKERTMANN (1971), S.587 f.; DICKERTMANN/HANSMEYER (1987), S.110 ff.;

4 Etwas anderes gilt z.B. für die Bundespost, die rechtlich ebenfalls als Sondervermögen ausgestaltet ist. Sie ist jedoch nicht Gegenstand dieser Arbeit.

5 Vgl. SCHEMMEL (1990), S.4.

6 Vgl. PIDUCH (1990), Anm. 1 zu § 113 BHO.

7 Vgl. FINANZBERICHT (1989), S. 207 f. 


\section{a. Sondervermögen des Bundes}

Sondervermögen werden insbesondere vom Bund intensiv zur Finanzierung öffentlicher Kredithilfen eingesetzt. Dabei werden die verschiedenen Möglichkeiten der institutionellen Ausgestaltung weitestgehend ausgeschöpft. Die Kredithilfe-Sondervermögen des Bundes werden im folgenden dargestellt.

\section{aa. Das ERP-Sondervermögen}

Das ERP-Sondervermögen wurde aus den DM-Gegenwerten der US-Exporte im Rahmen der GARIOA-Hilfe ${ }^{1}$ und des als Marshall-Plan bekanntgewordenen European Recovery Programme (ERP) aufgebaut. Es wurde mit den USA vereinbart, daß die aufgrund der US-Hilfe entstandenen und noch entstehenden Vermögenswerte der deutschen Wirtschaft in Form langfristiger Darlehen zur Verfügung gestellt werden ${ }^{2}$. Die heute noch geltende Zweckbestimmung des ERP-Sondervermögens wurde durch das ERP-Verwaltungsgesetz vom $31.08 .1953^{3}$ geregelt. Danach sind seine Mittel zum Wiederaufbau und zur Förderung der deutschen Wirtschaft zu verwenden ${ }^{4}$. Dabei soll das Sondervermögen in seinem Bestand erhalten bleiben ${ }^{5}$.

Die Förderung erfolgt in der Regel durch die Vergabe verzinslicher Darlehen, "deren Regelzins im Durchschnitt um etwa 2 v.H.-Punkte unter dem vergleichbaren Kapitalmarkt-

1 GARIOA = Government Appropriation and Relief for Import in Occupied Areas.

2 Diese Gegenwerte entstanden dadurch, daß die US-Exporteure von der US-Regierung in Dollar bezahlt wurden, während die deutschen Importeure dafür DM-Beträge zu entrichten hatten. Die Gegenwerte wurden jedoch nicht in die USA transferiert, sondern aufgrund des "Abkommens über Wirtschaftliche Zusammenarbeit zwischen den Vereinigten Staaten von Amerika und der Bundesrepublik Deutschland" vom 15.12.1949 (vgl. Ratifizierungsgesetz vom 31.01.1950, BGBl. S.9), dem ersten völkerrechtliche Vertrag der neugegründeten Bundesrepublik, zu einem Sondervermögen zusammengefaßt. Durch das Londoner Abkommen über deutsche Auslandsschulden vom 27.02.1953 wurde die Rückzahlungsverpflichtung der Bundesrepublik auf $1 \mathrm{Mrd}$. \$ festgesetzt, die mit 2,5 Prozent p.a. zu verzinsen war und ab 1958 in 60 Halbjahresraten aus Mitteln des Bundeshaushalts getilgt werden sollte. Aufgrund vorzeitiger Tilgungen wurden diese Forderungen bereits vor Ende der vorgesehenen Laufzeit erfüllt. Zur Geschichte des ERP-Sondervermögens vgl. SCHLAUWITZ (1966), S.17 ff; HEDTKAMP (1977), S.263 f.; BUNDESMINISTERIUM FÜR WIRTSCHAFT (1988), S.6 f.

BGBl.I S.1312.

4 Die durch das ERP-Entwicklungshilfegesetz von 1961 übertragene Aufgabe, Kredite zur Förderung der Zusammenarbeit mit den Entwicklungsländern zu gewähren, ist abgesehen von der Hilfe für die Exportfinanzierung auf den Bundeshaushalt übergegangen. Die Gewährung von Investitionskrediten an Gemeinden zur Konjunkturbelebung aufgrund des ERP-Investitionshilfegesetzes von 1967 war eine zeitlich und betragsmäßig begrenzte Aufgabe, die inzwischen in vollem Umfang abgedeckt worden ist. Vgl. BUNDESMINISTERIUM FÜR WIRTSCHAFT (1988), S.7.

5 Vgl. \& 5 Abs.1 ERP-Verwaltungsgesetz. 
zins liegt"1. Darlehenstilgungen und Zinsen sowie zurückgezahlte Zuschüsse fließen wiederum dem Sondervermögen zu und sind zweckentsprechend zu verwenden. In besonderen Fällen können unverzinsliche Darlehen und verlorene Zuschüsse gewährt und mit Zustimmung des Bundesministers der Finanzen auch Bürgschaften und sonstige Gewährleistungen übernommen werden.

Mit der Verwaltung des ERP-Sondervermögens ist der Bundesminister für Wirtschaft beauftragt. Er veranschlagt im Einvernehmen mit dem Bundesminister der Finanzen für jedes Rechnungsjahr die Ausgaben und Einnahmen in einem Wirtschaftsplan, der formal ausgeglichen sein muß und zu Beginn des Rechnungsjahres durch Gesetz festgestellt wird. Eine Kreditaufnahme des ERP-Sondervermögens ist dabei möglich.

Der Nettobestand des ERP-Sondervermögens ist bis 1988 auf 16,6 Mrd.DM angewachsen und hat sich damit seit 1953 mehr als verdoppelt. Bei den Verbindlichkeiten läßt sich insbesondere für die Jahre 1979 bis 1985 ein sehr starker Anstieg feststellen. Seither wurde der Schuldenstand des ERP-Sondervermögens wieder leicht gesenkt ${ }^{2}$. Durch die Beteiligung des ERP-Sondervermögens am wirtschaftlichen Wiederaufbau in der früheren DDR ist in den kommenden Jahren jedoch wieder eine positive Nettokreditaufnahme zu erwarten.

\section{bb. Der Lastenausgleichsfonds}

Der Lastenausgleichsfonds (LAF) wurde 1952 mit dem Inkrafttreten des Lastenausgleichsgesetzes (LAG) begründet, um Maßnahmen zum Ausgleich von Kriegsfolgelasten zu finanzieren. Er wurde aus dem Aufkommen der Vermögensabgabe, der Hypothekenund Kreditgewinnabgabe sowie erheblichen Zuschüssen des Bundes und der Länder gebil$\operatorname{det}^{3}$. Aus dem LAF werden seitdem Unterhaltshilfen, Entschädigungszahlungen sowie Aufbaudarlehen zur Beschaffung von Wohnraum und zum Aufbau einer beruflichen Existenz gewährt. Darüber hinaus übernimmt der LAF Rückbürgschaften gegenüber der Deutschen Ausgleichsbank.

Der LAF wird vom Präsidenten des Bundesausgleichsamtes, einer Bundesbehörde, verwaltet. Er stellt mit Zustimmung des Kontrollausschusses, dessen Mitglieder von Bundestag und Bundesrat gewählt werden, den jährlichen Wirtschafts- und Finanzplan auf, ohne daß eine gesetzliche Feststellung vorgesehen ist. Nachdem das LAG eine Kreditauf-

1 BUNDESREGIERUNG (1988), S.11.

2 Vgl. Anhang, Tabelle 14.

3 Zur Entstehungsgeschichte des Lastenausgleichsfonds, zu seinen Einnahmen sowie den verschiedenen Ausgleichsleistungen vgl. DEUTSCHE BUNDESBANK (1975), S.21 ff. 
nahme nur bis 1979 zugelassen hat, werden seitdem die Ermächtigungen zur Kreditaufnahme des LAF durch das jeweilige Haushaltsgesetz des Bundes erteilt. Nach \& 324 LAG unterliegt die Jahresrechnung des LAF zusammen mit der Bundeshaushaltsrechnung der Entlastung durch Bundestag und Bundesrat.

Aufgrund seiner Aufgabenstellung ist der LAF ein auslaufendes Sondervermögen. So wurden 1988 nur noch Darlehen in Höhe von 55 Mio. DM ausbezahlt. Der Bestand an Darlehensforderungen reduzierte sich von 1970 bis 1988 von 4,2 Mrd. DM auf 0,5 Mrd. $\mathrm{DM}^{1}$. Der Bruttovermögensbestand des LAF belief sich 1988 auf 0,9 Mrd. DM, dem eine Verschuldung in Höhe von 0,17 Mrd. DM gegenüberstand².

cc. Der Ausgleichsfonds für überregionale Maßnahmen zur Eingliederung Schwerbehinderter in Arbeit, Beruf und Gesellschaft

Der Ausgleichsfonds wurde gemäß § 12 Schwerbehindertengesetz (SchwbG) gebildet. Seine Mittel stammen in erster Linie aus dem Aufkommen der Ausgleichsabgabe, die nach $\S 11$ SchwbG von Arbeitgebern zu entrichten ist, die nicht die gesetzlich vorgeschriebene Quote Schwerbehinderter beschäftigen. Vom Aufkommen dieser Ausgleichsabgabe fließen 45 v.H. dem Ausgleichsfonds zu. Dieser hat hiervon 50 v.H. an die Bundesanstalt für Arbeit zur besonderen Förderung Schwerbehinderter zuzuweisen. Im übrigen sind die Mittel des Ausgleichsfonds zur Förderung von Einrichtungen und Maßnahmen zu verwenden, die den Interessen mehrerer Länder auf den Gebiet der Arbeits- und Berufsförderung Schwerbehinderter dienen. Die Förderung soll dabei durch Zuschüsse, Darlehen oder Zinszuschüsse erfolgen. Für die vom Ausgleichsfonds vergebenen Darlehen ist bestimmt, daß sie jährlich mit 2 v.H. zu verzinsen und in der Regel mit 2 v.H. zu tilgen sind. Dabei kann für 2 Jahre von der Verzinsung und Tilgung der Darlehen abgesehen werden ${ }^{3}$.

Der Ausgleichsfonds wird vom Bundesminister für Arbeit und Sozialordnung verwaltet, der für jedes Wirtschaftsjahr einen in Einnahmen und Ausgaben ausgeglichenen Wirtschaftsplan festzustellen hat. Dabei fließen Zinsen, Tilgungsbeträge aus Darlehen sowie zurückgezahlte Zuschüsse dem Ausgleichsfonds als Einnahmen zu. Kreditaufnahmen des Ausgleichsfonds sind, soweit ersichtlich, nicht gestattet.

1 Vgl. LASTENAUSGLEICHSBANK (1971), S.37; DEUTSCHE AUSGLEICHSBANK (1988), S.40 f., 81.

2 Vgl. FINANZBERICHT (1989), S.207.

3 Vgl. §§ 17, 24 der Zweiten Verordnung zur Durchführung des Schwerbehindertengesetzes (Ausgleichsabgabeverordnung Schwerbehindertengesetz - SchwbAV) vom 08.08.1978 (BGBl.I. S.1228). 
Der Vermögensbestand des Ausgleichsfonds betrug Ende 1982606 Mio. DM und stieg bis Ende 1988 auf 905 Mio. DM ${ }^{1}$. Ende 1988 wurden Darlehensforderungen in Höhe von 262 Mio. DM von der Deutschen Ausgleichsbank verwaltet, die seit 1983 als Geschäftsbesorgerin für den Ausgleichsfonds auftritt ${ }^{2}$.

dd. Landwirtschaftliche Sondervermögen

Im Bereich der Landwirtschaftsförderung existieren mit dem Zweckvermögen bei der Deutschen Siedlungs- und Landesrentenbank (DSLB) und dem Zweckvermögen bei der Landwirtschaftlichen Rentenbank (LRB) zwei Sondervermögen ${ }^{3}$ des Bundes.

Das Zweckvermögen bei der DSLB stammt noch aus vorkonstitutioneller Zeit und wurde seit Bestehen der Bundesrepublik durch Mittel des Bundes ergänzt ${ }^{4}$. Das Zweckvermögen ist insbesondere für zinsverbilligte und zinslose Darlehen sowie für Zinszuschüsse zu verwenden, die der Eingliederung der aus der Landwirtschaft stammenden Vertriebenen und Flüchtlinge einschließlich der Spätaussiedler dienen. Außerdem wurde das Zweckvermögen zur Aufstockung des Eigenkapitals der DSLB um 150 Mio. DM herangezogen. Die Kapitalaufstockung erfolgte durch Übertragung minderverzinslicher Darlehensforderungen des Zweckvermögens in das Eigenvermögen der DSLB 5 .

Das Zweckvermögen wird als Sondervermögen des Bundes von der 1989 teilprivatisierten DSLB verwaltet, die eine Verwendung nach Maßgabe der entsprechenden gesetzlichen Vorschriften sicherstellen muß $\beta^{6}$. Bei der Verwendung der Mittel handelt die DSLB im eigenen Namen ${ }^{7}$. Ein Wirtschaftsplan für das Zweckvermögen wird nicht aufgestellt ${ }^{8}$. Der Vermögensbestand des Zweckvermögens belief sich 1965 auf 2,73 Mrd. DM, stieg bis 1982 auf 4,46 Mrd. DM und verminderte sich dann bis auf 3,65 Mrd. DM im Jahr 19889.

1 BUNDESHAUSHALTSRECHNUNG (1984), S.152; FINANZBERICHT (1989), S.208.

Vgl. DEUTSCHE AUSGLEICHSBANK (1988), S.39, 67.

3 Die Bezeichnung dieser Sondervermögen als Zweckvermögen hat keinerlei rechtliche Bedeutung und ist allein historisch zu erklären. Vgl. SCHMIDT, G. (1971), S. 31.

4 Vgl. DICKERTMANN (1980), S.317.

5 Vgl. SEHRBROCK (1981), S.114 f.

6 Vgl. § 5 des Gesetzes über die Zusammenlegung der Deutschen Landesrentenbank und der Deutschen Siedlungsbank vom 27.08.1965 (BGBl.I S.1001) geändert durch Gesetz vom 22.08.1980 (BGBI.I S.1558).

7 Vgl. SCHMIDT, G. (1971), S. 20 f.

8 Vgl. FINANZBERICHT (1989), S.208.

9 Vgl. DICKERTMANN (1980), S.337; BUNDESHAUSHALTSRECHNUNG (1984), S.152; FINANZBERICHT (1989), S.208. 
Das Zweckvermögen bei der LRB wurde durch das Gesetz zur Abwicklung der landwirtschaftlichen Entschuldung vom 25.03.1952 ${ }^{1}$ mit einem Anfangskapital von 3,5 Mio. DM gegründet. Seitdem wurden dem Zweckvermögen Zuschüsse aus dem Bundeshaushalt und Gewinnanteile der Landwirtschaftlichen Rentenbank ${ }^{2}$ zugeführt. Die Mittel des Zweckvermögens werden zum Teil in Form zinsgünstiger Darlehen zur Finanzierung von Modellvorhaben im Agrarbereich, zum Teil aber auch als Zuschüsse für eine institutionenund projektbezogene Förderung eingesetzt ${ }^{3}$. Die Zinseinkünfte aus dem Zweckvermögen wurden bis 1981 an den sogenannten Absatzfonds abgeführt ${ }^{4}$. Seit Inkrafttreten des Subventionsabbaugesetzes vom $26.06 .1981^{5}$ fließen die Zinseinkünfte aus dem Zweckvermögen dem Bundeshaushalt zu.

Das Zweckvermögen wird von der Landwirtschaftlichen Rentenbank verwaltet. Ein jährlicher Wirtschaftsplan ist auch hier nicht vorgesehen. Die Höhe des Zweckvermögens lag 1960 bei 20 Mio. DM und erreichte 1988 den Betrag von 109 Mio. DM 6 .

ee. Das Treuhandvermögen für den Bergarbeiterwohnungsbau

Das Treuhandvermögen für den Bergarbeiterwohnungsbau beruht auf dem Gesetz zur Förderung des Bergarbeiterwohnungsbaues im Kohlebergbau in der Fassung vom 04.05.1957 7 und wurde durch die bis 1959 erhobene Kohleabgabe und durch Haushaltsmittel des Bundes aufgebaut. Aus den Mitteln des Treuhandvermögens werden Darlehen für den Bau von Bergarbeiterwohnungen gewährt. In besonderen Fällen dürfen auch Zuschüsse gegeben werden.

Das Treuhandvermögen wird durch Kreditinstitute in fünf Bergbauländern, den sogenannten Treuhandstellen, für den Bund treuhänderisch verwaltet. Dabei handeln die Treuhandstellen im eigenen Namen. Die Aufstellung eines Wirtschaftsplanes für das Treuhandvermögen ist nicht vorgesehen. Eine Kreditaufnahme des Treuhandvermögens und seine Haftung aufgrund von Kreditaufnahmen ist nur mit Zustimmung des Bundes-

BGBl.I S.203.

Zur Berechnung der dem Zweckvermögen zufließenden Gewinnanteile vgl. $\S 9$ Abs.3 des Gesetzes über die Landwirtschaftliche Rentenbank i.d.F. vom 12.07.1963 (BGBl.I S.465).

3 Vgl. SEIDEL (1982), S.398.

4 Vgl. dazu $\& 10$ Abs.1 des Gesetzes über die Errichtung eines zentralen Fonds zur Absatzförderung der deutschen Land-, Forst- und Ernährungswirtschaft vom 26.06.1969 (BGBl.I S.635).

BGBl.I S.537.

6 Vgl. DICKERTMANN (1980), S.337; FINANZBERICHT (1989), S.208.

7 BGBI.I S.418. 
ministers für den Wohnungsbau möglich. Der Vermögensbestand des Treuhandvermögens stieg von 1960 bis 1988 von 1,52 Mrd. DM auf 2,27 Mrd. DM¹.

\section{b. Sondervermögen der Länder}

Die folgende Darstellung der Sondervermögen der Länder kann keinen Anspruch auf Vollständigkeit erheben, da Informationen darüber insofern schwierig zu bekommen sind, weil bei den meisten Ländern eine komplette Vermögensübersicht als Anhang zum Haushaltsplan fehlt ${ }^{2}$.

aa. Wohnungsbauvermögen der Länder

In einigen Bundesländern erfolgt die Wohnungsbauförderung über WohnungsbauSondervermögen. Die Rückflüsse aus Darlehensforderungen, die mit Landesmitteln erworben wurden ${ }^{3}$, sind für die Wohnungsbauförderung, insbesondere für die Vergabe zinsverbilligter Darlehen, zweckgebunden zu verwenden. Die Wohnungsbau-Sondervermögen der Länder werden regelmäßig von Stellen verwaltet, die keine Landesbehörden sind.

In Hamburg wurde das Sonderkapital der Hamburgischen Wohnungsbaukreditanstalt als zweckgebundene Vermögensmasse aus Fördermitteln der Freien und Hansestadt Hamburg und von Dritten gebildet. Der Bestand des Sonderkapitals betrug Ende 1983 ca. 3,0 Mrd. DM ${ }^{4}$.

In Niedersachsen existiert zur Wohnungsbauförderung das Zweckvermögen bei der Landestreuhandstelle (LTS) für den Wohnungs- und Städtebau, einem rechtlich unselbständigen Teil der Norddeutschen Landesbank Girozentrale (NordLB), der betriebswirtschaftlich und organisatorisch von ihr getrennt ist ${ }^{5}$. Die Grundsätze über die Verwaltung der Zweckvermögen sind in einem Treuhandvertrag zwischen der LTS und dem Land

1 Vgl. DICKERTMANN (1980), S.337; FINANZBERICHT (1989), S.208.

2 Vgl. SCHEMMEL (1990), S. 7.

3 In diesem Zusammenhang ist darauf hinzuweisen, daB seit Inkrafttreten des Gesetzes zum Abbau der Fehlsubventionierung im Wohnungsbau vom 22.12.1981 (BGBl.I S.1523) die Mittel der Wohnungsbauvermögen der Länder zur Förderung des sozialen Wohnungsbaus verstärkt werden durch die als Fehlbelegungsabgabe geläufigen Ausgleichszahlungen von Inhabern öffentlich geförderter Wohnungen, die gewisse Einkommensgrenzen überschreiten (vgl. § 10 dieses Gesetzes). Dies gilt allerdings nur, wenn das jeweilige Land die Erhebung der Fehlbelegungsabgabe zugelassen hat.

4 Vgl. DICKERTMANN (1985), S.60 ff.

5 Vgl. DICKERTMANN (1985), S.57. 
Niedersachsen festgelegt. Danach sind die Jahresüberschüsse der LTS in eine Rücklage einzustellen, die für eine der Zweckbestimmung dieses Sondervermögens entsprechende Verwendung zur Verfügung steht.

Aus den Mitteln des Zweckvermögens einschließlich der laufenden Mittelzuweisungen werden vorwiegend Darlehen, aber auch Zuschüsse, vergeben. Außerdem werden auf das Zweckvermögen Bürgschaften übernommen ${ }^{1}$. Die Darlehensrückflüsse scheinen zumindest teilweise beim Zweckvermögen zu verbleiben, um revolvierend zweckentsprechend eingesetzt zu werden ${ }^{2}$. Der Bestand des Zweckvermögens belief sich Ende 1988 auf 5,7 Mrd. $\mathrm{DM}^{3}$.

Von der Wohnungsbauförderungsanstalt des Landes Nordrhein-Westfalen wird das Landeswohnungsbauvermögen dieses Landes verwaltet, das aus Landes- und Bundesmitteln gebildet worden ist. Für die Wohnungsbauförderungsanstalt wird ein in Vermögensund Ergebnisplan gegliederter Wirtschaftsplan aufgestellt, der als Beilage im Haushaltsplan enthalten ist. Im Vermögensplan sind die das Landeswohnungsbauvermögen betreffenden Einnahmen und Ausgaben gesondert aufgeführt und formell auszugleichen. Dabei fließen Tilgungsrückflüsse und Zinsen aus Darlehen des Landeswohnungsbauvermögens diesem als Einnahmen zu. Eine Kreditaufnahme des Landeswohnungsbauvermögens ist zulässig ${ }^{4}$. Die Aktiva des Landeswohnungsbauvermögens hatten 1983 ein Volumen von 19,8 Mrd. DM, dem Verbindlichkeiten in Höhe von 5,8 Mrd. DM gegenüberstanden5.

In Rheinland-Pfalz ist bei der dortigen Landesbank/Girozentrale eine Landestreuhandstelle eingerichtet, die den Landeswohnungsbaufonds verwaltet, der durch die Vergabe von Wohnungsbaudarlehen aus Landesmitteln entstanden ist. Aus Mitteln des Lan-

1 Die Höhe der jährlichen Bürgschaftsübernahmen hat seit Bestehen dieser LTS sehr stark geschwankt. Sie erreichten 1968 ihren Höchststand mit 229 Mio. DM und betrugen 1988 hingegen nur noch 6 Mio. DM.; vgl. LANDESTREUHANDSTELLE FÜR DEN WOHNUNGS- UND STÄDTEBAU (1988), VI.Tabellen, 4. Wohnungsbauförderung im ersten Förderungsweg in den Jahren 1948-1988.

2 Dies läßt sich aus den Tätigkeitsbericht dieser LTS schließen, wonach 1988 den Zuweisungen von 110 Mio. DM sowie den Darlehenstilgungen und -ablösungen von 295 Mio. DM Neuausleihungen von 260 Mio. DM und Zuschüsse von 31 Mio. DM gegenüberstanden. Genauere Angaben über die Verwendung der Darlehensrückflüsse fehlen jedoch im Tätigkeitsbericht dieser LTS. Vgl. LANDESTREUHANDSTELLE FÜR DEN WOHNUNGS- UND STÄDTEBAU (1988).

3 LANDESTREUHANDSTELLE FÜR DEN WOHNUNGS- UND STÄDTEBAU (1988), S.48.

4 Nach den Planzahlen für 1989 ist die Kreditaufnahme mit 915 Mio. DM noch vor den Tilgungsrückflüssen mit 850 Mio.DM, den Zuweisungen des Bundes mit 403 Mio. DM und den Zinsen aus gewährten Darlehen mit 210 Mio. DM die bedeutendste Einnahmenquelle des Landeswohnungsbauvermögens. Dies entspricht einer Kreditfinanzierungsquote seiner Ausgaben (1989: 2,64 Mrd. DM) von 35 Prozent 1989 gegenüber 23 Prozent im Jahr 1988. Vgl. NORDRHEINWESTFALEN (1989), Band XI, Einzelplan 11, Beilage 2, S.218.

Vgl. DICKERTMANN (1985), S.60 f. 
deswohnungsbaufonds werden wiederum in erster Linie zinsverbilligte Darlehen vergeben. Ihm fließen die Tilgungsrückflüsse und Zinsen aus diesen Darlehen zu, um für denselben Zweck verwendet zu werden. Der Vermögensbestand dieses Fonds betrug Ende 1983 2,4 Mrd. DM ${ }^{1}$.

Durch das Gesetz zur Förderung des Wohnungs- und Kleinsiedlungswesens in Schleswig-Holstein und über die Wohnungsbaukreditanstalt des Landes Schleswig-Holstein vom $08.02 .1960^{2}$ ist bestimmt, daß Rückflüsse und Erträge von den aus Landesmitteln zur Förderung des Wohnungsbaus vergebenen Darlehen laufend zur Förderung von Maßnahmen zugunsten des sozialen Wohnungsbaus zu verwenden sind. Die Landesmittel zur Förderung des Wohnungsbaus und die darauf beruhenden Rechte sind auf die Wohnungsbaukreditanstalt zu übertragen und bilden zusammen mit den Schuldendiensteinnahmen ein für die Schaffung von Wohnraum gebundenes Sondervermögen, das von der Wohnungsbaukreditanstalt verwaltet wird. Eine Kreditaufnahme zu Lasten des Sondervermögens ist aufgrund haushaltsgesetzlicher Ermächtigung möglich ${ }^{3}$. Der Bruttobestand des Sondervermögens erhöhte sich zwischen 1983 und 1987 von 3,31 Mrd. DM auf 4,19 DM4.

\section{bb. Sonstige Sondervermögen der Länder}

Soweit ersichtlich, gibt es lediglich in Niedersachsen weitere Sondervermögen zur Finanzierung öffentlicher Kredithilfen, die nicht die Wohnungsbauförderung betreffen. Ihre Verwaltung obliegt ebenfalls Landestreuhandstellen, die rechtlich unselbständige Teile der NordLB sind.

Der 1973 gegründeten Landestreuhandstelle für Agrarförderung obliegt die treuhänderische Verwaltung der aufgrund des Bundesgesetzes über die Gemeinschaftsaufgabe "Verbesserung der Agrarstruktur und des Küstenschutzes" sowie der im Rahmen der Förderungsmaßnahmen des Landes zum Zweck der Agrarförderung bereitgestellten Beträge. Die liquiden Mittel des Zweckvermögens werden zu einem geringeren Teil für die Vergabe von Darlehen, überwiegend jedoch für die Gewährung von Zuschüssen, darunter auch laufenden oder kapitalisierten Zinszuschüssen, verwendet. Dabei dürften auch hier Darlehensrückflüsse zumindest anteilig für den entsprechenden Zweck zur Verfügung stehen, wobei dies im Tätigkeitsbericht der Landestreuhandstelle nicht explizit zum Ausdruck

\footnotetext{
Vgl. DICKERTMANN (1985), S.58.

GVOBl. Schleswig-Holstein, S.31

3 Vgl. SCHLESWIG-HOLSTEIN (1989), Epl.04, Kap.0416, S.73.

4 Vgl. DICKERTMANN (1985), S.60; SCHLESWIG-HOLSTEIN (1989), EPI. 04, Kap. 0416, Anlage 1, S.102.
} 
gebracht wird. Der Bestand an Darlehensforderungen dieses Zweckvermögens lag 1988 bei 575 Mio. DM ${ }^{1}$.

Die 1977 gegründete Niedersächsische Landestreuhandstelle für Wirtschaftsförderung verwaltet treuhänderisch Landesmittel zur Förderung von Investitionen der gewerblichen Wirtschaft und seit 1988 auch zur Filmförderung. Diese Mittel werden überwiegend für Darlehensgewährungen in den genannten Bereichen eingesetzt. Die Darlehensrückflüsse standen bis 1987 dem in erster Linie aus den Darlehensforderungen bestehende Zweckvermögen vollständig zur Verfügung. Im Jahr 1988 mußten hingegen die Zinserträge aus den Förderdarlehen an das Land abgeführt werden, während das Tilgungsaufkommen bei Zweckvermögen verblieb und für neue Darlehensgewährungen verwendet werden konnte. Ende 1988 betrug das Fondsvolumen 802 Mio. DM².

\section{Außerbudgetäre Kredithilfe-Einrichtungen}

Eine andere Finanzierungsquelle für öffentliche Kredithilfen sind die außerbudgetären Kredithilfe-Einrichtungen. Sie werden wie die Sondervermögen unter den Oberbegriff der außerbudgetären Einheiten subsumiert. Dabei lassen sich bestimmte Sonderkreditinstitute und die als Parafisci bezeichneten Träger der Sozialversicherung unterscheiden. Die außerbudgetären Kredithilfe-Einrichtungen haben mit den Sondervermögen gemein, $\mathrm{da} ß$ sie vom übrigen Vermögen der Gebietskörperschaften abgesonderte Vermögensmassen bilden, die unter Verwendung staatlicher Einnahmen aufgebaut wurden und zur Finanzierung von Kredithilfen eingesetzt werden ${ }^{3}$. Sie unterscheiden sich hingegen von den betrachteten Sondervermögen dadurch, $d a B$ sie rechtlich verselbständigt sind und eigene Organe besitzen sowie mit Personal und Sachmitteln ausgestattet sind, was sie zur Einnahmenerzielung befähigt.

\section{a. Sonderkreditinstitute}

$\mathrm{Zu}$ den außerbudgetären Kredithilfe-Einrichtungen werden solche Sonderkreditinstitute gerechnet, die vollkommen oder weitgehend im öffentlichen Eigentum stehen und in wesentlichen Bereichen ihrer Aktivgeschäfte nicht mit sonstigen Kreditinstituten konkurrieren, weil sie in Erfüllung der zugewiesenen "öffentlichen Aufgaben" Kreditgeschäfte

1 Vgl. LANDESTREUHANDSTELLE FÜR AGRARFÖRDERUNG (1988), S.14 f.

2 Vgl. NIEDERSÄCHSISCHE LANDESTREUHANDSTELLE FÜR WIRTSCHAFTSFORDERUNG (1988), S.16.

3 Vgl. DICKERTMANN/HANSMEYER (1987), S.112. 
zu nichtmarktlichen Konditionen tätigen. Die Art der zugelassenen Passivgeschäfte ist hierbei weniger bedeutsam, da diese naturgemä $\beta$ darauf ausgerichtet sind, da $\beta$ diese Einrichtungen ihre Kreditaktivitäten refinanzieren und damit die ihnen zugewiesenen Aufgaben erfüllen können ${ }^{1}$. Zur Abgrenzung der hier betrachteten Einrichtungen ist zudem von Bedeutung, daß sie nicht nur im fremden Namen, sondern auch im eigenen Namen handeln und zumindest teilweise das Risiko aus der Gewährung öffentlicher Kredithilfen zu tragen haben.

Eine weitere Gemeinsamkeit der Mehrzahl dieser Einrichtungen betrifft die persönlichen Befreiungen bei der Körperschaft-, Gewerbe- und Vermögensteuer. Die Steuerbefreiung wird damit begründet, daß diese Einrichtungen mit anderen Kreditinstituten nicht im Wettbewerb stehen ${ }^{2}$. Eine andere Art der Steuerprivilegierung steht den beiden in Berlin tätigen Instituten zu, die ihre Aktivgeschäfte mittels steuerbegünstigter Darlehen refinanzieren können. Für einen Teil der Institute gibt es darüber hinaus bestimmte geldpolitische Privilegien in Form spezieller Rediskontkontingente und Mindestreservevorschriften, die die Refinanzierung ihrer Aktivitäten verbilligen ${ }^{3}$.

Die Organe der öffentlichrechtlichen Sonderkreditinstitute entsprechen weitgehend denen privatrechtlicher Kapitalgesellschaften. Üblicherweise gibt es einen Vorstand, der mit der Führung der Geschäfte beauftragt ist. Die Vorstandsmitglieder werden dabei regelmäßig privatrechtlich angestellt ${ }^{4}$. Die Kontrolle der Geschäftsführung und Entscheidungen besonderer Tragweite obliegen dem Verwaltungsrat, bei dessen Bestellung die Regierung der Eigentümer-Gebietskörperschaft maßgeblichen Einfluß ausübt. Darüber hinaus unterliegen die öffentlichrechtlich organisierten Sonderkreditinstitute der Rechtsaufsicht der jeweiligen Gebietskörperschaft.

Im Allein- oder Mehrheitsbesitz des Bundes befinden sich eine Reihe von Kreditinstituten, wobei einige mit ihrer Geschäftstätigkeit überwiegend in Konkurrenz zu anderen Kreditinstituten stehen ${ }^{5}$. Beispielhaft seien die Deutsche Siedlungs- und Landesrentenbank, die Deutsche Pfandbriefanstalt und die Deutsche Bau- und Bodenbank genannt, die vorwiegend im Bereich der Baufinanzierung tätig sind ${ }^{6}$. Zu nennen wäre hier auch die zur Bundespost gehörende Postbank, die praktisch keine Fördertätigkeit über-

1 Vgl. DEUTSCHER BUNDESTAG (1968), S.105.

2 Vgl. KLÄSCHEN (1990), Kommentar zu § 5 KStG, Anm.13, 14 und 17.

3 Vgl. DICKERTMANN (1980), S.304, 312; DICKERTMANN/HANSMEYER (1987), S.115.

4 Vgl. z.B. § 6 Abs.5 des Gesetzes über die Kreditanstalt für Wiederaufbau (KfW-Gesetz).

$5 \mathrm{Zu}$ einer ausführlichen Übersicht über die gesamten Bankbeteiligungen des Bundes vgl. DEUTSCHER BUNDESTAG (1968), S. 107 ff.; KAGE (1978); DICKERTMANN (1980), S.291 ff.; DICKERTMANN (1981), S.72 ff.; SCHIERENBECK (1987), S.80-82, 88.

6 Vgl. DICKERTMANN (1981), S.72 f., 74 f. 
nimmt. Auf diese Kreditinstitute soll nicht näher eingegangen werden. Nach der hier getroffenen Abgrenzung bleiben auch die in öffentlicher Gewährträgerschaft stehenden öffentlichrechtlichen Sparkassen unberücksichtigt, weil sie sich, wenn auch im Rahmen gesetzlicher Restriktionen, als Universalbanken betätigen und somit praktisch ausschließlich im Wettbewerbsbereich tätig sind ${ }^{1}$. Auch das Mandatarkonsortium aus der HERMES Kreditversicherungs-AG und der Treuarbeit AG, das mit der Durchführung der Ausfuhrgewährleistungen des Bundes beauftragt ist, wird hier nicht näher betrachtet, weil es ausschließlich im Namen und auf Rechnung des Bundes tätig wird ${ }^{2}$. Außerdem werden die Kreditgarantiegemeinschaften nicht zu den außerbudgetären Einrichtungen der Gebietskörperschaften gerechnet, weil es sich dabei um Selbsthilfeeinrichtungen der Wirtschaft handelt, an denen die Gebietskörperschaften formal nicht beteiligt sind. Schließlich werden auch Wirtschaftsförderungsgesellschaften der Kommunen aufgrund ihrer vielfältigen Gestaltungsformen, ihres im allgemeinen eher geringen Geschäftsvolumens und der untergeordneten Bedeutung von Kredithilfen im Rahmen ihrer Geschäftstätigkeit nicht weiter betrachtet ${ }^{3}$.

\section{b. Sonderkreditinstitute des Bundes}

Sonderkreditinstitute im Mehrheits- oder Alleinbesitz des Bundes, die als außerbudgetäre Kredithilfe-Einrichtungen im Sinne obiger Abgrenzung betrachtet werden können, sind die Kreditanstalt für Wiederaufbau (KfW), die Deutsche Ausgleichsbank (DAB) und die Berliner Industriebank AG (BIB). Wegen ihres Geschäftsschwerpunktes im Bereich von Unternehmensbeteiligungen und ihrer ganz speziellen Ausrichtung auf die Entwicklungshilfe bleibt hingegen die 1962 gegründete Deutsche Finanzierungsgesellschaft für Beteiligungen in Entwicklungsländern mbH (DEG) unberücksichtigt ${ }^{4}$.

aa. Die Kreditanstalt für Wiederaufbau

Die KfW wurde 1948 durch Gesetz in Form einer Körperschaft des öffentlichen Rechts gegründet ${ }^{5}$. Ihre Aufgabe bestand anfänglich in erster Linie darin, "durch Versorgung aller Zweige der Wirtschaft mit mittel- und langfristigen Darlehen die Durchführung

$1 \mathrm{Zu}$ einem knappen Überblick über die öffentlichrechtlichen Sparkassen vgl. HAHN (1978), S.265.

2 Vgl. HICHERT (1986), S.47 f.

3 Zum üblichen Tätigkeitsbereich der kommunalen Wirtschaftsförderungsgesellschaften vgl. WROBEL (1979).

4 Vgl. dazu ausführlich GLAGOW/HARTMANN/MENNE/POLLVOGT/SCHIMANK (1985).

5 Vgl. Gesetz über die Kreditanstalt für Wiederaufbau vom 05.11.1948, WiGBl. S.123. 
von Wiederaufbauvorhaben insoweit zu ermöglichen, als andere Kreditinstitute nicht in der Lage (waren), die erforderlichen Mittel aufzubringen"1. Bereits in den frühen fünfziger Jahren wurde die KfW zusätzlich für Aufgaben der Exportfinanzierung, einige Jahre später auch im Rahmen der Strukturpolitik eingesetzt. Seit einer Gesetzesänderung im Jahre 1961 obliegen der KfW ganz allgemein die Förderung der deutschen Wirtschaft und Aufgaben der Exportfinanzierung mittels Darlehensgewährung und Bürgschaftsübernahme sowie im Bereich der Entwicklungshilfe die Finanzierung förderungswürdiger Vorhaben im Ausland $^{2}$. Im Rahmen ihres gesetzlichen Auftrages vergibt die KfW auch zinsverbilligte Darlehen, deren Kosten formal von ihr getragen werden ${ }^{3}$.

Der Vorstand der KfW wird vom Verwaltungsrat bestellt und abberufen. Der Verwaltungsrat besteht aus sechs Mitgliedern der Bundesregierung, fünf vom Bundesrat bestellten Mitgliedern sowie 17 weiteren Mitgliedern aus dem Kreise des Kreditgewerbes, verschiedener anderer Wirtschaftszweige, der Gewerkschaften, der Bundesbank und der Gemeinden, die von der Bundesregierung nach Anhörung der beteiligten Gruppen bestellt werden. Weiterhin bestimmt die Bundesregierung den Vorsitzenden des Verwaltungsrats und seinen Stellvertreter ${ }^{4}$. Der Verwaltungsrat kann dem Vorstand allgemeine oder besondere Weisungen erteilen und sich die Zustimmung zum Abschluß bestimmter Geschäfte vorbehalten ${ }^{5}$.

Bei der Durchführung ihrer Geschäfte ist die KfW erheblichen Einschränkungen unterworfen. So sind ihr Depositen- und Kontokorrentgeschäfte im Regelfall ebenso untersagt wie der Effektenhandel auf fremde Rechnung. Bei der Gewährung von Darlehen sind, von Ausnahmen abgesehen, andere Kreditinstitute einzuschalten. Weiterhin ist die Vergabe kurzfristiger Darlehen nur mit Zustimmung des Verwaltungsrats gestattet. Außerdem geiten bei Darlehensvergaben und Bürgschaftsübernahmen regelmäßig strenge Besicherungsvorschriften ${ }^{6}$. Schließlich ist im KfW-Gesetz bestimmt, daß die KfW keine Gewinnausschüttung vornehmen darf. Vielmehr ist die Bildung einer gesetzlichen Rück-

1 BÄKOW (1984), S.413. Der anfängliche Stellenwert der KfW bei der Finanzierung des Wiederaufbaus wird dadurch deutlich, daß die von diesem Institut im Jahr 1950 gemachten Kreditzusagen in Höhe von 2,3 Mrd.DM rund ein Fünftel der Fremdfinanzierungsmittel der gesamten Volkswirtschaft ausmachten; vgl. BÄKOW (1984), S.413.

2 Vgl. \& 2 Abs. 1 und $2 \mathrm{KfW}-$ Gesetz.

3 Materiell werden die Kosten der Zinsverbilligung jedoch von ihren Eigentümern und damit letztlich von den Steuerzahlern getragen.

4 Verwaltungsratsvorsitzender ist dabei traditionell der Bundesminister der Finanzen, sein Stellvertreter der Bundesminister für Wirtschaft.

5 Vgl. $\$$ 6, $7 \mathrm{KfW}-$ Gesetz. Beispielsweise werden über alle Kredite zwischen 10 und 30 Mio. DM in einem Untergremium des Verwaltungsrates, über Kredite von mehr als 30 Mio. DM im Verwaltungsrat entschieden. Vgl. MÜLLER-KÄSTNER (1986), S.13.

6 Vgl. $\$ 2$ Abs.3, 3 Abs. 1 - 3 KfW-Gesetz. 
lage in Höhe von 125 Mio. DM vorgesehen, weitere Gewinne sind in eine Sonderrücklage einzustellen. Hinsichtlich der Besteuerung ist die KfW gem. § $11 \mathrm{KfW}-G e s e t z$ der Deutschen Bundesbank gleichgestellt und damit wie diese von Körperschaft-, Gewerbeund Vermögensteuer befreit.

Die Refinanzierung ihrer Aktivitäten erfolgt durch Mittel aus dem Bundeshaushalt, des ERP-Sondervermögens und durch Kreditaufnahme bei Kreditinstituten und sonstigen Gläubigern. Betrachtet man die Entwicklung der Gläubigerstruktur der KfW, so fällt auf, daß 1978 noch rund ein Drittel der Verbindlichkeiten gegenüber dem ERP-Sondervermögen geschuldet war, während dieser Anteil 1988 mit 15 Prozent einen neuen Tiefststand erreichte. Gegenläufig war die Entwicklung der beim Bund aus Haushaltsmitteln aufgenommenen Kredite, deren Anteil an den Verbindlichkeiten sich von 1978 bis 1982 in etwa verdoppelte und seither relativ konstant bei rund 40 Prozent liegt. Dagegen hat sich die relative Bedeutung der Kreditinstitute und der Sonstigen als Gläubiger der KfW im betrachteten Zeitraum wenig verändert ${ }^{1}$.

Als Grundkapital der KfW ist ein Betrag von einer Mrd. DM gesetzlich festgelegt, an dem der Bund einschließlich des ERP-Sondervermögens zu $80 \%$ und die Bundesländer zu $20 \%$ beteiligt sind. Nachdem auf das Grundkapital vom Bund und den Ländern anfänglich lediglich ein Betrag in Höhe von jeweils 500.000 DM einbezahlt worden war, wurde die Einzahlung später auf 150 Mio. DM aufgestockt ${ }^{2}$. Die Einzahlung der weiteren $85 \%$ des Grundkapitals kann vom Verwaltungsrat der $\mathrm{KfW}$ beschlossen werden, soweit dies zur Erfüllung ihrer Verbindlichkeiten erforderlich ist ${ }^{3}$. Auf die Anfang der achtziger Jahre zur Verstärkung des Eigenkapitals der Bank beschlossene Kapitalerhöhung in Höhe von 600 Mio. $\mathrm{DM}^{4}$ wurden die Zahlungen inzwischen weitgehend geleistet. Eine gesetzliche Änderung der Höhe des Grundkapitals steht allerdings noch aus.

Die Bilanzsumme der KfW stieg von 1974 bis 1988 von 31 Mrd. DM auf 105,5 Mrd. DM, das verfügbare Eigenkapital ${ }^{5}$ von 1,0 Mrd. DM auf 2,6 Mrd. DM. Damit fiel die

1 Vgl. Anhang, Tabelle 23.

2 Dazu wurden insgesamt 59 Mio. DM aus der gesetzlichen Rücklage zugunsten des Bundes und der Länder sowie Darlehensforderungen des Bundes von 90 Mio. DM, die dieser vom ERPSondervermögen erworben hat, in Grundkapital umgewandelt. Vom "eingezahlten" Grundkapital steht dem ERP-Sondervermögen nach § 1 Abs.4 KfW-Gesetz ein Betrag von 90 Mio. DM

zu. Vgl. MÜLLER-KÄSTNER (1986), S.10; HAGENMÜLLER/JACOB (1987), S.175.

3 Vgl. $\$ 1$ Abs. $3 \mathrm{KfW}-G$ esetz.

4 Vgl. MÜLLER-KÄSTNER (1986), S.12 f.

5 Eingezahlte Kapitalbeträge und Gewinnrücklagen. 
Eigenkapitalquote $^{1}$ im selben Zeitraum von 3,2 v.H. auf 2,5 v.H. Die Höhe der Eventualverbindlichkeiten stieg von 344 Mio. DM auf 3.198 Mio. DM².

\section{bb. Die Deutsche Ausgleichsbank}

Die bis 1986 als Lastenausgleichsbank firmierende DAB wurde 1950 unter dem Namen Vertriebenen-Bank AG gegründet und 1954 durch Gesetz in eine Anstalt des öffentlichen Rechts umgewandelt. Durch das Gesetz über die Deutsche Ausgleichsbank (DAB-Gesetz) ${ }^{3}$ erhielt die Deutsche Ausgleichsbank ein neues rechtliches Fundament.

Die Aufgabenstellung der Lastenausgleichsbank erstreckte sich in den ersten Jahren ihres Bestehens hauptsächlich auf die Finanzierung von Maßnahmen zur wirtschaftlichen Eingliederung und Förderung der Vertriebenen und Flüchtlinge sowie die finanzielle Abwicklung des Lastenausgleichs. Bereits frühzeitig übernahm sie zusätzlich die Durchführung von Programmen zur Förderung mittelständischer Existenzgründungen. In § 4 DABGesetz wird nun bestimmt, daß die DAB im wesentlichen Maßnahmen im Bereich der Wirtschaftsförderung, im sozialen Bereich, im Bereich des Umweltschutzes und zur wirtschaftlichen Eingliederung und Förderung von durch den Zweiten Weltkrieg und seine Folgen betroffenen Personen finanziert. Die Bank ist ferner im Rahmen des Lastenausgleichs tätig. Weiterhin kann die Bank die Übernahme von Bank-, Treuhand- und sonstigen Geschäften mit obersten Bundesbehörden vereinbaren. Schließlich kann die DAB zinsverbilligte Ergänzungsprogramme auflegen, die sie aus eigenen Mitteln finanziert.

Der Vorstand der DAB wird auf Vorschlag der Anstaltsversammlung, des Vertretungsorgans der Anteilseigner ${ }^{4}$, vom Verwaltungsrat bestellt. Der Verwaltungsrat hat höchstens 23 Mitglieder, von denen je fünf von Bundestag und Bundesrat entsandt und die weiteren von der Anstaltsversammlung bestimmt werden. Schließlich untersteht die DAB der Aufsicht der Bundesregierung.

Bei der Durchführung ihrer Geschäfte unterliegt die DAB vergleichbaren Beschränkungen wie die KfW. Von Ausnahmen abgesehen sind bei der Darlehensgewährung andere Kreditinstitute einzuschalten. Gewinne sind auch bei der DAB in Rücklagen einzustellen. Jedoch ist eine Gewinnausschüttung dann möglich, wenn sie von der Anstaltsversammlung beschlossen wird. Für die DAB gelten außerdem dieselben Steuerbefreiungen

1 Verfügbares Eigenkapital dividiert durch Bilanzsumme.

2 Vgl. DICKERTMANN (1980), S.303 f.; KREDITANSTALT FÜR WIEDERAUFBAU (1988), S.69.

3 BGBl.I 1986, S.1544.

4 Die Anstaltsversammlung stellt den JahresabschluB fest und beschlieBt die Satzung der DAB. 
wie für die KfW. Die Fremdmittel der DAB stammen in erheblichem Umfang aus staatlichen Quellen. Dabei entsprechen allein die dem ERP-Sondervermögen geschuldeten Beträge rund der Hälfte der Bilanzsumme ${ }^{1}$.

Das Grundkapital beträgt zur Zeit 120 Mio. DM. Dabei ist gesetzlich bestimmt, daß der Anteil der Bundesrepublik einschließlich ihrer Sondervermögen am Grundkapital 51 v.H. nicht unterschreiten darf und daß private Anteilseigner nicht zugelassen sind ${ }^{2}$. Die Anstaltsversammlung hat 1989 eine Verdoppelung des Grundkapitals beschlossen, die der Ausweitung der Geschäftstätigkeit der Bank Rechnung tragen soll ${ }^{3}$.

Das Eigenkapital der DAB (früher LAB) stieg von 1970 bis 1988 von 80 Mio. DM auf 368 Mio. DM. Im gleichen Zeitraum erhöhte sich die Bilanzsumme eher geringfügig von 9,1 Mrd. DM auf 14,2 Mrd. DM. Die Eigenkapitalquote stieg demnach von 0,9 v.H. auf 2,6 v.H. Die Eventualverbindlichkeiten stiegen von 224 Mio. DM auf 378 Mio. DM ${ }^{4}$.

\section{cc. Die Berliner Industriebank AG}

Die BIB wurde 1949 als Aktiengesellschaft errichtet, so daß für sie die allgemeinen aktienrechtlichen Vorschriften gelten. Die Aufgabe der BIB besteht in der Förderung der Berliner Wirtschaft durch Gewährung zinsgünstiger Finanzierungshilfen. Ihre Bedeutung kommt darin zum Ausdruck, daß die BIB an der Finanzierung von rund drei Vierteln aller Investitionen der Berliner Industrie beteiligt ist 5 .

Die BIB ist im Gegensatz zu den beiden vorgenannten Instituten nicht steuerbefreit. Dafür ist sie aber eine der Kapitalsammelstellen, die über die nach $\S 16$ BerlinFG steuerlich privilegierten Refinanzierungsmittel verfügen $\operatorname{kann}^{6}$. Den überwiegenden Teil der Refinanzierungsmittel erhält die BIB jedoch aus dem ERP-Sondervermögen. Die ERPMittel werden revolvierend eingesetzt, d.h. da $B$ auch die entsprechenden Darlehensrückflüsse zur Förderung der Berliner Wirtschaft verwendet werden ${ }^{7}$.

1 DEUTSCHE AUSGLEICHSBANK (1988), S.48.

2 Das Grundkapital wird bisher gehalten vom Bund (70 Mio. DM), dem ERP-Sondervermögen (28 Mio. DM) und dem Bundesausgleichsamt (22 Mio. DM); vgl. DEUTSCHE AUSGLEICHSBANK (1988), S.53.

3 Die Kapitalerhöhung wurde durch entsprechende Entnahmen aus den "Anderen Gewinnrücklagen" bewirkt, die dadurch auf 28 Mio. DM vermindert wurden; vgl. DEUTSCHE AUSGLEICHSBANK (1988), S.49.

4 LASTENAUSGLEICHSBANK (1970), Jahresbilanz; DEUTSCHE AUSGLEICHSBANK (1988), S.67.

5 Vgl. KIRCHHOFF (1987), S.71.

6 Allerdings sind diesbezüglich aufgrund der deutschen Einigung auf mittlere Sicht erhebliche Einschränkungen zu erwarten.

7 Vgl. DICKERTMANN (1981), S.75 f.; KIRCHHOFF (1987), S.71. 
Kapitaleigner der BIB sind der Bund über das ERP-Sondervermögen mit einem Anteil von 68 v.H., die KfW mit 20 v.H., das Land Berlin mit 4,8 v.H. und sonstige Anteilseigner mit 7,2 v.H. Das Grundkapital der BIB betrug Ende 197650 Mio. DM und wurde bis 1988 auf 65 Mio. DM erhöht. Das gesamte Eigenkapital stieg von 1976 bis 1988 von 99 Mio. DM auf 225 Mio. DM. Die Bilanzsumme erhöhte sich in diesem Zeitraum von 2,9 Mrd. DM auf 6,3 Mrd. DM ${ }^{1}$. Die Eigenkapitalquote stieg von 3,4 v.H. auf 3,6 v.H.

\section{c. Sonderkreditinstitute der Länder}

Bei den außerbudgetären Einrichtungen der Länder gibt es erhebliche Unterschiede in der rechtlichen Ausgestaltung und der wirtschaftlichen Bedeutung. Im folgenden sollen die Landeskreditbank Baden-Württemberg (LKB) und die Bayerische Landesanstalt für Aufbaufinanzierung (LfA) wegen ihres vergleichsweise hohen Geschäftsvolumens als Beispiele für außerbudgetäre Fördereinrichtungen der Länder ausführlicher betrachtet werden. Daran schließt sich ein knapper Überblick zu weiteren außerbudgetären Einrichtungen der Länder an.

\section{aa. Die Landeskreditbank Baden-Württemberg}

Die LKB wurde 1972 aufgrund eines Gesetzes durch Vereinigung der Badischen und der Württembergischen Landeskreditanstalt als Anstalt des öffentlichen Rechts errichtet ${ }^{2}$. Gewährträger ist das Land Baden-Württemberg, das den Gläubigern der Bank für deren Verbindlichkeiten unbeschränkt haftet, wenn diese aus dem Vermögen der Bank nicht befriedigt werden können.

Die LKB hat die gesetzlich zugewiesene Aufgabe, "das Land bei der Erfüllung seiner öffentlichen Aufgaben zu unterstützen", indem sie insbesondere bei der Förderung des Wohnungs- und Siedlungswesens, der Gemeindesanierung und -entwicklung, der gewerblichen Wirtschaft und der Land- und Forstwirtschaft sowie der Verbesserung der Infrastruktur mitwirkt ${ }^{3}$. Durch Änderung des LKB-Gesetzes, die zum 01.01.1989 in Kraft trat, wurde zudem gesetzlich festgeschrieben, daß die Bank neben ihrer Fördertätigkeit auch im Bereich der "Finanzierung sonstiger öffentlicher und privater Vorhaben, insbesondere

1 Vgl. KAGE (1978), S.51; DICKERTMANN (1981), S.79; BUNDESMINISTER DER FINANZEN (1989), S.201 f.

2 Vgl. § 1 des Gesetzes über die Landeskreditbank Baden-Württemberg (LKB-Gesetz) vom 11.4.1972 (GBl. S.129).

3 Vgl. § 3 Abs.1 LKB-Gesetz. 
wenn diese der Verbesserung der wirtschaftlichen und strukturellen Verhältnisse in BadenWürttemberg dienen", sowie sonstiger Bankleistungen und damit offenkundig in Konkurrenz zu anderen Kreditinstituten tätig werden darf ${ }^{1}$. Damit wurde einmal dem Umstand Rechnung getragen, daß das Fördergeschäft der Bank in den letzten Jahren deutlich zurückgegangen ist ${ }^{2}$ und zunehmend durch eine Ausweitung des Marktgeschäftes kompensiert wurde. Die zunehmende Bedeutung des Marktgeschäftes der LKB zeigt sich auch im Rückgang des Anteils der erfolgswirksam verbuchten Zinszuschüsse des Landes und aus bankeigenen Mitteln ${ }^{3}$ an den Zinserträgen, der 1974 bei 38,3 Prozent lag und 1988 noch 21,1 Prozent betrug ${ }^{4}$.

Im Zuge der genannten Gesetzesänderungen erfolgte durch Satzungsänderung eine organisatorische Neugliederung der LKB. So besteht seit dem 01.01.1989 unter der Bezeichnung Landeskreditbank Baden-Württemberg-Förderungsanstalt (LKB-FA) eine rechtlich unselbständige Anstalt des öffentlichen Rechts als Teil der LKB, die betriebswirtschaftlich und organisatorisch von den anderen Teilen der LKB getrennt ist ${ }^{5}$ und einen eigenen Jahresabschluß aufstellt ${ }^{6}$. Nach dem in die Satzung der LKB eingefügten $\S 5 \mathrm{a}$ führt die LKB-FA die der LKB obliegenden öffentlichen Förderungsprogramme durch, die in dieser Vorschrift beispielhaft aufgezählt sind. Die Förderungsaufgaben werden durch zinsverbilligte Darlehen, Zuschüsse, Bürgschaften und Gewährleistungen erfüllt, die auf der Grundlage von Gesetzen und Richtlinien des Bundes, des Landes und der LKB gewährt werden. Dazu gehören öffentliche Kredithilfen aus eigenen Mitteln der LKB.

Der Vorsitzende des Vorstands der LKB und sein Stellvertreter werden durch Beschluß der Landesregierung, die sonstigen Vorstandsmitglieder durch Verwaltungsratsbeschluß auf längstens fünf Jahre privatrechtlich angestellt ${ }^{7}$. Dabei obliegt die Geschäfts-

1 Vgl. Art.1 des Gesetzes zur Änderung des Gesetzes über die Landeskreditbank BadenWürttemberg v. 05.12.1988 (GBl. S.388).

2 So reduzierte sich das Bewilligungsvolumen der LKB im Bereich der Wohnungsbauförderung von 1978 bis 1988 von 1.700 Mio. DM auf 660 Mio. DM; vgl. LANDESKREDITBANK BADEN-WÜRTTEMBERG (1988), S.5.

3 Das Land Baden-Württemberg leistet an die LKB kapitalisierte Zinszuschüsse, die im Vergabejahr als Passiver Rechnungsabgrenzungsposten verbucht werden und über die Laufzeit der mit diesen Mitteln zinsverbilligten LKB-Darlehen erfolgswirksam aufgelöst werden. Sofern die Zinsverbilligung von Darlehen aus bankeigenen Mitteln erfolgt, werden dafür im Vergabejahr aufwandserhöhende Zuführungen zu Rückstellungen für Zinsverbilligungen vorgenommen, die dann ebenfalls über den Zeitraum der Zinsverbilligung aufgelöst werden.

4 Vgl. Anhang, Tabelle 3.

5 Vgl. Bekanntmachung der Landesregierung über die Änderung des Satzung der Landeskreditbank v. 12.12.1988 (GBl. S.404).

6 Lt. schriftlicher Auskunft der LKB an den Verfasser vom 21.08.1989 wird dieser gesonderte Jahresabschluß allerdings nur intern erstellt und nicht veröffentlicht.

7 Vgl. § 7 Abs.2 LKB-Gesetz. 
führung der LKB-FA einem oder mehreren Mitgliedern des Vorstands. Der Verwaltungsrat besteht aus acht Vertretern der Landesregierung und sieben weiteren Mitgliedern, die alle von der Landesregierung bestellt werden. Der Verwaltungsrat bestimmt u.a. die Richtlinien für die Geschäftstätigkeit der Bank und beschließt über die Verwendung des Bilanzgewinns. Als weiteres Organ gibt es einen Beirat, der im wesentlichen beratende Aufgaben hat ${ }^{1}$.

In der Satzung der LKB sind die zulässigen Geschäfte abschließend aufgezählt. Im Aktivgeschäft ist neben den bereits erwähnten Geschäften auch die Anlage von Geldern bei anderen Kreditinstituten zugelassen. Bei der Gewährung von Darlehen sollen in der Regel andere Kreditinstitute eingeschaltet werden, sofern es sich nicht um Darlehen zur Förderung des Wohnungsbaus handelt. Im Passivgeschäft ist die Ausgabe von Pfandbriefen, Kommunalobligationen und Schuldverschreibungen, nicht jedoch das Kontokorrentgeschäft zugelassen. Die LKB-FA ist von der Körperschaft-, Gewerbe- und Vermögensteuer befreit ${ }^{2}$.

Das Grundkapital der LKB wurde zunächst auf 500 Mio. DM festgesetzt und ist zwischenzeitlich auf 900 Mio. DM erhöht worden. Das Eigenkapital der LKB erhöhte sich von 1972 bis 1988 von 550 Mio. DM auf 1,96 Mrd. DM. Gleichzeitig stieg die Bilanzsumme von 9,1 Mrd. DM auf 46,1 Mrd. DM³. Die Eigenkapitalquote fiel damit von 6,0 v.H. auf 4,3 v.H. Die Verbindlichkeiten aus übernommenen Gewährleistungen, die 1973 bei 126 Mio. DM lagen, betrugen Ende 1988 2.035 Mio. DM.

\section{bb. Die Bayerische Landesanstalt für Aufbaufinanzierung}

Die LfA wurde 1950 durch das Gesetz über die Bayerische Landesanstalt für Aufbaufinanzierung (LfA-Gesetz) als rechtsfähige Anstalt des öffentlichen Rechts errichtet. Gewährträger mit voller Haftung und alleiniger Eigentümer ist der Freistaat Bayern.

Die LfA hat im Rahmen der staatlichen Finanz-, Wirtschafts-, Verkehrs- und Arbeitsmarktpolitik die Aufgabe, Maßnahmen zur Verbesserung und Stärkung der Wirtschafts- und Verkehrsstruktur Bayerns finanziell zu fördern. Daneben können der LfA auch Aufgaben in anderen Bereichen, wie der Familienförderung, übertragen werden. Als Förderungsinstrumente werden langfristige zinsgünstige Darlehen, Bürgschaften und Garantien, Zuschüsse und stille Beteiligungen eingesetzt. Außer der Durchführung staatli-

1 Vgl. § 4a der Satzung der Landeskreditbank Baden-Württemberg.

2 Vgl. Steuerreformgesetz v. 25.07.1988, BGBl.I S.1093.

3 Vgl. LANDESKREDITBANK BADEN-WÜRTTEMBERG (1988), S.5. 
cher Förderungsprogramme kann die LfA zur Erfüllung ihrer Aufgaben auch eigene Förderprogramme ohne Einsatz staatlicher Haushaltsmittel durchführen. Die zur Erfüllung ihrer Aufgaben notwendigen Mittel beschafft sich die LfA beim Freistaat Bayern, beim Bund und am Geld- und Kapitalmarkt. Insbesondere erhält die LfA vom Freistaat Zinszuschüsse, die zur Zinsverbilligung von LfA-Darlehen zu verwenden sind. Ihre Höhe betrug zwischen 1984 und 1988 jeweils mehr als 200 Mio. DM p.a. ${ }^{1}$

Der Vorstand der LfA hat die Stellung einer dem Staatsministerium der Finanzen nachgeordneten Behörde. Seine Mitglieder werden von der Staatsregierung bzw. dem Staatsministerium der Finanzen auf höchstens fünf Jahre bestellt und stehen in einem privatrechtlichen Dienstverhältnis. Aus wichtigem Grund können Vorstandsmitglieder unbeschadet ihres Dienstvertrages jederzeit abberufen werden ${ }^{2}$. Der Verwaltungsrat besteht aus mindestens neun Mitgliedern, davon fünf Vertretern von Ministerien, die vom Staatsministerium der Finanzen bestellt werden. Er erläßt allgemeine Richtlinien für LfAFörderprogramme und ist darüber hinaus bei einer Reihe von Geschäftsvorgängen eingeschaltet, die seiner Zustimmung bedürfen ${ }^{3}$. Die LfA steht außerdem unter der Aufsicht des Staatsministeriums der Finanzen, das zur Überwachung der Geschäftsführung einen ihm untergeordneten Staatsbeauftragten bestellt ${ }^{4}$.

Hinsichtlich der Gewinnverwendung ist bestimmt, daß mindestens 25 v.H. des Gewinns einer gesetzlichen Rücklage zuzuführen sind. Vom restlichen Gewinn können mit Genehmigung der Aufsichtsbehörde sonstige Rücklagen gebildet werden. Im übrigen ist der Gewinn an den Freistaat Bayern abzuführen, der ihn mindestens zur Hälfte zweckgebunden für die Aufgaben der Anstalt zu verwenden hat. Für die LfA gilt ebenfalls die persönliche Steuerbefreiung bei der Körperschaft-, Gewerbe- und Vermögensteuer.

Das Grundkapital der LfA wurde gesetzlich auf mindestens 50 Mio. DM festgesetzt und betrug Ende 1988300 Mio. DM5. Das gesamte Eigenkapital der LfA stieg von 1975 bis 1988 von 249 Mio. DM auf 756 Mio. DM. Die Bilanzsumme, die 1975 noch bei 6,0 Mrd. DM lag, erreichte 1988 die Höhe von 15,7 Mrd. DM. Die Eigenkapitalquote erhöhte sich

1 Vgl. Anhang, Tabelle 3.

2 Als wichtiger Grund gelten grobe Pflichtverletzung oder Unfähigkeit zur ordnungsgemäßen Geschäftsführung; vgl. § 10 LfA-Gesetz.

3 Dies gilt beispielsweise für die Gewährung von Darlehen, deren Betrag 4 Mio. DM übersteigt sowie für Bürgschaftsübernahmen von über 4 Mio. DM. Zu den weiteren zustimmungspflichtigen Geschäften der LfA vgl. § 13 der Satzung der LfA i.d.F. vom 26.9.1988 (Bayer. Staatsanzeiger Nr.44/1988).

4 Vgl. $\$ 2$ Abs. 2 und 3 LfA-Gesetz.

5 Eine Erhöhung des Grundkapitals kann durch Übertragung von Vermögensgegenständen auf die Anstalt, aber auch durch Eigenmittel der Anstalt erfolgen. Vgl. § 7 Abs.2 LfA-Gesetz. 
also von 4,2 v.H. auf 4,8 v.H. Die Eventualverbindlichkeiten stiegen im selben Zeitraum von 153 auf 186 Mio. $\mathrm{DM}^{1}$.

\section{cc. Weitere Sonderkreditinstitute der Länder}

Die Bayerische Landesbodenkreditanstalt ist eine rechtlich unselbständige Anstalt der Bayerischen Landesbank Girozentrale, die insbesondere im Bereich der Wohnungsbauförderung tätig ist. Sie nimmt zum Teil die treuhänderische Verwaltung von Darlehen für den Freistaat Bayern wahr und erhält darüber hinaus Darlehen aus Landesmitteln, die sie im Eigengeschäft an die Endkreditnehmer vergibt. Der Bestand an Forderungen des Freistaats aus Wohnungsbaudarlehen gegenüber der Landesbodenkreditanstalt belief sich Ende 1988 auf 12,1 Mrd. DM².

Die Wohnungsbaukreditanstalt Berlin, an der das Land Berlin zu 100 Prozent beteiligt ist, besteht als Anstalt des öffentlichen Rechts seit 1965, wobei ihre Ursprünge bis in die zwanziger Jahre zurückreichen. Ihre Hauptaufgabe liegt in der Förderung des sozialen Wohnungsbaus, die unter Verwendung von Fördermitteln des Bundes und des Landes Berlin durchgeführt wird. Des weiteren ist die Wohnungsbaukreditanstalt Kapitalsammelstelle für die steuerbegünstigten Berlin-Darlehen nach § 17 BerlinFG, die zur Förderung des Wohnungsbaus einzusetzen sind. Diese Darlehen werden von der Anstalt an die in Berlin tätigen Realkreditinstitute weitergeleitet, die sie zur Wohnungsbaufinanzierung verwenden müssen. Die Anstalt verfügte 1985 über ein Grundkapital von 93 Mio. DM und ein haftendes Eigenkapital von 1,2 Mrd. DM. Die Bilanzsumme belief sich in diesem Jahr auf 18,4 Mrd. DM $^{3}$.

Weitere Institute im Bereich der Wohnungsbauförderung sind die Hamburgische Wohnungsbaukreditanstalt (Bilanzsumme 1983: 5,4 Mrd. DM), die Niedersächsische Landestreuhandstelle für den Wohnungs- und Städtebau (Bilanzsumme 1988: 5,8 Mrd. DM) ${ }^{4}$, die Wohnungsbauförderungsanstalt Nordrhein-Westfalen (Bilanzsumme 1983: 30,4 Mrd. DM) sowie die Wohnungsbaukreditanstalt Schleswig-Holstein (Bilanzsumme 1983: 5,0 Mrd. DM) 5 .

1 Vgl. BAYERISCHE LANDESANSTALT FÜR AUFBAUFINANZIERUNG (1976); dies. (1988).

2 Vgl. DICKERTMANN (1985), S.56; FREISTAAT BAYERN (1989), Epl.13, Anlage E, S.234 ff.

3 Vgl. RIEBSCHLÄGER (1987).

4 Vgl. dazu oben Abschnitt B.II.2.b.

5 Vgl. DICKERTMANN (1985), S.60. 
Im Bereich der Wirtschaftsförderung gibt es in verschiedenen Bundesländern weitere außerbudgetäre Einrichtungen. Dazu gehören die Wirtschaftsförderung Hessen Investitionsbank $A G^{1}$, die Landestreuhandstellen für Wirtschaftsförderung und für Agrarförderung in Niedersachsen, die Finanzierungs-Aktiengesellschaft Rheinland-Pfalz (Finag), die Saarländische Investitionsbank AG, die Wirtschaftsaufbaukasse Schleswig-Holstein AG und die Landesgarantiekasse Schleswig-Holstein AG. Diese Einrichtungen zeichnen sich dadurch aus, daß sie sich im Allein- oder Mehrheitsbesitz des jeweiligen Bundeslandes befinden und für dieses im Bereich öffentlicher Kredithilfen tätig werden. Bei der Finag und bei der Landesgarantiekasse Schleswig-Holstein beschränkt sich die Tätigkeit auf die Übernahme von Gewährleistungen. Dabei steht bei beiden Instituten die treuhänderische Verwaltung von Gewährleistungen für das Land und andere Treugeber gegenüber der Übernahme eigener Gewährleistungen im Vordergrund ${ }^{2}$. Diese Institute besitzen sämtlich ein Grund- bzw. Stammkapital von unter 25 Mio. DM und eine Bilanzsumme, die deutlich unter einer Mrd. DM liegt ${ }^{3}$.

\section{d. Träger der Sozialversicherung}

Unter den Trägern der Sozialversicherung kommt der Bundesanstalt für Arbeit im Zusammenhang mit öffentlichen Kredithilfen besondere Bedeutung zu. Die Bundesanstalt für Arbeit ist eine rechtsfähige Körperschaft des öffentlichen Rechts ${ }^{4}$. Ihr obliegt die Durchführung der im Arbeitsförderungsgesetz (AFG) vorgesehenen Maßnahmen 5 . Dazu gehört in begrenztem Umfang auch die Gewährung zinsverbilligter Darlehen, beispielsweise zur Finanzierung beruflicher Fortbildungsmaßnahmen oder von Arbeitsbeschaffungsmaßnahmen ${ }^{6}$. Ihre Ausgaben finanziert die Bundesanstalt für Arbeit einerseits aus dem Aufkommen der Beiträge zur gesetzlichen Arbeitslosenversicherung und andererseits durch Zuschüsse aus dem Bundeshaushalt.

1 Die Wirtschaftsförderung Hessen Investitionsbank AG wurde 1990 umbenannt. Sie firmierte bis dahin als Hessische Landesentwicklungs- und Treuhandgesellschaft mbH (HLT). Vgl. o.V. (1990), S.13.

2 Bei der Landesgarantiekasse beliefen sich die Verbindlichkeiten aus eigenen Gewährleistungen Ende 1983 auf 270 Mio. DM, denen treuhänderisch verwaltete Bürgschaften mit einem Obligo von 925 Mio. DM gegenüberstanden; vgl. DICKERTMANN (1985), S.67. Bei der Finag lag die Haftsumme aus eigenen Bürgschaften und Garantien 1985 bei 20 Mio. DM gegenüber treuhänderisch verwalteten Gewährleistungen mit einer Haftsumme von 230 Mio. DM; vgl. FINAG (1985), S.16 f.

3 Vgl. DICKERTMANN (1985), S.60 f., Übersicht 5.

4 Vgl. $\$ 189$ Abs. 1 AFG.

5 Vgl. $\$ 3$ Abs. 1 AFG.

6 Vgl. $\$ 44$ Abs.2a, 91, 98 AFG. 
Die Organe der Bundesanstalt sind Verwaltungsrat und Vorstand sowie Verwaltungsausschüsse bei den Landesarbeitsämtern und Arbeitsämtern. Der Verwaltungsrat, der sich zu je einem Drittel aus Vertretern der Arbeitnehmer, Arbeitgeber und öffentlichen Körperschaften zusammensetzt ${ }^{1}$, erläßt für die Darlehen der Bundesanstalt Anordnungen, in denen der jeweilige Zinssatz festgelegt ist ${ }^{2}$.

\section{DIE BEDEUTUNG AUSSERBUDGETÄRER EINHEITEN BEI DER VERGABE ÖFFENTLICHER KREDITHILFEN}

Aufgrund der besonderen Bedeutung außerbudgetärer Einheiten bei der Vergabe öffentlicher Kredithilfen sollen ihre damit zusammenhängenden Funktionen genauer untersucht werden. Dabei werden die Sondervermögen, Sonderkreditinstitute sowie die Bundesanstalt für Arbeit als Sozialversicherungsträger getrennt betrachtet.

\section{Funktionen der Sondervermögen}

Bei den Sondervermögen lassen sich im wesentlichen zwei Funktionen ausmachen: die Finanzierung eigener Kredithilfeprogramme sowie die Bereitstellung liquider Mittel zur Finanzierung temporärer staatlicher Zusatzprogramme. Dagegen ist den Sondervermögen mangels persönlicher und sachlicher Ausstattung die Durchführung der Kredithilfeprogramme nicht möglich.

\section{a. Finanzierung eigener Programme}

Die Sondervermögen verfügen über eigene Einnahmen, die sie im gesetzlichen Rahmen zur Finanzierung von Kredithilfen verwenden können. Diese Einnahmen bestehen im wesentlichen aus Rückflüssen aufgrund der Darlehensvergabe früherer Perioden, dem Aufkommen spezieller Abgaben, Zuweisungen der Gebietskörperschaften aus allgemeinen Haushaltsmitteln und in einigen Fällen aus Krediteinnahmen.

Durch die aus der Darlehensvergabe der Sondervermögen resultierenden Zinserträge erhöht sich ihr nominaler Vermögensbestand auch ohne Zuführungen der Gebietskörperschaften, solange diese Erträge die Aufwendungen übersteigen. Zinsaufwendungen entstehen dabei nur insoweit, als die Sondervermögen am Kapitalmarkt verschuldet sind. Der

1 Vgl. $\$ \$ 192,195$ AFG.

2 Vgl. die schriftliche Auskunft der Bundesanstalt an den Verfasser vom 09.04.1990. 
größere Teil des zur Darlehensvergabe eingesetzten Kapitals wird den Sondervermögen jedoch von den Gebietskörperschaften unentgeltlich zur Verfügung gestellt. Damit ist es den Sondervermögen möglich, selbst bei bescheidener Verzinsung der erworbenen Darlehensforderungen einen "Gewinn" zu erwirtschaften. Da die Verzinsung der Darlehensforderungen der Sondervermögen jedoch regelmäßig unter der Verzinsung einer marktlichen Alternativanlage liegen, handelt es sich hierbei nicht um einen ökonomischen Gewinn, weil die Opportunitätskosten die Erträge übersteigen. Dementsprechend gilt auch hier, daß der Marktwert des Vermögensbestandes unter seinem Nominalwert liegt ${ }^{1}$.

Wenn sich ein Sondervermögen verschulden kann und mit den Krediteinnahmen zinsverbilligte Darlehen finanziert werden, bleibt der nominale Netto-Vermögensbestand in der Vergabeperiode unbeeinflußt. In den Folgeperioden ergeben sich jedoch Ausgabenüberschüsse, die zu einem Rückgang des realen Netto-Vermögensbestands gegenüber dem Verzicht auf die Vergabe kreditfinanzierter Darlehen führen. Dasselbe gilt, wenn aus Mitteln eines Sondervermögens Schuldendiensthilfen in entsprechender Höhe vergeben werden. Dieser Fall ist jedoch bei den Sondervermögen in der Regel nicht gegeben. Da die Wirtschaftspläne der Sondervermögen als Einnahmen-Ausgaben-Rechnung konzipiert sind, werden solche Verluste jedoch nicht sichtbar.

\section{b. Bereitstellung liquider Mittel für Zusatzprogramme der Gebietskörperschaften}

Bisweilen hatten die Sondervermögen des Bundes in der Vergangenheit auch die Aufgabe, liquide Mittel zur Finanzierung von Ausgabenüberschüssen staatlicher Kredithilfeprogramme bereitzustellen, die über das übliche Programmvolumen hinausgingen. Dazu wurden zum Teil vom betreffenden Sondervermögen Kredite aufgenommen, für die dann der Bund den gesamten Schuldendienst oder die Zinsaufwendungen übernahm. Auf diese Weise flossen dem Sondervermögen liquide Mittel zu, ohne seinen künftigen Aufwand zu erhöhen. Der Netto-Vermögensbestand des Sondervermögens veränderte sich durch diese Transaktionen somit nicht, weil die Kosten der Kredithilfeprogramme vom Bund getragen wurden.

Dieser Weg wurde vom Bund zur Finanzierung des ERP-Investitionshilfeprogramms beschritten, das 1967/68 als Beitrag zum 2.Konjunkturprogramm der Bundesregierung aufgelegt wurde. Dabei hat sich der Bund verpflichtet, die damit zusammenhängenden

1 Geht man beispielsweise von einer durchschnittlichen Zinsverbilligung von 2 Prozentpunkten bei Darlehen aus und sieht man von ausgabenwirksamen Aufwendungen ab, so wäre das potentielle Vermögen nach 35 Jahren doppelt so hoch wie das tatsächliche Vermögen (eigene Berechnung). 
Zinsaufwendungen des ERP-Sondervermögens zu übernehmen. Dieses Programm wurde 1984 abgewickelt. Dasselbe Vorgehen des Bundes war in Bezug auf das Zweckvermögen bei der DSLB zu verzeichnen. Hier hat die Rechtsvorgängerin der DSLB, die Deutsche Siedlungsbank, in den Haushaltsjahren von 1958 bis 1960 und 1965 im Auftrag des Bundes Kapitalmarktmittel von insgesamt 300 Mio. DM zur Finanzierung von Fördermaßnahmen im Bereich ländlicher Siedlung beschafft. Der Bund hat sich im Gegenzug dazu verpflichtet, die erforderlichen Beträge für die Verzinsung und Tilgung dieser Kredite bereitzustellen ${ }^{1}$. Neue derartige Maßnahmen sind jedoch seit der Finanzverfassungsreform von 1969 nicht mehr möglich ${ }^{2}$.

Eine alternative Methode der Bereitstellung liquider Mittel für zusätzliche Kredithilfeprogramme ist darin zu sehen, daß ein Sondervermögen eigene Forderungen entgeltlich an die entsprechende Gebietskörperschaft abtritt. So können Mittel, die in anderer Weise gebunden sind, für die gewünschten Zwecke eingesetzt werden. Diese Vorgehensweise trägt der geringen Liquidität der Aktiva der Sondervermögen Rechnung, welche auf die vergleichsweise langen Laufzeiten der von den Sondervermögen vergebenen Darlehen und den Verzicht auf eine "Privatisierung" von Forderungen der Sondervermögen zurückzuführen ist. Dabei führt die entgeltliche Abtretung von Forderungen an die Gebietskörperschaft zu einer Reduzierung des realen Vermögensbestandes des Sondervermögens, wenn sich der Erlös an dem (fiktiven) Marktwert der abgetretenen Forderungen orientiert und für zinsverbilligte Darlehen verwendet wird. Dagegen liegt ein reiner Aktivtausch vor, wenn die Forderungen zu ihrem Nominalwert von der Gebietskörperschaft übernommen werden und die Verzinsung der neuen und der abgetretenen Forderungen übereinstimmt.

Beispielsweise hat der Bund zwischen 1982 und 1986 verschiedene Forderungen des ERP-Sondervermögens in einer Gesamthöhe von 678 Mio. DM entgeltlich zu ihrem Nennwert erworben. Damit wurde die Finanzierung des ERP-Beitrags zu der von der Bundesregierung 1982 beschlossenen Gemeinschaftsinitiative für Arbeitsplätze, Wachstum und Stabilität und für "baurelevante Maßnahmen im Bundesgebiet" ermöglicht ${ }^{3}$.

\section{Funktionen der Sonderkreditinstitute}

Die Sonderkreditinstitute des Bundes und der Länder sind nahezu ausschließlich in die Vergabe öffentlicher Kredithilfen eingeschaltet, auf die kein Rechtsanspruch besteht.

\footnotetext{
1 SUBVENTIONSBERICHT (1987), S.66.

2 BUNDESREGIERUNG (1988), S.11.

3 BUNDESREGIERUNG (1988), S.11.
} 
In diesem Zusammenhang nehmen sie im wesentlichen vier Funktionen wahr: die Durchführung und Abwicklung von Kredithilfen der Gebietskörperschaften und ihrer Sondervermögen, die Beteiligung an der Finanzierung besonderer Kredithilfeprogramme, die vollständige Eigenfinanzierung von Kredithilfeprogrammen und die Einnahmenerzielung für die Gebietskörperschaften. Diese Aufgaben werden aber nicht von allen der oben vorgestellten Einrichtungen gleichermaßen wahrgenommen.

\section{a. Durchführung von Kredithilfeprogrammen der Gebietskörperschaften}

Die Funktion von Sonderkreditinstituten, die ursprünglich im Vordergrund gestanden hat, ist die Durchführung von Kredithilfeprogrammen der Gebietskörperschaften. Dazu gehört die Bearbeitung von Kredithilfeanträgen einschließlich der bankmäßigen Überprüfung des Risikos, häufig auch die Entscheidung über die Anträge sowie die Auszahlung der Mittel. Weiterhin ist bis zur Abwicklung der Maßnahme die Erfüllung der einzelnen Pflichten des Leistungsempfängers zu kontrollieren. Die erforderlichen finanziellen Mittel werden durch eine Gebietskörperschaft oder ein Sondervermögen bereitgestellt. Für die Durchführung der Kredithilfen der Gebietskörperschaften erhalten die Sonderkreditinstitute besondere Entgelte in Form von Provisionen, Vergütungen und Zinsmargen ${ }^{1}$ :

Während die Durchführung von Schuldendiensthilfe-Programmen keine größeren Besonderheiten aufweist ${ }^{2}$, kann bei Gewährleistungs- und Darlehensprogrammen danach unterschieden werden, ob das Sonderkreditinstitut lediglich treuhänderisch oder in eigenem Namen und auf eigene Rechnung tätig wird.

Bei der treuhänderischen Vergabe von Darlehen handeln die Sonderkreditinstitute in eigenem Namen, aber auf fremde Rechnung. Ihre Haftung beschränkt sich in diesen Fällen auf die Verletzung der banküblichen Sorgfalt bei der Bearbeitung der Kreditunterlagen und der Überwachung des Schuldendienstes ${ }^{3}$. Die quantitativ bedeutsamsten Treuhandkredite werden von der $\mathrm{KfW}$ im Rahmen der Kapitalhilfe an die Entwicklungsländer vergeben. Diese Kredite werden in vollem Umfang aus Mitteln des Bundeshaushalts refinanziert ${ }^{4}$.

Bei der anderen Variante stellt eine Gebietskörperschaft oder ein Sondervermögen die gesamten Mittel für die Darlehensvergabe dem Sonderkreditinstitut darlehensweise

1 Vgl. DICKERTMANN (1980), S.288.

2 Zum Verfahren bei der Durchführung von Zinszuschußprogrammen durch Sonderkreditinstitute vgl. LANDESTREUHANDSTELLE FÜR AGRARFÖRDERUNG (1988), S.12 ff.

3 Vgl. DICKERTMANN (1980), S.275.

4 Vgl. DICKERTMANN (1980), S.348 ff.; MÜLLER-KÄSTNER (1986), S.10 f. 
zur Verfügung, das dann in eigener Zuständigkeit Kredite vergibt ${ }^{1}$. Auf diese Weise geht das Kreditrisiko von der Gebietskörperschaft auf das Sonderkreditinstitut über. Als Entgelt für eine Programmdurchführung erhalten die Sonderkreditinstitute einen Zinsabschlag gegenüber den Zinskonditionen, die vom Endkreditnehmer zu tragen sind ${ }^{2}$. Diese Art der Durchführung ist u.a. bei den ERP-Darlehen üblich. Hier dienen die $\mathrm{KfW}$, die DAB und die BIB als sogenannte Hauptleihinstitute, über die alle ERP-Programme abgewickelt werden $^{3}$. Die Rechte und Pflichten dieser Institute bei der Durchführung von ERP-Programmen sind in Rahmenverträgen mit dem Verwalter des ERP-Sondervermögens geregelt ${ }^{4}$. Die Zinsmarge für diese Hauptleihinstitute beträgt 0,25 Prozent p.a. ${ }^{5}$

Eine treuhänderische Gewährleistungsübernahme erfolgt in der Regel in fremdem Namen und auf fremde Rechnung. Das Schadensrisiko verbleibt beim Treugeber ${ }^{6}$. Beispiele für solche treuhänderischen Gewährleistungsübernahmen von Sonderkreditinstituten finden sich insbesondere auf der Ebene der Länder ${ }^{7}$. Handelt das Sonderkreditinstitut bei Gewährleistungsübernahmen in eigenem Namen und auf eigene Rechnung, so trägt es im Außenverhältnis gegenüber dem Gewährleistungsgläubiger das volle Ausfallrisiko. Im Innenverhältnis hingegen wird ihm das Risiko durch Rückbürgschaften einer Gebietskörperschaft oder eines Sondervermögens in vollem Umfang abgenommen ${ }^{8}$. Ein typisches Beispiel hierfür sind Bürgschaften für die freien Berufe, die von der DAB übernommen werden und durch Rückbürgschaften des ERP-Sondervermögens abgesichert werden?.

\section{b. Finanzierungsbeteiligung bei öffentlichen Kredithilfen}

Wenn ein Sonderkreditinstitut an der Refinanzierung öffentlicher Kredithilfen beteiligt ist, obliegt ihm regelmäßig auch ihre Durchführung. Die am meisten verbreitete Form der Finanzierungsbeteiligung besteht darin, daß die Sonderkreditinstitute bei Darlehens-

1 Zur rechtlichen Stellung der Sonderkreditinstitute gegenüber dem Kreditantragsteller vgl. ausführlich HUISMANS (1971), S.32 ff.

2 Vgl. MENZEL (1960), S.194.

3 Vgl. v.WYSOCKI (1961), S.24; SCHLAUWITZ (1966), S.200; zur Verteilung der ERP-Mittel auf die drei Institute vgl. BUNDESREGIERUNG (1988), S.11.

4 Vgl. SCHETTING (1973), S.79; ; HENKE (1979), S.89; MÜLLER-KÄSTNER (1986), S.9.

5 Vgl. dazu die schriftliche Auskunft des Vorsitzenden des Haushaltsausschusses des Deutschen Bundestages vom 19.09.1989 an den Verfasser.

6 Vgl. DICKERTMANN (1980), S.278.

7 So übernimmt die LfA treuhänderisch Staatsbürgschaften des Freistaats Bayern, vgl. PETER (1973), S.1047. Vom Prinzip her gehören auch die Ausfuhrgewährleistungen des Bundes in diese Kategorie. Jedoch wurde das in diesem Bereich tätige Mandatarkonsortium hier nicht zu den Sonderkreditinstituten gerechnet.

8 Vgl. DICKERTMANN (1980), S.278.

9 Vgl. DEUTSCHE AUSGLEICHSBANK (1988), S.22. 
programmen die zur Refinanzierung erforderlichen Mittel beschaffen sowie die gesamten Kreditrisiken tragen. Dagegen stellen die Gebietskörperschaften den Sonderkreditinstituten Zinszuschüsse zur Verfügung, die von diesen zur Zinsverbilligung zu verwenden sind. Damit tragen die Gebietskörperschaften bei solchen Darlehensprogrammen die Kosten der Zinsverbilligung.

Die Beschaffung der Refinanzierungsmittel erfolgt im Regelfall durch die Aufnahme von Fremdmitteln auf dem Kapitalmarkt. Soweit verfügbar, kann dafür aber auch Eigenkapital der Sonderkreditinstitute verwendet werden. Sehen die Richtlinien der Darlehensprogramme eine Zinsverbilligung auf einen bestimmten konstanten Prozentsatz vor, so variiert das von dem Sonderkreditinstitut vergebene Darlehensvolumen gegenläufig zur Höhe des Kapitalmarktzinssatzes, falls die Höhe der Zinszuschüsse (relativ) konstant ist ${ }^{1}$.

Bei den Sonderkreditinstituten können laufende Zinszuschüsse im Jahr der Zuweisung den Zinserträgen zugerechnet werden ${ }^{2}$ oder aber aufwandsmindernd berücksichtigt werden $^{3}$. Kapitalisierte Zinszuschüsse sind hingegen als passive Rechnungsabgrenzungsposten zu bilanzieren, die dann über die Laufzeit der damit verbilligten Darlehen aufgelöst werden ${ }^{4}$. Sofern zur Refinanzierung der Darlehen Fremdkapital verwendet wird, stehen im Grenzfall den Erträgen in Form von Zinseinnahmen und -zuschüssen Aufwendungen in entsprechender Höhe gegenüber, so daß Programme mit diesem Finanzierungsmodell von den Sonderkreditinstituten erfolgsneutral durchgeführt werden können.

Diese Art der Finanzierungsbeteiligung von Sonderkreditinstituten ist weit verbreitet. So leistet der Bund für eine Reihe von KfW-Programmen Zinszuschüsse ${ }^{5}$. In Bayern werden der LfA Zinszuschüsse zur Verbilligung von Wirtschaftsförderungs-Darlehen gewährt ${ }^{6}$. In Baden-Württemberg stellt das Land seit 1985 Mittel zur Finanzierung der

1 So ging das Volumen der von der LfA vergebenen und mittels Zinszuschüssen verbilligten Darlehen 1981 wegen der hohen Kapitalmarktzinsen zurück, die bei relativ unveränderten Konditionen nicht vollständig durch eine Erhöhung der Zinszuschüsse kompensiert wurden.

Vgl. BAYERISCHE LANDESANSTALT FÜR AUFBAUFINANZIERUNG (1981), S.20.

2 Eine entsprechende Behandlung der Zinszuschüsse wurde von der LKB in ihren Geschäftsberichten bis 1986 explizit erwähnt.

3 Zur Behandlung von Zinszuschüssen allgemein vgl. GROH (1973), S.743; FELIX (1976), S.742.

4 Vgl. GROH (1973), S.743. Insbesondere in Baden-Württemberg und Bayern scheint die Gewährung kapitalisierter Zinszuschüsse üblich zu sein, was aus dem Umfang der passiven Rechnungsabgrenzungsposten für vorausbezahlte Zinszuschüsse geschlossen werden kann. Sie lagen bei der LKB 1986 bei 741 Mio. DM. In den Bilanzen der LfA wird dieser Rechnungsabgrenzungsposten mit sonstigen passiven Rechnungsabgrenzungsposten in aggregierter Form ausgewiesen, die 1988 in Höhe 1,416 Mrd. DM bilanziert waren. Jedoch wird darauf hingewiesen, daB sie überwiegend Zinszuschußmittel enthalten.

5 Vgl. BUNDESREGIERUNG (1988), S.21.

6 Vgl. PETER (1973), S.1046; BAYERISCHE LANDESANSTALT FÜR AUFBAUFINANZIERUNG (1985), S.2. 
Wohnungsbauförderung ausschließlich in Form von Zinszuschüssen an die Landeskreditbank bereit, die ihrerseits zinsverbilligte Wohnungsbaudarlehen vergibt ${ }^{1}$. Entsprechendes gilt auch bezüglich der im Rahmen des Wirtschaftsförderungsprogramms des Landes und der Gemeinschaftsaufgabe "Verbessersung der regionalen Wirtschaftsstruktur" vergebenen Förderdarlehen der $\mathrm{LKB}^{2}$.

Bei manchen besonders riskanten Darlehensprogrammen trägt eine Gebietskörperschaft neben den Kosten der Zinsverbilligung auch ganz oder zum Teil die Ausfallrisiken. Eine Ertragsbelastung bei den Sonderkreditinstituten findet nicht statt, soweit Forderungsausfälle durch die Gebietskörperschaft ersetzt werden. Entsprechende Risikobeteiligungen hat der Bund beim Eigenkapitalhilfeprogramm und beim Darlehensprogramm für Aussiedler und Zuwanderer übernommen, die beide von der DAB durchgeführt werden. Beim Eigenkapitalhilfeprogramm für Existenzgründer, in dessen Rahmen überdurchschnittlich riskante Darlehen vergeben werden, beträgt die Höhe der vom Bund übernommenen Ausfallgarantie gegenüber der DAB 750 Mio. DM, die bis Ende 1987 in Höhe von 90 Mio. $\mathrm{DM}$ in Anspruch genommen war ${ }^{3}$.

\section{c. Eigenfinanzierung öffentlicher Kredithilfen}

Eine weitere Funktion der Sonderkreditinstitute besteht in der Durchführung eigener Kredithilfemaßnahmen ohne unmittelbare Finanzierungsbeteiligung der Gebietskörperschaften. Aufgrund der bestehenden rechtlichen Grundlagen und der organisatorischen Gestaltung der Sonderkreditinstitute ist dabei aber sichergestellt, daß die Ausgestaltung der Eigenprogramme mit der Förderpolitik der jeweiligen Gebietskörperschaft abgestimmt ist $^{4}$. Diese Kredithilfen finden in den Haushalten der Gebietskörperschaften keinen

1 Vgl. BADEN-WÜRTTEMBERG (1989), Epl. O3, S.150 ff.

2 Daran ist der Umstand bemerkenswert, daB im Rahmen der Gemeinschaftsaufgabe üblicherweise Investitionszuschüsse vergeben werden. Das Land nimmt jedoch für sich einen "technischen Ermessensspielraum" in Anspruch, weil sie Darlehen bei mittelständischen Betrieben als die effektivere Förderungsform betrachtet. Vgl. dazu GOLDSCHMIDT (1987),

S. 165.

3 Die Ausfallquote der 1983 und 1984 vergebenen Darlehen betrug jeweils 5 Jahre später mehr als $6 \%$. Vgl. BUNDESREGIERUNG (1988), S.23; DEUTSCHE AUSGLEICHSBANK (1988), S.23.

4 Vgl. MÜLLER-KÄSTNER (1986), S.11. Teilweise drängt sich sogar der Eindruck auf, daß die Sonderkreditinstitute mit ihren Eigenprogrammen lediglich Beschlüsse der politischen Entscheidungsträger vollziehen. So wurde Ende 1987 von der Bundesregierung ein "Maßnahmepaket zur Stärkung der Wachstumskräfte" beschlossen, das auch eine Aufstockung des Eigenprogramms der KfW zur Mittelstandsförderung beinhaltete, ohne daß diesbezüglich ein Finanzierungsbeitrag des Bundes vorgesehen war; vgl. dazu o.V. (1987). Lt. schriftlicher Auskunft der LKB vom 21.08.1989 an den Verf. werden Eigenprogramme der LKB in Beneh- 
unmittelbaren Niederschlag. Deshalb werden die Sonderkreditinstitute bisweilen als "subventionspolitische Schattenhaushalte" beschrieben ${ }^{1}$. Hauptsächlich werden im Rahmen von Eigenprogrammen Darlehen vergeben, darüber hinaus werden aber auch Gewährleistungen übernommen.

Eigene Darlehensprogramme müssen von den Sonderkreditinstituten durch Kapitalmarktdarlehen refinanziert werden, sofern dafür kein Eigenkapital bereitsteht. Die Zinssätze für die im Rahmen der Eigenprogramme vergebenen Kredite liegen üblicherweise unterhalb der Zinssätze für marktliche Refinanzierungsdarlehen bzw. der für alternative Darlehen erzielbaren Zinssätze ${ }^{2}$. Da ein Ausgleich durch Zinszuschüsse der Gebietskörperschaften nicht erfolgt, führen die Eigenprogramme insoweit zu einer Reduzierung der Jahresüberschüsse (bzw. zu einer Erhöhung der -fehlbeträge) der Sonderkreditinstitute. Die entsprechenden Verluste der Sonderkreditinstitute sind zwangsläufig auch Verluste der Eigentümer-Gebietskörperschaften und damit der Steuerzahler. Denn die ohne solche Programme entsprechend höheren Jahresüberschüsse könnten thesauriert werden und somit den Wert des Beteiligungsvermögens der betreffenden Gebietskörperschaften steigern. Andernfalls würden sie bei ihrer Ausschüttung die Einnahmen der beteiligten Gebietskörperschaften erhöhen, die damit Steuersenkungen "finanzieren" könnten.

Dasselbe gilt, wenn die Sonderkreditinstitute Eigenkapital einsetzen und durch die Vergabe zinsverbilligter Kredite die Opportunitätskosten die Erträge übersteigen. Allerdings sind diese Opportunitätskosten nur dann sichtbar, wenn sie als Rückstellungen für Zinsverbilligungen bilanzmäßig erfaßt sind.

Bei der Betrachtung der Eigenprogramme ist schließlich zu beachten, daß die Sonderkreditinstitute auch Darlehen vergeben, die nach Aussage dieser Institute zu Kapitalmarktkonditionen ausgereicht werden. Sofern mit der Kreditvergabe jedoch erhöhte Risiken oder sonstige Kosten verbunden sind, enthalten diese Kredite dennoch kostenverursachende Subventionselemente.

Außer der Vergabe von Darlehen, die zu Lasten des eigenen Gewinns verbilligt werden, übernehmen die Sonderkreditinstitute in begrenztem Umfang auch Gewährlei-

men mit dem Land und mit Genehmigung des Verwaltungsrats der LKB, in dem die Vertreter der Landesregierung die Mehrheit haben, jährlich neu festgelegt.

1 Vgl. DICKERTMANN (1981); KIRCHHOFF (1987), S.205 ff.

2 Vgl. MÜLLER-KÄSTNER (1986), S.12. Vgl. auch BAYERISCHE LANDESANSTALT FÜR AUFBAUFINANZIERUNG (1987), S.22, wo zu dieser Frage folgendes ausgeführt wird: "Ihre Ergänzungsdarlehen reicht die LfA zum Einstandszinssatz aus. Sie verzichtet dabei auf eine eigene Zinsmarge und trägt die Marge der durchleitenden Hausbank zu Lasten ihres laufenden Ertrages." 
stungen, für die sie die volle Haftung tragen. Soweit bei Gewährleistungsmaßnahmen Kosten entstehen, sind diese von dem Sonderkreditinstitut zu tragen.

\section{d. Einnahmenerzielung für die Gebietskörperschaften}

Die Sonderkreditinstitute haben außerdem für die Gebietskörperschaften teilweise eine fiskalische Funktion, d.h. sie sollen zur Einnahmenerzielung der Gebietskörperschaften beitragen. Dies kann einmal durch Abführung von im Rahmen ihrer Geschäftstätigkeit erzielten Gewinnen an die jeweiligen Haushalte, zum anderen durch die Abtretung von Forderungen der Gebietskörperschaften an die Sonderkreditinstitute geschehen.

aa. Gewinnabführung an die Gebietskörperschaften

Die Gewinne der Sonderkreditinstitute beruhen auf den Überschüssen der Zinserträge über die Zinsaufwendungen sowie auf Provisionsüberschüssen im Zusammenhang mit Auftrags- und Treuhandgeschäften, denen der Verwaltungsaufwand und durch Wertberichtigungen auf Forderungen verursachte Aufwendungen gegenüberstehen ${ }^{1}$. Bei diesen Gewinnen handelt es sich jedoch nur in begrenztem Umfang um Marktgewinne. Da nämlich bei einer Vielzahl der Programme durch den Staat oder eines seiner Sondervermögen zinsverbilligte Refinanzierungsmittel bereitgestellt werden, verschleiert die Ausweisung von Gewinnen durch die Sonderkreditinstitute, daß ihre Geschäftstätigkeit unter Anwendung eines Opportunitätskostenkalküls mit Verlusten verbunden ist. Außerdem ist die "Gewinn"-Höhe insoweit politisch bestimmt, als Zinserträge und Zinsaufwendungen aus nichtmarktlichen Transaktionen resultieren. Etwas anderes gilt nur, wenn Sonderkreditinstitute, wie die LKB, in größerem Umfang auch marktliche Aktivgeschäfte tätigen.

Da die Gebietskörperschaften Eigentümer dieser Sonderkreditinstitute sind, stehen ihnen deren Ertragsüberschüsse zu, soweit diese ausgeschüttet werden. Allerdings sind Ausschüttungen der Überschüsse die Ausnahme. Lediglich die LfA führt regelmäßig Gewinnbeträge an den Freistaat Bayern ab, die aber zur Hälfte zweckgebunden für die Wirtschaftsförderung zu verwenden $\operatorname{sind}^{2}$. Bei anderen Einrichtungen werden die

1 Der auf das Geschäftsvolumen bezogene Jahresüberschuß betrug 1987 bei der KfW 0,13\%, bei der DAB $0,07 \%$, bei der LKB 0,37 \% und bei der LfA 0,48 \% (Eigene Berechnungen aufgrund der Angaben in den Geschäftsberichten dieser Institute). Die Schwankungsbreite dieser Kennzahl beruht nicht zuletzt darauf, daß die einzelnen Institute in unterschiedlichem Maß die Kosten von Zinsverbilligungen zu tragen haben.

2 Von 1976 bis 1988 wurden Gewinnanteile in einer Gesamthöhe von 260 Mio. DM an den Freistaat Bayern abgeführt (eigene Berechnungen aufgrund der Angaben in den Geschäftsberichten der LfA). 
Gewinne $^{1}$ ausschließlich zur Rücklagenbildung verwendet, weil auf die Gewinnausschüttung aus rechtlichen oder tatsächlichen Gründen verzichtet wird.

Das heißt aber nicht, daß die Sonderkreditinstitute bei Verzicht auf Gewinnausschüttungen für die jeweiligen Gebietskörperschaften fiskalisch unbeachtlich wären. Denn die dann gebildeten Gewinnrücklagen können zur Finanzierung von Eigenprogrammen verwendet werden, während bei einer vollen Gewinnausschüttung in höherem Maße Kapitalzuführungen erforderlich wären, um bei gleichbleibendem Programmvolumen eine Kapitalaufzehrung dieser Einrichtungen zu vermeiden. Insofern handelt es sich bei den Gewinnrücklagen um ein Substitut für Kapitalzuführungen der Eigentümer-Gebietskörperschaften.

bb. Liquidation von Forderungen der Gebietskörperschaften

Eine bisweilen praktizierte Variante der Einnahmenerzielung der Gebietskörperschaften besteht darin, daß sie eigene Darlehensforderungen aus öffentlichen Kredithilfen entgeltlich an ein Sonderkreditinstitut abtreten. Dieses Verfahren hat für die Gebietskörperschaft zur Folge, daß die ansonsten faktisch illiquiden Forderungsbestände ${ }^{2}$ durch die Abtretung zu höheren Haushaltseinnahmen der Gegenwart führen. Diese Einnahmen können als allgemeine Deckungsmittel verwendet werden, sofern die Darlehensrückflüsse nicht zweckgebunden zu verausgaben sind. Falls die mit den Einnahmen aus der Forderungsabtretung gedeckten zusätzlichen Ausgaben nicht vermögenswirksam sind, reduziert sich jedoch durch eine solche Transaktion das Vermögen der Gebietskörperschaft. Demgegenüber ist die Forderungsübernahme für die außerbudgetäre Einrichtung erfolgsneutral, weil sie diese zwar in der Regel über zusätzliche Fremdmittel finanzieren wird, jedoch im Gegenzug auch zusätzliche Aktiva erhält. Da die Darlehensforderungen der Gebietskörperschaften in aller Regel unterverzinslich sind, setzt dies allerdings voraus, da $B$ sie nicht zu ihrem Nominalwert, sondern zu ihrem durch Abdiskontierung zu errechnenden Marktwert abgetreten werden. Andernfalls würde die außerbudgetäre Einrichtung durch

1 Die Höhe der Jahresüberschüsse schwankte zwischen 1976 und 1988 bei der KfW zwischen 12 Mio. DM und 163,3 Mio. DM, bei der DAB zwischen 3 Mio. DM und 100 Mio. DM, bei der LKB zwischen 22 Mio. DM und 156 Mio. DM und bei der LfA zwischen 26 Mio. DM und 72 Mio. DM. Vgl. Anhang, Tabelle 24.

2 Theoretisch ist natürlich auch denkbar, daB die Gebietskörperschaften Forderungsbestände an Private Dritte veräußern. Diese Möglichkeit wird in der Bundesrepublik jedoch offenkundig nicht genutzt. 
ein solches Geschäft einen Verlust erleiden. Solche Transaktionen wurden in BadenWürttemberg in den vergangenen Jahren mehrfach durchgeführt ${ }^{1}$.

\section{Funktionen der Sozialversicherungsträger}

Die Bundesanstalt für Arbeit, die hier stellvertretend für alle Sozialversicherungsträger betrachtet werden soll, nimmt im Zusammenhang mit der Vergabe öffentlicher Kredithilfen zwei Funktionen wahr. Zum einen vergibt sie zinsgünstige Darlehen, soweit sie nach dem Leistungskatalog des AFG zugelassen sind. Diese Darlehen, die aus dem Haushalt der Bundesanstalt zu finanzieren sind, weisen keine größeren Besonderheiten auf und sind in Relation zum sonstigen Leistungskatalog quantitativ eher von untergeordneter Bedeutung. Andererseits hat die Bundesanstalt insbesondere in früheren Jahren in Zeiten geringer Arbeitslosigkeit zum Teil hohe Einnahmenüberschüsse zu verzeichnen gehabt. Solche Überschüsse sind in eine Rücklage einzustellen, die primär die dauerhafte Liquidität der Bundesanstalt sichern soll. "Soweit die Mittel der Rücklage dazu nicht benötigt werden, können sie verwendet werden, um die Voraussetzungen für die Beschäftigung von Arbeitnehmern in Dauerarbeit zu schaffen."2 Die Gewährung von Kredithilfen erfolgt unter diesen Voraussetzungen nicht mehr in Erfüllung der gesetzlich zugewiesenen Aufgaben. Vielmehr sind die vergebenen Darlehen eine Form der Finanzanlage, die allein aus verfassungsrechtlichen Gründen einen arbeitsmarktpolitischen Bezug aufweisen muß. Dieser arbeitsmarktpolitische Bezug wurde in den fünfziger und sechziger Jahren bei sehr niedriger Arbeitslosenquote auch bei Darlehen zur Förderung des sozialen Wohnungsbaus und zur Autobahnfinanzierung als gegeben angesehen ${ }^{3}$. Dabei ist zumindest fraglich, inwieweit eine derartige Verwendung von Überschüssen im besonderen Interesse der Arbeitslosenversicherten liegt. Diese Frage ist dann relevant, wenn solche Finanzanlage-Darlehen zinsverbilligt vergeben werden, weil in diesem Fall wiederum Kosten der Zinsverbilligung entstehen, indem auf die günstigere Alternativanlage zu marktlichen Konditionen verzichtet wird.

1 Dabei hat das Land abgezinste Darlehensforderungen entgeltlich an die LKB abgetreten und die Erlöse teilweise als allgemeine Deckungsmittel, teilweise aber auch zur Aufstockung der Mittel für die Wohnungsbauförderung verwendet. Vgl. Auskunft des Finanzministeriums Baden-Württemberg vom 28.09.1989 an den Verf.

$2 \S 220$ Abs.1 S.2 AFG. Eine vergleichbare Bestimmung war in $\$ 169$ des Gesetzes über Arbeitsvermittlung und Arbeitslosenversicherung, dem Vorläufer des AFG enthalten.

3 Vgl. QUELLMALZ (1963), S.81 f. 


\section{INSTITUTIONELLER RAHMEN FÜR ÖFFENTLICHE KREDITHILFEN}

In diesem Abschnitt soll untersucht werden, welchen institutionellen Regelungen die Vergabe öffentlicher Kredithilfen in der Bundesrepublik Deutschland unterworfen ist. Dabei wird zunächst auf die rechtsstaatlichen Grundsätze eingegangen, die bei der Vergabe öffentlicher Kredithilfen zu beachten sind. Anschließend wird geprüft, inwieweit sich aus den Finanzverfassungen der Gebietskörperschaften, den Rechtsgrundlagen für die Sondervermögen und die außerbudgetären Einrichtungen, aus verschiedenen Publizitätsvorschriften und supranationalen Regeln Beschränkungen für die Vergabe von Kredithilfen ergeben können.

\section{Rechtsstaatliche Grundsätze}

Es ist rechtlich unumstritten, daß den Trägern öffentlicher Gewalt erlaubt ist, öffentliche Kredithilfen zu vergeben, da ein generelles Subventionsverbot nicht existiert. Subventionen als wirtschaftslenkende Maßnahmen und sozialorientierte Kredithilfen werden durch das im Grundgesetz verankerte Sozialstaatsprinzip ${ }^{1}$, regionale Fördermaßnahmen durch das Verfassungsgebot der "Wahrung der Einheitlichkeit der Lebensverhältnisse"2 gerechtfertigt.

Aus formaler Sicht hat der Kredithilfegeber zu beachten, daß Kredithilfen und sonstige Subventionen einer hinreichenden Ermächtigungsgrundlage bedürfen, die durch Gesetze oder Verwaltungsrichtlinien in Verbindung mit dem allgemeinen Gleichheitssatz des Art.3 GG geschaffen werden kann ${ }^{3}$. Die bloße Veranschlagung von Ausgaben für Subventionszwecke in einem Haushaltsplan bildet hingegen nach § 3 Abs.2 HGrG keine hinreichende Rechtsgrundlage für die Vergabe von Kredithilfen.

In materieller Hinsicht sind bei der Vergabe von Kredithilfen und sonstigen Fördermaßnahmen neben den Regelungen der jeweiligen Ermächtigungsgrundlage auch die Grundrechte $\mathrm{zu}$ beachten. Relevant sind hier insbesondere die Wettbewerbsfreiheit (Art. 2 Abs.1GG), der allgemeine Gleichheitssatz (Art. 3 GG), die Berufsfreiheit (Art. 12 GG) und das durch Art. 14 GG garantierte Recht am eingerichteten und ausgeüb-

1 Vgl. BLECKMANN (1984), S. D 44; JOOSS (1987), S.288 f. m.w.N.

2 Vgl. Art. 72 Abs. 2 Nr.3 und Art. 106 Abs. 3 GG, wo dieses Gebot im Zusammenhang mit der Gesetzgebungskompetenz des Bundes bzw. der Verteilung des Umsatzsteueraufkommens explizit erwähnt ist.

3

Zur Diskussion um die Frage eines Gesetzesvorbehalts bei der Subventionsvergabe vgl. HENKE (1979), S.53 ff.; BLECKMANN (1984), S. D 57 ff.; FROTSCHER (1984), S.695 f.; JARASS (1984a); OLDIGES (1984) m.w.N. 
ten Gewerbebetrieb ${ }^{1}$. Grundrechtsverletzungen können vor allem bei Kredithilfen an Unternehmen relevant sein, welche die nichtbegünstigte Konkurrenz relativ diskriminieren. Dabei wird jedoch angenommen, daß die Grundrechte einen Gewerbetreibenden nicht davor schützen, daß ihm durch staatliche Maßnahmen neue Konkurrenz erwächst ${ }^{2}$. Rechtswidrig ist jedoch eine Nichtbegünstigung des Konkurrenten, wenn sie den allgemeinen Gleichheitssatz verletzt, indem er willkürlich, weil sachlich nicht gerechtfertigt, von der Subventionierung ausgenommen wird ${ }^{3}$. In solchen eng begrenzten Ausnahmefällen kann sich das Willkürverbot zu einem Anspruch auf eine entsprechende öffentliche Leistung verdichten. Aus dem Gleichheitssatz folgt jedoch kein allgemeines Teilhaberecht an der staatlichen Leistungsgewährung im Sinne einer zur steuerlichen Gerechtigkeit komplementären Ausgabengerechtigkeit ${ }^{4}$.

Die für die Leistungsverwaltung geltenden allgemeinen rechtsstaatlichen Grundsätze können daher unter bestimmten Voraussetzungen zu einer Rechtswidrigkeit einzelner Kredithilfe-Entscheidungen führen. Sie beinhalten jedoch kaum effektive Begrenzungen für Kredithilfen, da sie zwar vor einer rechtlich eng definierten staatlichen Willkür schützen, jedoch eine relative Diskriminierung nichtbegünstigter Individuen oder Unternehmen in erheblichem Ausmaß rechtlich zulassen. Deshalb soll das Augenmerk darauf gerichtet werden, ob die Vergabe öffentlicher Kredithilfen anderen rechtlichen Restriktionen unterliegt.

\section{Begrenzung öffentlicher Kredithilfen durch die Finanzverfassungen der Gebiets- körperschaften}

Unter den Finanzverfassungen der Bundes und der Länder werden hier die Vorschriften des Grundgesetzes und der Landesverfassungen über das Finanzwesen sowie die Regeln des Haushaltsgrundsätzegesetzes ( $\mathrm{HGrG)}$ und der Bundeshaushaltsordnung (BHO) bzw. der Landeshaushaltsordnungen (LHO) verstanden. Dabei ist durch das

1 Vgl. SCHERER (1985), S.14; JOOSS (1987), S.290.

2 Vgl. KNIRSCH (1984), S.496.

3 Vgl. OLDIGES (1984), S.1929 f.

4 Ansätze zu einem veränderten Verständnis der Grundrechte zeigen sich in der Rechtsprechung des Bundesverfassungsgerichts insbesondere in seiner Numerus-clausus-Entscheidung, vgl. BUNDESVERFASSUNGSGERICHT (1972), S.303 ff. Darin wird erstmalig bejaht, daB der Bürger ein subjektives Recht auf Teilhabe an staatlichen Leistungen haben kann. Grundrechte enthalten nach diesem Rechtsverständnis über die reinen Abwehrrechte hinaus zumindest in gewissem Umfang auch individuelle Forderungsrechte; vgl. SCHOLZ (1985), S.36. Welche Implikationen eines derart veränderten Grundrechtsverständnisses im gegebenen Zusammenhang folgen, kann hier jedoch nicht näher diskutiert werden. 
HGrG, das im Rahmen der Grundsatzgesetzgebungskompetenz des Bundes im Haushaltswesen erlassen wurde ${ }^{1}$, sichergestellt, daß sich die Regeln in den Finanzverfassungen des Bundes und der Länder zumindest sinngemäß gleichen, so daß sie zusammen behandelt werden können. Zur Finanzverfassung der Kommunen können die in den Bundesländern landesrechtlich geregelten kommunalen Haushaltsvorschriften ${ }^{2}$ gerechnet werden. Diese enthalten einige Besonderheiten, auf die jedoch nicht näher eingegangen werden soll ${ }^{3}$.

Die Finanzverfassungen des Bundes und der Länder enthalten verschiedene Regelungen, die öffentliche Kredithilfen betreffen. Hierbei sind in erster Linie die allgemeinen Haushaltsgrundsätze, die Verschuldungsvorschriften sowie die Zuwendungs- und Gewährleistungsvorschriften der Haushaltsordnungen zu nennen.

\section{a. Allgemeine Haushaltsgrundsätze}

Soweit öffentliche Kredithilfen von Bund und Ländern ausgaben- oder einnahmenwirksam werden, sind sie von der betreffenden Gebietskörperschaft entsprechend dem Budgetgrundsatz ${ }^{4}$ der Vollständigkeit ${ }^{5}$ im Haushaltsplan zu veranschlagen. Dieser Grundsatz soll sicherstellen, daß sämtliche öffentlichen Ausgaben und Einnahmen vom Gesetzgeber gebilligt werden ${ }^{6}$ und ist somit Kernstück des legislativen Budgetrechts ${ }^{7}$.

$\mathrm{Da}$ Gewährleistungen nur Eventualverbindlichkeiten sind, gleichwohl aber zu öffentlichen Ausgaben führen können, die dann wegen des Rechtsanspruchs des Berechtigten der Disposition des Haushaltsgesetzgebers entzogen sind, ist zur Wahrung seines Budgetrechts eine gesetzliche Ermächtigung der Exekutive zur Gewährleistungsübernahme notwendig. Dementsprechend ist in Art.115 Abs.1 S.1 GG für den Bund geregelt, daß Bürgschaften, Garantien und sonstige Gewährleistungen, die zu Ausgaben in künftigen Rechnungsjahren führen können, einer der Höhe nach bestimmten oder bestimmbaren gesetzlichen Ermächtigung bedürfen. Auch hier gelten für die Länder entsprechende Vorschriften. Diese Ermächtigung ist üblicherweise im Haushaltsgesetz enthalten.

1 Vgl. Art. 109 Abs.3 GG.

2 Vgl. dazu den Dritten Teil der GemO Baden-Württemberg (\$§ 77-117) und die GemHVO.

3 Beispielsweise gilt der Grundsatz, daB kommunale Subventionen die staatliche Wirtschaftsförderungspolitik nicht stören dürfen. Vgl. dazu ALTENMÜLLER (1981), S.205 ff.; KNEMEYER/ROST-HAIGIS (1981), S.247; STOBER (1984), S.110 ff.

$4 \mathrm{Zu}$ den überwiegend von der Finanzwissenschaft entwickelten Budgetgrundsätzen ausführlich SENF (1977).

5 Dieser Grundsatz erhielt durch Art. 110 Abs.1 S.1 GG Verfassungsrang. Vgl. PIDUCH (1990), Anm. 28 zu Art. 110 GG.

6 Vgl. HEDTKAMP (1977), S.81.

7 Vgl. BUNDESVERFASSUNGSGERICHT (1989), S. 329. 
Eine Begrenzung für Kredithilfen der Gebietskörperschaften ergibt sich aus diesen Vorschriften nur insoweit, als man annehmen kann, daß die Exekutive ohne das Erfordernis einer Ausgabenermächtigung solche Maßnahmen gegenüber dem aktuellen Rechtszustand ausweiten würde. Eine Begrenzung der Nettoausgaben öffentlicher Kredithilfen ist durch diese formalen Veranschlagungsregeln jedoch nicht möglich, da die öffentlichen Budgets als Einnahmen-Ausgaben-Rechnung konzipiert sind und die Kosten öffentlicher Kredithilfen somit nicht unmittelbar sichtbar werden ${ }^{1}$.

\section{b. Staatliche Verschuldungsvorschriften}

Öffentliche Kredithilfen, die ausgabenwirksam sind und nicht aus zweckgebundenen Einnahmen finanziert werden, konkurrieren mit anderen Ausgabearten um die im Rahmen der staatlichen Budgetrestriktion ${ }^{2}$ verfügbaren Haushaltsmittel. Die Grenzen des staatlichen Ausgabenspielraums werden dann durch die Möglichkeiten zur Erzielung ordentlicher Einnahmen, insbesondere aus Steuern, und die Höhe der zulässigen Kreditaufnahme gezogen.

Im gegebenen Zusammenhang ist nun zu fragen, ob Kredithilfen die zulässige Verschuldungshöhe und damit den staatlichen Ausgabenspielraum beeinflussen. Im Bund ist dafür Art. 115 Abs.1 S.2 GG maßgeblich, wobei die Landeshaushaltsordungen und teilweise auch die Landesverfassungen inhaltlich vergleichbare Regelungen enthalten ${ }^{3}$. Danach darf die Nettokreditaufnahme ${ }^{4}$ die Summe der im Haushaltsplan veranschlagten Ausgaben für Investitionen nicht übersteigen. Zur Abwehr einer Störung des gesamtwirtschaftlichen Gleichgewichts sind Ausnahmen von der Regelvorschrift zulässig.

Der Investitionsbegriff, dessen Abgrenzung im Regelfall für die zulässige Verschuldungshöhe entscheidend ist, soll durch die Änderung von $\mathrm{HGrG}$ und BHO entsprechend den Vorgaben des Bundesverfassungsgerichts näher bestimmt werden 5 . Im Gesetzentwurf zur Änderung des $\S 10$ Abs.3 HGrG und § 13 Abs.3 BHO werden Ausgaben für Darlehen

1 Vgl. DICKERTMANN (1980), S.483.

2 Zu einem Überblick dazu vgl. FOLKERS (1984).

3 Vgl. z.B. Art.84 LV Baden-Württemberg, Art.54 Niedersächsische Verfassung, Art.83 der Verfassung für das Land Nordrhein-Westfalen, Art.117 Verfassung für Rheinland-Pfalz.

4 Vgl. PIDUCH (1990), Anm.29 zu Art.115 GG. Siehe dazu auch § 15 Abs.1 S.2 BHO, der eine Netto-Veranschlagung der Krediteinnahmen vorschreibt.

5 Der Investitionsbegriff soll dabei so eng gefaBt werden, daB die maximale "Normal"-Kreditaufnahme den Entscheidungsspielraum künftiger Haushaltsgesetzgeber nicht über Gebühr beschneidet. Er soll insbesondere nicht weiter ausgelegt werden als in der bisherigen Staatspraxis. Vgl. BUNDESVERFASSUNGSGERICHT (1989), S. $311 \mathrm{ff}$. 
und die Inanspruchnahme aus Gewährleistungen als Investitionsausgaben genannt ${ }^{1}$. Dabei werden diese Ausgaben zu ihrem Nominalbetrag den Investitionen zugerechnet. Begründet wird dies damit, daß Darlehen "ohne Rücksicht auf ihren Verwendungszweck als Finanzinvestitionen anzusehen" seien, während die Inanspruchnahme aus Gewährleistungen "zum Teil auf Bürgschafts- und Gewährleistungsübernahmen für investitionswirksame Betätigungen des Gewährleistungsübernehmers" beruhe und "außerdem zur Entstehung von Rückgriffsforderungen" führe ${ }^{2}$. Schuldendiensthilfen, die wie Darlehen und Investitionszuschüsse in aller Regel der Förderung von Investitionen dienen ${ }^{3}$, werden anders als die beiden letztgenannten Förderarten nicht als Investitionen behandelt, weil "nur ein sehr loser sachlicher Zusammenhang zwischen Zinszuschüssen und den durch sie geförderten Investitionen" bestehe ${ }^{4}$.

Abgesehen von solchen wenig plausiblen Abgrenzungen der investitiven von den konsumtiven Kredithilfen ${ }^{5}$ ist problematisch, daß die Ausgaben zum Forderungserwerb in voller Höhe kreditfinanziert werden können, obwohl der Barwert der Forderungen unter diesen Ausgaben liegt. Damit kann die Verschuldungsgrenze des Art.115 GG bei gegebenen Steuereinnahmen eine Aufzehrung des staatlichen Vermögens infolge einer Kreditfinanzierung dieser "Finanzinvestitionen" nicht verhindern. Außerdem werden Investitionen im Sinne des Art.115 GG als Bruttoinvestitionen interpretiert, so daß Tilgungseinnahmen nicht von den Darlehensausgaben abzuziehen sind ${ }^{6}$. Damit wird jedoch eine Kreditfinanzierung öffentlicher Konsumausgaben in späteren Perioden möglich. Dies läßt sich anhand einer einfachen Überlegung zeigen. Es wird angenommen, daß der Staat in $t_{0}$ ein einperiodiges Darlehen in Höhe von $X$ vergibt, das er vollständig kreditfinanziert. In $t_{1}$ wird die Darlehenssumme X getilgt. Gleichzeitig wird ein neues Darlehen in Höhe von X vergeben. Damit ist in $t_{1}$ wiederum eine Nettokreditaufnahme in Höhe von $X$ zulässig. Wird dieser Verschuldungsspielraum in $t_{1}$ ausgeschöpft, erhöht sich der Schuldenstand auf 2X, während der Bestand an Darlehensforderungen $X$ beträgt. D.h. daß die kreditfinanzierten Ausgaben in $t_{1}$ um $X$ über den Darlehensausgaben liegen können, ohne

1 Zur entsprechenden Regelung nach der bisherigen Rechtslage vgl. PIDUCH (1990), Kommentar zu \& 13 BHO, S.13.

2 Vgl. BUNDESREGIERUNG (1990), S.5. Siehe dazu auch BUND/LÄNDER-ARBEITSAUSSCHUSS (1982), S.132.

3 Vgl. WISSENSCHAFTLICHER BEIRAT (1980), S.37.

4 BUND/LÄNDER-ARBEITSAUSSCHUSS (1982), S.132.

5 Inkonsistenzen bei der Bestimmung des Investitionsbegriffs treten jedoch auch in vielen anderen Bereichen auf. Dies gilt beispielsweise für die Zuordnung von Verteidigungsausgaben und die in den Ländern unterschiedlichen Wertgrenzen für Investitionen, vgl. WISSENSCHAFTLICHER BEIRAT (1980), S.40 f.

6 Vgl. BUND/LÄNDER-ARBEITSAUSSCHUSS (1982), S.131. 
daß ein Versto $ß$ gegen Art.115 GG vorliegt. Damit können staatliche Konsumausgaben kreditfinanziert werden, ohne daß ein Rechtsversto $ß$ vorliegt.

Da die Höhe der Ausgaben für Darlehen und die Inanspruchnahme aus Gewährleistungen vollständig kreditfinanziert werden können, führt die geltende staatliche Budgetrestriktion zu keiner Begrenzung dieser beiden Kredithilfearten. Bei Kreditgewährleistungen kommt paradoxerweise hinzu, daß sich der Verschuldungsspielraum mit zunehmendem Risiko der Gewährleistungen erhöht. Denn damit steigt die Wahrscheinlichkeit des Forderungserwerbs, dessen Höhe für den Verschuldungsspielraum maßgeblich ist. Hingegen beschränken die staatlichen Verschuldungsvorschriften im haushaltswirtschaftlichen Regelfall die Vergabe von Schuldendiensthilfen, sofern die Verschuldungshöchstgrenze ohne diese Maßnahmen bereits voll ausgeschöpft wird ${ }^{1}$.

Im Fall einer Störung des gesamtwirtschaftlichen Gleichgewichts, welche die Koppelung der Verschuldungshöchstgrenze an die Investitionsausgaben außer Kraft setzt, hat das Bundesverfassungsgericht dem Haushaltsgesetzgeber einen Einschätzungs- und Beurteilungsspielraum zugestanden, mit welchen Maßnahmen er einer solchen Störung entgegentreten will. Dabei muß seine Situationsbeurteilung "nachvollziehbar und vertretbar erscheinen"2. Durch diese weite Interpretation der Ausnahmeregelung des Art.115 GG wird die Effektivität dieser Vorschrift im allgemeinen und in Bezug auf einzelne Ausgabenansätze, wie Schuldendiensthilfen, zusätzlich eingeschränkt.

\section{c. Zuwendungs- und Gewährleistungsvorschriften der Haushaltsordnungen}

Schuldendiensthilfen und öffentliche Darlehen gehören neben anderen finanziellen Hilfen zu den haushaltsrechtlichen Zuwendungen ${ }^{3}$. "Ausgaben für Zuwendungen sollen nur veranschlagt werden, wenn der Zuwendungszweck durch die Übernahme von Bürgschaften, Garantien oder sonstigen Gewährleistungen nicht erreicht werden kann." Weiterhin sollen Ausgaben für nicht rückzahlbare Zuwendungen "nur veranschlagt werden, soweit der Zweck nicht durch unbedingt oder bedingt rückzahlbare Zuwendungen erreicht werden kann"4. Damit wird ein Vorrang von Gewährleistungen vor Darlehen und von Darlehen vor Schuldendiensthilfen und sonstigen Zuschüssen statuiert. Abgesehen davon, daß

1 Eine Ausnahme davon kann gelten, wenn Zinszuschüsse einem Sonderkreditinstitut zum Zwecke der Zinsverbilligung öffentlicher Darlehen gewährt werden. Solche Zinszuschüsse werden teilweise den Investitionsausgaben zugeordnet. Vgl. FREISTAAT BAYERN (1989), EPl. 07, Kap. 0704, Titelgruppe 71.

2 BUNDESVERFASSUNGSGERICHT (1989), S. 344.

3 Vgl. Nr.1.1 VV-BHO zu $\$ 23$.

4 Nr.3 VV-BHO zu § 23. 
es sich hier lediglich um eine Sollvorschrift handelt, ist diese Regelung insofern wenig wirkungsvoll, weil sie keine exakten Maßstäbe liefert, anhand derer die Eignung der möglichen Maßnahmen beurteilt werden kann. Eine Begrenzung der den Kredithilfen zurechenbaren Zuwendungen durch diese Regelung kann daher kaum erwartet werden.

Darüber hinaus ist in Nr.5 VV-BHO zu \& 39 geregelt, daß Gewährleistungen nicht übernommen werden dürfen, "wenn mit hoher Wahrscheinlichkeit mit einer Inanspruchnahme gerechnet werden muß", weil dann nämlich entsprechend dem Haushaltsgrundsatz der Haushaltswahrheit Ausgaben oder Verpflichtungsermächtigungen veranschlagt werden müßten. D.h. daß die Ermächtigung zur Gewährleistungsübernahme eine risikomäßige Begrenzung impliziert, die allerdings kaum quantifizierbar ist ${ }^{1}$. Damit ist jedoch nur in begrenztem Umfang zu verhindern, da $B$ aufgrund von Gewährleistungsermächtigungen Verpflichtungen übernommen werden, für die aufgrund einer hohen Schadenswahrscheinlichkeit Ausgaben oder Verpflichtungsermächtigungen veranschlagt werden müßten.

Außerdem ignorieren die haushaltsrechtlichen Zuwendungsvorschriften, daß das Risiko von Gewährleistungsprogrammen nicht nur durch die Höhe der jeweiligen Einzelrisiken bestimmt wird, sondern daß es hierbei wesentlich auf die Korrelation der Einzelrisiken ankommt. So ist die Gefahr hoher Gewährleistungsausgaben begrenzt, wenn die Einzelrisiken weitgehend unkorreliert sind. Umgekehrt besteht bei einer stark positiven Korrelation der Einzelrisiken ${ }^{2}$ selbst dann die Möglichkeit extrem hoher Gewährleistungsausgaben, wenn die Schadenswahrscheinlichkeiten der einzelnen Gewährleistungen vergleichsweise gering sind. Dazu wird es kommen, wenn der für alle Gewährleistungen gleichermaßen ungünstige Umweltzustand eintritt ${ }^{3}$. Insoweit sind die Zuwendungsvorschriften vollkommen wirkungslos.

1 Bei Ausfuhrgewährleistungen wird in diesem Zusammenhang von der risikomäßigen Vertretbarkeit gesprochen, die dann vorliegen soll, wenn in jedem Einzelfall "vernünftige Aussicht auf einen schadensfreien Verlauf" besteht. Sofern an der Durchführung des mit der Gewährleistung abgesicherten Geschäfts "ein besonderes gesamtwirtschaftliches Interesse" b3esteht - genannt wird insbesondere die Sicherung von Arbeitsplätzen - "kann die Grenze der Vertretbarkeit im Einzelfall weiter als im Regelfall gezogen werden". Vgl. Nr.2.2 der "Richtlinien für die Übernahme von Ausfuhrgewährleistungen" vom 30.12.1983 (abgedruckt in HICHERT (1986), S.252 ff.)

2 Eine hohe Korrelation von Einzelrisiken ist beispielsweise bei Gewährleistungen für Kredite an die stark verschuldeten Entwicklungsländer gegeben. Vgl. BOSKIN/BARHAM/CONE/ OZLER (1987), S.30.

3 Vgl. BOSKIN/BARHAM/CONE/OZLER (1987), S.15. 


\section{Spezialregelungen für Sondervermögen}

Für Einnahmen und Ausgaben von Sondervermögen wird in der Mehrzahl der Fälle ein Wirtschaftsplan aufgestellt, der jedoch nur ausnahmsweise, wie beim ERP-Sondervermögen, gesetzlich festgestellt wird ${ }^{1}$. Eine Beschränkung für öffentlichen Kredithilfen ist daher aufgrund solcher formalen Veranschlagungsregeln nicht zu erwarten. Vielmehr sind in den Errichtungsgesetzen regelmäßig die zulässigen Ausgaben des jeweiligen Sondervermögens spezifiziert. So ist in § 5 Abs.1 Satz 1 ERP-Verwaltungsgesetz bestimmt, daß das ERP-Sondervermögen in seinem Bestand erhalten bleiben soll. Diese Vorschrift wird in der Weise interpretiert, daß die Vergabe verlorener Zuschüsse aus dem ERP-Sondervermögen nur ausnahmsweise zulässig ist ${ }^{2}$.

Eine weitere Beschränkung der Ausgaben besteht darin, daß die Einnahmen der Sondervermögen durch fehlende eigene ordentlichen Einnahmequellen oder eingeschränkte Verschuldungsmöglichkeiten begrenzt sind. Bei einigen kleineren Sondervermögen, wie dem Ausgleichsfonds nach § 12 SchwbG und dem Zweckvermögen bei der Landwirtschaftlichen Rentenbank, ist eine Kreditaufnahme nicht zugelassen, so daß die Höhe der zu vergebenden Kredithilfen durch den Umfang der ordentlichen Einnahmen begrenzt wird. Dagegen ist in anderen Fällen, z.B. beim ERP-Sondervermögen und bei einigen Wohnungsbau-Sondervermögen der Länder, eine Kreditaufnahme möglich. Die Grenzen der Kreditaufnahme sollen am Beispiel des ERP-Sondervermögens näher betrachtet werden.

Für das ERP-Sondervermögen ist die für den Bundeshaushalt gültige Verschuldungsgrenze nicht anwendbar ${ }^{3}$ und wäre überdies auch sinnlos, da daraus ganz überwiegend Investitionsausgaben im Sinne des Art.115 GG finanziert werden. Der bereits angesprochene Grundsatz der Bestandserhaltung ist wohl im Sinne einer Erhaltung des nominalen Nettovermögens zu interpretieren. Die Erhaltung des Vermögensbestandes ist durch eine Verschuldung auf dem Kapitalmarkt zur Refinanzierung von ERP-Darlehen gefährdet, da die damit verbundenen Zinsaufwendungen die Zinserträge der damit refinanzierten Darlehen übersteigen. Fraglich ist allerdings, ob eine Bestandsgefährdung bereits bei einer temporären Reduzierung des Netto-Vermögensbestandes oder erst bei einer nachhaltigen "Vermögensaufzehrung" angenommen werden muß4. Solange Bestandserhaltung jedoch

1 Vgl. FINANZBERICHT (1989), S. 207 f.

2 Vgl. BRECKNER (1956), S.1678.

3 Vgl. PIDUCH (1990), Anm. 34 zu Art.115 GG.

4 Gleichwohl läßt sich feststellen, daß der Schuldenstand des ERP-Sondervermögens nach Jahren mit steilem Verschuldungsanstieg inzwischen wieder leicht zurückgeführt wurde. Vgl. Anhang, Tabelle 14. Dies dürfte auf den Bestanderhaltungsgrundsatz zurückzuführen sein. 
am nominalen Netto-Vermögensbestand bemessen wird, läßt sich mit einem entsprechenden Grundsatz die Höhe der Zinsverbilligungskosten nicht begrenzen, soweit die gewährten Darlehen "eigenkapitalfinanziert" sind.

\section{Spezialregelungen für Sonderkreditinstitute}

Der Frage nach der Begrenzung von Kredithilfen außerbudgetärer Einrichtungen ist die Frage nach der Rechtmäßigkeit ihrer Errichtung logisch vorgelagert. Dieses dem Staatsorganisationsrecht zuzuordnende Problem wird am Beispiel der Sonderkreditinstitute des Bundes betrachtet. In einem nächsten Schritt ist zu untersuchen, ob die für diese Einrichtungen geltenden Vorschriften Beschränkungen für öffentliche Kredithilfen enthalten ${ }^{1}$.

a. Rechtmäßigkeitsvoraussetzungen für die Errichtung von Sonderkreditinstituten

Nach Art. 87 Abs.3 GG können durch Bundesgesetz für Angelegenheiten, für die dem Bund die Gesetzgebung zusteht ${ }^{2}$, selbständige Bundesoberbehörden und neue bundesunmittelbare Körperschaften und Anstalten des öffentlichen Rechts errichtet werden. Sofern der Bund für die betreffenden Angelegenheiten die Gesetzgebungskompetenz besitzt, ist es nach der Rechtsprechung des Bundesverfassungsgerichts nicht erforderlich, ein besonderes Bedürfnis für die Errichtung einer entsprechenden Institution nachzuwei$\operatorname{sen}^{3}$. Allerdings müssen diese Institutionen ihre Aufgaben selbständig, ohne Zuhilfenahme von Bundes- oder Landesbehörden erledigen. Der Bund hat dabei lediglich ein Aufsichtsrecht ${ }^{4}$.

Da der Bund nach Art. 74 Nr.11 GG die konkurrierende Gesetzgebung für das Recht der Wirtschaft besitzt, ist davon auszugehen, daß die aufgrund von Gesetzen erfolgte Errichtung der Sonderkreditinstitute des Bundes verfassungsgemäß ist ${ }^{5}$. Entsprechendes dürfte für die Sonderkreditinstitute der Länder gelten.

Auf eine gesonderte Betrachtung der Sozialversicherungsträger wird dabei verzichtet.

2 Strittig ist, ob im Bereich der Rahmengesetzgebungskompetenz des Bundes die Errichtung solcher Verwaltungseinrichtungen zulässig ist. Vgl. dazu PRUNS (1976), S.218; SCHMIDTBLEIBTREU/KLEIN (1983), Anm. 8 zu Art.87.

3 Vgl. SCHMIDT-BLEIBTREU/KLEIN (1983), Anm. 7 zu Art.87.

4 Vgl. SCHOLZ (1984), S.83.

5 Vgl. PRUNS (1976), S.218; SCHMIDT-BLEIBTREU/KLEIN (1983), Anm.9 zu Art.87. 
b. Beschränkungen der Kredithilfevergabe durch die Errichtungsgesetze der Sonderkreditinstitute

In den gesetzlichen Vorschriften über die außerbudgetären Einrichtungen werden deren Aufgaben in sehr allgemeiner Form auf wirtschaftsfördernde Maßnahmen und Fördermaßnahmen in weiteren Bereichen eingegrenzt, die hauptsächlich in der Form öffentlicher Darlehen und Gewährleistungen durchzuführen sind ${ }^{1}$. Weiterhin enthalten die Gesetze über diese Einrichtungen Gewinnverteilungs- und Rücklagevorschriften sowie teilweise auch das Gebot zu einer Geschäftsführung nach kaufmännischen Grundsätzen². Daraus kann geschlossen werden, daß die Sonderkreditinstitute Gewinne im Sinne von Überschüssen über die Aufwendungen erzielen sollen. Eine Ausweitung von Kredithilfen zu Lasten eigener Erträge wäre danach zumindest dann rechtlich problematisch, wenn dadurch eine Gewinnerzielung auf Dauer unmöglich würde, die eine bankwirtschaftlich notwendige Dotierung der Rücklagen erlaubt. Man wird andererseits angesichts des regelmäBig hervorgehobenen öffentlichen Auftrags nicht davon ausgehen können, daß die Sonderkreditinstitute Gewinne in einer Höhe erwirtschaften müssen, die einer marktlichen Verzinsung des eingesetzten Eigenkapitals entsprechen. Eine Untergrenze für die angestrebte Gewinnerzielung und damit der Spielraum für Programme zu Lasten der eigenen Erträge läßt sich jedoch mit Hilfe der Errichtungsgesetze nicht ohne weiteres quantifizieren.

\section{Publizitătspflichten in bezug auf öfrentliche Kredithilfen}

Zur Finanzierung öffentlicher Kredithilfen müssen stets öffentliche Mittel eingesetzt werden. Damit werden den Steuerzahlern durch die Vergabe öffentlicher Kredithilfen Kosten in Form entgangener Steuersenkungen oder entgangener alternativer Staatsausgaben auferlegt. Da der Staat bei der Kredithilfevergabe wie bei allen sonstigen staatlichen Aktivitäten in Wahrnehmung fremder Interessen tätig wird, ergibt sich die Notwendigkeit zu kontrollieren, ob damit auch den Interessen der Bürger tatsächlich entsprochen wird. Andernfalls besitzen die staatlichen Akteure einen starken Anreiz, bei ihren Aktivitäten Eigeninteressen zu verfolgen, auch wenn dies den Bürgern schadet ${ }^{3}$. Eine wirksame Kontrolle des Staates setzt jedoch immer voraus, daß dieser über seine Aktivitäten

Vgl. dazu z.B. § 2 KfW-Gesetz; § 4 DAB-Gesetz; § 3 LfA-Gesetz.

Vgl. § 4 LKB-Gesetz; § 15 LfA-Gesetz.

Insofern handelt es sich bei den Beziehungen zwischen den Bürgern und dem Staat um eine typische Principal-Agent-Beziehung. Vgl. BLANKART (1983), S.28. Für solche Beziehungen gilt regelmäBig, daß der Agent, hier also der Staat, einen Anreiz zur Realisierung eigener Vorteile auf Kosten des Prinzipals hat, wenn letzterer unvollständige Informationen über die Aktionen des Agenten besitzt. Vgl. STIGLITZ (1987), S.967. 
Rechenschaft ablegt ${ }^{1}$ bzw. Informationen bereitstellt. Damit kommt den Publizitätspflichten des Staates im gegebenen Zusammenhang eine besondere Bedeutung $\mathrm{zu}$. Im wesentlichen sind folgende Instrumente zu beachten: die Haushaltspläne der Gebietskörperschaften einschließlich der Wirtschaftspläne ihrer Sondervermögen, die Geschäftsberichte der außerbudgetären Einrichtungen sowie spezielle Subventionsberichte.

\section{a. Haushalts- und Wirtschaftspläne als Publizitätsinstrument}

Die haushaltsmäßige Erfassung öffentlicher Kredithilfen bezieht sich auf alle unmittelbar ausgaben- und einnahmenwirksamen Vorgänge. Sie hat jedoch einige gravierende Lücken. Da die Budgets der Gebietskörperschaften nur laufende Cash-flows erfassen, geben sie im allgemeinen keinen Aufschluß über die Höhe der periodischen und der gesamten erwarteten Nettoausgaben der in der Haushaltsperiode vergebenen Kredithilfen ${ }^{2}$. Ebenso fehlt ein Überblick darüber, auf welchem Weg die Kredithilfen den Leistungsempfängern gewährt werden. Schließlich sind aus der haushaltsmäßigen Abgrenzung die Leistungsempfänger nicht ohne weiteres zu erkennen ${ }^{3,4}$. Bei Schuldendiensthilfen fehlen darüber hinaus Angaben, welches Darlehensvolumen diesen Maßnahmen zuzuordnen ist ${ }^{5}$. Die Gewährleistungsermächtigungen enthalten außerdem keine Hinweise auf die zulässige Risikostruktur dieser Maßnahmen, so daß Rückschlüsse über künftige Haushaltsbelastungen daraus nicht gezogen werden können. Damit sind die Informationen der Haushaltspläne bzw. -gesetze auch diesbezüglich unzureichend.

Hinsichtlich der Wirtschaftspläne der Sondervermögen sieht dieses Bild kaum anders aus, weil auch hier weder das Ausmaß der Zinsverbilligung vergebener Darlehen noch die Risikostruktur zu übernehmender Gewährleistungen explizit ausgewiesen werden. Darüber hinaus fällt hier ins Gewicht, daß deren Wirtschaftspläne teilweise weder veröffentlicht noch dem Parlament zur Beschlußfassung vorgelegt werden.

Vgl. SCHÄFER (1977), S.520.

2 Zum gleichgelagerten Problem in den USA vgl. BOSKIN/BARHAM/CONE/OZLER (1987), S.27.

3 So werden beispielsweise der Finanzierungsanteil des Bundes an den BAFöG-Darlehen und an der Wohnungsbauförderung unter Darlehen an die Länder veranschlagt, obwohl diese Beträge letztlich privaten Wirtschaftssubjekten zufließen

4 Zur budgetären Erfassung öffentlicher Kredithilfen vgl. DICKERTMANN (1980), S.446 f.

5 Vgl. DICKERTMANN (1980), S.480 f. 
b. Geschäftsberichte der Sonderkreditinstitute als Publizitätsinstrument

Die Geschäftsberichte der Sonderkreditinstitute genügen den auch für andere Kreditinstitute geltenden Publizitätspflichten. So enthalten sie den Jahresabschluß, der nach den allgemein geltenden externen Rechnungslegungsvorschriften aufzustellen ist. Darüber hinaus beinhalten die Geschäftsberichte zum Teil recht detaillierte Angaben über die Geschäftstätigkeit der Sonderkreditinstitute, insbesondere über die Höhe und die Verwendungszwecke der von ihnen zugesagten Kredite. Andererseits fehlen regelmäßig wesentliche Angaben über die Rolle der Sonderkreditinstitute bei der Vergabe öffentlicher Kredithilfen und die finanziellen Verflechtungen mit ihren jeweiligen Trägern. Beispielsweise wird die Höhe der erhaltenen staatlichen Zinszuschüsse in der Regel ebensowenig genannt wie die Zinssätze von bei den Gebietskörperschaften aufgenommenen Refinanzierungsdarlehen. Insbesondere werden die Kosten der Programme, die zu Lasten des eigenen Gewinns verbilligt werden, meist nicht oder lediglich in schwer nachvollziehbarer Weise dargestellt ${ }^{1}$.

Somit vermögen die Geschäftsberichte der Sonderkreditinstitute den Steuerzahlern kaum Hinweise auf die Kosten der von ihnen durchgeführten Kredithilfeaktivitäten zu geben. Überdies erschwert die Vielzahl entsprechender Einrichtungen den Überblick über deren Kredithilfeaktivitäten außerordentlich.

c. Subventionsberichterstattung als Publizitätsinstrument

Durch $\S 12$ StabWG $^{2}$ wurde eine gesetzliche Verpflichtung der Bundesregierung begründet, im zweijährigen Turnus einen Subventionsbericht vorzulegen. Jedoch fehlt in $\$ 12$ StabWG eine Legaldefinition von Subventionen. Statt dessen werden die Begriffe Finanzhilfen und Steuervergünstigungen verwendet. Unter die Finanzhilfen werden dabei alle Geldleistungen des Bundes an Stellen außerhalb der Bundesverwaltung subsumiert, die als Erhaltungs-, Anpassungs- oder Produktivitätshilfen an Betriebe oder Wirtschaftszweige

1 Eine gewisse Ausnahme bildet hier die LKB, in deren Geschäftsberichten Zuführungen zu Rückstellungen für Zinsverbilligungszuschüsse explizit als Aufwandsposten ausgewiesen werden. Bei dieser Rückstellungsart handelt es sich um einen Korrekturposten zu den unterverzinslichen langfristigen Förderdarlehen, der die in künftigen Jahren erforderlichen, nicht durch Zuschüsse Dritter gedeckten Unterschiedsbeträge zwischen den in der Periode der Zinsverbilligung zu leistenden Zinszahlungen der Schuldner und den fiktiven Erträgen eines im Zeitpunkt der Darlehensvergabe festgesetzten, am Kapitalmarkt orientierten Zinssatzes enthält. Vgl. LANDESKREDITBANK BADEN-WÜRTTEMBERG (1986), Erläuterungen zu den Bilanzposten, Passiva Nr.6.

BGBl.I S.582. 
qualifiziert werden können oder für private Haushalte in wichtigen Bereichen der Volkswirtschaft bestimmte Güter und Leistungen verbilligen und die Spartätigkeit anregen ${ }^{1}$. Nach ihren Arten wird zwischen Zuschüssen, Zuweisungen und Erstattungen, Schuldendiensthilfen sowie Darlehen unterschieden².

Aufgrund der Definition von Finanzhilfen werden von vornherein Kredithilfen an bestimmte Leistungsempfänger, insbesondere Kredithilfen an das Ausland, aus der Subventionsberichterstattung ausgegrenzt. Außerdem ist die Begriffsabgrenzung in wesentlichen Punkten nicht eindeutig und beläßt der Bundesregierung bezüglich der Finanzhilfen und der Steuervergünstigungen gleichermaßen einen erheblichen Interpretationsspielraum. So werden die jährlich vergebenen Darlehen mit der ausbezahlten Darlehenssumme den Finanzhilfen zugerechnet. Damit soll zum Ausdruck gebracht werden, "in welchem Maße die mit Finanzhilfen verfolgten Zielsetzungen bei den alljährlichen Entscheidungen über den Haushalt und die Fortschreibung der Finanzplanung mit anderen staatlichen Aufgaben im Wettbewerb stehen" ${ }^{\prime 3}$. Andererseits wird eingeräumt, daß unter ökonomischen Gesichtspunkten in erster Linie die mit der Darlehensvergabe. verbundene Zinsverbilligung als finanzielle Hilfe anzusehen ist. Dem wurde zeitweise dadurch Rechnung getragen, daß in einigen älteren Subventionsberichte nachrichtlich die geschätzten Zinsbegünstigungen angeführt wurden, die in der jeweiligen Periode mit dem Forderungsbestand des Bundes aus früher gewährten Finanzhilfe-Darlehen verbunden sind.

Bei der Abgrenzung der Finanzhilfen an private Haushalte wird darauf abgestellt, ob "sie gleichzeitig mittelbar auch dem Wirtschaftsgeschehen zugerechnet werden können und dieses in einem Ausmaß beeinflussen, das für die Erreichung gesamtwirtschaftlicher Zielsetzungen von erheblicher Bedeutung ist" ${ }^{\prime 4}$. Dieses aus ökonomischer Sicht als willkürlich erscheinende Kriterium wird bezüglich des Wohngeldes und der staatlichen Wohnungsbauund Sparförderung als erfüllt angesehen. Demgegenüber bleiben z.B. BAFöG-Darlehen ausgeklammert.

Auch öffentliche Bürgschaften und sonstige Gewährleistungen bleiben in den Subventionsberichten unberücksichtigt. Zwar wird von der Bundesregierung eingeräumt,

1 Vgl. SUBVENTIONSBERICHT (1985), S.6 f.; DICKERTMANN/DILLER (1986b), S.601 f.

2 Vgl. SUBVENTIONSBERICHT (1985), S.31. Die Abgrenzung der Finanzhilfen unterscheidet sich somit von den Subventionen im Sinne der volkswirtschaftlichen Gesamtrechnung, die unter den Subventionen laufende Einkommensübertragungen an Unternehmen versteht, denen z.B. laufende Zinszuschüsse zugerechnet werden, nicht aber die als Vermögensübertragungen erfaßten Investitionszuschüsse und Transferzahlungen an private Haushalte. Vgl. dazu SUBVENTIONSBERICHT (1985), S.296.

3 SUBVENTIONSBERICHT (1985), S.31.

4 SUBVENTIONSBERICHT (1985), S.9. 
daß deren ökonomische Förderwirkung der von Finanzhilfen ähnlich sei und dies eine Aufnahme in den Subventionsbericht erwägenswert erscheinen lasse. Aufgrund der Schwierigkeiten bei der Quantifizierung ihrer Förderwirkungen wird jedoch die Darstellung der Gewährleistungen im Subventionsbericht offenkundig für verzichtbar gehalten ${ }^{1}$. Ebenso fehlen im Subventionsbericht Angaben zu den unter Verwendung von Zinszuschüssen des Bundes gewährten Darlehen der außerbudgetären Einrichtungen, sowie über Kredithilfen dieser Einrichtungen, die zu Lasten ihrer Erträge vergeben werden ${ }^{2}$. Dagegen werden Finanzhilfen des ERP-Sondervermögens, der Länder, der Gemeinden und der EG zumindest nachrichtlich aufgeführt ${ }^{3}$.

Aufgrund der unvollständigen Erfassung öffentlicher Kredithilfen ${ }^{4}$ kann das im Subventionsbericht auszuweisende Finanzhilfevolumen gesenkt werden, wenn der Bund ein von ihm zunächst vollständig finanziertes Darlehensprogramm durch Schuldendiensthilfen an eine außerbudgetäre Einrichtung ersetzt, die das Darlehensprogramm zu denselben Konditionen durchführt und sich die notwendigen Refinanzierungsmittel selbst besorgt. Eine weitere Senkung des Subventionsvolumens gegenüber dem soeben genannten Fall läßt sich erreichen, wenn eine außerbudgetäre Einrichtung das Programm zu Lasten eigener Erträge durchführt oder wenn es durch ein Gewährleistungsprogramm ersetzt wird, das dieselben ökonomischen Effekte erzeugt. Der entscheidende Mangel der Subventionsberichterstattung besteht somit darin, daß sie gegenüber Subventionsgestaltungen zum Zwecke der Verschleierung der Subventionsaktivitäten des Staates nicht immun ist ${ }^{5}$.

Die Länder sind an § 12 StabWG nicht gebunden. Einige Länder erstellen jedoch, teilweise in bislang unregelmäßiger Erscheinungsfolge, eigene Subventionsberichte. In diesen Länderberichten wird jedoch kein einheitlicher Subventionsbegriff verwendet ${ }^{6}$. Hinsichtlich öffentlicher Kredithilfen dürften aber regelmäßig dieselben Kritikpunkte gelten wie bei den Subventionsberichten des Bundes.

\section{Beschränkungen für öffentliche Kredithilfen durch supranationale Regeln}

Im Zuge der zunehmenden internationalen Wirtschaftsbeziehungen der entwickelten Volkswirtschaften in der Nachkriegszeit wurden zahlreiche supranationale Regeln für

1 Vgl. SUBVENTIONSBERICHT (1985), S.296.

2 Vgl. SCHEMMEL (1990), S. 20.

3 Vgl. SUBVENTIONSBERICHT (1985), S.9; DICKERTMANN/DILLER (1986b), S.607.

4 Zur Kritik der Darstellung der Steuervergünstigungen im Subventionsbericht vgl. DICKERTMANN/DILLER (1986b), S.607.

5 Vgl. SCHEMMEL (1990), S. 20.

6 Vgl. SUBVENTIONSBERICHT (1989), S.239. 
staatliche Interventionen in den Wirtschaftsproze $B$ geschaffen, von denen einige auch Kredithilfen betreffen. Besonders bedeutsam für die Bundesrepublik sind dabei die Beihilferegelungen der Europäischen Gemeinschaften ${ }^{1}$. Beschränkungen für Export-Kredithilfen sind darüber hinaus durch den sogenannten OECD-Konsensus und im Rahmen des GATT eingeführt worden.

a. EG-rechtliche Beschränkungen für öffentliche Kredithilfen

Mit der Gründung der Europäischen Gemeinschaften ${ }^{2}$ wurden zahlreiche nationale Maßnahmen Restriktionen unterworfen. So sind in Art. 4 lit c) EGKSV und Art. 92 bis 94 EWGV die wesentlichen Regeln über die Statthaftigkeit mitgliedstaatlicher Beihilfen enthalten.

aa. Beihilfebegriff und Verfahrensrecht

Der Begriff der Beihilfen ist nach allgemeiner Meinung extensiv auszulegen, um zu verhindern, daß die EG-rechtlichen Beschränkungen durch die Mitgliedstaaten umgangen werden ${ }^{3}$. Dementsprechend werden von der Kommission der Europäischen Gemeinschaften den Beihilfen ${ }^{4}$ "Zuschüsse, Befreiungen von Steuern und Abgaben, Zinszuschüsse, Übernahme von Bürgschaften zu besonders günstigen Bedingungen (...) oder jede andere Maßnahme gleicher Wirkung"5 zugerechnet. Da der Sinn der gemeinschaftsrechtlichen Beihilferegeln darin liegt, Wettbewerbsverzerrungen innerhalb der EG durch mitgliedstaatliche Subventionierung zu verhindern ${ }^{6}$, gilt dies jedoch nur für Kredithilfen, die als Wirtschaftssubventionen qualifiziert werden können. Dabei kommt es wesentlich darauf

1 Vgl. ANDEL (1990), S. 259.

2 Dieser Zusammenschluß basiert u.a. auf dem "Vertrag über die Gründung der Europäischen Gemeinschaft für Kohle und Stahl (EGKS)" vom 18.4.1951 sowie auf dem "Vertrag zur Gründung der Europäischen Wirtschaftsgemeinschaft" vom 25.3.1957, die über die nach Art.59 Abs.2 GG vorgeschriebene Mitwirkung der Gesetzgebungsorgane des Bundes den Rang von Bundesgesetzen erhalten haben. Vgl. BGBl. II, 1952, S. 447; BGBl. II, 1957, S.766. Vgl. RENGELING (1984), S.26; CASPARI (1987), S.78 f.

4 Der EuGH differenzierte zunächst zwischen Beihilfen und Subventionen, indem er Subventionen ausschließlich als positive Leistungen an Unternehmen definierte und Beihilfen als den übergeordneten Begriff ansah, der zusätzlich auch sonstige MaBnahmen zur Belastungsminderung von Unternehmen umfaßt. Inzwischen herrscht weitestgehend Übereinstimmung darüber, $\mathrm{da} B$ es überflüssig ist, beide Begriffe unterschiedlich zu definieren, vgl. RENGELING (1984), S. 797 f., THIESING (1983), Vorbemerkung zu den Artikeln 92 bis 94, Rn.2.

ABl. vom 17.8.1963, S.2235.

6 Vgl. RENGELING (1984), S.23. 
an, daß öffentliche Kredithilfen nur an einzelne Wirtschaftsbereiche vergeben werden ${ }^{1}$. Dagegen werden staatliche Fördermaßnahmen allgemeiner Art, die die gesamte Wirtschaft eines Mitgliedstaates begünstigen, wie konjunkturpolitische Maßnahmen, die weder regional noch sektoral auf bestimmte Wirtschaftszweige beschränkt sind, nicht nach den Beihilfevorschriften, sondern nach Art.103 EWGV beurteilt ${ }^{2}$.

Von den Beihilfevorschriften werden alle staatlichen und aus staatlichen Mitteln gewährten Maßnahmen erfaßt. Als staatliche Maßnahmen gelten dabei nicht nur Beihilfen des Bundes, sondern auch solche der Bundesländer. Aus staatlichen Mitteln gewährte Beihilfen sind Maßnahmen der Gemeinden und Gemeindeverbände ${ }^{3}$, die ihre finanziellen Mittel durch Zuweisungen aus staatlichen Haushalten oder durch Steuern und Abgaben erhalten, zu deren Erhebung sie aufgrund staatlicher Regelungen befugt sind. Dasselbe gilt für andere öffentlich-rechtliche Körperschaften wie die außerbudgetären Einrichtungen, die durch staatliche Anordnungen geschaffen worden sind.

Um die Einhaltung der materiellen Beihilfevorschriften des EWGV kontrollieren zu können, schreibt Art.93 Abs.3 EWGV als Verfahrensvorschrift die Notifizierung aller beabsichtigten Beihilfen bei der Kommission der Europäischen Gemeinschaften durch die Mitgliedstaaten vor, die dabei auch die Notifizierung der Beihilfen anderer öffentlicher Stellen vornehmen ${ }^{4}$. Die Kommission kann dann bei Einzelfallbeihilfen binnen 30 Tagen, bei Beihilfeprogrammen innerhalb von zwei Monaten ${ }^{5}$ wegen eines Verstoßes gegen materielles EG-Recht Einwände erheben und ein Verfahren nach Art.93 Abs.2 EWGV zur Unterlassung oder Umgestaltung der Beihilfe einleiten. Gegen eine negative Entscheidung der Kommission steht den betroffenen Mitgliedstaaten der Rechtsweg zum EuGH offen. Sofern ein Verstoß gegen das EG-Recht nicht vorliegt, ist eine förmliche Entscheidung der Kommission nicht zwingend vorgeschrieben, so daß die notifizierte Beihilfe nach Ablauf der genannten Fristen gewährt werden darf.

Wurde eine Beihilfe materiell oder verfahrensrechtlich unrechtmäßig gewährt, kann die Kommission deren Rückzahlung verlangen. Diese Möglichkeit wird bei verfahrensrechtlich unrechtmäßigen Beihilfen jedoch, anders als bei materiell rechtswidrigen Beihilfen, offenbar noch nicht systematisch wahrgenommen ${ }^{6}$.

1 Vgl. THIESING (1983), Artikel 92, Rn.12; KOMMISION DER EUROPÄISCHEN GEMEINSCHAFTEN (1985), $145 \mathrm{f}$.

2 Vgl. RENGELING (1984), S.29 f., THIESING (1983), Artikel 92, Rn.3.

3 Vgl. CUNY (1987), S. 35; MOMBAUR (1989), S.247.

4 Vgl. THIESING (1983), Anm.35 zu Art.93; CUNY (1987), S.35.

5 Vgl. KOMMISSION DER EUROPÄISCHEN GEMEINSCHAFTEN (1987b), S.16.

6 Vgl. KOMMISSION DER EUROPÄISCHEN GEMEINSCHAFTEN (1987a), S.129. 
bb. Materielle Beihilferegelungen

Zwischen den Beihilferegelungen des EGKSV und des EWGV gibt es erhebliche Unterschiede. So enthält Art. 4 lit c) EGKSV ein generelles Verbot von Beihilfen zugunsten des Kohle- und Stahlsektors. Dieses Verbot wurde jedoch über lange Zeit hinweg umgangen, indem Beihilfen für Kohle und Stahl als regionale oder allgemeine Beihilfen deklariert wurden, die als Instrumente einer allgemeinen Wirtschaftspolitik nach dem EGKSV nicht von vornherein untersagt sind ${ }^{1}$. Darüber hinaus wurden von den EGBehörden mit Billigung des EG-Rates Entscheidungen erlassen, die den Mitgliedstaaten ermöglichten, Kohle- und Stahlbeihilfen zu gewähren². Wenngleich der Beihilfewettbewerb im Stahlbereich zwischenzeitlich über einen längeren Zeitraum hinweg schrittweise abgebaut wurde ${ }^{3}$ und das Beihilfeverbot des EGKSV von der Kommission insoweit wieder strikt angewendet wird, verbleiben dennoch erhebliche Zweifel, ob damit Beihilfen effektiv begrenzt werden können, solange hinreichende Sanktionsmöglichkeiten bei Verstößen fehlen.

Nach Art. 92 Abs. 1 EWGV gelten Beihilfen, die bestimmte Unternehmen oder Produktionszweige begünstigen, grundsätzlich als wettbewerbsverfälschend. Sie sind daher mit dem Gemeinsamen Markt unvereinbar und verboten, soweit sie den Handel zwischen den Mitgliedstaaten beeinträchtigen. Letzteres wird regelmäßig angenommen, sofern es sich nicht um Beihilfen lokalen Charakters handelt ${ }^{4}$. Vom Beihilfeverbot des Art.92 Abs.1 EWGV gibt es in Abs.2 abschließend aufgezählte Legalausnahmen, wie z.B. Beihilfen zum Ausgleich teilungsbedingter Nachteile in der Bundesrepublik ${ }^{5}$. Von größerer Bedeutung sind jedoch die Beihilfen, die nach Art.92 Abs.3 EWGV durch Entscheidung der Kommission (lit a-c) oder des Rates (lit d) als mit dem Gemeinsamen Markt vereinbar angesehen werden können. Die wichtigste Fallgruppe bilden dabei Beihilfen "zur Förderung der Entwicklung gewisser Wirtschaftszweige oder Wirtschaftsgebiete", d.h. Maßnahmen der regionalen und sektoralen Wirtschaftsförderung (lit c).

Bei der Beurteilung der Vereinbarkeit von beabsichtigten Beihilfen mit dem Gemeinsamen Markt hat der EWGV der Kommission eine weitgehende Ermessensfreiheit eingeräumt, wobei die in Art.92 Abs.3 EWGV enthaltenen Ausnahmeregeln restriktiv aus-

1 Vgl. NEUNDÖRFER (1984), S.90.

2 Vgl. THIESING (1983), Artikel 92, Rn.91; CASPARI (1987), S.83 ff.

3 Vgl. ZIPPEL (1984), S.5; KOMMISSION DER EUROPÄISCHEN GEMEINSCHAFTEN (1985).

4 Vgl. THIESING (1983), Artikel 92, Rn.34 f.

5 Diese Regelung dürfte wegen der deutschen Vereinigung mittelfristig aufgehoben werden. 
zulegen sind ${ }^{1}$. Insbesondere muß eine zulässige Beihilfe in einem angemessenen Verhältnis zu dem damit verfolgten Ziel stehen ${ }^{2}$.

Die Kommission wendet bei ihrer Genehmigungspraxis die Wettbewerbsregeln der Art.92 ff. EWGV insbesondere im Hinblick auf die geplante Vollendung des Binnenmarktes in den letzten Jahren zunehmend strikter $a^{3}$. So wurden in jüngerer Zeit beispielsweise mehrfach Regionalförderungsprogramme von Bundesländern untersagt bzw. lediglich in eingeschränktem Umfang gebilligt ${ }^{4}$.

Weiterhin kommt in der Beihilfepraxis der Kommission den in Netto-Subventionsäquivalenten bemessenenen Beihilfeintensitäten wesentliche Bedeutung zu. Dies gilt insbesondere für "Beihilfen von geringerer Bedeutung"5, für die Kumulierung von Beihilfen mit unterschiedlicher $Z_{\text {weckbestimmung }}{ }^{6}$ und für Regional- und Sektoralbeihilfen i.S.d.Art 92 Abs.3 lit c EWGV?.

Die Beihilfeintensitäten werden stets auf den mit der Beihilfe geförderten Investitionsbetrag bezogen. $\mathrm{Zu}$ ihrer Berechnung werden für die einzelnen Mitgliedstaaten unterschiedlich festgelegte Bezugszinssätze als Referenzgröße zur Bestimmung der Vergünstigungshöhe und als Diskontierungsfaktoren bei mehrperiodigen Beihilfen verwendet. Für die Bundesrepublik gilt der Zinssatz für Mittelstandskredite der KfW (M I/M IIProgramme) als Bezugssatz, wobei seine Höhe zu Beginn eines jeden Jahres aufgrund der

1 Vgl. THIESING (1983), Anm.51 zu Art.92.

2 Vgl. THIESING (1983), Anm.50 zu Art.92; CASPARI (1987), S.81.

3 Vgl. ANDEL (1990), S. 260.

4 Dies betrifft z.B. das Land Baden-Württemberg und den Freistaat Bayern; vgl. MOMBAUR (1989), S.247; BAYERISCHE LANDESANSTALT FÜR AUFBAUFINANZIERUNG (1988), S.16.

5 Als Beihilfen von geringerer Bedeutung, gegen die die Kommission im allgemeinen keine Einwände erhebt, werden solche Maßnahmen angesehen, die Unternehmen begünstigen, die weniger als 100 Arbeitskräfte beschäftigen, einen Jahresumsatz von nicht mehr als 10 Mio. ECU haben und bei denen die Intensität der Beihilfe für zu fördernde Investitionen vor Steuern 7,5 \% nicht übersteigt. Vgl. KOMMISSION DER EUROPÄISCHEN GEMEINSCHAFTEN (1987b), S.18. Alternative Begrenzungen gelten für Zuschüsse zur Schaffung von Arbeitsplätzen.

6 Für Beihilfekumulierungen bei einzelnen Investitionsvorhaben hat die Kommission 1985 alternative Meldeschwellen beschlossen, die bei einer kumulierten Beihilfeintensität von $25 \%$ Netto-Subventionsäquivalent eine Ex-ante-Anmeldepflicht auslöst. Vgl. KOMMISSION DER EUROPÄISCHEN GEMEINSCHAFTEN (1985), S.142.

7 Für sektorale Beihilfen ist bestimmt, daß die Beihilfeintensität im Verhältnis zu den anstehenden Problemen stehen muß, um Wettbewerbsverzerrungen auf ein Mindestma $B$ zu begrenzen. Vgl. THIESING (1983), Anm.68 zu Art.92. Hinsichtlich regionaler Beihilfen gelten "je nach Art und Schwierigkeitsgrad der regionalen Problemen unterschiedliche Intensitätshöchstgrenzen der Beihilfen. Sie schwanken zwischen $75 \%$ und $20 \%$ Netto-Subventionsäquivalent. Vgl. KOMMISSION DER EUROPÄISCHEN GEMEINSCHAFTEN (1979), S.10. 
durchschnittlichen Vorjahresrate für ein ganzes Jahr festgesetzt wird ${ }^{1}$. Aus dem Verhältnis von Barwert der Vergünstigungen und der geförderten Investitionssumme ergeben sich die sogenannten Subventionsäquivalente. Durch Einbeziehung der in den Mitgliedstaaten unterschiedlichen maximalen Marginalsätze ${ }^{2}$ der Unternehmenseinkommensteuer ${ }^{3}$ werden die als maßgeblich erachteten Netto-Subventionsäquivalente berechnet ${ }^{4}$.

Das Netto-Subventionsäquivalent eines Darlehens ist um so geringer, je niedriger der verwendete Bezugssatz und je kürzer die Laufzeit des Kredits ist, je früher die Tilgung erfolgt, je geringer der Finanzierungsanteil des Darlehens an der Investitionssumme und je höher der maximale Marginalsteuersatz ist. Entspricht der auf das Darlehen zu entrichtende Zinssatz dem Bezugssatz, so hat das Netto-Subventionsäquivalent, wie im Fall der KfW-Mittelstandskredite, den Wert null. Diese Kredite fallen damit aus der Beihilfendefinition heraus 5 .

Zur Berechnung des Netto-Subventionsäquivalents von Schuldendiensthilfen werden die tatsächlich gewährten Zuschüsse mit dem Bezugssatz abdiskontiert. Sofern der vom Beihilfeempfänger zu entrichtende Kreditzinssatz über dem Bezugssatz liegt, ist im Vergleich zu öffentlichen Darlehen das Netto-Subventionsäquivalent der Schuldendiensthilfe höher, sofern in beiden Fällen auf denselben Zinssatz verbilligt wird.

Das Netto-Subventionsäquivalent von Kreditgewährleistungen wird dadurch gemessen, daß der Wert der Gewährleistung einem Zinszuschuß für ein Darlehen in Höhe des abgesicherten Betrags gleichgesetzt wird. Als Höhe des fiktiven Zuschusses wird dabei das Produkt aus der Kredithöhe und der Differenz zwischen dem Bezugssatz und dem Zinssatz für Staatsanleihen für denselben Zeitabschnitt angesetzt. Vom Gegenwartswert dieses fiktiven Zinszuschusses wird gegebenfalls das jährliche prozentuale Gewährleistungsentgelt abgezogen. Die Differenz bildet dann das Netto-Subventionsäquivalent der Gewährleistung ${ }^{6}$.

Obwohl die Ermittlung von Netto-Subventionsäquivalenten wünschenswert erscheint, um die Förderintensitäten verschiedener Subventionsformen vergleichbar zu machen,

1 Vgl. KOMMISSION DER EUROPÄISCHEN GEMEINSCHAFTEN (1979), S.13 f.

2 Dabei wird unterstellt, daß der Begünstigte über den gesamten Zeitablauf der Förderung Gewinne in einer Höhe erzielt, die mit dem maximalen Grenzsteuersatz belegt sind. Unklar bleibt, welcher Steuersatz heranzuziehen ist, wenn die maximalen Einkommen- und Körperschaftsteuersätze voneinander abweichen, wie dies z.B. in der Bundesrepublik ab dem Veranlagungszeitraum 1990 gilt.

3 Dabei beibt die deutsche Gewerbesteuer, soweit ersichtlich, außer acht.

4 Vgl. KOMMISSION DER EUROPÄISCHEN GEMEINSCHAFTEN (1987b), S.88 f.

5 Vgl. MÜLLER-KÄSTNER (1986), S.17.

6 Vgl. KOMMISSION DER EUROPÄISCHEN GEMEINSCHAFTEN (1979), S.13. 
weist die Berechnungsmethode der EG eine Reihe gravierender Fehler auf. So wird zumindest für die Bundesrepublik der Bezugssatz systematisch zu niedrig angesetzt, da der Zinssatz für KfW-Mittelstandskredite aufgrund vorhandener Bonitätsunterschiede im allgemeinen unterhalb des für den Empfängerkreis staatlicher Beihilfen geltenden Marktzinssatzes liegt ${ }^{1}$. Dadurch wird die Zins- bzw. Prämienverbilligung bei Darlehen und Gewährleistungen zu niedrig ausgewiesen. Außerdem ist die Berechnung der Beihilfeintensitäten nicht neutral im Hinblick auf die unterschiedlichen Beihilfeformen, da Zinszuschüsse gegenüber Darlehen diskriminiert werden und bei Gewährleistungen nicht der Gegenwartswert der Entgelte berücksichtigt wird. Allerdings fallen diese Probleme nur dann ins Gewicht, wenn allein dadurch die von der Kommission festgelegten Grenzen der Beihilfeintensitäten unter- oder überschritten werden.

Wenngleich die EG-Beihilferegeln vergleichsweise restriktiv erscheinen, so ist doch zu beachten, daß allein schon die Berechnung der Netto-Subventionsäquivalente und die Genehmigungspraxis der Kommission für Beihilfen von geringerer Bedeutung den Mitgliedstaaten einen erheblichen Spielraum für die Vergabe von Beihilfen beläßt. Darüber hinaus hat die Kommission unter dem Gesichtspunkt "gemeinsamer Interessen" der Mitgliedstaaten immer wieder spezifische Beihilfen in einzelnen Bereichen zugelassen. Außerdem existieren vergleichsweise weniger restriktive Sondervorschriften für Beihilfen im Bereich der Landwirtschaft (Art.42 EWGV), des Verkehrs (Art.77 EWGV), zur Förderung der Arbeitsmobilität (Art.123 EWGV) und im Rüstungsbereich (Art.223 EWGV). Bei konjunkturpolitischen Maßnahmen hat der einzelne Mitgliedstaat die anderen Mitgliedstaaten und die Kommission nach Art.103 EWGV lediglich ins Benehmen zu setzen. Eine effektive Begrenzung öffentlicher Kredithilfen durch die EG-Regelungen ist daher nur in begrenztem Umfang zu erwarten.

\section{b. Weitere Beschränkungen öffentlicher Kredithilfen}

Beschränkungen für Export-Kredithilfen enthält einmal der sogenannte OECDKonsensus $^{2}$, der von 22 OECD-Mitgliedsländern vereinbart wurde und verhindern soll, daß exportierende Staaten den internationalen Wettbewerb auf den Güter- und Dienstleistungsmärkten durch das Angebot subventionierter Kredite verzerren ${ }^{3}$. Die Bestim-

1 Dies wird gerade für die KfW-Mittelstandskredite auch nirgendwo bestritten, da diese stets als Fördermaßnahmen zugunsten des Mittelstands betrachtet werden. Vgl. MÜLLER-KÄSTNER (1986), S.11 f.

2 Die offizielle Bezeichnung lautet: Arrangement on Guidelines for Officially Supported Export Credits.

3 Vgl. OECD (1987), S.7. 
mungen des OECD-Konsensus sind dabei auf öffentlich unterstützte Exportkredite anwendbar, die eine Laufzeit von mindestens zwei Jahren haben und sich auf Güterverkäufe und Dienstleistungen beziehen ${ }^{1}$. Als öffentlich unterstützte Kredite gelten Direktdarlehen, die Refinanzierung von Krediten Dritter, die Gewährung von Zinszuschüssen sowie Garantien und Kreditversicherungen von öffentlichen Exportkrediteinrichtungen.

Im Konsensus sind nun Regeln über Mindestzinssätze, Höchstkreditlaufzeiten und maximale Finanzierungsanteile des Exportgeschäfts durch Exportkredite enthalten, wobei die Zins- und Laufzeitkonditionen in Abhängigkeit vom Entwicklungsstand der Importländer variieren ${ }^{2}$. Sofern die öffentliche Unterstützung in Form von Kreditgewährleistungen erfolgt, sind für diese keine besonderen Bedingungen spezifiziert, jedoch dürfen die damit abgesicherten Kredite die festgelegten Kreditkonditionen nicht unterschreiten ${ }^{3}$.

Wenn einer der Teilnehmer des Konsensus plant, Exportkredite zu vergeben, deren Konditionen mit dem Konsensus nicht konform sind, muß er dies bei allen anderen Teilnehmern notifizieren, die dann ihrerseits dazu berechtigt sind, in gewissem Umfang ebenfalls Exportkredite zu Konditionen zu vergeben, die vom Konsensus abweichen ${ }^{4}$. Darüber hinausgehende Sanktionsmöglichkeiten der anderen Teilnehmer bestehen in diesen Fällen aber nicht.

Besondere Regelungen gelten für Hilfskredite an Entwicklungsländer. Als Kriterium für den überwiegenden Hilfscharakter einer staatlich unterstützten Finanzierung ist im Konsensus ein Mindestzuschußelement ${ }^{5}$ festgelegt, das bei gebundenen Hilfskrediten $35 \%$ (bzw. $50 \%$ bei Krediten an die am wenigsten entwickelten Länder) beträgt ${ }^{6}$.

Supranationale Regeln spielen auch für Ausfuhrgewährleistungen eine Rolle. So haben sich die Mitgliedsländer des GATT verpflichtet, staatliche Exportkreditversicherungssysteme so zu konstruieren, daß sie sich selbst tragen, d.h. keiner staatlichen

1 Besondere Bedingungen gelten für die Finanzierung von Agrar- und Rüstungsexporte sowie von Exporten spezieller Güter wie Schiffe, Flugzeuge usw. Vgl. § 1 des OECD-Konsensus i.d.F. vom 15.07.1988.

2 Vgl. §§ 4,5 des OECD-Konsensus i.d.F. vom 15.07.1988. Zu den weniger restriktiven Bestimmungen früherer Fassungen des Konsensus vgl. BARON (1983), S.306 ff.; OECD (1987), S.7 ff. Siehe auch CONGRESSIONAL BUDGET OFFICE (1981a), S.9.

4 Vgl. OECD (1987), S.9.

4 Vgl. $\$ \S 14,15$ des OECD-Konsensus.

5 Die Berechnung des Mindestzuschußelements erfolgt durch Abzug der gesamten abdiskontierten Schuldendienstverpflichtungen des Kreditnehmers vom Nominalbetrag des Kredits, wobei diese Differenz zum Nominalwert des Kredits in Beziehung gesetzt wird. Vgl. dazu $\$ 22 \mathrm{~m}$ des OECD-Konsensus.

6 Vgl. BUNDESMINISTER FÜR WIRTSCHAFT (1989), S.18. 
Subventionierung bedürfen ${ }^{1}$. Die Erfüllung dieser Verpflichtung setzt risikoadäquate Prämiensätze für Ausfuhrgewährleistungen voraus. Allerdings ist angesichts gravierender Prämienunterschiede für Gewährleistungen in den verschiedenen Vertragstaaten und kontinuierlicher Unterdeckungen ${ }^{2}$, z.B. in der Bundesrepublik in den letzten Jahren, zu bezweifeln, daß diese im GATT vereinbarte Verpflichtung konsequent eingehalten wird ${ }^{3}$.

\section{HÖHE UND FÖRDERZWECKE ÖFFENTLICHER KREDITHILFEN IN DER BUNDESREPUBLIK DEUTSCHLAND}

In diesem Abschnitt sollen die mit öffentlichen Kredithilfen verbundenen Ausgaben, Einnahmen und Einnahmenausfälle sowie das aus der Kredithilfevergabe resultierende Vermögen quantitativ erfaßt werden. Weiterhin wird untersucht, für welche Förderzwecke öffentliche Kredithilfen bereitgestellt werden. Dabei wird in bezug auf die Kredithilfen der außerbudgetären Einheiten auf Vollständigkeit verzichtet, da aggregierte Daten nicht zur Verfügung stehen.

\section{1. Öffentliche Kredithilfen der Gebietskörperschaften und Sondervermögen}

Die Höhe und Förderzwecke öffentlicher Kredithilfen sollen für die einzelnen Kredithilfeformen getrennt ermittelt werden. Dabei ergibt sich das Problem, daß bei Darlehen und Schuldendiensthilfen haushaltsrechtlich danach differenziert wird, ob diese Zahlungen an den öffentlichen oder an andere Bereiche erfolgen ${ }^{4}$. Bei den Schuldendiensthilfen und Darlehen an andere Bereiche handelt es sich vorwiegend um Kredithilfen an die Privaten und an andere Staaten, die Gegenstand dieser Arbeit sind. Jedoch können bei Darlehen und Schuldendiensthilfen an andere Bereiche auch entsprechende Hilfen für den öffentlichen Bereich, insbesondere für Gemeinden, "versteckt" sein, sofern sie über den Umweg außerbudgetärer Einrichtungen an den öffentlichen Bereich zurückgeleitet werden. Denn die außerbudgetären Einrichtungen werden in den amtlichen Statistiken nicht

1 Vgl. BUNDESMINISTER FÜR WIRTSCHAFT (1989), S.19.

2 Vgl. BUNDESMINISTER FÜR WIRTSCHAFT (1989), S.18.

3 Vgl. HICHERT (1986), S.136 ff.

4 Nach dem für Bund und Länder geltenden Gruppierungsplan gehören zu den Darlehen an den öffentlichen Bereich die Darlehen an Bund, Länder, Gemeinden und Gemeindeverbände, Lastenausgleichsfonds, ERP-Sondervermögen, Sozialversicherungsträger und Zweckverbände. Darlehen an alle übrigen Empfänger, insbesondere auch Darlehen an die außerbudgetären Einrichtungen und an das Ausland, werden unter Darlehen an andere Bereiche zusammengefaßt. Vgl. PIDUCH (1990), Kommentar zu $\& 13$ BHO, S.13. 
zum öffentlichen Bereich gezählt. Daher geben die Schuldendiensthilfen und Darlehen an andere Bereiche nicht exakt die Höhe der Kredithilfen im Sinne der Abgrenzung dieser Arbeit wieder. Will man die Höhe der Ausgaben für Kredithilfen der einzelnen staatlichen Ebenen ermitteln, ist die Betrachtung der Ausgaben für andere Bereiche ebenfalls unzureichend, da bei den Kredithilfen des Bundes vielfach die Länder zu ihrer Weiterleitung eingeschaltet sind. Andererseits würden die Kredithilfeausgaben in ihrer quantitativen Bedeutung überschätzt, wenn die entsprechenden Ausgaben an den öffentlichen Bereich und an andere Bereiche addiert würden, da sich dann Doppelzählungen ergeben würden. Außerdem würden dann auch die Ausgaben erfaßt, die im öffentlichen Bereich verbleiben und hier nicht näher untersucht werden sollen. Mangels anderer Daten ist man jedoch weitgehend auf die Angaben der amtlichen Statistiken angewiesen.

\section{a. Schuldendiensthilfen}

Im folgenden werden wegen der angesprochenen Schwierigkeiten die Ausgaben der Gebietskörperschaften für Schuldendiensthilfen an den öffentlichen Bereich nur teilweise berücksichtigt. Dies erscheint wegen ihrer vergleichsweise geringen Bedeutung im Betrachtungszeitraum vertretbar, obwohl damit die Höhe der Schuldendiensthilfen für Private zu gering ausgewiesen sein dürfte.

aa. Höhe der Ausgaben für Schuldendiensthilfen

Die Ausgaben des Bundes für Schuldendiensthilfen an andere Bereiche lagen 1986 mit 1.362 Mio. DM rund sechzehnmal höher als 1960 mit 86 Mio. DM. Diese Entwicklung läßt sich in zwei Phasen aufteilen. So ist die absolute Ausgabenhöhe im Zeitraum von 1960 bis 1971 relativ kontinuierlich angestiegen und war $1971 \mathrm{mehr}$ als vierzehnmal höher als 1960. Seit 1972 haben sich die Ausgaben dagegen nur noch relativ geringfügig erhöht. Sie erreichten 1984 mit 1.408 Mio. DM ihren Höchststand und lagen damit nicht einmal $20 \%$ höher als $1971^{1}$. Allerdings geht aus den vorliegenden Daten nicht hervor, welcher Anteil der Ausgaben auf kapitalisierte und periodische Zuschüsse entfällt. Außerdem bleibt unklar, in welchem Zeitraum die Verpflichtungen übernommen wurden, die im jeweiligen Haushaltsjahr Ausgaben für Schuldendiensthilfen nach sich zogen.

Setzt man die Ausgaben für Schuldendiensthilfen in Relation zum Haushaltsvolumen des Bundes, so ist daraus zu folgern, daß Schuldendiensthilfen seit Anfang der siebziger

1 Vgl. Anhang, Tabelle 1. 
Jahre viel von ihrer Attraktivität eingebüßt haben. Betrug die entsprechende Quote 1971 noch $1,20 \%$, so sank sie 1986 auf nur noch $0,52 \% 1$.

Weiterhin ist festzustellen, daß der Bund einen erheblichen Teil seiner gesamten Schuldendiensthilfen an die KfW leistet, von der diese Mittel zur Zinsverbilligung von Krediten verwendet werden. Zwischen 1978 und 1986 schwankten die Zinszuschüsse an die KfW zwischen 319 Mio. DM (1980) und 644 Mio. DM (1983)². Damit entfielen 1980 21,7\% und 1983 sogar 39,2\% der Ausgaben des Bundes für Schuldendiensthilfen auf Zinszuschüsse an die KfW. D.h. daß die Schuldendiensthilfen zumindest zu einem erheblichen Teil ihren Destinataren nicht direkt, sondern als zinsverbilligte Darlehen zufließen.

Bei den Ländern verlief die Entwicklung der Ausgaben für Schuldendiensthilfen an andere Bereiche nicht immer parallel zu der des Bundes. Während diese Ausgaben von 1960 bis 1971 bei Bund und Ländern nahezu gleich hoch waren, stiegen sie danach bei den Ländern wesentlich stärker als beim Bund. Seit 1975 sind die Ausgaben der Länder für Schuldendiensthilfen etwa doppelt so hoch wie die des Bundes. Dennoch hat auch bei den Ländern die relative Bedeutung der Schuldendiensthilfen abgenommen. So entfielen 1977 $1,82 \%$ der Gesamtausgaben der Länder auf Schuldendiensthilfen an andere Bereiche. Diese Quote betrug 1986 nur noch 1,32 \% ${ }^{3}$. Auch die Länder leiten einen Teil ihrer Schuldendiensthilfen an außerbudgetäre Einrichtungen weiter. So beliefen sich 1986 allein die vom Land Baden-Württemberg an die LKB ausbezahlten Zinszuschüsse zur Wohnungsbauförderung auf 5,8 \% der Schuldendiensthilfen aller Bundesländer an andere Bereiche ${ }^{4}$.

Die Schuldendiensthilfen von Gemeinden und sonstigen öffentlichen Haushalten sind nur von untergeordneter Bedeutung und werden daher nicht näher betrachtet.

\section{bb. Förderzwecke der Schuldendiensthilfen}

Hinsichtlich der Förderzwecke der Schuldendiensthilfen liegen neuere aggregierte Daten für Bund und Länder nicht vor. In den sechziger Jahren stand beim Bund die Förderung der Landwirtschaft eindeutig im Vordergrund. Von den Ausgaben für Schuldendiensthilfen an andere Bereiche entfielen von 1960 bis 1968 meist deutlich mehr als $50 \%$

1 Eigene Berechnungen nach den Angaben im Anhang, Tabelle 1 und Tabelle 16.

2 Vgl. Anhang, Tabelle 2.

3 Eigene Berechnungen nach STATISTISCHES BUNDESAMT (1978), S.59; STATISTISCHES BUNDESAMT (1987), S.27.

4 Eigene Berechnung nach Anhang, Tabelle 1 und BADEN-WÜRTTEMBERG (1989), EPI.03, Kap.0309, Titelgr.70, S.148. Zur Höhe der Zinszuschüsse des Freistaats Bayern an die LfA vgl. Anhang, Tabelle 3. Allerdings werden die Zinszuschüsse an die LfA im Haushaltsplan Bayern teilweise als Investitionszuschüsse ausgewiesen. 
auf diesen Förderbereich, wobei 1963 mit 96,8 \% der Höchstwert erreicht wurde. Seit 1969 ist der Anteil der Landwirtschaft auf unter $40 \%$ gefallen. Daneben waren von 1960 bis 1974 in einzelnen Jahren auch die Schuldendiensthilfen für den Wohnungsbau bedeutsam, die bis zu 18,6 \% (1962) der Ausgaben für Schuldendiensthilfen erreichten. Seit 1967 werden Schuldendiensthilfen auch in größerem Umfang zum Zwecke der Wirtschaftsförderung eingesetzt. Der Anteil an den Ausgaben für Schuldendiensthilfen für andere Bereiche stieg bis auf 40,4 \% (1968), war in den einzelnen Jahren jedoch starken Schwankungen unterworfen ${ }^{1}$. Beim Bund haben sich die Schwerpunkte seitdem deutlich verlagert. Von den als Finanzhilfen i.S.d. $\$ 12$ StabWG erfaßten Schuldendiensthilfen ${ }^{2}$ wurden 1986 (1981) nur noch 11,1\% (22,7\%) für die Landwirtschaft, 19,9\% (12,0\%) für die gewerbliche Wirtschaft und $69,0 \%(65,2 \%)$ für den Wohnungsbau verwendet ${ }^{3}$. Die nicht zu den Finanzhilfen gerechneten Schuldendiensthilfen des Bundes wurden in erster Linie an das Ausland im Rahmen der Entwicklungshilfe gewährt.

Bei den Ländern entfiel von 1960 bis 1974 der größte Teil der Ausgaben für Schuldendiensthilfen an andere Bereiche auf den Wohnungsbau. Der Anteil dieses Förderbereichs erreichte 1967 mit $91,5 \%$ das Maximum und fiel in den siebziger Jahren auf Werte zwischen 60 und $70 \%$. Daneben lag der Anteil des Bereichs Wirtschaftsförderung zwischen 1969 und 1974 bei 20 bis $25 \%{ }^{4}$. Wenngleich neuere aggregierte Daten fehlen, ist zu vermuten, daß auch in den letzten Jahren der überwiegende Teil der Schuldendiensthilfen der Länder auf den Wohnungsbau und auf die Wirtschaftsförderung entfallen ist.

\section{b. Darlehen}

Da Darlehen ausgaben-, einnahmen- und vermögenswirksam sind, sollen im folgenden die Darlehensausgaben, Tilgungs- und Zinseinnahmen und das Darlehensvermögen erfaßt werden. Darüber hinaus sollen die mit der Vergabe öffentlicher Darlehen durch die Gebietskörperschaften verbundenen Zinsverbilligungskosten geschätzt werden. Schließlich werden die Darlehensausgaben der öffentlichen Haushalte nach Förderzwecken betrachtet.

1 Vgl. Anhang, Tabelle 4. Allerdings ist festzustellen, daß sich seit 1969 die Ausgaben für Schuldendiensthilfen für Wirtschaftsunternehmen der öffentlichen Hand absolut und relativ stark erhöht haben. Vgl. DICKERTMANN (1980), S.570. Darunter dürften sich in erheblichem Umfang Zahlungen an die KfW verbergen, die zur Weiterleitung an die Privaten bestimmt waren.

2 Sie beliefen sich 1986 auf 1.528 Mio. DM und lagen damit über den Schuldendiensthilfen des Bundes an andere Bereiche, jedoch unter seinen gesamten Schuldendienstausgaben.

3 Vgl. Anhang, Tabelle 5.

4 Vgl. Anhang, Tabelle 4. 
aa. Höhe der Darlehensausgaben

Die Darlehensausgaben der öffentlichen Haushalte an Empfänger, die nicht zum öffentlichen Bereich gerechnet werden, waren 1988 mit 16,5 Mrd. DM rund achtmal höher als 1950, wo sie bei 2,2 Mrd. DM lagen ${ }^{1}$. Dabei ist jedoch zu berücksichtigen, daß im genannten Zeitraum die gesamten Ausgaben der öffentlichen Haushalte stark angestiegen sind. Setzt man die Darlehensausgaben zu den bereinigten Gesamtausgaben ${ }^{2}$ der öffentlichen Haushalte (ohne Sozialversicherung) in Beziehung, so ergibt für 1950 eine Darlehensausgabenquote von 7,7 \% und für 1988 von $2,6 \%{ }^{3}$. Allgemein zeigt sich, daß die relative Bedeutung der Darlehensausgaben seit den Anfangsjahren der Bundesrepublik deutlich abgenommen hat und seit Anfang der siebziger Jahre auf einem relativ gleichbleibenden Niveau verharrt.

Diese Feststellung gilt tendenziell für alle öffentlichen Haushalte gleichermaßen. Allerdings lag die Darlehensausgabenquote beim Bund 1950 nur bei 1,1\%, stieg danach bis auf 6,4 \% (1958) an, um ab 1970 wieder auf unter $3 \%$ zu fallen. Sie lag 1988 bei 2,3\%. Betrachtet man die absoluten Darlehensausgaben des Bundes in den einzelnen Jahre, so zeigt sich, daß sie im Zeitraum von 1950 bis 1988 in 27 Jahren gegenüber dem Vorjahr angestiegen und in 12 Jahren zurückgegangen sind. Dabei fällt auf, daß in den 10 Jahren mit Bundestagswahlen dieses Zeitraums ${ }^{4}$ ausnahmslos höhere Darlehensausgaben als in den jeweiligen Vorjahren zu verzeichnen waren.

Bei den Ländern erreichte die Darlehensausgabenquote 1952 mit 23,9\% einen Höchststand. Sie hat sich seitdem weitgehend den Verhältnissen beim Bund angenähert und lag 1988 bei 2,2 \%. Bei den Gemeinden haben die Darlehensausgaben nur noch eine vergleichsweise geringe Bedeutung. Die Darlehensausgabenquote erreichte 1988 nur noch 0,9 \%, nachdem ihr Maximum 1957 bei 7,9 \% lag. Die Entwicklung der Darlehensausgaben der beiden betrachteten Sondervermögen war im Betrachtungszeitraum gegenläufig. Während die Darlehensausgaben des LAF in den ersten Jahren der Bundesrepublik zum Teil über 1 Mrd. DM und damit über denen der Gemeinden lagen, betrugen sie 1988 nur noch

1 Vgl. Anhang, Tabelle 7.

2 Bei den Berechnungen in Anhang, Tabelle 7 sind dabei die Nettoausgaben der einzelnen Haushaltsebenen zugrundegelegt, die sich aus den Brutto-Gesamtausgaben durch Bereinigung um Zahlungen innerhalb derselben und zwischen verschiedenen Ebenen ergeben und bei der Betrachtung der Aggregate Doppelzählungen ausschalten. Vgl. STATISTISCHES BUNDESAMT (1988), S.20.

3 Eigene Berechnungen aufgrund Anhang, Tabelle 7, STATISTISCHES BUNDESAMT (1988), S.180 und FINANZBERICHT (1989), Ubersicht 8, S.232.

4 Bundestagswahlen fanden 1953, 1957, 1961, 1965, 1969, 1972, 1976, 1980, 1983 und 1987 statt. 
32 Mio. DM. Dagegen stiegen die Darlehensausgaben des ERP-Sondervermögens von 1960 mit 0,6 Mrd. DM bis 1988 auf 3,5 Mrd. DM an.

Die Angaben über die Darlehen der öffentlichen Haushalte an andere Bereiche geben keinen genauen Aufschluß über die Höhe öffentlicher Darlehen nach der hier getroffenen Abgrenzung, wenngleich diese Darlehen praktisch ausnahmslos zu nichtmarktlichen Konditionen ausgereicht wurden. Denn die genannten Zahlen enthalten auch die Ausgaben aus der Inanspruchnahme aus Gewährleistungen, die zu einem Übergang der abgesicherten Forderungen auf den Gewährleistungsübernehmer führen. Letztere Ausgaben sind damit durch öffentliche Kreditgewährleistungen verursacht ${ }^{1}$. Sie betrugen beim Bund 1978 rund $22 \%$, 1987 dagegen schon $50 \%$ der Darlehensausgaben an andere Bereiche? ${ }^{2}$.

Will man den Anteil des Bundes an der Gewährung öffentlicher Darlehen genauer abschätzen, muß zudem berücksichtigt werden, daß der Bund zahlreiche Darlehensausgaben insbesondere über die Länder an die Empfänger weiterleitet, die dann jedoch haushaltssystematisch als Darlehen an den öffentlichen Bereich erfaßt werden. Deshalb werden beim Bund die Ausgaben für öffentliche Darlehen unterschätzt, wenn man lediglich die Darlehensausgaben an andere Bereiche betrachtet. Umgekehrt resultiert bei den Ländern in diesem Fall eine Überschätzung der Ausgaben für öffentlichen Darlehen. Die Ausgaben des Bundes für Darlehen an den öffentlichen Bereich betrugen beispielsweise 1974 1,1 Mrd. DM und 1988 2,6 Mrd. DM³. Diese Ausgaben sind weitgehend den Kredithilfen nach der hier getroffenen Abgrenzung zuzurechnen ${ }^{4}$.

Weiterhin ist erwähnenswert, daß ein erheblicher Teil der öffentlichen Darlehen des Bundes und der Länder einschließlich ihrer Sondervermögen über Sonderkreditinstitute an ihre Empfänger ausgereicht werden 5 . Insbesondere die ERP-Darlehen werden praktisch ausschließlich von den Hauptleihinstituten weitergeleitet. Eine genauere Quantifizierung

1 Weder vom Statistischen Bundesamt noch in den Finanzberichten des Bundes wird eine entsprechende Differenzierung vorgenommen.

2 Eigene Berechnungen aufgrund der Angaben im Anhang, Tabellen 7 und 16. Da beim Bund bis 1977 die Ausgaben und Einnahmen aufgrund von Gewährleistungen lediglich saldiert veröffentlicht wurden und für die anderen öffentlichen Haushalte Angaben über die Gewährleistungsausgaben fehlen, wurde auf eine Bereinigung der Darlehensausgaben verzichtet.

3 Vgl. Anhang, Tabelle 6.

4 Von den im Bundeshaushaltsplan 1988 veranschlagten Darlehen an den öffentlichen Bereich in einer Gesamthöhe von 2,51 Mrd. DM waren 2,32 Mrd. DM oder $92 \%$ für die Ausbildungsförderung nach BAFöG und die Wohnungsbauförderung vorgesehen. Vgl. BUNDESHAUSHALTSPLAN (1988), Haushaltsquerschnitt, S.44 ff.

5 Dies gilt beim Bund insbesondere für die Entwicklungshilfe-Darlehen, deren Auszahlung durch die KfW erfolgt. Sonderkreditinstitute der Länder sind insbesondere bei der Wohnungsbauund Gewerbeförderung eingeschaltet. 
der Darlehen der öffentlichen Haushalte, die über Sonderkreditinstitute ausgereicht werden, ist jedoch mangels statistischer Angaben nicht möglich.

bb. Einnahmen aufgrund von öffentlichen Darlehen

Durch die Vergabe öffentlicher Darlehen bestimmter Perioden entstehen Darlehensforderungen, die in darauffolgenden Perioden zu Einnahmen in Form von Zins- und Tilgungszahlungen führen. Im folgenden sollen zunächst wiederum die Einnahmen von Schuldnern außerhalb des öffentlichen Bereichs betrachtet werden, um Doppelzählungen zu vermeiden ${ }^{1}$. Dabei ist allerdings zu beachten, daß auf diese Weise die effektiven Einnahmen aus öffentlichen Darlehen insbesondere bei Ländern zu hoch ausgewiesen sind. Denn die Länder refinanzieren öffentliche Darlehen in erheblichem Umfang durch Verschuldung beim Bund, so da $B$ insoweit den Darlehenseinnahmen Zins- und Tilgungsausgaben gegenüberstehen. Letztere werden beim Bund wiederum als Zahlungen vom öffentlichen Bereich vereinnahmt.

Die Höhe der Zinseinnahmen des öffentlichen Gesamthaushalts (ohne Sozialversicherung) von anderen Bereichen bewegte sich zwischen 1974 und 1988 zwischen 2,3 Mrd. DM und 4,2 Mrd. DM jährlich². Von den verschiedenen staatlichen Ebenen wurden die relativ höchsten Zinseinnahmen von den Gemeinden erzielt. Dabei ist jedoch zu berücksichtigen, daß die Zinseinnahmen der Gemeinden in erheblichem Umfang aus Rücklagen resultieren, die zu marktlichen Konditionen angelegt werden und damit nur zu einem allerdings nicht quantifizierbaren Anteil den öffentlichen Darlehen zugerechnet werden können ${ }^{3}$.

Die Tilgungseinnahmen des öffentlichen Gesamthaushalts schwankten von 1974 bis 1988 zwischen 3,8 Mrd. DM und 9,4 Mrd. DM. Damit war die Schwankungsbreite bei den Tilgungseinnahmen wesentlich höher als bei den Zinseinnahmen. Der größte Anteil der Tilgungseinnahmen der öffentlichen Haushalte entfällt seit einigen Jahren auf das ERPSondervermögen, gefolgt von den Ländern und vom Bund ${ }^{4}$.

Um das Ausmaß der budgetären Belastung durch öffentliche Darlehen zu erfassen, wird bisweilen dafür plädiert, die Periodeneinnahmen aufgrund von Darlehensforderungen

1 Dies wird von DICKERTMANN/HANSMEYER (1987), S.59 ff. übersehen, die bei der Betrachtung der Zinseinnahmen des Gesamthaushalts sämtliche Zinseinnahmen der verschiedenen Ebenen addieren.

2 Vgl. Anhang, Tabelle 8.

3 Vgl. DICKERTMANN/HANSMEYER (1987), S.64.

4 Vgl. Anhang, Tabelle 9. 
zu den Darlehensausgaben der einzelnen Perioden ins Verhältnis zu setzen ${ }^{1,2}$. Diese auch als Deckungsrelation bezeichnete Verhältniszahl streute beim öffentlichen Gesamthaushalt im Zeitraum von 1974 bis 1988 zwischen 58,7 und 91,9\% und lag in den meisten Jahren zwischen 70 und $80 \%^{3}$. D.h. daß die Ausgaben des Gesamthaushalts für öffentliche Darlehen gegenwärtig zu einem erheblichen Teil durch Einnahmen aus Darlehensforderungen gedeckt sind. Allerdings sind die angegebenen Prozentzahlen zu hoch, wenn man in die Deckungsrelation nur Einnahmen aus Forderungen aufgrund öffentlicher Darlehen einbeziehen will, da die Zinseinnahmen der Gemeinden zu einem wesentlichen Teil aus der Verzinsung von Rücklagen stammen.

Will man die Deckungsrelation für öffentliche Darlehen beim Bund berechnen, müssen aufgrund des bereits ausgeführten Zusammenhangs sinnvollerweise auch die Einnahmen vom und Ausgaben an den öffentlichen Bereich berücksichtigt werden ${ }^{4}$. Die Deckungsrelation, die sich bei entsprechendem Vorgehen errechnen läßt, schwankte in 12 Jahren des Zeitraums von 1974 bis 1988 zwischen 40 und $60 \% 5$. Damit lassen sich die öffentlichen Darlehen gegenwärtig etwa zur Hälfte aus Einnahmen finanzieren, die auf früher erworbenen Darlehensforderungen beruhen. Weiterhin läßt sich zeigen, daß die Deckungsrelation beim Bund höher ausfällt, wenn man ihm auch die Einnahmen und Ausgaben des ERP-Sondervermögen zurechnet ${ }^{6}$. Dies ist jedoch nicht überraschend, wenn man bedenkt, daß das ERP-Sondervermögen die Finanzierung von Darlehensausgaben weitgehend aus Darlehenseinnahmen zu bestreiten hat.

Die Verwendung der Deckungsrelation als Maßgröße für die budgetäre Belastung durch öffentliche Darlehen ist jedoch insbesondere insoweit problematisch, als sie die mit der Finanzierung der Darlehensforderungen verbundenen Ausgaben unberücksichtigt läßt. Sie kann daher das Ausmaß der budgetären Belastung durch öffentliche Darlehen nur dann zutreffend wiedergeben, wenn die Darlehensforderungen vollständig steuerfinanziert sind. Dies läßt sich jedoch bei Geltung des Gesamtdeckungsgrundsatzes nicht belegen.

1 Vgl. DICKERTMANN/HANSMEYER (1987), S.63 ff.; SUBVENTIONSBERICHT (1989), S.28.

2 Dabei wird unterstellt, daß eine budgetäre Belastung durch öffentliche Darlehen in einer Haushaltsperiode nur dann entsteht, wenn die Darlehensausgaben die -einnahmen übersteigen. Soweit eine Zweckbindung dieser Einnahmen nicht gegeben ist, widerspricht diese Betrachtungsweise allerdings formal dem haushaltsrechtlichen Gesamtdeckungsgrundsatz.

Vgl. Anhang, Tabelle 10.

4 Anderer Ansicht sind offensichtlich DICKERTMANN/HANSMEYER (1987), S.64 f. Dabei bleibt allerdings unklar, was die eng definierte Deckungsrelation des Bundes zum Ausdruck bringen soll.

5 Nur in jeweils einem Jahr gab es eine Abweichung nach oben bzw. unten von dieser Bandbreite. Vgl. Anhang, Tabelle 10.

6 Vgl. DICKERTMANN/HANSMEYER (1987), S. 64. 
Außerdem läßt die Verwendung der Deckungsrelation allein noch keine Rückschlüsse über künftige budgetäre Belastungen durch öffentliche Darlehen zu. Diese hängen allein von den konkreten Konditionen der gewährten Darlehen ab. Nur wenn diese bekannt sind, lassen sich Aussagen zum Verlauf der Einnahmen-Ausgaben-Relation bei öffentlichen Darlehen über einen längeren Zeitraum hinweg machen. Fest steht allerdings, daß die Deckungsrelation in einer Ausgangsperiode, in der zum erstenmal Darlehen gewährt werden, Null betragen muß. Wenn der Staat seinen Forderungsbestand konstant halten will, wird die Deckungsrelation $100 \%$ überschreiten (betragen), wenn die Darlehen zu einem positiven Zinssatz (unverzinslich) gewährt werden.

\section{cc. Zinsverbilligungskosten öffentlicher Darlehen}

Während bei der Betrachtung der Deckungsrelation nur Ausgaben und Einnahmen berücksichtigt werden, soll nun auf die Kosten öffentlicher Darlehen eingegangen werden. Diese beruhen auf einer Minderverzinslichkeit und einem erhöhten Ausfallrisiko öffentlicher Darlehen gegenüber einer marktlichen Alternativanlage ${ }^{1}$.

Die Höhe dieser Zinsverbilligungskosten ist schwierig zu bestimmen, da jeweils die Höhe der Opportunitätskostenrate des Staates im Zeitpunkt der Darlehensvergabe bekannt sein müßte. Dies impliziert auch, daß für alle mit öffentlichen Darlehen finanzierten Aktivitäten die Höhe des risikoangepaßten Marktzinssatzes bekannt sein müßte. Da solche Daten nicht vorhanden sind, ist man in diesem Zusammenhang auf mehr oder weniger grobe Schätzungen angewiesen.

Schätzungen über die Höhe der Zinsverbilligungskosten werden in einigen älteren Subventionsberichten des Bundes für den Bestand seiner Darlehensforderungen genannt ${ }^{2}$, die zur Kategorie der Finanzhilfen gerechnet werden ${ }^{3}$. Die angegebene Höhe der Zins-

1 Sofern der öffentliche Darlehensgeber verschuldet ist, wäre eine Tilgung von Kapitalmarktschulden eine mögliche Alternativanlage. Die Opportunitätskosten der Darlehensvergabe bestehen dann in einem Verzicht auf eine entsprechende Reduzierung der Zinsausgaben.

2 Im SUBVENTIONSBERICHT (1989), S.28 wird zwar ausgeführt:

"Unter ökonomischen Gesichtspunkten ist nicht die Darlehenssumme, sondern im wesentlichen die mit ihr verbundene Zinsbegünstigung als finanzielle Hilfe anzusehen."

Daraus wird jedoch nicht die Konsequenz gezogen, die Höhe dieser Zinsbegünstigung im Bericht zu quantifizieren.

3 Den Berechnungen ist dabei die Differenz zwischen dem vereinbarten Darlehenszins und dem langfristigen Kapitalmarktzins zum Zeitpunkt der Gewährung der zinsbegünstigten Bundesdarlehen zugrundegelegt. Vgl. SUBVENTIONSBERICHT (1985), S.35. 
verbilligungskosten ${ }^{1}$ lag 1977 bei 1,28 Mrd. DM und stieg 1984 auf 1,53 Mrd. DM. Bezogen auf den Bestand an Forderungen aus Finanzhilfe-Darlehen ergibt sich dabei eine durchschnittliche Zinsverbilligung zwischen 3,6 und 3,8 Prozentpunkten in den einzelnen Jahren dieses Zeitraums² .

Da die den Finanzhilfen zugerechneten Darlehensforderungen nur einen Teil der Darlehensforderungen des Bundes umfassen, liegen die gesamten Zinsverbilligungskosten aufgrund von öffentlichen Darlehen erheblich über den oben genannten Beträgen. Unterstellt man, daß für die nicht als Finanzhilfen erfaßten Darlehensforderungen derselbe durchschnittliche Zinsverbilligungssatz wie für die Finanzhilfe-Darlehen gilt, errechnen sich für 1984 Zinsverbilligungskosten in Höhe von 2,6 Mrd. DM. Diese Schätzung stellt eine Untergrenze für die tatsächlichen Zinsverbilligungskosten dar, weil die bei den Finanzhilfe-Darlehen nicht erfaßten Darlehensforderungen im wesentlichen aus nahezu unverzinslichen Forderungen aufgrund der "Finanziellen Zusammenarbeit" mit Entwicklungsländern und unverzinslichen BAFöG-Forderungen bestehen.

Um zu einer realistischeren Schätzung des durchschnittlichen Zinsverbilligungssatzes für den gesamten Darlehensbestand des Bundes zu gelangen, sind die durchschnittlichen prozentualen Zinseinnahmen aus dem Darlehensvermögen des Bundes zu ermitteln und von den durchschnittlichen prozentualen Zinsausgaben für die Bundesschuld zu subtrahieren, wobei letztere als Näherungswert für die Opportunitätskostenrate verwendet werden. Die prozentualen Zinseinnahmen wurden hier durch Division der Zinseinnahmen eines Haushaltsjahres durch den Darlehensbestand am Beginn des Haushaltsjahres berechnet. Die prozentualen Zinsausgaben wurden in analoger Weise ermittelt. Die Höhe des Zinsverbilligungssatzes schwankte bei dieser Berechnungsmethode von 1974 bis 1986 zwischen 5,0 (1976) und 6,9 (1983) Prozentpunkten ${ }^{3}$, wobei die durchschnittliche prozentuale Verzinsung der Forderungen aus öffentlichen Darlehen zwischen 1,4 und 2,0\% $\mathrm{lag}^{4}$. Der Schätzwert für die Zinsverbilligungskosten ergibt sich durch Multiplikation des durchschnittlichen Zinsverbilligungssatzes eines Jahres mit dem Darlehensbestand am Jahresanfang. Sie betragen nach der hier vorgenommenen Berechnung für 1984 rund 4,44 Mrd. DM

1 Es wird hier aus Vereinfachungsgründen angenommen, daß die Höhe der Zinsverbilligungskosten mit der Zinsbegünstigung für die Darlehensnehmer übereinstimmt, auf die in den Subventionsberichten abgestellt wird. Vgl. SUBVENTIONSBERICHT (1985), S.31.

3 Vgl. Anhang, Tabelle 11.

Vgl. Anhang, Tabelle 12.

4 Der durchschnittliche Zinsertrag der verzinslichen Darlehensforderungen aller öffentlichen Haushalte wird von der DEUTSCHEN BUNDESBANK (1985), S.21 mit 2,5\% angegeben. 
(1986: 4,37 Mrd. DM) ${ }^{1}$ und liegen damit rund dreimal so hoch wie die für die Darlehensforderungen aus Finanzhilfen genannten Zahlen.

Allerdings weist diese Schätzung einige Fehlermöglichkeiten auf. So kann sich die Fristenstruktur der Forderungen aus öffentlichen Darlehen und der Bundesschuld erheblich unterscheiden. Ist die durchschnittliche Laufzeit der Darlehensforderungen länger als die der Bundesschuld, wovon auszugehen ist, wenn man die Laufzeiten verschiedener Darlehensprogramme betrachtet ${ }^{2}$, so ist der durchschnittliche Zinsverbilligungssatz tendenziell höher als in der hier vorgenommenen Schätzung. Denn mit zunehmender Laufzeit steigt üblicherweise die Opportunitätskostenrate, da langfristige Forderungen illiquider sind als kurzfristige Forderungen ${ }^{3}$. Andererseits schwanken die prozentualen Zinsausgaben wegen der vergleichsweise kurzen Durchschnittslaufzeit der Staatsschuldtitel entsprechend den Schwankungen des allgemeinen Zinsniveaus relativ stark. Geht man davon aus, daß die Schwankungsbreite langfristiger Zinssätze geringer ist als diejenige kurzfristiger Zinssätze, so dürften die durchschnittlichen Zinsverbilligungskosten in Jahren mit einem relativ hohen (niedrigen) Zinsniveau nach der hier durchgeführten Vorgehensweise überschätzt (unterschätzt) werden. Außerdem resultieren die Zinseinnahmen des Bundes zum Teil auch aus Geldmarktanlagen zu marktlichen Konditionen, die mit öffentlichen Darlehen nicht in Verbindung stehen ${ }^{4}$. D.h. da $\beta$ die Durchschnittsverzinsung des Forderungsbestandes aus öffentlichen Darlehen bei der durchgeführten Schätzung zu hoch angesetzt wird. Zumindest teilweise werden sich diese möglichen Fehler kompensieren, so daß die genannten Schätzgrößen vertretbare Näherungswerte darstellen dürften.

Bei den ERP-Darlehen beträgt die durchschnittliche Zinsverbilligung nach Angaben der Bundesregierung ca. 2 Prozentpunkte p.a. ${ }^{5}$ Bezogen auf den Bestand an Darlehensforderungen des ERP-Sondervermögens, der Ende 1987 bei 20,2 Mrd. DM lag ${ }^{6}$, beliefen sich die Einnahmeausfälle aufgrund der Zinsverbilligung 1987 damit auf rund 400 Mio. DM.

Auf eine Schätzung der Einnahmenverluste der anderen öffentlichen Haushalte durch öffentliche Darlehen wird hier verzichtet. Jedoch dürften sie insbesondere bei den Ländern eine ganz beträchtliche Größenordnung erreichen, wenn man berücksichtigt, daß die Darlehensausgaben der Länder über lange Zeit hinweg die Darlehensausgaben des Bundes überschritten haben.

\footnotetext{
Vgl. Anhang, Tabelle 12.

2 Vgl. DICKERTMANN (1980), S.262 f.

3 Zur näheren Begründung vgl. MILBRADT (1975), S.26 f.

4 Vgl. DICKERTMANN/HANSMEYER (1987), S.66.

5 Vgl. BUNDESREGIERUNG (1988), S.11.

6 Vgl. BUNDESMINISTERIUM FÜR WIRTSCHAFT (1988), S.10.
} 
dd. Bestand an Darlehensforderungen

Die Betrachtung des Darlehensvermögens der Gebietskörperschaften wird hier auf den Bund und das ERP-Sondervermögen beschränkt, da aggregierte Daten für die Länder und Gemeinden nicht zur Verfügung stehen.

Der in der Vermögensrechnung ausgewiesene nominale Bestand des Darlehensvermögens des Bundes ${ }^{1}$ stieg von 1952 bis 1988 relativ kontinuierlich von 3,0 Mrd. DM auf 78,7 Mrd. $\mathrm{DM}^{2}$.

Da öffentliche Darlehen als "Finanzinvestitionen" den Verschuldungsspielraum des Bundes ausweiten können, ist es sinnvoll, den Forderungsbestand zum Schuldenstand des Bundes in Beziehung zu setzen. Die entsprechende Verhältniszahl betrug 1952 25,8 \% und stieg bis 1965 auf $87,8 \%$ an. Sie fiel seit 1974 stark und betrug 1988 nur noch $16,6 \%$. Während also in den ersten beiden Jahrzehnten des Bestehens der Bundesrepublik Deutschland den Verbindlichkeiten des Bundes in ganz erheblichem Umfang Vermögensaktiva in Form von Darlehensforderungen gegenüberstanden, wurde diese Entwicklung in den letzten beiden Jahrzehnten aufgrund des steilen Anstiegs der Staatsverschuldung nachhaltig umgekehrt ${ }^{3}$.

Diese Aussagen sind insofern zu relativieren, als der in der Vermögensrechnung des Bundes ausgewiesene Forderungsbestand aufgrund der Minderverzinslichkeit und des vergleichsweise hohen Risikos dieser Forderungen den Gegenwartswert der mit ihnen verbundenen künftigen Einnahmenströme deutlich übersteigt. Da Angaben über Ausfallwahrscheinlichkeiten und die durchschnittliche Restlaufzeit der Darlehensforderungen fehlen und hinsichtlich der durchschnittlichen Zinsverbilligungen ebenfalls nur vergleichsweise grobe Schätzungen möglich sind, lassen sich zuverlässige Angaben zum realen Wert des Forderungsvermögens des Bundes nicht machen. Legt man eine durchschnittliche Verzinsung von $2 \%$, eine Opportunitätskostenrate von $7,5 \%$ und eine durchschnittliche Restlaufzeit von $5 \mathrm{Jahren}^{4}$ zugrunde und unterstellt man eine Tilgung am Ende der Dar-

$1 \mathrm{Zu}$ den für die Vermögensrechnung des Bundes geltenden Grundsätzen vgl. PIDUCH (1990), Anm. 2 zu $\$ 86$ BHO.

2 Vgl. Anhang, Tabelle 13.

3 Damit soll jedoch nicht gesagt werden, daß eine dem Anstieg der Staatsverschuldung entsprechende Ausweitung des Darlehensvermögens wünschenswert gewesen wäre. Vielmehr wirft dieser Zusammenhang ein schlechtes Licht auf das AusmaB der mittlerweile erreichten Staatsverschuldung.

4 Diese Annahme läßt sich dadurch rechtfertigen, daß die vom Bund vergebenen Darlehen zum Teil sehr lange Laufzeiten haben. Beispielsweise betrug die durchschnittliche Laufzeit der von der Bundesrepublik 1978 vergebenen Entwicklungshilfe-Kredite 37,8 Jahre; vgl. BUNDES- 
lehenslaufzeit, so liegt der Gegenwartswert der Forderungen lediglich bei rund $77 \%$ ihres Nominalwertes. Geht man von einer durchschnittlichen Restlaufzeit von 10 Jahren aus, beträgt der Gegenwartswert der Forderungen nur noch $59 \%$ ihres Nominalwertes. Dementsprechend würde der Marktwert des Darlehensbestandes des Jahres 1987 seinen Nominalwert um 18,3 Mrd. DM bzw. um 32,6 Mrd. DM unterschreiten. Wenngleich sich Aussagen über die Güte der errechneten Zahlenwerte nicht machen lassen, kann daraus zumindest geschlossen werden, daß das Forderungsvermögen des Bundes seine Verbindlichkeiten zu einem wesentlich geringeren Anteil deckt, als durch die Vermögensrechnung suggeriert wird.

Der Brutto-Vermögensbestand der Kredithilfe-Sondervermögen des Bundes betrug Ende 1988 30,4 Mrd. DM ${ }^{1}$. Davon entfielen allein 22,5 Mrd. DM auf das ERP-Sondervermögen $^{2}$. Die Aktiva der Sondervermögen bestehen ganz überwiegend aus Darlehensforderungen ${ }^{3}$. Auch bei den Sondervermögen gilt, daß der ausgewiesene Vermögensbestand nicht seinem Marktwert entspricht.

\section{ee. Förderzwecke öffentlicher Darlehen}

Bei der Ermittlung der Förderzwecke der Darlehen besteht wie bei den Schuldendiensthilfen die Schwierigkeit, daß aktuelle zusammenfassende Übersichten nicht verfügbar sind. So wurden die Darlehensausgaben der öffentlichen Haushalte ${ }^{4}$ vom Statistischen Bundesamt nur bis 1983 nach Aufgabenbereichen geordnet veröffentlicht. Im entsprechenden Haushaltsjahr entfielen von den Darlehensausgaben an den nichtöffentlichen Bereich $37,5 \%$ auf die gewerbliche Wirtschaft einschließlich Verkehrs- und Nachrichtenwesen, 26,6\% auf das Wohnungswesen, 18,7\% auf Auswärtige Angelegenheiten (Entwicklungshilfe), 7,2 \% auf das Bildungswesen, 4,6\% auf die Soziale Sicherung und $1,7 \%$ auf den Agrarbereich ${ }^{5}$. Jedoch sind auch diese Zahlen insoweit verzerrt, als hierbei wiederum die Ausgaben aufgrund einer Inanspruchnahme aus Gewährleistungen, die ganz

MINISTERIUM FÜR WIRTSCHAFTLICHE ZUSAMMENARBEIT (1980), S.145, Anhang, Tabelle 32.

1 Eigene Berechnung nach den Angaben in FINANZBERICHT (1989), S.207 f.

2 Vgl. Anhang, Tabelle 14.

3 Z.B. belief sich 1987 beim ERP-Sondervermögen der Anteil der Darlehensforderungen an den gesamten Aktiva auf $92 \%$; eigene Berechnung aufgrund der Angaben in BUNDESMINISTERIUM FÜR WIRTSCHAFT (1988), S.10.

4 Als öffentliche Haushalte sind dabei Bund, Länder, Gemeinden, Gemeinde- und Zweckverbände, ERP-Sondervermögen, Lastenausgleichsfonds und Sozialversicherungen erfaßt.

5 Eigene Berechnungen nach den Angaben in STATISTISCHES BUNDESAMT (1984), S.96 ff. 
überwiegend an die gewerbliche Wirtschaft fließen, den Darlehensausgaben hinzugerechnet sind.

Betrachtet man allein den Bund, so entfielen 1988 von den gesamten Darlehensausgaben (ohne Gewährleistungsausgaben) auf die Auswärtigen Angelegenheiten 47,6\%, auf die Förderung des Bildungswesens 20,4 \% und auf das Wohnungswesen 19,0 \% 1 .

Beim ERP-Sondervermögen steht dagegen die Förderung kleiner und mittlerer Unternehmen im Vordergrund. Von den Kreditzusagen des Jahres 1987 in Höhe von 5,0 Mrd. DM entfielen 53,3\% auf sogenannte Mittelstandskredite mit den Schwerpunkten Regional- und Existenzgründungsförderung, 29,6\% auf Kredite für Umweltschutzmaßnahmen ${ }^{2}$ und 12,8 \% auf die Berlinhilfe ${ }^{3}$.

\section{c. Gewährleistungen}

Die Quantifizierung der Kreditgewährleistungen ist problematisch, weil die vorliegenden Daten nicht nach den verschiedenen Arten von Gewährleistungen differenzieren. Daher muß im folgenden auf eine solche Differenzierung ebenfalls verzichtet werden. Weiterhin beschränkt sich die Betrachtung teilweise auf den Bund. Es sollen nun das Haftungsvolumen aus öffentlichen Gewährleistungen, die damit verbundenen Einnahmen und Ausgaben, das Gewährleistungsrisiko, der Forderungsbestand aufgrund von Gewährleistungen sowie ihre Förderzwecke untersucht werden.

\section{aa. Das Haftungsvolumen aus öffentlichen Gewährleistungen}

Das Haftungsvolumen öffentlicher Gewährleistungen ist eine Bestandsgröße, die Aufschluß über die maximale Höhe der möglichen Verbindlichkeiten gegenüber den Gewährleistungsgläubigern gibt. Es deckt sich aber nicht mit dem haushaltsrechtlichen Ermächtigungsrahmen für Gewährleistungen, der lediglich die Obergrenze für das Haftungsvolumen markiert. Die periodische Veränderung des Haftungsvolumens entspricht der Differenz zwischen Neuhaftungen und Enthaftungen in der jeweiligen Periode.

Das Haftungsvolumen aus Gewährleistungen der öffentlichen Haushalte hat sich von 1960 bis 1984 in jedem Jahr erhöht und war 1984 mit 276,5 Mrd. DM zehnmal so hoch wie

1 Eigene Berechnungen nach BUNDESHAUSHALTSPLAN (1988), Gruppierungsübersicht, S.44 ff. Den Berechnungen liegen dabei Soll-Zahlen zugrunde.

2 Die Umweltschutzkredite fließen jedoch in erheblichem Umfang an die Gemeinden.

3 Eigene Berechnungen nach BUNDESMINISTERIUM FÜR WIRTSCHAFT (1988), S.17. 
1960 mit 27,8 Mrd. DM. Seit 1984 ist ein Rückgang des Haftungsvolumens festzustellen, das 1988 noch bei 255,5 Mrd. DM lag ${ }^{1}$. D.h. daß in den letzten Jahren die Summe der Enthaftungen die Höhe der neuen Gewährleistungszusagen überstieg.

Der weitaus größte Anteil des gesamten Haftungsvolumens der öffentlichen Haushalte entfällt auf den Bund. Er belief sich 1960 auf 66,8\%, stieg seit 1976 deutlich an und erreichte 1984 83,1\%. Bis 1988 ging dieser Anteil wieder leicht auf 80,7\% zurück. Dagegen sank der Anteil der Länder, der 1960 noch bei 25,5\% lag bis 1984 auf 12,3\%, um danach wieder auf 13,7\% anzusteigen. Relativ gering sind der Anteil der Gemeinden, der im gesamten Betrachtungszeitraum unter $10 \%$ lag, und des ERP-Sondervermögens ${ }^{2}$.

Die wachsende relative Bedeutung von Gewährleistungen beim Bund wird sichtbar, wenn man das Haftungsvolumen des Bundes zu den Gesamtausgaben ins Verhältnis setzt. Diese Verhältniszahl erreichte 1961 mit 47,2\% ihren niedrigsten Wert. Sie stieg bis auf $90,9 \%$ und fiel 1988 wieder auf 74,2\%3. Diese Entwicklung ist um so bemerkenswerter, als die relative Bedeutung von Schuldendiensthilfen in den achtziger Jahren erheblich zurückgegangen ist.

bb. Einnahmen und Ausgaben aufgrund von Gewährleistungen

Über die Einnahmen und Ausgaben aufgrund von Gewährleistungen der Gebietskörperschaften sind aggregierte Statistiken für alle Gebietskörperschaften und ihre Sondervermögen nicht vorhanden. Beim Bund lassen sich diese Größen aus der Bundeshaushaltsrechnung vergleichsweise einfach ermitteln ${ }^{4}$.

Es zeigt sich, daß eine Haushaltsbelastung des Bundes aufgrund von Gewährleistungen bis Anfang der achtziger Jahre praktisch nicht auftrat. So wurden von 1960 bis 1982 in 17 Haushaltsjahren Einnahmenüberschüsse erzielt, so daß sich ein kumulierter Einnahmenüberschuß in Höhe von 2,3 Mrd. DM ergab ${ }^{5}$. Dieser kumulierte Überschuß kehrte sich jedoch innerhalb von nur drei Jahren in einen kumulierten Ausgabenüberschuß um. Der kumulierte Ausgabenüberschuß belief sich von 1983 bis 1988 auf 7,5 Mrd. DM. Für den Zeitraum von 1960 bis 1988 errechnet sich damit ein kumulierter Ausgabenüberschuß in Höhe von 5,2 Mrd. $\mathrm{DM}^{6}$. Diese Trendwende beruht insbesondere auf den stark gestiege-

1 Vgl. Anhang, Tabelle 15.

2 Eigene Berechnungen aufgrund der Angaben in Anhang, Tabelle 15.

3 Vgl. Anhang, Tabelle 16.

4 Vgl. DICKERTMANN/HANSMEYER (1987), S.72.

5 Eigene Berechnungen aufgrund der Angaben in Anhang, Tabelle 16. Siehe auch DICKERTMANN (1980), S.130 für den Zeitraum von 1960 - 1974.

6 Eigene Berechnungen aufgrund der Angaben in Anhang, Tabelle 16. 
nen Schadensfällen bei außenwirtschaftlichen Gewährleistungen, die wiederum auf die in den letzten Jahren verschlechterte wirtschaftliche Situation der Schuldnerländer der abgesicherten Forderungen zurückzuführen sind. Die vorstehenden Zahlen zeigen, daß die Gewährleistungsübernahme insbesondere dann ein haushaltspolitisch gefährliches Förderinstrument darstellt, wenn in großem Umfang positiv korrelierte Risiken abgesichert werden.

Eine Aufschlüsselung der Einnahmen und Ausgaben sämtlicher Gewährleistungen läßt sich aus der Bundeshaushaltsrechnung nicht ermitteln. Jedoch enthalten die Finanzberichte des Bundes differenzierte Angaben hinsichtlich der Einnahmen und Ausgaben außenwirtschaftlicher Gewährleistungen. So wurden von 1950 bis zum 30.6.1989 in diesem Bereich Gesamteinnahmen 19,1 Mrd. DM erzielt, wovon 9,2 Mrd. DM auf Entgelte und Gebühren, 3,4 Mrd. DM auf Zinsen und Wechselkursgewinne und 6,6 Mrd. DM auf Rückflüsse aus den übergegangenen Forderungen entfallen. Die Gesamtausgaben im selben Zeitraum in Höhe von 23,5 Mrd. DM setzen sich aus den Mandatarkosten von 1,1 Mrd. DM und Schadensleistungen von 22,4 Mrd. DM zusammen, wobei die Ausgaben für politische Schadensfälle einschließlich Umschuldungen 21,6 Mrd. DM betrugen ${ }^{1}$.

\section{cc. Das Gewährleistungsrisiko}

Die Ermittlung des Gegenwartswerts der Nettoausgaben von Gewährleistungsübernahmen einer Periode erfordert die Kenntnis sämtlicher Ausgaben- und Einnahmenströme aller relevanten Zukunftsperioden ${ }^{2}$. Da weder Ausgaben und Einnahmen, die durch Gewährleistungsübernahmen bestimmter Jahre in einzelnen Haushaltsperioden zu erwarten sind, noch Schätzungen über künftige Zahlungsströme genannt werden ${ }^{3}$, ist auch für den Bund eine quantitative Aussage über die Veränderung des Gewährleistungsrisikos im Zeitablauf nicht möglich ${ }^{4}$.

1 Vgl. FINANZBERICHT (1989), S.216.

2 Beispielsweise hat der Bund in den letzten Jahren durch die Entschädigung privater bundesdeutscher Gläubiger in erheblichem Umfang Forderungen gegenüber zahlreichen Schuldnerländern erworben, deren Konditionen in Umschuldungsabkommen geregelt sind. Kernstück dieser Umschuldungsabkommen sind Tilgungsstreckungen und günstige Zinsen. Vgl. FINANZBERICHT (1989), S.215. Wenn man davon ausgeht, daß die Schuldnerländer ihren Verpflichtungen aus den Umschuldungsabkommen zumindest partiell nachkommen, werden die Nettoausgaben entsprechender Gewährleistungen überschätzt, wenn man lediglich die Entschädigungszahlungen berücksichtigt.

3 In den Finanzberichten sind bei den einzelnen Programen lediglich qualitative Angaben zu den erwarteten Rückflüssen aus den übergegangenen Forderungen enthalten. Vgl. FINANZBERICHT (1989), S.217 ff.

4 Bei den anderen öffentlichen Haushalten scheitert dieses Unterfangen bereits am Fehlen aggregierter Daten über die Gewährleistungsausgaben und -einnahmen. 
Um überhaupt eine Aussage über die Entwicklung des Gewährleistungsrisikos zu erhalten, sollen die jeweiligen Zahlungsüberschüsse der einzelnen Haushaltsjahre zum Haftungsvolumen am Ende der jeweiligen Jahre in Beziehung gesetzt werden. Diese Verhältniszahl gibt ex post Auskunft über das Risiko, daß der Bestand an Eventualverbindlichkeiten am Ende eines Jahres in demselben Jahr zu Ausgabenüberschüssen führt. Sind alle übrigen Gewährleistungseinnahmen und -ausgaben konstant, so hängt dieses Risiko von den realisierten relativen Schadenshäufigkeiten der einzelnen Gewährleistungsprogramme ab. Versieht man Ausgabenüberschüsse (Einnahmenüberschüsse) mit positivem (negativem) Vorzeichen, so erreichte diese Verhältniszahl von 1960 bis 1988 im letzten Jahr dieses Zeitraums mit 7,7 v.T. ihren höchsten Wert. Insgesamt hat das auf diese Weise gemessene Risiko seit 1982 zugenommen ${ }^{1}$. Da die Gewährleistungen durchschnittlich eine mehrjährige Laufzeit besitzen, kann bei aller gebotenen Vorsicht geschlossen werden, daß sich das Haftungsrisiko der ab Mitte bis Ende der siebziger Jahre übernommenen Gewährleistungen gegenüber den Vorjahren erhöht hat.

Betrachtet man einzelne Gewährleistungsprogramme des Bundes, so ergeben sich bei der Relation der Überschüsse der Schadenszahlungen über die -rückflüsse zum jeweiligen Haftungsvolumen am Ende der Betrachtungsperiode gravierende Unterschiede. Während bei einigen Gewährleistungsprogrammen Schadenszahlungen bisher nicht fällig waren, betrug diese Relation z.B. bei der Bürgschaftshilfe für den Steinkohlebergbau 1987/88 $2,8 \%^{2}$.

dd. Forderungsbestand aufgrund der Inanspruchnahme aus Gewährleistungen

Die dem Bund aufgrund der Inanspruchnahme aus Gewährleistungen zustehenden Forderungen werden in der Vermögensrechnung in nominaler Höhe als Geldforderungen ausgewiesen. Der Bestand dieser Forderungen (einschließlich Umschuldungen) hat sich im Zeitraum 1974 bis 1988 von 1,2 Mrd. DM auf 12,4 Mrd. DM verzehnfacht ${ }^{3}$. Da die daraus resultierenden durchschnittlichen Einnahmenströme nicht genau bekannt sind, läßt sich ihr Gegenwartswert und damit der Wert dieses gesamten Forderungsbestandes kaum quantifizieren. Allerdings kann festgestellt werden, daß sich der Wert der in Schadensfällen übergehenden Forderungen bei den verschiedenen Gewährleistungsprogrammen stark unterscheidet. So sind von den Schadenszahlungen des Bundes für Ausfuhrgewährleistungen, die sich am Stichtag 30.06.1989 auf insgesamt 20,3 Mrd. DM summierten, bis zu diesem

1 Vgl. Anhang, Tabelle 16.

2 Vgl. FINANZBERICHT (1989), S.214 ff.

3 Vgl. Anhang, Tabelle 17. 
Stichtag 6,4 Mrd. DM oder 33,3 \% zurückgeflossen. Die entsprechende Relation betrug bei Garantien für Kredite an ausländische Schuldner an demselben Stichtag lediglich 8,0\%. Bei den Bürgschaften für den Steinkohlebergbau waren bis zu dem entsprechenden Zeitpunkt Schadenszahlungen in einer Gesamthöhe von 778 Mio. DM zu leisten. Rückflüsse waren jedoch bis dahin nicht zu verzeichnen ${ }^{1}$.

ee. Förderzwecke der Gewährleistungen

Betrachtet man die Förderzwecke der von den Gebietskörperschaften übernommenen Gewährleistungen, so läßt sich ein deutliches Schwergewicht der außenwirtschaftlichen Gewährleistungen erkennen ${ }^{2}$. Das Haftungsvolumen für außenwirtschaftliche Gewährleistungen des Bundes schwankte zwischen 1980 und 1988 zwischen 120 und 170 Mrd. DM. Der Anteil des Haftungsvolumens der außenwirtschaftlichen Gewährleistungen am gesamten Haftungsvolumen aller öffentlichen Haushalte belief sich 1988 (1980) auf $58 \%$ (57\%), nachdem es $198363 \%$ erreicht hatte. Das Haftungsvolumen der beiden anderen größeren Förderbereiche, Wohnungsbau und allgemeine Wirtschaftsförderung, betrug zwischen 1980 und 1988 am Stichtag jeweils rund 25 Mrd. DM, was einem Anteil von etwa $10 \%$ am gesamten Haftungsvolumen entspricht. Der Anteil der Gewährleistungen für Wirtschaftsunternehmen der Gemeinden lag in diesem Zeitraum in den einzelnen Perioden jeweils bei rund $3 \%{ }^{3}$.

\section{Kredithilfen der außerbudgetären Einrichtungen}

Im folgenden sollen die Kredithilfen der außerbudgetären Einrichtungen quantifiziert werden. Bei den Sonderkreditinstituten werden dabei mangels umfassender Daten lediglich die KfW, DAB, LKB und LfA berücksichtigt. Außerdem wird die Bundesanstalt für Arbeit betrachtet.

a. Kredithilfen der Sonderkreditinstitute

Wie bereits ausgeführt wurde, sind die Sonderkreditinstitute in erheblichem Umfang mit der Durchführung von Darlehens- und Gewährleistungsprogrammen beschäftigt. Im

1 Vgl. FINANZBERICHT (1989), S.215 f., 220.

2 Die außenwirtschaftlichen Gewährleistungen waren bis 1979 in den Finanzberichten des Bundes der allgemeinen Wirtschaftsförderung zugeordnet. Vgl. DICKERTMANN/ HANSMEYER (1987), S.74.

3 Vgl. Anhang, Tabelle 18. 
folgenden sollen der Umfang der von diesen Einrichtungen durchgeführten DarlehensEigenprogramme, die damit verbundenen Zinsverbilligungskosten sowie die der Eigenhaftung unterliegenden Gewährleistungsprogramme näher betrachtet werden.

\section{aa. Darlehens-Eigenprogramme}

Von der KfW, der DAB und der LfA wird die Höhe der zu Lasten eigener Erträge vergebenen Darlehen in den Geschäftsberichten ausgewiesen. Dabei zeigt sich, daß diese Eigenprogramme bei den genannten Instituten in den letzten Jahren deutlich ausgeweitet wurden. Die Darlehenszusagen der KfW aus den Eigenprogrammen beliefen sich 1976 auf 1,6 Mrd. DM und 1988 auf 7,1 Mrd. DM. Der Anteil dieser Darlehen an den gesamten Darlehenszusagen der KfW schwankte im genannten Zeitraum zwischen 24 und $53 \%$. Diese Zahlen zeigen, daß die Durchführung der Eigenprogramme inzwischen einen der Schwerpunkte der Tätigkeit der KfW bedeuten ${ }^{1}$. Außerdem verdeutlicht die Höhe der Kreditzusagen der KfW im Vergleich zu den Darlehensausgaben des Bundes, daß mittlerweile der Großteil der Darlehensaktivitäten des Bundes von der KfW "auf eigene Rechnung" durchgeführt wird. Um so problematischer erscheint es, wenn diese Aktivitäten von der Subventionsberichterstattung ausgeklammert bleiben.

Demgegenüber wurden von der DAB und der LfA in wesentlich geringerem Umfang zu Lasten eigener Erträge verbilligte Darlehen vergeben. Ihre Höhe bewegte sich im genannten Zeitraum bei der DAB zwischen 16 Mio. DM (1981) und 363 Mio. DM (1988) und bei der LfA zwischen 73 Mio. DM (1976) und 914 Mio. DM (1988). Allerdings gilt für diese beiden Institute, da $B$ im Rahmen ihres Kreditgeschäfts die Eigenprogramme wachsende Bedeutung besitzen. Ihr Anteil an den gesamten Darlehenszusagen stieg bei der DAB von 1,2 \% im Jahr 1981 bis auf $11,7 \%$ in 1988, bei der LfA von 6,5\% in 1979 auf $33,4 \%$ in $1988^{2}$. Die LKB veröffentlicht hingegen keine Zahlen über die Höhe der aus eigenen Mitteln verbilligten Darlehen.

Umgekehrt lassen sich die von der LKB zu tragenden Zinsverbilligungskosten für Darlehensprogramme aus ihren Jahresabschlüssen entnehmen, da dort Zuführungen zu Rückstellungen für Zinsverbilligungszuschüsse ausgewiesen werden. Dieser Posten gibt Aufschluß über die von der LKB zu tragenden, kapitalisierten Zinsverbilligungskosten für im Berichtsjahr vergebene Darlehen. D.h. daß die Ertragsminderung durch eigene Zins-

1 Dies ist um so bemerkenswerter, wenn man berücksichtigt, daß die KfW erst Anfang der siebziger Jahre mit der Durchführung solcher Programme begonnen hat. Vgl. MÜLLER-KÄSTNER (1986), S.11.

2 Vgl. Anhang, Tabelle 19. 
verbilligungen bereits im Jahr der Darlehensvergabe im Jahresabschluß realisiert wird. Die Auflösung dieser Rückstellungen in den Folgeperioden ist dagegen erfolgsneutral. Die Höhe der Zuführungen zu diesem Rückstellungsposten bewegte sich von 1976 bis 1988 zwischen 43 Mio. DM (1979) und 239 Mio. DM (1981), wobei zwischen den einzelnen Jahren auffallende Schwankungen festzustellen sind. Aufschluß über die relative Bedeutung dieser Zinsverbilligungskosten erhält man, wenn man sie zu den Jahresüberschüssen der entsprechenden Jahre in Beziehung setzt. Dabei zeigt sich, daß die ausgewiesenen Zinsverbilligungskosten von 1976 bis 1988 abgesehen von drei Geschäftsjahren stets über dem Jahresüberschuß lagen ${ }^{1}$.

Dagegen werden von der KfW entsprechende Rückstellungen nicht gebildet. Die Ermittlung der von der KfW zu tragenden Zinsverbilligungskosten wird dadurch erschwert, da $\beta$ von ihr der Forderungsbestand aus den im Rahmen der Eigenprogramme vergebenen Darlehen nicht bekanntgegeben wird. Aufgrund der Daten über den Anteil der Eigenprogramme an den gesamten Darlehenszusagen läßt sich jedoch vermuten, daß in den letzten Jahren mindestens ein Drittel der Kreditforderungen der KfW auf Eigenprogramme zurückgeht. Unterstellt man bei diesen Programmen eine durchschnittliche Zinsverbilligung von $0,75 \%(1 \%)^{2}$, so wurde der Jahresüberschuß der KfW 1988 durch die Eigenprogramme um ca. 225 (300) Mio. DM vermindert ${ }^{3}$. Dabei ist noch nicht berücksichtigt, da bei einem Wegfall der Eigenprogramme vermutlich ein erheblicher Teil der Sach- und Personalkosten eingespart werden könnte. Auch wenn diese Schätzung nicht sehr genau sein kann, so dürfte sie dennoch den Schluß zulassen, daß die jährlichen Zinsverbilligungskosten sehr deutlich über dem ausgewiesenen Jahresüberschuß liegen, der 1988134 Mio. DM betragen hat. Damit wird zugleich offenbar, da $B$ der Spielraum für eine weitere Ausweitung der Eigenprogramme bei gegebener Eigenkapitalausstattung sehr begrenzt ist.

Die DAB veröffentlicht in ihren Geschäftsberichten den Forderungsbestand aus Eigenprogrammen, der für $1988 \mathrm{mit}$ rund $1 \mathrm{Mrd}$. DM angegeben wird. Unterstellt man dieselbe durchschnittliche Zinsverbilligung wie bei der KfW, so ergeben sich für 1988 Zinsverbilligungskosten von 7,5 (10) Mio. DM. Wenngleich dieser Betrag sehr viel niedriger ist

1 Vgl. Anhang, Tabelle 20.

2 Beispielsweise entsprechen beim M I/M II-Programm die den Darlehensschuldnern in Rechnung gestellten Zinssätze ungefähr den Refinanzierungs-Zinssätzen der KfW. Eine Ertragsbelastung entsteht durch die Einräumung einer Zinsmarge für die durchleitenden Hausbanken in Höhe von 0,75 \% p.a. Vgl. GOLDSCHMIDT (1987), S.95. Beim in jüngerer Zeit ausgeweiteten KfW-Umweltprogramm ist der Nominalzinssatz um einen halben Prozentpunkt niedriger als beim M I/M II-Programm.

3

In der Bilanz zum 31.12.1988 sind Kreditforderungen in Höhe von 89 Mrd. DM ausgewiesen. 
als bei der $\mathrm{KfW}$, gilt auch für die $\mathrm{DAB}$, daß die Höhe der Zinsverbilligungskosten kaum Spielraum für eine weitere Ausdehnung der Eigenprogramme beläßt ${ }^{1}$.

Für die LfA fehlen wiederum Angaben über die Höhe des Forderungsbestands aufgrund von Eigenprogrammen. Er dürfte jedoch erheblich höher sein als bei der DAB. Damit liegen die Zinsverbilligungskosten der LfA bei einer Zinsmarge für die durchleitenden Hausbanken in Höhe von $0,75 \%$ p.a. ${ }^{2}$ schätzungsweise deutlich über denen bei der DAB.

Die umfangreichsten Eigenprogramme der Sonderkreditinstistute sind das KfW-Mittelstandsprogramm, mit dem die Investitionsfinanzierung mittelständischer Unternehmen ${ }^{3}$ gefördert werden soll, und das KfW-Umweltprogramm, das der Förderung von Umweltschutzinvestitionen dient. Die Eigendarlehen der DAB werden in erster Linie zur Finanzierung von Existenzgründungen eingesetzt. Die LKB führt zahlreiche Darlehensprogramme im Bereich der Wirtschaftsförderung durch, für die sich den Großteil der Zinsverbilligungskosten selbst zu tragen hat. Die LfA vergibt Eigendarlehen als Ergänzung zu anderen Wirtschaftsförderungsmaßnahmen ${ }^{4}$.

\section{bb. Gewährleistungen}

Die von den Sonderkreditinstituten mit eigenem Haftungsrisiko übernommenen Gewährleistungen sind im Vergleich zu den Darlehensprogrammen weniger bedeutsam. Ihre Höhe lag in den Jahren von 1982 bis 1988 bei DAB, LKB und LfA jeweils unter 90 Mio. DM. Bei der KfW schwankten die Gewährleistungsübernahmen in diesem Zeitraum zwischen 100 Mio. DM und 2.833 Mio. DM ${ }^{5}$. Allerdings geht aus den Geschäftsberichten dieser Institute nicht hervor, wie hoch das mit diesen Maßnahmen verbundene Kostenrisiko ist. Bei der DAB werden die Gewährleistungen teilweise von Dritten rückverbürgt, ohne daß klar wird, wie hoch ihr verbleibendes effektives Eigenobligo ist.

1 Dies wird im Jahresbericht 1988 der DAB mit den folgenden Ausführungen indirekt bestätigt: "Die Zinserträge der Bank werden sich zukünftig in eher noch engeren Grenzen halten, weil die Bank sich weiter aufgerufen fühlt, ein Maximum ihrer eigenen Mittel zur Verbilligung der Zinsen in ihren Ergänzungsprogrammen und damit zur weiteren Aufstockung ihrer Programme einzusetzen. Die Bank wird dabei den "Fördereinsatz" ihrer Erträge allerdings so zu steuern suchen, daß, wie bisher, ein angemessener Teil davon zur Stärkung ihrer Reserven verbleiben wird." Vgl. DEUTSCHE AUSGLEICHSBANK (1988), S.49.

2 Vgl. die schriftliche Auskunft der LfA vom 21.11.1989 an den Verfasser.

3 Antragsberechtigt für dieses Programm sind Unternehmen, deren Umsatz 500 Mio. DM p.a. nicht übersteigt. Vgl. KREDITANSTALT FÜR WIEDERAUFBAU (1988), S.12 f.

4 Vgl. dazu die Geschäftsberichte dieser Sonderkreditinstitute.

5 Vgl. Anhang, Tabelle 21. 
Die Gewährleistungen der DAB, LKB und LfA dienen überwiegend der Wirtschaftsförderung. Die LKB übernimmt Bürgschaften zur Erleichterung der Finanzierung von Investitionen, des Betriebsmittelbedarfs und von Konsolidierungsmaßnahmen gewerblicher Unternehmen und wirtschaftsnaher freier Berufe. Außerdem übernimmt sie Gewährleistungen im Rahmen ihres Exportförderungsprogramms ${ }^{1}$. Die LfA übernimmt Gewährleistungen für Investitionskredite von Unternehmen aus Wirtschaftsbereichen, für die keine Kreditgarantiegemeinschaften eingerichtet sind. Darüber hinaus trägt sie das Rückbürgschaftsrisiko des Freistaats Bayern aus Bürgschaften der Kreditgarantiegemeinschaften. Schließlich übernimmt sie in kleinerem Umfang Garantien bei Exportgeschäften ${ }^{2}$. Bei der DAB stehen die Bürgschaften für die freien Berufe im Vordergrund. Außerdem dient ein Teil der Gewährleistungen der Förderung des Wohnungsbaus. Die Wohnungsbauförderung steht bei den Gewährleistungen der KfW im Vordergrund. Daneben hat die KfW in den letzten Jahren in größerem Umfang Gewährleistungen im Energie-, Stahl- und Schiffbausektor übernommen ${ }^{3}$.

\section{b. Kredithilfen der Bundesanstalt für Arbeit}

In absoluten Zahlen hat der Umfang der Darlehensausgaben der Bundesanstalt für Arbeit in den letzten Jahren deutlich zugenommen. Während sie 1981 bei 128 Mio. DM lagen, beliefen sie sich 1988 auf 478 Mio. DM ${ }^{4}$. Nicht erfaßt sind damit die Darlehensausgaben zum Zweck der Rücklagenbildung. Damit sind jedoch die Ausgaben für Förderdarlehen an den Gesamtausgaben der Bundesanstalt vergleichsweise unbedeutend. Thr Anteil an den Gesamtausgaben betrug 1988 nur $1,2 \% 5$.

Der nominale Bestand an Forderungen aus Förderdarlehen hat mittlerweile eine erhebliche Größenordnung angenommen. Er betrug 1987 2,3 Mrd. DM und stieg 1988 auf 2,6 Mrd. $\mathrm{DM}^{6}$.

Die Höhe der Zinsverbilligungskosten wird von der Bundesanstalt für Arbeit nicht angegeben. Bei einer Schätzung der Zinsverbilligungskosten kann man jedoch auf die Tatsache zurückgreifen, daß der überwiegende Teil der Darlehen von der Bundesanstalt zins-

1 Vgl. WIRTSCHAFTSFÖRDERUNGSPROGRAMM BADEN-WÜRTTEMBERG (1985), S. 23 f.; GOLDSCHMIDT (1987), S.114.

2 Vgl. BAYERISCHE LANDESANSTALT FÜR AUFBAUFINANZIERUNG (1988), S.42 f.

3 Vgl. dazu die Geschäftsberichte der genannten Institute.

4 Vgl. Anhang, Tabelle 22.

5 Eigene Berechnung nach den Angaben in Anhang, Tabelle 22 und BUNDESANSTALT FÜR ARBEIT (1988), S.73.

6 Vgl. BUNDESANSTALT FÜR ARBEIT (1988), S.73. Jedoch gilt auch hier, daB der reale Wert dieser Forderungen weit niedriger ist. 
los vergeben werden. Der Anteil der zinslosen Darlehen an den gesamten Darlehensausgaben lag 1982 bei $64 \%$ und stieg 1989 auf $91 \%$ an. Für die verzinslichen Darlehen werden mit $2 \%$ bzw. $4 \%$ ebenfalls sehr niedrige Zinssätz verlangt ${ }^{1}$. Der gewichtete durchschnittliche Zinssatz der 1989 vergebenen Förderdarlehen der Bundesanstalt beläuft sich auf ca. $0,25 \%$ p.a. ${ }^{2}$. Unterstellt man eine Opportunitätskostenrate von $7,5 \%$, so errechnen sich für die 1989 vergebenen Darlehen periodische Zinsverbilligungskosten in Höhe von rund 30 Mio. DM. Geht man von einer durchschnittlichen Kreditlaufzeit von 5 (10) Jahren aus, beträgt der Gegenwartswert der gesamten Zinsverbilligungskosten für die 1989 vergebenen Darlehen 120 (205) Mio. DM³

Die Darlehen der Bundesanstalt für Arbeit werden, sofern sie nicht der Rücklagenbildung dienen, aufgrund der gesetzlichen Aufgabenstellung ausschließlich für arbeitsmarktpolitische Maßnahmen vergeben. Während 1980 der größte Anteil der Darlehensausgaben mit 42,8\% auf Darlehen zur Finanzierung allgemeiner Arbeitsbeschaffungsmaßnahmen entfiel, war 1989 das als Darlehen gewährte Unterhaltsgeld für Teilnehmer an beruflichen Bildungsmaßnahmen mit einem Anteil von 88,0\% an den gesamten Darlehensausgaben am bedeutsamsten ${ }^{4}$.

\section{ZUSAMMENFASSUNG}

In diesem Kapitel wurden zunächst Schuldendiensthilfen, öffentliche Darlehen und Gewährleistungen als Gestaltungsformen öffentlicher Kredithilfen näher betrachtet. Die Gemeinsamkeit aller Kredithilfen besteht darin, daß sie den Kreditpreis, also den Zinssatz, für Kreditnehmer verbilligen sollen. Dabei werden bei Schuldendiensthilfen und Gewährleistungen private Kredite verbilligt, während bei öffentlichen Darlehen vom Kredithilfegeber Kredite zu günstigeren Konditionen als bei marktlichen Alternativkrediten angeboten werden. Die Kosten öffentlicher Kredithilfen ergeben sich als Überschuß des Gegenwartswerts der Ausgabenströme über den Gegenwartswert der Einnahmenströme.

Zur Finanzierung der Ausgaben für öffentliche Kredithilfen bedient sich die öffentliche Hand vielfältigen Quellen. Dabei kann generell zwischen budgetären und außerbudgetären Finanzierungsquellen unterschieden werden. Bei der budgetären Finanzierung gibt es die Möglichkeit, daß die Kredithilfeausgaben aus allgemeinen oder aus zweck-

1 Vgl. Anhang, Tabelle 22.

2 Eigene Berechnung aufgrund der Angaben in Anhang, Tabelle 22.

3 Eigene Berechnung.

4 Eigene Berechnungen nach der schriftlichen Auskunft der BfA vom 9.4.1990 an den Verf. 
gebundenen Haushaltseinnahmen bestritten werden. Außerdem ist bisweilen eine budgetäre Mischfinanzierung durch mehrere staatliche Ebenen zu beobachten.

Als außerbudgetäre Finanzierungsquellen stehen beim Bund und den Ländern zum einen Sondervermögen als verselbständigte Vermögensmassen ohne Personal- und Sachmittelausstattung zur Verfügung. Das quantitativ bedeutendste Kredithilfe-Sondervermögen des Bundes ist das ERP-Sondervermögen. In den Bundesländern existieren solche Sondervermögen insbesondere im Zusammenhang mit der Wohnungsbauförderung.

Weitere außerbudgetäre Einheiten, die Kredithilfen finanzieren, sind spezielle Sonderkreditinstitute und die Träger der Sozialversicherung, unter ihnen insbesondere die Bundesanstalt für Arbeit. Als wichtigste Sonderkreditinstitute des Bundes wurden die Kreditanstalt für Wiederaufbau und die Deutsche Ausgleichsbank betrachtet. Stellvertretend für die Vielzahl von Sonderkreditinstituten der Länder wurden die Landeskreditbank Baden-Württemberg und die Bayerische Landesanstalt für Aufbaufinanzierung behandelt. Diese Sonderkreditinstitute weisen im Hinblick auf Aufgabenstellung, Eigentumsverhältnisse und organisatorische Gestaltung starke Ähnlichkeiten auf. Der staatliche Einfluß auf diese Institute ist dadurch gewährleistet, daß die Eigentümer-Gebietskörperschaften über die Besetzung der leitenden Positionen entscheiden und über die jeweiligen Aufsichtsorgane die Geschäftspolitik der Institute in wesentlichen Bereichen bestimmen können.

Für alle außerbudgetären Einheiten gilt, daß ihnen regelmäßig oder zumindest im Errichtungszeitpunkt staatliche Einnahmen zufließen müssen, um ihnen ihre Kredithilfeaktivitäten zu ermöglichen. Damit sind durch die von den außerbudgetären Einheiten getragenen Kosten öffentlicher Kredithilfen mittelbar immer die Steuerzahler betroffen.

In einem nächsten Schritt wurden die Funktionen der außerbudgetären Einheiten bei der Vergabe öffentlicher Kredithilfen aufgezeigt. Bei den Sondervermögen steht die Finanzierung spezieller Kredithilfeprogramme im Vordergrund. Hierzu werden überwiegend die zweckgebundenen Einnahmen aus der Kredithilfegewährung früherer Perioden und laufende Zuweisungen der Gebietskörperschaften eingesetzt. Teilweise können auch Kredite aufgenommen werden.

Im Zusammenhang mit öffentlichen Kredithilfen nehmen die Sonderkreditinstitute vier Grundfunktionen wahr. Die erste Funktion betrifft die Durchführung von Kredithilfeprogrammen für die Gebietskörperschaften oder deren Vermögensmassen. Bei Darlehensgewährung erhalten die Sonderkreditinstitute von den Gebietskörperschaften den gesamten Darlehensbetrag zur Verfügung gestellt, den sie treuhänderisch oder in eigenem Namen, in der Regel unter Einschaltung von Hausbanken, an die Endkreditnehmer wei- 
terleiten. Bei Gewährleistungsübernahmen werden die Risiken durch die Gebietskörperschaften abgesichert. Zum Teil werden auch Zuschüsse der Gebietskörperschaften weitergeleitet. Weiterhin stellen die Sonderkreditinstitute das Kapital zur Finanzierung bestimmter Darlehen bereit, während die Gebietskörperschaften die Zinsverbilligungskosten durch die Gewährung von Zinszuschüssen an die Sonderkreditinstitute tragen. Solche Darlehensprogramme werden damit bei den Gebietskörperschaften lediglich in Höhe der Zinszuschüsse ausgabenwirksam. Die dritte Funktion der Sonderkreditinstitute besteht in der Bereitstellung von öffentlichen Kredithilfen, die zu Lasten des eigenen Gewinns verbilligt werden. Dabei handelt es sich überwiegend um Darlehensprogramme. Die vierte Funktion dieser Einrichtungen ist ihre fiskalische Funktion. Sie beruht einmal auf ihrer Gewinnerzielung, die jedoch in den meisten Fällen nicht zu Gewinnauschüttungen führt. Für die Gebietskörperschaften sind diese Gewinne dennoch von fiskalischer Bedeutung, da sie die Durchführung öffentlicher Kredithilfen erlauben, ohne daß dafür haushaltsmäßige Ausgaben veranschlagt werden müssen.

Im nachfolgenden Abschnitt wurde der institutionelle Rahmen für öffentliche Kredithilfen untersucht. Dabei wurde gezeigt, daß die Gewährung öffentlicher Kredithilfen bestimmten rechtsstaatlichen Anforderungen genügen muß, was materiellrechtlich vor allem die Beachtung der Grundrechte und formalrechtlich das Bestehen einer ausreichenden Ermächtigungsgrundlage voraussetzt.

Im weiteren Verlauf wurde diskutiert, inwieweit die Vergabe öffentlicher Kredithilfen bestimmten Begrenzungen unterworfen ist. Für die Kredithilfen der Gebietskörperschaften ist dafür deren jeweilige Finanzverfassung maßgeblich. Es wurde jedoch festgestellt, daß die darin enthaltenen Begrenzungen wenig effektiv sind. Dies gilt insbesondere für Darlehen und die Inanspruchnahme aus Gewährleistungen des Bundes und der Länder, die haushaltsrechtlich als Investitionen gelten und daher die Budgetrestriktion über eine Erhöhung des Verschuldungsspielraums ausweiten können. Auch die für Bund und Länder geltenden Zuwendungsvorschriften sind zu wenig konkret, als daß sie einzelne Kredithilfeaktivitäten effektiv begrenzen könnten. Die Vergabe von Kredithilfen der Sondervermögen wird durch vorhandene Einnahmerestriktionen, einschließlich der bestehenden Verschuldungsgrenzen, eingeschränkt.

Die Errichtung außerbudgetärer Kredithilfeeinrichtungen steht weitgehend im Ermessen der Legislative der betreffenden Gebietskörperschaft. Aus den Errichtungsgesetzen sind Beschränkungen für die Vergabe von Kredithilfen zu Lasten eigener Erträge allenfalls insoweit zu entnehmen, als darin eine gewisse Gewinnerzielung zur Bildung bankwirtschaftlich notwendiger Reserven vorgeschrieben ist. 
Strikte Publizitätspflichten für Kredithilfen, die durch umfassende Informationen über diese Maßnahmen begrenzende Wirkungen entfalten könnten, bestehen nicht. Abgesehen von der Veranschlagung haushaltswirksamer Kredithilfen in den Haushaltsplänen der Gebietskörperschaften werden in den Subventionsberichten des Bundes diejenigen Kredithilfen ausführlich dargestellt, die als Finanzhilfen angesehen werden. Dies gilt z.B. nicht für Kredithilfen an das Ausland, Kredithilfen zur Ausbildungsförderung sowie für sämtliche Gewährleistungsmaßnahmen. Nicht aus Bundesmitteln finanzierte Kredithilfen werden zum Teil nachrichtlich erwähnt. Insoweit vermitteln die Subventionsberichte nur ein sehr unvollständiges Bild über das Ausmaß öffentlicher Kredithilfen in der Bundesrepublik Deutschland. Aus den Geschäftsberichten der außerbudgetären Einrichtungen ist ebenfalls nicht ohne weiteres ersichtlich, in welchem Umfang und in welcher Weise diese Einrichtungen in Kredithilfeaktivitäten involviert sind und welche Kosten für sie damit verbunden sind.

Gewisse Begrenzungen für Kredithilfen ergeben sich aus supranationalen Regeln. So können Kredithilfen, die als Beihilfen im Sinne des EG-Rechts gelten, von der EG-Kommission untersagt werden, wenn sie mit dem Gemeinsamen Markt unvereinbar sind. Wenngleich die Kommission auch im Hinblick auf den Europäischen Binnenmarkt zunehmend strenge Maßstäbe anlegt, bleibt für Beihilfen mit geringer Beihilfeintensität, die als Bagatellfälle gelten, ein beträchtlicher Spielraum. Dieser Spielraum wird durch Inkonsistenzen bei der Berechnung der Beihilfeintensitäten noch erweitert.

Für Exportkredithilfen existieren Beschränkungen durch den OECD-Konsensus, der Subventionierungen nur bei Exportkrediten an Entwicklungsländer erlaubt, die zudem ein bestimmtes Mindestzuschußelement aufweisen müssen. Sofern in anderen Fällen die im Konsensus festgelegten Konditionen durch ein Teilnehmerland unterschritten werden, sind allerdings nur begrenzte Sanktionsmöglichkeiten der anderen Teilnehmerländer vorhanden. Inwieweit die im GATT enthaltene Verpflichtung, staatliche Exportversicherungssysteme nicht zu subventionieren, effektiv ist, bleibt angesichts der Kostenunterdeckungen bei den Ausfuhrgewährleistungen des Bundes fraglich.

Am Ende dieses Kapitels wurde ein Überblick über Umfang und Förderzwecke öffentlicher Kredithilfen gegeben. Dabei zeigte sich, daß die relative Bedeutung budgetärer Schuldendiensthilfen und Darlehen gegenüber den Anfangsjahren des Bestehens der Bundesrepublik nachgelassen hat. Dennoch gilt in bezug auf öffentliche Darlehen, daß ihre Vergabe zu einer Akkumulation eines beträchtlichen Forderungsvermögens geführt hat, dessen nominale Höhe sich beim Bund auf rund 80 Mrd. DM beläuft. Da die Darlehen zu verbilligten Zinssätzen vergeben werden, resultieren aus diesem Forderungsbestand 
Zinsmindereinnahmen gegenüber einer marktlichen Alternativanlage, die sich allein beim Bund jährlich auf mehrere Mrd. DM belaufen, ohne daß dies aus dem Haushaltsplan unmittelbar sichtbar wird. Anders als die beiden anderen Kredithilfeformen wurden die budgetären Gewährleistungen auch in ihrer relativen Höhe bis in die achtziger Jahre ausgeweitet. Außerdem wurde festgestellt, daß die Gewährleistungen beim Bund gerade in den letzten Jahren hohe Nettoausgaben verursacht haben.

Die außerbudgetären Kredithilfen haben dagegen im Verlauf der letzten Jahre an Bedeutung gewonnen. Dies gilt einmal für die Sondervermögen, insbesondere das ERPSondervermögen, sowie für die Sonderkreditinstitute. Dabei vergeben die außerbudgetären Einheiten in erster Linie öffentliche Darlehen, bei denen das Ausmaß der Zinsverbilligung im Durchschnitt jedoch geringer ist als bei den Darlehen der Gebietskörperschaften.

Bei der Betrachtung der Förderzwecke öffentlicher Kredithilfen zeigte sich, daß ein hoher Anteil öffentlicher Kredithilfen der Gebietskörperschaften für den Bereich des Wohnungswesens bestimmt ist. Gewährleistungen werden allerdings schwerpunktmäßig im außenwirtschaftlichen Bereich übernommen. Daneben haben Kredithilfen an das Ausland, für die gewerbliche Wirtschaft und zur Ausbildungsförderung die größte quantitative Bedeutung. Bei den Kredithilfen der außerbudgetären Einheiten steht die Förderung der gewerblichen Wirtschaft und hier insbesondere die sogenannte Mittelstands- einschließlich der Existenzgründungsförderung im Vordergrund. Eine Ausnahme bildet insoweit die Bundesanstalt für Arbeit, die entsprechend ihrem gesetzlichen Auftrag Darlehen für arbeitsmarktpolitische Maßnahmen vergibt.

Nach dieser Bestandsaufnahme über öffentliche Kredithilfen in der Bundesrepublik Deutschland soll im nächsten Kapitel eine ökonomische Analyse dieser Subventionsformen erfolgen. 


\section{C. ÖKONOMISCHE ANALYSE ÖFFENTLICHER KREDITHILFEN BEI GEGEBENEN INSTITUTIONELLEN BEDINGUNGEN}

Die im folgenden durchgeführte Analyse öffentlicher Kredithilfen bezieht sich sowohl auf die normative Fragestellung der ökonomischen Begründung von Kredithilfen als auch auf die positive Fragestellung ihrer ökonomischen Wirkungen. Die Entscheidungen, die zur Wahl von Kredithilfen als Subventionsform führen, bleiben in diesem Kapitel unberücksichtigt.

Zunächst soll der Kreditmarkt unter Berücksichtigung des Kreditversicherungsmarktes als Ausgangspunkt für die weiteren Analysen theoretisch erfaßt werden. Daran anschließend werden die üblicherweise vorgetragenen normativen Begründungen für öffentliche Kredithilfen untersucht. Darauf folgt die positive Analyse der allokativen und distributiven Wirkungen öffentlicher Kredithilfen.

\section{DER KREDITMARKT ALS ANALYTISCHER AUSGANGSPUNKT}

Zunächst sollen die Determinanten der Kreditnachfrage und des Kreditangebots in einer risiko- und transaktionskostenfreien Welt mit vollständiger Information betrachtet werden. Da Versicherungen notwendigerweise das Bestehen von Unsicherheit voraussetzen $^{1}$, sind Kreditversicherungen unter diesen Annahmen nicht erklärbar. Danach werden die zuvor getroffenen Annahmen gelockert und es wird untersucht, welche Implikationen sich daraus für den Kredit- und Kreditversicherungsmarkt ergeben.

\section{Das Grundmodell des Kreditmarkts}

Das Grundmodell des Kreditmarkts basiert auf einem intertemporalen Konsummodell ${ }^{2}$. Dabei wird jede Kreditbeziehung als Austausch von Konsumgütern - oder von Geld und damit von Güteransprüchen - über die Zeit charakterisiert. Ein Kreditmarkt kann entstehen, wenn sich durch intertemporale Tauschhandlungen in Gestalt von Kreditbeziehungen Tauschgewinne realisieren lassen ${ }^{3}$.

1 Vgl. EHRLICH/BECKER (1972), S.624.

2 In diesem mikroökonomischen Erklärungsmodell des Kreditmarktes, das sich auf reale Größen bezieht, bleiben die Kreditschöpfungsmöglichkeiten des Bankensystems, die sich auf die Geldmenge und damit das Preisniveau auswirken, unberücksichtigt.

3 Vgl. HIRSHLEIFER (1970), S.31 ff. Da Unsicherheit und Transaktionskosten zunächst unberücksichtigt bleiben, kann von der Existenz von Finanzintermediären an dieser Stelle abgesehen werden; vgl. dazu BALTENSBERGER/MILDE (1987), S.5. 
Anhand des auf Irving Fisher zurückgehenden zweiperiodigen intertemporalen Konsummodells ${ }^{1}$ wird ein einfaches Kreditmarktmodell entwickelt ${ }^{2}$, bei dem Investitionen zunächst unberücksichtigt bleiben.

\section{a. Der Kreditmarkt ohne Investitionen}

Die Bestimmung von Kreditnachfrage und Kreditangebot erfolgt formal in derselben Weise. Es wird unterstellt, daß das betrachtete Individuum eine intertemporale Nutzenfunktion besitzt, die als Argumente den aggregierten Konsum in Gegenwart und Zukunft enthält. Die gesamten ökonomischen Transaktionen sollen in zwei Zeitpunkten stattfinden, die eine Periodenlänge voneinander entfernt sind. Für das einzelne Individuum soll gelten:

$$
\begin{aligned}
& \mathrm{U}=\mathrm{U}\left(\mathrm{C}_{0}, \mathrm{C}_{1}\right) \mathrm{mit} \\
& \partial \mathrm{U} / \partial \mathrm{C}_{0}>0 ; \partial \mathrm{U} / \partial \mathrm{C}_{1}>0, \\
& \partial^{2} \mathrm{U} / \partial \mathrm{C}_{0}{ }^{2}<0 ; \partial^{2} \mathrm{U} / \partial \mathrm{C}_{1}{ }^{2}<0 \\
& \text { und } \partial^{2} \mathrm{U} /\left(\partial \mathrm{C}_{0} \partial \mathrm{C}_{1}\right)=0,
\end{aligned}
$$

wobei $U$ den Nutzen des Individuums sowie $C_{0}$ und $C_{1}$ den aggregierten Konsum in den Zeitpunkten $t_{0}$ und $t_{1}$ repräsentieren. Weiterhin wird angenommen, daß sich das Individuum einer Vermögensrestriktion gegenübersieht, die besagt, daß der Gegenwartswert des Konsums beider Perioden den Gegenwartswert des modellexogen gegebenen Einkommens beider Perioden, das Vermögen, nicht übersteigen darf ${ }^{3}$. Die Vermögensrestriktion läßt sich folgendermaßen darstellen:

$$
\mathrm{W} \equiv \mathrm{Y}_{0}+\mathrm{Y}_{1} /(1+\mathrm{r})=\mathrm{C}_{0}+\mathrm{C}_{1} /(1+\mathrm{r})
$$

wobei $W$ das Vermögen, $Y_{0}$ bzw. $Y_{1}$ die Einkommensströme in $t_{0}$ und $t_{1}$ und $r$ den Marktzinssatz bezeichnen.

Ein Individuum wird Kredite nachfragen, wenn seine Periodeneinkünfte so verteilt sind, da $\beta$ es bei gegebener intertemporaler Preisrelation durch Kreditaufnahme in der Gegenwart seinen Nutzen erhöhen kann. Die Höhe der möglichen Kreditaufnahme wird dabei durch die Vermögensrestriktion begrenzt. Aus (C.I.2) ergeben sich folgende Periodenrestriktionen:

$$
\mathrm{C}_{0}=\mathrm{Y}_{0}+\mathrm{K}
$$

1 Vgl. FISHER (1930).

2 Die Modelldarstellung erfolgt in Anlehnung an TERBERGER (1987), S.130 ff. und BALTENSBERGER/MILDE (1987), S.88 f.

3 Vgl. HIRSHLEIFER (1970), S.62 f. 
(C.I.4)

$$
\mathrm{C}_{1}=\mathrm{Y}_{1}-(1+\mathrm{r}) \mathrm{K}
$$

Gilt $\mathrm{K}>0$, so ist das betrachtete Individuum Kreditnachfrager.

Aus (C.I.1), (C.I.3) und (C.I.4) folgt:

$$
\mathrm{U}=\mathrm{U}\left[\mathrm{Y}_{0}+\mathrm{K}, \mathrm{Y}_{1}-(1+\mathrm{r}) \mathrm{K}\right] \text {. }
$$

Durch Maximierung von (C.I.5) erhält man die Optimalbedingung erster Ordnung:

$$
\left(\partial \mathrm{U} / \partial \mathrm{C}_{0}\right) /\left(\partial \mathrm{U} / \partial \mathrm{C}_{1}\right)=1+\mathrm{r} \text {. }
$$

D.h. die Grenzrate der Substitution zwischen Zukunfts- und Gegenwartskonsum, die dem Verhältnis der Grenznutzen von Gegenwarts- und Zukunftskonsum entspricht, ist im Optimum gleich dem intertemporalen Preisverhältnis $1+r^{1}$.

Gleichung (C.I.6) gibt in impliziter Form die Kreditnachfragefunktion des Kreditnehmers in Abhängigkeit von $\mathrm{r}$ an. Es gilt:

$$
\mathbf{K}^{\mathbf{N}}=\mathbf{K}^{\mathbf{N}}(\mathbf{r}) \text {. }
$$

Graphisch läßt sich die individuelle Kreditnachfragefunktion als geometrischer Ort der Maxima der Indifferenzkurven im K,r-Raum konstruieren ${ }^{2}$. Ihre Steigung ist über ihren gesamten Verlauf negativ ${ }^{3}$, da Substitutions- und Einkommenseffekt in dieselbe Richtung gehen, wenn der Gegenwartskonsum ein superiores Gut ist ${ }^{4}$. Die gesamtwirtschaftliche Kreditnachfragefunktion läßt sich nun durch horizontale Aggregation sämtlicher individueller Kreditnachfragefunktionen ermitteln.

1 Die Bedingung zweiter Ordnung für ein Nutzenmaximum ist erfüllt, weil gilt: $\partial^{2} U / \partial K^{2}=\partial^{2} U / \partial C_{0}^{2}+(1+r)^{2} \partial^{2} U / \partial C_{1}^{2}<0$.

2 Die Steigung der Indifferenzkurven ergibt sich durch implizite Differentiation von (C.I.5) folgendermaßen:

$$
\left.\frac{\mathrm{dr}}{\mathrm{dK}}\right|_{\mathrm{dU}=0}=-\frac{\partial \mathrm{U} / \partial \mathrm{K}}{\partial \mathrm{U} / \partial \mathrm{r}}=\frac{\partial \mathrm{U} / \partial \mathrm{C}_{0}-(1+\mathrm{r}) \partial \mathrm{U} / \partial \mathrm{C}_{1}}{\mathrm{~K} \partial \mathrm{U} / \partial \mathrm{C}_{1}} .
$$

Durch implizite Differentiation von (C.I.5a) erhält man:

$$
\frac{\mathrm{d}^{2} \mathrm{r}}{\mathrm{dK^{2 }}}=-\frac{\partial^{2} \mathrm{U} / \partial \mathrm{K}^{2}+2 \cdot \partial^{2} \mathrm{U} / \partial \mathrm{K} \partial \mathrm{r} \cdot \mathrm{dr} / \mathrm{dK}+\partial^{2} \mathrm{U} / \partial \mathrm{r}^{2}(\mathrm{dr} / \mathrm{dK})^{2}}{\partial \mathrm{U} / \partial \mathrm{r}} .
$$

Wegen Gleichung (C.I.6) ist $\mathrm{dr} / \mathrm{dK}$ im Optimum gleich Null. Da aber $\partial^{2} \mathrm{U} / \partial \mathrm{K}^{2}<0$ und $\partial U / \partial r<0$ gilt, folgt $d^{2} r / d^{2}<0$. Daraus ergibt sich, daB die Indifferenzkurven im $K, r-R a u m$ einen konkaven Verlauf haben und daß die optimale $\mathrm{K}, \mathrm{r}-\mathrm{K}$-Kmbination für jedes gegebene Nutzenniveau im Maximum der dazugehörigen Indifferenzkurve liegt.

3

Dies ergibt sich durch implizite Differentiation von (C.I.6.). Man erhält:

$$
\text { (C.I.6a) } \frac{\mathrm{dK}^{\mathrm{N}}}{\mathrm{dr}}=-\frac{\partial^{2} \mathrm{U} / \partial \mathrm{K} \partial \mathrm{r}}{\partial^{2} \mathrm{U} / \partial \mathrm{K}^{2}}=-\frac{(1+\mathrm{r}) \mathrm{K} \cdot \partial^{2} \mathrm{U} / \partial \mathrm{C}_{1}{ }^{2}-\partial \mathrm{U} / \partial \mathrm{C}_{1}}{\partial^{2} \mathrm{U} / \partial \mathrm{C}_{0}{ }^{2}+(1+\mathrm{r})^{2} \cdot \partial^{2} \mathrm{U} / \partial \mathrm{C}_{1}{ }^{2}}<0 \text {. }
$$

4 Vgl. VARIAN (1989), S.176. 
Zur Ableitung des Kreditangebots wird unterstellt, daß die Kreditvergabe zum Marktzinssatz bzw. der Erwerb von Darlehensforderungen die einzige verzinsliche Sparform darstellt. Sie wird unter den Bedingungen des vollkommenen Kapitalmarktes dem Horten der ersparten Einkommensbeträge vorgezogen, wenn $r>0$ gilt. Die Zielfunktion des Kreditanbieters ist ebenfalls durch Gleichung (C.I.5) bestimmt, wobei hier $\mathbf{K}<0$ ist. Dementsprechend gilt die durch Gleichung (C.I.6) beschriebene Optimalbedingung auch hier. Durch sie wird folglich auch die Kreditangebotsfunktion implizit definiert. Es ergibt sich also:

$$
\mathbf{K}^{\mathbf{A}}=\mathrm{K}^{\mathbf{A}}(\mathrm{r}) \text {. }
$$

Die Kreditangebotsfunktion ergibt sich als geometrischer Ort der Minima der Indifferenzkurven im K,r-Raum ${ }^{1}$. Die Steigung der Kreditangebotsfunktion kann größer oder kleiner Null $\operatorname{sein}^{2}$. Dies beruht darauf, daß der Substitutionseffekt bei einer Zinssatzerhöhung in Richtung auf eine Ausdehnung des Zukunftskonsums und damit auf eine Erhöhung des Kreditangebots wirkt, während der Einkommenseffekt eine Reduzierung des Zukunftskonsums nach sich zieht, sofern der Gegenwartskonsum ein superiores Gut ist. Deshalb kann die Kreditangebotskurve einen Ast mit negativer Steigung enthalten ${ }^{3}$. Dies steht jedoch einem stabilen Kreditmarktgleichgewicht mit einem gleichgewichtigen Marktzinssatz nicht entgegen, wenn bei einem Überschreiten des Gleichgewichtszinssatzes das aggregierte Kreditangebot die Nachfrage und im umgekehrten Fall die Nachfrage das Angebot übersteigt ${ }^{4}$.

\section{b. Der Kreditmarkt unter Berücksichtigung von Investitionen}

Nun soll berücksichtigt werden, daß Kredite nicht vorrangig zur Konsumfinanzierung, sondern primär zur Finanzierung von Investitionen verwendet werden. Unter Investitionen soll die produktive Transformation von Ressourcen in der Gegenwart verstanden werden, die einen Verzicht auf Gegenwartskonsum voraussetzt ${ }^{5}$. Eine Investition entspricht damit der Akkumulation von Realkapital, das für einem bestimmten Zeitraum als Inputfaktor im

1 Diese Indifferenzkurven haben einen konvexen Verlauf, da Gleichung (C.I.5b) in diesem Fall größer Null ist, weil hier der Nenner einen positiven Wert annimmt.

2 Formal ergibt sich dies daraus, daß der Nenner von Gleichung (C.I.6a) eindeutig negativ ist, der Zähler aber positive oder negative Werte annehmen kann.

3 Vgl. GISSER (1981), S.525; VARIAN (1989), S.176 f.

4 Vgl. GISSER (1981), S.527 f.

5 Vgl. HIRSHLEIFER (1970), S.37. 
Produktionsprozeß dient. Umgekehrt wird die Bereitstellung ersparter Beträge für den Erwerb von Realkapital als Finanzierung bezeichnet. Investition und Finanzierung sind daher zwei Seiten ein und desselben Sachverhalts ${ }^{1}$. Investitionskredite sind also Kredite, mit denen die Akkumulation von Realkapital finanziert wird.

Zunächst wird nun die Nachfrage nach Investitionskrediten isoliert betrachtet. Es wird angenommen, daß die im Zeitpunkt $t_{0}$ vorgenommenen Investitionen vollständig kreditfinanziert ${ }^{2}$ und nach einer Periode vollständig abgeschrieben seien. Ihr Bruttoertrag bestehe aus Konsumgütern im Zeitpunkt $t_{1}$. Die Gewinnmaximierungsbedingung des Investors lautet bei einem unterstellten Outputpreis von 1 folgendermaßen:

$$
\begin{aligned}
& G=-K^{n}+x\left(K^{n}\right) /(1+r)=M a x ! \\
& \text { mit } \partial x / \partial K^{n}>0 ; \partial^{2} x / \partial\left(K^{n}\right)^{2}<0 .
\end{aligned}
$$

Dabei repräsentiert $\mathbf{G}$ den Gewinn, $K^{\mathrm{n}}$ die Investitionskreditnachfrage und $\mathbf{x}$ den Output, der allein vom Kapitalinput $K^{\mathrm{n}}$ abhängt. Durch partielle Differentiation von (C.I.9) erhält man als Maximierungsbedingung:

$$
\partial \mathrm{x} / \partial \mathrm{K}^{\mathbf{n}}=1+\mathrm{r} .
$$

D.h. der Netto-Grenzertrag der Investition muß im Optimum den marginalen Finanzierungskosten $r$ entsprechen. Durch (C.I.10) ist die Kreditnachfrage des betrachteten Investors implizit als Funktion des Zinssatzes bestimmt. Graphisch ergibt sich die individuelle Investitionskreditnachfragefunktion als geometrischer Ort der Maxima sogenannter Iso-Endwertkurven ${ }^{3}$, die wiederum von den intertemporalen Produktionsmöglichkeiten abhängen.

Betrachtet man die individuellen Kreditentscheidungen simultan, indem man die Investitionsfunktion aus Gleichung (C.I.9) in die Nutzenfunktion einbezieht, so ergibt sich als Zielfunktion:

$$
\mathrm{U}=\mathrm{U}\left[\mathrm{Y}_{0}+\mathrm{K}, \mathrm{Y}_{1}-\mathrm{K}(1+\mathrm{r})+\mathrm{x}\left(\mathrm{K}^{\mathrm{n}}\right)-\mathrm{K}^{\mathrm{n}}(1+\mathrm{r})\right]=\mathrm{Max} \text { ! }
$$

Im Optimum gilt nun wiederum, daß das Verhältnis der Grenznutzen von $\mathrm{C}_{0}$ und $\mathrm{C}_{1}$ dem Diskontierungsfaktor $(1+r)$ entsprechen muß. Hinsichtlich der Investitionsentscheidung ergibt sich, daß unabhängig von den Konsumentenpräferenzen stets die Optimalbedingung aus Gleichung (C.I.10) erfüllt sein muß. Dieser Satz wird als Separationstheorem

1 Vgl. SCHNEIDER (1990), S.24.

2 Diese Annahme ist hier unproblematisch, weil Eigen- und Fremdkapital unter den genannten Bedingungen homogene Finanzierungsinstrumente darstellen.

3 Vgl. BALTENSBERGER/MILDE (1987), S.86 f. 
bezeichnet ${ }^{1}$. Allerdings ist zu beachten, daß der Gegenwartswert des Einkommens des Individuums bei Berücksichtigung von Investitionen höher ist als ohne Investitionen. Deshalb ergeben sich hier auch andere Kreditnachfrage- und -angebotsfunktionen. Im Kreditmarktgleichgewicht muß das gesamte Kreditangebot mit der Nachfrage nach Konsumtivund Investivkrediten übereinstimmen.

\section{Kreditmarkt und Kreditversicherungsmarkt bei Unsicherheit}

Nun soll die Annahme vollständiger Sicherheit gelockert werden, indem Unsicherheit im Sinne mehrerer möglicher Umweltzustände zugelassen wird, von denen die Wahrscheinlichkeitsverteilungen und die jeweiligen zustandsabhängigen Ergebnisse sicher und bekannt seien ${ }^{2}$. D.h. daß trotz Unsicherheit vollständige Information aller Marktteilnehmer herrschen soll ${ }^{3}$. Bei riskanten Krediten führt das Eintreten ungünstiger Umweltzustände zu Verlusten des Kreditgebers. Aus Vereinfachungsgründen wird weiterhin angenommen, daß Kreditnachfrage und -angebot gegeben seien ${ }^{4}$. Dadurch wird das Problem auf die Frage reduziert, welche Preise sich für Kredite mit unterschiedlichem Risiko auf einem vollkommenen Kapitalmarkt ergeben. Entscheidend dabei ist, daß die Höhe des Konsums der Kreditnachfrager bzw. -anbieter zukünftig unsicher ist, wenn die Kreditbeziehung durch Kreditrisiken gekennzeichnet ist.

Kreditrisiken treten als Kreditausfallrisiko des Kreditgebers, bei festverzinslichen Krediten als Zinsänderungsrisiko und als Liquiditätsrisiko in Erscheinung ${ }^{5}$. Zunächst soll das Kreditausfallrisiko näher betrachtet werden.

1 Vgl. HIRSHLEIFER (1970), S.63.

2 Diese Art der Unsicherheit, bei der Wahrscheinlichkeiten kalkulierbar sind wird seit KNIGHT (1921) mit dem Begriff Risiko belegt, während bei fehlender Kalkulierbarkeit von Ungewißheit (uncertainty) gesprochen wird. Vgl. HEY (1979), S.40.

3 Vgl. SWOBODA (1989), S.168.

4 Zur Auswirkung von Unsicherheit auf die Nachfrage nach Investitionen und damit nach Investitionskrediten vgl. BATRA/ULLAH (1974); HARTMAN, R. (1975); HEY (1979), S.151 ff.; LIPPMAN/MCCALL (1981). Die Auswirkungen auf die Nachfrage nach Gegenwartskonsum und damit auf die Konsumkreditnachfrage bzw. das Kreditangebot analysieren vgl. SANDMO (1969); HAKANSSON (1970); SANDMO (1970); LEVHARI/MIRMAN (1977). Zu einem zusammenfassenden Überblick vgl. LIPPMAN/MCCALL (1981), S.236 ff. Das Ergebnis dieser Untersuchungen besteht darin, daß unter plausiblen Annahmen Unsicherheit zu einer verringerten Investitionsnachfrage und zu einem reduzierten Gegenwartskonsum führt. Unter bestimmten Bedingungen kann jedoch auch das gegenteilige Ergebnis resultieren. 


\section{a. Das Kreditausfallrisiko}

Das Kreditausfallrisiko ist abhängig von der Wahrscheinlichkeitsverteilung der vollständigen Erfüllung der Kreditforderungen durch den Kreditnehmer. Sie hängt bei Investitionskrediten, die der folgenden Betrachtung zugrunde gelegt werden, vom Ertragsrisiko der mit dem Kredit finanzierten Investition $\mathrm{ab}^{1}$.

Die mit dem Kreditausfallrisiko verbundenen Schadensmöglichkeiten der Kreditgeber können u.a. durch die Bereitstellung von Kreditsicherheiten durch die Kreditnehmer oder eine Kreditversicherung gesenkt werden ${ }^{2}$. Dabei werden Haftungszusagen Dritter wie Bürgschaften, Garantien u.ä. zu den Kreditversicherungen gerechnet ${ }^{3}$. Zunächst soll jedoch von der Möglichkeit von Kreditversicherungen abgesehen werden.

\section{aa. Der Kreditmarkt ohne Kreditversicherung}

Zur Analyse der Auswirkung von Kreditausfallrisiken auf den Zinssatz wird zunächst ein risikoneutraler Kreditgeber betrachtet, der seinen erwarteten Gewinn und damit auch seinen Erwartungsnutzen maximiert ${ }^{4}$. Es wird wiederum ein Zweiperiodenmodell zugrundegelegt, wobei der Kreditgeber in $t_{0}$ zwischen dem Erwerb einer risikolosen und einer riskanten Kreditforderung $\mathrm{K}$ zu entscheiden hat, die in beiden Alternativen eine Laufzeit von einer Periode hat und endfällig ist. Der Zinssatz $r$ des risikolosen Kredits sei gegeben. Das Ausfallrisiko wird durch zwei mögliche Umweltzustände bestimmt, wobei der ungünstige Zustand mit einer Wahrscheinlichkeit von p eintritt und einen vollständigen Kreditausfall in $t_{1}$ zur Folge hat, während mit der Wahrscheinlichkeit (1-p) in $t_{1}$ sämtliche Darlehensforderungen erfüllt werden. Der Kreditgeber ist zwischen dem riskanten und dem risikolosen Kredit dann indifferent, wenn der Erwartungswert des Rückflusses des riskanten Kredits dem sicheren Rückfluß des risikolosen Kredits entspricht.

Es gilt also:

$$
K(1+r)=(1-p) K\left(1+r^{*}\right) \text { bzw. }
$$

1 Vgl. BALTENSBERGER/MILDE (1987), S.92 ff.

2 Vgl. BALTENSBERGER/MILDE (1987), S.111 ff. Außer durch Kreditsicherheiten können die Ansprüche des Kreditgebers auch durch bestimmte Kreditvertragsgestaltungen wie z.B. Negativklauseln, Dividendenbeschränkungen usw. geschützt werden, welche die Wahrscheinlichkeit des Kreditausfalls und damit das entsprechende Risiko reduzieren. Vgl. dazu KLUG (1985), S.86 ff.

3 Vgl. KLUG (1985), S.95 ff.; SCHNEIDER (1990), S.532.

$4 \mathrm{Zu}$ dem auf Bernoulli zurückgehenden und von v.Neumann und Morgenstern spezifizierte Erwartungsnutzenkonzept vgl. z.B. HIRSHLEIFER (1970), S.215 ff.; HIRSHLEIFER/RILEY (1979); HEY (1979), S.41 ff.; KRUSCHWITZ (1987), S.567. 


$$
\begin{array}{lll}
\text { (C.I.12a) } & 1+r^{*} & =(1+r) /(1-p), \\
\text { (C.I.12b) } & r^{*} & =(r+p) /(1-p) .
\end{array}
$$

Dabei bezeichnet $r$ den Zinssatz des riskanten Kredits. Die Differenz der Zinssätze des riskanten und risikolosen Kredits beträgt demnach $(1+r) p /(1-p)$. Mit (C.I.12b) läßt sich außerdem zeigen, daß der nominale Zinssatz eines riskanten Kredits um so höher sein muß, je größer die Ausfallwahrscheinlichkeit ist. Danach wäre der nominale Zinssatz für Kredite zur Finanzierung langfristiger Projekte höher als bei kurzfristigen Projekten, sofern man die plausible Annahme trifft, daß die Ausfallwahrscheinlichkeit im ersten Fall höher ist ${ }^{1}$.

Bemißt man das Risiko riskanter Kredite an der Höhe der Kreditausfallwahrscheinlichkeit und den Risikopreis an der Abweichung vom erwarteten Zinssatz E( $\left.r^{*}\right)$, so beträgt der Risikopreis bei Risikoneutralität sämtlicher Kreditgeber Null, d.h. daß das Angebot riskanter Kredite in bezug auf die Risikohöhe bei gegebenem $\mathrm{E}\left(\mathrm{r}^{*}\right)$ vollkommen elastisch verläuft. Der Risikopreis ist folglich bei Risikoneutralität der Krediianbieter von der Höhe der Nachfrage nach Krediten mit unterschiedlichem Risiko unabhängig.

Ist der Kreditgeber risikoavers, so wird er zur Kompensation der Risikoübernahme einen Risikozuschlag fordern, um den die erwartete Verzinsung des riskanten Kredits sein Sicherheitsäquivalent, nämlich den risikolosen Marktzinssatz, übersteigt ${ }^{2}$. Die Höhe des Risikozuschlags, der den Verlauf der individuellen Angebotskurve für riskante Kredite bestimmt, steigt mit zunehmendem Risiko ${ }^{3}$. Bei fallender Nachfragekurve wird sich also ein positiver Risikopreis ergeben.

Kann der Kreditgeber zwischen mehreren riskanten Krediten entscheiden, so läßt sich durch Bildung eines Forderungsportfolios das Kreditrisiko reduzieren. Denn der erwartete Portfolioertrag entspricht dem mit den Mengenanteilen der Kredite im Portfolio gewichteten Durchschnitt der Ertragserwartung, während das an der Standardabweichung gemessene Portfoliorisiko ${ }^{4}$ unterhalb des gewichteten Durchschnittsrisikos der einzelnen Kredite liegt, sofern die Einzelrisiken nicht vollständig positiv korreliert sind ${ }^{5}$. D.h. daß bei einer Portfoliobildung ein Teil des Risikos durch Diversifikation verschwindet und insoweit

\footnotetext{
1 Vgl. BOADWAY/WILDASIN (1984), S.219.

2 Vgl. MCCALL (1971), S.412 f.

3 Vgl. ATKINSON/STIGLITZ (1980), S.126 f.

4 Die Verwendung der Standardabweichung als Risikomaß enthält implizit die Annahme einer normalverteilten Schadenswahrscheinlichkeit oder aber einer qudratischen Nutzenfunktion. Vgl. EISEN (1979), S.51. Zu anderen, weniger restriktiven Risikomaßen vgl. ROTHSCHILD/STIGLITZ (1970) und DIAMOND/STIGLITZ (1974).

Vgl. BITZ (1981), S.117 ff.; SCHMIDT, R.H. (1986), S.145.
} 
keine Risikokosten entstehen. Deshalb muß im Kapitalmarktgleichgewicht der Preis der Übernahme eines solchen diversifizierbaren oder unsystematischen Risikos gleich Null sein $^{1}$. Damit reduziert sich bei unterstellter Risikoaversion für den Einzelkredit der zur Kompensation der Risikoübernahme erforderliche Risikozuschlag. Sind die Kreditausfallrisiken vollständig unkorreliert und strebt die Zahl der Einzelkredite gegen unendlich, so ist das Portfolio frei von systematischem Risiko; die Standardabweichung der Rückflußerwartung des Portfolios strebt gegen Null ${ }^{2}$. Deshalb erhält auch ein risikoaverser Kreditgeber im Gleichgewicht für den Einzelkredit lediglich einen Zinssatz, bei dem $r=E\left(r^{*}\right)$ gilt $^{3}$. Sofern aber ein systematisches, nichtdiversifizierbares Risiko besteht, wird sich bei Risikoaversion aller Kreditanbieter im Kapitalmarktgleichgewicht ein positiver Risikopreis ergeben, wie sich mit Hilfe des Capital Asset Pricing-Modells ${ }^{4}$ zeigen läßt. Dieser Risikopreis ist unter Berücksichtigung einer risikolosen Kreditalternative für jede Risikoeinheit identisch ${ }^{5}$. Der Anteil riskanter und risikoloser Kredite im Kreditportfolio eines einzelnen Kreditgebers hängt nun von seinen Risikopräferenzen und seiner Budgetrestriktion ab, die den Risikopreis beinhaltet ${ }^{6}$.

\section{bb. Der Kreditversicherungsmarkt}

Die Risikodiversifikation kann auch über vollkommene Kreditversicherungsmärkte erfolgen. Jedoch kann damit bei vollkommenem Kapitalmarkt die Existenz von Kreditversicherungen nicht erklärt werden, da in diesem Fall jeder einzelne Kreditgeber ein vollkommen diversifiziertes Kreditportfolio halten wird ${ }^{7}$. Im folgenden wird daher analysiert, inwieweit ein risikoaverser Kreditgeber seine individuelle Position durch Versicherung seiner mit systematischem Risiko behafteten Kreditforderungen verbessern kann. Dazu wird angenommen, da $\beta$ die Versicherungsanbieter risikoneutral sind. Im Gleichgewicht ergibt

1 Vgl. SCHMIDT, R.H. (1986), S.165.

2 Vgl. BOADWAY/BRUCE (1984), S.326 f.

3 Für dieses Ergebnis ist entscheidend, daß Transaktionskosten von Null bei der Risikodiversifikation unterstellt werden.

4 Vgl. dazu SHARPE (1964); LINTNER (1965); MOSSIN (1966).

5 Er beträgt $[E(M)-(1+r)] / \sigma(M)$, wobei $E(M)$ den erwarteten Bruttoertrag (Tilgung plus Verzinsung) eines Anteils am Marktportfolio riskanter Kredite, $\sigma(M)$ seine Standardabweichung und $1+r$ den Bruttoertrag des sicheren Kredits bezeichnen. Die "Menge" von Risikoeinheiten eines einzelnen Kredits ergibt sich als Quotient aus der Kovarianz des Ertrags des einzelnen Kredits mit dem Portfolioertrag und der Standardabweichung des Portfolioertrags. Zu einer ausführlichen Herleitung des Risikopreises im Kapitalmarktgleichgewicht vgl. FAMA/ MILLER (1972), S.290 ff.

6 SCHMIDT, R.H. (1986), S.162 f.

7 Die entscheidenen Annahmen sind dabei vollkommene Information, die beliebige Teilbarkeit von Kreditforderungen und das Fehlen von Transaktionskosten. 
sich demzufolge in einer Welt ohne Transaktions- und Informationskosten eine faire Versicherungsprämie ${ }^{1}$. D.h. daß der erwartete Gegenwartswert der Versicherungsleistung der Versicherungsprämie bzw. die erwartete Versicherungsleistung dem Endwert der Versicherungsprämie entspricht. Tritt der ungünstige Umweltzustand und damit der Versicherungsfall mit der Wahrscheinlichkeit $p$ ein, so gilt:

$$
\begin{aligned}
& \mathrm{vV}=(p+1-p) v V=p V /(1+r) \text { oder } \\
& \mathrm{vV}=[1-v(1+r)] p V /(1-p)(1+r),
\end{aligned}
$$

wobei v den Prämiensatz, V die Versicherungssumme und $p /(1-p)$ den relativen Preis des Austauschs von Vermögen im günstigen gegen Vermögen im ungünstigen Umweltzustand bezeichnen $^{2}$. Der Prämiensatz $\mathrm{v}$ entspricht der mit $1+\mathrm{r}$ abdiskontierten Schadenswahrscheinlichkeit $\mathrm{p}^{3}$.

Hat der ungünstige Umweltzustand einen vollständigen Ausfall der versicherten Kreditforderung $\mathrm{K}\left(1+\mathrm{r}^{\prime}\right)$ zur Folge, so gilt bei einer Kreditversicherung durch den Kreditgeber für seinen von den Vermögensendwerten in beiden möglichen Umweltzuständen $\mathbf{W}_{\mathbf{0}}$ bzw. $W_{1}$ abhängige Erwartungsnutzen $E^{4}$ :

$$
E U=(1-p) U\left(K\left(1+r^{\prime}\right)-v(1+r) V\right)+p U([1-v(1+r)] V) .
$$

Maximiert man Gleichung (C.I.14) unter der durch Gleichung (C.I.13a.) repräsentierten Nebenbedingung ${ }^{5}$, so ergibt sich die Optimalitätsbedingung erster Ordnung ${ }^{6}$ als

$$
\left(\partial \mathrm{U} / \partial \mathrm{W}_{0}\right) /\left(\partial \mathrm{U} / \partial \mathrm{W}_{1}\right)=1 \text {. }
$$

Ist die Nutzenfunktion des Kreditgebers streng konkav, liegt also Risikoaversion vor, so folgt daraus, daß sein Vermögen im Optimum in beiden Umweltzuständen dieselbe Höhe erreichen muß. Aus (C.I.14) folgt dann:

$$
\mathrm{V}=\mathbf{K}\left(1+\mathbf{r}^{\prime}\right) \text {, }
$$

1 Vgl. STRASSL (1988), S.31.

$2 \mathrm{Zu}$ einer analogen Herleitung für Versicherungen allgemein vgl. EHRLICH/BECKER (1972), S.625.

3 Vgl. STRASSL (1988), S.31.

4 Es wird also implizit unterstellt, daB die Höhe des individuellen Kreditangebots, die durch die Konsum-Spar-Entscheidung determiniert wird, von der Versicherungsentscheidung unabhängig ist. Weiterhin wird angenommen, daB der Kreditgeber die Versicherungsprämie zum risikolosen Marktzinssatz finanzieren kann und da $\mathrm{B}$ er in $\mathrm{t}_{1}$ nur Vermögenseinkünfte bezieht.

Dazu sind $K\left(1+r^{\prime}\right)-v(1+r) V$ und $[1-v(1+r)] V$ durch den Vermögensendwert nach Abschlu $B$ der Versicherung im günstigen Umweltzustand $W_{1} b z w$. im ungünstigen Umweltzustand $W_{0} z u$ substituieren.

Die Optimalitätsbedingung zweiter Ordnung wird als erfüllt angenommen. 
d.h. die Versicherungssumme entspricht dem Schaden des Kreditgebers im ungünstigen Zustand ohne Versicherung. Der Kreditgeber wird demnach sein gesamtes Kreditausfallrisiko durch eine Versicherung abdecken ${ }^{1}$. Daraus wird auch deutlich, daß ein Versicherungsnachfrager bei Bestehen von Versicherungsmärkten stets risikoavers sein wird, weil nur risikoaverse Individuen den bei Vollversicherung sicheren Vermögenswert dem unsicheren Vermögen derselben erwarteten Höhe vorziehen werden²

Der vollversicherte riskante Kredit und ein risikoloser Kredit sind homogene Güter, da ersterer für den Kreditgeber ebenfalls risikolos ist. Deshalb müssen beide Alternativen zu demselben Ertrag führen. Unter Verwendung von Gleichung (C.I.13) folgt:

$$
(1-p) K\left(1+r^{\prime}\right)=K(1+r) \text { bzw. }
$$

Damit ist der Zinsfaktor $(1+r$ ') eines zur fairen Prämie vollversicherten Kredits auch bei Risikoaversion des Kreditgebers mit dem von einem risikoneutralen Kreditgeber geforderten Zinsfaktor bei vollkommenem Kapitalmarkt identisch. Anders ausgedrückt wird ein risikoaverser Kreditgeber auf einen Risikozuschlag zum Zinssatz verzichten, wenn er die Möglichkeit besitzt, das Ausfallrisiko zu einer fairen Prämie zu versichern ${ }^{3}$.

Die Kreditversicherung kann ohne Wohlfahrtsverluste auch statt vom Kreditgeber vom Kreditnehmer abgeschlossen werden, wenn der Kreditnehmer auch die Versicherungsprämie kreditfinanziert. Seine Schuldendienstleistungen betragen im einen wie im anderen Fall im günstigen Umweltzustand $K(1+r) /(1-p)$ und im Schadensfall $\mathrm{Null}^{4}$, während das Vermögen des Kreditgebers in der Zukunft $\mathrm{K}(1+r)$ beträgt.

Existiert jedoch ein systematisches Risiko und sind auch die Versicherer risikoavers, so übersteigt die Versicherungsprämie den Gegenwartswert des Erwartungsschadens um einen Risikozuschlag 5 . Dann gilt im Optimum des Kreditgebers für das Grenznutzenverhältnis des Vermögens im ungünstigen und günstigen Umweltzustand $U_{0}{ }^{\prime} / U_{1}{ }^{\prime}>1$. D.h.

1 Vgl. zum allgemeinen Fall der Versicherung EHRLICH/BECKER (1972), S.625 ff.

2 Vgl. STRASSL (1988), S.19 f. Dies schlieBt jedoch nicht aus, da B die Erwartungsnutzenfunktion des Versicherten auch konvexe Bereiche aufweisen kann, so daB ein Versicherter gleichzeitig auch ein Spieler sein kann. Vgl. FRIEDMAN/SAVAGE (1948).

3 Zum selben Ergebnis gelangt man, wenn Kreditsicherheiten vom Kreditnehmer kostenlos gestellt werden können. Vgl. MATTESINI (1986), S.87 ff.

4 Bei Vollversicherung der gesamten Kreditbeziehung gilt:

$\mathrm{V}=\mathbf{K}(1+\mathrm{r})+\mathrm{pV}$ oder umgeformt

$V=K(1+r) /(1-p)$.

D.h. daB der Kreditnehmer im günstigen Umweltzustand $\mathbf{K}(1+r)$ für den Kredit $\mathbf{K}$ und $K(1+r) p /(1-p)$ für den Prämienkredit als Schuldendienst zu leisten hat.

5 Vgl. EISEN (1979), S.48 f. 
daß im Optimum das Vermögen im günstigen Umweltzustand höher sein wird als im Schadensfall ${ }^{1}$ und nur eine Teildeckung des Risikos erfolgt ${ }^{2}$.

Generell gilt, daß über vollkommene Versicherungsmärkte eine effiziente Allokation von Risiken erfolgt. Dabei treten Wirtschaftssubjekte mit der geringeren Risikoaversion als Versicherer und die mit der höheren Risikoaversion als Versicherte auf ${ }^{3}$.

\section{b. Das Zinsänderungs- und Liquiditätsrisiko}

Das Zinsänderungsrisiko bedeutet, daß sich die Opportunitätskosten eines festverzinslichen Kredits im Zeitablauf verändern können ${ }^{4}$. Dabei kann das Zinsänderungsrisiko sowohl den Kreditgeber als auch den Kreditnehmer treffen, wenn eine Zinsänderung bezogen auf den vereinbarten Zinssatz in beide Richtungen möglich ist. Damit eng verbunden ist das Liquiditätsrisiko, da bei Zinsänderungen ein Kursrisiko für Kreditforderungen entsteht, das deren Liquidität negativ beeinflußt ${ }^{5}$. Es kann gezeigt werden, daß das Kursrisiko bei kurzfristigen Krediten geringer und ihre Liquidität damit höher ist als bei langfristigen Krediten ${ }^{6}$. Dementsprechend werden die Kreditanbieter zur Vergabe langfristiger Kredite nur bereit sein, wenn sie für ihre geringere Liquidität eine Kompensation in Form eines höheren Zinssatzes erhalten ${ }^{7}$. Umgekehrt werden risikoaverse Kreditnachfrager auch bereit sein, für langfristige festverzinsliche Kredite einen Zinssatz zu entrichten, der den Erwartungswert des durchschnittlichen Zinssatzes kurzfristiger Kredite in demselben Zeitraum übersteigt. Denn Risikoaversion impliziert, daß die Verlusterwartung aufgrund von möglichen Zinsänderungen bei kurzfristigen Krediten den Erwartungsnutzen mehr reduzieren, als er bei einer gleich hohen Gewinnerwartung erhöht wird ${ }^{8}$. Auch bei Zinsänderungs- und Liquiditätsrisiken können unsystematische Risiken diversifiziert werden? . Darüber hinaus gibt es auch Versicherungsmöglichkeiten dieser Risiken, wie z.B.

1 Es wird hier ein abnehmender Grenznutzen des Vermögens unterstellt.

2 Vgl. EHRLICH/BECKER (1972), S.626 f.; EISEN (1979), S.47, 55 ff.

3 Vgl. EISEN (1979), S.48 f.; STRASSL (1988), S.25 ff.

4 Vgl. RHYNE (1988), S.93.

5 Vgl. MILBRADT (1975), S.26.

6 Vgl. MALKIEL (1962).

7 Ein ähnliches Argument gilt auch für Banken und sonstige Kreditgeber, welche die Kredite durch andere Kredite refinanzieren, sofern die Laufzeit der vergebenen Kredite die der aufgenommenen Kredite übersteigt. Aufgrund der Opportunitätskosten der dadurch erforderlichen Reservehaltung wird der Zinssatz im Normalfall für langfristige Kredite höher sein als für kurzfristige Kredite. Zum Liquiditätsrisiko bei Banken, das bei den Bankgläubigern ein Ausfallrisiko nach sich zieht, vgl. BALTENSBERGER/MILDE (1987), S.19 ff.

Vgl. MILBRADT (1975), S.27.

9 Vgl. WONDRAK (1986) zu Zinsänderungsrisiken und BALTENSBERGER/MILDE (1987), S.33 ff. zu Liquiditätsrisiken. 
Zinsoptionen, die bei vollkommenen Märkten zu einer effizienten Risikoallokation führen. Jedoch sind diese Risiken in bezug auf öffentliche Kredithilfen von geringerer Bedeutung. Sie bleiben daher im weiteren Verlauf der Arbeit unberücksichtigt.

\section{Der Kreditmarkt bei Existenz von Transaktionskosten}

Läßt man nun Transaktionskosten zu, ist also der Tausch auf dem Kreditmarkt nicht kostenlos $^{1}$, so fallen Soll- und Habenzinsen auseinander. Dies führt dazu, daß die Investitionsentscheidungen in der Regel nicht mehr unabhängig von den individuellen intertemporalen Präferenzen getroffen werden ${ }^{2}$. Außerdem ist die Diversifikation des unsystematischen Kreditrisikos nicht mehr kostenlos, so daß sein Preis größer Null sein wird. Durch Transaktionskosten läßt sich auch die Existenz von Finanzintermediären als Einrichtungen erklären, die bei der "Herstellung" von Kreditbeziehungen und der Risikodiversifikation Kostenvorteile besitzen ${ }^{3}$.

Betrachtet man Kreditverwaltungskosten als Beispiel für Transaktionskosten, so läßt sich zeigen, daß der gleichgewichtige Zinssatz von der Höhe dieser Kosten abhängt. Es wird angenommen, daß ein Kreditgeber, der seine Kreditaktivitäten zum Zinssatz r refinanziert, nur risikolose, einperiodige Kredite vergibt. Die gewinnmaximale Kreditsumme beträgt K. Der Kreditgeber hat einmal die Möglichkeit, K zum Zinssatz i an einen einzigen Kreditnehmer zu vergeben. Alternativ kann er $\mathrm{K}$ in $\mathrm{n}$ gleich große Kredite aufteilen, wobei dann für jede Mengeneinheit zusätzliche Kreditverwaltungskosten mit dem Endwert c anfallen. Der Kreditgeber ist zwischen beiden Alternativen indifferent, wenn gilt:

$$
\begin{aligned}
& K(1+i)-K(1+r)=n\left(1+i^{*}\right) K / n-K(1+r)-n c K / n \text { bzw. } \\
& i^{*}=i+c .
\end{aligned}
$$

D.h. da $\beta$ der Kreditgeber zu einer Aufteilung der Kreditsumme zwischen $\mathbf{n}$ verschiedenen Kreditnehmern nur bereit sein wird, wenn der Kreditzinssatz $i$ um $c$ größer ist als i. Steigt c mit zunehmendem n, so folgt daraus, daß der Kreditzinssatz um so höher sein muß, je geringer die Kreditsumme des einzelnen Kredits ist. Aus diesen Zusammenhängen erklärt sich, weshalb der Zinssatz für Kleinkredite regelmäßig höher ist als für Großkredite.

1 Vgl. SCHUMANN (1987), S.391 ff.

2 Vgl. HIRSHLEIFER (1970), S.195 ff.

3 Vgl. BALTENSBERGER/MILDE (1987), S.5. 
Auf den Kreditversicherungsmärkten führen Transaktionskosten dazu, daß auch ein risikoneutraler Versicherer eine höhere als die faire Versicherungsprämie verlangen wird. Unter diesen Bedingungen ist eine vollständige Verlustdeckung nicht optimal ${ }^{1}$.

\section{Kredit- und Kreditversicherungsmarkt bei Informationsunvollkommenheiten}

Abgesehen von Informationskosten, die zu den oben behandelten Transaktionskosten gerechnet werden können ${ }^{2}$, sind auf dem Kredit- und dem Kreditversicherungsmarkt Informationsunvollkommenheiten in Form asymmetrischer Informationsverteilung zwischen Kreditgeber und Kreditnehmer bzw. Kreditversicherer und Versichertem möglich. Diese Informationsasymmetrien beziehen sich einmal auf die gegebene Qualität der Leistung eines der beiden Vertragspartner ${ }^{3}$, zum anderen auf Handlungen eines Vertragspartners, die sich auf die Qualität einer vertraglichen Leistung auswirken. Bei Krediten und Kreditversicherungen ist das entscheidende Qualitätsmerkmal das Kreditausfallrisiko. Aus solchen Informationsasymmetrien resultieren nun typischerweise zwei Arten von Anreizproblemen: adverse Selektion und moral hazard ${ }^{4}$.

\section{a. Adverse Selektion}

Unterscheiden sich die auf dem Kreditmarkt gehandelten Kredite in bezug auf ihre Kreditausfallwahrscheinlichkeit und kennt der Kreditgeber lediglich die durchschnittliche Ausfallwahrscheinlichkeit, während dem einzelnen Kreditnehmer seine individuelle, von ihm jedoch unbeeinflußte Ausfallwahrscheinlichkeit ${ }^{5}$ bekannt ist, kann es zu adverser Selektion kommen ${ }^{6}$. Dies läßt sich anhand eines einfachen Modells demonstrieren.

Es wird angenommen, daß alle Kreditnehmer einperiodige, riskante Investitionsprojekte gleicher Größe mit demselben erwarteten Ertragsfaktor $\mathbf{R}$ ausschließlich kreditfinanzieren wollen. Weiterhin soll gelten, daß $\mathbf{R}$ den Ertragsfaktor $1+r$ einer risikolosen

1 Vgl. EISEN (1979), S.57.

2 Vgl. SCHUMANN (1987), S.392.

3 Grundlegend dazu AKERLOF (1970), der die Problematik asymmetrischer Information anhand des Gebrauchtwagenmarkts illustriert.

4 Zu einem knappen Überblick vgl. INMAN (1987), S.659 ff.

5 Läßt man eine Beeinflussung der Ausfallwahrscheinlichkeiten durch die Kreditnehmer zu, so lassen sich adverse Selektion und moral hazard analytisch nicht trennen. Vgl. STRASSL (1988), S.123 f.

6 Das Problem adverser Selektion kann auch auftreten, wenn die Kreditnehmer dieselben Investitionen durchführen und der Investitionsertrag von den für den Kreditgeber nicht zu beobachtenden individuellen Fähigkeiten der Kreditnehmer abhängt. Vgl. CLEMENZ (1986), S.60 ff. 
Anlage übersteigt. Die individuelle Kreditausfallwahrscheinlichkeit $\mathrm{p}^{\mathbf{i}}$ variiere aufgrund unterschiedlicher Erfolgswahrscheinlichkeiten der Investitionen und sei im Gegensatz zu R lediglich den Kreditnehmern bekannt. Im ungünstigen Umweltzustand beträgt der Investitionsertrag der Kreditnehmer Null. Zur Vereinfachung wird weiterhin Risikoneutralität aller Wirtschaftssubjekte unterstellt. Da individuelle risikoangepaßte Zinssätze nicht festgelegt werden können, wird der Kreditgeber für jeden Kredit unter den genannten Bedingungen folgenden Zinsfaktor $1+\mathrm{i}$ verlangen:

$$
1+\mathrm{i}=(1+\mathrm{r}) /(1-\pi)
$$

wobei $\pi$ die durchschnittliche Ausfallwahrscheinlichkeit repräsentiert. Der einzelne Kreditnachfrager wird die Investition nur durchführen, wenn gilt:

$$
R \geq\left(1-p^{i}\right)(1+i)
$$

Geht man zur Vereinfachung davon aus, daß $\mathrm{p}^{\mathrm{i}}$ über alle Kreditnehmer von 0 bis 1 gleichverteilt ist, so werden die Kreditnehmer, für die $\mathrm{p}^{\mathrm{i}}=\mathbf{0}$ gilt, die Investition nur durchführen, wenn $R \geq 2(1+r)$ ist $^{1}$. Ist dagegen $R<2(1+r)$, so werden alle Kredite mit $1>\mathrm{R} /(1+\mathrm{i})$, d.h. die besten Risiken, vom Kreditmarkt verdrängt. Dadurch steigt jedoch die durchschnittliche Ausfallwahrscheinlichkeit und damit der Kreditzinssatz ${ }^{2}$. Dieser Prozeß setzt sich solange fort, bis nur noch die schlechtesten Risiken als Kreditnachfrager auftreten $^{3}$. Der Kreditmarkt bricht damit zusammen. Sofern die Investitionen nicht eigenfinanziert werden können, erfolgt damit über den Kreditmarkt eine Verdrängung effizienter Investitionen, da für alle Investitionen annahmegemäß $R>(1+r)$ gilt. Dieser Proze $B$ wird mit dem Begriff "adverse Selektion" umschrieben. Ursache dafür ist letztlich der Umstand, daß die Kreditnehmer mit hoher Ausfallwahrscheinlichkeit einen Anreiz besitzen, das individuelle Kreditrisiko zu untertreiben, um in den Genuß einer Subventionierung durch die Kreditnehmer mit niedrigem Kreditrisiko zu gelangen. Letztere sind also externen Kosten ausgesetzt ${ }^{4}$ und werden sich aus dem Kreditmarkt zurückziehen, obwohl die Durchführung der Investitionen wohlfahrtssteigernd wäre. Wenngleich sich die einzelnen Individuen rational verhalten, kommt es zu einem kollektiv irrationalen Ergebnis. Dementsprechend läßt sich die Informationsasymmetrie, bei welcher der Kreditgeber unvollständige Kenntnis über die Qualität der Kreditforderungen besitzt, als Gefangenendilemma charakterisieren.

1 Da unter dieser Annahme $\pi=1 / 2$ beträgt, gilt $1+i=2(1+r)$ und demgemä $B \geq 2(1+r)$.

2 Die Kosten adverser Selektion werden nur dann vom Kreditgeber getragen, wenn dieser die mit der Informationsasymmetrie verbundenen Anreizeffekte nicht wahrnimmt und somit den Zinssatz nicht entsprechend anpaßt. Vgl. JENSEN/MECKLING (1976), S.335 ff.

Vgl. MANKIW (1986), S.463.

4 Vgl. ROTHSCHILD/STIGLITZ (1976), S.629. 
Da ein vollkommener Zusammenbruch des Kreditmarkts ineffizient ist, besteht ein Anreiz, durch spezifische, sogenannte anreizkompatible Vertragsgestaltungen eine Paretoverbesserung zu erreichen. Als typisches Beispiel hierfür gilt die Bereitstellung von Kreditsicherheiten durch den Kreditnehmer. Sie führen im ungünstigen Umweltzustand zu einem Verlust des Kreditnehmers. Die Bereitschaft, Sicherheiten zu stellen, dient damit als Signal für die Höhe des individuellen Kreditrisikos. Denn mit steigender Kreditausfallwahrscheinlichkeit fallen die Gewinne der Kreditnehmer. Aufgrund der Kreditsicherheiten wird der Kreditgeber den Zinsfaktor auf $1+i^{\prime}<(1+r) /(1-\pi)$ festlegen. Der Anreiz für die guten Kreditrisiken, aus dem Markt auszuscheiden, verringert sich entsprechend. Ist der Wert der Kreditsicherheit für jeden Kredit $K$ kleiner als als $\left(1+i^{\prime}\right) K^{1}$, so haben die besten Kreditrisiken gleichwohl noch einen Anreiz, sich aus dem Kreditmarkt zurückzuziehen, da ihr Erwartungsgewinn jenseits eines bestimmten Zinssatzes negativ werden kann. Allerdings wird der Kreditgeber diesen adversen Selektionseffekt nicht unbegrenzt durch einen höheren Zinssatz auszugleichen versuchen. Vielmehr gibt es einen optimalen Zinssatz i ${ }^{*}$ für den Kreditgeber ${ }^{2}$, bei dem sein Erwartungsgewinn maximal ist ${ }^{3}$. Liegt $i^{*}$ unterhalb des Markträumungszinssatzes, kommt es zu einem Rationierungsgleichgewicht, bei dem die Kreditnachfrage mengenmäßig begrenzt wird ${ }^{4}$.

Außer der Bereitstellung von Kreditsicherheiten kann eine Signalfunktion bezüglich des Kreditrisikos auch durch die Begrenzung der Laufzeit von Kreditverträgen ${ }^{5}$ sowie den Aufbau langfristiger Geschäftsbeziehungen ${ }^{6}$ erreicht werden, wenn die Kreditnehmer mehrperiodige Projekte kreditfinanzieren wollen bzw. im Zeitablauf mehrfach Kredite nachfragen. Andererseits werden die Kreditgeber Ressourcen zur "Produktion" von Infor-

1 Stimmen die Höhe der Kreditsicherheit und der Kreditforderung überein, wird dagegen ein paretooptimales Markträumungsgleichgewicht resultieren. Vgl. CLEMENZ (1986), S.98, 112, 120 ff.; BESTER (1987), S.229.

2 Vgl. STIGLITZ/WEISS (1981), S.395 ff.; CLEMENZ (1986), S.48 ff.

3 Das Gewinnmaximum wird dann erreicht, wo der Grenzertrag einer Zinssatzerhöhung den Grenzkosten aufgrund adverser Selektion entspricht.

4 Vgl. STIGLITZ/WEISS (1981), S.397 f. Zu einem instruktiven Beispiel vgl. WILSON (1987), S.33. Zu den verschiedenen Varianten der Kreditrationierung vgl. KEETON (1979); CLEMENZ (1986), S.18 f.

5 Vgl. STIGLITZ/WEISS (1983). Kürzere Kreditlaufzeiten sind jedoch bei asymmetrischer Information längeren Laufzeiten nicht in jedem Fall überlegen. Vielmehr hängen die optimalen Kreditlaufzeiten auch von der Art der kreditfinanzierten Investitionen ab. Es läßt sich zeigen, $\mathrm{da} B$ die optimale Laufzeit um so länger ist, je höher die relativen sunk costs einer Investition sind bzw. je irreversibler die Investition ist. Vgl. KRAHNEN (1988).

$6 \mathrm{Zu}$ langfristigen Geschäftsbeziehungen wird es nur kommen, wenn Kreditnehmer sich in früheren Perioden als gute Risiken erwiesen haben. Daraus kann dann geschlossen werden, da $B$ sie fähiger oder vertragstreuer sind als der Durchschnitt der Neukreditnehmer. Die Konsequenz daraus ist das sogenannte experience rating, wonach bei einer Finanzierung identischer Investitionsvorhaben für erfolgreiche "alte" Kunden der Zinssatz geringer ist als für Neukunden. Vgl. CLEMENZ (1986), S.80. Siehe auch BESTER (1987), S.234 f. 
mation bei der Auswahl ("screening") und Überwachung ("monitoring") von Kreditnehmern bis zu einer Höhe einsetzen, bei welcher Grenznutzen und -kosten entsprechender Aktivitäten übereinstimmen ${ }^{1}$.

Jedoch läßt sich durch solche marktlichen Anpassungsprozesse bei asymmetrischer Information nur unter sehr restriktiven Bedingungen eine erstbeste Kreditallokation erreichen $^{2}$. Im Normalfall sind die optimalen Kreditkontrakte bei asymmetrischer Information lediglich Second-best-Lösungen, die im Vergleich zur Situation bei vollständiger Information ein höheres Kreditrisiko und geringere Investitionssummen beinhalten ${ }^{3}$.

Wie auf dem Kreditmarkt kann es auch auf dem Kreditversicherungsmarkt zu adverser Selektion kommen ${ }^{4}$, wenn der Kreditversicherer die Versicherungsprämie entsprechend der durchschnittlichen Schadenswahrscheinlichkeit aller Versicherten festlegt. Hierbei kann eine second-best-optimale Risikoallokation erreicht werden, wenn der risikoneutrale Kreditversicherer Versicherungskontrakte mit unterschiedlichem Deckungsgrad anbietet. Dieses differenzierte Vertragsangebot dient als Selbstselektionsmechanismus. Dabei werden die schlechten Risiken die Vollversicherung wählen, während die guten Risiken einen Vertrag mit geringerem Deckungsgrad vorziehen werden. Der Deckungsgrad für die guten Risiken muß um so geringer sein, je höher das Verhältnis der Nettodeckung ${ }^{5}$ und der Prämie relativ zum entsprechenden Verhältnis für die schlechten Risiken ist, um zu vermeiden, da $B$ auch die schlechten Risiken den für die geringen Risiken vorgesehen Vertrag auswählen ${ }^{6}$. Da die guten Risiken jedoch eine Vollversicherung nicht wählen werden, läßt sich durch diesen Selbstselektionsmechanismus ein First-bestOptimum nicht herstellen ${ }^{7,8}$.

\section{b. Moral hazard}

Moral hazard auf dem Kreditmarkt beruht darauf, daß der einzelne Kreditnehmer die Kreditausfallwahrscheinlichkeiten durch eigene, für den Kreditgeber nicht oder nicht

\footnotetext{
1 Vgl. JENSEN/MECKLING (1976), S.338.

Vgl. CLEMENZ (1986), S.201; BESTER/HELLWIG (1989), S.143 ff., $157 \mathrm{ff}$.

3 Vgl. GALE/HELLWIG (1985), S.657; BESTER (1987), S.230 ff.

4 Vgl. HUNTER (1981), S.244 ff.; zu Versicherungen allgemein ROTHSCHILD/STIGLITZ (1976); STRASSL (1988), S.123 ff.

5 Versicherungssumme minus Versicherungsprämie.

6 Vgl. STRASSL (1988), S.140 f.

7 Vgl. STRASSL (1988), S.146 ff.

8 Im Falle von adverser Selektion auf Versicherungsmärkten wird von PAULY (1974) eine staatliche Zwangsversicherung vorgeschlagen. Dieser Vorschlag wird jedoch in bezug auf Kreditversicherungen nicht aufgegriffen.
} 
kostenlos kontrollierbare Handlungen nach Vertragsschluß zum eigenen Nutzen und zum Nachteil Dritter erhöhen kann ${ }^{1}$. Deshalb läßt sich eine Kreditbeziehung unter asymmetrischer Information auch als Principal-Agent-Beziehung beschreiben, die dadurch gekennzeichnet ist, daß der Prinzipal bestimmte Aufgaben an den Agenten überträgt, ohne dessen Handlungen vollständig kontrollieren zu können².

Handlungen, die für Dritte nachteilig sind, können bei Kreditbeziehungen darin bestehen, daß der Kreditnehmer einen Kreditausfall vorsätzlich herbeiführt ${ }^{3}$ oder Anstrengungen für einen schadensfreien Verlauf der Kreditbeziehung unterläßt, sofern für ihn damit Kosten verbunden sind ${ }^{4}$. Folglich kann der einzelne Kreditnehmer seine Kreditausfallwahrscheinlichkeit $p$ beeinflussen. Zum anderen kann er auf Projekte ausweichen, die im Vergleich zu den im Kreditvertrag vereinbarten Projekten eine geringere Erfolgswahrscheinlichkeit, aber einen höheren Ertrag im Erfolgsfall aufweisen ${ }^{5}$. Da die Handlungen des Kreditnehmers nicht kontrollierbar sind, kann bei einem Kreditausfall nicht festgestellt werden, ob er auf ungünstige Umweltzustände oder auf die Handlungen des Kreditnehmers zurückzuführen ist ${ }^{6}$.

Der Fall einer vorsätzlichen Kreditgeber-Schädigung ${ }^{7}$ kann an folgendem Beispiel verdeutlicht werden. Es wird angenommen, daß ein langfristiger Kredit zur Finanzierung einer langfristigen Investition eingesetzt wird. Die Darlehensforderungen des Kreditgebers, d.h. Tilgungs-, Zins- und Zinseszinsansprüche seien vollständig am Ende der Kreditlaufzeit fällig. Der Investor könnte nun seine intertemporalen Konsumentscheidungen so treffen, daß sein Vermögen genau im Zeitpunkt der Darlehensfälligkeit Null beträgt. Damit könnte er bei Fristenkongruenz der Kreditlaufzeit und Investitionsnutzungsdauer sein Lebenseinkommen maximieren, indem er die gesamten Investitionserträge einnimmt und konsumtiv verausgabt, ohne die Kosten der Investition zu tragen.

Weiterhin soll nun der Fall der Unterlassung risikomindernder Aufwendungen betrachtet werden. Es soll für die als identisch angenommenen risikoneutralen Kreditnehmer gelten:

\footnotetext{
Vgl. KOTOWITZ (1987), S.549.

Vgl. ARROW (1968), S.538.

3 Auf diese Möglichkeit weist bereits Keynes in seiner "General Theory" hin. Vgl. KEYNES (1936/1951), S.144.

4 Vgl. WATSON (1984); CHANEY/THAKOR (1985), S.175 f.; CLEMENZ (1986), S.47.

5 Vgl. JENSEN/MECKLING (1976), S.334; STIGLITZ/WEISS (1981), S.393; CHANEY/ THAKOR (1985), S.175.

6 Vgl. KOTOWTTZ (1987), S.549.

7 In der Finanzierungstheorie wird in diesem Zusammenhang vom Vermögensverschiebungsrisiko gesprochen. Vgl. SCHMIDT, R.H. (1981), S.191.
} 


$$
\mathrm{p}=\mathrm{p}\left(\mathrm{p}^{\mathrm{e}}, \Omega\right) \text { mit } \mathrm{p}_{\Omega}<\mathrm{O},
$$

wobei $\mathrm{p}^{\mathrm{e}}$ die durch die Umweltbedingungen vorgegebene Kreditausfallwahrscheinlichkeit und $\Omega$ den Ressourceneinsatz zur Verminderung der Ausfallwahrscheinlichkeit repräsentieren. Weiterhin soll eine Investition kreditfinanziert werden, deren Ertragsfaktor im günstigen Umweltzustand $\mathrm{R}$ beträgt. Kann der Kreditgeber $\Omega$ beobachten, wird jeder Kreditnehmer in seinem individuellen Optimum soviel Ressourcen zur Schadensminderung einsetzen, daß der marginale Netto-Investitionsertrag den Grenzkosten des Ressourceneinsatzes entspricht ${ }^{1}$. Kann nicht die individuelle, sondern nur die durchschnittliche Menge $\Omega$ beobachtet werden, so trägt der einzelne Kreditnehmer bei einem Verzicht auf einen Ressourceneinsatz nur einen kleinen Teil der dadurch verursachten Kosten selbst, weil sich dadurch der durchschnittliche Ressourceneinsatz nur unwesentlich ändern wird. Ansonsten werden diese Kosten Dritten als externe Kosten auferlegt. Wenn sich alle Kreditnehmer in entsprechender Weise verhalten, ist $\Omega$ gleich Null. D.h. aber, daß die Produktionseffizienz und damit das Paretooptimum verfehlt wird².

Es läßt sich zeigen, daß der Anreiz zu schädigenden Handlungen mit steigendem Zinssatz zunimmt. Dieser Moral-hazard-Effekt ist dem bei steigendem Zinssatz erzielbaren Ertragszuwachs des Kreditgebers entgegengerichtet, so da $ß$ auch moral hazard zu einem optimalen Zinssatz führen kann, der ein Rationierungsgleichgewicht zur Folge hat ${ }^{3}$.

Auch in bezug auf moral hazard werden verschiedene Varianten von anreizkompatiblen Vertragsgestaltungen zur Verminderung der perversen Anreize diskutiert. Ein wichtiges Instrument ist hierbei die vertragliche Vereinbarung von Kontrollrechten des Kreditgebers während der Vertragslaufzeit ${ }^{4}$. Außerdem lassen sich auch hier Kreditsicherheiten und die Gestaltung von Kreditvertragslaufzeiten als Anreizinstrument einsetzen ${ }^{5}$. Der vorsätzlichen Herbeiführung eines Kreditausfalls kann zusätzlich durch die vertragliche Vereinbarung von Zins- und Schuldendienstzahlungen über die gesamte Kreditlaufzeit hinweg begegnet werden. Im Falle von Investitionskrediten werden die Tilgungsraten den anteiligen, durch Abschreibungen bedingten Wertverlust regelmäßig überschreiten.

1 Beträgt der marginale Brutto-Investitionsertrag im günstigen Umweltzustand $\mathbf{R}$ und im ungünstigen Umweltzustand Null, so folgt aus der Gewinngleichung $G=(1-p) R-(1+r)-x \cap$ die Optimalbedingung $-\mathrm{p}_{0} \mathrm{R}=\mathrm{x}$, wobei $\mathrm{x}$ den Preis von $\Omega$ bezeichnet.

2 Vgl. JAFFEE/RUSSELL (1976); CLEMENZ (1986), S. 56 ff.; KOTOWITZ (1987), S.549.

3 Vgl. STIGLITZ/WEISS (1981), S.401 ff.; CLEMENZ (1986), S.64 ff.; TERBERGER (1987), S.81 f., $138 \mathrm{f}$.

4 Vgl. BALTENSBERGER/DEVINNEY (1985), S.493 ff.; WILLIAMSON, St.D. (1986).

5 Vgl. SCHMIDT, R.H. (1981), S.207 ff.; STIGLITZ/WEISS (1983); MATTESINI (1986), S.94 ff.; BESTER (1987), S.231 ff.; KRAHNEN (1988). Darüber hinaus werden eine ganze Reihe weiterer anreizkompatibler Vertragsgestaltungen diskutiert. Vgl. dazu BALTENSBERGER/ DEVINNEY (1985), S.491 ff.; BESTER (1987), S.229 f.; TERBERGER (1987), S.173 ff. 
Dadurch erhöht (reduziert) sich die Kreditsicherheit (Fremdkapitalquote) mit zunehmender Kreditlaufzeit. Eine vollständige Kredittilgung und damit eine vollständige Eigenkapitalfinanzierung wird unter diesen Bedingungen bereits erreicht, wenn der Restwert des zu Investitionszwecken erworbenen Kapitalguts noch positiv ist. Durch eine kontinuierliche Erhöhung der Kreditsicherheit und eine Verminderung der Kreditforderungen vermindern (erhöhen) sich für den Kreditgeber (Kreditnehmer) die Kosten künftig möglicher, schädigender Handlungen ${ }^{1}$. Durch entsprechende Tilgungsregelungen kann zudem der zur Kontrolle des Kreditnehmers erforderliche Ressourceneinsatz weitgehend darauf beschränkt werden, die Einhaltung der periodischen Schuldendienstverpflichtungen zu überwachen. Jedoch ist auch im Falle von Moral hazard eine erstbeste Kreditallokation regelmäßig nicht erreichbar ${ }^{2}$.

Auf dem Kreditversicherungsmarkt führen asymmetrische Informationen ebenfalls zu moral hazard ${ }^{3}$. Es läßt sich zeigen, daß eine Prämienfestsetzung entsprechend dem vom Versicherten gewählten Deckungsgrad als Selbstselektionsmechanismus wirkt, da eine solche Prämiengestaltung einen Anreiz zur Schadensvorsorge beinhaltet ${ }^{4}$. Dadurch kann im Second-best-Optimum auch bei Risikoneutralität des Versicherers im Gegensatz zur Situation mit vollständiger Information eine Teilversicherung des Kreditrisikos gegenüber der Vollversicherung paretosuperior sein ${ }^{5}$. Die Anreizprobleme auf dem Versicherungsmarkt können darüber hinaus durch ein "experience rating" oder durch Ressourceneinsatz zur Informationsgewinnung über die Versicherten vermindert werden ${ }^{6}$. Diese Maßnahmen bewirken jedoch regelmäßig keine erstbeste Risikoallokation ${ }^{7}$.

1 Solche Vertragsgestaltungen entsprechen somit bei asymmetrischer Information der Interessenlage der Kreditgeber. Die Kreditnehmer werden diesen Vertragsgestaltungen zustimmen, obwohl sie bei vollständiger Information eine fristenkongruente Finanzierung präferieren werden, wenn sie dadurch Wohlfahrtsgewinne erzielen können. Vgl. RHYNE (1988), S.93.

2 Vgl. CLEMENZ (1986), S.201; BESTER/HELLWIG (1989), S.143 ff., $157 \mathrm{ff}$.

3 Vgl. HUNTER (1981), S.242 ff.; zu Versicherungen allgemein ARROW (1968); SPENCE/ZECKHAUSER (1971); PAULY (1974); SHAVELL (1979); EISEN (1979), S.118; STRASSL (1988), S.35 ff. Zu den verschiedenen Formen des moral hazard bei Versicherungs-

verhältnissen vgl. EISEN (1979), S.119 f.

4 Vgl. STRASSL (1988), S.272.

5 Vgl. STRASSL (1988), S.79 ff. Zu einer Vollversicherung wird es jedoch auch bei moral hazard um so eher kommen, je risikoaverser der Versicherte und je geringer die Produktivität von Schadensverhütungsmaßnahmen ist. Vgl. STRASSL (1988), S.272.

6 Vgl. McCALL (1987), S.869.

7 Vgl. STRASSL (1988), S.138 ff. 


\section{NORMATIVE BEGRÜNDUNGEN ÖFFENTLICHER KREDITHILFEN}

Im nächsten Schritt soll untersucht werden, wodurch öffentliche Kredithilfen ökonomisch gerechtfertigt werden können, die als gegebene Subventionsinstitutionen staatlich bereitgestellt werden. Interpretiert man Kredithilfen als Instrumente rationaler Wirtschaftspolitik, so erscheinen sie dann als vorteilhaft, wenn damit allokative, distributive oder stabilisatorische Ziele erreicht werden können. Die Notwendigkeit des staatlichen Instrumenteneinsatzes beruht nach dieser Vorstellung auf dem Versagen marktlicher Koordinationsmechanismen bei der Erreichung der angestrebten Ziele. D.h. daß durch den Einsatz von Kredithilfen eine effizientere Ressourcenallokation, eine gerechtere Einkommensverteilung und eine höhere gesamtwirtschaftliche Stabilität erreicht werden soll. Zusätzlich werden öffentliche Kredithilfen auch als Instrument zur Meritorisierung bestimmter Güter ${ }^{1}$ aus übergeordneten Gründen jenseits individueller Präferenzen gerechtfertigt ${ }^{2}$. Ohne darauf näher eingehen zu wollen, besteht dabei die Gefahr, daß die Festlegung meritorischer Bedürfnisse nicht frei ist von Willkür und mit dem Meritorisierungsargument häufig individuelle Interessen verschleiert werden ${ }^{3}$.

Im folgenden wird analysiert, inwieweit im Falle allokativen, distributiven oder stabilisatorischen Marktversagens mit Hilfe öffentlicher Kredithilfen wünschenswerte ökonomische Effekte erzielt werden können. In einem gesonderten Abschnitt wird die übliche Argumentation zur Rechtfertigung von Kredithilfen einer Kritik unterzogen.

\section{Korrektur von allokativem Marktversagen}

Als typische Fälle von allokativem Marktversagen werden im gegebenen Zusammenhang spezifische Kapitalmarktunvollkommenheiten sowie die Existenz externer Effekte und sonstiger Marktstörungen genannt. In diesen Fällen soll mit dem Einsatz öffentlicher Kredithilfen eine Wohlfahrtssteigerung bewirkt werden.

1 Grundlegend dazu MUSGRAVE (1959/1966), S.14 ff. Einen Überblick zur Diskussion meritorischer Güter im Zusammenhang mit Subventionen enthält GRÖBNER (1983), S.81 ff.

2 Vgl. HARTLAND-THUNBERG/CRAWFORD (1982), S.12 ff., die Export-Kredithilfen aus Gründen nationaler Sicherheit für gerechtfertigt halten.

3 Vgl. FOLKERS (1974); GRÖBNER (1983), S.85; FOLKERS (1987b), S.119. 
a. Kapitalmarktunvollkommenheiten

Auf vollkommenen Märkten werden homogene Güter zum einheitlichen Preis gehandelt. Deshalb existiert auf einem vollkommenen Kapitalmarkt ein einheitlicher, gleichgewichtiger Marktzinssatz für Kredite mit demselben Risiko und denselben Transaktionskosten. D.h. umgekehrt, daß unter diesen Bedingungen für Kredite mit unterschiedlichen Risiko- oder Transaktionskosten auch entsprechend unterschiedliche Marktzinssätze gelten.

Kredithilfen können deshalb nicht damit begründet werden, daß beispielsweise Mittelstandskredite nur zu höheren Zinssätzen als Großkredite erhältlich sind, sofern erstere mit höheren Risiken und/oder höheren Kreditverwaltungskosten verbunden sind ${ }^{1}$. Denn eine effiziente Kreditallokation setzt voraus, daß sämtliche Kreditkosten bei der Kredittransaktion internalisiert werden. Ebensowenig genügt in diesem Zusammenhang der Hinweis auf einen "objektiv nachweisbaren Bedarf an langfristigen Krediten zu festen Konditionen", der von den Banken nicht in ausreichendem Maße gedeckt werde ${ }^{2}$. Denn der Bedarf an solchen Krediten ist gerade nicht objektiv gegeben, vielmehr ist die Nachfrage danach eine Funktion des Preises. Wenn sich ein vergleichsweise hoher Gleichgewichtspreis für langfristige Kredite bei relativ geringen Mengen ergibt, dann spricht dies zunächst dafür, daß viele Kreditnachfrager angesichts der Preisrelationen zwischen den Krediten mit unterschiedlicher Laufzeit Kredite mit kürzerer denen mit längerfristiger Laufzeit vorziehen. Eine Ineffizienz der Kreditmärkte ist damit jedoch nicht zu belegen ${ }^{3}$.

Ein anderes Argument bezieht sich auf die Tatsache, daß Zinssätze für staatliche Schuldtitel regelmäßig niedriger sind als für Kredite der besten privaten Risiken ${ }^{4}$. Daraus könnte geschlossen werden, daß der Staat Kredite aufnehmen sollte, um sie dann zu ihrem Einstandszinssatz an private Kreditnehmer weiterzuleiten ${ }^{5}$, weil dadurch Investitionen zu einem niedrigeren Zinssatz finanziert werden könnten und sich somit eine Paretoverbesserung realisieren ließe $\mathrm{e}^{6}$.

Die These, daß aufgrund dieses Zusammenhangs eine "kostenlose" Form der Kredithilfe vorhanden ist, ist jedoch nicht haltbar, weil sich durch die Art der Finanzierung einer

1 Vgl. SCHLESINGER (1987), S.32; RHYNE (1988), S.95.

2 MÜLLER-KÄSTNER (1986), S.12.

3 Vgl. RHYNE (1988), S.95.

4 Dieser Umstand beruht darauf, daß die Bankrottwahrscheinlichkeit bei privaten Kreditnehmern höher ist als beim Staat, da letzterer im Rahmen seiner Besteuerungsgewalt für Kredite unbegrenzt haften kann. Vgl. WAGNER (1983), S.211.

5 Von Transaktionskosten soll hier abgesehen werden.

6 In diesem Sinne wohl MÜLLER-KÄSTNER (1986), S.12. 
Investition ihre sozialen Opportunitätskosten nicht verändern ${ }^{1}$. Deshalb werden bei einer Finanzierung riskanter Projekte mit relativ günstigen staatlichen statt mit marktlichen Krediten lediglich die Risikokosten vom Investor auf die Steuerzahler überwälzt ${ }^{2}$.

Während die bisher genannten Argumente nicht belegen können, daß der Kapitalmarkt Unvollkommenheiten aufweist, die den Einsatz von Kredithilfen rechtfertigen könnten, soll im folgenden analysiert werden, bei welchen Arten von tatsächlichen Kapitalmarktunvollkommenheiten ein Einsatz von Kredithilfen grundsätzlich zu Effizienzsteigerungen führen kann.

\section{aa. Monopolistische Tendenzen auf den Kreditmärkten}

Zur normativen Begründung öffentlicher Kredithilfen wird angeführt, daß kleinere und mittlere Unternehmen allein wegen ihrer schwächeren Verhandlungsposition Kredite nur zu schlechteren Konditionen erhalten können als große Unternehmen ${ }^{3}$. Dieses Argument ist angesichts des zu beobachtenden Wettbewerbs auf dem Bankenmarkt wenig plausibel ${ }^{4}$. Unterstellt man dennoch, daß der Wettbewerb auf dem Bankenmarkt beschränkt ist und dadurch eine Preisdiskriminierung zwischen Krediten für Groß- und Kleinunternehmen möglich wird, so führt dies im Vergleich zu kompetitiven Kreditmärkten regelmäßig zu Wohlfahrtsverlusten ${ }^{5}$. Aber auch in diesem Fall ist es nicht zwingend, daß der Teil der Kreditnachfragerrente, den sich ein preisdiskriminierender Monopolist aneignet, bei kleineren Unternehmen höher ist als bei Großunternehmen. Denn bei Preisdiskriminierung wird der Monopolist für die Nachfrager mit der geringeren Preiselastizität der Nachfrage einen höheren Preis festsetzen ${ }^{6}$. Ob dies für kleinere Unternehmen zutrifft, ist eher zweifelhaft. Insbesondere ist jedoch evident, daß bei Wettbewerbsbeschränkungen auf dem Bankenmarkt der Einsatz wettbewerbspolitischer Instrumente in aller Regel die effizientere Maßnahme darstellen wird als die Vergabe von Kredithilfen?

\footnotetext{
1 Vgl. MCKIE (1963), S.321.

2 Vgl. WAGNER (1983), S.211 f.

3 Vgl. MÜLLER-KÄSTNER (1986), S.12; GOLDSCHMIDT (1987), S.53.

4 So bemühen sich gerade in jüngerer Zeit alle Bankengruppen intensiv darum, gerade auch der mittelständischen Wirtschaft geeignete Finanzdienstleistungen zur Verfügung zu stellen. Vgl. GOLDSCHMIDT (1987), S.51 f. Zur Wettbewerbssituation auf dem Bankenmarkt vgl. GEIGANT (1984), S.559 ff.

5 Geht man vom Monopolfall aus, sind diese Wohlfahrtsverluste bei Preisdiskriminierung jedoch abgesehen vom Fall linearer Kreditnachfragekurven geringer als ohne Preisdiskriminierung, da die Kreditmenge bei Preisdiskriminierung höher ist. Vgl. SCHUMANN (1987), S.255; VARIAN (1989), S.413 f.

6 Vgl. VARIAN (1989), S.412.

7 Vgl. MCKIE (1963), S.340.
} 
bb. Staatliche Regulierung der Kreditmärkte

Unvollkommenheiten der Kreditmärkte können darauf beruhen, daß staatliche Regulierungen bestimmten Gruppen von Kreditinteressenten den Zugang zum Kreditmarkt versperren. So können Gesetze gegen Kreditwucher unter Umständen das Entstehen legaler Märkte für besonders riskante Kredite verhindern ${ }^{1}$. Teilweise existieren Beschränkungen des Bankensektors, so durch das Regionalprinzip bei den Sparkassen in der Bundesrepublik, durch welches die Kapitalmobilität behindert und damit beispielsweise das lokale Kreditangebot beeinträchtigt werden kann. Mit solchen Unvollkommenheiten werden im allgemeinen Agrarkreditprogramme gerechtfertigt ${ }^{2}$. Auch hier ist jedoch zu erwarten, daß die Vergabe von Kredithilfen allenfalls eine suboptimale Reaktion darstellt, da diese Unvollkommenheiten durch geeignete Deregulierungsmaßnahmen beseitigt werden könnten ${ }^{3}$.

cc. Fehlende Kreditsicherheiten für einzelne Gruppen von Kreditnachfragern

Eine andere Form von Kapitalmarktunvollkommenheiten wird darin gesehen, daß für bestimmte Arten von Investitionen der erwartete Investitionsertrag als Kreditsicherheit nicht akzeptiert wird, so daß entsprechende Investitionen ohne vorhandenes Eigenkapital oder andere Kreditsicherheiten nicht finanziert werden können. Als Beispiel gilt einmal die Finanzierung von Humankapitalinvestitionen, bei denen im Fall fehlender Eigenmittel eine Finanzierung durch externes Eigenkapital regelmäßig ausscheidet ${ }^{4}$. Die fehlende Akzeptanz der erwarteten Zukunftseinkünfte als Sicherheit wird damit erklärt, daß sie bei Zahlungsverzug des Kreditnehmers nicht verwertbar ist, da der Gläubiger dem Schuldner keinen Arbeitszwang auferlegen kann ${ }^{5}$. Rationale Kreditgeber werden deshalb Ausbildungsdarlehen allenfalls gegen Zinssätze vergeben, welche entsprechende Risikozuschläge beinhalten. Dadurch werden wiederum zahlreiche potentielle Kreditnachfrager von der Investition in Humankapital abgehalten ${ }^{6}$.

Der zweite typische Fall mangelnder Kreditsicherheiten tritt im Zusammenhang mit Existenzgründungen auf. Es wird argumentiert, daß die Bereitschaft der Banken zur Kreditvergabe zu Kapitalmarktbedingungen bei einer vergleichsweise niedrigen Eigenkapital-

\footnotetext{
Vgl. MCKIE (1963), S.325 f.; STIGLITZ/WEISS (1981), S.393; MANKIW (1986), S.456.

2 Vgl. DAVIE/DUNCOMBE (1971), S.481; BOSWORTH/CARRON/RHYNE (1987), S.7.

3 Vgl. MCKIE (1963), S.340.

4 Vgl. MANKIW (1986), S.457.

5 Dies wäre nur in einem Staat möglich, in dem irgendwelche Formen der Leibeigenschaft zugelassen sind. Vgl. FRIEDMAN (1962), S.102.

6 Vgl. FRIEDMAN (1962), S.102 f.; BECKER, G.S. (1964), S.56; NERLOVE (1972), S.S 184 f.
} 
ausstattung zahlreicher Existenzgründer sowie dem Fehlen dinglicher Sicherheiten in der Regel gering sei, zumal Leistungsdaten aus der Vergangenheit nicht existierten ${ }^{1}$. Deshalb seien viele potentielle Existenzgründer auf staatliche Hilfe angewiesen ${ }^{2}$.

Bei beiden Fallgruppen ist zu beachten, daß unter vollkommener Information eine effiziente Allokation von riskanten Krediten über risikoangepaßte Zinssätze erfolgt. D.h. $\mathrm{da} ß$ aus allokativer Sicht nicht jede Humankapital- oder Gründungsinvestition per se wünschenswert ist. Vielmehr ist es effizient, daß bestimmte riskante Investitionen nicht durchgeführt werden, wenn der entsprechend dem jeweiligen Risiko bewertete Grenzertrag solcher Investitionen ihre Grenzkosten unterschreitet ${ }^{3}$. Weiterhin gilt bei vollkommenen Kapitalmärkten mit symmetrischer Informationsverteilung, daß die Bereitstellung von Kreditsicherheiten, sofern sie mit Kosten verbunden ist, zu Mehrbelastungen führt und damit ineffizient ist ${ }^{4}$. Daher ist das Fehlen von Kreditsicherheiten keine hinreichende Begründung für eine ineffiziente Kreditallokation, die öffentliche Kredithilfen rechtfertigt.

Sofern die Grenzertragsraten bei Humankapital- und Gründungsinvestitionen in systematischer Weise die entsprechenden risikoangepaßten Zinssätze, d.h. die Opportunitätskostenrate, übersteigen ${ }^{5}$, sind dafür andere Faktoren als fehlende Kreditsicherheiten ursächlich. Insbesondere ist $\mathrm{zu}$ beachten, daß bei der überwiegenden Zahl von Investitionen außer einer Fremdkapital- auch eine Eigenkapitalfinanzierung denkbar ist. Führen nun beispielsweise institutionelle Beschränkungen der Eigenkapitalfinanzierung zu einem suboptimalen Ausmaß bestimmmter Investitionen, so läßt sich damit die Änderung von Kapitalmarktbestimmungen rechtfertigen ${ }^{6}$. Die Gewährung von Kredithilfen wäre demgegenüber allenfalls eine zweitbeste Politik.

\section{dd. Fehlendes Kreditversicherungsangebot}

Öffentliche Kreditgewährleistungen werden bisweilen mit dem Fehlen eines hinreichenden marktlichen Kreditversicherungsangebots gerechtfertigt ${ }^{7}$. Dabei wird argumentiert, daß ein fehlendes Kreditversicherungsangebot die Entstehung von Sekundärmärkten für riskante Kreditforderungen behindere und damit deren Liquidität reduziere, was einen

1 Vgl. SCHINKEL/STEINER (1980), S.490; MAY (1981), S.80 f. Siehe auch HERB (1988), S.135.

2 Vgl. SACHVERSTÄNDIGENRAT (1977), S.181.

3 Vgl. KASTROP/BERGMANN (1988), S.320.

4 Vgl. MATTESINI (1986), S.87 ff.; CLEMENZ (1986), S.120; BESTER (1987).

5 Bezüglich der Humankapitalinvestitionen sieht FRIEDMAN (1962), S.101 f. die Unterinvestitionshypothese als bestätigt an.

6 Vgl. HERB (1988), S.203 ff.

7 Vgl. PENNER/SILBER (1972), S.668. 
kompensierenden Anstieg des Zinssatzes oder eine Verkürzung von Kreditlaufzeiten erfordere. Umgekehrt könnten Kreditversicherungen die Handelbarkeit von Kreditforderungen erhöhen und daher zu einer Senkung von Transaktionskosten sowie einer Effizienzsteigerung führen ${ }^{1}$. Diesem Argument ist jedoch entgegenzuhalten, daß die Existenz von Sekundärmärkten keineswegs von dem Risiko der Kreditforderungen abhängt. Vielmehr können riskante Forderungen mit entsprechenden Risikoabschlägen gehandelt werden. Fehlende Sekundärmärkte dürften demnach eher auf institutionelle Hindernisse oder zu hohe Kosten von Sekundärmarkttransaktionen als auf ein fehlendes Kreditversicherungsangebot zurückzuführen sein.

Gleichwohl kann das Fehlen von Kreditversicherungsmärkten zu paretoinferioren Ergebnissen führen, weil dadurch die Diversifikation von unsystematischen Kreditrisiken und ein Risikotausch erschwert sein können. Inwieweit sich daraus Argumente für öffentliche Kredithilfen ergeben, läßt sich nur beantworten, wenn man die Ursachen für das Fehlen eines privaten Versicherungsangebots kennt.

Als mögliche Ursache werden economies of scale bei der Bereitstellung von Kreditversicherungsleistungen genannt ${ }^{2}$, so da 3 der Fall eines natürlichen Monopols ${ }^{3}$ gegeben sei. Selbst wenn man die Existenz von steigenden Skalenerträgen für möglich hält, kann damit lediglich das Fehlen eines kompetitiven Kreditversicherungsangebots begründet werden. Darüber hinaus folgt aus der Existenz natürlicher Monopole keinesfalls generell ein Argument für eine staatliche Erstellung entsprechender Güter, da es aufgrund fehlender Anreize zur Kostenminimierung zu X-Ineffizienzen kommen kann ${ }^{4}$.

Schließlich wird in bezug auf Auslandskredite argumentiert, daß damit politische Kreditrisiken ${ }^{5}$ verbunden seien. Diese seien durch private Anbieter nicht versicherbar, weil bei versicherten Krediten ein erhöhter Anreiz für eine Nichterfüllung der Forderungen durch die Schuldner bestehe ${ }^{6}$. Abgesehen davon, da $B$ es in gewissem Umfang auch ein privates Angebot zur Absicherung politischer Risiken gibt ${ }^{7}$, ist es zweifelhaft, ob im hier angesprochenen Fall des moral hazard bei Schuldnern versicherter Kredite öffentliche Kreditgewährleistungen eine Wohlfahrtssteigerung erwarten lassen ${ }^{8}$. Denn es ist kaum zu

\footnotetext{
Vgl. BOSWORTH/CARRON/RHYNE (1987), S.8.

Vgl. BOSWORTH/CARRON/RHYNE (1987), S.8.

Vgl. allgemein zu natürlichen Monopolen BOADWAY/WILDASIN (1984), S.171 f.

Vgl. LEIBENSTEIN (1966); BOADWAY/WILDASIN (1984), S.173.

Zu den verschiedenen Arten politischer Risiken vgl. HICHERT (1986), S.56, $258 \mathrm{f}$.

6 Vgl. BARON (1983), S.62.

7 Zu nennen wäre hier insbesondere die Lloyd's Versicherung; vgl. BARON (1983), S.62; HICHERT (1986), S.67.

8 Der Aspekt möglicher externer Nutzen bei einer Absicherung politischer Risiken bleibt an dieser Stelle unberücksichtigt.
} 
begründen, da $ß$ der Staat gegenüber privaten Anbietern Vorteile bei der Gestaltung anreizkompatibler Verträge oder bei der Überwachung der Kreditschuldner besitzt ${ }^{1}$.

Aber auch wenn man davon ausgeht, daß die Situation mit einem öffentlichen Gewährleistungsangebot gegenüber der Situation ohne ein Kreditversicherungsangebot paretosuperior ist, ergibt sich daraus keine Rechtfertigung für Gewährleistungsprogramme mit subventionierten Prämien ${ }^{2}$. Weiterhin ist zu beachten, daß Kreditgewährleistungen regelmäßig selektiv vergeben werden. Treten Marktstörungen der genannten Art auch in Bereichen auf, in denen der Staat Aktivitäten unterläßt, so können sich Verzerrungen durch die Beeinflussung der Kreditallokation ergeben, die ihrerseits mit Wohlfahrtsverlusten verbunden $\operatorname{sind}^{3}$.

\section{ee. Fehleinschätzung von Kreditrisiken}

Kredithilfen werden teilweise auch damit gerechtfertigt, daß die privaten Kreditanbieter das Kreditrisiko bei der Finanzierung bestimmter Investitionsarten, wie Humankapital-, Existizenzgründungs- und Innovationsinvestitionen, verglichen mit sonstigen Investitionsarten in systematischer Weise zu hoch einschätzen ${ }^{4}$, so daß die Opportunitätskosten die sozialen Opportunitätskosten der Investoren übersteigen. Dabei handelt es sich um eine typische Second-best-Störung ${ }^{5}$, die dazu führt, daß das Ausmaß solcher Investitionen zu niedrig sein wird.

Wenn man unterstellt, daß der Staat die Überschätzung von Kreditrisiken durch die privaten Kreditanbieter erkennt, kann eine Ausweitung dieser Investitionen aufgrund öffentlicher Kredithilfen dennoch zu Wohlfahrtsverlusten führen. Dies soll mit Hilfe von Abb.1 gezeigt werden. Dabei bezeichnet $r_{0}$ den den marktlichen risikoangepaßten Zinssatz für Existenzgründungskredite $\mathrm{K}$, der aufgrund der Fehleinschätzung des Kreditrisikos durch die privaten Kreditanbieter den Zinssatz $r^{*}$ übersteigt, dessen Höhe dem tatsächlichen Kreditrisiko entspricht. Gewährt nun der Staat einen Zinszuschuß für Existenzgründungsdarlehen in Höhe von $r_{0}-r^{*}$, so läßt sich dadurch ein Wohlfahrtsgewinn in Höhe des Dreiecks abc realisieren. Liegt der Zinszuschuß hingegen bei $r_{0}-r_{1}$, so verursacht der Staat selbst eine Mengenstörung, die in ihrer Höhe bei linearem Verlauf der kompensierten Kreditnachfragekurve genau der Mengenstörung ohne Zinszuschuß entspricht, so daß der

Vgl. BOADWAY/WILDASIN (1984), S.492 f.

Vgl. BARON (1983), S.64.

3 Vgl. PENNER/SILBER (1972), S.668; CHANEY/THAKOR (1985), S.183.

4 Vgl. MCKIE (1963), S.325; DAVIE/DUNCOMBE (1972), S.481; LEONARD (1986), S.104.

5 Grundlegend zur Theorie des Second best LIPSEY/LANCASTER (1956/57). 


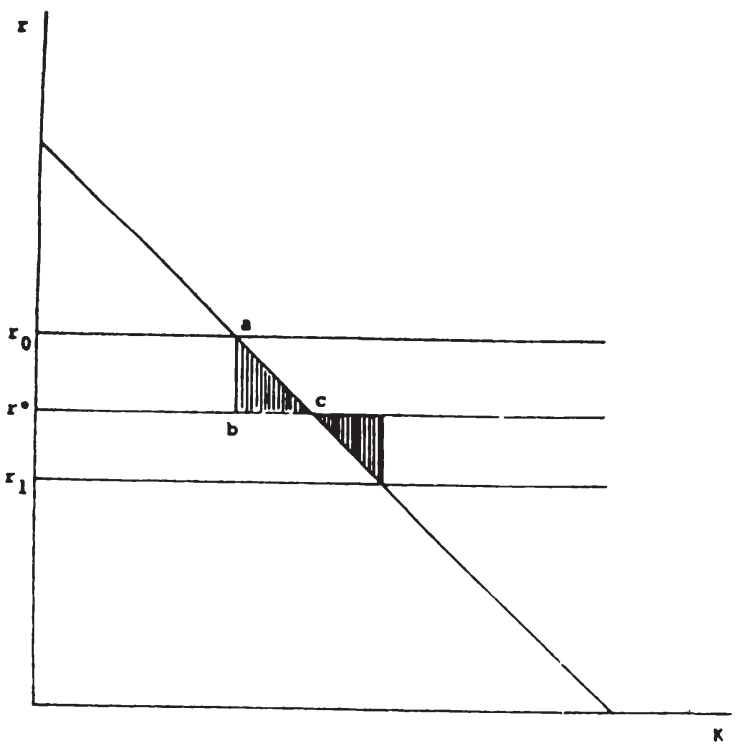

Abb.1

Wohlfahrtsgewinn der Second-best-Maßnahme Null beträgt ${ }^{1}$. Übersteigt der Zinszuschuß den Betrag $r_{0}-r_{1}$, so resultiert aus der Kredithilfe ein Wohlfahrtsverlust, der mit zunehmender Mengenstörung überproportional zunimmt ${ }^{2}$.

Interpretiert man $\mathrm{r}_{1}$ als risikolosen Marktzinssatz und liegt der korrekte risikoangepaßte Zinssatz mit gleicher Wahrscheinlichkeit zwischen $\mathrm{r}_{0}$ und $\mathrm{r}_{1}$, so liegt der erwartete wohlfahrtsoptimale Zinssatz bei $r^{*}$, so daß ein Zinszuschuß von $r_{0}-r^{*}$ bei unterstellter Risikoneutralität der Entscheidungsträger wohlfahrtsoptimal wäre. Demgegenüber resultieren aus jeder Zinsverbilligung, die zu einer Unterschreitung des erwarteten risikoangepaßten Zinssatzes führt, marginale Wohlfahrtsverluste, während eine Zinsverbilligung unter den risikolosen Marktzinssatz zu einem Wohlfahrtsverlust gegen-

1 Dies gilt nur, wenn die Einnahmen zur Finanzierung des Zinszuschusses durch eine Pauschalsteuer erzielt werden. Führt die staatliche Einnahmenerzielung jedoch zu Verzerrungen, so tesultieren Wohlfahrtsverluste bereits bei einem Zinszuschuß von $r_{0}-r_{1}$.

Vgl. FOLKERS (1987b), S.173. 
über dem Verzicht auf eine Zinssubventionierung führt. Selbst wenn man die Richtung der Mengenstörung kennt, sind somit Wohlfahrtsverluste durch Second-best-Kredithilfen nicht auszuschließen ${ }^{1}$.

Es sei nun unterstellt, daß die Fehleinschätzung des Risikos durch die privaten Kreditanbieter nicht dauerhaft ist, weil diese nach einem gewissen Zeitraum die tatsächlichen Risiken wahrnehmen werden. Bieten die privaten Kreditanbieter dementsprechend nach einer "Lernphase" Kredite an, die mit $r$ " verzinslich sind, würde jede weitere staatliche Zinsverbilligung zu Wohlfahrtsverlusten führen. Deshalb sind bei einer falschen Risikoeinschätzung dauerhafte Kredithilfeprogramme in aller Regel allokativ schädlich ${ }^{2}$.

Für staatliche Kreditgewährleistungen gilt entsprechend, daß damit bei einer Risikofehleinschätzung durch private Versicherer demonstriert werden kann, daß entsprechende Versicherungen vorteilhaft sein können. Auch hier gilt jedoch, daß damit nur zeitlich befristete Programme ohne Subventionierung der Prämien gerechtfertigt werden ${ }^{3}$.

\section{ff. Liquiditätsbeschränkungen für bestimmte Kreditnachfrager}

Nach verbreiteter Auffassung sind Kredithilfen dazu geeignet, Liquiditätsmängel bestimmter Kreditnachfrager zu überwinden, welche die Durchführung rentabler Investitionen verhindern ${ }^{4}$. Dem scheint die Vorstellung zugrunde zu liegen, daß die privaten Kreditgeber rentable Investitionen nicht finanzieren, wenn im ungünstigen Umweltzustand eine bestimmte maximale Kreditausfallhöhe überschritten wird. Diese Vorstellung erscheint dann nicht ohne weiteres einsichtig, wenn die Kreditgeber die Kreditrisiken durch Portfoliobildung zumindest teilweise "vernichten" können. Sie ließe sich allenfalls damit begründen, daß den Kreditgebern bei unterstellter vollkommener Information aufgrund rechtlicher Restriktionen die Überschreitung einer festgesetzten maximalen Kreditausfallhöhe untersagt ist. In diesem Fall könnten öffentliche Darlehen und Kreditgewährleistungen mit einem entsprechenden Deckungsgrad dazu eingesetzt werden, um solche Liquiditätsbeschränkungen zu überwinden.

1 Vgl. allgemein zur Möglichkeit von Wohlfahrtstverlusten durch staatliche Second-best-Eingriffe NG (1977); BRENNAN/BUCHANAN (1983); FOLKERS (1987b), S.177 f.; HERB (1988), S. $155 \mathrm{ff}$.

2 In diesem Sinn wohl auch DICKERTMANN (1980), S.526. Siehe auch VAUBEL (1990), S.259, der bei Informationsvorteilen nichtmarktlicher Institutionen gegenüber privaten Kreditgebern dafür plädiert, da $B$ erstere ihre vorhandenen Informationen glaubhaft veröffentlichen.

3 Vgl. BOSWORTH/CARRON/RHYNE (1987), S.8.

4 Vgl. z.B. LÜDER (1984), S.535; DICKERTMANN/HANSMEYER (1987), S.22. 
Weiterhin wird bisweilen unterstellt, daß der Kreditmarkt durch eine Kreditrationierung für bestimmte Gruppen von Kreditnachfragern gekennzeichnet ist. Dadurch werden ihre Kreditwünsche zum gegebenen Marktzinssatz nicht vollständig erfüllt, ohne $\mathrm{da}$ durch die Überschußnachfrage eine markträumende Zinssatzsteigerung hervorgerufen wird $^{1}$. Die Kreditrationierung bewirkt somit eine Liquiditätsbeschränkung von Kreditnachfragern, welche die Durchführung rentabler Investitionen verhindert.

Nach der älteren "availability doctrine $\mathrm{e}^{\text {2 }}$ beruht Kreditrationierung auf einer konjunkturbedingten Einschränkung der Kreditvergabemöglichkeiten des Bankensystems, die nicht durch entsprechende Zinssteigerungen ausgeglichen werden. Dadurch erfolgt die Kreditallokation nach Kriterien, die bestimmte Kreditnachfrager diskriminieren können ${ }^{3}$. In einer weiteren Variante der "availability doctrine" wird darauf abgestellt, daß die individuelle Kreditangebotskurve von einer bestimmten Kreditmenge an vollkommen unelastisch wird, wenn nämlich die Kreditverbindlichkeiten dem Maximalertrag von kreditfinanzierten Investitionen entsprechen ${ }^{4}$. Allerdings genügt die Annahme einer unelastischen Kreditangebotskurve für die Annahme einer Kreditrationierung nicht, da diese das Bestehen einer Überschußnachfrage erfordert ${ }^{5}$. Außerdem wäre es allokativ verfehlt, durch öffentliche Kredithilfen Investitionen zu ermöglichen, deren Kosten über ihrem Ertrag liegen.

Überzeugender ist daher eine Rechtfertigung öffentlicher Kredithilfen mit einer informationsbedingten Kreditrationierung ${ }^{6}$. Die Argumentation soll anhand des in Abschnitt C.I.4.a. verwendeten Modells der Kreditrationierung bei adverser Selektion verdeutlicht werden. Dort wurde gezeigt, daß nur die schlechtesten Kreditrisiken Kredite nachfragen und andere effiziente Investitionen über den Kreditmarkt verdrängt werden, sofern der erwartete Brutto-Investitionsertrag $\mathbf{R}$ für die besten Risiken kleiner ist als die erwarteten individuellen Kreditverbindlichkeiten $\left(1-\mathrm{p}^{\mathrm{i}}\right)(1+\mathrm{i})$.

Um die informationsbedingte Ineffizienz zu vermeiden, wird vorgeschlagen, daß der Staat Kredithilfen in einem Umfang gewährt, bei dem auch für die besten Risiken der erwartete Investitionsertrag mindestens die erwarteten Kreditkosten deckt. D.h. die Höhe der Subventionen $S$ muß so festgelegt werden, da $\beta$ auch für die Investoren mit dem geringsten Investitionsrisiko mindestens $R+S=\left(1-p^{i}\right)\left(1+i^{\prime}\right)$ gilt, wobei $i$ ' den Kreditzinssatz bei Subventionierung bezeichnet. Die Subventionierung kann dabei in Form von Kredit-

1 Vgl. MCKIE (1963), S.324.

2 Vgl. ROOSA (1951); SCOTT (1957).

3 Vgl. MCKIE (1963), S.326. Beispielhaft genannt wird die Diskriminierung neuer gegenüber alten Kreditkunden durch die Banken.

4 Vgl. HODGMAN (1960).

5 Vgl. CLEMENZ (1986), S.21; MATTESINI (1986), S.10.

6 Vgl. MANKIW (1986), S.456 f. 
hilfen erfolgen. Wenn der Staat die individuellen Investitionsrisiken ebenfalls nicht identifizieren kann, muß er die Subventionshöhe für alle Kreditnachfrager in gleicher Höhe festsetzen, will er ein Ausscheiden der besten Risiken aus dem Markt ausschließen. Es soll nun angenommen werden, daß die risikoärmsten Investitionen risikolos sind, d.h. daß $p^{i}$ Null beträgt.

Gewährt der Staat einen Zinszuschuß mit dem Zuschußsatz z, so betragen die Subventionsausgaben für den einzelnen Investor

$$
z=(1+r)-(1-\pi) R^{1} \text {. }
$$

Wird statt des Zinszuschusses ein öffentliches Darlehen gewährt, so muß sein Zinssatz dem Brutto-Investitionsertrag $R$ entsprechen. Die durchschnittliche Zinsverbilligung je Krediteinheit stimmt dabei mit der Höhe des Zinszuschusses überein.

Als nächstes soll eine entgeltlose Kreditgewährleistung betrachtet werden. Thr Deckungsgrad $D$ muß dabei so hoch sein, daß $1+i^{*}=R$ gilt, wobei $i^{*}$ den nominalen Kreditzinssatz bei Vergabe von Kreditgewährleistungen bezeichnet. Diese Bedingung ist erfüllt, wenn der Kreditgeber zwischen einem Kredit an die betreffenden Kreditnachfrager und einer risikolosen Alternativanlage indifferent ist. Es muß also gelten:

$$
(1-\pi) \mathrm{R}+\pi \mathrm{DR}=1+\mathrm{r},
$$

wobei $\pi \mathrm{DR}$ den Erwartungswert der durchschnittlichen staatlichen Schadensleistung je Krediteinheit bezeichnet.

Aus (C.II.2) folgt:

$$
\begin{aligned}
& \mathrm{D}=[(1+r)-(1-\pi) \mathrm{R}] / \pi \mathrm{R} \text { bzw. } \\
& \pi \mathrm{DR}=(1+\mathrm{r})-(1-\pi) \mathrm{R} .
\end{aligned}
$$

D.h. daß bei allen Kredithilfeformen mit denselben erwarteten Subventionsausgaben dieselben Effekte erzielt werden können. Der erwartete Wohlfahrtsgewinn der durch die öffentlichen Kredithilfen induzierten Investitionen beträgt für jede Einheit $R-(1+r)$.

Es muß jedoch berücksichtigt werden, daß auch bei asymmetrischer Information marktliche Reaktionen möglich sind, die zu einer Verminderung des Ausmaßes adverser Selektion führen können. Im vorgestellten Modell würde der adverse Selektionseffekt im

1 Für die Investoren mit $p^{i}=0$ muB gelten: $R+z \geq(1+r-\pi z) /(1-\pi)$. Dieses Ergebnis folgt daraus, da $B$ der Kreditrückfluß der Kreditgeber bei einer Subventionierung der Kreditnehmer durch Zinszuschüsse im ungünstigen Umweltzustand von Null auf $z$ steigt. Demnach folgt: $\left(1+i^{\prime}\right)=(1+r-\pi z) /(1-\pi)$, wobei $i^{\prime}$ den aufgrund des Zinszuschusses veränderten nominalen Kreditzinssatz bezeichnet. 
Hinblick auf die Investitionen vollständig verschwinden, wenn die Investoren auf eine Eigenkapitalfinanzierung ausweichen könnten, da dann jede Investition wegen $R>1+r$ durchgeführt würde, weil die Investoren als Eigenkapitalgeber annahmegemäß das Projektrisiko kennen. Im Vergleich dazu würden Kredithilfen, die durch verzerrende Steuern finanziert werden, stets zu einer Paretoverschlechterung führen.

Insgesamt ist zu erwarten, daß die Gewährung öffentlicher Kredithilfen bei asymmetrischer Information nur in relativ wenigen Fällen, am ehesten bei einmaligen Investitionen oder bei fehlendem Eigenkapital bzw. fehlenden Kreditsicherheiten, zur Verhinderung adverser Selektion erforderlich ist und gegenüber dem marktlichen Ergebnis eine Wohlfahrtssteigerung bewirkt. Am ehesten dürfte diese Art der Rechtfertigung auf Ausbildungsund Existenzgründungs-Kredithilfen zutreffen.

Eine andere Argumentation ist im Hinblick auf moral hazard denkbar. Werden aus diesem Grund lediglich Kreditverträge angeboten, die von Beginn der Kreditlaufzeit an Schuldendienstzahlungen vorsehen, so resultieren daraus für den Kreditnehmer auch im Falle rentabler Investitionen Periodenrestriktionen. Diese führen bei vergleichsweise niedrigem anfänglichem Periodeneinkommen und Anfangsvermögen zu einer informationsbedingten Liquiditätsbeschränkung für rentable Investitionen. Mit solchen Überlegungen ließen sich beispielsweise Kredithilfen für Bildungsinvestitionen oder Wohnungsbauinvestitionen für junge Familien begründen. Allerdings bleibt dann unklar, inwieweit die Kosten des moral hazard, die annahmegemäß die Ursache für entsprechende Kreditvertragsgestaltungen sind und im Falle der Kredithilfen vom Steuerzahler zu tragen $\operatorname{sind}^{1}$, den mit der Durchführung rentabler Investitionen verbundenen Wohlfahrtssteigerungen entgegenwirken.

\section{b. Allokatives Marktversagen auf Gütermärkten}

Öffentliche Kredithilfen werden auch damit gerechtfertigt, daß auf Gütermärkten Störungen auftreten können, die eine effiziente Ressourcenallokation verhindern. Dazu gehören externe Effekte, steigende Skalenerträge und sonstige nicht behebbare Marktstörungen, die im folgenden näher betrachtet werden sollen.

1 Denn der Staat wird mit denselben Informationsproblemen konfrontiert wie private Kreditgeber bzw. -versicherer. Vgl. SANDMO (1990), S.150. 


\section{aa. Externe Effekte}

Von realen externen Effekten ${ }^{1}$ spricht man dann, wenn ökonomische Aktivitäten eines Haushalts oder Unternehmens den Nutzen oder die Produktionsmöglichkeiten von Dritten beeinflussen, ohne daß sich dies in den Marktpreisen auswirkt. Dadurch fehlt dem Wirtschaftssubjekt, das durch seine Aktivitäten externe Effekte erzeugt, der Anreiz, die für Dritte nützlichen oder schädlichen Effekte in seinem Kalkül zu berücksichtigen. Daraus resultieren volkswirtschaftliche Fehlallokationen, die in einem ineffizient hohen bzw. niedrigen Niveau entsprechender Aktivitäten zum Ausdruck kommen².

Zur Rechtfertigung öffentlicher Kredithilfen wird nun argumentiert, daß damit durch Senkung von Kapitalkosten ${ }^{3}$ eine Internalisierung positiver externer Effekte ${ }^{4}$ erzielt werden könne, die eine Ausweitung von im Marktprozeß suboptimal durchgeführter Aktivitäten und eine Wohlfahrtssteigerung bewirkt. Im Paretooptimum muß der auf die Mengeneinheiten der geförderten Aktivitäten bezogene marginale Vergünstigungssatz den marginalen externen Nutzen entsprechen.

Diesen Internalisierungs-Kredithilfen wird wohl die Mehrzahl aller öffentlichen Kredithilfen zugerechnet. Dies gilt für Kredithilfen in den Bereichen Ausbildung, Umweltschutz und Wohnraumversorgung 5 . Darüber hinaus werden Regionalhilfen als Mittel zur Verminderung externer Agglomerationskosten betrachtet ${ }^{6}$. Die Aktivitäten mittelständischer Unternehmen sollen eine höhere Wettbewerbsintensität als positive Externalität erzeugen, die durch Kredithilfen zu internalisieren sei $^{7}$. Außerdem werden auch "Rettungs-

1 Davon sind die pekuniären externen Effekten zu unterscheiden. Als pekuniäre externe Effekte werden solche Externalitäten bezeichnet, die aus der Beeinflussung der "marktlichen Umgebung" des betroffenen Wirtschaftssubjektes, nämlich der Änderung von Preisen für Outputs und Inputs, resultieren. Aus wohlfahrtsökonomischer Sicht können die pekuniären Externalitäten im Hinblick auf wirtschaftspolitische Eingriffe vernachlässigt werden, weil angenommen wird, daß die Marktkräfte in Richtung auf eine Überkompensation möglicher Verluste durch mögliche Gewinne wirken. Vgl. BUCHANAN/FAITH (1981), S.102 ff., die jedoch zu Recht darauf hinweisen, daß eine präzise analytische Abgrenzung beider Arten von Externalitäten noch aussteht.

2 Vgl. BOADWAY/WILDASIN (1984), S.105.

3 Die Kapitalkostensenkung soll üblicherweise durch eine Verbilligung von Zins- bzw. Prämiensätzen bei Kredithilfen in Relation zu den marktlichen Entgelten erfolgen.

4 Diese positiven externen Effekte können auch in einer Verminderung negativer externer Effekte bestehen, da Kosten negative Nutzen darstellen und umgekehrt.

5 Vgl. DAVIE/DUNCOMBE (1972), S.481; NERLOVE (1972), S.S191 ff.; PENNER/SILBER (1973), S.838; PLANTES/SMALL (1981), S.15.; BOSWORTH/CARRON/RHYNE (1987), S.9.

6 Vgl. GOLDSCHMIDT (1987), S.149.

7 Vgl. GOLDSCHMIDT (1987), S.43. 
Kredithilfen" für konkursreife Unternehmen, die meist als Bürgschaften gewährt werden, mit externen Effekten gerechtfertigt ${ }^{1}$.

Es bleibt allerdings fraglich, inwieweit mit solchen Internalisierungs-Kredithilfen tatsächlich Wohlfahrtssteigerungen realisiert werden können ${ }^{2}$. So erfordert die Festlegung optimaler Kredithilfen ein überaus hohes $\mathrm{MaB}$ an Informationen. Daher müssen die paretooptimalen Preis-Mengen-Kombinationen ex ante bekannt sein. Dies impliziert die Ex-ante-Kenntnis der relevanten privaten und sozialen Nachfrage- und Angebotsfunktionen. Da sich die individuellen Präferenzen sowie Produktions- und Finanzierungsmöglichkeiten jedoch erst in den realisierten Aktivitäten konkretisieren, sind die entsprechenden Größen ex ante kaum bestimmbar. Da Investitions-Kredithilfen an den Inputfaktor Kapital anknüpfen, können dadurch die Faktorpreisrelationen und damit auch die gewählten Produktionsbedingungen verändert werden, was die Bestimmung der optimalen Vergünstigungshöhe zusätzlich erschwert. Wird die Vergünstigungshöhe jedoch vor dem Hintergrund geringer Information festgelegt, so nimmt die Wahrscheinlichkeit von Wohlfahrtsverlusten mit steigendem marginalen Vergünstigungssatz zu.

Außerdem können Kredithilfen, die zur Internalisierung externer Kosten eingesetzt werden, bei entsprechenden Vergabebedingungen statt einer Reduzierung der Externalitäten verursachenden Aktivitäten deren Ausweitung induzieren. Dies kann mit einem einfachen Beispiel gezeigt werden. Es sei unterstellt, daß eine Gruppe von Produzenten das Gut $\mathrm{X}$ herstellen, bei dessen Produktion das Kuppelprodukt $\mathrm{Y}$ anfällt, das bei den Produzenten anderer Güter externe Produktionskosten verursacht. Werden nun Kredithilfen eingesetzt, um die Menge von Y unter ein staatlich festgesetztes Niveau Y' zu senken, so resultiert daraus wegen der Abweichung vom Produktionsoptimum ein Anstieg der Grenzkosten und somit bei gegegebenen Outputpreisen ein Rückgang des Angebots von X. Da andererseits durch die Kredithilfen die Durchschnittskosten sinken, können die ursprünglichen Anbieter Gewinne realisieren, die jedoch bei freiem Marktzutritt auf längere Sicht durch zusätzliche Anbieter von X wegkonkurriert werden. Damit kann aber der Fall eintreten, daß die Produktion von $X$ und damit von $Y$ über das Ausmaß ohne Kredithilfe hinaus steigt, sofern auch die zusätzlichen Anbieter die Kredithilfe erhalten. Unter diesen Bedingungen bewirken Kredithilfen über alle Anbieter betrachtet eine Erhöhung externer Kosten ${ }^{3}$.

1 Vgl. SCHLECHT (1982), S.427. ZINN (1982), S.430 f. Dabei wird offenkundig unterstellt, daß bei konkursreifen Großunternehmen die externen Kosten eines Konkurses relativ höher sind als bei kleineren Unternehmen, da eine generelle Vermeidung von Konkursen durch staatliche Intervention regelmäßig nicht gefordert wird. Dagegen ZEITEL (1982).

2
Zum analogen Fall der Internalisierungssteuern vgl. FOLKERS (1987
Vgl. TRESCH (1981), S.148 ff.; BAUMOL/OATES (1988), S. 218 ff. 
Berücksichtigt man zusätzlich die Kosten der Finanzierung öffentlicher Kredithilfen und ihre Rückwirkungen auf andere Märkte, so dürften sie in zahlreichen Fällen ihre Optimalitätseigenschaften verlieren. Daher wird die Verwendbarkeit von InternalisierungsKredithilfen zur Allokationsverbesserung zumindest außerordentlich eingeschränkt ${ }^{1}$. Darüber hinaus bleibt die Frage offen, weshalb bei wohlfahrtsökonomisch sinnvollen staatlichen Internalisierungsmaßnahmen Kredithilfen anderen Subventionsformen überlegen sein sollen.

\section{bb. Sinkende Durchschnittskosten}

Eine Wohlfahrtssteigerung durch öffentliche Kredithilfen ist auch bei natürlichen Monopolen denkbar. Diese sind durch Produktionstechnologien mit hohen fixen Kapitalkosten gekennzeichnet. Dadurch ergeben sich bis zu hohen Outputniveaus steigende Skalenerträge bzw. sinkende Durchschnittskosten. Schneidet die Nachfragekurve die Durchschnittskostenkurve in deren fallendem Bereich, so kann der Output durch einen einzelnen Produzenten zu geringeren Kosten angeboten werden als durch eine Vielzahl kleiner Produzenten mit identischer Produktionsfunktion. Dadurch kommt es hier regelmäßig zu einem Monopolangebot. Ist dem Monopolisten Gewinnmaximierung gestattet, so wird er seinen Output zu Cournotpreisen anbieten, woraus dann die für den Monopolfall typischen Wohlfahrtsverluste resultieren. Wohlfahrtsverluste geringeren Ausmaßes ergeben sich, wenn der Monopolist durch staatliche Regulierung zu einem Angebot zu Durchschnittskosten verpflichtet ist. Darf hingegen der Outputpreis seine Grenzkosten bei der paretooptimalen Menge, die durch den Schnittpunkt der Nachfrage- und der Grenzkostenkurve bestimmt ist, nicht überschreiten, so erleidet der Anbieter einen Verlust und wird daher den Rückzug aus dem Markt vorziehen².

Durch die Gewährung von Kredithilfen für natürliche Monopole können die fixen Kapitalkosten gesenkt werden ${ }^{3}$. Dadurch werden die totalen Durchschnittskosten für jede Outputmenge reduziert. Außerdem wird das Minimum der totalen Durchschnittskosten bei einer geringeren Menge realisiert ${ }^{4}$. Soll durch die Kredithilfen eine Optimallösung erreicht werden, so muß das Minimum der totalen Durchschnittskosten genau im Schnittpunkt der

\footnotetext{
So auch BOSWORTH/CARRON/RHYNE (1987), S.9 f.

Vgl. BROWNING/BROWNING (1989), S.364 ff.

Vgl. SHOUP (1972), S.70.

Dies wird unmittelbar einsichtig, wenn die Kredithilfen die Fixkosten auf Null reduzieren. Dadurch fallen die totalen und variablen Durchschnittskosten zusammen. Bei positiven Fixkosten ergibt sich das Minimum der variablen Durchschnittskosten dagegen stets bei einer geringeren Menge als das Minimum der totalen Durchschnittskosten. Vgl. SCHUMANN (1987), S.134.
} 
Nachfragekurve und der Grenzkostenkurve des Anbieters liegen. Unter diesen Bedingungen wird der Monopolist auch bei vorgeschriebenen Grenzkostenpreisen seine Kosten decken. D.h. daß bei Kombination einer Preisregulierung mit öffentlichen Kredithilfen eine Mengenausweitung gegenüber der unregulierten Monopolpreisbildung oder auch gegenüber einer vorgeschriebenen Durchschnittspreisbildung resultieren kann. Damit verschwindet die andernfalls zu verzeichnende Mehrbelastung. Auf diese Weise könnten beispielsweise Kredithilfen für die Elektrizitätswirtschaft gerechtfertigt werden ${ }^{1}$, weil die Elektrizitätsversorgung als typischer Fall eines natürlichen Monopols gilt ${ }^{2}$. Allerdings können Kredithilfen dadurch zu Effizienzverlusten führen, daß sie einen Anreiz zur Erhöhung der Fixkosten und damit zur Abweichung von der Minimalkostenkombination bewirken ${ }^{3}$.

\section{cc. Sonstige Marktstörungen}

Öffentliche Kredithilfen werden schließlich als Second-best-Maßnahmen bei nicht behebbaren Störungen auf anderen Märkten als dem Kreditmarkt gerechtfertigt ${ }^{4}$. So wird bei Export-Kredithilfen argumentiert, daß ein Land, dessen Weltmarktkonkurrenten Exporte in Drittländer subventionieren, eigene Exporte ebenfalls subventionieren muß, um Unterinvestitionen im Exportsektor des betreffenden Landes zu vermeiden ${ }^{5}$. Wenngleich die Subventionierung eigener Exporte zu Wohlfahrtsverlusten im Vergleich zu perfekt funktionierenden Weltmärkten führt, läßt sich dadurch bei vollkommener Information eine Paretoverbesserung erreichen, sofern Exportsubventionen anderer Länder nicht vermeidbar sind ${ }^{6}$. Rückt man jedoch von der Annahme vollkommener Information ab, so kann wie bei allen Second-best-Politiken leicht der Fall eintreten, da $B$ der Erwartungswert der Wohlfahrtsänderung durch Exportsubventionen negativ wird, so daß ein Verzicht darauf vielfach allokativ vorteilhaft sein wird ${ }^{7}$.

Andererseits werden Exportsubventionen eines Landes als Sanktionsmittel betrachtet, um die Konkurrenzländer zur Aufgabe ihrer Subventionspraktiken zu zwingen ${ }^{8}$. Diesem Argument liegt eine Modellierung des internationalen "Subventionswettlaufs" als

1 So hat der Freistaat Bayern immer wieder Bürgschaften für Kredite der Energieversorgungsunternehmen übernommen. Vgl. z.B. BAYERISCHE LANDESANSTALT FUR AUFBAUFINANZIERUNG (1976), S.40.

2 Vgl. SCHUMANN (1987), S.259.

3 Vgl. BROWNING/BROWNING (1989), S.368.

4 Grundlegend zur Theorie des Second best LIPSEY/LANCASTER (1956/57).

5 Vgl. BARON (1983), S.83.

6 Vgl. HARTLAND-THUNBERG/CRAWFORD (1982), S.8 f.

7 Vgl. BRENNAN/MCGUIRE (1975); NG (1977); FOLKERS (1987b), S.171 ff.

8 Vgl. CONGRESSIONAL BUDGET OFFICE (1981a), S.9; BARON (1983), S.84. 
Gefangenendilemma zugrunde ${ }^{1}$. Dabei führt ein kollektiver Verzicht auf Exportsubventionen zu einer Nutzenmaximierung der gesamten Gruppe der Exportländer. Eine Übereinkunft über einen solchen Verzicht ist deshalb wohlfahrtssteigernd. Allerdings kann jedes einzelne Exportland die eigene Position zu Lasten der ganzen Gruppe verbessern, wenn es sich nichtkooperativ verhält und als einziges Exportsubventionierung betreibt. Die Exportsubventionierung wird dadurch zum Negativsummenspiel. Durch nichtkooperatives Verhalten können die kooperationsbereiten Gruppenmitglieder das betreffende Land bestrafen und es somit in anschließenden Spielrunden zwingen, sich künftig ebenfalls kooperativ zu verhalten ${ }^{2}$. Interpretiert man Export-Kredithilfen einzelner Exportländer als Sanktionsmittel, so war diese Strategie in den vergangenen Jahren in gewissem Umfang erfolgreich, da z.B. die Regeln des sogenannten OECD-Konsensus über Exportkredite verschärft wurden ${ }^{3}$. Daß eine Übereinkunft über ein vollständiges Verbot von Export-Kredithilfen bislang nicht zustandegekommen ist, kann damit zusammenhängen, daß die Grenzkosten der erforderlichen Sanktionen zur Durchsetzung eines solchen Verbots ihren Grenzertrag übersteigen und ein solches Verbot daher nicht zu einem paretooptimalen Ergebnis führen würde ${ }^{4}$. Somit können Export-Kredithilfen als Sanktionsinstrumente ökonomisch sinnvoll sein, auch wenn sie keine Wohlfahrtsverbesserung im Sinne einer Secondbest-Politik bewirken. Dies gilt allerdings dann nicht, wenn eine Exportsubventionierung unabhängig davon gewährt wird, ob die Weltmarktkonkurrenten zu einem Subventionsverzicht bereit sind oder nicht 5 .

\section{Reduzierung von Einkommensdisparitäten und Absicherung sozialer Hărtefălle}

Außer den genannten allokativen Argumenten werden öffentliche Kredithilfen jenseits wohlfahrtsökonomischer Überlegungen verteilungs- und sozialpolitisch gerechtfertigt. Aus verteilungspolitischer Sicht wird argumentiert, da $B$ marktliche Redistributionsprozesse $^{6}$ nicht ausreichen, um eine wünschenswerte Einkommensverteilung sicherzustellen. Zur Erfüllung der daraus resultierenden Umverteilungsaufgabe des Staates können u.a.

1 Eine entsprechende Argumentation wäre auch in bezug auf die Subventionskonkurrenz zwischen den einzelnen Kommunen bzw. Bundesländern denkbar. Vgl. GRÖBNER (1983), S.182.

2 Zur analogen Gefangenendilemma-Situation bei der Bereitstellung öffentlicher Güter vgl. MUELLER (1979), S.14 ff.

3 Vgl. BARON (1983), S.306 ff.; OECD (1987), S.7 ff. und oben Abschnitt B.IV.

4 Dementsprechend ist eine Reduzierung der Zahl von Verbrechen auf Null regelmäBig nicht paretooptimal, weil in dieser Situation die Grenzkosten von Strafen ihren Grenzertrag übersteigen. Vgl. BECKER, G.S. (1982), S.52 ff.

5 Vgl. CONGRESSIONAL BUDGET OFFICE (1981a), S.9 f.; BARON (1983), S.311.

6 Zum Konzept der paretooptimalen Umverteilung vgl. HOCHMAN/ROGERS (1969) 
öffentliche Kredithilfen eingesetzt werden. Das Ziel redistributiver Kredithilfen besteht danach nicht in einer Änderung des ökonomischen Verhaltens der Empfänger, sondern in der Übertragung von Einkommen ${ }^{1}$. Dementsprechend wird der Kreis der Anspruchsberechtigten durch politisch festgelegte Einkommensgrenzen bestimmt. Außerdem müssen redistributiv motivierte Kredithilfen, die als Darlehen oder Gewährleistungen vergeben werden, eine Zins- bzw. Prämiensatzverbilligung gegenüber den Marktkonditionen enthalten, um einen Einkommenstransfer zu bewirken ${ }^{2}$. Zu dieser Kategorie werden beispielsweise Kredithilfen für einzelne Regionen, für bestimmte Wirtschaftssektoren wie die Landwirtschaft, zur Ausbildungs- und Wohnungsbauförderung und zur Behebung von Katastrophenschäden gerechnet ${ }^{3}$.

Werden mit Kredithilfen spezielle Umverteilungsziele verfolgt, so stellt sich bei den einzelnen Maßnahmen nicht die Frage, ob umverteilt werden soll, sondern vielmehr ob Kredithilfen die geeignete Form der Umverteilung darstellen. Dabei kommt es darauf an, ob die aus Kredithilfen resultierenden Verteilungseffekte im Sinne der Umverteilungszielsetzung erwünscht sind. Diese Frage erfordert jedoch eine eine positive Wirkungsanalyse von Kredithilfen, die in den nächsten beiden Abschnitten folgen soll.

Allerdings sind Kredithilfeprogramme oftmals so konzipiert, daß sie von vornherein eine Begünstigung der unteren Einkommensschichten nicht erwarten lassen. Beispielsweise setzt die Finanzierung eines Eigenheims, auch wenn sie gegenüber den Marktkonditionen verbilligt ist, ein bestimmtes Lebenszeiteinkommen bzw. Vermögen voraus, um die Kreditsumme zurückzahlen zu können ${ }^{4}$. Damit scheiden jedoch gerade die Bezieher mit den geringsten Lebenszeiteinkommen aus dem Kreis der möglichen Empfänger aus. Da die Anspruchsberechtigung für Kredithilfen von der Höhe des aktuellen Perioden- statt Lebenszeiteinkommens abhängt, werden tendenziell auch die Gruppen begünstigt, deren Periodeneinkommen ausgehend von einem vergleichsweise niedrigen Niveau im Verlauf der Lebenszeit relativ steil ansteigt. Deshalb kann bereits an dieser Stelle festgestellt werden, da $B$ bei zahlreichen Kredithilfen eine auf Umverteilungsüberlegungen basierende Begründung wenig überzeugend ist ${ }^{5}$.

1 Vgl. BOSWORTH/CARRON/RHYNE (1987), S.10.

2 Vgl. WESTON (1963), S.613.

3 Vgl. WESTON (1963), S.613; AARON (1972b), S.9; HARTMAN, R.W. (1971), S.3; BOSWORTH/CARRON/RHYNE (1987), S.10; GOLDSCHMIDT (1987), S.149.

4 Dementsprechend werden in den Wohnungsbauprogrammen in der Bundesrepublik bei der Eigentumsforderung zum Zeitpunkt des Erwerbs eine anteilige Eigenkapitalfinanzierung sowie die "Tragbarkeit der Belastung" des Schuldendienstes als Fördervoraussetzung genannt. Vgl. INNENMINISTERIUM BADEN-WÜRTTEMBERG (1989). Vgl. AARON (1972b), S.11. 
Eine räumliche Umverteilungszielsetzung wird häufig mit speziellen Regionalprogrammen verfolgt. Dabei werden entsprechende Kredithilfen als geeignete Maßnahmen zur Erhöhung der regionalen Beschäftigung und des Arbeitseinkommens betrachtet, wenn bei gegebenem Lohnsatz ein Arbeitsangebotsüberschuß besteht ${ }^{1}$. In diesem Fall soll durch öffentliche Investitions-Kredithilfen die regionale Kapitalausstattung und damit die Grenzproduktivität der Arbeit erhöht werden. Nimmt die regionale Kapitalausstattung aufgrund von Kredithilfen tatsächlich zu, so kann dies bei gegebenem Lohnsatz zu einer Ausweitung der regionalen Beschäftigung führen ${ }^{2}$. Wie noch gezeigt wird, kann dieser Beschäftigungseffekt jedoch konterkariert werden, weil durch Kredithilfen die Faktorpreisrelationen verzerrt werden ${ }^{3}$. Außerdem wird bei angebotsseitig bedingter Unterbeschäftigung, die z.B. durch staatliche Mindestlohnvorschriften oder einheitliche, nicht an unterschiedliche regionale Grenzproduktivitäten angepaßte Tarifverträge verursacht sein $\mathbf{k a n n}^{4}$, eine Beseitigung der Unterbeschäftigungsursachen im Hinblick die verfolgte Zielsetzung regelmäßig einen höheren Zielerreichungsgrad erwarten lassen als die Gewährung von Kredithilfen. So können andere Formen der Subventionierung, wie z.B. die Gewährung von Lohnsatzsubventionen oder Maßnahmen zur Mobilitätsförderung gegenüber Kredithilfen für Investitionen überlegen $\operatorname{sein}^{5}$.

Kredithilfen werden sozialpolitisch begründet, wenn ohne staatliche Intervention für bestimmte Bevölkerungsgruppen als unzumutbar erachtete soziale Härten entstehen würden. Dieses Argument wird stets in bezug auf Kredithilfen verwendet, die als Erhaltungssubventionen zu klassifizieren sind ${ }^{6}$. Es ist sicherlich richtig, da $B$ die bei einem Verzicht auf Erhaltungssubventionen ablaufenden strukturellen Anpassungsprozesse zu erheblichen sozialen Härten für die betroffenen Arbeitnehmer führen können. Da Erhaltungshilfen jedoch die aufgrund der Marktverhältnisse gebotenen Anpassungsprozesse verzögern oder gar überkommene Strukturen konservieren, führen sie zu einer ineffizienten Ressourcenallokation sowie längerfristig zu Wachstumsverlusten und damit zu erheblichen volkswirtschaftlichen Kosten ${ }^{7}$. Damit dürften direkte Einkommensübertragungen an die Beschäftigten strukturschwacher Sektoren regelmäßig eine günstigere Nutzen-KostenRelation versprechen als die Berücksichtigung sozialer Belange durch Erhaltungshilfen.

\footnotetext{
Vgl. GOLDSCHMIDT (1987), S.152.

Vgl. DORNBUSCH/FISCHER (1989), S.409.

3 Vgl. unten Abschnitt C.III.3.

4 Vgl. BUCHANAN/MOES (1960), S.434.

5 Vgl. BUCHANAN/MOES (1960), S.435 f.

6 Vgl. SUBVENTIONSBERICHT (1985), S.6.

7 Vgl. z.B. PEFFEKOVEN (1988), S.489; KLEMP (1990), S.91. Siehe auch HANSMEYER (1977), S.982.
} 
Dies gilt um so mehr, wenn Erhaltungshilfen zeitlich unbegrenzt gewährt werden und damit zu Dauersubventionen werden.

\section{Behebung gesamtwirtschaftlicher Ungleichgewichte}

Insbesondere im älteren Schrifttum werden öffentliche Kredithilfen auch als stabilitätspolitische Instrumente diskutiert ${ }^{1}$. Ausgangspunkt dieser Überlegungen sind keynesianische Vorstellungen über die Wirksamkeit staatlicher Fiskalpolitik in nachfragebedingten Unterbeschäftigungssituationen. Kredithilfen sollen dabei eine Ausdehnung der gesamtwirtschaftlichen Nachfrage und damit eine Beschäftigungserhöhung bewirken ${ }^{2}$.

Der ganz überwiegende Teil öffentlicher Kredithilfen kann schon deshalb nicht aus stabilisatorischen Gründen gerechtfertigt werden kann, weil sie selektiv zur Förderung bestimmter ökonomischer Aktivitäten und regelmäßig unabhängig von der konkreten konjunkturellen Situation gewährt werden ${ }^{3}$. Letzteres wird beispielsweise durch verschiedene empirische Studien über Kredithilfen in den USA bestätigt. So zeigen SAULNIER/HALCROW/JACOBY ${ }^{4}$ für einen Untersuchungszeitraum von 1932-1953, $\mathrm{da} ß$ das Nettovolumen öffentlicher Darlehen in zwei von sieben Jahren mit sinkendem Bruttosozialprodukt abgenommen und in acht von siebzehn Jahren mit steigendem Bruttosozialprodukt zugenommen hat. BREAK ${ }^{5}$ stellt bei der Untersuchung von Kreditgewährleistungen fest, daß nur in fünf von dreizehn Jahren des Untersuchungszeitraums (19471959) das Programmvolumen zur Veränderung des Bruttosozialprodukts gegenläufig war. LARKINS $^{6}$ kommt unter Verwendung von bestimmten Zielgrößen der Arbeitslosigkeit und der Preisniveauveränderung zu dem Ergebnis, daß im Untersuchungszeitraum von 1946-1970 in neunzehn Jahren Signale für stabilitätspolitisches Handeln vorhanden waren. Andererseits erfolgte die Veränderung der Netto-Darlehensauszahlungen in zehn Jahren in die stabilitätspolitisch falsche Richtung.

Auch wenn mit Kredithilfeprogrammen tendenziell antizyklische Wirkungen erzielt werden können, reicht der damit verbundene Nutzen indessen keineswegs zu deren Rechtfertigung aus, da diesen die volkswirtschaftlichen Kosten der Maßnahmen gegen-

1 Vgl. z.B. SAULNIER/HALCROW/JACOBY (1958), S.110 ff.; LAW (1963), S.273; BREAK 2 (1965). Siehe auch DICKERTMANN (1980), S.509 ff.

2 Vgl. ZEITEL (1977), S.1022.

3 Vgl. LAW (1963), S.274 f.

4 Vgl. SAULNIER/HALCROW/JACOBY (1958), S.120 f.

5 Vgl. BREAK (1962), S.33.

6 LARKINS (1972) S.21 f. 
übergestellt werden müssen. Derartige Kosten entstehen insbesondere dadurch, daß Kredithilfen zu allokativen Verzerrungen führen können. Bei Berücksichtigung dieses Zusammenhangs ist es wahrscheinlich, daß nichtdiskriminierende Maßnahmen mit gleichen budgetären Kosten den öffentlichen Kredithilfen überlegen sind, weil sie die Erreichung der stabilisatorischen Effekte mit geringeren sozialen Kosten erwarten lassen ${ }^{1}$.

Schließlich kann eine antizyklische Variation von Investitions-Kredithilfen statt des erhofften Stabilisierungserfolgs geradezu das Gegenteil bewirken. Denn auf längere Sicht ist der stabilitätspolitische Einsatz von Kredithilfen allenfalls dann erfolgversprechend, wenn es den staatlichen Entscheidungsträgern immer wieder gelingt, die privaten Wirtschaftssubjekte zu überraschen. Ansonsten werden diese antizipieren, daß der Umfang der staatlichen Investitionsanreize im Konjunkturverlauf schwankt. Dadurch hätten sie einen Anreiz, auf "schlechtere Zeiten" zu warten, um sich mit Hilfe von Kredithilfen dann günstigere Finanzierungskonditionen zu sichern. Durch diesen Attentismus würde die Fähigkeit des Wirtschaftssystems vermindert, Stabilisierungskrisen aus eigener Kraft zu bewältigen. Die konjunkturellen Schwankungen würden sich erhöhen und Rezessionen würden wahrscheinlicher werden ${ }^{2}$.

Aus diesen Gründen wird im folgenden darauf verzichtet, die stabilisatorischen Effekte öffentlicher Kredithilfen weiter zu untersuchen.

\section{Kritik: Die Kosten öffentlicher Kredithilfen}

Die üblichen Begründungen öffentlicher Kredithilfen beziehen sich in erster Linie auf die tatsächlichen oder vermuteten Nutzen öffentlicher Kredithilfen. Es ist jedoch eine ökonomische Trivialität, da $B$ das Ausma $B$ des Nutzens öffentlicher Maßnahmen allein keinerlei Rückschlüsse auf ihre ökonomische Vorteilhaftigkeit zuläßt. Demnach müssen auch in bezug auf öffentliche Kredithilfen die damit verbundenen Kosten berücksichtigt werden. Nur wenn sich ein Überschuß der Nutzen über die Kosten ergibt, führen Kredithilfen zu einer Wohlfahrtssteigerung.

Da zusätzliche Kredithilfen zu marginalen staatlichen Nettoausgaben und damit zu einem marginalen Einnahmenbedarf führen, müssen zunächst die marginalen Kosten öffentlicher Einnahmen berücksichtigt werden ${ }^{3}$, die hier als marginale Finanzierungskosten

Vgl. ZEITEL (1977), S.1022.

2 Vgl. DORNBUSCH/FISCHER (1989), S.306 f.

3 In der angelsächsischen Literatur spricht man in diesem Zusammenhang von den "marginal costs of public funds". Vgl. BROWNING (1976); HANSSON/STUART (1989). 
bezeichnet werden. Diese marginalen Einnahmen muß sich der Staat letztlich immer als marginale Steuereinnahmen beschaffen. Dies gilt auch dann, wenn zur Finanzierung der Nettoausgaben vorübergehend Krediteinnahmen verwendet werden oder außerbudgetäre Einrichtungen eingesetzt werden, sofern man unterstellt, daß der Staat sein "Lebenseinkommen" lediglich durch Variation der Steuereinnahmen verändern kann. Beispielsweise führt die Ausweitung von Darlehen der außerbudgetären Einrichtungen, die zu Lasten eigener Erträge verbilligt werden, zu einer Reduzierung des staatlichen Beteiligungsvermögens und macht damit ceteris paribus eine Erhöhung der Steuereinnahmen erforderlich.

Die marginalen Finanzierungskosten öffentlicher Kredithilfen hängen davon ab, ob und gegebenenfalls in welchem Ausma $B$ die notwendigen marginalen Steuereinnahmen zu Mehrbelastungen führen. Diese werden um so höher sein, je elastischer die Bemessungsgrundlage auf Steuersatzänderungen reagiert und je höher der marginale Steuersatz ist ${ }^{1}$. Weiterhin kommt es darauf an, ob zur Finanzierung der Nettoausgaben öffentlicher Kredithilfen spezielle Steuereinnahmen zur Verfügung stehen oder ob sie aus dem Aufkommen aller Steuern finanziert werden. Je höher die Mehrbelastung aufgrund der zusätzlichen Steuereinnahmen ist, desto höher muß der Brutto-Wohlfahrtsgewinn eines Kredithilfeprogramms sein, damit es insgesamt eine Wohlfahrtssteigerung bewirkt. Weitere Kosten von Kredithilfen können u.a. daraus resultieren, daß dadurch bestimmte Individuen aufgrund marktlicher Anpassungsreaktionen Rentenverluste erleiden ${ }^{2}$.

Abgesehen davon, daß eine schlüssige normative Begründung von Kredithilfen stets einen Kosten-Nutzen-Kalkül erfordert, ist der Ansatz des Marktversagens mit einer weiteren Einschränkung zu versehen. Während Marktversagen aus der Sicht der Wohlfahrtsökonomik die ökonomischen Ergebnisse des Marktprozesses unerwünscht erscheinen lä $\mathrm{Bt}^{3}$, ist dies lediglich eine notwendige, nicht aber eine hinreichende Bedingung für staatliche Interventionen. Denn

"das entscheidende Problem des Ansatzes besteht (...) in der Tatsache, daß er auf einem gedanklichen Fehler beruht: er vergleicht unvergleichbare Alternativen und zieht folglich unvergleichbare Schlüsse. Er beruht einerseits auf der positiven Analyse der unvollkommenen Ergebnisse eines realen Marktprozesses, andererseits auf der normativen Fiktion eines idealen Staates, der alle relevanten Informationen und poli-

1 Zur Berechnung des Anteils der Mehrbelastung am Steueraufkommen HARBERGER (1974), S.34; BROWNING (1976), S.285 f.; FOLKERS (1988c), S.218 f. Siehe auch den Überblick zu neueren Ansätze, die allgemeine Gleichgewichtszusammenhänge einbeziehen, bei HANSSON/STUART (1989).

3 Vgl. WOLF (1979), S.107; FOLKERS (1986c), S.208. 
tische Fähigkeiten besitzt, um gesellschaftlich optimale oder doch zumindest superiore Ergebnisse zu erzeugen. Bei diesem Argumentationsmuster ist das Ergebnis vorgezeichnet: der Markt muß in allen Fällen schlechter abschneiden. ${ }^{1}$

Geht man demgegenüber von realen politischen Prozessen aus, so muß auch die Möglichkeit von Staatsversagen bei staatlichen Eingriffen in das Marktgeschehen berücksichtigt werden ${ }^{2}$. Folglich müssen bei Kredithilfen, wie bei anderen staatlichen Maßnahmen, die Kosten des Staatsversagens erfaßt werden, wenn ihre ökonomische Vorteilhaftigkeit beurteilt werden soll. D.h. daß Kredithilfen nur dann gerechtfertigt sind, wenn ihr Nutzen sämtliche Kosten einschließlich der Kosten des Staatsversagens übersteigt.

Aufgrund bestehender Informationsprobleme sind die Kosten des Staatsversagens schwierig zu ermitteln ${ }^{3}$. Damit wird ein umfassender Kosten-Nutzen-Kalkül entscheidend erschwert. Allerdings kann daraus nicht gefolgert werden, daß staatliche Eingriffe zur Korrektur von Marktversagen generell schädlich sind. Andererseits wird der Spielraum für wohlfahrtssteigernde Maßnahmen bei Marktversagen aufgrund des Staatsversagens erheblich eingeengt. Darüber hinaus ist zu diskutieren, ob die Veränderung institutioneller Strukturen zu einer Reduzierung der Kosten des Staatsversagens der Subventionierung führen kann ${ }^{4}$. Dieser Frage wird jedoch an anderer Stelle in dieser Arbeit nachgegangen ${ }^{5}$.

\section{ANREIZWIRKUNGEN ÖFFENTLICHER KREDITHILFEN}

Analog zur Steuerwirkungslehre kann bei der positiven Wirkungsanalyse öffentlicher Kredithilfen zwischen Anreiz- und Wohlfahrtseffekten unterschieden werden. Während die Anreizeffekte die Mengenreaktionen, die durch öffentliche Kredithilfen ausgelöst werden, bei verschiedenen ökonomischen Entscheidungen umschreiben, soll mit der Analyse von Wohlfahrtseffekten die Frage nach den Nutzeneffekten von Kredithilfen beantwortet werden. In diesem Abschnitt sollen die Anreizwirkungen öffentlicher Kredithilfen auf die Konsumkreditnachfrage, das Investitionsverhalten, die Beschäftigung und die Risikoübernahme untersucht werden. Zunächst sollen jedoch die von öffentlichen Kredithilfen vermittelten Anstoßwirkungen ${ }^{6}$ auf die Preise betrachtet werden.

1 FOLKERS (1986c), S.208.

$2 \mathrm{Zu}$ den Erscheinungsformen und Konsequenzen des Staatsversagens vg. BUCHANAN (1977b), S.11 f.; WOLF (1979); FOLKERS (1986b); FOLKERS (1986c).

Vgl. WOLF (1979), S.117 f.

4 Vgl. FOLKERS (1986c), S.208 f.

5 Vgl. unten Abschnitt D.II.

6 Dieser Begriff entspricht dem in der Steuertheorie üblichen Begriff der Inzidenz des Steueranstoßes. Vgl. dazu MUSGRAVE (1959/1966), S.180 ff. 


\section{Anstoßwirkungen öfientlicher Kredithilfen}

Im Gegensatz zu Preissubventionen von Gütern besteht das Subventionselement von Kredithilfen nicht in einer unmittelbaren Reduzierung der Preise der subventionierten Güterkäufe. Vielmehr beinhaltet eine Kredithilfe zunächst lediglich eine Verbilligung des Kreditzinssatzes für den Kreditnehmer.

Bei Schuldendiensthilfen, die als Zinszuschuß gewährt werden, ergibt sich die Zinsverbilligung je Krediteinheit in Höhe des Zuschußsatzes ${ }^{1}$, der bezogen auf den marktlichen Kreditzinssatz fix oder variabel sein kann. Letzteres ist dann relevant, wenn die Zinsverbilligung auf einen bestimmten Zinssatz erfolgt. Der Zuschußsatz variiert dann, wenn der vereinbarte Kreditzinssatz variabel ist ${ }^{2}$. Außerdem steigt er, wenn durch das Zinszuschußprogramm, das über einen längeren Zeitraum durchgeführt wird, aufgrund ökonomischer Anpassungsreaktionen ein Anstieg des Marktzinssatzes induziert wird. Schließlich werden bei einem Zinszuschuß nach der "Methode auf" relativ riskante Kredite stärker begünstigt als risikolose Kredite.

Es sei unterstellt, daß die Kreditportfolios der Kreditgeber kein systematisches Risiko beinhalten, so daß sich die Kreditgeber wie risikoneutrale Individuen verhalten. Die Haftung der Kreditnehmer sei auf ihr Vermögen im Zeitpunkt der Fälligkeit der Darlehensforderungen beschränkt. Die Tilgungsforderungen sollen von den Kreditnehmern in jedem Umweltzustand erfüllt werden. Dagegen sollen die Zinszahlungen der einzelnen Kreditnehmer mit der Wahrscheinlichkeit $\mathrm{p}^{\mathrm{i}}$ Null betragen. Bei einem risikolosen Marktzinssatz $\mathrm{r}$ ergibt sich ohne Zinszuschuß ein individueller Kreditzinssatz in Höhe von $r /\left(1-p^{i}\right)$. Damit entsprechen die erwarteten Zinskosten eines Kreditnehmers dem risikolosen Marktzinssatz. Soll der Zinssatz für den einzelnen Kreditnehmer auf $r^{2}$ verbilligt werden, so reduzieren sich die erwarteten Zinskosten des Kreditnehmers von $r$ auf $\left(1-p^{i}\right) r^{2}$. D.h. daß die erwarteten Zinskosten um so mehr fallen, je höher $\mathrm{p}^{\mathrm{i}}$ und damit das Kreditrisiko ist. Gleichzeitig fällt der nominale Kreditzinssatz von $r /\left(1-p^{i}\right)$ auf $r+p^{i} r^{z}{ }^{3}$ Dagegen werden die erwarteten Zinskosten bei einer Zinsverbilligung nach der "Methode um" unabhängig von der Ausfallwahrscheinlichkeit um den Zuschußsatz $\mathrm{z}$ reduziert ${ }^{4}$.

1 Dabei sind Zinszuschüsse üblicherweise als Mengenzuschüsse ausgestaltet.

2 Vgl. DICKERTMANN/HANSMEYER (1987), S.41 ff.

3 Da durch den ZinszuschuB ein Teil der Zinsforderungen auch im ungünstigen Umweltzustand erfüllt wird, reduziert sich der Kreditzinssatz.

4 Die erwartete Zinskostenverbilligung setzt sich zusammen aus der unmittelbaren Verbilligung $\left(1-p^{1}\right) z$ und der induzierten Verbilligung, die aus der Senkung des Kreditzinssatzes um $p^{2} z /\left(1-p^{i}\right)$ resultiert. 
Bei öffentlichen Darlehen wird der Kreditzinssatz häufig ohne Risikodifferenzierung auf eine bestimmte Höhe festgelegt. Erfolgt die Festsetzung dieses Zinssatzes durch einen prozentualen Abschlag vom Marktzinssatz, so ergibt sich bei risikolosen Krediten eine Anstoßwirkung wie bei einem Zinszuschuß nach der "Methode um". Ist der Zinssatz des öffentlichen Darlehens unabhängig vom Kreditrisiko gegeben, erhält man bei riskanten Krediten eine Anstoßwirkung wie bei einem Zinszuschuß nach der "Methode auf" und damit eine stärkere Begünstigung riskanter Kredite.

Im Fall einer Kreditgewährleistung tritt eine Anstoßwirkung nur bei riskanten Krediten ein, da andernfalls das Kreditrisiko für den Kreditgeber mit und ohne Gewährleistung jeweils Null beträgt. Bei riskanten Krediten ist die Anstoßwirkung von der Prämienhöhe und dem Deckungsgrad D der Kreditforderung abhängig. Wird die Kreditgewährleistung zu einer fairen Versicherungsprämie angeboten, so reduziert sich der Kreditzinssatz bei Volldeckung und unterstellter Risikoaversion des Kreditgebers so weit, daß die erwarteten Zinskosten des Kreditnehmers den Zinskosten eines risikolosen Kredits entsprechen ${ }^{1}$. Die Gewährleistung senkt den Risikopreis auf Null. Wird die Gewährleistung unentgeltlich gewährt, so reduziert sich der Kreditzinssatz unabhängig vom Kreditrisiko und der Risikoeinstellung des Kreditgebers auf die Höhe des risikolosen Marktzinssatzes r, da der Kredit für den Kreditgeber risikolos wird. Die erwarteten Zinskosten des Kreditnehmers betragen unter den oben getroffenen Annahmen (1-pi)r und fallen mit steigender Ausfallwahrscheinlichkeit. Die Kreditgewährleistung entspricht einem Zinszuschuß, der den Zinssatz auf $r$ reduziert. Ist $D$ kleiner als $100 \%$, so verbleibt auch bei einem Prämiensatz von Null ein Teil des Risikos beim Kreditgeber. Daher liegt der nominale Kreditzinssatz über dem risikolosen Marktzinssatz. Die erwarteten Zinskosten fallen dagegen unter den risikolosen Marktzinssatz und nehmen mit steigendem Deckungsgrad ab ${ }^{2}$.

Da die Kredithilfen bzw. die mit ihnen verbilligten Kredite jedoch regelmäßig für Güterkäufe zu verwenden sind, werden durch Kredithilfen indirekt auch Güterpreise beeinflußt. Wird die Kredithilfe zu Konsumzwecken gewährt, so resultiert durch sie im oben dargestellten intertemporalen Konsummodell bei einem Zinszuschuß von z eine Reduzierung der intertemporalen Preisrelation zwischen Gegenwarts- und Zukunftskonsum von $1+r$ auf $1+r-z$. D.h. der Gegenwartskonsum wird billiger.

Im Fall von Investitions-Kredithilfen wird dagegen der Kapitalgüterpreis beeinflußt. Da der Kapitalgüterpreis im neoklassischen Investitionsmodell dem Gegenwartswert der

1 Vgl. oben Abschnitt C.I.2.a.bb., insbespndere Gleichung (C.I.17).

2 Für den Kreditgeber soll gelten: $\left(1 \cdot p^{1}\right) r^{\prime}+p^{i} D r^{\prime}=r$ bzw. $r^{\prime}=r /\left[1-p^{i}(1-D)\right]$. Die erwarteten Zinskosten des Kreditnehmers betragen demnach $\left(1-p^{1}\right) r /\left[1-p^{i}(1-D)\right]<r$, weil $p^{i}<p^{i}(1-D)$. 
künftigen Erträge der marginalen Kapitaleinheit entspricht, und diese wiederum mit den marginalen Kapitalnutzungskosten übereinstimmen ${ }^{1}$, reduziert sich durch eine Kredithilfe indirekt der Kapitalgüterpreis q. Denn eine marginale Kapitalgütereinheit, die mit einem Kredit finanziert wird, dessen Zinssatz um den Zuschußsatz z verbilligt wird, führt außer dem Wertgrenzprodukt des Kapitals $\mathrm{oF}_{\mathbf{K}}$ zu einem zusätzlichen Periodenertrag je Kapitalgütereinheit in Höhe von qz, wobei o den Outputpreis bezeichnet. Betrachtet man eine einperiodige sichere Investition, so gilt ohne Kredithilfe $q=o F_{K} /(1+r)$ und mit Kredithilfe $q=\left(o F_{K}+q z\right) /(1+r)$ bzw. $q[1-z /(1+r)]=o F_{K} /(1+r)^{2}$. Insoweit entspricht die Kredithilfe einer Wertsubvention von Kapitalgüterkäufen, d.h. einem Investitionszuschuß mit dem Zuschußsatz $z /(1+r)^{3}$. Der dargestellte Zusammenhang gilt mutatis mutandis auch für die anderen Kredithilfeformen. Dabei ist aus den obigen Ausführungen zu folgern, da $B$ der einer Zinsverbilligung nach der "Methode auf" äquivalente Investitionszuschuß um so höher sein muß, je riskanter die Investition ist.

Zusammenfassend ist festzuhalten, daß die Anstoßwirkungen unterschiedlicher Formen von Kredithilfen bei entsprechender Ausgestaltung äquivalent sind. Bei riskanten Krediten entspricht ein Zinszuschuß, der den Zinssatz auf $r$ reduziert, einem öffentlichen Darlehen mit einem Zinssatz von $r$ und einer entgeltlosen Kreditgewährleistung mit einem Deckungsgrad von $100 \%$. Sollen die Finanzierungskosten für Aktivitäten mit unterschiedlichem Risiko durch eine Zinsverbilligung nach der "Methode auf" auf dieselbe Höhe gesenkt werden, so lassen sich äquivalente Anstoßwirkungen nur erzielen, wenn die Kredithilfe-Konditionen dem Risiko entsprechend differenziert werden.

Nachdem gezeigt wurde, wie sich öffentliche Kredithilfen unmittelbar auf die Höhe des Zinssatzes auswirken, soll im folgenden untersucht werden, wie die Entscheidungen der Individuen durch entsprechende Zinskostenverbilligungen beeinflußt werden.

\section{Wirkungen öffentlicher Kredithilfen auf die Konsumkreditnachfrage}

Insbesondere aus sozialpolitischen Gründen werden bisweilen öffentliche Kredithilfen zur Förderung des Gegenwartskonsums ihrer Empfänger gewährt. Zur Analyse der Anreizeffekte dieser Konsum-Kredithilfen wird eine graphische Version des in Abschnitt C.I.1. dargestellten intertemporalen Konsummodells verwendet.

1 Vgl. BOADWAY (1979), S.267 f.

2 Dieses Ergebnis resultiert daraus, daB Erträge negative Kosten sind.

3 Wird die Investition lediglich mit einem Anteil $\mathrm{b}(0<\mathrm{b}<1)$ fremdfinanziert, reduziert sich der äquivalente Zuschußsatz auf $b z /(1+r)$. 
In Abb. 2, wo auf der Abszisse der Gegenwartskonsum $\mathrm{C}_{\mathbf{G}}$ und auf der Ordinate der Zukunftskonsum $\mathrm{C}_{\mathrm{Z}}$ abgetragen sind, repräsentieren der Punkt $\mathrm{A}$ die Periodeneinkünfte, die Gerade $\mathrm{AB}$ die Ausgangsbudgetgerade ${ }^{1}$, der Punkt I das individuelle Optimum ohne Kredithilfe und OD die Kreditnachfrage des betrachteten Individuums. Aufgrund einer zur Finanzierung von Gegenwartskonsum zu verwendende öffentliche Kredithilfe in Form eines Zinszuschusses oder eines zinsverbilligten Darlehens ${ }^{2}$ ergibt sich durch Drehung der Budgetgeraden in A die neue Budgetgerade AL, sofern die Zinsverbilligung für die gesamte vom Individuum nachgefragte Kreditsumme gewährt wird. Der neue Optimalpunkt III liegt auf dem höheren Indifferenzkurvenniveau $i_{3}$. Dabei befindet sich III stets rechts oberhalb von II, sofern der Gegenwartskonsum ein superiores Gut ist. Denn dann führen sowohl der Substitutions- als auch der Einkommenseffekt zu einer Ausweitung des Gegenwartskonsums. Die Kreditnachfrage des Individuums steigt um DM auf OM. D.h. jedoch andererseits, daß die Ausweitung des Gegenwartskonsums lediglich einen Bruchteil der zinsverbilligten Kreditsumme ausmacht. Im Vergleich zu einem ungebundenen Einkommenstransfer in Höhe von BG, der dem Gegenwartswert der Nettoausgaben der Kredithilfe entspricht ${ }^{3}$, ergibt sich bei letzterer aufgrund des Substitutionseffekts eine Mehrbelastung ${ }^{4}$, eine höhere Kreditnachfrage und damit ein höherer Gegenwartskonsum.

Weiterhin läßt sich mit Abb. 2 zeigen, daß öffentliche Kredithilfen keine optimalen Instrumente zur Erreichung eines als Existenzminimum definierten Konsumniveaus in beiden Betrachtungsperioden sind, sofern die reine Zeitpräferenzrate ${ }^{5}$ der einkommensschwachen Gruppe den Marktzinssatz nicht unterschreitet ${ }^{6}$. In Abb. 2 wird das staatlicherseits als Existenzminimum festgelegte Konsumniveau in beiden Perioden durch den Schnittpunkt E der Geraden PP' und ZZ' repräsentiert, wobei OP $=\mathrm{OZ}$ gelten soll.

Während die Sicherstellung eines existenzminimalen Konsumniveaus in beiden Perioden im Falle der Kredithilfe einen Gegenwartswert staatlicher Nettoausgaben von BG

1 Dabei entspricht unter der Annahme eines vollkommenen Kapitalmarkts OA dem Endwert und OB dem Gegenwartswert des Gesamteinkommens des Individuums.

2 Eine Kreditgewährleistung wäre hingegen wirkungslos, da in diesem Modell von Unsicherheit abgesehen wird.

3 Die in der Zukunft fälligen Nettoausgaben der Kredithilfe entsprechen der Strecke AH.

4 Sie folgt daraus, daB bei einem Einkommenstransfer das Indifferenzkurvenniveau $\mathrm{i}_{4}$ realisiert wird, während bei der Kredithilfe lediglich i 3 erreichbar ist.

5 Die reine Zeitpräferenzrate ergibt sich aus der Steigung der Indifferenzkurven im Schnittpunkt mit der Winkelhalbierenden. Sie ist bei homothetischen intertemporalen Nutzenfunktionen für alle Nutzenniveaus konstant. Vgl. BOADWAY/WILDASIN (1984), S.42 f.

6 D.h. daB im individuellen Optimum der Gegenwartskonsum den Zukunftskonsum übersteigt. Zur Annahme einer relativ hohen Zeitpräferenzrate der ärmeren Einkommensgruppen vgl. SCHMAH (1967), S.234 f.; GANDENBERGER (1981), S.37. 


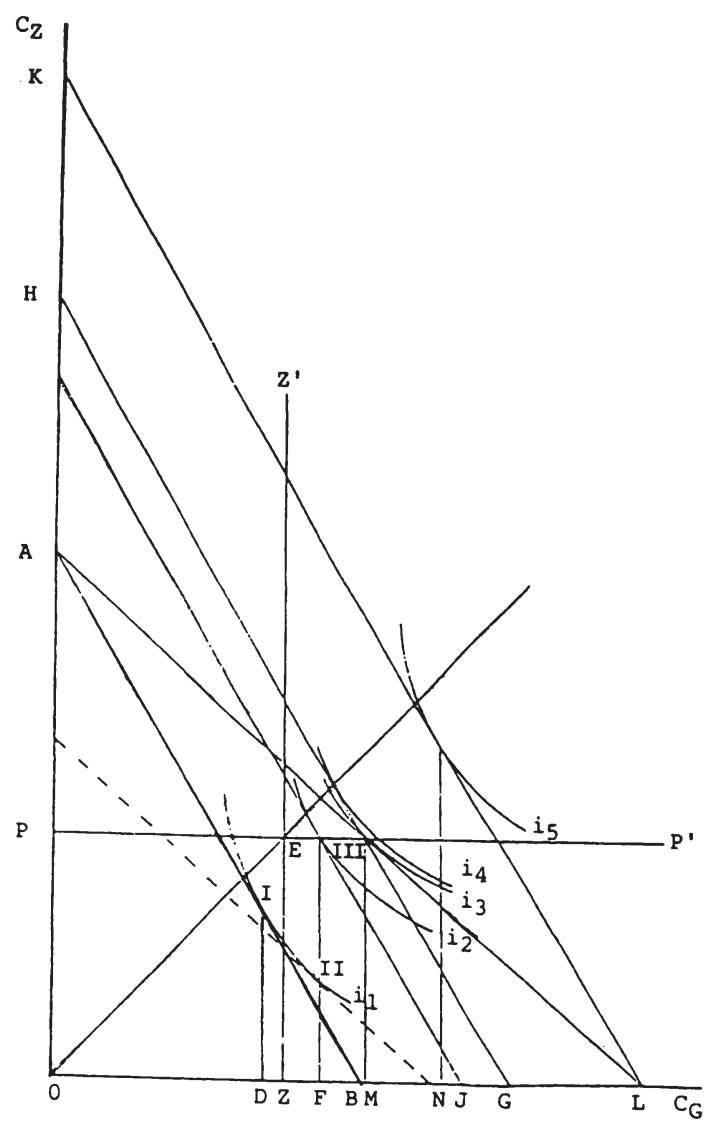

Abb. 2

erfordert, damit Punkt III und damit die staatliche Zielsetzung erreicht wird, genügen bei Einkommenstransfers Ausgaben in Höhe von BJ, um das Existenzminimum in beiden Perioden zu sichern. Dabei ist der Gegenwartskonsum beim Einkommenstransfer mit OF kleiner als im Fall der Kredithilfe, in dem er OM beträgt. Unterstellt man, daß alle staatlichen Ausgaben mit verzerrenden Einnahmen finanziert werden müssen, ist ein ungebundener Einkommenstransfer zur Sicherung staatlich festgelegter Existenzminima auch insoweịt mit geringeren sozialen Kosten verbunden als eine Kredithilfe entsprechender Zielsetzung. 
Ein weiteres Problem öffentlicher Kredithilfen ergibt sich, wenn die Verwendung der zinsverbilligten Kreditsumme nicht kontrolliert werden kann, so daß der Staat einem Moral-hazard-Verhalten des Kredithilfe-Empfängers ausgesetzt sein kann. Im Extremfall wird das anspruchsberechtigte Individuum verbilligte Kredite in Höhe von OL nachfragen, die es dann zum Marktzinssatz anlegen wird. Dadurch ergibt sich seine neue Budgetgerade $\mathrm{KL}$ als Parallele zu AB durch den Punkt $\mathrm{L}^{1}$. Im individuellen Optimum beträgt der Gegenwartskonsum lediglich $\mathrm{ON}$. Da die Anlage der zinsverbilligten Kreditsumme im vorliegenden Partialmodell die intertemporale Preisrelation gegenüber der Ausgangssituation ohne Kredithilfe nicht verzerrt, entfällt bei mangelnder Kontrollierbarkeit der Verwendung der Substitutionseffekt. Allerdings werden die Zinsverbilligungskosten des Staates und damit auch die einnahmeseitigen Verzerrungen in diesem Fall maximal.

Ist die Höhe der zinsverbilligten Kredithilfe hingegen betragsmäßig begrenzt, so führt dies zu einer geknickten Budgetgerade des Individuums. Unterhalb des Knicks entspricht ihre Steigung dem intertemporalen Preisverhältnis ohne Kredithilfe, oberhalb des Knicks verläuft sie flacher und wird durch die Höhe des verbilligten Zinssatzes bestimmt. Bei Individuen mit starken Präferenzen für Gegenwartskonsum liegt der Optimalpunkt unterhalb des Knicks. Die Kredithilfe ist dann einem Einkommenstransfer äquivalent und der Gegenwartskonsum wird über die Höhe der zinsverbilligten Kreditsumme hinaus ausgedehnt. Im umgekehrten Fall wird das Individuum bei Kontrollierbarkeit der Verwendung die maximal mögliche zinsverbilligte Kreditsumme nicht ausschöpfen.

\section{Wirkungen öffentlicher Kredithilfen auf die Investitionshöhe}

Da Kredithilfen in den meisten Fällen zur Finanzierung von Investitionen gewährt werden, ist es notwendig, in einem nächsten Schritt ihre Wirkungen auf die individuellen Investitionsentscheidungen zu analysieren. Dazu wird hier, anders als zuvor, zunächst ein langfristiges neoklassisches Investitionsmodell verwendet ${ }^{2}$. Da dieses Modell partieller Natur ist, können damit lediglich die Auswirkungen von Kredithilfen auf den optimalen Kapitalbestand bei unveränderten Güter- und Faktorpreisen und konstantem risikolosen Zinssatz analysiert werden. Dieses Vorgehen scheint zumindest in Bezug auf relativ "kleine" Kredithilfe-Programme vertretbar zu sein, welche die relativen Preise vergleichsweise wenig ändern.

1 Dabei ist unterstellt, daß Transaktionskosten im diesem Zusammenhang nicht entstehen.

2 Vgl. JORGENSON (1963), HALL/JORGENSON (1967), SANDMO (1974), AUERBACH (1979). 
a. Wirkungen öffentlicher Kredithilfen bei sicheren Investitionen

Aus Vereinfachungsgründen beschränkt sich die Analyse auf Sachkapital ${ }^{1}$. Investitionen in Sachkapital erfordern den Erwerb von Kapitalgütern, deren Bestand den Kapitalstock bildet. Es wird nun ein Unternehmen betrachtet, das über einen unendlichen Zeitraum mit der Produktionsfunktion $\mathrm{F}(\mathrm{A}, \mathrm{K})$ den Output $\mathrm{X}$ herstellt, wobei $\mathrm{A}$ den Faktor Arbeit und $\mathrm{K}$ den Faktor Kapital bezeichnet. Weiterhin soll $F_{A}, F_{K}>0$ und $F_{A A}, F_{K K}<0$ gelten $^{2}$. Der Outputpreis o, der Lohnsatz 1 und der Kapitalnutzungspreis ohne Kredithilfe seien gegeben. Der Kapitalnutzungspreis als Schattenpreis der Nutzung der gesamten Kapitalgüter errechnet sich aus ihrem gegebenen Preis q multipliziert mit der Summe aus dem risikolosen Marktzinssatz $\mathrm{r}$ und der Abschreibungsrate $\delta^{3}$. Darüber hinaus wird angenommen, daß die Produktionstechnologie vor und nach Kredithilfe konstant ist und $\mathrm{da} \beta$ die Investitionen vollständig mit Fremdkapital finanziert werden ${ }^{4}$. Schließlich wird ein vollkommener Kapitalmarkt unterstellt. Unter diesen Bedingungen gilt das Fishersche Separationstheorem, wonach es für die Eigentümer - unabhängig von ihren intertemporalen Konsumpräferenzen - stets vorteilhaft ist, wenn der Nettogegenwartswert V des Unternehmens maximiert wird ${ }^{5}$.

Es gilt demnach 6 :

$$
V=\sum_{t=0}^{\infty}(1+r)^{-t}\left[o F\left(K_{t}, A_{t}\right)-1 A_{t}-q(r+\delta) K_{t}\right]
$$

wobei $r$ den risikolosen Marktzinssatz als Diskontierungsrate, $F\left(\mathbf{K}_{\mathbf{t}}, \mathbf{A}_{\mathbf{t}}\right)$ den Output einer Periode und $\mathrm{q}(\mathrm{r}+\delta)$ den Kapitalnutzungspreis darstellen. Demnach umschreiben der erste Ausdruck in der eckigen Klammer den bewerteten Output und die beiden anderen Ausdrücke die Kosten der jeweiligen Periode.

1 Unberücksichtigt bleiben Investitionen in immaterielles Realkapital, wie z.B. Humankapital. Vgl. dazu ausführlich BECKER, G.S. (1964).

2 Die Indizes bezeichnen hier die partiellen Ableitungen der Produktionsfunktion nach $\mathrm{A}$ und $\mathrm{K}$.

3 Vgl. SANDMO (1974), S.290 f. Dies ist leicht einsichtig, weil der Kapitalnutzungspreis die Opportunitätskosten des Kapitaleinsatzes widerspiegelt. Da aber weder die Nettoinvestitionen noch das zu ihrer Finanzierung zugeführte zusätzliche Finanzkapital in der Investitionsperiode Kosten verursachen, ergeben sich die Opportunitätskosten des Kapitaleinsatzes als Summe der Opportunitätskosten der Kapitalhaltung, den Zinsen, und denjenigen der Kapitalverwendung, nämlich den Abschreibungen.

5 Vgl. BOADWAY (1979), S.266.

5 Siehe dazu oben Abschnitt C.I.1.

6 Zur Herleitung des Modells vgl. BOADWAY (1979), S.265 ff.; HERB (1988), S.43 ff. 
Der optimale Kapitalbestand des betrachteten Unternehmens ist dann erreicht, wenn der Nettogegenwartswert des Unternehmens maximal ist. Durch partielle Differentiation von (C.III.1) erhält man als notwendige Bedingung für einen optimalen Kapitaleinsatz:

(C.III.2) $\quad \mathrm{oF}_{\mathrm{K}}=(\mathrm{r}+\delta) \mathrm{q}$.

D.h. im Optimum entspricht das Wertgrenzprodukt des Kapitals dem Kapitalnutzungspreis bzw. es stimmen Grenzertrag und Grenzkosten einer marginalen Kapitaleinheit überein.

Erhält der Investor zur Finanzierung seiner Investitionen für beliebige Investitionsbeträge permanent eine Kredithilfe in Form eines mit $r-z$ zu verzinsenden Darlehens oder eines Zinszuschusses mit dem Zuschußsatz z, so reduzieren sich die marginalen Finanzierungskosten auf $q(r-z)$. Die Grenzkosten des Kapitaleinsatzes werden auf $q(r-z+\delta)$ verringert. D.h. im Optimum wird das Wertgrenzprodukt des Kapitals im Vergleich zur Situation ohne Kredithilfe geringer ${ }^{1}$. Da die Grenzerträge des Kapitals mit zunehmendem Kapitaleinsatz fallen, erhöht sich der optimale Kapitalbestand durch die Kredithilfe. Um das neue Optimum zu erreichen, sind also zusätzliche Investitionen erforderlich. Das Aus$\mathrm{ma} ß$ der Investitionssteigerung wird dabei um so höher sein, je größer die Zinselastizität der Investitionsnachfrage ist.

\section{b. Wirkungen öffentlicher Kredithilfen bei riskanten Investitionen}

aa. Risikoneutralität des Investors

Die Investitionsanreize öffentlicher Kredithilfen bei riskanten Investitionen und Risikoneutralität des Investors sollen nun mit Hilfe eines leicht abgewandelten Modells untersucht werden. Dabei soll das Risiko darin bestehen, daß der Outputpreis o eine Zufallsvariable ist ${ }^{2}$. Mit der Wahrscheinlichkeit $p$ sei der Outputpreis Null, während er mit der Gegenwahrscheinlichkeit 1-p einen positiven Wert annehmen soll. Weiterhin wird eine fristenkongruente Fremdkapitalfinanzierung des Kapitals unterstellt, bei der Abschreibungs- und Tilgungsbeträge übereinstimmen. Dabei sei die Haftung des Investors gegenüber den Fremdkapitalgebern auf die periodischen Investitionserträge beschränkt. Die Höhe der vom Investor zu tragenden marginalen Kapitalkosten qC ist damit zustandsabhängig. Von der Möglichkeit eines Bankrotts wird abgesehen. Sind der Investor und die

1 Dabei wird unterstellt, daB sich durch die Kredithilfe die intertemporalen Opportunitätskosten der Investitionen nicht verändern und $\mathrm{r}$ damit konstant bleibt.

2 Die Auswirkungen auf das Investitionsverhalten bei Unsicherheit über den Outputpreis untersuchen BATRA/ULLAH (1974); HARTMAN, R. (1975). 
Fremdkapitalgeber risikoneutral, so wird der Investor den erwarteten Nettogegenwartswert $\mathrm{E}(\mathrm{V})$ des Unternehmens maximieren ${ }^{1}$. Es gilt:

$$
E(V)=\sum_{t=0}^{\infty}(1+r)^{-t}\left[E(0) F\left(K_{t}, A_{t}\right)-1 A_{t}-q E(C) K_{t}\right],
$$

wobei $\mathrm{E}(\mathrm{o})$ den erwarteten Outputpreis und $\mathrm{qE}(\mathrm{C})$ die erwarteten marginalen Kapitalkosten des Investors bezeichnen. Gilt nun $\mathrm{E}(\mathrm{o})=0$ und $\mathrm{qE}(\mathrm{C})=\mathrm{q}(\mathrm{r}+\delta),{ }^{2}$ so resultiert ohne Kredithilfe dasselbe Ergebnis wie bei vollständiger Sicherheit ${ }^{3}$.

Wird der Kreditzinssatz durch einen Zinszuschuß um z verringert, so ergibt sich gegenüber der sicheren Investition wiederum kein Unterschied, wenn der Zinszuschuß den Fremdkapitalgebern im ungünstigen Zustand zufließt. Denn die erwarteten marginalen Kapitalkosten sinken dann genau um z. Sollen die erwarteten Grenzkosten des Kapitaleinsatzes für den Investor auf $(1-p)(r+\delta)$ gesenkt werden, so können dazu gleichermaßen mit $r$ verzinsliche Darlehen, ein Zinszuschuß mit dem Zuschußsatz $p(r+\delta)^{4}$ oder eine entgeltlose Kreditgewährleistung eingesetzt werden, die das Fremdkapital vollständig absichert. Unter dieser Konstellation sind die Wirkungen aller Kredithilfeformen auf die Investitionsentscheidungen des betrachteten Investors äquivalent ${ }^{5}$. Sollen die erwarteten marginalen Kapitalkosten unter die Höhe von $(1-p)(r+\delta)$ reduziert werden, so kann dies mit Kreditgewährleistungen allein nicht erreicht werden.

Es seien zwei Investoren 1 und 2 betrachtet, bei denen unter Beibehaltung der sonstigen Annahmen $p_{1}>p_{2}$ gilt. Wird ein mit $r$ verzinsliches Darlehen ${ }^{6}$ gewährt, so gelten die Optimalbedingungen $o F_{K}=q\left(1-p_{1}\right)(r+\delta)$ bzw. $o F_{K}=q\left(1-p_{2}\right)(r+\delta)$. Daher ist der optimale Kapitalbestand von Investor 1 höher als der von Investor 2. Umgekehrt bedeutet dies, daß der Zinssatz des öffentlichen Darlehens für Investor 2 niedriger sein müßte als für Investor 1, um jeweils dieselbe Investitionsausweitung zu bewirken.

1 Vgl. BATRA/ULLAH (1974), S.537.

2 Diese Bedingung ist erfült, wenn $r^{\prime}=(r+p \delta) /(1-p)$, wobei $r^{\prime}$ die nominalen Grenzfinanzierungskosten bezeichnet. Denn dann gilt $(1-p)\left(r^{\prime}+\delta\right)=r+\delta$.

3 Vgl. BATRA/ULLAH (1974), S.537; HEY (1979), S.129; HENDERSON/QUANDT (1983). S.122.

4 Soll der vom Kreditnehmer im günstigen Umweltzustand zu tragende Kreditzinssatz durch einen Zinszuschuß auf $r$ reduziert werden, so bestimmt sich der an den Kreditgeber im günstigen Zustand zu entrichtende Zinssatz $r$ " folgendermaßen: $(1-p)(r "+\delta)+p(r "-r)=r+\delta$ bzw. $r "=r+p(r+\delta)$.

6 Die Argumentation gilt für Zinszuschüsse und Kreditgewährleistungen mit entsprechenden Konditionen analog. 


\section{bb. Risikoaversion des Investors}

Wesentlich komplizierter sind die Zusammenhänge, wenn man von risikoaversen Investoren ausgeht. Hier ist zunächst zu fragen, wie sich das Preisrisiko auf die optimale Outputmenge auswirkt. Es läßt sich zeigen, daß der Output eines risikoaversen Investors im allgemeinen geringer sein wird als der eines risikoneutralen Investors ${ }^{1}$. Im Optimum gilt daher, daß das erwartete Wertgrenzprodukt des Kapitals (der Arbeit) die marginalen Kapitalnutzungskosten (Arbeitskosten) übersteigt ${ }^{2}$. Unterstellt man beispielsweise eine homothetische Produktionsfunktion, so wird der optimale Kapitaleinsatz gegenüber dem Fall der Risikoneutralität ceteris paribus geringer sein ${ }^{3}$.

Wird eine Kredithilfe gewährt, so reduzieren sich auch hier die marginalen Kapitalkosten, so daß zusätzliche Investitionen angeregt werden. Will man die Anreizwirkungen von Kredithilfen auf die Investitionen bei Risikoaversion und Risikoneutralität miteinander vergleichen, so kommt es auf die Veränderung der Risikoaversion des Investors bei zunehmendem Vermögen an. Ist die Risikopräferenz des Investors beispielsweise durch eine abnehmende relative Risikoaversion gekennzeichnet, so kann der Fall eintreten, daß durch die Kredithilfe höhere zusätzliche Investitionen induziert werden als bei einem risikoneutralen Investor mit derselben Produktionsfunktion. Da bei anderen Risikopräferenzen des Investors auch das gegenteilige Ergebnis denkbar ist, läßt sich nicht generell sagen, ob die durch Kredithilfen induzierten Investitionen bei risikoaversen Investoren höher sind als bei risikoneutralen Investoren.

\section{c. Die Bedeutung der institutionellen Bedingungen}

Auch die jeweiligen institutionellen Bedingungen, unter denen öffentliche Kredithilfen gewährt werden, beeinflussen das Ausmaß der Anreizeffekte bezüglich der Investitionshöhe entscheidend. So ist die Ausgestaltung der Zinsverbilligung ${ }^{4}$ von erheblicher Bedeutung. Bei einem bezogen auf die Kreditsumme proportionalen Zinsverbilligungssatz ist die Investitionsausweitung bei gegebenen Zinsverbilligungsausgaben stets geringer als

1 Vgl. HEY (1979), S.128 f.; LIPPMAN/McCALL (1981), S.248 f. Allerdings kann daraus noch nicht geschlossen werden, daß jeder Anstieg des Preisrisikos zu einem geringeren Output führt. Vgl. dazu LIPPMAN/MCCALL (1981), S.255.

2 Vgl. LIPPMAN/MCCALL (1981), S.256.

$3 \mathrm{Zu}$ Unrecht wird dieses Ergebnis von BATRA/ULLAH (1974), S.547 verallgemeinert. Denn geringere Outputs können bei konstanter Faktorpreisrelation je nach Produktionsfunktion mit höherer, gleichbleibender oder geringerer Kapitalintensität produziert werden. Im ersteren Fall kann der Kapitalinput bei Risikoaversion höher sein als bei Risikoneutralität. Vgl.

HARTMAN, R. (1975); LIPPMAN/MCCALL (1981), S.254 ff.

4 Entsprechendes gilt für die Prämiensatzverbilligung bei Gewährleistungen. 
bei einem von niedrigerem Niveau aus progressiv steigenden Zinsverbilligungssatz, da letzterer den abnehmenden Grenzerträgen des Kapitals entgegengerichtet ist. Die maximale Investitionsausweitung wäre im Fall eines vollkommen diskriminierenden Kredithilfeprogramms gegeben ${ }^{1}$.

Weiterhin ist zu beachten, daß die Vergabe von Investitions-Kredithilfen häufig mit bestimmten Auflagen verbunden ist, welche die Kosten der Investoren erhöhen bzw. ihre Erträge reduzieren. Dadurch steigen die Grenzkosten der geförderten Investitionen in Höhe der Grenzkosten der Auflage gegenüber einer auflagenfreien Kredithilfe. D.h. die Ausweitung der Investitionen wird überschärzt, wenn man die Grenzkosten der Auflage außer acht läßt. Entsprechen die Grenzerträge der Kredithilfe und die Grenzkosten der damit verbundenen Auflagen bei der Investitionsmenge ohne Kredithilfe einander, so verfehlt die Kredithilfe das Ziel, die geförderten Investitionen auszuweiten. Dieselben Effekte können sich ergeben, wenn die Antragstellung für eine Kredithilfe Kosten verursacht ${ }^{2}$.

Umgekehrt kann aber auch der Fall eintreten, daß durch die Kredithilfe eine Ausweitung der geförderten Investitionsart induziert wird, daß aber das mit der Investitionsausweitung verfolgte Ziel zumindest partiell verfehlt wird. Dazu wird es insbesondere dann kommen, wenn sich die Opportunitätskosten der Erfüllung der Förderungsauflagen im Zeitablauf erhöhen, während die Höhe der Begünstigung konstant bleibt oder gar abnimmt. Typisches Beispiel dafür ist die Förderung des Mietwohnungsbaus für sozial Schwächere. Nach dem Landeswohnungsbauprogramm 1990 von Baden-Württemberg wird die Errichtung von Mietwohnungen, die für mindestens 10 Jahre an Berechtigte i.S.d. $\$ 25$ II.WoBauG vermietet werden, mit zinsverbilligten Darlehen mit zehnjähriger Laufzeit getördert. Die Höhe der Zinsverbilligung reduziert sich alle zwei Jahre um einen bestimmten Prozentsatz, wobei die Verminderung der Zinsverbilligung durch eine Erhöhung der vorab festgelegten Maximalmiete in entsprechendem Ausma $B$ ausgeglichen werden kann ${ }^{3}$. Der "effektive" Mietertrag bleibt damit über die gesamte Mietpreisbindungsdauer konstant. Steigen nun die Marktmieten während dieses Zeitraums, so erhöhen sich die Opportunitätskosten des Investors im Zeitablauf. Damit wird es denkbar, daß die Opportunitätskosten den Ertrag vor Ablauf der Mietpreisbindungsdauer übersteigen. Sofern nach den

1 Vollkommen diskriminierende Kredithilfen sind dadurch gekennzeichnet, daß sie die marginalen Kapitalnutzungskosten in Höhe der Abnahme der Grenzerträge des Kapitaleinsatzes senken.

2 Vgl. MITTELSTANDSBERICHT (1982), S.60; GRÖBNER (1983), S.133; HERB (1988),

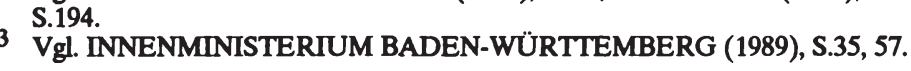


Kreditbedingungen eine vorzeitige Darlehenstilgung möglich ist, die mit dem Wegfall der Mietpreisbindung verbunden ist, besteht für den Investor der Anreiz zu einer Verkürzung der Mietpreisbindung. Damit wäre das Ziel, die Bereitstellung preisgünstigen Mietwohnraums zu erhöhen, teilweise verfehlt. Kann die Erfüllung der Auflagen dagegen auch bei steigenden Marktmieten nicht vermieden werden, so erhöhen sich das mit einer entsprechenden Investition verbundene Risiko und damit ihre Opportunitätskosten. Im letzteren Fall wird die induzierte Erhöhung der geförderten Mietbauinvestitionen geringer als bei möglicher Auflagenvermeidung ausfallen.

Die Wirkungen verschiedener Kredithilfeformen können auch aufgrund unterschiedlicher steuerlicher Behandlung voneinander abweichen. So werden öffentliche Darlehen und Kreditgewährleistungen die steuerlich erheblichen Finanzierungskosten in aller Regel senken ${ }^{1}$. Dagegen ist bei Zinszuschüssen vorstellbar, daß sie als steuerfreie Einnahmen zu behandeln sind. Unter diesen Bedingungen könnten bei einem Zinszuschuß höhere Finanzierungskosten geltend gemacht werden als im Fall öffentlicher Darlehen bzw. Kreditgewährleistungen. Damit wären im Fall von Zinszuschüssen die Grenzkosten des Kapitals geringer und der optimale Kapitalbestand höher.

\section{d. Die Berücksichtigung von ökonomischen Anpassungsreaktionen}

Bewirkt ein Kredithilfeprogramm wegen seines Umfangs Änderungen von Faktorund Güterpreisrelationen, so stellt sich die Frage nach der Erreichung der damit verfolgten Ziele noch wesentlich schärfer. Denn sämtliche diskriminierenden staatlichen Maßnahmen von gewissem Ausmaß werden tendenziell durch marktliche Mechanismen abgebaut ${ }^{2}$. Führt ein Kredithilfeprogramm beispielsweise zu einer Erhöhung des Marktzinssatzes ${ }^{3}$, so reduziert sich dadurch die effektive Zinsverbilligung und damit die Senkung der Kapitalnutzungskosten, sofern die Zinsverbilligung um einen bestimmten Zuschußsatz erfolgt. Die Investitionssteigerung wird damit um so geringer ausfallen, je kleiner der Anteil der Zinsverbilligung ist, der den Kredithilfe-Empfängern nach den marktlichen Anpassungsreaktionen verbleibt. Bei Zinsverbilligung auf einen bestimmten Zinssatz wird sich die Investitionssteigerung ebenfalls reduzieren, sofern die Höhe der staatlichen Nettoausgaben für das Programm im Vergleich zum vorgenannten Fall konstant ist. Denn ein steigender

1 Dies gilt nur dann nicht, wenn steuerlich die fiktiven, ohne Kredithilfe fälligen Kapitalkosten ertragsmindernd geltend gemacht werden können.

2 Vgl. FOLKERS (1988c), S.222 f.

3 Vgl. CONRAD (1967), S.97; PENNER/SILBER (1973); DICKERTMANN (1980) S.406; KAUFMAN (1981); SILBER/BLACK (1981); BENNETT/DıLORENZO (1986), S.283 ff. Siehe auch unten Abschnitt C.IV.2. 
Marktzinssatz impliziert einen steigenden Zuschußsatz, während die Kreditsumme, die mit gegebenem staatlichen Ausgabevolumen verbilligt werden kann, bei einem einheitlichen Zuschußsatz für jede Krediteinheit sinkt ${ }^{1}$.

Der abschwächende Effekt auf die Höhe der geförderten Investitionen bei steigenden Marktzinssätzen wird begleitet von einer Verdrängung nicht geförderter Investitionen. Dies gilt beispielsweise bei regionalen Kredithilfen, die auch bei Investitionen innerhalb der geförderten Region diskriminieren, sowohl für die Region selbst als auch für die gesamtwirtschaftliche Investitionssumme. Bei einer vollständig unelastischen Kapitalangebotsfunktion werden die nichtgeförderten Investitionen im Ausmaß der zusätzlichen geförderten Investitionen verdrängt ${ }^{2}$.

\section{e. Das Problem der Mitnahmeeffekte}

Im Schrifttum wird von Mitnahmeeffekten einer Investitionssubvention ${ }^{3}$ dann gesprochen, wenn durch die Subventionierung keine zusätzlichen Investitionen induziert werden und die öffentlichen Mittel allein wegen ihrer günstigen Konditionen in Anspruch genommen werden ${ }^{4}$. Soweit Mitnahmeeffekte vorliegen, erhält die Kredithilfe den Charakter einer reinen Umverteilungsmaßnahme ${ }^{5}$. Teilweise wird die "Mitnahme" von Kredithilfen gar als mißbräuchlich bezeichnet ${ }^{6}$. Deshalb wird gefordert, Mitnahmeeffekte weitestmöglich zu verhindern, sofern das Ziel der Fördermaßnahme in einer Ausweitung von Investitionen besteht ${ }^{7}$. Im folgenden sollen nun die Ursachen von Mitnahmeeffekten auf der individuellen Ebene näher betrachtet werden. Das Ausmaß der Mitnahmeeffekte eines Kredithilfeprogramms ergibt sich dann durch Aggregation der individuellen Mitnahmeeffekte.

1 Ein haushaltsmäßig unbeschränktes Kredithilfeprogramm mit einer Zinsverbilligung nach der "Methode auf" führt auch bei steigender Kapitalangebotskurve zum selben Ergebnis wie bei einer horizontalen Kreditangebotskurve, da die Grenzkostenkurve des Investors in diesem Fall einen horizontalen Verlauf hat. Allerdings ist das staatliche Ausgabevolumen im ersteren Fall höher. Vgl. DICKERTMANN (1980), S.77.

2 Vgl. hierzu unten Abschnitt C.IV.2.

3 Mitnahmeeffekte können jedoch nicht nur im Zusammenhang mit Investitionssubventionen auftreten. Sie sollen jedoch hier behandelt werden, weil die meisten Kredithilfen als Investitionsfördermaßnahmen konzipiert sind. Vgl. DICKERTMANN (1980), S.156; FREUND (1982), S.63; ASMACHER/SCHALK/ THOSS (1987), S.122; GOLDSCHMIDT (1987), S.37; ZIMMERMANN (1987), S.339.

5 Vgl. ZIMMERMANN (1987), S.340, der den Mitnahmeeffekt als finanziellen Entlastungseffekt charakterisiert.

6 Vgl. DICKERTMANN/HANSMEYER (1987), S.160.

7 Vgl. GRÖBNER (1983), S.135; SUBVENTIONSBERICHT (1983), S.7; ALBRECHT/ THORMÄLEN (1985), S.55; GOLDSCHMIDT (1987), S.37. Siehe auch LÜDER (1984), S.542. 
Erhält ein Investor bei unterstellter vollständiger Fremdfinanzierung für die gesamte Investitionssumme Zinsverbilligungen, so gilt generell, daß die Investitionen nur dann in voller Höhe der begünstigten Kreditsumme zunehmen, wenn sie ohne Kredithilfe nicht durchgeführt worden wären ${ }^{1}$. Andernfalls sind bei vollkommenem Kapitalmarkt und einer stetigen Kapitalertragskurve die inframarginalen Investitionseinheiten bei einer marktlichen Finanzierung auch ohne Kredithilfe rentabel. Geht man von abnehmenden Grenzerträgen des Kapitals aus, so wächst dem Investor bei einer Kredithilfe mit einheitlichem Zinsverbilligungssatz für die inframarginalen Investitionseinheiten bis zur Investitionshöhe ohne Kredithilfe über die Produzentenrente hinaus eine zusätzliche ökonomische Rente $\mathrm{zu}^{2}$. In diesen Fällen sind Mitnahmeeffekte generell nicht die Ausnahme, sondern geradezu typischer Begleitumstand jeder Kredithilfemaßnahme ${ }^{3}$. Die Höhe des individuellen Mitnahmeeffektes kann dabei durch die Relation der Investitionshöhe ohne Kredithilfe zur Investitionshöhe mit Kredithilfe erfaßt werden. Würden die geförderten Investitionen teilweise auch ohne Kredithilfe durchgeführt, so nimmt der Mitnahmeeffekt mit fallender Zinselastizität der Investitionsnachfrage zu. Eine vollständige Vermeidung von Mitnahmeeffekten ist nur bei perfekt diskriminierenden Kredithilfen möglich. Eine solche Förderpolitik muß jedoch allein schon aufgrund der damit verbundenen Informationserfordernisse scheitern.

Geht man alternativ von unteilbaren Investitionsprojekten aus, so werden Mitnahmeeffekte vollkommen vermieden, wenn durch eine Kredithilfe nur Investitionen induziert werden, deren Nettogegenwartswert allein durch die Kredithilfe positiv wird ${ }^{4}$. Umgekehrt beträgt der Mitnahmeeffekt 100 Prozent, wenn die unteilbare Investition auch ohne Kredithilfe rentabel ist.

Unterstellt man, daß sich die einzelnen Unternehmen jeweils einer steigenden Kapitalangebotsfunktion gegenübersehen ${ }^{5}$, so können ebenfalls Mitnahmeeffekte auftreten. Dieser Zusammenhang wird in der Betriebswirtschaftslehre häufig mit dem von DEAN entwickelten Kapitalbudgetmodell ${ }^{6}$ abgebildet $^{7}$. Danach ergibt sich die Kapitalnachfrage

1 Vgl. LÜDER (1984), S.536.

2 Vgl. BOSWORTH/CARRON/RHYNE (1987), S.36.

3 FREUND (1982), S.63 f., spricht in diesen Zusammenhang von "Mitnahmeeffekten der Höhe nach" im Gegensatz zu "Mitnahmeeffekten dem Grunde nach", die auftreten, wenn keine Investitionen induziert werden.

4 Vgl. LÜDER (1984), S.535.

5 Diese Annahme widerspricht jedoch in gewissem Maße der verbreiteten Behauptung, daß Großunternehmen Finanzierungsvorteile gegenüber kleineren Unternehmen besitzen.

6 Vgl. DEAN (1956), S.62 ff. Zur Kritik dieses Modells aus betriebswirtschaftlicher Sicht vgl. SCHMIDT, R.H. (1986), S.108 f.

7 Vgl. GUTENBERG (1972), S.361 ff.; SCHMIDT, R.H. (1986), S.105 ff. 
eines Unternehmens durch Reihung der möglichen, als unteilbar angenommenen Investitionsobjekte nach fallenden internen Zinsfüßen, während die Kapitalangebotsfunktion aus den nach steigenden Kapitalkosten geordneten Finanzierungsmöglichkeiten folgt ${ }^{1}$. Durch eine Kredithilfe kann es danach zu einer Ausweitung des Finanzierungsspielraums eines Unternehmens kommen. Soweit die Kredithilfe jedoch nicht zu einer Senkung der marginalen Finanzierungskosten führt bzw. die dadurch bewirkte Senkung der marginalen Finanzierungskosten nicht ausreicht, um zusätzlichen, ohne Kredithilfe unrentablen Investitionen über die Rentabilitätsschwelle zu verhelfen, wird die Förderung lediglich mitgenommen ${ }^{2}$. Werden nur Investitionen gefördert, die auch ohne Kredithilfe realisiert worden wären, kann sich eine Investitionssteigerung jedoch über den sog. Volumeneffekt ergeben. Bewirkt die Kredithilfe durch die Verminderung des marktlichen Finanzmittelbedarfs des Unternehmens aufgrund reduzierter marginaler Finanzierungskosten eine Senkung der erforderlichen Grenzertragsraten der Investitionen, so können zusätzliche Investitionen in das Investitionsprogramm aufgenommen werden. Dieser Volumeneffekt führt zwar zu einer Erhöhung der gesamten Investitionssumme, nicht aber zu einer Steigerung der Investitionsarten, deren Realisierung durch die Förderung bewirkt werden soll ${ }^{3}$.

Ist der Kreditmarkt aufgrund asymmetrischer Information durch adverse Selektion gekennzeichnet, können auch bei Kreditrationierung Mitnahmeeffekte auftreten, wenn die geförderten rentablen Investitionen ohne Kredithilfen mittels Eigenkapitalfinanzierung realisiert würden ${ }^{4}$.

Darüber hinaus treten ausschließlich Mitnahmeeffekte ohne jede Anreizwirkung auf, wenn eine Investition ohne Kredithilfe rentabel ist, andererseits aber eine marginale Investitionserhöhung trotz Kredithilfe zu Verlusten führt, weil der Grenzertrag einer zusätzlichen Investitionseinheit unter ihren Grenzkosten liegt. Die Investitionskreditnachfragekurve hat danach im relevanten Bereich einen unelastischen Verlauf. Ursache dafür kann eine Unstetigkeitsstelle der Kapitalertragsfunktion bei der ohne Kredithilfe realisierten Kapitalmenge sein. Sofern die Verwendung des zinsverbilligten Kredits kontrollierbar ist, bewirkt die Kredithilfe unter diesen Bedingungen nur eine Substitution von marktlichem durch zinsverbilligtes Fremdkapital bzw. von Eigen- durch Fremdkapital, d.h. eine Erhöhung der Fremdkapitalquote ${ }^{5}$. Dadurch erhöht sich das Lebenseinkommen der Investoren,

\footnotetext{
1 Vgl. SCHMIDT, R.H. (1986), S.105 f.

2 Vgl. KRIST/MAAS (1983), S.51 ff., insbesondere S.54.

3 Vgl. LÜDER (1984), S.536.

4 Vgl. oben Abschnitt C.II.1.a.ff.

5 Vgl. SILBER/BLACK (1981), S.121.
} 
und sie können aufgrund der veränderten Vermögensrestriktion ihre intertemporalen Konsum- und Produktionsentscheidungen anpassen.

Eine Substitution von marktlichem durch zinsverbilligtes Fremdkapital liegt bei Umschuldungs-Kredithilfen vor ${ }^{1}$. Werden dadurch nicht geförderte Investitionen oder Gewinnausschüttungen erhöht ${ }^{2}$, ist ein vollständiger Mitnahmeeffekt gegeben ${ }^{3}$. Auch bei Kredithilfen für Humankapitalinvestitionen dürften Mitnahmeeffekte keine Ausnahme sein. Ist z.B. der Anspruch auf eine Ausbildungs-Kredithilfe lediglich vom Periodeneinkommen der Unterhaltsverpflichteten abhängig, können auch Studenten aus Familien mit relativ hohem Vermögen in ihren Genuß kommen, wenn die relevanten Periodenerträge des Vermögens vergleichsweise gering sind. Unter diesen Bedingungen kann der Fall eintreten, daß das Studium aufgrund der Kredithilfe fremdfinanziert wird und die Eigenmittel, die ohne Kredithilfe zur Finanzierung des Studiums eingesetzt worden wären, zur Erhöhung des künftigen Einkommens der Unterhaltsverpflichteten bzw. zur Erhöhung ihres Gegenwartskonsums verwendet werden ${ }^{4}$.

Teilweise sind Kredithilfeprogramme so konstruiert, daß lediglich inframarginale Investitionseinheiten begünstigt werden. So werden Kredithilfen bisweilen auf einen bestimmten Investitionsbetrag beschränkt, während darüber hinausgehende Investitionen zu marktlichen Konditionen finanziert werden müssen ${ }^{5}$. Übersteigt der Investitionsbetrag ohne Kredithilfe die maximal förderfähige Investitionssumme, so beeinflußt die Kredithilfe die Investitionshöhe nicht. Es werden nur marktliche Kredite durch staatlich verbilligte Kredite substituiert ${ }^{6}$. Dadurch steigen lediglich die durchschnittliche Nettoertragsrate und die ökonomische Rente des Investors, d.h. es ergeben sich ausschließlich Mitnahmeeffekte. Dies gilt allerdings nicht, wenn durch Kredithilfen unteilbare Investitionen gefördert werden. Denn dann kann auch eine auf einen Investitionsteilbetrag beschränkte Kredit-

1 Vgl. v.WYSOCKI (1961), S.241 ff. DICKERTMANN (1980), S.156 spricht hier von repressiven Kredithilfen.

2 Vgl. v.WYSOCKI (1961), S.244 f.

3 Wenn mit Umschuldungs-Kredithilfen Desinvestitionen vermieden werden können, so ergibt sich aber im Vergleich zur Referenzsituation ohne Kredithilfe eine Erhöhung des Kapitalstocks. Demnach liegen insoweit keine Mitnahmeeffekte vor.

4 Vgl. BOSWORTH/CARRON/RHYNE (1987), S.9. Für diesen Zusammenhang scheint es empirische Belege zu geben. So stellen BENNETT/DıLORENZO (1986), S.288 im Hinblick auf zinsverbilligte Studentendarlehen in den USA fest: "As the spread between interest rates on student loans and market rates widened, new student loans rose from \$2.7 billion in 1979 to $\$ 7,2$ billion in 1981 , reflecting a widespread recognition of the opportunities to borrow thousands of dollars at 7 percent and invest the proceeds in long-term bonds or money market funds paying 14 to 16 percent."

5

So sind die von der DAB und der LKB vergebenen Existenzgründungsdarlehen auf maximal 300 TDM begrenzt. Vgl. GOLDSCHMIDT (1987), S.69, 71.

6 Vgl. DICKERTMANN (1980), S.156 f. 
hilfe eine Investitionssteigerung bewirken. Dies gilt einmal dann, wenn eine Investition aufgrund der mit der Kredithilfe verbundenen Zinsverbilligung rentabel wird ${ }^{1}$. Zum anderen können Kredithilfen beispielsweise bei diskontinuierlicher Investitionsneigung ihrer Empfänger deren Periodeneinkommen so weit erhöhen, daß die entsprechende Investition im Falle unvollkommener Kapitalmärkte nicht länger an den Periodenrestriktionen scheitert $^{2}$. In beiden Fällen entsprechen Kredithilfen jedoch in ihrer Wirkung direkten, an die Investitionen gebundenen Transferzahlungen an ihre Empfänger.

Ist ein Kredithilfeprogramm budgetmäßig bei gegebenem Zinsverbilligungssatz auf einen Betrag begrenzt, der zur vollständigen Befriedigung der Nachfrage nach zinsverbilligten Krediten nicht ausreicht ${ }^{3}$, kommt es zu einer Mengenrationierung der Kredithilfen. Ihre Verteilung auf die einzelnen Kreditnachfrager bestimmt dann die Höhe der Mitnahmeeffekte. Erfolgt diese nach dem sogenannten Windhundverfahren, so werden die Investoren, die bedient werden, bis zu derjenigen Menge verbilligte Kredite nachfragen, bei der Grenzertrag und Grenzkosten des Kapitals übereinstimmen. Ob die Kredithilfe eine Investitionssteigerung oder nur Mitnahmeeffekte bewirkt, läßt sich nicht generell beantworten. Dies soll nun anhand von Abb.3 verdeutlicht werden.

Es werden zwei Individuen A und B mit der vollkommen unelastischen Investitionskredit-Nachfragekurve $D_{A}$ bzw. der elastischen Nachfragekurve $D_{B}$ betrachtet ${ }^{4}$. Das Gleichgewicht ohne Kredithilfe ergibt sich im Schnittpunkt Angebotskurve $S$ mit der aggregierten Nachfragekurve $D_{(A+B)}$ bei der Kreditmenge $K_{0}$. Wird nun Nachfragern eine unbeschränkte Kredithilfe mit dem Zuschußsatz z gewährt, so erhält man durch Parallelverschiebung des unteren Astes von $D_{(A+B)}$ um $z$ nach oben die neue Nachfragekurve $D_{(A+B)}$, und die erhöhte Kreditnachfrage $K_{1}$. Die Ausgaben für das Programm betragen dann $\mathbf{z K}_{1}$. Ist nun das Ausgabevolumen bei gegebenem Zuschußsatz auf $\mathbf{z K}_{0}$ begrenzt, so soll zunächst angenommen werden, daß sich Individuum B zuerst um eine Kredithilfe bewirbt und deshalb vorrangig bedient wird. In diesem Fall erhält man ebenfalls die aggregierte Nachfragekurve $D_{(A+B)}$, und damit dieselbe Gleichgewichtsmenge $K_{1}$ wie bei einer unbeschränkten Kredithilfe. Dieses Ergebnis ist darauf zurückzuführen, daß Individuum A keine Anpassungsreaktionen vornimmt und im Vergleich zur unbeschränkten

1 Vgl. LÜDER (1984), S.535.

2 Diese Konstellation wird offensichtlich bei sog. "Sprunginvestitionen" mittelständischer Unternehmen als relevant erachtet. Vgl. GOLDSCHMIDT (1987), S.49 f. Sie kann auch in Bezug auf Wohnungsbauinvestitionen der privaten Haushalte auftreten. Vgl. oben Abschnitt C.II.1.a.ff.

3 Dieser Fall kann immer nur bei den Kredithilfeprogrammen eintreten, auf die kein Rechtsanspruch besteht.

4 Von einer Nachfrage nach Konsumkrediten wird hier abgesehen. 


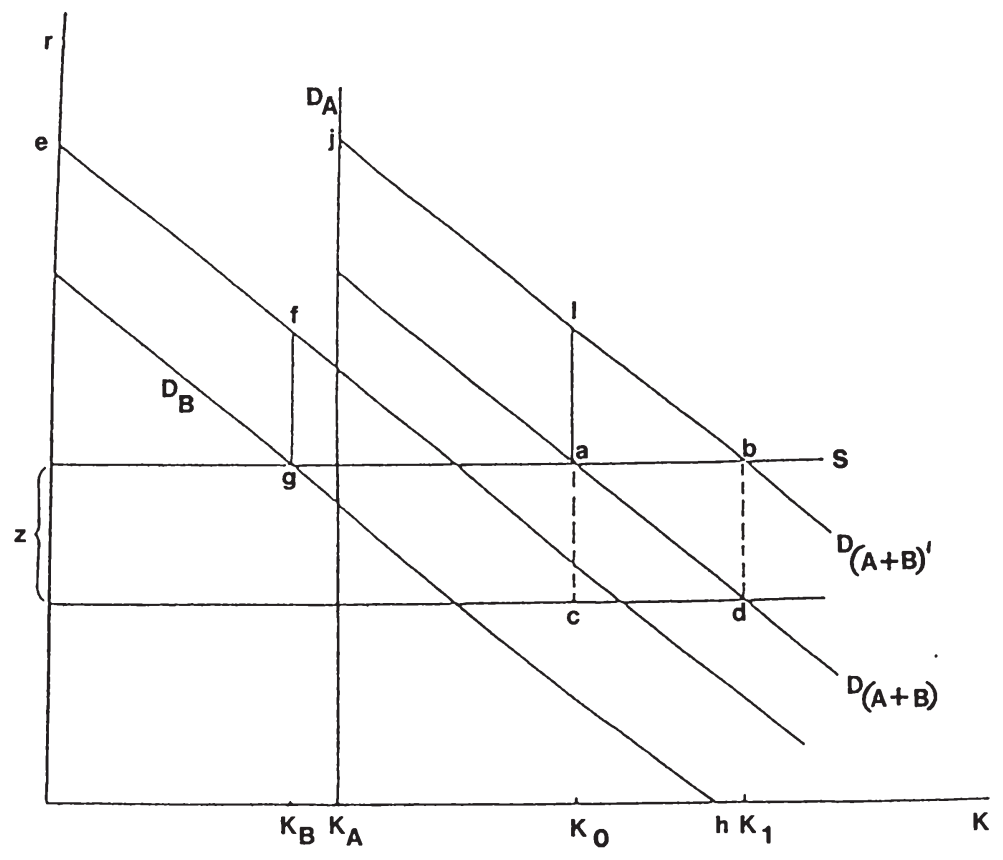

Abb. 3

Kredithilfe lediglich einen Rentenverlust in Höhe von abcd erleidet. Stellt hingegen Individuum A seinen Kredithilfeantrag zuerst und erhält deshalb eine Zinsverbilligung von $\mathrm{zK}_{\mathrm{A}}$, so verbleibt $B$ nur noch ein "Rest" an begünstigten Krediten in Höhe von $K_{0}-K_{A}=K_{B}$. Die Nachfragefunktion des B entspricht dem Linienzug efgh und die aggregierte Nachfragefunktion dem Linienzug jlad. D.h. daß sich im Gleichgewicht wieder die Kreditmenge $\mathrm{K}_{0}$ wie im Fall ohne Kredithilfe ergibt und somit ausschließlich Mitnahmeeffekte zu verzeichnen sind. Dieses Beispiel zeigt, daß das Ausmaß der Investitionssteigerung bei einer Kredithilfe, die nach dem Windhundverfahren vergeben wird, außerordentlich unsicher ist. Je unelastischer die Kreditnachfrage der erfolgreichen Kredithilfebewerber im Vergleich zu den erfolglosen Bewerbern ist, desto geringer wird die Investitionssteigerung und desto höher werden die Mitnahmeeffekte ${ }^{1}$. Da Informationen darüber regelmäßig nicht vorhan

1 Im Gegensatz dazu vertreten SILBER/BLACK (1981), S. 136 die Auffassung, daß ein Windhundverfahren zu keiner Investitionssteigerung führt, wenn es sich bei den erfolgreichen 
den sein werden, welche Investoren ihre Nachfrage nach Kredithilfen zuerst geltend machen, werden die Anreizwirkungen auf die Investitionshöhe und damit die Zielerreichung eines quantitativ beschränkten Kredithilfeprogramms weitgehend zufällig. Darüber hinaus wird eine Investitionssteigerung um so unwahrscheinlicher, je geringer das beschränkte Ausgabevolumen im Vergleich zum Ausgabevolumen eines entsprechenden unbeschränkten Kredithilfeprogramms ist.

Geht man alternativ davon aus, daß die begrenzten Mittel anteilsmäßig verteilt werden, wenn die gesamte Nachfrage nach verbilligten Krediten bekannt ist, so werden in jedem Fall Mitnahmeeffekte auftreten. Sie werden dann 100 Prozent betragen, wenn die zugeteilte zinsverbilligte Kreditmenge für jeden Investor geringer ist als die Kreditnachfrage ohne Zinsverbilligung.

Wenngleich das Ausmaß der aggregierten Mitnahmeeffekte von Kredithilfen im Einzelfall einer empirischen Betrachtung bedürfte ${ }^{1}$, zeigt die vorstehende Diskussion, daß man das Ausmaß der investitionsfördernden Wirkung regelmäßig weit überschätzt, wenn man als "Erfolgsmaßstab" für die Zielerreichung lediglich das mit Kredithilfen zinsverbilligte Kreditvolumen heranzieht.

\section{Wirkungen öfientlicher Kredithilfen auf die Arbeitsnachfrage}

Da mit Kredithilfen häufig das Ziel verfolgt wird, in den geförderten Bereichen die Zahl der Arbeitsplätze und damit die Beschäftigungsmöglichkeiten zu erhöhen ${ }^{2}$, soll im folgenden untersucht werden, ob die Vergabe von Kredithilfen die Erreichung dieses Ziel erwarten läßt. Dagegen soll an dieser Stelle nicht diskutiert werden, inwieweit Kredithilfen dazu geeignet sind, in gesamtwirtschaftlichen Unterbeschäftigungssituationen positive Beschäftigungseffekte $\mathrm{zu}$ induzieren ${ }^{3}$.

Kredithilfe-Nachfragern um inframarginale Kreditnachfrager handelt. Dahinter steht offensichtlich die Vorstellung, daB es Kreditnachfrager gibt, die ihre Kreditnachfrage nicht bis zu ihrem individuellen Optimum ausdehnen, wo sich Grenzertrag und Grenzkosten ausgleichen. Diese Annahme ist im gegebenen Modellrahmen jedoch nicht plausibel.

1 Diese Untersuchungen stehen für die großen Kredithilfeprogramme noch aus. Hinsichtlich anderer regionalpolitischer Investitionsfördermaßnahmen liegen verschiedene Untersuchungen vor, die zu deutlich divergierenden Ergebnissen hinsichtlich des Umfangs der Mitnahmeeffekte gelangen. Vgl. FRANZ/SCHALK (1982), S.5; KRIST/NICOL (1982), S.135; ASMACHER/ SCHALK/THOSS (1987), S.109 ff.

2 Diese Zielsetzung wird im Bereich der Regionalpolitik mit dem Stichwort "aktive Sanierung" umschrieben. Vgl. GOLDSCHMIDT (1987), S.138.

Vgl. dazu oben Abschnitt C.II.3. 


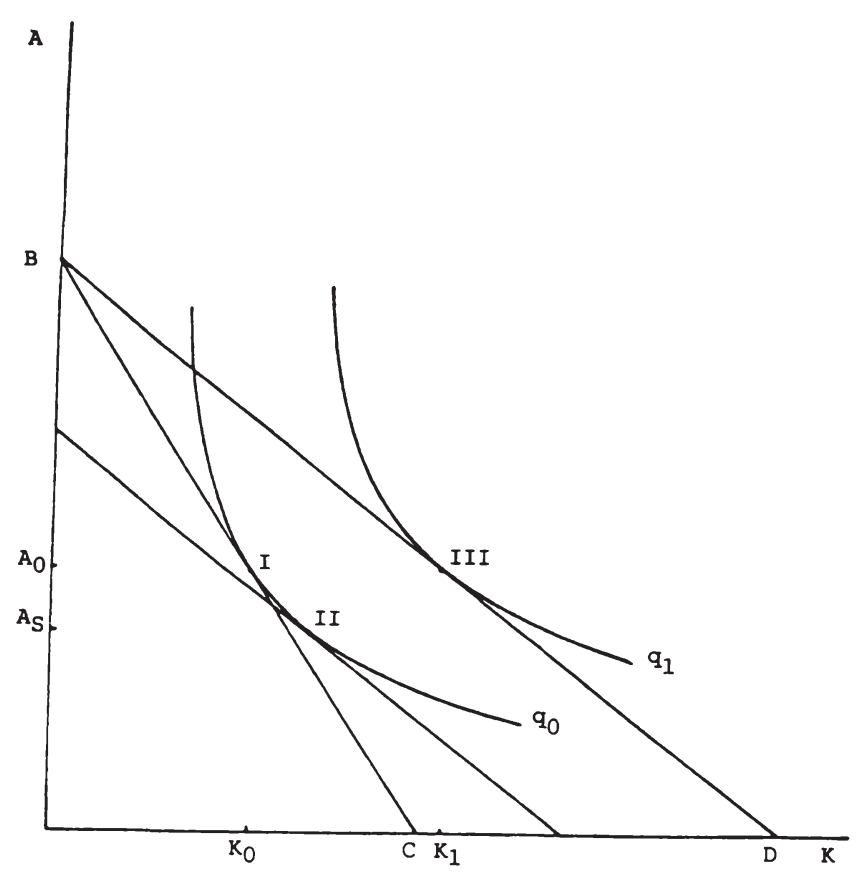

Abb. 4

Die Wirkung von Kredithilfen auf die Arbeitsnachfrage kann mit Hilfe von Abb. 4 aufgezeigt werden. Dabei wird unterstellt, daß die beiden Produktionsfaktoren Arbeit A und Kapital $\mathrm{K}$ ex ante gegeneinander substituierbar sind ${ }^{1}$. Weiterhin wird wiederum angenommen, daß die Finanzierung des Realkapitaleinsatzes allein durch Fremdkapital erfolgt. Die Iso-Kostenlinie BC gibt die minimalen Kosten an, zu denen der Output $\mathbf{q}_{0}$ produziert werden kann. Das kostenminimale Faktoreinsatzverhältnis ist in I bei einem Arbeitseinsatz von $A_{0}$ und einem Kapitaleinsatz von $K_{0}$ gegeben. Wird nun eine unbeschränkte Kredithilfe gewährt, so dreht sich die Iso-Kostenlinie im Gegenuhrzeigersinn in B auf BD. D.h. daß mit gegebenen Kosten ein höherer Output $q_{1}$ produziert werden kann. Der neue Optimalpunkt liegt in III. Die Bewegung von I nach III kann nun in einen Substitutions- und Outputeffekt zerlegt werden ${ }^{2}$. Der Substitutionseffekt, der durch die Bewegung von I nach

1 Vgl. ASMACHER/SCHALK/THOSS (1987), S.45.

2 Vgl. ASMACHER/SCHALK/THOSS (1987), S.45 f. 
II beschrieben wird, zeigt, daß aufgrund der geänderten Faktorpreisrelation bei konstantem Output Arbeit durch Kapital substituiert wird und die Arbeitsnachfrage auf $\mathbf{A}_{S}$ zurückgeht. Aufgrund des Rückgangs der Gesamtkosten für den konstanten Output ist für den Produzenten bei gegebenem Outputpreis eine Ausweitung seines Outputs vorteilhaft ${ }^{1}$. Dieser Outputeffekt bewirkt nun im Normalfall eine Erhöhung der Nachfrage nach beiden Faktoren, so daß Punkt III erreicht wird. Damit führen Substitutions- und Einkommenseffekt zu einer erhöhten Kapitalnachfrage, während sie im Hinblick auf die Arbeitsnachfrage gegenläufig wirken. In Abb. 4 kompensieren sich beide Effekte vollständig, so daß die Arbeitsnachfrage aufgrund der Kredithilfe konstant bleibt. Jedoch sind die Fälle einer verringerten und erhöhten Arbeitsnachfrage in Abhängigkeit von der relativen Stärke von Substitutions- und Outputeffekt ebenfalls denkbar ${ }^{2}$. Der die Arbeitsnachfrage mindernde Substitutionseffekt und damit die Höhe der Kapitalintensität nehmen mit betragsmäßig steigender Faktor-Substitutionselastizität zu. Umgekehrt tritt bei einer streng limitationalen Produktionsfunktion kein Substitutionseffekt auf ${ }^{3}$. Andererseits ist der Outputeffekt auf die Arbeitsnachfrage um so höher, je geringer die Skalenelastizität der Produktionsfunktion ist, da dann die durch die Marktverhältnisse gegebene optimale Outputerhöhung eine um so größere Inputsteigerung erfordert. Damit sind die Beschäftigungswirkungen von Kredithilfen um so geringer, je größer die gegenseitige Substituierbarkeit der Faktoren und die Skalenerträge sind ${ }^{4}$. Weiterhin führt die Kredithilfe zu einer Mehrbelastung und damit zu Wohlfahrtsverlusten aufgrund der Verzerrung der Faktorpreisrelation. Diese ließe sich bei einer allgemeinen Faktorsubventionierung vermeiden, die das Faktorpreisverhältnis unverändert läßt.

Betrachtet man den allgemeinen Gleichgewichtszusammenhang, so läßt sich zeigen, daß bei einer speziellen Kredithilfe, die in einem Sektor gewährt wird, der Arbeitseinsatz im geförderten Sektor konstant bleibt, wenn man Cobb-Douglas-Funktionen bei Produktion und Konsum unterstellt, die Faktor- bzw. Güter-Substitutionselastizitäten von -1 implizieren ${ }^{5}$. Damit wird deutlich, daß die Beschäftigungseffekte öffentlicher Kredithilfen in den geförderten Bereichen ohne genaue Kenntnis der relevanten Elastizitäten als außerordentlich unsicher einzuschätzen sind ${ }^{6}$.

1 Dies ergibt sich aufgrund der Dualität von Kostenminimierung und Outputmaximierung. Zu einem knappen Überblick dazu vgl. SCHUMANN (1987), S.134 ff.

2 Vgl. ASMACHER/SCHALK/THOSS (1987), S.47.

3 Vgl. BOADWAY/WILDASIN (1984), S.359; ASMACHER/SCHALK/THOSS (1987), S.48.

4 Vgl. ASMACHER/SCHALK/THOSS (1987), S.48.

5 Vgl. BROWN/JACKSON (1986), S.289.

6 Dennoch sind positive Beschäftigungseffekte nicht auszuschließen. So zeigen ökonometrische Untersuchungen der Wirkungen der regionalpolitischen Instrumente in der Bundesrepublik, die zu einer Verbilligung der Kapitalnutzungskosten führen, daß sich kurzfristig zwar ein Rück- 


\section{Wirkungen öffentlicher Kredithilfen auf die Risikoübernahme}

Mit der Gewährung öffentlicher Kredithilfen wird häufig das Ziel verfolgt, den Leistungsempfängern Anreize zu einer erhöhten Risikoübernahme zu geben ${ }^{1}$, um damit volkswirtschaftliche Gewinne zu realisieren. Deshalb soll im folgenden analysiert werden, wie die Risikoübernahme durch Investitions-Kredithilfen beeinflußt wird. Dabei werden die Effekte von Kredithilfen auf das Investitionsrisiko bei vollständiger und unvollständiger Information analysiert.

\section{a. Das Investitionsrisiko bei vollständiger Information}

Um die Auswirkungen öffentlicher Kredithilfen auf das Investitionsrisiko zu analysieren, wird zunächst Risikoneutralität und daran anschließend Risikoaversion des betrachteten Investors unterstellt. Dabei wird angenommen, daß vollständige Information besteht, so $\mathrm{da} \beta$ der Staat sicherstellen kann, da $\beta$ risikoreichere Investitionen nur gefördert werden, wenn ihre erwartete Ertragsrate zumindest gleich hoch ist wie die erwartete Ertragsrate risikoärmerer Investitionen. Damit wird implizit unterstellt, daß das gesamtwirtschaftliche Investitions-Portfolio kein systematisches Risiko aufweist und der Staat deshalb zwischen Investitionen mit unterschiedlichem Risiko aber identischer erwarteter Ertragsrate indifferent ist.

\section{aa. Risikoneutralität des Investors}

Im Fall der Risikoneutralität wird angenommen, daß der Investor in der Gegenwart eine vollständig kreditfinanzierte Investitionssumme in Höhe von 1 entweder für Projekt A oder Projekt B verwenden kann. Beide Projekte seien einperiodig und führen nach einer Periode mit der Wahrscheinlichkeit $1-\mathrm{p}_{\mathrm{A}}$ zum Brutto-Investitionsertrag $1+\mathbf{R}_{\mathrm{A}}$ bzw. mit der Wahrscheinlichkeit $1-p_{B}$ zum Brutto-Investitionsertrag $1+R_{B}$. Bei den jeweiligen Gegenwahrscheinlichkeiten $\mathrm{p}_{\mathrm{A}}$ bzw. $\mathrm{p}_{\mathrm{B}}$ betrage der Investitionsertrag Null. Dabei soll $\mathrm{p}_{\mathrm{A}}<\mathrm{p}_{\mathrm{B}}$ gelten. Die Haftung gegenüber dem Kreditgeber sei auf den Investitionsertrag beschränkt. Weiterhin wird unterstellt, daß auch der Kreditgeber risikoneutral ist. Der risi-

gang, längerfristig jedoch eine Erhöhung der Arbeitsnachfrage in den Förderregionen ergibt. Vgl. ASMACHER/SCHALK/THOSS (1987), S.117 ff. Dabei ist jedoch zu berücksichtigen, $\mathrm{da} \beta$ sich diese Untersuchung nicht auf Kredithilfen, sondern auf andere Subventionsformen, insbesondere Investitionszulagen und Sonderabschreibungen, bezieht.

Vgl. z.B. ARTMANN (1981), S.400. 
kolose Marktzinssatz betrage r. Ohne Kredithilfe sei der Investor zwischen beiden Projekten indifferent, weil hinsichtlich des Investitionsgewinns gelten soll:

$$
\left(1-p_{A}\right)\left[1+R_{A}-(1+r) /\left(1-p_{A}\right)\right]=\left(1-p_{B}\right)\left[1+R_{B}-(1+r) /\left(1-p_{B}\right)\right] \quad \text { bzw. }
$$

$$
1+R_{A}=\left(1+R_{B}\right)\left(1-p_{B}\right) /\left(1-p_{A}\right) \text {. }
$$

Wird nun bei beiden Projektalternativen ein Zinszuschuß in Höhe von z gewährt, der im ungünstigen Zustand dem Kreditgeber zufließen soll, so erhöht sich der Investitionsgewinn bei beiden Projektalternativen um z. D.h. daß der Investor auch nach dem Zinszuschuß zwischen beiden Alternativen indifferent ist.

Werden die Zinskosten des Investors im günstigen Umweltzustand dagegen durch einen Zinszuschuß, ein öffentliches Darlehen oder eine Kreditgewährleistung auf $1+r$ reduziert, so gilt unter den getroffenen Annahmen:

$$
\left(1-p_{A}\right)\left[1+R_{A}-(1+r)\right]<\left(1-p_{B}\right)\left[1+R_{B}-(1+r)\right]
$$

Unter diesen Voraussetzungen wird der Investor zwischen beiden Projektalternativen nicht mehr indifferent sein, sondern das riskantere Projekt B vorziehen. Die soziale Wohlfahrt wird dadurch jedoch nicht berührt, weil die sozialen Opportunitätskosten des Risikos Null betragen ${ }^{1}$.

\section{bb. Risikoaversion des Investors}

Zur Analyse des Verhaltens risikoaverser Investoren soll im folgenden ein PortfolioModell verwendet werden, nach dem der Investor eine gegebene Investitionssumme $\mathrm{I}_{0}$ so zwischen einer riskanten und einer risikolosen Investitionsalternative aufteilt, daß sein Erwartungsnutzen maximiert wird. Dabei wird unterstellt, daß riskante und risikolose Investitionen beliebig teilbar sind. Das Maß für die Risikoübernahme ist hier in der individuellen Nachfrage nach der riskanten Investitionsalternative zu sehen, die durch ihren Anteil im Portfolio gemessen wird ${ }^{2}$. Der Vorteil des Erwartungsnutzenkonzepts ${ }^{3}$ gegenüber den in der älteren Literatur verwendeten Erwartungswert-Verlust- oder ErwartungswertVarianz-Ansätzen ${ }^{4}$ besteht darin, daß die Erwartungsnutzenfunktion keinen Beschränkun-

$1 \mathrm{Zu}$ vergleichbaren Konsequenzen bei der Analyse von Besteuerung und Risiko siehe BOADWAY/WILDASIN (1984), S. 317.

2 Vgl. STIGLITZ (1969), S.269.

3 Vgl. dazu MOSSIN (1968), S.74 ff.; STIGLITZ (1969), S.263 ff.; ATKINSON/STIGLITZ (1980), S.99 ff.; HERB (1988), S.84 ff.

4 Vgl. zu ersterem DOMAR/MUSGRAVE (1944); grundlegend zu letzterem TOBIN (1957/58), S. $65 \mathrm{ff}$. 
gen unterliegt ${ }^{1}$. Bei der folgenden Betrachtung handelt es sich um eine Partialanalyse, in der von einem konstanten Marktzinssatz ausgegangen wird.

Es wird unterstellt, daß beide Investitionsalternativen einperiodig und ihre Grenzerträge bei gegebener Investitionssumme konstant sind ${ }^{2}$. Die gesamte Investitionssumme soll fremdfinanziert sein, wobei für beide Investitionsalternativen gesonderte Kredite aufzunehmen sind. Die Kreditgeber sollen sich risikoneutral verhalten ${ }^{3}$. Die Haftung des Investors für Kreditforderungen sei auf die Erträge der damit finanzierten Alternative begrenzt. Es werden zwei mögliche Umweltzustände 1 und 2 unterstellt, die mit der Wahrscheinlichkeit (1-p) bzw. p eintreten. Der Netto-Investitionsertrag ${ }^{4}$ der risikolosen Alternative betrage in beiden Zuständen je Investitionseinheit $R$ und der Kreditzinssatz sei $r$, wobei $\mathrm{R}>\mathrm{r}$ gelten soll. Bei der riskanten Alternative entspreche der NettoInvestitionsertrag $X$ im Zustand $1 X_{1}>R /(1-p)$ und im Zustand $2 X_{2}=0$. Daraus folgt ein Zinssatz des riskanten Kredits in Höhe von $r /(1-p)$, wobei $X_{1}-r /(1-p)>R-r$ gilt 5 . Der Anteil der riskanten Alternative im Investitionsportfolio soll a betragen.

Der Investor wird das Portfolio so zusammenstellen, daß der Erwartungsnutzen maximal wird, der vom Vermögen am Periodenende abhängt und allein von den Gewinnmöglichkeiten bestimmt sein soll. Es gilt:

$$
\begin{aligned}
\mathrm{E}[\mathrm{U}(\mathrm{W})]= & (1-\mathrm{p}) \mathrm{U}\left\{\left[\mathrm{R}-\mathrm{r}+\mathrm{a}\left(\mathrm{X}_{1}-\mathrm{pr} /(1-\mathrm{p})-\mathrm{R}\right)\right] \mathrm{I}_{0}\right\} \\
& +\mathrm{pU}\left\{[(1-\mathrm{a})(\mathrm{R}-\mathrm{r})] \mathrm{I}_{0}\right\}=\mathrm{Max} !
\end{aligned}
$$

Die Optimalbedingung erster Ordnung lautet demnach:

$$
\begin{aligned}
& (1-p) U^{\prime}\left(W_{1}\right)\left[X_{1}-p r /(1-p)-R\right]-p U^{\prime}\left(W_{2}\right)(R-r)=0 \text { bzw. } \\
& \frac{(1-p) U^{\prime}\left(W_{1}\right)}{p U^{\prime}\left(W_{2}\right)}=\frac{(R-r)}{X_{1}-p r /(1-p)-R} .
\end{aligned}
$$

1 Vgl. STIGLITZ (1969), S.263; HERB (1988), S.84.

2 So wohl auch HERB (1988), S.84 ff. Auf diese Weise ist gewährleistet, daB die Zusammensetzung des Portfolios allein von dem Risiko der Investitionserträge abhängig ist.

3 Diese Annahme ist nicht völlig unplausibel, wenn man unterstellt, daB ein Kreditgeber ein diversifiziertes Kreditportfolio hält, in dem das unsystematische Risiko entfällt. Gibt es auch kein systematisches Risiko, bieten risikoaverse und risikoneutrale Kreditgeber im Kapitalmarktgleichgewicht Kredite zum selben Zinssatz an. Vgl. oben Abschnitt C.I.2.

4 Brutto-Investitionsertrag (1+R) abzüglich Abschreibungen.

5 Im Modell wird damit implizit unterstellt, daB die Investitionserträge bei der riskanten und risikolosen Alternative jeweils die Kapitalkosten übersteigen. Unter den gegebenen Annahmen, ist es wenig plausibel, daB der Investor die Investitionssumme nicht ausdehnt. Aus Vereinfachungsgründen soll daher unterstellt werden, $\mathrm{da} B$ die Investitionserträge der beiden Alternativen in der Weise von der Höhe der Investitionssumme abhängen, daB die marginalen Investitionserträge jenseits von $\mathrm{I}_{0}$ unter ihre Kapitalkosten fallen. 
D.h. daß sich im Optimum die Grenznutzen des Vermögens in Zustand $1\left(W_{1}\right)$ und $2\left(W_{2}\right)$ ausgleichen müssen. Diese Bedingung ist dann erfüllt, wenn die Grenzrate der Substitution gleich der Steigung der Budgetgeraden ist, also (C.III.7a) gilt ${ }^{1}$.

Erhält nun der Investor eine entgeltlose Kreditgewährleistung mit dem Deckungsgrad D, so bekommt man die neue Zielfunktion

$$
\begin{aligned}
E\left[U\left(W^{G}\right)\right]= & (1-p) U\left\{\left[R-r+a\left(X_{1}-\operatorname{pr}(1-D) /[1-p(1-D)]-R\right)\right] I_{0}\right\} \\
& +p U\left\{[(1-a)(R-r)] I_{0}\right\}=\operatorname{Max} !
\end{aligned}
$$

Die neue Optimalbedingung lautet:

$$
(1-p) U^{\prime}\left(W_{1}^{G}\right)\left\{X_{1}-p r(1-D) /[1-p(1-D)]-R\right\}-p^{\prime}\left(W_{2}^{G}\right)(R-r)=0
$$

bzw.

$$
\frac{(1-\mathrm{p}) \mathrm{U}^{\prime}\left(\mathrm{W}_{1}^{\mathrm{G}}\right)}{\mathrm{pU^{ \prime }}\left(\mathrm{W}_{2} \mathrm{G}_{2}\right)}=\frac{(\mathrm{R}-\mathrm{r})}{\mathrm{X}_{1}-\mathrm{pr}(1-\mathrm{D}) /[1-\mathrm{p}(1-\mathrm{D})]-\mathrm{R}} .
$$

$\mathrm{Da} \operatorname{pr}(1-\mathrm{D}) /[1-\mathrm{p}(1-\mathrm{D})]<\mathrm{pr} /(1-\mathrm{p})$ gilt $^{2}$, ist die betragsmäßige Steigung der Budgetgeraden geringer als ohne Gewährleistung. Dies impliziert einen Substitutionseffekt in Richtung auf eine Erhöhung des Vermögens im günstigen Umweltzustand 1 und seine Reduzierung im ungünstigen Umweltzustand 2. Ist das Vermögen in Zustand 1 ein superiores Gut, so wirkt auch der durch die Drehung der Budgetgeraden verursachte Vermögenseffekt in Richtung auf eine Erhöhung des Vermögens in Zustand $1^{3}$. Allerdings sagt dieses Ergebnis noch nichts darüber aus, ob durch die Kreditgewährleistung auch a, der Anteil der riskanten Investition im Portfolio und damit die Risikoübernahme, erhöht wird. Denn der Substitutionseffekt bewirkt eine Erhöhung von $W_{1}^{G}$ allein schon durch die Reduzierung der Finanzierungskosten in Zustand 1 bei unverändertem a. Darüber hinaus ist Superiorität des Vermögens in Zustand 1 unter bestimmten Bedingungen auch mit einer Reduzierung von a vereinbar.

Anhand von Abb. 5 soll nun veranschaulicht werden, unter welchen Bedingungen das intuitiv zu erwartende Ergebnis resultiert, daß die Erhöhung der relativen Gewinnrate 4 in Zustand 1 zu einer Erhöhung von a und damit zu einer höheren Risikoübernahme führt. In

1 Vgl. STIGLITZ (1969), S.267.

2 Dies gilt, weil d $\{\operatorname{pr}(1-\mathrm{D}) /[1-\mathrm{p}(1-\mathrm{D})]\} / \mathrm{dD}=\cdot \mathrm{pr} /[1-\mathrm{p}(1-\mathrm{D})]^{2}<0$.

3 Dieser Zusammenhang wird deutlich, wenn man die Portfolio-Entscheidung des Investors als eine Art Versicherungsentscheidung interpretiert, wobei sich der Investor gegen die Folgen des ungünstigen Zustands durch Beimischung von Investitionseinheiten der risikolosen Alternative versichert. Eine Kreditgewährleistung ist insoweit nichts anderes als eine Erhöhung des Versicherungspreises. Vgl. EHRLICH/BECKER (1972), S.628.

Nettoertragsrate abzüglich marginale Finanzierungskosten. 
Abb. 5 a repräsentiert die Geraden AB die Budgetgerade vor der Kreditgewährleistung. Durch die Gewährleistung dreht sich die Budgetgerade in A auf AC. Dadurch wird ein höheres Erwartungsnutzenniveau erreicht.

Aufgrund des Strahlensatzes gilt, daß $a=A D / A B$ konstant bleibt, wenn das neue Optimum in Punkt P liegt, der sich als Schnittpunkt einer Parallelen zur Abszisse durch D mit der Geraden AC ergibt. Dies ist auch ökonomisch leicht einsichtig, weil im Modellzusammenhang ein unveränderter Anteil a ein konstantes Vermögen in Zustand 2 impliziert, so daß durch die Gewährleistung nur das Vermögen in Zustand 1 erhöht wird.

In Abb. 5 a ist weiterhin der Fall dargestellt, daß der Substitutionseffekt den Portfolioanteil der riskanten Investition unverändert läßt ${ }^{1}$. Dies ergibt sich daraus, daß $\mathrm{JF} / \mathrm{JI}=\mathrm{GH} / \mathrm{GI}$ gilt $^{2}$. Andererseits gilt $\mathrm{GH} / \mathrm{GI}=\mathrm{AD} / \mathrm{AB}^{3}$. Daraus folgt, daß $\mathrm{JF} / \mathrm{JI}=\mathrm{AD} / \mathrm{AB}$ gilt ${ }^{4}$. Unterstellt man eine homothetische Erwartungsnutzenfunktion des Investors ${ }^{5}$, so ergibt sich Punkt $P$ als Optimalpunkt nach Kreditgewährleistung. Es gilt dann $\mathrm{JF} / \mathrm{JI}=\mathrm{AP} / \mathrm{AC}$, was einen unveränderten Anteil a impliziert. Die unterstellte Nutzenfunktion impliziert eine konstante relative Risikoaversion, d.h. eine Vermögenselastizität der Nachfrage von $1^{6}$ und eine fallende absolute Risikoaversion des Investors ${ }^{7}$. Damit erhält man unter den gegebenen Bedingungen das. kontraintuitive Ergebnis, daß Kreditgewährleistungen, die lediglich riskante Investitionen unmittelbar begünstigen, keine Erhöhung des Portfolio-Anteils dieser riskanten Investitionen bewirken.

Liegt der neue Optimalpunkt links oberhalb von Punkt $P$, so impliziert dies eine steigende relative Risikoaversion und einen Rückgang der Nachfrage nach der riskanten

1 Diese Möglichkeit wird von ATKINSON/STIGLITZ (1980), S.116 übersehen, wenn sie in bezug auf eine Steuer, die nur die Erträge der risikolosen Anlage erfaßt, lapidar feststellen: "The latter (der Substitutionseffekt, Anm.d.Verf.) is in the direction of increased risk-taking." Die Hilfslinie FH besitzt die Steigung 1.

3 Vgl. ATKINSON/STIGLITZ (1980), S.102.

$4 \mathrm{Zu}$ einer ähnlichen Konstruktion vgl. STIGLITZ (1969), S.280, der damit eine Differentialbetrachtung zwischen einer Einkommensteuer auf alle Erträge und einer Einkommensteuer nur auf sichere Erträge anstellt, die zum selben Erwartungsnutzenniveau des Investors führen.

$5 \mathrm{Zu}$ homothetischen Nutzenfunktionen vgl. BOADWAY/BRUCE (1984), S.35.

6 Vgl. STIGLITZ (1969). S.267.

$7 \mathrm{Zu}$ den Risikomaßen der absoluten und relativen Risikoaversion vgl. PRATT (1964); ARROW (1965). Die relative Risikoaversion entspricht der Vermögenselastizität der Nachfrage nach der riskanten Alternative bzw. der Elastizität des marginalen Erwartungsnutzens in bezug auf das Vermögen. Vgl. HEY (1979), S.49; ATKINSON/STIGLITZ (1980), S.103. Graphisch ergibt sich eine konstante relative Risikoaversion als Strahl aus dem Ursprung durch den Optimalpunkt vor einer Vermögensänderung. Konstante absolute Risikoaversion ist demgegenüber durch eine $45^{\circ}$-Linie durch den Optimalpunkt D gekennzeichnet. Vgl. ATKINSON/STIGLITZ (1980), S.102. 


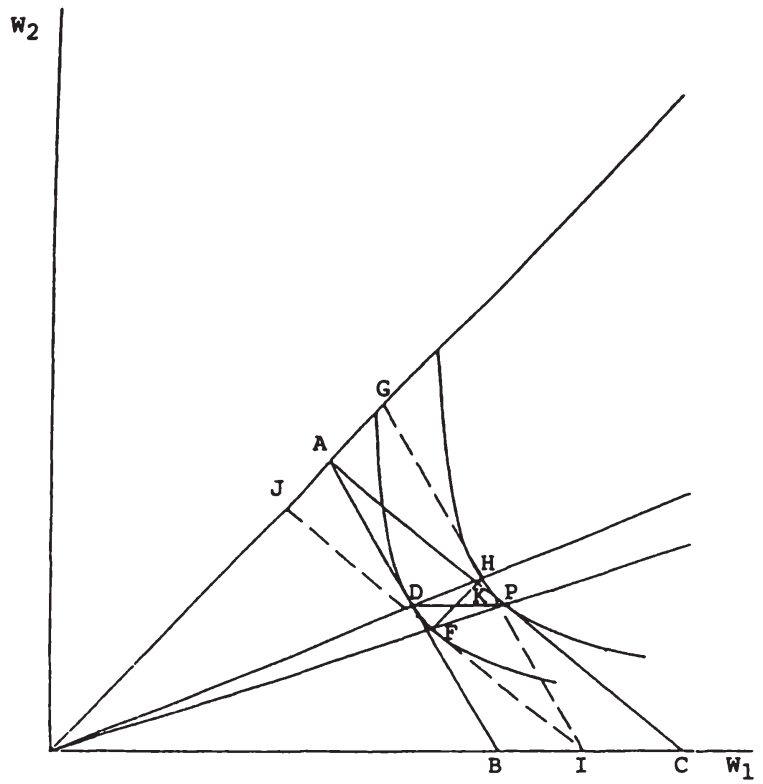

(a)

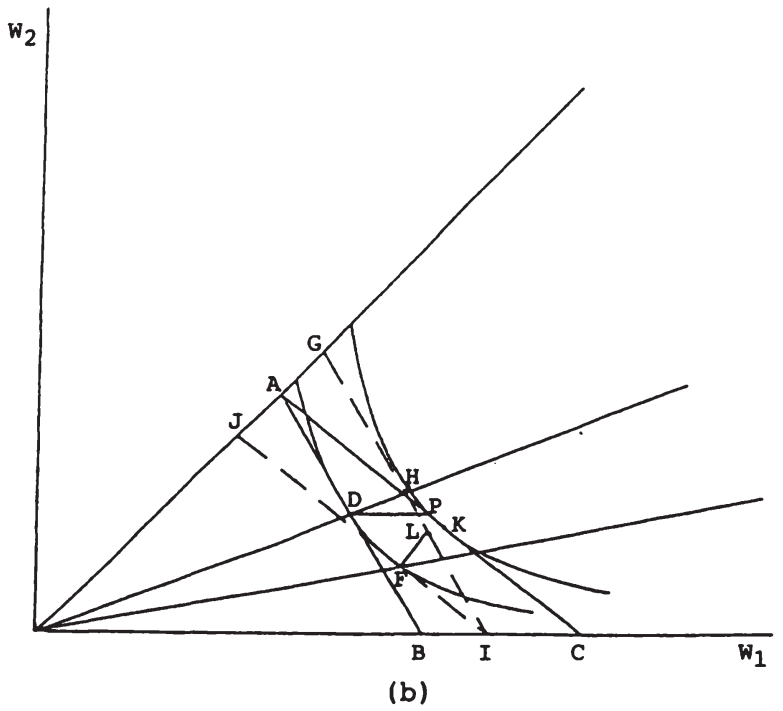

Abb. 5 
Alternative. Dieses Ergebnis ist je nach Lage des neuen Optimalpunktes mit einer fallenden, konstanten oder steigenden absoluten Risikoaversion vereinbar ${ }^{1}$. Konstante absolute Risikoaversion, die bei einem neuen Optimalpunkt in $\mathbf{K}$ gegeben wäre, ist hier ökonomisch in der Weise zu interpretieren, daß durch den Vermögenseffekt das aus der riskanten Alternative resultierende absolute Vermögen vor und nach Änderung der relativen Gewinnraten unverändert bleibt. Dies wiederum ist jedoch nur mit einem fallenden a vereinbar ${ }^{2}$. Nur wenn der neue Optimalpunkt rechts unterhalb von $\mathbf{P}$ liegt, erhält man das erwartete Ergebnis eines steigenden Anteils a. Es ist eine fallende relative und absolute Risikoaversion gegeben ${ }^{3}$.

In Abb. 5 b ist der Fall dargestellt, daß der Substitutionseffekt eine Erhöhung von a bewirkt, weil GL/GI > GH/GI und damit JF/JI > AD/AB gilt. Der Gesamteffekt auf a ist hier bei konstanter oder fallender relativer Risikoaversion, was jeweils eine fallende absolute Risikoaversion impliziert, eindeutig. Bei steigender relativer Risikoaversion kommt es auf die relative Stärke des Substitutions- und des Vermögenseffektes an, ob der neue Optimalpunkt oberhalb, in oder unterhalb von Punkt $P$ liegt und der Gesamteffekt damit zu einem Rückgang, einer Konstanz oder einem Anstieg von a führt. Darüber hinaus ließe sich auch der Fall konstruieren, daß der Substitutionseffekt die Nachfrage nach der riskanten Investitionsalternative reduziert ${ }^{4}$. Unter diesen Bedingungen ergibt sich bei steigender und konstanter absoluter Risikoaversion das eindeutige Ergebnis, daß der Portfolio-Anteil der riskanten Alternative aufgrund der Kreditgewährleistung abnimmt. Die Wirkung des Substitutionseffektes auf a hängt von der Krümmung der Indifferenzkurve ab, die das Erwartungsnutzenniveau ohne Kreditgewährleistung repräsentiert. Die Krümmung der Indifferenzkurve wird dabei durch die Substituierbarkeit des Vermögens in Zustand 1 und 2 bestimmt. Je besser die Vermögen in beiden Zuständen gegeneinander substituierbar sind, desto eher wird das intuitiv zu erwartende Ergebnis resultieren, daß der Substitutionseffekt den Anteil a erhöht.

In einem nächsten Schritt soll nun die Wirkung eines Zinszuschusses untersucht werden, dessen Zuschußsatz z für risikolose und riskante Kredite identisch sei. Da der Zinszuschuß jedoch die Ausfallhöhe des Kreditgebers in Zustand 2 reduziert, summiert sich die Zinsverbilligung für riskante Kredite in Zustand 1 auf $z /(1-p)$. Danach ergibt sich die folgende Optimalbedingung:

1 Vgl. SCHNEIDER (1990), S.392.

2 Dies zeigt sich wiederum darin, daß das Einkommen in Zustand 2 bei einem Optimalpunkt K höher ist als in der Ausgangssituation.

3 Vgl. SCHNEIDER (1990), S.392.

4 Vgl. STIGLITZ (1969), S.280, Figure $V_{B}$. 


$$
\text { (C.III.10) } \quad \frac{(1-p) U^{\prime}\left(W_{1}^{Z}\right)}{p U^{\prime}\left(W^{Z}{ }_{2}\right)}=\frac{(R-r+z)}{X_{1}-(r-z) p /(1-p)-R} \text {, }
$$

wobei $\mathrm{W}^{\mathrm{Z}}$ das Vermögen nach Zinszuschuß bezeichnet. Die betragsmäßige Steigung der neuen Budgetgeraden, die durch die rechte Seite von Gleichung (C.III.10) wiedergegeben wird, ist dabei größer als die der Ausgangsbudgetgeraden ${ }^{1}$. Da der Zinszuschuß auch den Kredit für die risikolose Anlage verbilligt, verschiebt sich die Budgetgerade außerdem nach rechts. Die Wirkung des Zinszuschusses läßt sich daher gedanklich aufspalten in eine relative Erhöhung der Gewinnrate in Zustand 2, die wiederum zu einem Vermögens- und Substitutionseffekt führt, und eine zusätzliche Vermögenserhöhung. Der Effekt auf die Höhe von a hängt damit einmal von der Wirkung des Substitutionseffekts und des Vermögenseffekts auf a ab. Allerdings wirkt der Substitutionseffekt bei einem Zinszuschuß in Richtung einer Erhöhung des Vermögens in Zustand 2. Jedoch gilt auch hier, daß a durch den Substitutionseffekt steigen, fallen oder konstant bleiben kann. Darüber hinaus ist es für den Gesamteffekt wesentlich, wie die zusätzliche Vermögenserhöhung auf a wirkt. Lassen Vermögens- und Substitutionseffekt der Veränderung der relativen Gewinnrate den Anteil a unverändert, so wird der Gesamteffekt auf a durch das Ausmaß der relativen Risikoaversion bestimmt. Beispielsweise ergibt sich bei konstanter relativer Risikoaversion ein konstantes a. Im übrigen gelten mutatis mutandis die obigen Ausführungen. D.h. daß auch bei Zinszuschüssen die Wirkung auf die Risikoübernahme nicht eindeutig ist.

Erfolgt die Zinsverbilligung durch einen Zinszuschuß oder ein öffentliches Darlehen, wodurch der Zinssatz auf $r$ verbilligt wird, erhält man dasselbe Ergebnis wie bei einer entgeltlosen Kreditgewährleistung mit Volldeckung. Soll die Zinsverbilligung darüber hinausgehen, kommt auch hier ein zusätzlicher Vermögenseffekt hinzu. Der Gesamteffekt ist wiederum nicht eindeutig.

Allerdings bleibt festzuhalten, daß das obige Ergebnis nur unter sehr restriktiven Bedingungen abgeleitet wurde. Läßt man fallende Grenzerträge des Kapitals zu, so wird sich das Ergebnis in seiner Richtung jedoch nur unwesentlich verändern. Es würden sich mit steigendem (fallendem) a geringere Grenzerträge der riskanten (risikolosen) Investition ergeben und umgekehrt. Unter diesen Bedingungen wird die Wirkung des Substitutionseffektes auf die Nachfrage nach riskanten Investitionen noch geringer sein.

Da sich gezeigt hat, daß die Wirkungen öffentlicher Kredithilfen auf die Risikoübernahme bei risikoaversen Investoren entscheidend von deren Erwartungsnutzenfunktion

1 Dies folgt daraus daß Ableitung der betragsmäBigen Steigung nach $z$ unter den getroffenen Annahmen größer Null ist. 
abhängen, läßt sich ohne empirische Analysen somit nicht generalisierend feststellen, ob die Gewährung von Kredithilfen zu einer Erhöhung der erwarteten Investitionserträge führen wird ${ }^{1}$. Dementsprechend ist auch die Wirkung von Kredithilfen auf die soziale Wohlfahrt nicht eindeutig bestimmbar.

\section{b. Das Investitionsrisiko bei unvollständiger Information}

Will man die Beeinflussung der Risikoentscheidungen von Investoren durch Kredithilfen realitätsnäher modellieren, liegt es nahe, die obigen Informationsannahmen zu modifizieren. Es soll daher im folgenden unterstellt werden, daß der Staat das Risiko der geförderten Investitionen im Gegensatz zu den Investoren und den privaten Kreditgebern nicht kennt. Damit ist es dem Staat nicht möglich, solche Investitionen von der Förderung auszuschließen, deren erwarteter Ertrag kleiner ist als der Ertrag sicherer Investitionen.

\section{aa. Risikoneutralität des Investors}

Es wird wiederum ein risikoneutraler Investor betrachtet, der alternativ ein Investitionsprojekt A oder B realisieren kann. Im Gegensatz zu oben soll aber gelten: $\left(1-p_{A}\right)\left[1+R_{A}-(1+r) /\left(1-p_{A}\right)\right]>\left(1-p_{B}\right)\left[1+R_{B}-(1+r) /\left(1-p_{B}\right)\right]$. Dagegen sei wie im Fall vollkommener Information $R_{B}>R_{A}$ und $1+R_{B}>(1+r) /\left(1-p_{B}\right)$. Dementsprechend wird der Investor ohne Kredithilfe Projekt $A$ bevorzugen. Dasselbe gilt bei einem Zinszuschuß in Höhe von z. Wird dagegen eine Kredithilfe gewährt, durch die der Zinssatz bei beiden Projektalternativen im günstigen Umweltzustand auf $r$ reduziert wird, so gilt $\left(1-\mathrm{p}_{\mathrm{A}}\right)\left[1+\mathrm{R}_{\mathrm{A}}-(1+\mathrm{r})\right]<\left(1-\mathrm{p}_{\mathrm{B}}\right)\left[1+\mathrm{R}_{\mathrm{B}}-(1+\mathrm{r})\right]$ unter der Bedingung

$$
\left(1-p_{A}\right) R_{A}-r\left(p_{B}-p_{A}\right)<\left(1-p_{B}\right) R_{B} \text {. }
$$

In diesem Fall wird der Investor durch die Kredithilfe veranlaßt, statt des risikoärmeren Projekts A das risikantere Projekt B zu realisieren, obwohl die erwartete Gewinnrate von Projekt $B$ ohne Kredithilfe geringer ist ${ }^{2}$. Dies impliziert einen sozialen Wohlfahrtsverlust in Höhe von $\left(1-p_{A}\right)\left(1+R_{A}\right)-\left(1-p_{B}\right)\left(1+R_{B}\right)$. Je höher die Zinsverbilligung aufgrund der Kredithilfe im günstigen Umweltzustand ist, desto kleiner ist der Grenzwert von $R_{B}$, der den Investor zu einem Projektwechsel veranlaßt. Damit steigt der soziale

$1 \mathrm{Zu}$ einem Überblick über empirische Untersuchungen hinsichtlich der Beeinflussung der Risikoübernahme durch die Besteuerung vgl. SANDMO (1985), S.302 f.

2 Zum selben Ergebnis gelangen CHANEY/THAKOR (1985) aufgrund eines komplexeren Modells mit ähnlicher Grundstruktur, wobei dort die Wahrscheinlichkeit, eine Kredithilfe zu erhalten, als zusätzliche Variable eingeführt wird. 
Wohlfahrtsverlust bei der betrachteten Form der Informationsunvollkommenheit tendenziell mit zunehmender Zinsverbilligung.

\section{bb. Risikoaversion des Investors}

Im folgenden soll wieder ein risikoaverser Investor betrachtet werden, der eine gegebene Investitionssumme zwischen einer risikolosen und einer riskanten Investitionsalternative aufteilen kann. Dabei soll die riskante Alternative im Gegensatz zum entsprechenden Modell bei vollkommener Information in Zustand 1 lediglich einen Netto-Investitionsertrag von $X_{1}^{*}$ erbringen, wobei $X_{1}^{*}+\varepsilon=R /(1-p)$ gelten soll ${ }^{1}$. Die anderen obigen Modellannahmen werden dagegen beibehalten. Strebt $\varepsilon$ gegen Null, reduziert sich die Optimalbedingung von Gleichung (C.III.7a) auf

$$
\frac{(1-\mathrm{p}) \mathrm{U}^{\prime}\left(\mathrm{W}_{1}\right)}{\mathrm{pU^{ \prime }}\left(\mathrm{W}_{2}\right)}=\frac{(1-\mathrm{p})}{\mathrm{p}}
$$

D.h. die betragsmäßige Steigung der Budgetgeraden des Investors entspricht dem Verhältnis aus Erfolgs- und Ausfallwahrscheinlichkeit der riskanten Alternative. Umgeformt folgt daraus das bereits bekannte Ergebnis, daß bei der Preisrelation (1-p)/p das Verhältnis der Grenznutzen des Vermögens in Zustand 1 und 2 den Wert eins annimmt. Dies impliziert aber, da $B$ das Vermögen in beiden Umweltzuständen genau gleich hoch sein muß, was wiederum nur bei einem Portfolio möglich ist, das ausschließlich aus der risikolosen Investitionsalternative besteht ${ }^{2}$.

Dies wird in Abb.6 verdeutlicht, wo die Budgetgerade vor Kredithilfe AB mit der Tangente an die Erwartungsnutzenfunktion im Schnittpunkt mit der Winkelhalbierenden übereinstimmt. Erhält der Investor eine Kreditgewährleistung, dreht sich die Budgetgerade auf AC. Da die betragsmäßige Steigung der neuen Budgetgeraden kleiner ist als (1-p)/p, liegt der neue Optimalpunkt unterhalb der Winkelhalbierenden. Da alle Punkte auf der Budgetgeraden unterhalb der Winkelhalbierenden a $>0$ implizieren, wird die Kreditgewährleistung unabhängig von der Krümmung der Indifferenzkurve und der Änderung der Risikoaversion des Investors bei steigendem Vermögen unter den getroffenen Annahmen stets eine Erhöhung des Portfolioanteils der riskanten Anlage von Null auf einen positiven Wert bedingen. Lediglich das Ausmaß des Anstiegs von a wird von den oben beschriebe

1 Dieselbe Analyse ließe sich durchführen, wenn man einen konstanten Wert von $\mathrm{X}_{1}$ und ein höheres p unterstellen würde.

2 Vgl. Abschnitt C.I.2.a.bb. 


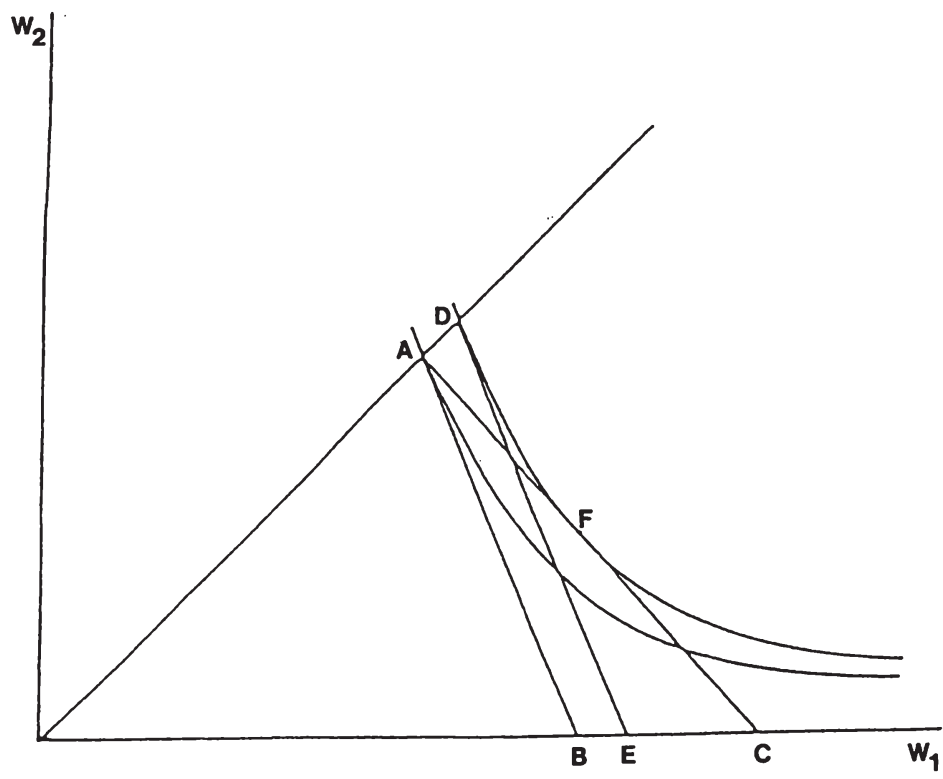

Abb. 6

nen Zusammenhängen bestimmt. Qualitativ dasselbe Ergebnis erhält man für alle $\mathrm{X}_{1}{ }^{*}<\mathrm{R} /(1-\mathrm{p})$, sofern nur die betragsmäßige Steigung der Budgetgeraden nach Gewährleistung kleiner als (1-p)/p ist. Daher impliziert eine Kreditgewährleistung bei der unterstellten Informationsverteilung stets einen perversen Anreiz, auch solche Investitionen durchzuführen, die unter allokativen Gesichtspunkten nicht wünschenswert sind ${ }^{1,2}$.

Betrachtet man demgegenüber einen Zinszuschuß, durch den der Kreditzinssatz jeweils um den Zuschußsatz z reduziert wird, entspricht die Optimalbedingung erster Ordnung des Investors Gleichung (C.III.12) ${ }^{3}$. Daraus folgt dann, daß auch nach dem Zinszuschuß das Vermögen in beiden Umweltzuständen gleich hoch sein muß und somit allein

1 Vgl. KASTROP/BERGMANN (1988), S.324.

2 Ein vergleichbares Phänomen läßt sich im Zusammenhang mit Regelungen feststellen, welche die Abweichung von der Minimalkostenkombination steuerlich begünstigen und damit Investitionen anreizen, die ohne Vergünstigung unrentabel wären. Typisches Beispiel hierfür ist die

Vielzahl der sogenannten Bauherrenmodelle.

3 Dies ist leicht erkennbar, wenn man in Gleichung (C.III.10) für $X_{1}$ den Wert $R /(1-p)$ einsetzt. 
die risikolose Alternative gewählt wird. Dies ist auch ohne weiteres einsichtig, weil hier kein Substitutionseffekt auftritt und der Vermögenseffekt unabhängig von der Veränderung der Risikoaversion keine Erhöhung von a bewirkt. Denn Risikoaversion impliziert, daß die Investition mit dem sicheren Gewinn der riskanten Alternative mit demselben Erwartungsgewinn vorgezogen wird.

\section{cc. Einbeziehung von Subventionsmittlern}

Schließlich soll die Analyse erweitert werden, indem man die bei der Gewährung von Kredithilfen häufig als Subventionsmittler tätigen Banken berücksichtigt. Dabei soll unterstellt werden, daß eine asymmetrische Informationsverteilung auch zwischen den Banken und den kreditnehmenden Investoren besteht. Die betrachtete und als risikoneutral angenommene repräsentative Bank soll ein Kreditportfolio in gegebener Höhe $\mathbf{K}$ halten. Sie vergibt einperiodige, riskante Einzelkredite derselben Höhe, bei denen mit der Wahrscheinlichkeit $\mathrm{p}^{\mathrm{i}}$ ein vollständiger Ausfall der Kreditforderungen zu verzeichnen ist. Die Bank kennt dabei nicht die Ausfallwahrscheinlichkeit $p^{i}$ der Einzelkredite, sondern nur die durchschnittliche Wahrscheinlichkeit $p$ ihres Kreditportfolios. Durch den Ressourceneinsatz 8 , der einen Preis von eins haben soll, kann die Bank p in der Weise beeinflussen, daß Kredite mit hohem Ausfallrisiko durch risikoärmere Kredite ersetzt werden. Dabei sei $\mathrm{p}_{\Omega}<0$ und $\mathrm{p}_{\Omega}>0$. Weiterhin wird angenommen, daß die durchschnittliche Ausfallwahrscheinlichkeit des Kreditportfolios ohne Ressourceneinsatz $\pi$ betragen soll. Die Banken können sich durch fristenkongruente, risikolose Kredite zum Marktzinssatz r refinanzieren. Die Investitionskredite werden zum Zinssatz $(r+\pi) /(1-\pi)$ angeboten. Außerdem wird angenommen, daß der Gewinn sämtlicher Investoren, die ebenfalls risikoneutral sein sollen, beim genannten Zinssatz Null beträgt. Dies impliziert, daß bei $p^{i}<\pi\left(p^{i}>\pi\right)$ der Brutto-Investitionsertrag $1+R^{i}$ im günstigen Zustand größer (kleiner) als $(1+r) /\left(1-p^{i}\right)$ ist. Damit werden mit den unterdurchschnittlich (überdurchschnittlich) riskanten Krediten Investitionen finanziert, die unter den Bedingungen vollständiger Information ausnahmslos rentabel (unrentabel) sind, wobei die Rentabilität der Investitionen mit sinkender Ausfallwahrscheinlichkeit steigt. Schließlich sei der Kreditmarkt aufgrund der asymmetrischen Information durch eine Mengenrationierung gekennzeichnet. Unter diesen Bedingungen gilt für den Bankengewinn::

$$
\begin{aligned}
G= & {[1-p(\pi, \Omega)][K(1+r) /(1-\pi)-K(1+r)-\Omega] } \\
& +p(\pi, \Omega)[-K(1+r)-\Omega]=\text { Max! }
\end{aligned}
$$

Daraus folgt die Gewinnmaximierungsbedingung erster Ordnung: 


$$
-\mathrm{p}_{\Omega}[\mathrm{K}(1+\mathrm{r}) /(1-\pi)]=1 .
$$

Dabei repräsentiert die linke Seite von Gleichung (C.III.14) den Grenzertrag und die rechte Seite die Grenzkosten des Ressourceneinsatzes. Der Ausdruck in der eckigen Klammer auf der linken Seite von Gleichung (C.III.14) repräsentiert dabei den Preis des aus dem Ressourceneinsatz resultierenden Outputs. Der optimale Ressourceneinsatz ist damit implizit bestimmt. Er führt gegenüber der Situation bei $\Omega=0$ zu einer Reduzierung der durchschnittlichen Ausfallwahrscheinlichkeit und einer Erhöhung der Durchschnittsrentabilität der kreditfinanzierten Investitionen und damit zu einer effizienteren Ressourcenverwendung.

Erhalten die Investoren eine entgeltlose staatliche Kreditgewährleistung mit dem Deckungsgrad D, so ergibt sich für die Bank folgende Gewinngleichung:

$$
\begin{aligned}
G= & {[1-p(\pi, \Omega)][K(1+r) /[1-\pi(1-D)]-K(1+r)-\Omega] } \\
& +p(\pi, \Omega)[D K(1+r) /[1-\pi(1-D)]-K(1+r)-\Omega] .
\end{aligned}
$$

Die Bedingung erster Ordnung für ein Gewinnmaximum lautet:

$$
-\mathrm{p}_{\Omega}[(1-\mathrm{D}) \mathrm{K}(1+\mathrm{r}) /(1-\pi(1-\mathrm{D})]=1 \text {. }
$$

Durch Umformung läßt sich zeigen, daß der Preis des Grenzprodukts von $\Omega$ kleiner ist als in (C.III.14). Daraus folgt, daß der optimale Ressourceneinsatz bei einer Teildeckung der Kreditforderungen durch eine entgeltlose Kreditgewährleistung positiv, aber geringer ist als ohne Gewährleistung ${ }^{1}$. D.h. die durchschnittliche Ausfallwahrscheinlichkeit des Kreditportfolios steigt, während die Durchschnittsrentabilität der kreditfinanzierten Investitionen fällt und somit Allokationsverluste verursacht werden.

Bei einem Deckungsgrad von 100 Prozent werden alle Einzelkredite risikolos, so daß sich (C.III.15) auf

(C.III.17) $\quad \mathrm{G}=[1-\mathrm{p}(\pi, \Omega)](-\Omega)+\mathrm{p}(\pi, \Omega)(-\Omega)=-\Omega$

reduziert. Daraus folgt unmittelbar, da $\beta$ die Bank ihr Gewinnmaximum erreicht, wenn $\Omega=0$ gilt. Denn bei jedem positiven Ressourceneinsatz gilt, daß seine Grenzkosten den Grenzertrag übersteigen. D.h. die Bank wird sämtliche Aktivitäten unterlassen, um die überdurchschnittlichen Risiken zu eliminieren ${ }^{2}$. Dementsprechend sind hier die Allokationsverluste noch höher als bei Teildeckung. Dies kann erklären, weshalb Gewährleistungsprogramme in der Realität regelmäßig einen Deckungsgrad von kleiner als eins vorsehen ${ }^{3}$.

1 Zum selben Ergebnis gelangt HUNTER (1981), S.249 ff. in einem Modell mit risikoaversen Banken.

2 Vgl. HUNTER (1981), S.255 f.

3 Vgl. HUNTER (1981), S.252. 
Wird den Investoren statt der Kreditgewährleistung ein Zinszuschuß gewährt, so wird sich der Anreiz für die Bank zum Ressourceneinsatz ebenfalls verringern, wenn sie den Zuschuß im ungünstigen Zustand für sich beanspruchen kann. Denn auch dadurch sinkt der Preis des Grenzprodukts von $\Omega$ gegenüber dem Fall ohne Kredithilfe. Für die relative Stärke der Effekte im Vergleich zu den Kreditgewährleistungen kommt es auf die relative Höhe des Zinszuschusses an.

\section{dd. Konsequenzen}

In der vorstehenden Analyse wurde gezeigt, daß durch öffentliche Kredithilfen perverse Anreize zu einem individuellen Moral-hazard-Verhalten induziert werden können, das sich gesamtwirtschaftlich in einem suboptimalen Ressourceneinsatz äußert. Diese Konsequenz tritt immer dann auf, wenn solche staatlichen Fördermaßnahmen unabhängig vom individuellen Verhalten der Empfänger oder der beteiligten Banken gewährt werden und der Staat unvollständige Informationen besitzt ${ }^{1}$. Daher ist es sinnvoll, wenn der Staat bis zu einer bestimmten Grenze Ressourcen zur Überwachung der Kredithilfe-Empfänger bzw. der in die Kreditvergabe eingeschalteten Subventionsmittler oder zur Ausarbeitung und Überwachung anreizkompatibler Verträge ${ }^{2}$ einsetzt. Da auf diese Weise erstbeste Lösungen üblicherweise nicht erreicht werden können ${ }^{3}$, führen asymmetrische Informationen zwischen Staat und den sonstigen Beteiligten eines Subventionsverhältnisses zu zusätzlichen Wohlfahrtsverlusten, welche in den meisten Analysen nicht berücksichtigt sind. Dadurch ist der Spielraum für wohlfahrtssteigernde Subventionen noch geringer, als üblicherweise angenommen wird. Darüber hinaus kann aus der vorstehenden Analyse gefolgert werden, daß die institutionelle Ausgestaltung der Kredithilfen von wesentlicher Bedeutung ist. Dabei ist tendenziell zu erwarten, daß der Anreiz zu wohlfahrtsminderndem Moral-hazard-Verhalten dann geringer ist, wenn sich die Begünstigung des Empfängers nicht mit steigendem Risiko erhöht.

1 Vgl. HUNTER (1981), S.252.

2 Zur Bedeutung anreizkompatibler Verträge bei asymmetrischer Informationsverteilung siehe oben Abschnitt C.I.4. Zu speziellen Vertragsgestaltungen in gegebenem Zusammenhang vgl. HUNTER (1981), S.257 ff.

3 Vgl. oben Abschnitt C.I.4. m.w.N. 


\section{Kapitalstrukturefiekte öfientlicher Kredithilfen}

Während bisher die Frage nach der optimalen Kapitalstruktur, d.h. dem optimalen Verhältnis von Fremd- und Eigenkapital, bei der Investitionsfinanzierung ausgeklammert blieb, sollen nun die Kapitalstruktureffekte von öffentlichen Kredithilfen analysiert werden. Dabei wird untersucht, wie die Fremdkapitalquote als Maß für die Kapitalstruktur bei eines Unternehmens mit gegebenem Kapitalstock durch Kredithilfen beeinflußt wird. D.h. die Auswirkungen von Kredithilfen auf die Höhe des Kapitaleinsatzes des Unternehmens sollen unberücksichtigt bleiben. Mithin wird unterstellt, daß die betrachteten Kredithilfen lediglich Mitnahmeeffekte hervorrufen. Dabei werden die Kapitalstruktureffekte öffentlicher Kredithilfen aus der Sicht der traditionellen Finanzierungstheorie, unter der Annahme vollkommener Kapitalmärkte und aus der Sicht der Agency-Theorie betrachtet. Ausgangspunkt der Analyse ist jeweils die Überlegung, daß eine optimale Kapitalstruktur bei gegebenem Kapitaleinsatz durch das Kapitalkostenminimum bestimmt wird.

\section{a. Kapitalstruktureffekte nach der traditionellen Finanzierungstheorie}

Nach der traditionellen Finanzierungstheorie sind für die Bestimmung des Kapitalkostenminimums drei Effekte wesentlich. Zum einen ist Eigenkapital relativ teurer als Fremdkapital, so daß insoweit die Kapitalkosten mit steigender Fremdkapitalquote fallen. Außerdem erhöhen sich das Eigenkapitalrisiko und das Kreditausfallrisiko der Fremdkapitalgeber und damit die Kapitalkosten mit zunehmender Fremdkapitalquote. D.h. der erste Effekt und die beiden anderen Effekte wirken gegenläufig auf die Höhe der Kapitalkosten. Es wird nun üblicherweise angenommen, daß die durchschnittlichen Kapitalkosten zunächst mit steigender Fremdkapitalquote fallen ${ }^{1}$, um danach wieder zu steigen. Es gibt demnach ein Minimum der durchschnittlichen Kapitalkosten und damit eine optimale Kapitalstruktur ${ }^{2}$. Im Kapitalkostenminimum ist gleichzeitig die Eigenkapitalrentabilität maximal. Formal läßt sich die optimale Kapitalstruktur folgendermaßen bestimmen:

$$
G=R K-r(F / K) E-i(F / K) F=M a x !
$$

Dabei bezeichnen $\mathbf{G}$ den Gewinn des Investors, $\mathrm{K}$ den gesamten, konstant gesetzten Kapitaleinsatz, E und F die Höhe des Eigen- bzw. Fremdkapitals, R die als konstant angenommene Kapitalertragsrate sowie $r$ und $i$ die jeweils von der Kapitalstruktur abhängigen

\footnotetext{
1 Anders ausgedrückt steigt zunächst die Eigenkapitalrentabilität (Eigenkapitalverzinsung + Gewinn bezogen auf Eigenkapitaleinsatz) an. Diese Wirkung wird in der Betriebswirtschaftslehre als Leverage-Effekt bezeichnet. Vgl. SCHNEIDER (1990), S.466.

2 Vgl. SCHMIDT, R.H. (1986), S.223 f.; SCHNEIDER (1990), S.471.
} 
Eigen- bzw. Fremdkapitalkosten. Weiterhin gilt annahmegemäß K = E + F. Aus (C.III.18) folgt als Optimalbedingung:

$$
\mathrm{r}-\mathrm{i}=(\mathrm{F} / \mathrm{K}) \mathrm{i}^{\prime}+(\mathrm{E} / \mathrm{K}) \mathrm{r}^{\prime} .
$$

Im Optimum müssen also Grenzertrag und Grenzkosten einer marginalen Erhöhung der Fremdkapitalquote übereinstimmen ${ }^{1}$. Wird nun für jede Fremdkapitaleinheit ein Zinszuschuß in konstanter Höhe von $\mathrm{z}$ gewährt, so resultiert daraus als neue Optimalbedingung:

$$
\mathrm{r}-\mathrm{i}+\mathrm{z}=(\mathrm{F} / \mathrm{K}) \mathrm{i}^{\prime}+(\mathrm{E} / \mathrm{K}) \mathrm{r}^{\prime} .
$$

Da der Grenzertrag einer marginalen Erhöhung der Fremdkapitalquote durch die Kredithilfe steigt, wird das Unternehmen die Fremdkapitalquote erhöhen, um zum Kapitalkostenminimum zu gelangen ${ }^{2}$. Diese traditionelle These basiert jedoch im wesentlichen auf relativ willkürlichen Verhaltensannahmen, welche die Kapitalmarktbeziehungen unberücksichtigt lassen ${ }^{3}$.

\section{b. Kapitalstruktureffekte bei vollkommenen Kapitalmärkten}

Unter der Annahme vollkommener Kapitalmärkte wurde die Vorstellung der traditionellen Finanzierungstheorie durch das sogenannte Modigliani-Miller-Theorem widerlegt ${ }^{4}$. Sie zeigen, da $ß$ die Kapitalstruktur eines Unternehmens bei gegebenen Investitionsplänen für den Wert eines Unternehmens, der sich als Summe aus Eigen- und Fremdkapital ergibt, irrelevant ist, weil die Höhe der Kapitalkosten von der Kapitalstruktur nicht beeinflußt wird ${ }^{5}$. Da zwei Unternehmen mit demselben Investitionsrisiko unabhängig von ihrer Kapitalstruktur homogene Güter sind, führen unterschiedliche Unternehmenswerte zu risikolosen Gewinnmöglichkeiten durch Arbitrageprozesse ${ }^{6}$.

Bisweilen wird jedoch die Auffassung vertreten, daß mit zunehmender Fremdkapitalquote die Konkurs-Wahrscheinlichkeit steigt ${ }^{7}$. Sind Konkurse mit realen Kosten verbunden, so führt dies bei steigender Fremdkapitalquote zu einem überproportionalen Anstieg

$1 \mathrm{Zu}$ einer graphischen Herleitung des Kapitalkostenminimums nach der traditionellen Finanzierungstheorie vgl. SCHNEIDER (1990), S.470.

2 Zum selben Ergebnis gelangen BOADWAY/WILDASIN (1984), S.327 für den Fall einer relativen steuerlichen Begünstigung des Fremdkapitals gegenüber dem Eigenkapital.

3 Vgl. SCHMIDT, R.H. (1986), S.225.

4 Vgl. MODIGLIANI/MILLER (1958).

5 Vgl. MODIGLIANI/MILLER (1958), insbes. S.268 f.

6 Ein anschauliches Zahlenbeispiel zu diesem Arbitragebeweis enthält SCHMIDT, R.H. (1986), S.229 ff.

7 Vgl. BOADWAY/WILDASIN (1984), S.325. 
der Fremdkapitalkosten. Daraus wird gefolgert, daß die optimale Kapitalstruktur eine Fremdkapitalquote von unter 100 Prozent impliziert. Allerdings wird bestritten, da $ß$ es bei einem vollkommenen Kapitalmarkt zu einem durch die Kapitalstruktur bedingten Konkurs kommen kann, da dieser durch eine Änderung der Kapitalstruktur abwendbar ist. Dies läßt sich illustrieren, wenn man unterstellt, daß der Marktpreis des Risikos Null beträgt. Liegt der erwartete Ertragswert eines Unternehmens über seinem Liquidationserlös, so wird der Unternehmenseigner bei vollständiger Eigenkapitalfinanzierung auf die Liquidation verzichten ${ }^{1}$. Bei vollständiger Fremdkapitalfinanzierung ist ein Verzicht auf die Liquidation aufgrund des Kapitalstrukturrisikos ebenso vorteilhaft. Sind die Fremdkapitalgeber beispielsweise risikoavers, wären sie bereit, eine Liquidation in Kauf zu nehmen, auch wenn der als sicher angenommene Liquidationserlös unter dem erwarteten Ertragswert liegt. Dadurch ergeben sich jedoch Arbitragemöglichkeiten für andere Kapitalgeber, die bereit sind, die Forderungen der risikoaversen Fremdkapitalgeber für einen Preis zu erwerben, der maximal dem Ertragswert des Unternehmens entspricht. Die bisherigen Kapitalgeber werden also bereit sein, ihre Forderungen zu jedem Preis zu veräußern, der über ihrem Sicherheitsäquivalent, dem Liquidationserlös, liegt. Ein Konkurs wird unter diesen Bedingungen auch bei vollständiger Fremdkapitalfinanzierung vermieden ${ }^{2}$. Dieser Zusammenhang wird durch das Auftreten von Konkursen in der Realität nicht widerlegt, da er nur gilt, wenn die Zukunftserwartungen der verschiedenen Kapitalgeber identisch sind ${ }^{3}$, d.h. wenn vollständige Information gegeben ist. Wenngleich es daran in der Realität regelmäBig fehlen wird, sollen die Kapitalstruktureffekte öffentlicher Kredithilfen dennoch unter den Bedingungen eines vollkommenen Kapitalmarktes untersucht werden.

Es sollen identische Unternehmen einer bestimmten Risikoklasse betrachtet werden, deren erwarteter periodischer Bruttogewinn B (Gewinn + Kapitalkosten) ${ }^{4}$ ewig fließt. Kapitalentnahmen finden nicht statt und die von der Kapitalstruktur unabhängige Opportunitätskostenrate betrage i. Der Marktwert V der Unternehmen entspricht danach bei jeder Kapitalstruktur B/i. Wird für ein Unternehmen $\mathrm{X}$ dieser Risikoklasse auf das Fremdkapital $F$ ein periodischer Zinszuschuß in Höhe von $2 \mathrm{~F}$ gewährt ${ }^{5}$, so bleiben die Opportunitätskosten des Kapitaleinsatzes konstant. Unterstellt man eine vollständige

\footnotetext{
1 Vgl. SWOBODA (1989), S.169.

Vgl. HAUGEN/SENBET (1978). Siehe auch SCHNEIDER (1990), S.479 f.

3 Vgl. SCHNEIDER (1990), S.480.

4 Vgl. SCHNEIDER (1990), S.478.

5 Dabei gilt $F=K-E$, wobei $K$ den als konstant angenommenen Kapitaleinsatz und $E$ das Eigenkapital bezeichnen.
} 
Kapitalisierung des Zinszuschusses im Marktwert ${ }^{1}$ dieses Unternehmens und beträgt der risikolose Marktzinssatz r, so gilt für seinen Marktwert $V_{x}$ :

$$
V_{x}=\frac{B}{i}+\frac{z F}{r}
$$

Da der Marktwert des Unternehmens bei jeder marginalen Erhöhung des Fremdkapitals $^{2}$ um $z / r$ steigt, wird Eigenkapital so lange durch Fremdkapital substituiert, bis die Fremdkapitalquote 100 Prozent erreicht. Die Kapitalstruktur wird damit für den Marktwert des Unternehmens relevant. Allerdings werden durch den Anreiz zu vollständiger Fremdkapitalfinanzierung keine sozialen Kosten erzeugt, da diese auch ohne Kredithilfe kostenminimal und damit wohlfahrtsoptimal ist. Außerdem ist zu beachten, daß der rechtliche Eigentümer bei vollkommenem Kapitalmarkt einen mit $r$ verzinslichen Kredit in Höhe $\mathrm{zF} / \mathrm{r}$ aufnehmen kann. Die periodische Zinszahlung in Höhe von $\mathrm{zF}$ entspricht genau dem periodischen Zinszuschuß. Damit kommt die Kreditaufnahme einer Liquidation der ökonomischen Rente aufgrund der Kredithilfe gleich. Kann der Kreditbetrag außerhalb des betrachteten Unternehmens verwendet werden, so fällt sein Marktwert unabhängig von der Kapitalstruktur wiederum auf $B / i$.

\section{c. Kapitalstruktureffekte nach der Agency-Theorie}

In einem nächsten Schritt werden Kapitalmarktunvollkommenheiten in Form von Informationsasymmetrien bei Risikoneutralität der beteiligten Individuen zugelassen. Es wird angenommen, daß das betrachtete Unternehmen von einem Manager geführt wird, der an dem Unternehmen mit einem konstanten Anteil des gegebenen Kapitaleinsatzes an der Unternehmensfinanzierung beteiligt ist und einen Teil des Residualgewinns für sich beanspruchen kann. Die Unternehmensfinanzierung soll im übrigen über externes Eigenkapital $^{3}$ oder Fremdkapital erfolgen. Dabei haben die externen Eigenkapitalgeber Anspruch auf den Teil des Residualgewinns, der nicht dem Manager zufließt. Dagegen besitzen die Fremdkapitalgeber Festbetragsansprüche, die in Abhängigkeit von den Unternehmenserträgen ganz, teilweise oder nicht erfüllt werden. Während der Manager die künftigen Ergebnisse durch sein Verhalten beeinflussen kann, sollen die externen Kapi-

1 Es wird bei dieser Partialbetrachtung also angenommen, daB der Zinszuschuß sämtliche Güterund Faktorpreise unbeeinflußt läßt und allein zu erhöhten Bruttogewinnen führt, deren kapitalisierter Wert der Erhöhung des Marktwertes des Unternehmens entspricht. Zum Begriff der Kapitalisierung vgl. ANDEL (1970), S.20.

2

Sie entspricht bei konstantem Kapitaleinsatz einer marginalen Senkung des Fremdkapitals.

Zum Begriff externes Eigenkapital vgl. z.B. JENSEN/MECKLING (1976), S.312. 
talgeber ex post nur die Unternehmensergebnisse kostenlos wahrnehmen können. Dementsprechend erhält der Manager diskretionäre Handlungsspielräume, die er zur Erhöhung eigener Vorteile auf Kosten der externen Kapitalgeber ausnutzen kann. Diese Handlungsspielräume ermöglichen unproduktive Ausgaben, die dem Manager Nutzen stiften und gleichzeitig den erwarteten Bruttogewinn schmälern. Außerdem wird eine Reduzierung des unter vollständiger Information optimalen Engagements möglich, das für den Manager mit negativen Nutzen verbunden ist und andererseits den Erwartungswert des künftigen Unternehmensergebnisses vermindert ${ }^{1}$. Da die Vermögensposition der Kapitalgeber von den Handlungen des Managers abhängig ist, läßt sich die Beziehung zwischen Kapitalgebern und Unternehmensführung als typische Principal-Agent-Beziehung charakterisieren ${ }^{2}$. Über die reinen Finanzierungskosten hinaus entstehen sogenannte agency costs. Sie geben den Wohlfahrtsverlust der Beteiligten gegenüber der Situation bei vollständiger Information an. Da rationale Kapitalgeber erkennen, daß die Informationsasymmetrie agency costs verursacht, werden sie zur Kapitalbereitstellung nur unter der Bedingung bereit sein, daß sie dafür eine Kompensation in Form höherer Kapitalerträge erhalten ${ }^{3}$, ohne daß damit ein erstbestes Optimum erreicht wird. Sowohl die externen Kapitalgeber als auch der Manager werden sich um eine Reduzierung der agency costs bemühen, da sie dadurch Vorteile realisieren können. Dabei können die agency costs durch Ressourceneinsatz vermindert werden. Dies geschieht einmal durch die Überwachung des Managers durch die externen Kapitalgeber, um sein vom Optimum abweichendes Verhalten zu begrenzen, zum anderen durch "Produktion" von Glaubwürdigkeit, durch welche der Manager einen Verzicht auf schädigende Handlungen signalisiert. Allerdings lassen sich die agency costs damit regelmäßig nicht auf Null reduzieren.

Es wird weiterhin angenommen, daß mit steigender Fremdkapitalquote die agency costs des Eigenkapitals fallen und die des Fremdkapitals steigen ${ }^{4}$. Ist die Höhe der reinen Finanzierungskosten von der Kapitalstruktur unabhängig, so wird nunmehr die kostenminimale Kapitalstruktur allein durch die Höhe der agency costs bestimmt.

Dieser Zusammenhang soll mit Abb. 7 verdeutlicht werden. Während auf der Abszisse die Fremdkapitalquote abgetragen ist, bezeichnet die Ordinate die von der Kapitalstruktur abhängigen durchschnittlichen Kapitalkosten. Die erwarteten reinen Finanzierungskosten, die von der Kapitalstruktur unabhängig sind, sollen r betragen. Die Kurven

Vgl. hierzu bereits WILLIAMSON, O. (1964); LEIBENSTEIN (1966).

2 Vgl. JENSEN/MECKLING (1976), S.309; PRATT/ZECKHAUSER (1985), S.2.

3 Vgl. JENSEN/MECKLING (1976), S313 ff.

4 Vgl. JENSEN/MECKLING (1976), S.345. 


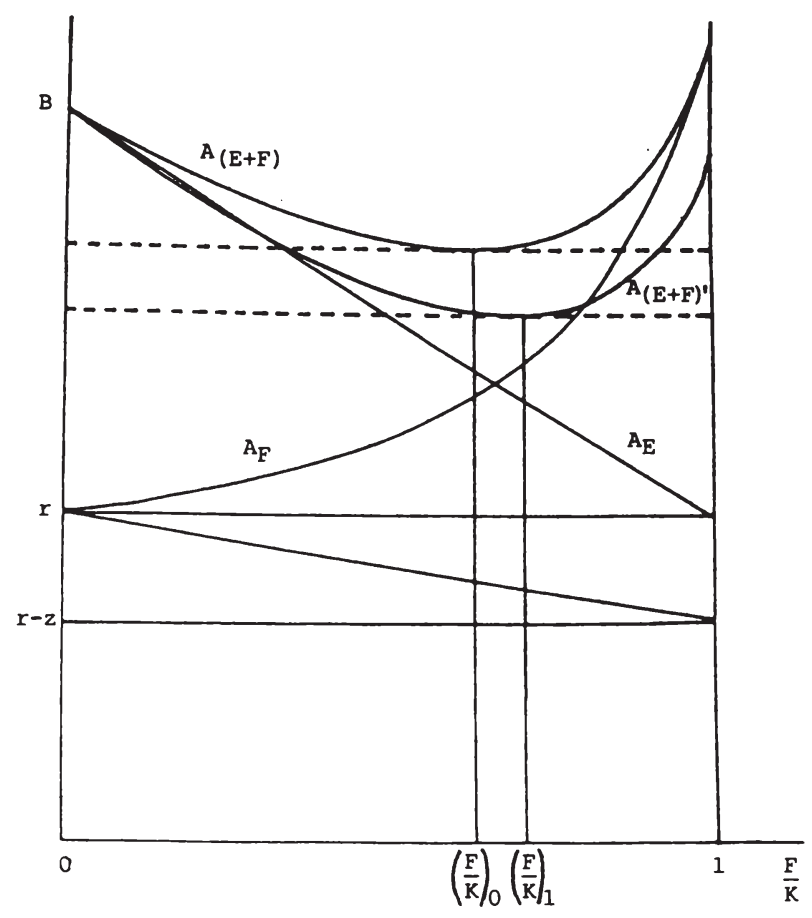

Abb. 7

$A_{F}$ und $A_{E}$ stellen die Summe aus den reinen Finanzierungskosten und den agency costs der Finanzierung mit Fremd- bzw. Eigenkapital dar und steigen bzw. fallen mit steigender Fremdkapitalquote $F / K^{1}$. Da theoretische Aussagen zum tatsächlichen Verlauf von $A_{F}$ und $A_{E}$ nicht möglich sind ${ }^{2}$, wird hier vereinfachend für $A_{E}$ ein linearer Verlauf und für $A_{F}$ eine mit zunehmender Fremdkapitalquote wachsende Steigung angenommen. Die kostenminimale und damit optimale Kapitalstruktur wird durch den Tiefpunkt der aggregierten Kapitalkostenkurve $A_{(E+F)}$ bestimmt. Er liegt dort, wo die betragsmäßige Steigungen von $A_{F}$ und $A_{E}$ übereinstimmen ${ }^{3}$. Im Normalfall wird die Fremdkapitalquote im

1 K entspricht hier der Summe aus extermem Eigenkapital und Fremdkapital.

2 Vgl. JENSEN/MECKLING (1976), S.346.

3 Vgl. JENSEN/MECKLING (1976), S.346. 
Optimum kleiner als 100 Prozent sein. Allerdings folgt aus den getroffenen Annahmen keinesfalls zwingend, da $\beta$ bei asymmetrischer Information die optimale Kapitalstruktur eindeutig bestimmbar ist. Haben $A_{F}$ und $A_{E}$ in jedem Punkt betragsmäßig dieselbe Steigung und entspricht bei vollständiger Eigenkapitalfinanzierung der Wert von $A_{E}$ dem Wert von $A_{F}$ bei vollständiger Fremdkapitalfinanzierung, so sind die agency costs bei jeder Kapitalstruktur gleich hoch. In diesem Spezialfall sind die Kapitalkosten und damit die Höhe des Marktwerts des Unternehmens wie nach dem Modigliani-Miller-Theorem von der Kapitalstruktur unabhängig.

Werden die erwarteten Finanzierungskosten des Fremdkapitals durch eine Zinsverbilligung um einen Zinszuschußsatz $z$ reduziert und unterstellt man, daß sich die Höhe der agency costs durch die Kredithilfe nicht verändert, so dreht sich $A_{(E+F)}$ in $B$ auf $A_{(E+F) \text {. }}$ Dadurch erhöht sich die kostenminimale Fremdkapitalquote $(F / K)_{0}$ auf $(F / K)_{1}$, wobei $(\mathrm{F} / \mathrm{K})_{1}$ üblicherweise unter 100 Prozent liegen wird. Man erhält also das intuitiv einsichtige Ergebnis, daß die Senkung des relativen Preises des Fremdkapitals eine Erhöhung der Fremdkapitalquote bewirkt. Durch die Verzerrung der Finanzierungsentscheidung ergeben sich Wohlfahrtsverluste, weil die agency costs steigen, während die Senkung der Finanzierungskosten lediglich eine Umverteilung zwischen den Steuerzahlern und dem Unternehmen bewirkt ${ }^{1}$. Allerdings erscheint es keinesfalls gesichert, daß die Höhe der agency costs aufgrund des Zinszuschusses nicht beeinflußt wird. Da der Zinszuschuß die Fremdkapitalkosten reduziert und den Residualgewinn erhöht, steigen für den Manager die Kosten unproduktiver Ausgaben, die demzufolge eingeschränkt werden. Es ist also denkbar, daß die agency costs des externen Eigenkapitals sinken, so da $\beta$ dadurch die Fremdkapitalquote bei konstanten agency costs des Fremdkapitals fällt. Unter diesen Bedingungen werden durch den Zinszuschuß zwei gegenläufige Effekte auf die Kapitalstruktur ausgelöst. Ist die Höhe der aggregierten agency costs in diesem Fall im neuen Optimum geringer als ohne Zinszuschuß, wird durch die Kredithilfe eine Wohlfahrtssteigerung hervorgerufen.

Erfolgt die Zinsverbilligung bei Fremdkapitalfinanzierung dagegen auf einen bestimmten Zinssatz, so sind die individuellen Kapitalkosten des Managers bei $F / K=1$ minimal. D.h. die agency costs der Fremdkapitalfinanzierung bleiben im Kalkül des Managers unberücksichtigt. Die Wohlfahrtsverluste sind demnach in diesen Fällen stets höher als bei einer Zinsverbilligung um einen bestimmten Zuschußsatz. Berücksichtigt man überdies, daß der Anreiz der Investoren zu Moral-hazard-Verhalten bei dieser Art der

1 Zusätzliche Wohlfahrtsverluste entstehen, wenn die staatlichen Einnahmen zur Finanzierung der Zinsverbilligung über verzerrende Steuern erzielt werden. 
Zinsverbilligung steigt, der Anreiz zu ihrer Überwachung durch die Fremdkapitalgeber dagegen fällt, werden sich die agency costs und somit auch die Wohlfahrtsverluste zusätzlich erhöhen. Deshalb liegt es nahe, daß die Kredithilfe-Bedingungen eine vollständige Finanzierung von Investitionen durch zinsverbilligte Kredite in der Regel nicht zulassen. Dennoch können Wohlfahrtsverluste durch Kredithilfen im gegebenen Zusammenhang nur dann vermieden werden, wenn sowohl die optimale Kapitalstruktur als auch das Ausmaß der agency costs durch die Kredithilfen bei gegebener Kapitalstruktur nicht erhöht werden.

Unter der Annahme asymmetrischer Information ergibt sich, daß Mitnahmeeffekte keinesfalls nur wegen der Verfehlung von Subventionszielen zu kritisieren sind. Vielmehr können sie unter bestimmten Bedingungen mit Wohlfahrtsverlusten verbunden sein, obwohl sie die Investitionshöhe völlig unbeeinflußt lassen. Generell ist jedoch festzuhalten, $\mathrm{da} ß$ öffentliche Kredithilfen in den diskutierten Modellvarianten regelmäßig zu einer Erhöhung der Fremdkapitalquote führen werden.

\section{DISTRIBUTIVE WIRKUNGEN ÖFFENTLICHER KREDITHILFEN}

Da Kredithilfen häufig mit distributiven Argumenten gerechtfertigt werden, sollen im letzten Teil dieses Kapitels ihre distributiven Wirkungen untersucht werden. In der Diskussion über die Vorteilhaftigkeit öffentlicher Kredithilfen nimmt die sogenannte Subventionswertermittlung oftmals großen Raum ein. Daher wird zunächst analysiert, inwieweit Subventionswerte Rückschlüsse auf die Verteilungswirkungen öffentlicher Kredithilfen zulassen. In einem nächsten Schritt wird die materielle Inzidenz öffentlicher Kredithilfen anhand partialanalytischer Modelle diskutiert. Danach wird ein einfaches allgemeines Gleichgewichtsmodell zur Analyse dieser Frage verwendet. Zum Abschluß werden die intertemporalen Verteilungswirkungen öffentlicher Kredithilfen untersucht.

\section{Der Subventionswert offentlicher Kredithilfen}

Abgesehen von ihrer Bedeutung als Vergleichsmaßstab für die Anstoßwirkungen alternativer Subventionsformen bzw. für deren Förderintensität wird die Relevanz der Ermittlung von Subventionswerten kaum schlüssig begründet. Während einerseits in erster Linie auf die aus den Subventionsmaßnahmen resultierenden staatlichen Mehrausgaben 
bzw. Mindereinnahmen abgestellt wird ${ }^{1}$, scheint nach anderer Meinung die Erfassung des Ausmaßes der Vergünstigung für die Empfänger der Kredithilfe oder sonstiger Subventionen im Vordergrund zu stehen ${ }^{2}$. Eine Zuordnung der Diskussion um die Subventionswertermittlung zum Problem der Verteilungswirkungen öffentlicher Kredithilfen erscheint jedoch sinnvoll, weil auch die Vertreter der ersten Position die aus Kredithilfen resultierenden staatlichen Mehrausgaben und Mindereinnahmen offensichtlich den Begünstigungsdestinataren als Vorteil zurechnen wollen ${ }^{3}$.

\section{a. Das Grundkonzept der Subventionswertermittlung}

Der periodische Subventionswert öffentlicher Darlehen entspricht dem Produkt der Kreditsumme und der Differenz zwischen demjenigen Zinssatz, bei dem die privaten Kreditnehmer die vom Staat nachgefragten Kreditbeträge am Markt nachfragen würden, und dem vom Staat verlangten Zinssat ${ }^{4}$. Bei Schuldendiensthilfen wird die mit dem Zuschußsatz multiplizierte Kreditsumme als Subventionswert betrachtet, während er bei Kreditgewährleistungen dem Produkt aus versicherter Kreditsumme und der Prämiensatzdifferenz zwischen einer marktlichen und der öffentlichen Kreditversicherung entspricht ${ }^{5}$. Da die Vergünstigungen öffentlicher Kredithilfen regelmäßig über mehrere Perioden hinweg zufließen, erfolgt die Ermittlung des totalen Subventionswertes durch Berechnung des Barwertes der periodischen Subventionswerte ${ }^{6}$. Sind die periodischen Subventionswerte über den gesamten Subventionierungszeitraum hinweg identisch, können sie als Postnumerando-Rente interpretiert werden. Der totale Subventionswert errechnet sich dann durch Multiplikation des periodischen Subventionswerts mit dem Rentenbarwertfaktor unter Verwendung des risikoangepaßten Marktzinssatzes als Diskontierungsrate ${ }^{7}$.

Die totalen Subventionswerte werden bei Investitions-Kredithilfen regelmäßig zum damit geförderten Investitionsvolumen in Beziehung gesetzt, um den relativen Subventionswert $\mathrm{zu}$ bestimmen ${ }^{8}$.

\footnotetext{
Vgl. DICKERTMANN (1980), S.63; DICKERTMANN/HANSMEYER (1987), S.25.

Vgl. ZEITEL (1967), S.202 f.; BARON (1983), S.142; GRÖBNER (1983), S.171, Fn.1; SCHMIDT, D. (1984), S.64; GOLDSCHMIDT (1987), S.24.

Vgl. DICKERTMANN (1980), S.48 ff., insbesondere S.63.

Vgl. v.WYSOCKI (1961), S.160 ff.; ZEITEL (1977), S.1008; KRAUSE-JUNK (1981), S.283.

Vgl. DICKERTMANN (1980), S.69; DICKERTMANN/HANSMEYER (1987), S.40.

Vgl. v.WYSOCKI (1961), S.155; ALEWELL (1965), S.125

Vgl. v.WYSOCKI (1961), S.159.

8 Vgl. SCHMIDT, D. (1984), S.64 f.; GOLDSCHMIDT (1987), S.25.
} 


\section{b. Praktische Probleme bei der Subventionswertermittlung}

Als methodische Alternativen zur praktischen Bestimmung von Subventionswerten werden der Preis- und der Kostenansatz diskutiert ${ }^{1}$. Nach dem Preisansatz wird davon ausgegangen, daß sich Marktpreise für marktliche Kredite und Kreditgewährleistungen finden lassen, deren Höhe, Laufzeitenstruktur und Risiko mit den entsprechenden Merkmalen subventionierter Kredite und Kreditgewährleistungen übereinstimmen ${ }^{2}$. Wenn die entsprechenden Referenzzins- und -prämiensätze nicht bekannt sind, läßt sich bei Darlehen und Gewährleistungen weder die Höhe des periodischen Vorteils einer Kredithilfe noch der Barwert der periodischen Subventionswerte korrekt bestimmen. Aus Vereinfachungsgründen wird daher vorgeschlagen, zur Subventionswertermittlung nur einen einheitlichen Referenzzinssatz zu verwenden ${ }^{3}$. Sind die Konditionen eines Kredithilfe-Programms für alle Empfänger identisch und sind andererseits Risikounterschiede vorhanden, so wird der Subventionswert öffentlicher Darlehen bei relativ hohem Risiko zu gering ausgewiesen. Ein anderes Problem besteht darin, daß unter bestimmten Bedingungen, insbesondere bei asymmetrischer Information oder Kreditmarktregulierungen, marktliche Kredite bzw. Kreditgewährleistungen für die Kredithilfe-Empfänger nicht erhältlich sind, so daß die Verwendung von Marktpreisen als Referenzmaßstab wenig sinnvoll erscheint ${ }^{4}$.

Aufgrund dieser Schwierigkeiten wird empfohlen, auf den sogenannten Kostenansatz auszuweichen ${ }^{5}$. Dabei wird der Gegenwartswert sämtlicher der Kredithilfevergabe zurechenbaren Ausgaben einschließlich der Verwaltungsausgaben dem Gegenwartswert der Einnahmen aufgrund der Kredithilfe gegenübergestellt ${ }^{6}$, wobei der Differenzbetrag den Subventionswert der Kredithilfe beschreiben soll ${ }^{7}$. Abgesehen von Problemen der Zurechnung von Verwaltungsausgaben ${ }^{8}$ erhält man das seltsame Ergebnis, daß der Subventionswert einer Kredithilfe um so höher ist, je ineffizienter die Kredithilfe-Verwaltung

1 Grundlegend dazu LARKINS (1972), S.31 ff. Vgl. dazu auch DICKERTMANN (1980), S.64 ff.; DICKERTMANN/HANSMEYER (1987), S.35 ff.

2 Vgl. LARKINS (1972), S.32.

3 So wird bei Kredithilfen im Rahmen der Gemeinschaftsaufgabe "Verbesserung der regionalen Wirtschaftsstruktur" ein "Normalzinssatz" von 7,5\% als Referenzzinssatz zur Subventionswertermittlung herangezogen. Vgl. GOLDSCHMIDT (1987), S.25. LARKINS (1972), S.36 schlägt vor, den durchschnittlichen Marktzinssatz für versicherte Kredite zur Subventionswertberechnung heranzuziehen.

Vgl. LARKINS (1972), S.36; DICKERTMANN/HANSMEYER (1987), S.40; GOLDSCHMIDT (1987), S.27.

5 Vgl. DICKERTMANN (1980), S.68.

$6 \mathrm{Zu}$ den zu berücksichtigenden Ausgabenarten vgl. LARKINS (1972), S.33 ff.; DICKERTMANN (1980), S.64; DICKERTMANN/HANSMEYER (1987), S.36.

7 Vgl. DICKERTMANN/HANSMEYER (1987), S.35.

8 Vgl. DICKERTMANN (1980), S.65; DICKERTMANN/HANSMEYER (1987), S.36. 
arbeitet. Darüber hinaus ist unklar, ob der Kostenansatz auf Ex-ante- oder Ex-post-Größen basieren soll ${ }^{1}$.

\section{c. Das Inzidenzkonzept der Subventionswertermittlung}

Zur Ermittlung von Verteilungseffekten wird der errechnete Subventionswert einer Kredithilfe in voller Höhe ihrem rechtlichen Empfänger als ökonomischer Vorteil in Form eines höheren Einkommens zugerechnet ${ }^{2}$. Haben z.B. die Eigenkapitalbesitzer einen Anspruch auf den Residualgewinn, sind sie danach durch eine Investitions-Kredithilfe begünstigt. Dementsprechend scheidet eine Begünstigung anderer Faktoranbieter oder der Konsumenten aus dieser Sichtweise aus, eine Konsequenz, die jedoch regelmäßig nicht expliziert wird.

Die Berechnung von Subventionswerten ist damit nichts anderes als ein Konzept der Formalinzidenz, da die ökonomischen Vorteile aus den Kredithilfen ohne Rücksicht auf dadurch verursachte ökonomische Anpassungsreaktionen ihren Destinataren, also den rechtlichen Leistungsempfängern, zugerechnet werden. Damit trifft die Subventionswertberechnung jedoch die gesamte Kritik, die gegen jedwede Art von Formalinzidenzanalyse vorgetragen wird. So liegt z.B. bei öffentlichen Konsumdarlehen auf der Hand, daß nicht jede Abweichung des Zinssatzes vom Marktzinssatz einen Einkommensvorteil repräsentiert, da ihre Empfänger zu den marktlichen Konditionen abgesehen vom Fall unelastischer Kreditnachfrage eine geringere Kreditsumme nachfragen würden ${ }^{3}$. Kredithilfen für Unternehmen kann man nicht einmal ex post ansehen, ob sie nur zu einer Erhöhung der Gewinne oder (auch) zu einer Veränderung der Güter- und Faktorpreise führen ${ }^{4}$. Deshalb gelangt man auch kaum zu einer positiveren Einschätzung der Subventionswertermittlung, wenn man sie als reine Ex-post-Rechnung begreift 5 .

1 Während LARKINS (1972), S.32 eine Ex-ante-Betrachtung zu favorisieren scheint, ist nach DICKERTMANN (1980), S.70 f., 75 nur eine Ex-post-Rechnung möglich. Allerdings beruht die Ablehnung des Kostenansatzes durch DICKERTMANN auf einem grundlegenden MiBverständnis, weil er die Kosten einer Kreditgewährleistung auf den Einzelfall beziehen will und dementsprechend bei realisierten Schadensfällen einen hohen Subventionswert und bei einem schadensfreien Verlauf des abgesicherten Kredits von einem Subventionswert von Null ausgeht. Die Vorteile aus einer Kredithilfe durch eine Ex-post-Rechnung zu ermitteln, bedeutet jedoch nicht zwingend, diese vom zufallsabhängigen Schadensverlauf im Einzelfall abhängig zu machen.

2 Vgl. v.WYSOCKI (1961), S.131.

3 Vgl. KRAUSE-JUNK (1981), S.283.

4 Vgl. KRAUSE-JUNK (1981), S.286.

5 Vgl. KRAUSE-JUNK (1981), S.307. 
Wie jede Formalinzidenzanalyse, ist auch die Berechnung von Subventionswerten aufgrund der Ignorierung sämtlicher möglichen Preis- und Mengen-Reaktionen in erheblichem, jedoch kaum abschätzbaren, Ausmaß mit Fehlern behaftet. Will man sich nicht mit dem Argument begnügen, daß eine fehlerhafte Rechnung besser sei als gar keine, so kommt man nicht umhin, theoretische Modelle zur Analyse der Verteilungswirkungen von Kredithilfen heranzuziehen ${ }^{1}$.

\section{Die materielle Inzidenz öffentlicher Kredithilfen im Partialmodell}

Während die bisher behandelten Ansätze Rückwirkungen öffentlicher Kredithilfen auf die Preise einzelner Märkte unberücksichtigt ließen, sollen nun die marktlichen Anpassungsreaktionen im Rahmen einer Partialanalyse untersucht werden. Dabei wird bei einer Partialanalyse nur der Markt betrachtet, auf dem die staatliche Maßnahme unmittelbar ansetzt $^{2}$. Kredithilfen beeinflussen jedoch sowohl Finanzierungs- als auch Realgüterentscheidungen unmittelbar ${ }^{3}$. Letzteres wird besonders deutlich, wenn man sich vergegenwärtigt, daß zahlreiche Kredithilfen zweckgebunden für den Erwerb spezieller Kapitalgüter vergeben werden. Deshalb soll im folgenden zwischen der Inzidenz auf dem Kreditmarkt und auf einem exemplarischen Kapitalgütermarkt unterschieden werden.

\section{a. Die Inzidenz öffentlicher Kredithilfen auf dem Kreditmarkt}

Aus Vereinfachungsgründen wird im folgenden angenommen, daß auf dem Kreditmarkt vollkommene Sicherheit besteht. Weiterhin soll vollkommene Konkurrenz der Kreditanbieter gegeben sein. Es werden nur homogene Kredite gehandelt, d.h. daß sämtliche Kreditforderungen für die Anbieter perfekte Substitute darstellen und dementsprechend im Gleichgewicht ein einheitlicher Kreditzinssatz gilt. Auf der Nachfrageseite lassen sich zwei Gruppen von Kreditnachfragern unterscheiden, von denen eine Gruppe eine Kredithilfe erhält. Darüber hinaus wird angenommen, daß die Preise der kreditfinanzierten Güter durch die Kredithilfe nicht verändert werden. Im Falle einer Investitions-Kredithilfe impliziert dies ein völlig elastisches Kapitalgüterangebot.

\footnotetext{
Vgl. KRAUSE-JUNK (1981), S.307 ff.

2 Vgl. BOADWAY/WILDASIN (1984), S.349.

3 Vgl. SILBER/BLACK (1981), S.121.
} 


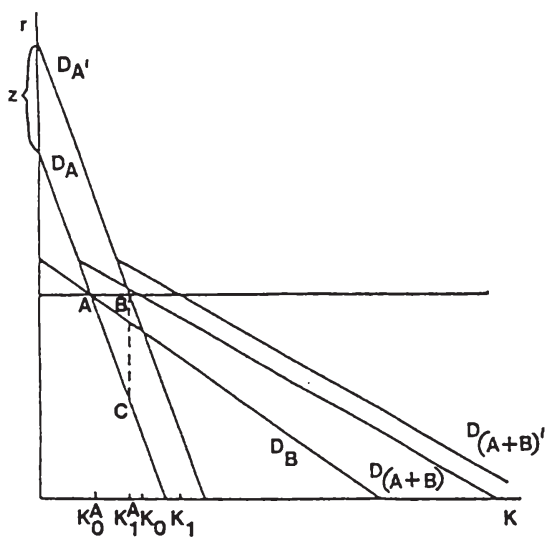

(a)

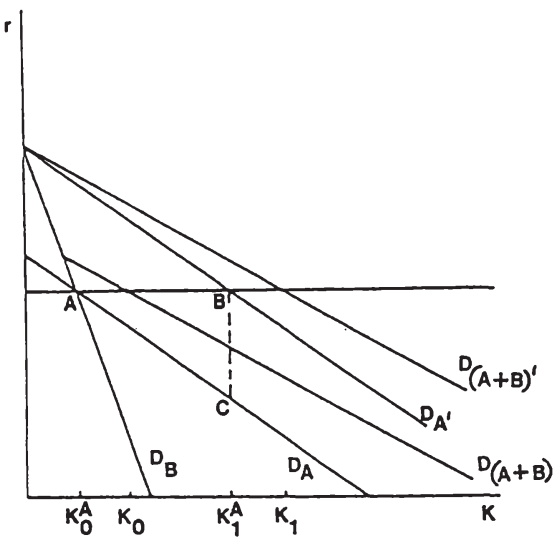

(b)

Abb. 8

Mit Abb. 8 sollen die Verteilungswirkungen einer Kredithilfe in Form eines Zinszuschusses betrachtet werden, der den Zinssatz um einen bestimmten Betrag $\mathrm{z}$ verbilligt ${ }^{1}$ und den Kreditnachfragern der Gruppe A gewährt wird, während die Nachfrager der Gruppe B Kredite nur zu marktlichen Konditionen erhalten. Dadurch verschiebt sich die Nachfragekurve $D_{A}$ um $z$ auf $D_{A^{\prime}}$ und die aggregierte Kreditnachfragekurve von $D_{(A+B)}$ nach $\mathrm{D}_{(\mathrm{A}+\mathrm{B}) \text {. }}$. Dabei ist in Abb. 8a (Abb. 8b) der Fall dargestellt, daß die Kreditnachfrage der Gruppe A relativ unelastisch (elastisch) ist. $\mathrm{Da}$ in Abb. 8 eine vollkommen elastische Kreditangebotskurve unterstellt wird, verändert sich der gleichgewichtige Kreditzinssatz durch die Kredithilfe nicht. Da sich aber der Netto-Zinssatz für Gruppe A um z ermäßigt, wird sie allein durch die Kredithilfe begünstigt. Es resultiert außerdem eine Erhöhung der nachgefragten Kreditmenge von $K_{0}$ auf $K_{1}$, die der zusätzlichen Nachfrage von Gruppe $A$ entspricht. Die Kosten des Zinszuschusses belaufen sich dabei auf $\mathrm{zK}_{1}{ }^{\mathrm{A}}$. Wie Abb. 8 zeigt, sind die Erhöhung der gesamten nachgefragten Kreditmenge und die staatlichen Ausgaben für die Zinszuschüsse um so höher, je elastischer die Nachfragekurve der Kredithilfe-Empfänger verläuft. $\mathrm{Da}$ die Individuen der Gruppe $A$ die Menge $\mathrm{K}_{1}{ }^{\mathbf{A}}-\mathrm{K}_{0}{ }^{\mathrm{A}}$ ohne den Zinszuschuß nicht nachgefragt hätten, führt er verglichen mit einer nicht verzerrenden pauschalen

1 Diese Art von Zinszuschüssen entspricht mutatis mutandis einer Mengensteuer, vgl. SILBER/BLACK (1981), S.124. 
Übertragungszahlung in Höhe von $\mathrm{zK}_{1}{ }^{\mathrm{A}} \mathrm{zu}$ einer Mehrbelastung, die bei Vernachlässigung von Einkommenseffekten durch das Dreieck $\mathrm{ABC}$ wiedergegeben wird. Damit geht genau die Hälfte der durch die Zunahme der Kreditnachfrage bewirkten Zuschußausgaben bei den Begünstigten wieder verloren. Bei linearem Verlauf der Kreditnachfragekurve bestimmt sich die Mehrbelastung $M$ entsprechend der bekannten HARBERGER-Formel ${ }^{1}$ folgendermaßen:

$$
M=1 / 2 \eta\left(K_{0}^{A} / r_{0}\right) z^{2} .
$$

D.h. die absolute Mehrbelastung steigt mit zunehmender Nachfrageelastizität $\eta$ der begünstigten Gruppe mit einer konstanten Rate. Der Anteil der Mehrbelastung an den gesamten Zinsverbilligungsausgaben $\mathrm{Z}=\mathrm{zK}_{1}{ }^{\mathrm{A}}$ beträgt

$$
M / Z=1 / 2 \eta\left(z / r_{0}\right)\left(K_{0}^{A} / K_{1}^{A}\right) .
$$

Unterstellt man identische Nachfrageanteile von Gruppe A und B ohne Kredithilfe, so reduziert sich (C.IV.2) auf

$$
\mathrm{M} / \mathrm{Z}=\mathbf{1 / 2}\left(\mathrm{K}_{1}{ }^{\mathrm{A}}-\mathrm{K}_{0}{ }^{\mathrm{A}}\right) / \mathrm{K}_{1}{ }^{\mathrm{A}} \text {. }
$$

Da $\mathrm{K}_{1}^{\mathrm{A}}$ um so größer ist, je elastischer die Kreditnachfrage der begünstigten Gruppe ist, ergibt die Ableitung von (C.IV.2a) nach $\mathrm{K}_{1}{ }^{\mathrm{A}}$, daß auch die relative Mehrbelastung mit zunehmender Nachfrageelastizität steigt ${ }^{2}$. D.h. der relative Verteilungsverlust des Kredithilfe-Empfängers wird gegenüber einer ungebundenen Transferzahlung um so höher, je erfolgreicher die Kredithilfe im Hinblick auf die Erzielung von Anreizwirkungen ist.

Modifiziert man die obigen Annahmen, indem man eine Elastizität des Kreditangebots kleiner unendlich unterstellt, so resultiert daraus eine Erhöhung des Marktzinssatzes, die zu einer verringerten Mengenreaktion führt. Aufgrund des gestiegenen Marktzinssatzes verbleibt den Empfängern der Kredithilfe lediglich ein Teil der Zinsverbilligung. Diese Konsequenz entspricht der allgemeinen Erkenntnis der mikroökonomischen Inzidenztheorie, wonach jedwede Art diskriminierender staatlicher Maßnahmen tendenziell durch marktliche Anpassungsprozesse abgebaut wird ${ }^{3}$.

Wie aus Abb. 9 ersichtlich wird, wo aus Vereinfachungsgründen identische Kreditnachfragefunktionen von Gruppe A und B ohne Kredithilfe unterstellt sind, führt ein steigender Marktzinssatz nicht nur dazu, daß sich der Verteilungsvorteil der Gruppe A von

1 Vgl. HARBERGER (1974), S.34. Zu einer Variante der Harberger-Formel vgl. FOLKERS 2 (1988c), S.219.

$\frac{\mathrm{d}(\mathrm{M} / \mathrm{Z})}{\mathrm{dK}_{1}{ }^{\mathrm{A}}}=\frac{1 / 2 \mathrm{~K}_{0}^{\mathrm{A}}}{\left(\mathrm{K}_{1}^{\mathrm{A}}\right)^{2}}>0$ für alle $\mathrm{K}_{0}^{\mathrm{A}}>0$.

3 Vgl. FOLKERS (1988c), S.222 f. 


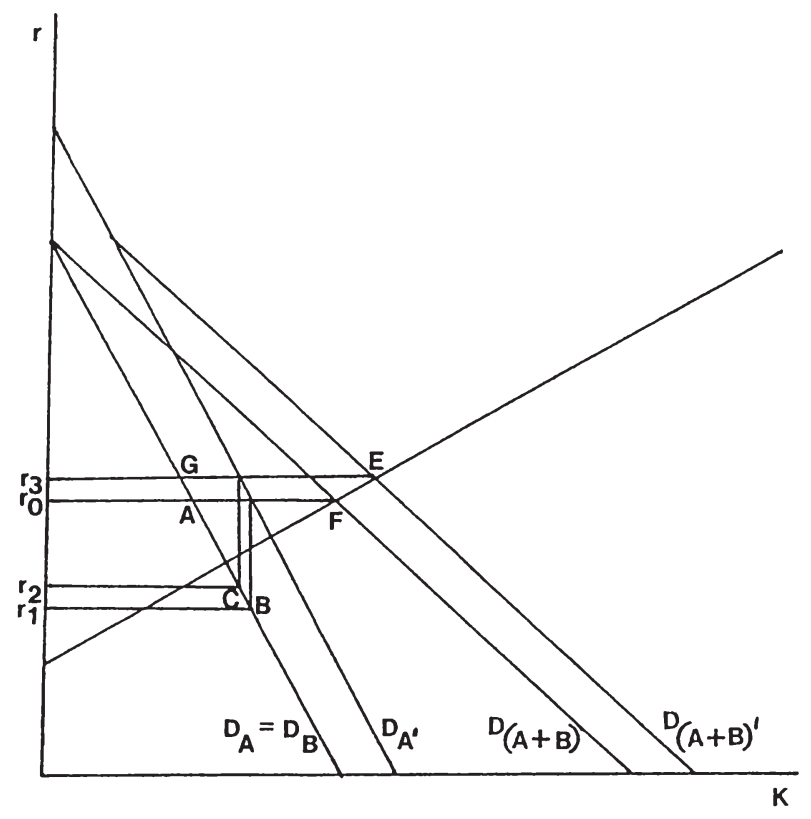

Abb. 9

$\mathrm{r}_{0} \mathrm{ABr}_{1}$ auf $\mathrm{r}_{0} \mathrm{ACr}_{2}$ reduziert. Vielmehr wächst auch der formal nicht begünstigten Angebotsseite ein Vorteil in Höhe von $\mathrm{r}_{3} \mathrm{EFr}_{0}$ zu. Darüber hinaus erleidet die nicht zum Empfängerkreis der Kredithilfe gehörige Gruppe B einen Verlust ${ }^{1}$ im Ausmaß der Fläche $\mathrm{r}_{3} \mathrm{GAr}_{0}$. Außerdem führt der Anstieg des Marktzinssatzes zu Vermögensverlusten für die Inhaber alter Kreditforderungen. Denn durch den höheren Marktzinssatz fällt der Gegenwartswert der aus diesen Forderungen resultierenden künftigen Einnahmenströme ${ }^{2}$. Damit unterscheidet sich das Verteilungsergebnis in diesem Fall wesentlich vom vorgenannten Fall mit konstantem Marktzinssatz. Der Verlust der nicht begünstigten Kreditnachfrager und Forderungsinhaber sowie die Minderung des Verteilungsvorteils der formal

1 Vgl. BREAK (1965), S.29 ff.; DICKERTMANN (1980), S.190.

2 D.h. daß sich durch die Möglichkeit der Durchführung zusätzlicher Kredithilfen Zinsänderungsrisiken ergeben, die üblicherweise dazu führen werden, daß die Kreditgeber einen um eine Risikoprämie erhöhten Zinssatz schon vor dem Inkraftsetzen des Kredithilfeprogramms verlangen werden. Erste Verteilungskonsequenzen öffentlicher Kredithilfen ergeben sich also bereits dann, wenn ihre Vergabe mit gewisser Wahrscheinlichkeit möglich erscheint. 
Begünstigten sind dabei um so höher, je unelastischer das Kreditangebot ist ${ }^{1}$. Weiterhin ist der Verlust von Gruppe B um so höher, je größer der Anteil der Gruppe A an der Gesamtnachfrage und je größer die Preiselastizität der Nachfrage von Gruppe A relativ zur Preiselastizität von Gruppe B ist ${ }^{2}$.

Allerdings verbleibt der begünstigten Nachfragergruppe auch bei vollkommen unelastischem Kreditangebot ein Teil der Zinsverbilligung, während bei einer Kredithilfe für alle Nachfragergruppen ein unelastisches Angebot dazu führen würde, daß der gesamte Vorteil der Vergünstigung der Anbieterseite zufließt ${ }^{3}$. Wird die Kredithilfe ausschließlich dazu eingesetzt, um der formal begünstigten Nachfragergruppe A Verteilungsvorteile zu gewähren, so wird dieses Ziel bei einer steigenden Kreditangebotskurve jedoch in jedem Fall partiell verfehlt.

Es soll nun angenommen werden, daß die Kredithilfe prinzipiell für alle Kreditnachfrager zur Verfügung stehen soll, die Ausgaben zur Zinsverbilligung jedoch in einer Höhe budgetmäßig begrenzt sind, die den Ausgaben der Kredithilfe nur für Gruppe A im obigen Beispiel entspricht. Wenn im "Windhundrennen" nur Gruppe A bedient wird, so wird deutlich, daß das Ergebnis geradezu eine Perversion gegebenenfalls verfolgter verteilungspolitischer Zielsetzungen bedeutet. Denn Gruppe B wird gegenüber der Gruppe A nicht nur relativ benachteiligt, sondern erleidet effektive Verluste, obwohl sie grundsätzlich begünstigt werden soll ${ }^{4,5}$.

Außer dieser häufig unerwünschten Abweichung des Verteilungsergebnisses von der formalen Begünstigung, resultiert bei einem Anstieg des Marktzinssatzes stets eine Mehrbelastung. Dies gilt auch dann, wenn man eine unelastische Angebotskurve unterstellt ${ }^{6}$. In Abb. 10 betragen die gesamten Ausgaben zur Zinsverbilligung bei unelastischem Kreditangebot $\mathrm{r}_{1} \mathrm{CEr}_{2}$. Der Verteilungsvorteil der Nachfragergruppe $A$ beläuft sich auf $\mathrm{r}_{0} \mathrm{FEr}_{2}$ und der Vorteil der Anbieter auf $\mathrm{r}_{1} \mathrm{GHr}_{0}$. Dem steht ein Verteilungsverlust von

1 Vgl. SILBER/BLACK (1981), S.132.

2 Vgl. WHITE/WHITE (1977), S.117.

3 Vgl. SILBER/BLACK (1981), S.125; FOLKERS (1988c), S.224.

$4 \mathrm{Zu}$ der Möglichkeit entsprechender Konsequenzen bei Steuervergünstigungen vgl. FOLKERS (1988c), S.228.

5 Berücksichtigt man diesen Zusammenhang, so müBte das "Windhundverfahren" bei größeren Kredithilfeprogrammen unzulässig sein, wenn man, wie der BUNDESGERICHTSHOF (1959), S.710, fordert, daB die nicht bedienten Kredithilfe-Interessenten über den AusschluB aus dem Empfängerkreis hinaus durch die Förderung Dritter keine zusätzlichen Nachteile erleiden dürfen.

6 Unter diesen Bedingungen beträgt die Mehrbelastung einer Kredithilfe für alle Kreditnachfrager Null. 


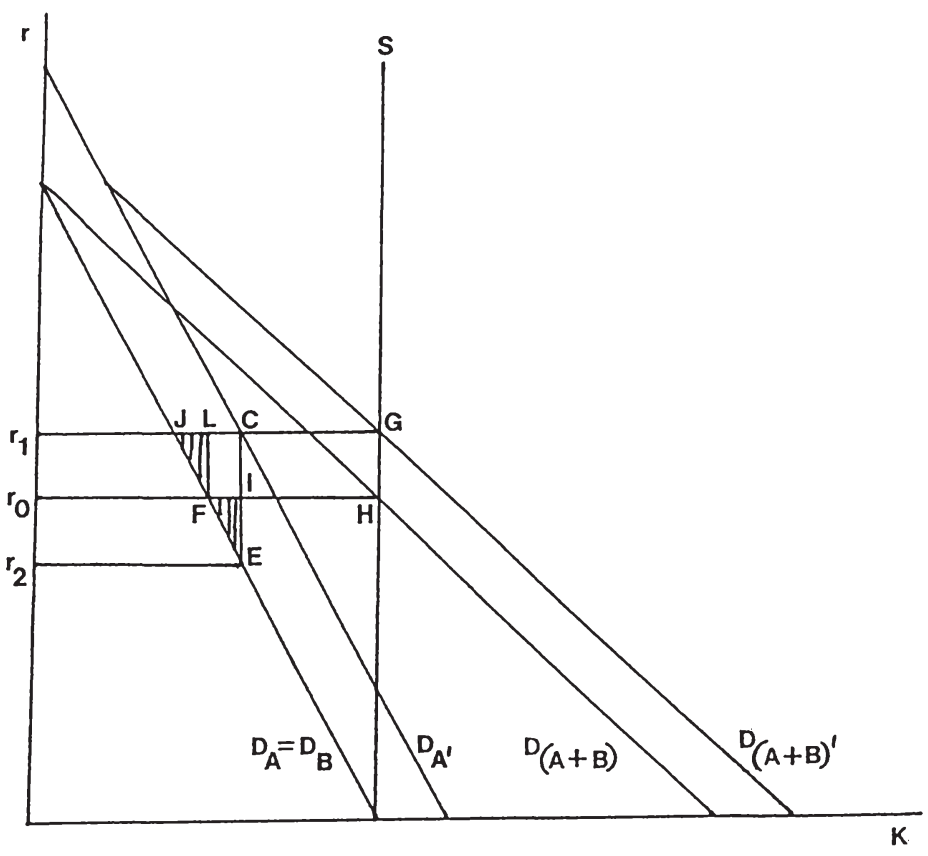

Abb. 10

$\mathrm{r}_{1} \mathrm{JFr}_{0}$ der Nachfragergruppe $\mathrm{B}$ gegenüber. Da die Flächen JGHF und $\mathrm{r}_{0} \mathrm{FEr}_{2}$ gleich gro $B$ sind, entspricht die Mehrbelastung dem Rechteck CIFL. D.h. daß bei Kredithilfen für einzelne Nachfragergruppen das Verteilungsvolumen in jedem Fall durch die damit verursachten Wohlfahrtsverluste geschmälert wird. Daraus kann zudem gefolgert werden, daß die Wohlfahrtsverluste eines Kredithilfeprogramms für einzelne Nachfragergruppen höher sind als bei einer ausgabengleichen Zinssubventionierung sämtlicher Nachfrager ${ }^{1}$. Die Messung von Wohlfahrtsverlusten mit Hilfe des Harberger-Dreiecks unter den Schnittpunkten der Marktangebots- und -nachfragekurven führt demnach zu einer Unterschätzung der Mehrbelastung von Kredithilfen für einzelne Nachfragergruppen ${ }^{2}$. Dieses Ergebnis beruht darauf, daß die durch das Kredithilfeprogramm bei den begünstigten und

1 Vgl. WHTTE/WHTTE (1977), S.117 f.

2 Vgl. WHITE/WHITE (1977), S.118. 
nichtbegünstigten Nachfragergruppen induzierten Mehrbelastungen nicht saldiert werden dürfen, sondern zu kumulieren sind.

\section{b. Die Inzidenz öffentlicher Kredithilfen auf dem Kapitalgütersektor}

Kredithilfen werden häufig zur Förderung spezifischer Realgütertransaktionen gewährt und unterliegen somit einer bestimmten Zweckbindung ${ }^{1}$. Dies trifft insbesondere auf Investitions-Kredithilfen zu, wenn dadurch bestimmte Investitionsarten, wie z.B. Wohnungsbauinvestitionen, begünstigt werden sollen. Da Investitionen aber regelmäßig den Erwerb von Kapitalgütern erfordern, wird durch entsprechende Kredithilfen der Markt für die betreffenden Kapitalgüter beeinflußt. Im folgenden soll daher die Inzidenz öffentlicher Kredithilfen auf dem Markt für ein exemplarisches Kapitalgut untersucht werden. Dabei wird hier unterstellt, daß die Kredithilfen den Marktzinssatz nicht verändern.

Der Preis einer Einheit des Kapitalguts entspricht im Gleichgewicht dem Gegenwartswert der künftigen Erträge des Kapitalguts ${ }^{2}$ und dieser wiederum dem Gegenwartswert der Kapitalnutzungskosten. Werden nun die Kapitalnutzungskosten jeder Periode durch eine Kredithilfe gesenkt, übersteigt der Gegenwartswert der Zukunftserträge die Kapitalnutzungskosten und den Kapitalgüterpreis. Aufgrund der Kapitalisierung der erhöhten Zukunftserträge durch die Empfänger der Kredithilfe ${ }^{3}$ dreht sich ihre Nachfragekurve im Uhrzeigersinn nach oben ${ }^{4}$.

Betrachtet man nun wiederum den Fall, daß nur eine Gruppe der Nachfrager des Kapitalguts die Kredithilfe erhält, so gelten die bei der Inzidenzanalyse des Kreditmarkts abgeleiteten Ergebnisse analog. D.h. daß die Kredithilfe bei fallender Nachfragekurve der geförderten Nachfrager des Kapitalguts unabhängig von der Steigung der Angebotskurve zu Mehrbelastungen führt. Bei steigender Angebotskurve führt die Drehung der Nachfragekurve zu einem Anstieg des Kapitalgüterpreises. Dadurch ergibt sich ein Verlust für

Vgl. MOLITOR (1980), S.290.

Vgl. BOADWAY (1979), S.267; HERB (1988), S.46.

3 Kapitalisierung einer Kredithilfe bedeutet also nichts anderes als die relative Neubewertung der geförderten Einheiten des Kapitalgutes gegenüber den nicht geförderten Einheiten. Vgl. ANDEL (1970), S.20. Zu einer entsprechenden Interpretation von Kapitalisierung im Falle diskriminierender Kapitalsteuern vgl. MUSGRAVE (1959/1966), S.348 f.; ATKINSON/ STIGLITZ (1980), S.67. Siehe auch KOTLIKOFF/SUMMERS (1987), S.1086 ff.

4 Diese Konsequenz ist ohne weiteres nachvollziehbar, da der absolute Zinszuschuß bei einem Kapitalgüterpreis von Null ebenfalls Null beträgt und mit steigendem Kapitalgüterpreis proportional zunimmt. Die Kredithilfe entspricht somit einer Wertsubvention des Kapitalgutes. Siehe dazu oben Abschnitt C.III.1. 
die nicht geförderten Nachfrager des Kapitalgutes, während der Vorteil der Kredithilfe zwischen den geförderten Nachfragern und den Anbietern aufgeteilt wird ${ }^{\mathbf{1}}$.

Umfaßt die Förderung den Erwerb von gebrauchten und von neuen Kapitalgütern, dann erlangen sowohl die Produzenten des Kapitalgutes als auch die Besitzer gebrauchter Einheiten des Kapitalgutes Verteilungsvorteile. Wird eine Kredithilfe dagegen ausschließlich zur Finanzierung neu hergestellter Kapitalgütereinheiten gewährt und unterstellt man, daß neue und gebrauchte Einheiten des Kapitalgutes perfekte Substitute darstellen, so fällt für die Empfänger der Kredithilfe der relative Preis von neuen gegenüber den gebrauchten Einheiten. Dadurch steigt die Nachfrage nach neuen Einheiten, während die Nachfrage nach gebrauchten Einheiten zurückgeht. Im Regelfall resultiert daraus ein Anstieg des Marktpreises für erstere und ein Rückgang des Preises für letztere. Die Kredithilfe führt damit über die Nachteile für die nicht geförderten Nachfrager des Kapitalgutes hinaus auch zu Verteilungsnachteilen für die Besitzer des Bestandes an gebrauchten Einheiten des mit der Kredithilfe geförderten Kapitalgutes ${ }^{2}$.

Im folgenden soll die Nachfrage nach Kapitalgüter-Outputs am Beispiel der Förderung des Wohnungseigentums berücksichtigt werden. Es wird unterstellt, daß die Kredithilfe nur dann gewährt wird, wenn die Investoren den mit staatlicher Förderung erworbenen Wohnraum selbst nutzen. Damit sind die Kapitalgut-Nachfrager gleichzeitig auch Nachfrager nach dem Output des Kapitalgutes. Die Zahl der Wohnraumnachfrager soll konstant bleiben.

Die Kredithilfe führt für die Kredithilfe-Empfänger zu einer Reduzierung des Preises für Wohnraum. Sie werden zusätzliche Wohneinheiten ${ }^{3}$ nachfragen, wenn der Nutzungspreis für gemieteten und selbstgenutzten Wohnraum vor Kredithilfe identisch ist. Damit steigt die Gesamtnachfrage nach Wohnraum, da die Nachfrage nach selbstgenutztem Wohnraum stärker steigt, als die Nachfrage nach Mietwohnraum fällt. Bei einer steigenden Angebotskurve für Wohnraumnutzungen wird der Marktpreis je Wohneinheit ${ }^{4}$ steigen. Als Konsequenz werden die Mieter einen höheren Mietpreis zu zahlen haben und weniger Wohneinheiten nachfragen. D.h. sie erleiden durch die Kredithilfe Verteilungsnachteile. Berücksichtigt man, daß die Erwerber von staatlich gefördertem Wohnungseigentum im Hinblick auf das Lebenseinkommen höheren Einkommensklassen angehören dürften als

1 Vgl. WHITE/WHITE (1977), S.115 ff.; MOLITOR (1980), S.290.

2 Vgl. KOTLIKOFF/SUMMERS (1987), S.1085 f. Die Autoren verweisen auf eine entsprechende Wirkung einer Reduktion von Neuwagenpreisen auf die Gebrauchtwagenpreise.

3 Die Wohneinheiten können in diesem Modell als Flächeneinheiten interpretiert werden. Vgl. WHITE/WHITE (1977), S.115.

4 Der Preis von Wohnraum wird gemessen als Preis der jährlichen Nutzung einer Wohneinheit. Vgl. WHITE/WHITE (1977), S.115. 
Mieter, so ergibt sich unter den getroffenen Annahmen das verteilungspolitisch perverse Ergebnis, daß durch die Förderung des Erwerbs von Wohnungseigentum gerade die sozial schwächeren Bevölkerungsgruppen geschädigt werden ${ }^{1}$. Die Wohlfahrtsverluste derartiger Kredithilfen setzen sich zusammen aus der Mehrbelastung aufgrund der Umlenkung von Ressourcen in den Wohnungssektor, aufgrund der Einschränkung des Wohnkonsums der Mieter und aufgrund der Ausweitung des Wohnkonsums der Eigennutzer ${ }^{2}$. Dieses Ergebnis läßt sich nur vermeiden, wenn die Mehrnachfrage der Kredithilfe-Empfänger nach Wohnraumnutzungen von einer Rechtsverschiebung der Angebotskurve begleitet wird. Eine verteilungspolitische Begründung von Programmen zur Schaffung von Wohnraumeigentum erscheint somit vor allem dann außerordentlich problematisch, wenn der induzierten Nachfrageausweitung ein relativ starres Wohnraumangebot gegenübersteht.

Wird die Nachfrage nach dem Output des geförderten Kapitalgutes durch eine Kredithilfe nicht beeinflußt und erhöht sich andererseits das Angebot des Kapitalgüter-Outputs, so sinkt bei fallender Nachfragekurve der Outputpreis. Dadurch kommt es zu Verteilungsverlusten der nichtgeförderten Anbieter des entsprechenden Outputs. Dieser Zusammenhang wird besonders deutlich, wenn man annimmt, daß der betrachtete Output von mehreren Unternehmen angeboten wird, deren Kostenfunktionen bei der optimalen Betriebsgröße unterschiedlich verlaufen. Während die inframarginalen Anbieter im Betriebsoptimum Gewinne realisieren, kann der Grenzanbieter bei gegebenem Outputpreis aus den Produktionserlösen gerade die Produktionskosten decken ${ }^{3}$. Kommt es nun zu einem exogenen Nachfragerückgang, so sinkt der Gleichgewichtspreis. Damit wird die Produktion des Grenzanbieters X unrentabel. Scheidet dieses Unternehmen aus dem Markt aus, erhält ein anderes Unternehmen $Y$ beim neuen Gleichgewichtspreis die Stellung des Grenzanbieters. Erhält nun Unternehmen X eine Kredithilfe, um zu "überleben", so erhöht sich das Angebot gegenüber der Situation ohne Kredithilfe. Bei unveränderter Nachfragekurve fällt der Outputpreis. Damit wird Unternehmen $Y$ allein durch die Förderung von Unternehmen $\mathbf{X}$ unrentabel und ist gezwungen, aus dem Markt auszuscheiden, obwohl es kostengünstiger als Unternehmen $\mathbf{X}$ produziert. Will der Staat Unternehmen $\mathbf{Y}$ ebenfalls nicht "sterben lassen" und gewährt ihm deshalb auch eine Kredithilfe, so kommt es zu einem Prozeß, der mit dem Begriff Interventionsakzeleration zutreffend umschrieben werden $\mathbf{k a n n}^{4}$. Thre ökonomische Konsequenz besteht in der Erhaltung von Überkapazitäten, deren Kosten durch Markterlöse nicht gedeckt werden und somit immer neue Subven-

\footnotetext{
1 Vgl. WHITE/WHITE (1977), S.116 f.

2 Vgl. WHITE/WHITE (1977), S.117.

3 Vgl. SCHUMANN (1987), S.199 ff.

4 Vgl. FOLKERS (1978) in bezug auf Steuerreformprozesse.
} 
tionierungen erforderlich machen. Die Kosten dafür tragen die in den Unternehmen beschäftigten Faktoren, die ohne staatliche Hilfe rentabel sind, während sich die Vorteile auf die Faktoranbieter der geförderten Unternehmen und die Nachfrager nach dem entsprechenden Output verteilen.

Berücksichtigt man schließlich die zeitliche Dimension ökonomischer Anpassungsprozesse, so können sich die kurzfristigen von den langfristigen Verteilungseffekten öffentlicher Kredithilfen erheblich unterscheiden. Geht man davon aus, daß das kurzfristige Kapitalgüterangebot bei Vollbeschäftigung relativ unelastisch ist, so werden die Anbieter des Kapitalgutes Preiserhöhungen durchsetzen können und damit einen Gewinn erzielen ${ }^{1,2}$. Wird die Kredithilfe über weitere Perioden gewährt, werden die von den Anbietern des Kapitalgutes erzielten Gewinne bei freiem Marktzutritt langfristig zu einer Erhöhung des Angebots und damit wieder zu einem fallenden Kapitalgüterpreis führen ${ }^{3}$. Dadurch erhöht sich aber nicht nur der Verteilungsvorteil der Nachfrager nach geförderten Einheiten in den folgenden Perioden. Vielmehr werden diejenigen Besitzer des Kapitalgutes Vermögensverluste erleiden, die es in der ersten Periode zum höheren .Preis erworben haben. Solche Vermögensverluste lassen sich jedoch vermeiden, wenn die Nachfrager der ersten Periode antizipieren, daß die Kredithilfe über mehrere Perioden gewährt wird, da sie dann mit langfristig steigendem Angebot bzw. fallendem Preis rechnen ${ }^{4}$. Hierbei handelt es sich wiederum um einen Kapitalisierungseffekt, indem die Nachfrager die für sie aus einer künftigen Angebotsausweitung resultierenden Nachteile in ihrem Kalkül berücksichtigen.

Diese Überlegungen zeigen, daß Kapitalisierungseffekte von dem Zeitpunkt an auftreten, in dem den Marktteilnehmern bestimmte Arten staatlicher Maßnahmen bewußt werden ${ }^{5}$. Außerdem wird deutlich, daß das Verteilungsergebnis von Kredithilfen ${ }^{6}$ entgegen der üblicherweise vertretenen Auffassung nicht allein von den Steigungen der Nachfrage-

1 Vgl. MANN (1987), S.176 f.

2 Betreiben die Anbieter eine Preisdiskriminierung zwischen begünstigten und nichtbegünstigten Nachfragern, so erhöhen sie den Preis für die geförderten Einheiten soweit, bis die Ertragsraten des Kapitaleinsatzes beim Erwerb der geförderten und nicht geförderten Einheiten des Kapitalgutes identisch sind. In diesem Fall erhält man das aus der Monopoltheorie bekannte Ergebnis, daß trotz der Beschränkung des Kredithilfe-Angebots auf einen Teil der Nachfrager des Kapitalgutes im Gegensatz zu den obigen Überlegungen keine Wohlfahrtsverluste entstehen. Die Diskriminierung der Nachfrager durch den Staat wird dann mittels einer gegenläufigen Diskriminierung durch die Anbieter exakt kompensiert.

3 Vgl. ATKINSON/STIGLITZ (1980), S.67 f.

4 Rechnen die Nachfrager der ersten Periode aufgrund der Kredithilfe mit einem langfristig vollkommen elastischen Angebot, wird ihre Nachfrage tendenziell sehr elastisch sein, da sich dann Vermögensverluste in künftigen Perioden begrenzen lassen.

6 Entsprechendes gilt auch für andere Subventionsmaßnahmen und Steuern. 
und Angebotskurven abhängt, sondern entscheidend auch von den Erwartungen der beiden Marktseiten über die Zeitdauer von Subventionsmaßnahmen bestimmt wird. Ist die Information über die staatlichen Subventionsplanungen zwischen beiden Marktseiten asymmetrisch verteilt, so wird die besser informierte Marktseite durch frühzeitige Anpassungen entsprechende Vorteile daraus ziehen können, während die schlechter informierte Marktseite die Kosten des relativen Informationsnachteils zu tragen hat. Dieser Zusammenhang zeigt, daß Lobbyaktivitäten einzelner Interessengruppen bereits dann ökonomisch erklärbar sind, wenn sie sich damit, ohne die Politikerentscheidungen zu beeinflussen, Informationsvorteile verschaffen können.

\section{c. Grenzen der Partialanalyse}

Während bisher angenommen wurde, daß sich durch eine Kredithilfe nur der Marktzinssatz oder der Kapitalgüterpreis erhöht, werden die Verteilungswirkungen öffentlicher Kredithilfen noch unübersichtlicher, wenn sich beide Preise simultan erhöhen. Unter diesen Bedingungen wird sich die Nachfrage nach dem betrachteten Kapitalgut und damit der Kapitalgüterpreis in geringerem Ausmaß erhöhen. Nimmt man an, daß die nicht geförderten Kreditnachfrager mit den Krediten den Kauf eines anderen Kapitalgutes finanzieren wollen, so fällt die Nachfrage nach diesem anderen Kapitalgut und bei steigendem Angebot auch sein Preis. Somit erleiden die Anbieter dieses anderen Kapitalgutes Verluste, während die anderen Nachfrager Verteilungsgewinne realisieren können. Mit diesen Überlegungen, die sich nahezu beliebig weiterentwickeln ließen, stößt man jedoch an die Grenze dessen, was mit einer Partialanalyse untersucht werden kann. Andererseits wird bereits damit deutlich, daß die Verteilungskonsequenzen öffentlicher Kredithilfen so weit gestreut sein können, daß sie für den Staat kaum zu überblicken sind ${ }^{1}$. Damit entfällt jedoch für eine verteilungspolitisch motivierte Kredithilfevergabe in aller Regel die ökonomische Grundlage.

\section{Differentialinzidenz öffentlicher Kredithilfen im Partialmodell}

In einem weiteren Schritt soll die Differentialinzidenz zwischen Kredithilfen und Investitionszuschüssen analysiert werden. Dabei wird angenommen, daß der Endwert der Zinsverbilligungskosten von Kredithilfen und der Endwert der in der Gegenwart ausge-

1 Zum gleichen Ergebnis gelangt FOLKERS (1988c) in bezug auf die Verteilungswirkungen für spezielle Steuervergünstigungen. Siehe auch FOLKERS (1988a). 
zahlten Investitionszuschüsse gleich hoch sind. Weiterhin sollen die Steuern zur Finanzierung der Subventionen bei allen Subventionsformen an demselben Zeitpunkt in der $\mathrm{Zu}$ kunft erhoben werden.

Es sei eine einperiodige, kreditfinanzierte Investition mit dem Restwert Null am Periodenende betrachtet. Unterstellt man einen vollkommenen Kapitalmarkt und vollständige Sicherheit, so sind Zinszuschüsse, die den Zinssatz um einen bestimmten Prozentsatz reduzieren, in ihren Inzidenzwirkungen mit denen von Investitionszuschüssen identisch, wenn die Anstoßwirkungen übereinstimmen. Die Bedingung ist erfüllt, wenn gilt:

$$
\mathrm{q}(1-\mathrm{Z})(1+\mathrm{r})=\mathrm{q}(1+\mathrm{r}-\mathrm{z}) \text { bzw. }
$$

$$
Z=z /(1+r),
$$

wobei $\mathbf{Z}$ den Zuschußsatz des Investitionszuschusses, $\mathbf{z}$ den prozentualen Zinsverbilligungssatz, $\mathrm{r}$ den Marktzinssatz und q den Kapitalgüterpreis bezeichnen. Gelten diese Beziehungen, so ist die Verbilligung des Kapitalnutzungspreises bei beiden Subventionsformen identisch.

Allerdings erscheint fraglich, ob von identischen Verteilungsimplikationen auch dann noch ausgegangen werden kann, wenn man den Kreditmarkt mitberücksichtigt. Denn die Kreditnachfrage der Investoren ist im Fall eines Investitionszuschusses für jede Investitionseinheit um qZ geringer ist als bei einem Zinszuschuß. Danach wäre die Erhöhung des Zinssatzes bei einer steigenden Kreditangebotskurve im letzteren Fall höher. Unter den getroffenen Annahmen gilt dies jedoch nicht, da die Kreditnachfrage des Staates beim Investitionszuschuß je geförderter Investitionseinheit genau um $\mathrm{qZ}$ höher ist als beim Zinszuschuß. Damit wird die verringerte Kreditnachfrage der Investoren durch die erhöhte staatliche Kreditnachfrage genau ausgeglichen. Die Auswirkungen beider Subventionsformen auf den Marktzinssatz stimmen damit überein.

Es wird nun angenommen, da $ß$ die Bestimmung des Investitionszuschußsatzes auf der Grundlage des als fix angenommenen Zinszuschußsatzes $z$ und des Marktzinssatzes vor Bekanntgabe der Subventionierung erfolgt. Unterstellt man außerdem einen Anstieg des Zinssatzes aufgrund der Subventionierung, so ist der Investor beim Investitionszuschu $B$ jedoch dadurch begünstigt, daß er den erhöhten Zinssatz für eine geringere Kreditsumme zu entrichten hat als bei einem Zinszuschuß. Dafür wäre jedoch entgegen den getroffenen Annahmen der Endwert des Investitionszuschusses höher als der in der Zukunft ausbezahlte Zinszuschuß. Sollen die Annahmen eingehalten werden, ist es folglich notwendig, den Investitionszuschußsatz entsprechend dem durch die Subventionierung induzierten Zinssatzanstieg niedriger festzusetzen, wenn identische Verteilungsimplikationen beider 
Subventionsformen angestrebt werden. Dies würde jedoch voraussetzen, daß der Staat bereits im voraus sämtliche Zinsreaktionen antizipieren kann. Ist dies nicht der Fall, werden beide Subventionsformen allenfalls zufällig äquivalente Verteilungswirkungen haben.

Dasselbe Ergebnis erhält man, wenn man bei unterstellter Risikoneutralität aller Individuen Unsicherheit hinsichtlich der Investitionserträge zuläßt. Dabei werden wiederum zwei mögliche Investitionserträge unterstellt, wobei der Investitionsertrag mit der Wahrscheinlichkeit $\mathbf{p}$ Null betragen soll. Erfolgt die Zinsverbilligung bei den Kredithilfen um denselben Zinsverbilligungssatz, so muß auch ein Investitionszuschuß für jede beliebige Höhe von p gleich hoch sein, um dieselben Anstoßwirkungen wie die Kredithilfen zu bewirken. Erfolgt bei den Kredithilfen die Zinsverbilligung auf einen bestimmten Zinssatz, so ist im Fall von Investitionszuschüssen neben der Antizipation der Zinsreaktionen ein System von differenzierten Zuschußsätzen erforderlich, damit die Anstoßwirkung von Investitionszuschüssen bei unterschiedlich riskanten Investitionen der von Kredithilfen entspricht. Dabei muß der Investitionszuschußsatz um so höher sein, je größer die Wahrscheinlichkeit eines Investitionsertrags von Null ist. Denn die erwarteten Kapitalkosten fallen bei der Kredithilfe mit steigender Ausfallwahrscheinlichkeit p.

Es wird nun unterstellt, daß ein Teil der Subventionsdestinatare einer Liquiditätsbeschränkung unterliegt, also aus Liquiditätsmangel an der Durchführung rentabler Investitionen gehindert ist ${ }^{1}$, während die übrigen Subventionsdestinatare zum Marktzinssatz über Kredite in beliebiger Höhe verfügen können. Außerdem wird angenommen, daß die aus der Subventionierung resultierende Einkommenserhöhung nicht ausreicht, um die Liquiditätsbeschränkung zu überwinden. Schließlich wird ein unendlich elastisches Kapitalgüterangebot unterstellt. Unter diesen Bedingungen können die gewählten Subventionsformen das Inzidenzergebnis in einigen Punkten entscheidend beeinflussen.

Erfolgt die Subventionierung in Form eines Investitionszuschusses, so werden die in ihrer Liquidität beschränkten potentiellen Subventionsdestinatare aus der Subventionierung keinen Vorteil ziehen können, da sie nach wie vor wegen fehlender Finanzierungsmöglichkeiten die Investitionen nicht durchführen können. Andererseits werden sie, im Gegensatz zu den nichtbegünstigten Kreditnachfragern, bei steigendem Verlauf der Kreditangebotskurve, keinen absoluten Verteilungsverlust erleiden. Dasselbe gilt bei Zinszuschüssen.

Dagegen führen öffentliche Darlehen zu einer Beseitigung der Liquiditätsbeschränkung. Die liquiditätsbeschränkten Subventionsempfänger werden einen Verteilungsvorteil

1 Dabei kann hier offen bleiben, worin die Ursache für die Liquiditätsbeschränkung liegt. 
in Höhe der bei der realisierten Investitionsmenge entstehenden Investorenrente erzielen. Ist diese höher als die staatlichen Zinsverbilligungsausgaben für den einzelnen Investor, lassen sich durch den Übergang von Investitionszuschüssen auf Darlehen in jedem Fall Wohlfahrtsgewinne erzielen. Denn Investitionszuschüsse verursachen bei den geförderten Subventionsempfängern abgesehen vom Grenzfall einer vollkommen unelastischen Investitionsnachfrage stets eine Mehrbelastung. Ist die bei öffentlichen Darlehen realisierbare Investorenrente geringer als die Zinsverbilligungsausgaben, kann der Wechsel der Subventionsform jedoch auch zu Wohlfahrtsverlusten führen. Weiterhin erleiden die nicht liquiditätsbeschränkten Investoren bei Darlehen gegenüber Investitionszuschüssen relative Verteilungsverluste, weil sich ein gegebenes Ausgabevolumen zur Verbilligung der Kapitalkosten auf eine größere Zahl von Subventionsempfängern verteilt, so daß die Verbilligung der Kapitalkosten bei Investitionszuschüssen höher ist.

Ist die Liquiditätsbeschränkung risikobedingt, werden die Wirkungen von Kreditgewährleistungen tendenziell denen öffentlicher Darlehen entsprechen. Einschränkend ist allerdings anzumerken, daß die differentiellen Verteilungswirkungen öffentlicher Kredithilfen davon abhängen, welche Kriterien für die Subventionierung maßgeblich sind. Werden nur solche Subventionsbewerber berücksichtigt, die auch ohne Subventionierung als kreditwürdig gelten, so ist eine differentielle Verteilungswirkung der einzelnen Subventionsformen nicht vorhanden, weil die liquiditätsbeschränkten potentiellen Investoren ausgeschlossen bleiben.

Differentielle Verteilungswirkungen bei den einzelnen Subventionsformen ergeben sich außerdem dann, wenn die Subventionsintensität, also die Höhe der Reduzierung der Kapitalnutzungskosten, bei den verschiedenen Subventionsformen in unterschiedlicher Weise restringiert ist. Es soll angenommen werden, daß ein Investitionszuschuß nur zu einem einheitlichen Zuschußsatz vergeben werden darf. Die differentielle Verteilungswirkung eines mit dem risikolosen Marktzinssatz verzinslichen öffentlichen Darlehens bestimmt sich entscheidend durch die Privilegierung riskanterer gegenüber risikoärmeren Investitionen bei Darlehen, während die Verbilligung der Kapitalkosten beim Investitionszuschuß für alle Risikoklassen gleich hoch ist. Dadurch werden die Subventionsempfänger mit hohem (geringem) Risiko bei der Förderung durch Darlehen (Investitionszuschuß) relativ stärker begünstigt. Unterstellt man, daß prinzipiell alle Investoren förderungsberechtigt sind und daß es nur risikolose und riskante Investitionen einer bestimmten Risikoklasse gibt, werden bei der Darlehenssubventionierung im Vergleich mit der Subventionierung durch den Investitionszuschuß die Investoren mit den risikolosen (riskanten) Investitionen zumindest relative Verteilungsverluste (Verteilungsgewinne) realisieren. 
Für die differentiellen Verteilungswirkungen der einzelnen Subventionsformen kommt es also entscheidend darauf an, in welchem Ausmaß sie gleiche Sachverhalte gleich und unterschiedliche Sachverhalte diesen Unterschieden entsprechend ungleich behandeln ${ }^{1}$.

\section{Die materielle Inzidenz öffentlicher Kredithilfen in einem allgemeinen Gleich- gewichtsmodell}

Im folgenden wird die Analyse in einem allgemeinen Gleichgewichtsmodell fortgeführt. Dabei wird ein vollkommener Kapitalmarkt unterstellt, der vollkommene Sicherheit und vollständige Information sowie das Fehlen von Transaktionskosten impliziert. Dementsprechend sind Eigen- und Fremdkapital vollkommen homogene Finanzierungsarten. Die Inzidenz öffentlicher Kredithilfen läßt sich unter diesen Bedingungen analog zum Fall einer Subvention auf den Faktor Kapital analysieren. Aus Vereinfachungsgründen wird eine Volkswirtschaft mit zwei Sektoren $\mathrm{X}$ und $\mathrm{Y}$ betrachtet, wobei in beiden Sektoren die beiden Produktionsfaktoren Arbeit A und Kapital K eingesetzt werden, die beide vollbeschäftigt seien. Die Produktionsfunktionen beider Sektoren seien linear-homogen. Außerdem sollen beide Sektoren bei gegebener LohnZins-Relation $w / r$ unterschiedliche Kapitalintensitäten und damit unterschiedliche Substitutionselastizitäten aufweisen ${ }^{2}$. Weiterhin wird angenommen, daß der marginale Kapitaleinsatz ausschließlich fremdfinanziert sei. Schließlich ist die nachfolgende Inzidenzbetrachtung als Differentialanalyse konzipiert, in der ein Pauschaltransfer durch eine ausgabengleiche Kredithilfe mit einem Zinsverbilligungssatz von z substituiert wird ${ }^{3}$.

Im weiteren werden mit diesem auf HARBERGER (1962) zurückgehenden Inzidenzmodell nur spezielle Kredithilfen analysiert, da Kredithilfen in aller Regel nur an einzelne Wirtschaftssektoren vergeben werden.

Es sei angenommen, daß der X-Industrie Kredithilfen gewährt werden. Dabei wird zunächst der Fall eines konstanten Faktorangebots und vollständiger Faktormobilität

1 Dies gilt auch für Steuervergünstigungen bei der Einkommensteuer, wo es darauf ankommt, ob die Steuervergünstigung als Abzug von der Steuerbemessungsgrundlage oder als Minderung der Steuerschuld konzipiert ist. Unterscheiden sich die Destinatare lediglich durch eine unterschiedliche Einkommenshöhe, werden im ersteren Fall die geförderten Aktivitäten der Steuerzahler mit einem relativ niedrigen Marginalsatz diskrimniert. Vgl. FOLKERS (1988c), S.227.

$2 \mathrm{Zu}$ vergleichbaren Modellannahmen für den Steuerfall vgl. BOADWAY/WILDASIN (1984), S.357 ff.

3 Dabei sollen die Ausgaben für die Zinsverbilligung den Ausgaben für die Pauschalsubvention entsprechen. Erfolgt die Kredithilfe in Form offentlicher Darlehen, entspricht dies innerhalb des Modells einer Kombination marktlicher Kredite mit einer entsprechenden Zinsverbilligung. 
betrachtet. Wird die Pauschalsubvention durch Kredithilfen mit dem Zuschußsatz $\mathbf{z}_{\mathbf{x}}$ substituiert, resultieren daraus zwei Effekte. Einmal sinkt der relative Preis von $\mathrm{X}$, weil sich die Kapitalkosten der X-Industrie reduzieren ${ }^{1}$. Dadurch erhöht sich die relative Nachfrage nach X, was zu einer Reallokation der Ressourcen von der Y- zur X-Industrie führt. Andererseits kommt es zu einer Verletzung der Bedingungen für ein gesamtwirtschaftliches Produktionsoptimum, weil die Grenzraten der technischen Substitution (GRTS $\mathrm{KA}_{\mathrm{A}}$ ) in der X-Industrie mit $\left(r-z_{\chi}\right) / w$ und in der Y-Industrie mit $r / w$ voneinander abweichen. Denn im Gleichgewicht muß $\left(r-z_{x}\right)+z_{x}=r$ gelten, da andernfalls ein Anreiz zur Reallokation des Kapitals besteht. Dabei entspricht $\left(r-z_{\mathbf{x}}\right)$ dem Wertgrenzprodukt in der X-Industrie, welches kleiner ist als in der Y-Industrie ${ }^{2}$.

Der erste Effekt, der in der Inzidenztheorie als Outputeffekt bezeichnet wird ${ }^{3}$, entspricht den Effekten einer speziellen Gütersubvention für $\mathrm{X}^{4}$. Die erhöhte Nachfrage nach Faktoren in der X-Industrie führt zu steigenden Faktorentgelten und einer reduzierten Beschäftigung in der Y-Industrie. Produziert die X-Industrie kapitalintensiver als die nicht subventionierte Y-Industrie, so steigt die Arbeitsintensität in beiden Sektoren, um die Vollbeschäftigung zu erhalten. Dies führt zu einem Anstieg von r/w. Denn das Verhältnis von Arbeit zu Kapital ist bei den in Y freigesetzten Faktoren größer als die Arbeitsintensität in X ohne Kredithilfen und Arbeit wird damit im Vergleich zu Kapital weniger knapp. Ist die Produktion im X-Sektor hingegen arbeitsintensiver, gilt das Umgekehrte, d.h. r/w wird fallen. Der Outputeffekt führt damit zu einer stärkeren Erhöhung des Preises des in der subventionierten Industrie relativ intensiv eingesetzten Faktors ${ }^{5}$.

Der zweite Effekt, der Faktorsubstitutionseffekt, entspricht dem Effekt der Substitution einer Gütersubvention für $\mathrm{X}$ durch die Subventionierung eines Faktors in der X-Industrie $^{6}$ und basiert auf der Verzerrung der relativen Faktorpreise in der X-Industrie. Die Anstoßwirkung der Kredithilfe besteht in einer Reduktion der Kapitalkosten in der XIndustrie. Dadurch erhöht sich dort die Nachfrage nach Kapital, das aus dem anderen Sektor abgezogen wird. Die Kapitalintensität in der X-Industrie (Y-Industrie) steigt (fällt). Die Kapitalübertragung setzt sich solange fort, bis $r / w$ soweit gestiegen ist, da GRTS $^{X}{ }_{K A}=\left(r-z_{x}\right) / w$ und GRTS $^{Y}{ }_{K A}=r / w$ gilt. Anders als der Outputeffekt führt der

\footnotetext{
Vgl. MCLURE/THIRSK (1975), S.10.

2 Vgl. für den Fall einer Kaptitalsteuer BOADWAY/WILDASIN (1984), S.365.

3 Vgl. MIESZKOWSKI (1967).

4 Vgl. MCLURE (1971b), S.44.

5 Vgl. zum analogen Fall einer speziellen Verbrauchsteuer FOLKERS (1987b), S.153.

6 Vgl. MCLURE (1971b), S.44.
} 
Faktorsubstitutionseffekt eindeutig zu einer Erhöhung von r/w und begünstigt daher sämtliche Kapitalanbieter im Vergleich zu den Arbeitsanbietern ${ }^{1}$.

Produziert die X-Industrie relativ kapitalintensiv, so führen beide Effekte zu einer Erhöhung von $\mathrm{r} / \mathrm{w}$, d.h. daß die Kapitalanbieter ihre relative Position im Vergleich zum Fall einer Pauschalübertragungszahlung verbessern können. Bei arbeitsintensiver Produktion in der X-Industrie wirken beide Effekte gegenläufig. Der Gesamteffekt der Kapitalhilfe hängt dann von ihrer relativen Stärke ab. Wenn sie sich genau ausgleichen, bleibt $r / w$ konstant und die Inzidenz der Kredithilfe entspricht den Verteilungswirkungen einer allgemeinen Faktorsubvention. In diesem Fall wächst den Arbeitsanbietern ein Teil der Vorteile der Kredithilfe zu. Darüber hinaus kann r/w sogar fallen, wenn die Arbeitsintensität in der X-Industrie und der Outputeffekt hoch sind. Im einzelnen hängt die Änderung der Zins-Lohn-Relation also von den Nachfrage- und Produktionsbedingungen in der Volkswirtschaft ab. Der Outputeffekt ist dabei um so größer, je größer die Nachfrageelastizität nach Gut $\mathrm{X}$ ist und je stärker sich die Arbeitsintensitäten in beiden Sektoren unterscheiden. Weiterhin ist der Outputeffekt um so größer, je größer der Anteil des Kapitals an den Produktionskosten von $\mathrm{X}$ ist, weil die Höhe der relativen Güterpreisänderung davon abhängt, und je kleiner die Substitutionselastizitäten der Produktionsfaktoren sind, weil sich dann bei einer gegebenen Veränderung der Arbeitsintensität die Zins-Lohn-Relation um so stärker ändern muß. Der Faktorsubstitutionseffekt ist um so höher, je größer die Substitutionselastizitäten der Faktoren in beiden Sektoren sind ${ }^{2}$. Nimmt die Güter- und die Faktorsubstitutionselastizität jeweils betragsmäßig den Wert eins an, wird sich das Arbeitseinkommen nicht verändern und der ökonomische Vorteil der Kredithilfe fließt in vollem Umfang den Kapitaleignern $\mathrm{zu}^{3}$.

Läßt man ein variables Kapitalangebot zu, so steigt (sinkt) dieses mit steigender (sinkender) Zins-Lohn-Relation, wodurch $\mathrm{r} / \mathrm{w}$ fällt (steigt). Damit wird bei variablem Kapitalangebot die Änderung der Zins-Lohn-Relation durch eine Kredithilfe tendenziell abgeschwächt.

Modifiziert man die Annahme vollständiger Faktormobilität und unterstellt man, daß lediglich Kapital mobil ist, während Arbeit immobil sein soll ${ }^{4}$, führt die Kredithilfe über die Verringerung der Kapitalkosten zu einem erhöhten Kapitaleinsatz in der X-Industrie. Dadurch erhöht sich das physische Grenzprodukt der als konstant angenommenen Arbeit

1 Vgl. BOADWAY/WILDASIN (1984), S.366; BROWN/JACKSON (1986), S.285 ff.

2 Vgl. BOADWAY/WILDASIN (1984), S.366 f.; zum algebraischen Beweis siehe S.395 ff.

3 Vgl. BROWN/JACKSON (1986), S.289.

4 Dies Annahme liegt regelmäßig regionalpolitischen Fördermaßnahmen zugrunde; vgl. MCLURE (1971a), S.545. 
und der Output der X-Industrie, während die Zins-Lohn-Relation in der X-Industrie und der relative Preis von $\mathrm{X}$ sinken. Die Effekte in der Y-Industrie sind genau gegenläufig. Der Lohnsatz in der X-Industrie wird sich nur dann erhöhen, wenn die Preiselastizität der Nachfrage nach $\mathrm{X}$ die Elastizität der Faktorsubstitution übersteigt ${ }^{1}$. Umgekehrt kann sich bei relativ hoher Substitutionselastizität der Faktoren und relativ geringer Preiselastizität der Nachfrage für X eine Reduzierung des Lohnsatzes in der X-Industrie ergeben ${ }^{2}$.

Nachdem bisher implizit unterstellt wurde, daß die Konsumenten identische Präferenzen haben, soll nun angenommen werden, daß die Konsumenten mit unterschiedlichen Präferenzen ausgestattet sind. Dadurch wird für die Inzidenz öffentlicher Kredithilfen die Verwendungsseite des Volkseinkommens relevant. Durch den Rückgang des relativen Preises von $\mathrm{X}$ werden dabei die Konsumenten begünstigt, die $\mathrm{X}$ relativ stärker nachfragen ${ }^{3}$.

Die Mehrbelastung infolge spezieller Kredithilfen soll mit Hilfe von Abb. 11 analysiert werden. Dabei wird ein konstantes Kapitalangebot in der Volkswirtschaft unterstellt. In der linken Abbildung wird die Kapitalnachfrage der X-Industrie durch $\mathrm{D}_{\mathbf{K X}}$ dargestellt, während $D_{K Y}$ in der rechten Abbildung die Kapitalnachfrage der Y-Industrie repräsentiert. Die Summe $\mathbf{K}_{\mathbf{X} 0}+\mathrm{K}_{\mathrm{Y}_{0}}$ bezeichnet das aggregierte Kapitalangebot. Die beiden Nachfragekurven sollen identische Verläufe haben. Die Opportunitätskostenrate des Kapitals vor Gewährung der Kredithilfe beträgt $\mathrm{r}_{0}$. Wenn nun in der X-Industrie ein MengenZinszuschuß in Höhe von z gewährt wird, so führt dies, wie bereits ausgeführt, zu einer Reallokation des Kapitals von der Y- zur X-Industrie, die solange fortgeführt wird, bis die Opportunitätskostenrate einschließlich des Zinszuschusses in der X-Industrie der Opportunitätskostenrate in der Y-Industrie entspricht. Das Gleichgewicht ist bei $r_{1}$ erreicht, wobei sich die Opportunitätskostenrate in der X-Industrie auf $r_{1}-z$ beläuft. Aufgrund der Erhöhung der (Brutto-) Opportunitätskostenrate fällt der Kapitaleinsatz in der Y-Industrie auf $\mathrm{K}_{\mathrm{Y} 1}$, während er in der $\mathrm{X}$-Industrie auf $\mathrm{K}_{\mathrm{X} 1}$ steigt. Dadurch erhöht sich das Gesamtprodukt des zusätzlichen Kapitaleinsatzes in der X-Industrie um $\mathbf{K}_{\mathbf{X} 0}{ }^{a b K_{X 1}}$. Das Gesamtprodukt des verminderten Kapitaleinsatzes in der Y-Industrie beläuft sich dagegen auf $\mathrm{K}_{\mathrm{Y} 1} \mathrm{egK}_{\mathrm{Y} 0}$. Da $\mathrm{K}_{\mathrm{X} 0} \mathrm{~K}_{\mathrm{X} 1}$ genau $\mathrm{K}_{\mathrm{Y} 1} \mathrm{~K}_{\mathrm{Y} 0}$ entspricht, gilt $\mathrm{K}_{\mathrm{Y} 1} \mathrm{egK}_{\mathrm{Y} 0}$ gleich $\mathrm{K}_{\mathrm{X} 0} \mathrm{cdK} \mathrm{K}_{\mathrm{X} 1}$. Der durch die Kredithilfe verursachte gesamtwirtschaftliche Verlust in Form eines verringerten Gesamtproduktes des Kapitals und damit die Mehrbelastung entspricht danach der

1 Vgl. MCLURE (1971b), S.45.

2 Vgl. MCLURE (1971a), S.547.

3 Vgl. BOADWAY/WILDASIN (1984), S.367. 

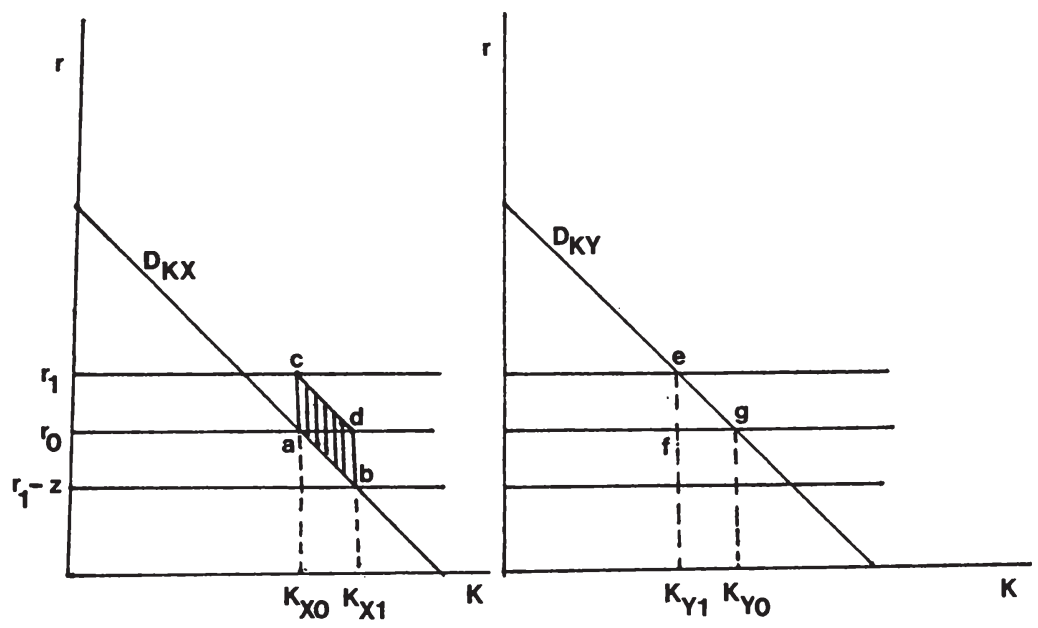

Abb. 11

Fläche abcd ${ }^{1}$. Sie setzt sich zusammen aus der Mehrbelastung in der X-Industrie aufgrund der Zweckbindung der Übertragungszahlung für den Kapitaleinsatz in Höhe von abd und dem Verlust an Produzentenrente in der Y-Industrie in Höhe von efg = cad.

Zusammenfassend kann festgestellt werden, daß sich die Inzidenz öffentlicher Kredithilfen nicht a priori vorhersagen läßt. Vielmehr hängt diese von den Güter- und FaktorSubstitutionselastizitäten sowie den relativen Faktorintensitäten in beiden Sektoren ab. Jedoch legt die Inzidenzanalyse mit einem allgemeinen Gleichgewichtsmodell nahe, daß das Ergebnis der Partialanalyse, wonach bei konstantem Kapitalangebot die aus Kredithilfen resultierenden Vergünstigungen den Kapitaleignern zufließen, nur unter äußerst restriktiven Annahmen erwartet werden kann. Vielmehr läßt die Analyse erwarten, daß bei der Vergabe von Kredithilfen in erster Linie mit einer weitgehend willkürlichen

1 Vgl. BOADWAY/WILDASIN (1984), S.389 f. für den Fall einer Kapitalsteuer in einem Sektor. 
Begünstigung der verschiedenen Faktoranbieter und der Konsumenten zu rechnen ist und damit die Verteilungskonsequenzen von Kredithilfen kaum berechenbar sind ${ }^{1}$.

\section{Intertemporale Verteilungswirkungen öfentlicher Kredithilfen}

Zum Abschluß der Analyse der Verteilungskonsequenzen öffentlicher Kredithilfen soll ein Aspekt untersucht werden, der bislang vergleichsweise wenig Beachtung gefunden hat, nämlich die Frage nach ihren intertemporalen Verteilungswirkungen. Dabei geht es um die Frage, welche Generation ${ }^{2}$ die Last von Kredithilfen trägt. Wesentlich ist auch hier die differentielle Betrachtungsweise, mit der die intertemporalen Belastungskonsequenzen unterschiedlicher Subventionsformen untersucht werden. Die Diskussion basiert im wesentlichen auf den Argumenten zu den intertemporalen Verteilungswirkungen der Staatsverschuldung 3 .

Im folgenden wird für den Fall vollständiger Sicherheit die Gewährung eines Investitionszuschusses mit der Gewährung einer Zinsverbilligung durch einen Zinszuschu $B^{4}$ bzw. ein zinsverbilligtes Darlehen verglichen. Aus Vereinfachungsgründen wird angenommen, da $ß$ durch die Subventionierung keine Preisreaktionen hervorgerufen werden. Außerdem sollen beide Subventionsalternativen denselben Gegenwartswert staatlicher Nettoausgaben $^{5}$ und denselben optimalen Kapitalbestand implizieren. Dazu wird ein vollkommener Kapitalmarkt, vollständige Kreditfinanzierung der Investitionen und eine Kapitalnutzungsdauer von einer Periode unterstellt. Der Restwert des eingesetzten Kapitals am Periodenende betrage Null. Die Finanzierung der Subvention für die Investitionen soll jeweils im Zeitpunkt ihrer Ausgabenwirksamkeit durch eine Pauschalsteuer erfolgen. Danach gelten im Optimum wieder die Bedingungen von Gleichung (C.IV.3) und (C.IV.4). Der Gegenwartswert der Subventionierung sowie der staatlichen Nettoausgaben beträgt je Investitionseinheit Z. Der Unterschied zwischen beiden Subventionsalternativen besteht darin, daß der Investitionszuschuß in der Gegenwart fällig ist, während die Zinsverbilligung

1 Vgl. zum analogen Fall einer speziellen Verbrauchsteuer FOLKERS (1987b), S.155 f.

2 Als Generation wird die Gruppe von Individuen definiert, die zu einem bestimmten Zeitpunkt leben. Vgl. BUCHANAN (1964a), S.56.

3 Vgl. zu einem Überblick dazu GANDENBERGER (1981), S.28 ff.; MÜLLER (1987).

4 Die folgende Betrachtung gilt nicht für kapitalisierte Zinszuschüsse, bei denen die Auszahlung im Investitionszeitpunkt erfolgt. Diese sind im gegebenen Zusammenhang mit Investitionszuschüssen äquivalent.

5 Bei öffentlichen Darlehen wird also implizit unterstellt, daß die Darlehenssumme durch staatliche Kreditaufnahme refinanziert wird. 
bei Kredithilfen erst in der Zukunft ausgabenwirksam wird ${ }^{1}$.

Versteht man unter der Last der Kredithilfe den durch die Kredithilfe induzierten Ressourcenentzug für andere Verwendungen, nämlich die durchgeführte Investition, so wäre die Last einer Kredithilfe von der gegenwärtigen Generation zu tragen ${ }^{2}$. Nach dieser Lastdefinition ist die intertemporale Lastverteilung per definitionem für alle Subventionsformen identisch. Es wird damit jedoch die Frage nach der Inzidenzwirkung von Subventionen gegenüber der Situation ohne Subventionen aufgeworfen. Folglich kann die Frage nach den differentiellen Verteilungswirkungen der in Zukunft ausgabewirksamen Kredithilfen und der in der Gegenwart fälligen Investitionszuschüsse auf diese Weise nicht beantwortet werden.

Andererseits könnte man die Last als Nutzeneinbuße definieren, die in dem Zeitpunkt entsteht, in dem die Steuerzahler zwangsweise zur Steuerzahlung herangezogen werden $^{3}$. Da bei Kredithilfen die Steuerzahlung anders als bei Investitionszuschüssen erst in der Zukunft erfolgt, kommt es bei den Kredithilfen zu einer Lastverschiebung in die Zukunft, während die Last der Investitionszuschüsse von der gegenwärtigen Generation getragen wird. Allerdings gilt diese Aussage nicht generell. Impliziert nämlich die Annahme eines vollkommenen Kapitalmarktes auch vollkommene Voraussicht der Steuerzahler und besitzen sie alle denselben Zeithorizont ${ }^{4}$, so besteht Äquivalenz zwischen beiden betrachteten Subventionsformen. Denn die Steuerzahler nehmen es wahr, daß sich ihr Lebenszeiteinkommen durch die Veränderung der Subventionsform nicht ändert. Die Konsum- und Ersparnisströme der gesamten Volkswirtschaft bleiben unverändert ${ }^{5}$. Die auf der Subventionssteuer beruhende Last ist vom Zeitpunkt der Steuerzahlung unabhängig. Eine differentielle Belastungswirkung der Subventionsformen existiert folglich nicht.

Läßt man hingegen bei den Steuerzahlern Fiskalillusion ${ }^{6} \mathrm{zu}^{7}$, werden sie ihre künftige Steuerbelastung unterschätzen ${ }^{8}$ und unter der Annahme des Gegenwartskonsums als

1 Von der Möglichkeit kapitalisierter Zinszuschüsse wird an dieser Stelle abgesehen.

2 Zum entsprechenden Ergebnis der Vertreter der "Neuen Orthodoxie" bei der Staatsverschuldung vgl. LERNER (1948/1964). Siehe auch GANDENBERGER (1981), S.29.

3 Diese Vorstellung entspricht dem Nutzenansatz in der Lastverschiebungskontroverse bei der Staatsverschuldung. Vgl. BUCHANAN (1958).

4 Die Individuen verhalten sich danach so, als ob sie über den gesamten Betrachtungszeitraum leben würden. Vgl. BUCHANAN/ROBACK (1987), S.7.

5 Diese Ergebnis entspricht dem des "Ricardianischen Äquivalenztheorems" bezüglich der Differentialinzidenz der Steuer- und Kreditfinanzierung staatlicher Ausgaben. Vgl. dazu BUCHANAN (1958), S.43 ff., 114 ff.; BUCHANAN/ROBACK (1987), S.8.

6 Grundlegend dazu PUVIANI (1903/1960).

7 Das Auftreten von Illusionen bei den Steuerzahlern ist kein Widerspruch zur Annahme vollkommener Voraussicht bei den geförderten Investoren, da für die künftigen Steuerzahler die 
superiores Gut in der Gegenwart mehr und in der Zukunft weniger als ihre optimale Menge konsumieren. Dementsprechend wird bei Kredithilfen das intertemporale Nutzenoptimum verfehlt. Die Nutzeneinbuße wird erst in der Zukunft wahrgenommen, so daß Kredithilfen gegenüber Investitionszuschüssen eine Lastverschiebung in die Zukunft bedeuten.

Aber auch ohne Fiskalillusion kann sich bei Kredithilfen eine Lastverschiebung in die Zukunft ergeben. Dazu wird es dann kommen, wenn sich die gegenwärtige Generation aus zwei Gruppen zusammensetzt. Die Gruppe A hat Nachkommen, die in der Zukunft leben, und deren Nutzen von den Mitgliedern der Gruppe A vollständig internalisiert werden. Die Gruppe B hat dagegen keine Nachkommen und maximiert nur ihren eigenen Nutzen. Demzufolge wird der Nutzen der künftigen Generation bei Kredithilfen geringer sein als bei Investitionszuschüssen, weil die Gruppe B im ersteren Fall in der Gegenwart mehr konsumiert ${ }^{1}$. Kredithilfen implizieren damit wiederum eine Lastverschiebung in die Zukunft.

Schließlich soll die Frage der Lastverschiebung aus makroökonomischem Blickwinkel betrachtet werden. Im Fall der Kredithilfe ist die Kreditaufnahme jedes geförderten Investors je Investitionseinheit um $\mathrm{qZ}$ höher als beim Investitionszuschuß. Es soll nun angenommen werden, daß bei einer Steuerfinanzierung der Kosten der Investitionsförderung in der Gegenwart überwiegend der Konsum verdrängt wird, während eine Kreditfinanzierung zu einer relativ stärkeren Verdrängung nichtgeförderter Investitionen über den Kapitalmarkt führt. Damit werden im Fall des Investitionszuschusses gesamtwirtschaftlich höhere Investitionen realisiert. Aufgrund des höheren Kapitalstocks wird das gesamtwirtschaftliche Einkommen mit einer höheren Rate wachsen als bei einer Kredithilfe. Die Last der Kredithilfe besteht insoweit in dem geringeren Einkommen in der Zukunft ${ }^{2}$.

Die genannten Argumente lassen sich bezüglich der Kreditgewährleistungen analog anwenden, wenn man die Fälle mit und ohne Rücklagenbildung für durch Prämieneinnahmen nicht gedeckte Schadensfälle gegenüberstellt ${ }^{3}$. Dabei entspricht der Fall ohne Rücklagenbildung im Ergebnis dem des Zinszuschusses bzw. des öffentlichen Darlehens.

Höhe ihrer Steuerschuld wesentlich schwieriger zu kalkulieren sein dürfte als für die geförderten Investoren ihre künftige Kreditschuld. Vgl. BUCHANAN (1964b), S.154 f.

8 Diese Auffassung wurde von Ricardo im Zusammenhang mit der Staatsverschuldung vertreten. O'DRISCOLL (1977) spricht demzufolge vom "Ricardian Non-Equivalence Theorem".

1 Vgl. BUCHANAN/ROBACK (1987), S.14 ff.

2 Diese Argumentation entspricht der in der Staatsverschuldungsdebatte als Aggregate Investment Approach geläufigen Argumentation. Vgl. dazu MODIGLIANI (1961), S.730 ff.

3 Zum Vorschlag, solche Rücklagen zu bilden, vgl. CONRAD (1967), S.63 ff.; DICKERTMANN (1980), S.481 ff. 
Damit läßt sich festhalten, daß bei öffentlichen Kredithilfen unter den getroffenen Annahmen abgesehen vom Fall vollkommener Voraussicht und homogener Präferenzen der Steuerzahler stets eine Lastverschiebung in die Zukunft resultieren wird. Die intertemporalen Verteilungswirkungen von Kredithilfen entsprechen damit auch in ihren einzelnen Begründungen den intertemporalen Verteilungswirkungen der Staatsverschuldung. Dies ist insofern auch wenig überraschend, weil hier wie dort bestimmte staatliche Maßnahmen durch Steuerzahlung in der Gegenwart oder in der Zukunft finanziert werden können. Der Unterschied besteht darin, daß bei der Staatsverschuldung die staatlichen Maßnahmen beim Staat ausgabenwirksam werden. Dagegen induzieren Kredithilfen bei den privaten Kreditgebern im Vergleich zum Investitionszuschuß höhere Darlehensausgaben, da ein Investitionszuschuß den Finanzierungsbedarf der Investoren in entsprechender Höhe reduziert. Da die aus Kredithilfen resultierenden Verbindlichkeiten anders als bei der Staatsverschuldung im Budget nicht ohne weiteres erkennbar sind, lassen sich die Kosten der Zins- bzw. Prämiensatzverbilligung öffentlicher Kredithilfen, die erst in künftigen Perioden zu Ausgaben führen, als verbongene Verschuldung charakterisieren ${ }^{1}$. Welche Implikationen damit verbunden sind, soll im weiteren Verlauf dieser Arbeit näher untersucht werden.

\section{ZUSAMMENFASSUNG}

Zur Schaffung eines Analyserahmens wurde zunächst der Kreditmarkt mikroökonomisch modelliert. Dabei wurde verdeutlicht, daß die individuellen Entscheidungen über die Kreditnachfrage und das Kreditangebot bei gegebenem Lebenseinkommen von der durch den Marktzinssatz bestimmten intertemporalen Preisrelation abhängen. Bei Einbeziehung von Investitionen resultierte unter den Bedingungen eines vollkommenen Kapitalmarkts das Fishersche Separationstheorem, wonach die optimale Investitionshöhe und damit die Nachfrage nach Investitionskrediten von den individuellen intertemporalen Präferenzen unabhängig ist.

Sind Kredite mit Ausfallrisiken behaftet, so werden auch risikoneutrale Kreditgeber dafür einen höheren Zinssatz verlangen als für risikolose Kredite. Risikoaverse Kreditgeber müssen zusätzlich durch einen Risikozuschlag kompensiert werden, so daß bei ihnen

1 IPPOLITO (1984) spricht im gegebenen Zusammenhang dagegen von "hidden spending". Dieser Begriff erscheint nicht ganz geeignet, da die Ausgaben zur Zinsverbilligung im Zeitpunkt ihrer Fälligkeit sehr wohl erkennbar sind. Verborgen sind vielmehr die Verbindlichkeiten des Staates, die durch die Gewährung von Kredithilfen in der Gegenwart entstehen und den unbedingten Rechtsgrund für künftige Ausgaben bilden. 
der erwartete Kreditertrag den Ertrag sicherer Kredite übersteigt. Allerdings strebt dieser Risikozuschlag gegen Null, wenn die Einzelkredite lediglich unsystematische Risiken enthalten, die sich durch Portfoliobildung vermeiden lassen. Können die Kreditgeber Kreditversicherungen zu einer fairen Prämie erhalten, werden sie auch bei Risikoaversion bereit sein, riskante Kredite zu denselben Konditionen wie ein risikoneutraler Kreditgeber zu gewähren. Darüber hinaus ist eine Kreditversicherung auch bei risikoaversen Kreditversicherern wohlfahrtssteigernd, wenn bei ihnen das Ausmaß der Risikoaversion geringer ist als bei den Kreditgebern.

Werden Transaktionskosten auf dem Kreditmarkt berücksichtigt, so zeigt sich, daß der Kreditzinssatz um so höher sein wird, je höher die Kosten der Kredittransaktionen sind. Ist der Kredit- bzw. Kreditversicherungsmarkt durch Informationsunvollkommenheiten in Form asymmetrischer Information zwischen Kreditnehmern und -gebern gekennzeichnet, kann daraus adverse Selektion und moral hazard auf dem Kreditmarkt resultieren. Durch Ressourceneinsatz und spezielle Vertragsgestaltungen können Secondbest-Ergebnisse in bezug auf eine optimale Ressourcenallokation gefunden werden, die jedoch nicht verhindern können, daß beim marktlichen Kreditzinssatz Mengenrationierungen auftreten.

In einem nächsten Schritt wurden die normativen Begründungen für öffentliche Kredithilfen analysiert. Sie setzen daran an, daß marktliche Wirtschaftssysteme regelmäßig durch allokatives, distributives und stabilisatorisches Marktversagen gekennzeichnet sind, das mit Kredithilfen korrigiert werden soll. Im Hinblick auf Marktversagen auf den Kreditmärkten erscheint ein wohlfahrtssteigernder Einsatz von Kredithilfen am ehesten dann möglich, wenn die Kreditanbieter die Kreditrisiken in systematischer Weise falsch wahrnehmen oder wenn auf den Kreditmärkten asymmetrische Informationsverteilungen auftreten. In anderen Fällen von allokativem Marktversagen, wie bei externen Effekten oder natürlichen Monopolen, können Kredithilfen unter idealen Bedingungen ebenfalls zu einer Wohlfahrtssteigerung führen, ohne da $\beta$ jedoch klar wird, weshalb unter diesen Bedingungen Kredithilfen anderen Subventionsformen überlegen sein sollen. Bei verteilungspolitisch motivierten Kredithilfen besteht einmal die Frage, ob und in welchem Ausmaß die Destinatare der Kredithilfen nach Ablauf ökonomischer Anpassungsprozesse begünstigt werden. Außerdem ist festzustellen, daß redistributiv begründete Kredithilfen teilweise so konzipiert sind, daß gerade die einkommensschwächsten Schichten faktisch aus dem Kreis der potentiellen Empfänger ausgeschlossen bleiben. Eine stabilitätspolitische Begründung öffentlicher Kredithilfen erscheint insofern fragwürdig, als die meisten Programme selektiv für einzelne Wirtschaftssektoren und nicht antizyklisch vergeben werden. 
Selbst wenn Kredithilfen prinzipiell antizyklisch wirken könnten, wecken die gleichzeitig hervorgerufenen allokativen Verzerrungen und die individuellen Anreize zu destabilisierenden Verhaltensweisen Zweifel, ob ein stabilitätspolitischer Einsatz dieser Subventionsformen gesamtwirtschaftlich wünschenswert ist.

Generell gilt, daß sich die Vorteilhaftigkeit öffentlicher Kredithilfen nur belegen läßt, wenn sich bei Gegenüberstellung sämtlicher Nutzen und Kosten ein Nutzenüberschuß ergibt. So sind einmal die volkswirtschaftlichen Kosten der Finanzierung öffentlicher Kredithilfen in Rechnung zu stellen. Zum anderen sind auch die Kosten des Staatsversagens zu berücksichtigen. Denn es spricht nichts dafür, daß der Staatssektor in der Realität im Gegensatz zu den Märkten perfekt funktioniert. Angesichts der Kosten öffentlicher Kredithilfen ist der Spielraum für ihren wohlfahrtssteigernden Einsatz weit geringer, als die üblichen normativen Begründungen glauben machen. Genauere Aussagen setzen jedoch eine positive Wirkungsanalyse von Kredithilfen voraus, die in einem nächsten Schritt durchgeführt wurde.

Im Rahmen dieser Wirkungsanalyse wurde zunächst die Anstoßwirkung öffentlicher Kredithilfen untersucht. Dabei wurde gezeigt, daß es für die Anstoßwirkung entscheidend darauf ankommt, ob der Kreditzinssatz um oder auf einen bestimmten Prozentsatz verbilligt wird. Außerdem wurde festgestellt, daß Investitionszuschüsse bei unterschiedlich riskanten Investitionen unterschiedliche Zuschußsätze aufweisen müssen, wenn sie äquivalente Anstoßwirkungen besitzen sollen wie Kredithilfen, die unabhängig vom Risiko eine Zinsverbilligung auf denselben Zinssatz implizieren.

Die Analyse von Konsum-Kredithilfen ergab, daß sie zu einem höheren Gegenwartskonsum führen als ungebundene Einkommenstransfers in Höhe des Gegenwartswerts der Zinsverbilligungskosten der Kredithilfen. Andererseits verursachen Kredithilfen Mehrbelastungen. Außerdem wurde gezeigt, unter welchen Bedingungen die Sicherung einer als Existenzminimum festgesetzten Konsummenge in verschiedenen Perioden im Fall von Konsum-Kredithilfen höhere staatliche Ausgaben erfordert als ungebundene Einkommenstransfers. Schließlich wurde demonstriert, daß die Individuen bei mangelnder Kontrollierbarkeit der Verwendung der Kredithilfen ihre Nachfrage danach übertreiben werden, um sich zusätzliche Vorteile zu verschaffen. Dieser Effekt kann vermieden werden, wenn die Maximalhöhe der Kredithilfe für den einzelnen Empfänger mengenmäßig begrenzt wird. Jedoch besteht dann wiederum die Gefahr, daß das Ziel einer Ausweitung des Gegenwartskonsums zumindest partiell verfehlt wird.

Bei der Analyse der Anreizwirkungen auf die Investitionsentscheidungen wurde gezeigt, daß Investitions-Kredithilfen bei sicheren und riskanten Investitionserträgen zu 
einer Erhöhung des optimalen Kapitalstocks und damit zu zusätzlichen Investitionen führen können. Allerdings werden Kredithilfen unter plausiblen Bedingungen teilweise oder gar vollständig "mitgenommen", so daß die Höhe der induzierten Investitionen regelmäßig unter dem Investitionsvolumen liegen wird, zu dessen Finanzierung Kredithilfen eingesetzt werden. Sind die Kredithilfen in ihrem Umfang begrenzt, ist das Ausmaß zusätzlicher Investitionen aufgrund von Kredithilfen außerordentlich unsicher, wobei es in diesem Zusammenhang wesentlich auf das Verfahren zur Verteilung der quantitativ begrenzten Fördermittel ankommt.

Weiterhin wurde untersucht, ob Investitions-Kredithilfen die Arbeitsnachfrage bzw. das Arbeitsplatz-Angebot in den geförderten Bereichen erhöhen. Da Kredithilfen zu einem Anstieg des relativen Preises des Faktors Arbeit führen, ziehen sie abgesehen vom Fall limitationaler Produktionsfunktionen einen Substitutionseffekt nach sich, der einen Rückgang der Arbeitsnachfrage bewirkt. Dem Substitutionseffekt steht ein üblicherweise beschäftigungserhöhender Outputeffekt gegenüber. Deshalb kommt es für den Gesamteffekt von Kredithilfen auf die Arbeitsnachfrage auf die relative Stärke von Substitutions- und Outputeffekt an. Es ist jedoch nicht ausgeschlossen, daß Kredithilfen statt der vielfach intendierten beschäftigungserhöhenden Wirkung einen Rückgang der Arbeitsnachfrage in den geförderten Bereichen zur Folge haben können.

Die Analyse der Konsequenzen von Kredithilfen auf die Risikoübernahme ergab bei unterstellter Risikoaversion der Investoren das kontraintuitive Ergebnis, daß Kreditgewährleistungen, die scheinbar nur riskante Investitionen begünstigen, keinesfalls zwingend zu einer Erhöhung riskanter Investitionen führen. Andererseits können Zinsverbilligungen um einen bestimmten Prozentsatz, die risikolose gegenüber riskanten Investitionen relativ stärker begünstigen, dennoch zu einer Erhöhung der Risikoübernahme führen. Jedoch ist auch das jeweils gegenteilige Ergebnis möglich.

Besteht asymmetrische Information zwischen dem Kredithilfegeber und -empfänger, so werden durch bestimmte Formen von Kredithilfen unter realistischen Bedingungen ineffiziente Investitionen induziert. D.h. daß die Kredithilfen dann zu einer Wohlfahrtsverschlechterung führen und allokativ nicht gerechtfertigt werden können. Sind Banken in die Vergabe von Kredithilfen als Subventionsmittler eingeschaltet und übernimmt der Staat durch die Kredithilfen zumindest teilweise das Kreditrisiko, so verlieren sie den Anreiz, Ressourcen einzusetzen, um schlechte von guten Kreditrisiken zu unterscheiden. Auch insoweit sind Kredithilfen mit Wohlfahrtsverlusten verbunden.

Öffentliche Kredithilfen können weiterhin bei vollkommenen Kapitalmärkten im Grenzfall dazu führen, daß die Fremdkapitalquote auf 100 Prozent erhöht wird, obwohl 
die Höhe der Kapitalkosten ohne Kredithilfe von der Kapitalstruktur unabhängig ist. Kann die Vergünstigung jedoch liquidiert werden, ist die Beeinflussung der Kapitalstruktur durch die Kredithilfe nur temporärer Natur:

Verursacht die Bereitstellung von externem Eigen- und Fremdkapital dagegen sogenannte agency costs, ergibt sich regelmäßig eine kostenminimale Kapitalstruktur, die durch das Minimum der agency costs bestimmt wird. Durch die Gewährung von Kredithilfen wird sich die Fremdkapitalquote ceteris paribus erhöhen. Sie liegt damit nicht mehr im Minimum der agency costs. Vielmehr werden zusätzliche agency costs in dem Ausma $\beta$ in Kauf genommen, als der dadurch bedingte Anstieg der Brutto-Kapitalkosten durch die Zinsverbilligung aufgrund von Kredithilfen überkompensiert wird. Die Abweichung von den minimalen agency costs impliziert aber wiederum soziale Wohlfahrtsverluste.

Bei der Untersuchung der Verteilungswirkungen öffentlicher Kredithilfen wurde zunächst das Konzept der Subventionswertermittlung diskutiert. Dabei handelt es sich um einen Ansatz der Formalinzidenzanalyse, nach dem Kredithilfen allein ihre Empfänger begünstigen. $\mathrm{Da}$ hier marktliche Anpassungsreaktionen vollkommen ausgeklammert bleiben, entsprechen die damit abgeleiteten Verteilungsergebnisse nur selten den realen Verteilungskonsequenzen öffentlicher Kredithilfen.

Im Rahmen einer partialanalytischen Betrachtung wurde die materielle Inzidenz öffentlicher Kredithilfen unter der Annahme untersucht, daß nur ein Teil der Kreditnachfrager eine Kredithilfe erhält. Es wurde gezeigt, daß ihre Verteilungskonsequenzen sich sowohl auf den Kreditmarkt als auch auf Gütermärkte erstrecken können. Die Nachfrage- und Angebotselastizitäten auf den relevanten Märkten bestimmen, wer durch Kredithilfen effektiv begünstigt wird. Ist beispielsweise das Kreditangebot auf einem kompetitiven Kreditmarkt vollkommen elastisch, so werden durch eine Kredithilfe nur die geförderten Kreditnachfrager begünstigt, die allerdings im Vergleich zu einem ungebundenen Transfer Wohlfahrtsverluste erleiden. Besitzt die Kreditangebotskurve eine positive Steigung, so müssen sich die geförderten Kreditnachfrager die Begünstigung mit den Kreditanbietern teilen. Gleichzeitig erleiden die nichtgeförderten Nachfrager effektive Verteilungsverluste. Dieses Ergebnis folgt auch bei einem vollkommen unelastischen Kreditangebot. Weiterhin wurde gezeigt, daß die Mehrbelastung bei selektiven Kredithilfen für einzelne Nachfragergruppen größer ist als bei einer Förderung aller Nachfrager. Berücksichtigt man weiterhin Rückwirkungen von Kredithilfen auf den Gütermärkten, so zeigt sich, daß durch Kredithilfen auch die Verteilungsposition formal nicht tangierten Güteranbieter und nachfrager beeinflußt werden kann. 
Die Analyse der Differentialinzidenz öffentlicher Kredithilfen im Rahmen einer Partialbetrachtung ergab, daß sie unter realistischen Bedingungen zu einer Begünstigung einzelner Gruppen führen. Untersucht man die Differentialinzidenz öffentlicher Kredithilfen im Rahmen einer allgemeinen Gleichgewichtsanalyse, so wird deutlich, daß dadurch auch die Faktor- und Güterpreisrelationen verzerrt werden. Ein allgemein gültiges Verteilungsergebnis läßt sich daraus jedoch nicht ableiten. Dieses hängt u.a. von den Produktionsbedingungen und den Güterpräferenzen ab. Allerdings folgt auch aus dem allgemeinen Gleichgewichtszusammenhang, daß öffentliche Kredithilfen Mehrbelastungen hervorrufen.

Insgesamt zeigt die Analyse, daß kaum etwas dafür spricht, daß Kredithilfen allein für die formal Begünstigten Verteilungsimplikationen besitzen. Vielmehr dürften die Verteilungsvorteile und -verluste üblicherweise breit gestreut sein. Dies bestätigt sich, wenn man die intertemporalen Verteilungswirkungen öffentlicher Kredithilfen einbezieht. Unter der Annahme, daß staatliche Einnahmen zur Finanzierung der Subventionskosten erst im Zeitpunkt ihrer Zahlungsfälligkeit erforderlich sind, läßt sich zeigen, daß öffentliche Kredithilfen im Vergleich zu Investitionszuschüssen im Normalfall zu einer Belastung künftiger Generationen führen.

Als Ergebnis der ökonomischen Analyse kann festgehalten werden, daß sich mit öffentlichen Kredithilfen die angestrebten Ziele vielfach nicht erreichen lassen. So ist keinesfalls gesichert, daß Kredithilfen zu einer Ausweitung der Investitionen und der Arbeitsnachfrage sowie zu einer verstärkten Risikoübernahme führen. Eine Einkommensumverteilung durch Kredithilfen zugunsten der formal Begünstigten erscheint nach der vorstehenden Inzidenzanalyse ebenfalls kaum möglich. Darüber hinaus verursachen Kredithilfen durch die Verzerrung unterschiedlicher individueller Entscheidungen regelmäßig volkswirtschaftliche Kosten. Wenngleich sich deren Höhe von Fall zu Fall unterscheidet, so erscheint es äußerst fraglich, ob Kredithilfen die vielfach behaupteten sozialen Wohlfahrtsgewinne zu erzeugen. Daher ist aufgrund der ökonomischen Analyse öffentlicher Kredithilfen nicht zu belegen, daß sie gegenüber alternativen Subventionsformen ökonomisch vorteilhafte Subventionsinstitutionen darstellen. Dementsprechend ist aufgrund der ökonomischen Analyse auch nicht erklärbar, weshalb Kredithilfen bei der Entscheidung über die Form einer Subventionsmaßnahme alternativen Subventionsformen vorgezogen werden. Außerdem bleibt unklar, wie sich die Entscheidungen über die Subventionsform auf die Höhe des Subventionsvolumens auswirken. Schließlich kann mit der vorstehenden Analyse nicht erklärt werden, weshalb zahlreiche Kredithilfen außerbudgetär vergeben werden. Daher ist es notwendig, die Annahme gegebener institutioneller Bedingungen aufzuheben und die Entscheidungen zwischen verschiedenen Sub- 
ventionsinstitutionen zu untersuchen sowie daraus normative Konsequenzen abzuleiten.

Diese Fragestellungen sollen im folgenden Kapitel im Rahmen einer politischinstitutionellen Analyse öffentlicher Kredithilfen betrachtet werden. 


\section{POLITISCH-INSTITUTIONELLE ANALYSE ÓFFENTLICHER KREDITHILFEN}

Die ökonomische Analyse öffentlicher Kredithilfen als gegebene Subventionsinstitutionen ist nicht geeignet, um die Verwendung dieser Subventionsformen positiv zu erklären oder normativ zu bewerten. Daher soll in diesem Kapitel die politische Entscheidung über Kredithilfen als mögliche Subventionsformen zum Gegenstand der Analyse gemacht werden. D.h. es wird unterstellt, daß bei der Entscheidung über die Form der Subventionierung zwischen verschiedenen Alternativen gewählt werden kann. Demnach ist zunächst zu analysieren, unter welchen Bedingungen Kredithilfen gegenüber anderen Subventionsformen vorgezogen werden. In einem weiteren Schritt wird sodann untersucht, inwiefern eine Entscheidung zugunsten von Kredithilfen aus normativer Sicht wünschenswert oder unerwünscht ist. Dabei besteht das grundlegende Problem, welche normativen Kriterien für diese Frage heranzuziehen sind. Darüber hinaus ist zu untersuchen, wie die allgemeinen politisch-institutionellen Bedingungen geändert werden müssen, wenn die Entscheidungen über die Subventionsform so zu beeinflußt werden sollen, daß unerwünschte Ergebnisse weitestmöglich vermieden werden. Weiterhin werden außerbudgetäre Einheiten als mögliche Organisationsformen für die Kredithilfevergabe analysiert. Dabei steht die Frage im Vordergrund, wie die Errichtung außerbudgetärer Einheiten positiv erklärt werden kann und welche Konsequenzen aus ihrer Existenz resultieren. Schließlich wird auch in bezug auf außerbudgetäre Einheiten diskutiert, welche institutionellen Vorkehrungen getroffen werden müssen, um unerwünschte Konsequenzen im Hinblick auf die Wahl dieser Organisationsformen zu verhindern.

\section{POSITIVE ERKLÄRUNGSANSÄTZE FÜR ÖFFENTLICHE KREDITHILFEN}

Wenngleich positive Erklärungsansätze für öffentliche Kredithilfen im Schrifttum kaum explizit diskutiert werden ${ }^{1}$, erscheint eine derartige Analyse als wesentlicher Bestandteil einer umfassenden positiven Subventionstheorie unverzichtbar. Denn die Individuen werden sich mit ihren ökonomischen Entscheidungen nicht nur an bestehende Subventionsinstitutionen anpassen, um die aus einer Subventionierung resultierenden

1 Unterstellt man, daß der Staat in perfekter Weise funktioniert, ist diese Frage auch weniger bedeutsam. Denn unter dieser Annahme wird der Staat nur solche Maßnahmen durchführen, die dem, wie auch immer definierten, Gemeinwohl dienen. Vgl. BRENNAN/BUCHANAN (1980/1988), S.5 f. Danach werden öffentliche Kredithilfen immer dann gewährt, wenn sie im "öffentlichen Interesse" liegen, weil sie den optimalen Zielerreichungsgrad gegebener staatlicher Zielsetzungen erwarten lassen. 
individuellen Vorteile zu maximieren bzw. die Nachteile zu minimieren. Vielmehr werden sie mit diesem Ziel auch auch Bemühungen im Rahmen gegebener politisch-institutioneller Bedingungen zur Beeinflussung der institutionellen Gestaltung von Subventionen in einer für sie vorteilhaften Art und Weise unternehmen ${ }^{1}$. Eine vollständige positive Subventionstheorie hat demnach die Analyse marktmäßiger Wirkungen von Subventionen mit interessenbedingten Einflußnahmen auf die Subventionsstruktur und dem daraus resultierenden politischen Entscheidungsverhalten zu integrieren.

Bei der folgenden Untersuchung wird angenommen, daß sich die Entscheidungen über eine Subventionierung bestimmter Aktivitäten und die Form der Subventionierung analytisch trennen lassen. Dabei wird unterstellt, daß die Subventionsform gegebener Subventionsprogramme im Rahmen eines politischen Prozesses bestimmt wird. An diesem Prozeß sind einerseits die Bürger als Nachfrager öffentlicher Leistungen beteiligt. Andererseits werden politische Entscheidungen durch die staatlichen Akteure, nämlich die Politiker und Bürokraten, als Anbieter öffentlicher Leistungen beeinflußt. Die Erklärung der Bereitstellung von Kredithilfen als Subventionsinstitution setzt folglich voraus, daß die Interessen der am politischen Prozeß beteiligten Akteure spezifiziert werden, die im Rahmen der gegebenen allgemeinen politisch-institutionellen Bedingungen das Ergebnis von Subventionsform-Entscheidungen bestimmen ${ }^{2}$. Im folgenden werden zur analytischen Vereinfachung die Interessen der Nachfrager und Anbieter öffentlicher Leistungen an der "Bereitstellung" öffentlicher Kredithilfen getrennt betrachtet ${ }^{3}$.

\section{Nachfrageseitige Erklărungsansătze für öffentliche Kredithilfen}

In neueren politisch-ökonomischen Analysen werden zunehmend die redistributiven Aspekte staatlicher Maßnahmen als zentrale Dimension für ihre positive Erklärung hervorgehoben ${ }^{4}$. "Die Erreichbarkeit privater Vorteile überlagert die Entscheidungen über öffentliche Aufgaben in allen Bereichen staatlicher Tätigkeit und lenkt Art und Umfang der Staatsaufgaben nach Kriterien, die im normativen Modell keine Entsprechung finden." ${ }^{5}$ Danach werden Kredithilfen von denjenigen Bürgern präferiert, die dadurch

$1 \mathrm{Zu}$ einer vergleichbaren Unterscheidung zwischen der traditionellen und der institutionenökonomischen Steuertheorie vgl. FOLKERS (1985), S.274 f.

2 Vgl FOLKERS (1986d) in bezug auf Entscheidungen über steuerliche Institutionen.

3 Die Bedeutung einer Unterscheidung zwischen der Nachfrage- und der Angebotsseite im Hinblick auf die Bereitstellung öffentlicher Leistungen wird im Rahmen der Public-Choice-Theorie regelmäßig hervorgehoben. Vgl. dazu POSNER (1974), S.344; FOLKERS (1986d), S.6 ff.;

HARTWIG (1990), S.99 ff.; MÄRTZ (1990), S.140 ff.

4 Vgl. z.B. STIGLER (1971).

5 FOLKERS (1990), S.1. 
gegenüber der Realisierung alternativer Subventionsformen spezielle Verteilungsvorteile erzielen können. Die übrigen Bürger werden Kredithilfen nicht ablehnen, wenn durch diese Subventionsform niemand Nachteile erleidet. Unter diesen Bedingungen entspricht die Entscheidung zugunsten von Kredithilfen dem Paretokriterium und ist somit nicht nur aus normativer Sicht erwünscht, sondern zugleich auch einfach erklärbar. Sind Kredithilfen die paretooptimale Subventionsform, so ist nämlich zu erwarten, daß sich die Bürger einstimmig für Kredithilfen aussprechen werden ${ }^{1}$. Eine solche Konstellation ist theoretisch allerdings nur denkbar, wenn zumindest einzelne Individuen durch die Entscheidung für Kredithilfen reale Nettonutzen erzielen können, während die ökonomische Position der übrigen Individuen nicht tangiert wird. Treten die Vorteile öffentlicher Kredithilfen dagegen lediglich als pekuniäre Vorteile für bestimmte Gruppen auf, dann stehen diesen Vorteilen pekuniäre Nachteile anderer Gruppen gegenüber, so daß die Subventionsform-Entscheidung ein reines Nullsummenspiel darstellt. In diesem Fall ergibt sich ein Interessenkonflikt zwischen verschiedenen Gruppen, wobei diejenigen, die durch Kredithilfen gewinnen, diese Subventionsform durchsetzen wollen, während die Verlierer dagegen opponieren werden. Dies gilt um so mehr, wenn Kredithilfen gegenüber anderen Subventionsformen zusätzlich zu den pekuniären Effekten reale Nettokosten verursachen. Aber auch dann, wenn eine vollständige Kompensation der Verlierer ${ }^{2}$ bei Kredithilfen durch die Gewinner möglich ist und sich die Gewinner dennoch verbessern, werden Interessenkonflikte zwischen den verschiedenen Gruppen auftreten, wenn die Kompensation nicht tatsächlich durchgeführt wird.

Damit wird deutlich, daß untersucht werden muß, welche Gruppen unter welchen Bedingungen durch Kredithilfen Vorteile erzielen können und somit als Nachfrager von Kredithilfen zu betrachten sind. Als mögliche Nachfrager von Kredithilfen werden dabei zum einen die Steuerzahler, die für die Finanzierung der Subventionsausgaben aufkommen müssen, zum anderen die Gruppe der durch die Subventionierung materiell Begünstigten berücksichtigt. Dagegen werden die Interessen der staatlichen Akteure bei der Subventionsform-Entscheidung aus Gründen analytischer Vereinfachung in diesem Abschnitt außer acht gelassen.

Kommt es bei der Entscheidung über die Subventionsform zu Interessenkonflikten, so hängt es von dem Entscheidungsverfahren ab, ob die Nachfrage nach Kredithilfen effektiv wird. Eine effektive Nachfrage nach Kredithilfen liegt dann vor, wenn die

1 Zum Zusammenhang zwischen Paretooptimalität und der Einstimmigkeit von Entscheidungen vgl. BUCHANAN (1962).

2 Verlierer von Kredithilfen sind dabei alle, die bei alternativen Subventionsformen relative Vorteile erreichen könnten. 
Nachfrager von Kredithilfen bei der Entscheidung ein höheres "Gewicht" besitzen als die jeweiligen Opponenten. Die Nachfrage nach Kredithilfen läßt sich wie die Nachfrage nach anderen öffentlichen Leistungen in verschiedener Weise artikulieren. Zum einen werden die Individuen in der Demokratie ihre Ansprüche an den Staat in Abstimmungen und Wahlen zum Ausdruck bringen ${ }^{1}$. Andererseits bestehen vielfältige Möglichkeiten der Einflußnahme auf politische Entscheidungen durch Bildung spezieller Interessengruppen. Diese Interessengruppen stehen bei öffentlichen Leistungen mit redistributiven Konsequenzen im Wettbewerb um politische Einflußnahme mit dem Ziel, die jeweiligen Interessen im politischen Prozeß durchzusetzen².

In diesem Zusammenhang wird zuerst analysiert, unter welchen Bedingungen sich eine effektive Nachfrage nach Kredithilfen ergibt, wenn damit die Subventionsausgaben minimiert werden können. Daran anschließend wird untersucht, inwieweit sich die Vergabe öffentlicher Kredithilfen erklären läßt, wenn bei konstanten Subventionsausgaben im Vergleich zu alternativen Subventionsformen differentielle Verteilungswirkungen zu verzeichnen sind. In einem weiteren Schritt wird analysiert, unter welchen Bedingungen öffentliche Kredithilfen nachgefragt werden, wenn sie sich von alternativen Subventionsformen allein durch den Zeitpunkt der (Netto-)Subventionsausgaben unterscheiden. Außerdem wird untersucht, wie es sich auf die Nachfrage nach Kredithilfen auswirkt, wenn sie gegenüber anderen Subventionsformen eine Ausweitung der Subventionsausgaben ermöglichen. Schließlich wird diskutiert, inwieweit sich in dynamischer Perspektive eine Nachfrage nach Kredithilfen ergeben kann.

\section{a. Minimierung der Subventionsausgaben durch öffentliche Kredithilfen}

In gegebenen Zusammenhang sei angenommen, daß der Entscheidung über die Subventionsform die Entscheidungen über die zu fördernden Aktivitäten und den Kreis der Subventionsempfänger vorgelagert sind. Dabei möge mit der Subventionierung das allokative Ziel verfolgt werden, die Durchführung von rentablen Investitionen zu ermöglichen, die ohne staatliche Intervention bei fehlendem Eigenkapital nicht realisiert würden. Der Kreis der Subventionsberechtigten sei abgrenzbar und allen Beteiligten bekannt. Unter diesen Bedingungen kann durch die Entscheidung über die Subventionsform implizit die Höhe der staatlichen Subventionsausgaben bestimmt werden.

1 Grundlegend dazu BLACK (1948); DOWNS (1957/1968).

2 Vgl. OLSON (1965); BECKER, G.S. (1983); FOLKERS (1983b), S.195 ff.; FOLKERS (1985), S.276 ff.; HARTWIG (1990), S.104 ff.; MÄRTZ (1990), S.89 ff. 
Zunächst ist allerdings zu analysieren, ob der angestrebte Subventionserfolg bei Kredithilfen und alternativen Subventionsformen mit unterschiedlichen Subventionsausgaben verbunden ist. Dabei wird zuerst der Fall adverser Selektion auf dem Kreditmarkt betrachtet. Danach wird angenommen, daß die privaten Kreditgeber trotz unterstellter Risikoneutralität, z.B. aufgrund bestehender rechtlicher Beschränkungen, rentable Investitionen nicht finanzieren, wenn diese im ungünstigen Umweltzustand einen bestimmten Mindestertrag unterschreiten.

Im Hinblick auf eine Subventionierung bei adverser Selektion soll auf das bereits in den Abschnitten C.I.4.a. und C.II.1.ff. verwendete Modell zurückgegriffen werden. Dabei wurde unterstellt, daß asymmetrische Information zwischen den jeweils risikoneutralen Kreditgebern und -nehmern vorliegt. Die Höhe der vollständig kreditfinanzierten, einperiodigen Investitionen ist bei allen Investoren gleich und wird im folgenden auf den Wert eins normiert. Der erwartete Brutto-Investitionsertrag soll für alle Investitionen $\mathbf{R}$ betragen. Der nominale Kreditzinssatz i ohne Subventionierung soll sich danach bestimmen, $\mathrm{da} B 1+\mathrm{i}=(1+\mathrm{r}) /(1-\pi)$ gilt, wobei $\mathrm{r}$ den risikolosen Marktzinssatz und $\pi$ die durchschnittliche Kreditausfallwahrscheinlichkeit bezeichnen. Dabei wird aus Vereinfachungsgründen unterstellt, daß im ungünstigen Umweltzustand ein vollständiger Kreditausfall zu verzeichnen ist. Gilt für die Investoren mit der geringsten individuellen Ausfallwahrscheinlichkeit $p^{i}$ die Ungleichung $R<\left(1-p^{i}\right)(1+i)$, so werden diese ihre Kreditnachfrage zurückziehen. Dadurch erhöht sich $\pi$, so daß ein Prozeß einsetzt, der zum Zusammenbruch dieses Teil-Kreditmarktes führt.

Wie in Abschnitt C.II.1.ff. gezeigt wurde, kann unter den genannten Bedingungen mit Kredithilfen die Durchführung dieser Investitionen ermöglicht werden, wobei alle Kredithilfeformen zu denselben erwarteten durchschnittlichen Subventionsausgaben in Höhe von $(1+r)-(1-\pi) R$ führen.

Um zu untersuchen, ob die Subventionsausgaben mit Kredithilfen gesenkt werden können, soll ermittelt werden, welche Höhe ein Investitionszuschuß $Z$ als alternative Subventionsinstitution im gegebenen Modellrahmen annehmen müßte. Wird der Investitionszuschuß in der Gegenwart ausgezahlt, so muß für den Investor mit dem geringsten Risiko gelten:

(D.I.1) $\quad R=(1+i)(1-Z)$

bzw.

(D.I.2) $Z=[(1+r)-(1-\pi) R] /(1+r)$. 
Da der Investitionszuschuß als sichere Subventionszahlung mit dem risikolosen Marktzinssatz aufgezinst werden kann, ist der Endwert der Subventionsausgaben beim Investitionszuschuß genau so hoch wie die (erwarteten) Ausgaben im Fall der Kredithilfen. Anders als man möglicherweise vermuten könnte, lassen sich unter den genannten Bedingungen die Subventionsausgaben durch Kredithilfen nicht minimieren. Erfolgt die Subventionsform-Entscheidung durch Mehrheitswahl ${ }^{1}$, werden die Wähler zwischen den Subventionsformen indifferent sein, sofern man die unterschiedlichen Ausgabenzeitpunkte außer acht läßt. Denn weder die Steuerzahler noch die Subventionsempfänger können von der Subventionsform abhängige Vorteile realisieren. Aus diesem Grund werden sich auch keine Interessengruppen bilden, die eine bestimmte Subventionsform durchsetzen wollen. Insofern läßt sich die Vergabe von Kredithilfen im gegebenen Zusammenhang nicht erklären.

$\mathrm{Zu}$ einem anderen Ergebnis gelangt man, wenn die privaten Kreditgeber Fremdkapital zur Finanzierung bestimmter riskanter Aktivitäten nur bereitstellen, wenn von den Kreditforderungen im ungünstigen Umweltzustand mindestens ein Anteil $\mathbf{x}$ erfüllt werden kann, wobei $0<\mathrm{x}<1$ gilt.

Es sei unterstellt, daß bei bestimmten Investitionen, für die Eigenkapital nicht zur Verfügung steht, $R>1+r$ gilt, wobei $R$ wiederum den erwarteten Brutto-Investitionsertrag und $\mathrm{r}$ den risikolosen Marktzinssatz repräsentieren. Da der Brutto-Investitionsertrag im ungünstigen Umweltzustand Null beträgt, wird die Investitionsfinanzierung bei unterstellter Haftungsbeschränkung auf den Investitionsertrag ohne staatliche Intervention an Liquiditätsmangel scheitern.

Das Subventionsziel, die Realisierung der betreffenden Investitionen, läßt sich im Fall von Investitionszuschüssen nur realisieren, wenn sie in Höhe der gesamten Investitionssumme gewährt werden, weil nur dadurch der Liquiditätsmangel überwunden werden kann. Außerdem können die Investitionen durchgeführt werden, wenn der Staat Kreditgewährleistungen, durch die die privaten Kreditforderungen in Höhe von $\mathbf{x}$ abgesichert werden, oder öffentliche Darlehen vergibt ${ }^{2}$. Unter den getroffenen Annahmen werden die Investoren bei unterstellter Risikoneutralität die Investitionen auch dann durchführen, wenn die Kreditgewährleistungen zu einer fairen Versicherungsprämie bzw. die öffentlichen Darlehen zu einem Zinssatz vergeben werden, der erwartete Zinskosten des Investors von $1+r$ impliziert. Demnach läßt sich durch öffentliche Darlehen und Kreditgewährleistungen

1 Für einem Überblick zu den Modellen der Mehrheitswahl vgl. BOADWAY/WILDASIN (1984), S.143 ff.; zur Kritik an den Mehrheitswahlmodellen vgl. ROWLEY (1984).

2 Dagegen können Zinszuschüsse den Liquiditätsmangel nur überwinden, wenn der im ungünstigen Umweltzustand dem Kreditgeber zufließende Zuschußbetrag den Wert x überschreitet. 
das Subventionsziel mit erwarteten (Netto-) Subventionsausgaben von Null erreichen, während die Subventionsausgaben im Fall von Investitionszuschüssen maximal werden.

Die Steuerzahler werden in diesem Fall ceteris paribus eine Investitionsförderung durch Kreditgewährleistungen bzw. öffentliche Darlehen präferieren, da sich dadurch das angestrebte Subventionsziel mit minimalen staatlichen Ausgaben erreichen läßt. Durch die Realisierung der ausgabenminimalen Subventionsform können die Steuerzahler gegenüber alternativen Subventionsformen Steuersenkungen erwarten, wenn die sonstigen staatlichen Ausgaben konstant gehalten werden. Da eine Reduzierung des staatlichen Steueraufkommens im allgemeinen eine Senkung von Mehrbelastungen impliziert, sind Kredithilfen insoweit auch allokativ wünschenswert. Andererseits können aber die Subventionsempfänger zusätzliche Vorteile realisieren, wenn nicht die ausgabenminimale Subventionsform gewählt wird.

Bei einer Entscheidung über die Subventionsform durch Mehrheitswahl, wird die Mehrheit für öffentliche Darlehen oder Kreditgewährleistungen stimmen, weil Kredithilfen regelmäßig nur einem begrenzten Personenkreis gewährt werden ${ }^{1}$, so daß die Steuerzahler die Subventionsempfänger überstimmen können. Damit werden die Präferenzen der Steuerzahler für Kredithilfen nachfragewirksam. Dasselbe Ergebnis folgt, wenn die Entscheidungsalternative zwischen nicht ausgabenminimalen Kredithilfen und Investititionszuschüssen besteht, sofern der Gegenwartswert der erwarteten Nettoausgaben bei Darlehen und Kreditgewährleistungen kleiner ist als die Ausgaben für die Investitionszuschüsse ${ }^{2}$. Außerdem wird die Mehrheit regelmäßig für entgeltlose Kreditgewährleistungen, die den Kreditzinssatz auf den risikolosen Marktzinssatz verbilligen, gegenüber Darlehen präferieren, bei denen der Darlehenszinssatz unterhalb des risikolosen Marktzinssatzes liegt. Kann die Wählermehrheit die Entscheidungsalternativen selbst festlegen, wird sich jedoch nur für solche Programme eine Mehrheit ergeben, deren erwartete Nettoausgaben Null betragen.

Die Präferenz einer Wählermehrheit für die ausgabenminimale Subventionsform hängt jedoch davon $a b$, daß die Ausgabeneinsparungen bei der Subventionierung den Steuerzahlern tatsächlich in irgendeiner Form, z.B. durch Steuersenkungen oder Transferzahlungen, zugute kommen. Unterstellt man dagegen, daß sich der Staat die Ausgabeneinsparungen bei den kostenminimalen Subventionsformen komplett aneignet, so sind die Individuen, die keine Subventionen erhalten, zwischen allen Subventionsformen indiffe-

1 Vgl. ZEITEL (1977), S.1004.

2 Sind die Wähler risikoavers, so müssen die erwarteten Nettoausgaben der Kredithilfen mindestens um das Sicherheitsäquivalent niedriger sein als die Zuschußausgaben. Andernfalls werden die Investitionszuschüsse präferiert. 
rent. Dagegen werden die Subventionsempfänger für die Subventionsform stimmen, die ihre Nettovorteile maximiert ${ }^{1}$. Bleiben Stimmenthaltungen bei der Stimmenauszählung unberücksichtigt, wird sich also in diesem Fall eine Mehrheit für die ausgabenmaximale Subventionsform aussprechen. Dieses Ergebnis kann sich wiederum umkehren, wenn der Staat mit den Ausgabeneinsparungen bei der Wahl von Kredithilfen zusätzliche Subventionen in anderen Bereichen finanzieren kann. In diesem Fall werden die Steuerzahler zwischen den verschiedenen Subventionsformen indifferent sein. Dagegen werden die Individuen, die durch eine zusätzliche Subventionierung begünstigt werden, für die ausgabenminimale Subventionsform stimmen. Insoweit kommt es bei der Mehrheitswahl auf das zahlenmäßige Verhältnis der verschiedenen Gruppen von sicheren oder möglichen Subventionsempfängern an, die durch die ausgabenminimale Subventionsform Vorteile bzw. Nachteile zu verzeichnen haben.

Andererseits kann die Vorstellung, daß die Entscheidung über die Subventionsform durch Mehrheitswahl getroffen wird, kaum empirische Relevanz beanspruchen. Vielmehr werden Interessengruppen Einflußnahme-Aktivitäten entfalten, um die für sie vorteilhafte Subventionsform durchzusetzen. Die gegebenen Möglichkeiten individueller Verteilungsvorteile lassen vermuten, daß die Realisierung der ausgabenminimalen Subventionsform keine stabile Konstellation im Rahmen des politischen Prozesses darstellt. Der politische Druck zur Durchsetzung der mit den höheren Ausgaben verbundenen Subventionsform ist um so höher, je mehr dadurch kleine Gruppen begünstigt werden, da in diesem Fall die Organisationskosten vergleichsweise gering sind ${ }^{2}$. Die Wahrscheinlichkeit, daß nicht die ausgabenminimale Subventionsform gewählt wird, ist weiterhin von der Oppostition der Steuerzahler gegen eine Ausweitung der Subventionsausgaben über das aus allokativer Sicht notwendige $\mathrm{Maß}$ hinaus abhängig. Sie wird um so geringer ausfallen, je geringer das Ausmaß der Schlechterstellung der Verlierer, je höher die Dispersion der Nachteile und je geringer die Information der Verlierer über die realen Effekte der unterschiedlichen Subventionsformen sind ${ }^{3}$. Selbst wenn Kredithilfen unter idealen Bedingungen zu einer Minimierung der Subventionsausgaben führen könnten, ist somit im realen politischen Prozeß regelmäßig nicht damit zu rechnen, daß diese Zielsetzung für die Nachfrage nach Kredithilfen wesentliche Bedeutung besitzt. Diese Aussage ist jedoch zu modifizieren,

1 Sind die Subventionsempfänger zugleich auch Steuerzahler, so werden sie die Vorteile der ausgabenmaximalen Subventionsform mit ihren Kosten in Form entgangener Steuerentlastungen oder Transfers saldieren. Dabei kann jedoch unterstellt werden, da $B$ die Subventionsempfänger bei der ausgabenmaximalen Subventionsform Nettovorteile realisieren, da ihre Opportunitätskosten bei der ausgabenmaximalen Subventionsform relativ gering ausfallen werden.

2 Vgl. OLSON (1965); FOLKERS (1983b), S.196 in bezug auf Steuervergünstigungen.

3 Vgl. FOLKERS (1983b), S.197. 
wenn feststeht, daß Ausgabeneinsparungen bei der kostenminimalen Subventionsform zur Finanzierung von Vorteilen eines kleineren, abgrenzbaren Personenkreises eingesetzt werden. In diesem Fall hängt das Ergebnis der Entscheidung über die Subventionsform davon ab, welche Gruppe im Wettbewerb um politische Einflußnahme überlegen ist.

\section{b. Erzielung von Verteilungsvorteilen durch Kredithilfen bei gegebenem Subventions- volumen}

Anders als im vorhergehenden Abschnitt wird nun unterstellt, daß die Höhe des durch den Gegenwartswert der Netto-Subventionsausgaben bemessenen Subventionsvolumens vor der Entscheidung über die Subventionsform festgelegt sei ${ }^{1}$. Damit wird durch die Subventionsform-Entscheidung implizit bestimmt, wer durch die Subventionierung in welchem Ausmaß begünstigt wird. Es wird zunächst angenommen, daß die Subventionsausgaben bei allen Formen zu demselben Zeitpunkt fällig sind. Damit sind die Steuerzahler gegenüber den verschiedenen Subventionsformen indifferent. Unter dieser Prämisse wird einmal diskutiert, wodurch die Nachfrage nach öffentlichen Kredithilfen bestimmt wird, wenn als Entscheidungsalternative lediglich Investitionszuschüsse zur Verfügung stehen. In einem nächsten Schritt werden Steuervergünstigungen als zusätzliche Entscheidungsalternative zugelassen. Daran anschließend werden die Annahme des gleichen Auszahlungszeitpunkts aufgehoben und die damit verbundenen Implikationen für die Nachfrage nach öffentlichen Kredithilfen analysiert.

aa. Entscheidung zwischen Kredithilfen und Investitionszuschüssen

Die als gegeben angenommenen Subventionsausgaben, die vom Staat für einen bestimmten Zweck bereitgestellt werden, sollen nun entweder in Form von öffentlichen Darlehen oder von Investitionszuschüssen an den durch den Subventionszweck nur abstrakt abgrenzbaren Empfängerkreis von Investoren ausgeschüttet werden ${ }^{2}$. Der Staat sei bei der Subventionsvergabe an den Grundsatz der Gleichbehandlung gebunden. Dabei

1 Zur Bestimmung der Höhe der Subventionsausgaben durch den politischen Interessenwettbewerb vgl. BECKER, G.S. (1983); BECKER, G.S. (1985); MÄRTZ (1990). Siehe auch FOLKERS (1990), S.21.

2 Diese Annahme findet in der Realität ihre Entsprechung. Beispielsweise weist der Bund den Ländern im Rahmen der Gemeinschaftsaufgabe "Verbesserung der regionalen Wirtschaftsstruktur" Mittel in bestimmter Höhe zu, die von diesen zur Regionalförderung einzusetzen sind. Diese Mittel werden von den meisten Ländern in Form von Investitionszuschüssen ausgezahlt. Dagegen weicht das Land Baden-Württemberg von dieser Praxis ab, indem es im Rahmen seines "technischen Ermessensspielraums" zinsverbilligte Darlehen vergibt. Vgl. KLEIN (1982), S.35 f.; GOLDSCHMIDT (1987), S.165. 
wird der Gleichheitssatz in der Weise interpretiert, daß allen potentiellen Subventionsempfängern unabhängig von unterschiedlichen individuellen Merkmalen dieselben Subventionskonditionen eingeräumt werden müssen ${ }^{1}$. D.h. der Zinssatz öffentlicher Darlehen und der Zuschußsatz bei Investitionszuschüssen müssen für alle Subventionsempfänger jeweils gleich hoch $\operatorname{sein}^{2}$. Die begünstigten Investitionen sollen unterschiedliche Investitionsrisiken und demnach bei unterstellter vollständiger Kreditfinanzierung auch unterschiedliche Kreditrisiken aufweisen. Weiterhin soll der Investitionszuschuß pro Investitionseinheit dem Gegenwartswert der durchschnittlichen Zinsverbilligung bei öffentlichen Darlehen entsprechen.

Geht man von einem bei beiden Subventionsformen einheitlichen Empfängerkreis aus, so werden im Fall öffentlicher Darlehen die Investoren mit überdurchschnittlichem (unterdurchschnittlichem) Investitionsrisiko gegenüber dem Investitionszuschuß begünstigt (benachteiligt) ${ }^{3}$. Unterstellt man zusätzlich, daß die unterschiedlichen Subventionsformen keine differentiellen Verteilungseffekte auf formal nicht beteiligte Dritte haben ${ }^{4}$, so treten die für Distributionskonflikte typischen Interessengegensätze zwischen den Individuen mit über- und unterdurchschnittlichem Investitionsrisiko auf. Erfolgt die Entscheidung über die Subventionsform im Rahmen des Wettbewerbs von Interessengruppen, so wird die Interessengruppe der von öffentlichen Darlehen relativ begünstigten Individuen diese Subventionsform durchzusetzen versuchen. Umgekehrt wird die Interessengruppe der relativ benachteiligten Individuen dagegen opponieren. Der Staat wird in diesem Zusammenhang als "Transfermakler"5 gesehen, der "lediglich die aus dem Wettbewerb der Gruppen um politischen Einfluß resultierenden Maßnahmen"6 ausführt.

Die jeweils tangierten Interessengruppen werden Ressourcen zur "Produktion" politischen Drucks einsetzen, um die Entscheidungen der staatlichen Akteure im Sinn ihrer

1 Bekanntlich wird der Gleichheitssatz in der Bundesrepublik Deutschland vom Bundesverfassungsgericht in der Weise ausgelegt, daß "weder wesentlich Gleiches willkürlich ungleich, noch wesentlich Ungleiches willkürlich gleich zu behandeln" sei. Vgl. BUNDESVERFASSUNGSGERICHT (1956), S.155. Der Gleichheitssatz verlangt damit nicht, "daß bei der Ordnung eines bestimmten Lebensgebietes (...) alle vorgegebenen Ungleichheiten berücksichtigt werden." Siehe GUBELT (1985), Rz.10. Die hier getroffene Annahme bedeutet also, daB individuelle

Unterschiede im gegebenen Zusammenhang als rechtlich unwesentlich angesehen werden.

2 Unter dieser Prämisse sind Kreditgewährleistungen mit einem einheitlichen Deckungsgrad und Prämiensatz mit öffentlichen Darlehen, Zinszuschüsse mit einem einheitlichen Zuschußsatz mit Investitionszuschüssen vergleichbar.

3 Vgl. AARON (1972a), S.582.

4 Diese Annahme trifft nur dann zu, wenn beide Subventionsformen die Marktpreise in derselben Weise beeinflussen.

5 MCCORMICK/TOLLISON (1981), S.15.

6 MÄRTZ (1990), S.89. 
Mitglieder zu beeinflussen ${ }^{1}$. Welche Subventionsform sich im Interessenwettbewerb durchsetzen wird, läßt sich nicht generell sagen. Allgemein kann jedoch erwartet werden, daß Interessengruppen bei der Durchsetzung spezieller Verteilungsvorteile um so erfolgreicher sind, je kleiner ihre Klientel in Relation zur Gruppe der relativ benachteiligten Individuen ist $^{2}$. Dies läßt sich wiederum damit begründen, daß in diesem Fall "die Kosten der Organisation und der Vermeidung des Free-rider-Verhaltens (...) vergleichsweise gering sind" ${ }^{\prime 3}$. Außerdem können die Belastungen der Verlierergruppe breit gestreut werden und haben ein geringes Ausmaß für die Individuen.

Ist die Gruppe der Investoren mit überdurchschnittlichem Investitionsrisiko relativ klein und die Streuung des Investitionsrisikos gering, so wird der relative Verteilungsnachteil der Investoren mit unterdurchschnittlichem Investitionsrisiko bei einer Subventionierung durch öffentliche Darlehen relativ gering ausfallen. Dieser Effekt wird verstärkt, weil sich bei einem verringerten Verbilligungssatz der Kapitalkosten der Anteil der Mehrbelastung an der Subventionszahlung reduziert ${ }^{4}$. Da die Gruppe mit unterdurchschnittlichem Investitionsrisiko nur unwesentlich schlechter gestellt wird, ist bei gegebenen Kosten der politischen Einflußnahme mit einer vergleichsweise geringen Opposition gegen öffentliche Darlehen zu rechnen ${ }^{5}$. Hinzu kommt, daß bei der größeren Gruppe der durch öffentliche Darlehen relativ Benachteiligten der Anreiz besteht, sich als Free-rider bezüglich der Einflußnahmeaktivitäten der betreffenden Interessengruppe zu verhalten. Dadurch sinkt die Produktionseffizienz dieser Interessengruppe bei der Erzeugung politischen Drucks ${ }^{6}$. Dementsprechend kann erwartet werden, daß unter den gegebenen Prämissen tendenziell die Subventionierung eher durch öffentliche Darlehen als durch Investitionszuschüsse erfolgt. Dieses Ergebnis kann sich allerdings umkehren, wenn die Streuung der Investitionsrisiken relativ hoch ist, der Zugang zum "Markt" für politische Einflußnahme beschränkt ist oder erhebliche Unterschiede in der Produktionseffizienz von politischem Druck existieren?.

1 Dieser Ressourceneinsatz stellt nach der Rent-seeking-Theorie gesamtwirtschaftlich eine Ressourcenverschwendung dar, weil damit keine Güter produziert werden, sondern lediglich Einkommen für bestimmte Individuen auf Kosten anderer Individuen umverteilt werden. Vgl. KRUEGER (1974); POSNER (1975), BUCHANAN/TOLLISON/TULLOCK (1980); FOLKERS (1985), S.285 f.; MÄRTZ (1990). Vgl. BECKER, G.S. (1983).

3 FOLKERS (1985), S.277.

4 Vgl. für Steuervergünstigungen FOLKERS (1988c), S.219. Siehe auch MÄRTZ (1990), S.128.

5 Vgl. FOLKERS (1983b), S.197; FOLKERS (1985), S.277 f.; MÄRTZ (1990), S.130.

6 Vgl. OLSON (1965); BECKER, G.S. (1985); S.332; HYMAN (1990), S.206; MÄRTZ (1990), S.107.

7 Vgl. MÄRTZ (1990), S.130 f. 
Ist der Empfängerkreis bei den verschiedenen Subventionsformen unterschiedlich abgegrenzt, so ist das wahrscheinliche Ergebnis des Interessenwettbewerbs dagegen in weit höherem Maße unbestimmt. Denn unter dieser Bedingung wird beispielsweise die Gruppe, die durch Investitionszuschüsse begünstigt wird, bei einer Subventionierung durch Darlehen im Durchschnitt vergleichsweise hohe relative Verteilungsverluste erleiden. Demzufolge wird ihr Widerstand gegen die Darlehenssubventionierung höher ausfallen als bei einem von der Subventionsform unabhängigen Empfängerkreis. Daher erscheint eine Entscheidung zugunsten der Subventionsinstitution des Investitionszuschusses um so eher möglich, je unterschiedlicher der Kreis der Empfänger bei beiden Subventionsformen ist.

\section{bb. Entscheidung zwischen Kredithilfen, Investitionszuschüssen und} Steuervergünstigungen

Im folgenden werden als dritte Entscheidungsalternative Steuervergünstigungen zugelassen, wobei die Subventionsausgaben bei allen Subventionsformen wiederum zu demselben Zeitpunkt ausgabenwirksam sein sollen ${ }^{1}$. Dabei wird unterstellt, daß bestimmte Kapitalgüterkäufe in der Ausgangssituation bereits durch Steuervergünstigungen "gefördert" werden. Die Entscheidungsalternative besteht demnach darin, die gegebene Subventionsform beizubehalten oder durch Investitionszuschüsse bzw. öffentliche Darlehen zu ersetzen. Die Subventionskonditionen sollen wieder für alle Individuen gleich sein. Der Empfängerkreis sei bei allen Alternativen identisch. Außerdem soll die Subventionierung ausschließlich distributive Konsequenzen besitzen, d.h. lediglich Mitnahmeeffekte hervorrufen $^{2}$. Weiterhin wird unterstellt, daß die Entscheidung über die Form der Subventionsmaßnahme durch Mehrheitswahl getroffen wird, wobei lediglich die Subventionsempfänger an der Wahl teilnehmen sollen. Über die Subventionsalternativen soll paarweise abgestimmt werden.

An der Entscheidung seien $n$ Wähler beteiligt, die jeweils eine einperiodige Investition in Höhe von $\mathbf{K}$ unabhängig von einer Subventionierung durchführen. Die vollständig kreditfinanzierten Investitionen seien in unterschiedlichem Maß riskant, wobei der BruttoInvestitionsertrag mit der jeweils bekannten Wahrscheinlichkeit $p^{i}$ für $i=1, \ldots, n$ Null betragen soll, während er mit der Gegenwahrscheinlichkeit (1-pi) die Höhe der Kreditfor-

1 Die "Subventionsausgaben" bei Steuervergünstigen ergeben sich in Form von negativen Einnahmen.

2 Diese Annahme dürfte beispielsweise in bezug auf die Wohnungsbauförderung plausibel sein, wo regelmäßig zumindest von hohen Mitnahmeeffekten ausgegangen wird. Vgl. z.B. KARLBRÄUER-INSTITUT DES BUNDES DER STEUERZAHLER (1990), S.96 und oben Abschnitt C.III.3.e. 
derungen überschreiten soll. Die Haftung der Investoren für Kreditforderungen sei auf den Brutto-Investitionsertrag beschränkt. Alle Individuen seien risikoneutral. Aus Vereinfachungsgründen wird unterstellt, da $\mathrm{B}$ öffentliche Darlehen und Investitionszuschüsse steuerlich irrelevant sind.

Im ersten Fall wird nun angenommen, daß die Steuervergünstigung in der Weise ausgestaltet ist, daß jedem Investor je Investitionseinheit ein pauschaler Abzug von der Steuerschuld gewährt wird.

Bei der Abstimmung zwischen der Beibehaltung der Steuervergünstigung und ihrer Ersetzung durch einen Investitionszuschuß werden alle Individuen beiden Alternativen indifferent gegenüberstehen. Denn jeder Wähler erhält genau den Betrag als Investitionszuschuß, der ihm als Steuervergünstigung entgeht. Die Änderung der Subventionsform wird für jeden einzelnen Subventionsempfänger zum Nullsummenspiel.

In der nächsten Runde wird über die Alternative Steuervergünstigung oder Darlehensgewährung abgestimmt. Hier zeigt sich kein eindeutiges Ergebnis. Entspricht die Höhe der öffentlichen Darlehen der Investitionssumme $\mathbf{K}$ und ist der nominale Darlehenszinssatz beispielsweise mit dem risikolosen Marktzinssatz identisch, so ergibt sich für den einzelnen Wähler am Periodenende ein erwarteter Verteilungsvorteil von $\left[(1+r)-\left(1-p^{i}\right)(1+r)\right] K=p^{i}(1+r) K^{1}$ Da dieser Wert in Abhängigkeit von $p^{i}$ variiert, während die Steuervergünstigung für jeden Wähler $\left[\Sigma p^{i} / n\right](1+r) K$ beträgt, werden diejenigen Individuen für das Darlehensprogramm stimmen, deren individuelle Kreditausfallwahrscheinlichkeit $\mathrm{p}^{\mathrm{i}}$ größer $\left[\Sigma \mathrm{p}^{\mathrm{i}} / \mathrm{n}\right]$ ist. D.h. daß alle Wähler mit überdurchschnittlichem Investitionsrisiko das Darlehensprogramm befürworten, da sie durch diese Form der Subventionierung Nettovorteile realisieren können. Umgekehrt werden die Wähler mit unterdurchschnittlichem Investitionsrisiko für die Steuervergünstigung stimmen.

Da bei der Mehrheitswahl die Stimme des Medianwählers dafür ausschlaggebend ist, ob ein Vorschlag eine Mehrheit findet ${ }^{2}$, ist die Verteilung des Investitionsrisikos über die gesamte Wählerschaft entscheidend. Übersteigt das Investitionsrisiko des Medianwählers das durchschnittliche Risiko aller Wähler, so wird er mit seiner Stimme dem Darlehensprogramm zu einer Mehrheit verhelfen ${ }^{3}$.

1 Da die Verbindlichkeiten der Investoren am Periodenende im Erfolgsfall $(1+r) /\left(1-p^{i}\right)$ betragen, ist ihr Erwartungswert 1+r.

Vgl. MUELLER (1989), S.65 f.

3 Ein entsprechendes Ergebnis folgt für Kreditgewährleistungen. 
man, wenn zwischen Investitionszuschüssen und Darlehen abgestimmt wird. Damit besteht unter den gegebenen institutionellen Bedingungen, anders als bei Investitionszuschüssen, die Möglichkeit, daß ein rein redistributiv wirkendes Darlehensprogramm eine Mehrheit erhält. Das Ergebnis der Abstimmung über die drei Entscheidungsalternativen ist unter den getroffenen Annahmen eindeutig. Dies beruht auf der Eingipfligkeit der Präferenzen der Wähler bezüglich dieser Alternativen ${ }^{1}$. Denn die Wähler präferieren entweder öffentliche Darlehen gegenüber Investitionszuschüssen bzw. der Steuervergünstigung oder umgekehrt ${ }^{2}$. Insgesamt handelt es sich bei der Entscheidung unter den gegebenen Bedingungen um ein Nullsummenspiel, weil die Summe der Vorteile der Gewinner der Summe der Nachteile der Verlierer entspricht.

Wird die Steuervergünstigung hingegen in Form eines Abzugsbetrags von der Steuerbemessungsgrundlage, z.B. der Einkommensteuer, gewährt, so zeigt sich, daß die Annahme eines überdurchschnittlichen Investitionsrisikos des Medianwählers keine hinreichende Bedingung für eine positive Entscheidung für das Darlehensprogramm darstellt. Dies soll anhand des einfachen Zahlenbeispiels in Schaubild 1 demonstriert werden.

In dem Beispiel wird unterstellt, da $B$ die Individuen $A, B$ und $C$ über ein unterschiedliches Einkommen $\mathrm{Y}$ verfügen. Es gelte $\mathrm{Y}_{\mathrm{A}}<\mathrm{Y}_{\mathrm{C}}<\mathrm{Y}_{\mathrm{B}}$. Bei einem progressiven Steuertarif führt der Wegfall der Steuervergünstigung somit zu einer zusätzlichen Einkommensteuerschuld von unterschiedlicher Höhe. Weiterhin wird berücksichtigt, daß durch den Wegfall der Steuervergünstigung der marginale Einkommensteuersatz steigt, so da $ß$ die Verzerrung der individuellen Arbeits-Freizeit-Entscheidung verstärkt wird. Vereinfachend wird hier angenommen, daß die zusätzliche Mehrbelastung bei Wegfall der Steuervergünstigung 10 Prozent der zusätzlichen Steuerschuld beträgt. Demnach ist die Summe der Nettovorteile aus der Subventionierung durch Darlehen bzw. Investitionszuschüsse kleiner Null. Weiterhin wird angenommen, daß das Investitionsrisiko einer Wählermehrheit (B und C) und damit ihr Bruttovorteil aus öffentlichen Darlehen überdurchschnittlich hoch ist.

Damit gilt zwar, daß die Mehrheit Darlehen gegenüber Investitionszuschüssen präferiert. Denn die Mehrheit kann bei Darlehen überdurchschnittliche, bei Investitionszuschüssen dagegen nur durchschnittliche Bruttovorteile realisieren. Deshalb sind die Nettovorteile der Mehrheit im Fall der Subventionierung durch Darlehen stets höher. Andererseits verliert Wähler B bei der Subventionierung durch Investitionszuschüsse und Darlehen ge-

1 Zur Analyse eingipfliger Präferenzen grundlegend BLACK (1948).

2 An der Eindeutigkeit des Ergebnisses ändert sich nichts, wenn die Wähler zwischen zwei der drei Alternativen indifferent sind. Vgl. KELLY (1988), S.30 f. 
Schaubild 1: Die Entscheidung über verschiedene Subventionsformen bei unterschiedlicher Ausgestaltung von Steuervergünstigungen

\begin{tabular}{|c|c|c|c|}
\hline Alternativen & $\mathbf{A}$ & $\begin{array}{r}\text { Vähler } \\
\text { B }\end{array}$ & $\mathrm{C}$ \\
\hline $\begin{array}{l}\text { Alternative I } \\
\text { (Beibehaltung } \\
\text { der Steuer- } \\
\text { vergünstigung) }\end{array}$ & 0 & 0 & 0 \\
\hline $\begin{array}{l}\text { Alternative II } \\
\text { Zuschuß: } \\
\text { Bruttovorteil } \\
\text { Entgangene Steuer- } \\
\text { vergünstigung } \\
\text { Zusätzliche } \\
\text { Mehrbelastung } \\
\text { Nettovorteil }\end{array}$ & $\begin{array}{r}1.000 \\
500 \\
\\
50 \\
450\end{array}$ & $\begin{array}{r}1.000 \\
1.600 \\
160 \\
-760\end{array}$ & $\begin{array}{r}1.000 \\
900 \\
90 \\
10\end{array}$ \\
\hline $\begin{array}{l}\text { Alternative III } \\
\text { Darlehen: } \\
\text { Bruttovorteil } \\
\text { Entgangene Steuer- } \\
\text { vergünstigung } \\
\text { Zusätzliche } \\
\text { Mehrbelastung } \\
\text { Nettovorteil }\end{array}$ & $\begin{array}{r}0 \\
500 \\
50 \\
-550\end{array}$ & $\begin{array}{r}1.200 \\
1.600 \\
160 \\
-560\end{array}$ & $\begin{array}{r}1.800 \\
900 \\
90 \\
810\end{array}$ \\
\hline $\begin{array}{l}\text { Paarweise } \\
\text { Abstimmungen } \\
\text { I gegen II } \\
\text { II gegen III } \\
\text { III gegen I }\end{array}$ & $\underset{\text { I }}{\text { II }}$ & $\underset{\text { III }}{\text { I }}$ & $\begin{array}{l}\text { II } \\
\text { III }\end{array}$ \\
\hline
\end{tabular}

"Die Zahlenwerte repräsentieren Geldeinheiten.

genüber dem Fall der Steuervergünstigung (Alternative I). Wähler B zieht die Alternativen I und III der mittleren Alternative II vor und besitzt damit eine mehrgipflige Präferenzordnung. Dagegen ist die Präferenzordnung von A und C eingipflig. Diese Konstellation führt zum sogenannten Wahlparadoxon, nach dem sich bei paarweiser Abstimmung zyklische Mehrheiten ergeben ${ }^{1}$.

Daran ändert sich nichts, wenn man Logrolling-Prozesse ${ }^{2}$ zuläßt, bei denen die Stimmen der Individuen gehandelt werden können. Nimmt man beispielsweise an, daß C dem B eine Ausgleichszahlung in Höhe von 685 Einheiten anbietet, wenn B bei der

1 Vgl. dazu den Überblick bei MUELLER (1989), S.63 ff.

2 Vgl. z.B. BUCHANAN/TULLOCK (1962), S.134 ff. 
Abstimmung I gegen III für das Darlehensprogramm stimmt, so hätten beide Individuen einen Nettovorteil von jeweils 125 Einheiten, während sich der Verlust von A auf 550 Einheiten beläuft. Daraufhin kann A dem B jedoch bis zu 999 Einheiten anbieten, wenn dieser die Koalition mit $\mathbf{C}$ verläßt und in den Abstimmungen Alternative II gegenüber III vorzieht. Die neue Koalition kommt zustande, weil A und B ihre Position auf - 549 bzw. + 239 Einheiten verbessern. Diese Koalition ist jedoch ebenfalls instabil. Denn C kann dem A ein "Koalitionsangebot" machen, durch das sich diese beiden Wähler verbessern können. Damit beginnt der Zyklus von neuem¹ ${ }^{1}$ D.h. daß die Mehrheitswahl zur Durchführung des Darlehensprogramms, des Zuschußprogramms oder zur Beibehaltung der Steuervergünstigung führen kann. Das Ergebnis hängt davon ab, wann die Abstimmungsfolge abgebrochen wird.

Wird die Abstimmungsfolge nicht durch das Zufallsprinzip, sondern durch eine vorgegebene Tagesordnung bestimmt, so kommt dem Agenda-Setter entscheidende Bedeutung $\mathrm{zu}^{2}$. Dabei ist denkbar, daß entweder einer der Wähler oder eine außenstehende Person die Kontrolle über die Tagesordnung erhält ${ }^{3}$. Nimmt man an, daB es eine Regel gibt, die verbietet, Entscheidungsvorschläge, die einmal abgelehnt wurden, später nochmals zur Abstimmung zu stellen ${ }^{4}$, so wird der Agenda-Setter die Abstimmungsreihenfolge in der Weise festlegen, daß die von ihm präferierte Alternative in der Schlußabstimmung gewinnt ${ }^{5}$. Besitzt beispielsweise Wähler $\mathrm{C}$ die vollständige Kontrolle über die Tagesordnung, so wird er zunächst die Alternativen I und II gegeneinander abstimmen lassen, um Alternative I aus dem Abstimmungsproze $\mathbf{z u}$ eliminieren. In der Abstimmung über die Alternativen II und III wird die Alternative III und damit das Darlehensprogramm obsiegen. Ohne genaue Analyse, unter welchen Bedingungen welcher Wähler die Rolle des Agenda-Setters erhält, läßt sich im gegebenen Modellrahmen jedoch nicht prognostizieren, welche Subventionsform sich unter den gegebenen Bedingungen durchsetzen wird.

Legen die Anbieter öffentlicher Leistungen die Tagesordnung für politische Entscheidungen fest, so läßt sich jedoch anhand dieser einfachen Modellüberlegungen verdeutlichen, daß deren Präferenzen ebenfalls zu analysieren sind, wenn man einen umfassenden positiven Erklärungsansatz für unterschiedliche Subventionsformen erhalten will.

1 Vgl. MUELLER (1989), S.85 f. Eine Möglichkeit, den Zyklus wirksam zu unterbrechen, besteht darin, daß den Wählern die Einstimmigkeitsregel auferlegt wird. Vgl. BERNHOLZ (1973).

2 Grundlegend dazu McKELVEY (1976).

3 Vgl. MCKELVEY (1976), S.480.

4 Vgl. VICKREY (1983), S.133.

5 Vgl. MUELLER (1989), S.91. 
Da der Agenda-Setter das endgültige Abstimmungsergebnis bei zyklischen Mehrheiten allerdings nur unter vergleichsweise restriktiven Bedingungen bestimmt ${ }^{1}$, muß zusätzlich die Möglichkeit in Betracht gezogen werden, daß sich die Wähler an die Tagesordnung anpassen, um eventuelle individuelle Nachteile zu vermeiden. Deshalb besteht auch bei Existenz von Wahlzyklen ein Anreiz, stabile Koalitionen zu bilden, in denen sich zwar der maximale Vorteil für die einzelnen Mitglieder nicht realisieren läßt, andererseits aber eine relativ vorteilhafte Position für die jeweiligen Koalitionsmitglieder gesichert werden kann.

Einigen sich beispielsweise $A$ und $C$ darauf, dem Investitionszuschuß zur Mehrheit zu verhelfen, wobei A dem C eine Ausgleichszahlung in Höhe von 220 Einheiten leistet, so können beide Seiten mit dem Verlassen der Koalition drohen. Da dies für die jeweils andere Seite schädlich wäre, werden die Individuen erkennen, daß die Einhaltung der Koalitionsabsprache einen sicheren Vorteil verspricht ${ }^{2}$. Dabei kann vermutet werden, daß sich diejenigen Wähler zu einer stabilen Koalition zusammenschließen werden, die eine maximale Ausbeutung der maximalen Minderheit erlaubt ${ }^{3}$. Es läßt sich allerdings nicht voraussagen, wie die Mehrheit den aus der Ausbeutung der Minderheit resultierenden Vorteil unter ihren Mitgliedern aufteilt ${ }^{4}$. Unter den in dem Beispiel genannten Bedingungen ist danach eine Koalition zwischen $\mathrm{A}$ und $\mathrm{C}$ am wahrscheinlichsten, die gemeinsam die Investitionszuschüsse durchsetzen werden ${ }^{5}$. Dieses Ergebnis hängt jedoch neben der Risikoverteilung über die einzelnen Individuen ganz wesentlich von der Verteilung der Vorteile bei der Steuervergünstigung und damit letztlich von der Steuerstruktur $a b^{6}$. Eine generalisierende Aussage, daß öffentliche Kredithilfen gegenüber anderen Subventionsformen vorgezogen werden, ist daher im Modellzusammenhang nicht möglich.

1 So muß unterstellt werden, daß der Agenda-Setter vollständige Information über die Präferenzen der Wähler besitzt. Darüber hinaus ist erforderlich, daß die Wähler vor ihrer Stimmabgabe keinerlei Kenntnis über die Abstimmungsfolge haben oder sich bei Stimmabgabe zumindest so verhalten, als ob sie die Tagesordnung nicht kennen. Vgl. MUELLER (1989), S.249.

2 Vgl. MUELLER (1989), S.91 f.

3 Vgl. BRENNAN/BUCHANAN (1981b), S.120; Siehe auch in anderem Modellzusammenhang BRENNAN/BUCHANAN (1980/1988), S.27.

4 Vgl. BRENNAN/BUCHANAN (1981b), S.120.

5 Läßt man $\mathrm{zu}$, daß auch mehrere Subventionsprogramme nebeneinander durchgeführt werden können, können sich A und C sowohl auf das Darlehens- als auch auf das Investitionsprogramm verständigen, sofern $C$ den $A$ an seinen Nettovorteilen beteiligt. Denn in beiden Fällen muß B für die Kosten der Umverteilung aufkommen.

6 Allgemein zur Abhängigkeit der Nachfrage nach öffentlichen Leistungen von der Steuerstruktur vgl. FOLKERS (1986d), S.12 ff. 
cc. Fälligkeit der Subventionsausgaben verschiedener Subventionsformen zu unterschiedlichen Zeitpunkten

Wie bereits gezeigt, besitzen verschiedene Subventionsformen differentielle intertemporale Verteilungswirkungen, wenn die Subventionsausgaben zu unterschiedlichen Zeitpunkten anfallen. Es soll für Individuen mit vollkommener Voraussicht analysiert werden, ob die Vergabe öffentlicher Kredithilfen durch eine unterschiedliche zeitliche Verteilung der Subventionausgaben bei verschiedenen Subventionsformen erklärt werden kann. Dabei wird unterstellt, daß die Nettoausgaben der Subventionierung bei Kredithilfen regelmäßig zu einem späteren Zeitpunkt anfallen als bei der betrachteten alternativen Subventionsform ${ }^{1}$.

Um diesen Aspekt analytisch zu isolieren, wird unterstellt, daß den Wählern durch exogene Entscheidung vorgegeben ist, daß bestimmte risikolose Investitionen subventioniert werden sollen. Die Wähler sollen entscheiden, ob die Subventionierung in Form zinsverbilligter öffentlicher Darlehen oder als Investitionszuschuß durchgeführt werden soll $^{2}$. Dabei sei der mit dem risikolosen Marktzinssatz abdiskontierte Gegenwartswert der Zinsverbilligung der Darlehen ebenso hoch wie der Investitionszuschuß. Weiter soll unterstellt werden, daß die Subventionsempfänger zwischen beiden Subventionsformen indifferent sind. Deshalb kommt es hier allein darauf an, wer bei beiden Subventionsalternativen die Kosten der Subventionierung zu tragen hat.

Die Finanzierung des Investitionszuschusses bzw. der Zinsverbilligung des Darlehens soll durch eine Subventionssteuer erfolgen, die beim Investitionszuschuß in der Gegenwart, bei öffentlichen Darlehen in der Zukunft zu entrichten ist. Der Gegenwartswert der Subventionssteuer bei öffentlichen Darlehen entspricht der in der Gegenwart fälligen Subventionssteuer beim Investitionszuschuß. Die sonstigen staatlichen Einnahmen und Ausgaben seien von der Subventionsform unabhängig. Weiter wird unterstellt, daß sich die Wählerschaft in zwei Gruppen A und B aufteilen läßt, wobei die Individuen jeweils eine Periode leben. Dabei sollen sich die Mitglieder der Gruppe A im Gegensatz zu denen der Gruppe B so verhalten, als ob sie auch in der Zukunft leben. Sie werden also in der Gegenwart nur einen Teils ihres Einkommens konsumieren, den Rest dagegen sparen und ihren Nachkommen als Erbschaft hinterlassen.

1 Dies gilt allerdings nicht, wenn Zinszuschüsse in kapitalisierter Form vergeben werden.

2 Die folgende Analyse ließe sich ohne weiteres auch für die anderen Kredithilfeformen durchführen. Darauf kann jedoch verzichtet werden, da die Konsequenzen in allen Fällen identisch sind, wenn Kredithilfen erst in späteren Perioden Ausgaben verursachen. 
Unter diesen Bedingungen werden die B-Individuen die Verschiebung der Kosten der Subventionierung in die Zukunft präferieren. Die Institution öffentlicher Darlehen erlaubt ihnen, diese Zielsetzung zu verwirklichen ${ }^{1}$. Allerdings stellt sich die Frage, wie es der Gruppe B gelingt, politische Dominanz zu erreichen. Dazu sollen zwei vereinfachende Fallkonstellationen untersucht werden ${ }^{2}$.

Im ersten Fall wird angenommen, daß die Nachkommenschaft beider Gruppen relativ gleich gro $B$ ist und da $B$ die Subventionssteuer von beiden Gruppen bzw. deren Nachkommen in Form einer Kopfsteuer zu entrichten ist. Die Mitglieder der Gruppe A werden die bei einer Darlehensvergabe relativ höheren künftigen Steuerverpflichtungen vollständig in ihrem Kalkül berücksichtigen. Dementsprechend werden ihre intertemporalen Konsumentscheidungen durch die Wahl der Subventionsform nicht verändert. D.h. die A-Individuen werden bei der Darlehensvergabe das gegenüber dem Investitionszuschuß um den Gegenwartswert der Zinsverbilligung höhere Gegenwartseinkommen in vollem Umfang sparen. Ihre Nutzenposition ist von der Wahl der Subventionsform unabhängig. Daher sind sie gegenüber beiden betrachteten Subventionsformen indifferent.

Dagegen erhöht sich die Nutzenposition der B-Individuen bei der Darlehensvergabe gegenüber dem Investitionszuschuß, da sie dann über ein höheres Gegenwartseinkommen verfügen und demzufolge mehr konsumieren können. Die Mitglieder von Gruppe B werden daher die Darlehensvergabe als Subventionsform präferieren. Da die Gruppe A dagegen nicht opponieren wird, kann mit fast jedem Modell des politischen Prozesses vorausgesagt werden, daß die Subventionierung unter diesen Bedingungen durch öffentliche Darlehen erfolgt ${ }^{3}$. Die Kosten der Entscheidung für Darlehen tragen in diesem Fall die Nachkommen der zur Gruppe B gehörenden Individuen.

Im zweiten Fall wird unterstellt, daß nur die A-Individuen Nachkommen haben. Während in der Gegenwart beide Gruppen die Subventionssteuer zu entrichten haben, müssen in der Zukunft lediglich die Nachkommen der Gruppe A für die Subventionssteuer aufkommen. In diesem Fall werden die A-Individuen die bei Darlehensvergabe resultierenden künftigen Subventionssteuerzahlungen als Einkommensminderung gegenüber dem Investitionszuschuß wahrnehmen und dementsprechend unter normalen Bedingungen ${ }^{4}$ ihren Konsum und ihre Ersparnis reduzieren ${ }^{5}$. Dadurch ergeben sich bei der Darlehens-

$1 \mathrm{Zu}$ dem selben Ergebnis gelangen BUCHANAN/ROBACK (1987), S.22 in bezug auf das analytisch gleich gelagerte Problem staatlicher Verschuldung.

2 Vgl. BUCHANAN/ROBACK (1987), S.14 ff.

3 Vgl. BUCHANAN/ROBACK (1987), S.22 zum analogen Fall der Staatsverschuldung.

4 Gegenwarts- und Zukunftskonsum seien jeweils superiore Güter.

5 Eine Reduzierung der Ersparnis würde allerdings entfallen, wenn die Höhe der Erbschaften von der Einkommenshöhe unabhängig ist. Vgl. BUCHANAN/ROBACK (1987), S.16 f. 
vergabe sowohl für die Mitglieder von Gruppe A wie für ihre Nachkommen Nutzenverluste. Demgegenüber erhöht sich das Einkommen der B-Individuen bei Darlehensvergabe gegenüber dem Investitionszuschuß. Sie können deshalb mehr konsumieren und erzielen somit einen Nutzengewinn ${ }^{1}$.

Bei dieser Konstellation wird Gruppe A die Darlehensvergabe ablehnen, die andererseits von Gruppe B unterstützt wird. Die Entscheidung für eine Darlehensvergabe resultiert hier bei Verwendung einfacher Mehrheitswahlmodelle nur dann, wenn die Mitgliederzahl von Gruppe B höher ist als von Gruppe A. Deshalb läßt sich unter den getroffenen Annahmen nicht eindeutig vorhersagen, ob die Nachfrage der Gruppe B nach Darlehen bei der Entscheidung über die Subventionsform durchgesetzt werden kann. Allerdings kann sich eine wirksame nachfrageseitige Präferenz für Kredithilfen ergeben, wenn die Individuen künftige Zahlungsverpflichtungen nur unvollständig wahrnehmen, da die Gruppe A dann gegen diese Subventionsform in geringerem Ausma $B$ opponieren wird. Auf diesen Zusammenhang soll im folgenden Abschnitt näher eingegangen werden.

c. Erzielung von Verteilungsvorteilen durch Erhöhung der Subventionsausgaben bei öffentlichen Kredithilfen

Nachdem zuvor untersucht wurde, wie sich die Nachfrage nach Kredithilfen im Hinblick auf eine Minimierung der Subventionsausgaben bzw. bei konstanten Subventionsausgaben erklären läßt, soll nun betrachtet werden, inwieweit Kredithilfen die Erringung individueller Verteilungsvorteile durch Ausweitung der staatlichen Subventionsausgaben erlauben. Es wird also danach gefragt, ob die Entscheidung über die Subventionsform implizit auch eine Entscheidung über das Ausmaß der geförderten Aktivitäten und damit über die Höhe der Subventionsausgaben enthält. Dabei wird angenommen, da $B$ das Subventionsvolumen erst nach der Entscheidung über die Subventionsform festgelegt wird. Die analytische Referenzgröße für öffentliche Kredithilfen sollen hier wiederum Investitionszuschüsse bilden.

Im folgenden wird unterstellt, daß die individuellen Vorteile bei Kredithilfen und Investitionszuschüssen gleichermaßen, die Kosten der Kredithilfen jedoch in relativ geringerem Ausmaß wahrgenommen werden ${ }^{2}$. So stellen BUCHANAN/FLOWERS in bezug auf öffentliche Darlehen fest: "The costs (...) are effectively hidden. The average taxpayer would find it difficult, if not impossible, to measure the costs of the transfer involved in

1 Vgl. BUCHANAN/ROBACK (1987), S.19.

2 Vgl. LEONARD/RHYNE (1981), S.41; BENNETT/DiLORENZO (1986), S.295. 
subsidized government credit ..."1 ${ }^{11}$ Damit soll nicht unterstellt werden, daß die Individuen die Nutzen der Subventionierung exakt wahrnehmen. Vielmehr sollen diesbezüglich zwischen den verschiedenen Subventionsformen keine differentiellen Effekte bestehen.

Die Ursache für die relative Falschwahrnehmung der Kosten von Kredithilfen gegenüber Investitionszuschüssen kann zum einen in rationaler Ignoranz ${ }^{2}$ der Individuen, zum anderen in einer relativ höheren Fiskalillusion bei Kredithilfen liegen.

\section{aa. Rationale Ignoranz}

Rationale Ignoranz basiert generell auf dem Umstand, daß Informationen über die Kosten und Nutzen öffentlicher Leistungen in der Regel nicht kostenlos verfügbar sind. Die Individuen werden diejenige Informationsmenge nachfragen, bei der die Grenzerträge und Grenzkosten der Informationsbeschaffung übereinstimmen ${ }^{3}$. Steigen die Grenzkosten und fallen die Grenzerträge der Informationsbeschaffung mit zunehmender Informationsmenge, so werden die Individuen im Informationsoptimum keine vollständige Information nachfragen. Impliziert erst vollständige Information die korrekte Wahrnehmung der Kosten der Subventionierung, so werden sie im Fall positiver Informationskosten aufgrund des individuellen Kosten-Nutzen-Kalküls stets falsch wahrgenommen. Sind die marginalen Informationskosten bei Kredithilfen im relevanten Bereich höher als bei Investitionszuschüssen, so werden die Individuen bei unterstellter Konstanz der Grenzerträge der Informationsbeschaffung im ersten Fall eine geringere Informationsmenge nachfragen. Daraus resultiert eine relative Unterschätzung der Kosten öffentlicher Kredithilfen.

Es sprechen mehrere Gründe dafür, daß die Informationskosten bei Kredithilfen im Vergleich zu Investitionszuschüssen höher liegen. So fehlen bei Kredithilfen in den ohne größeren Aufwand zugänglichen Informationsquellen regelmäßig vollständige Angaben über das Ausmaß der in künftigen Perioden anfallenden Kosten der Zins- bzw. Prämiensatzverbilligung. Dies ist einmal dadurch bedingt, daß bei budgetären Kredithilfen nur die Einnahmen und Ausgaben der jeweiligen Haushaltsperiode zu veranschlagen sind. Da bei Kredithilfen allenfalls ein Bruchteil der gesamten Zins- bzw. Prämiensatzverbilligung in der Vergabeperiode zu (Netto-)Subventionsausgaben führt, sind die gesamten Subventionsausgaben ohne spezielle Informationsbeschaffung in der Vergabeperiode nur in begrenztem Umfang zu erkennen. Außerdem ist bei Kredithilfen, die eine Verbilligung auf einen bestimmten Zinssatz implizieren, die Höhe des Kreditrisikos für die Höhe der

1 BUCHANAN/FLOWERS (1987), S.169.

2 Vgl. DOWNS (1965), S.79 ff.; TULLOCK (1972), S.102 ff.

3 Vgl. BARTLETT (1973), S.29 f.; MÄRTZ (1990), S.156. 
(Netto-)Subventionsausgaben maßgeblich. Dieses Risiko ist im Vergabezeitpunkt bereits für den Staat nur schwer quantifizierbar. Für die Bürger ist es ungleich schwerer zu erkennen, inwieweit die vom Staat offiziell genannten Risikoeinschätzungen realistisch sind. Dazu kommt, daß im Gegensatz zu Investitionszuschüssen ein erheblicher Anteil öffentlicher Kredithilfen, insbesondere öffentlicher Darlehen, durch außerbudgetäre Einheiten vergeben wird. Informationen über deren Kredithilfeaktivitäten sind vergleichsweise schwer zugänglich. Außerdem werden Kredithilfen z.B. in der Bundesrepublik bei der Subventionsberichterstattung weit weniger umfassend dargestellt als andere Subventionsformen 1 .

Im folgenden soll dementsprechend von einer relativen Unterschätzung der Subventionierungskosten von Kredithilfen ausgegangen werden. Es soll angenommen werden, da $B$ eine Verteilungskoalition durch staatliche Subventionsmaßnahmen spezifische Verteilungsvorteile im Wettbewerb der Interessengruppen durchsetzen will ${ }^{2}$. Dabei sollen als Subventionsalternativen Kreditgewährleistungen und Investitionszuschüsse zur Verfügung stehen. Von Anpassungsreaktionen der Subventionsempfänger aufgrund der Subventionierung wird aus Vereinfachungsgründen abgesehen. Außerdem wird angenommen, daß die Gruppenvorteile aus der Subventionierung bei beiden Subventionsalternativen durch gruppeninterne Kompensationsleistungen so ausgeglichen werden, da $\beta$ der individuelle Verteilungsvorteil jedes Gruppenmitglieds gleich hoch ist. Weiterhin wird angenommen, $\mathrm{da} ß \mathrm{im}$ Wettbewerb der Interessengruppen von den potentiellen Gewinnern einer Subventionierung Ressourcen eingesetzt werden, um politischen Druck zu erzeugen und damit politischen Einfluß zu nehmen. Der Umfang der Subventionierung wird durch das Ausmaß der Einflußnahme der Subventionsempfänger bestimmt. Der Einfluß der Subventionsempfänger kann gemindert werden, wenn die Verlierer der Subventionierung ebenfalls Ressourcen zur Erzeugung politischen Drucks einsetzen. Im Optimum müssen dabei die Grenzkosten des Ressourceneinsatzes dem marginalen Distributionsgewinn der jeweiligen Gruppe entsprechen ${ }^{3}$. Weiterhin soll mit einer Erhöhung der Einflußnahme einer Gruppe eine gleich hohe Verminderung der Einflußnahme der anderen Gruppe einhergehen ${ }^{4}$. Schließlich wird unterstellt, $\mathrm{da} B$ alle Individuen risikoneutral seien.

Im Fall rationaler Ignoranz wird der politische Druck der Steuerzahler gegen erwartete Subventionsausgaben gegebener Höhe bei Kreditgewährleistungen geringer ausfallen

1 Vgl. z.B. DICKERTMANN (1987).

2 Vgl. BECKER, G.S. (1983); MÄRTZ (1990), S.89 ff.

3 Vgl. MÄRTZ (1990), S.110. Dabei ergeben sich auch für die Verlierer der Subventionierung durch den Ressourceneinsatz marginale Distributionsgewinne, weil sie dadurch ihren Verteilungsverlust reduzieren können.

4 Vgl. BECKER, G.S. (1983), S.376; COE/WILBER (1985), S.41. 
als bei Investitionszuschüssen. Denn der wahrnehmbare Grenzertrag des Ressourceneinsatzes ist bei Kreditgewährleistungen geringer als bei Investitionszuschüssen. Der politische Druck der Steuerzahler wird dabei mit zunehmender relativer Höhe ihrer Informationskosten bei den Kreditgewährleistungen fallen. Bei gegebenem politischen Druck der Subventionsempfänger können diese dann im Fall der Kreditgewährleistungen ein höheres Einflußniveau erreichen ${ }^{1}$. Dadurch sind die erwarteten Verteilungsvorteile der Gruppe der Subventionsempfänger bzw. die erwarteten Subventionsausgaben bei Kreditgewährleistungen höher als bei Investitionszuschüssen ${ }^{2}$. Folglich werden die Subventionsempfänger tendenziell die Subventionsinstitution der Kredithilfen nachfragen.

Dieses Ergebnis kann sich ändern, wenn Anpassungsreaktionen an die Subventionierung zugelassen sind und die beiden betrachteten Subventionsformen differentielle Anreizwirkungen induzieren. Erwarten die Steuerzahler beispielsweise, daß Kreditgewährleistungen, anders als Investitionszuschüsse, aufgrund von Moral-hazard-Verhalten der Subventionsempfänger zusätzliche Subventionsausgaben induzieren, wird dadurch der politische Druck gegen Kreditgewährleistungen stärker sein als gegen Investitionszuschüsse. Diese Effekte können in der Weise zusammenwirken, daß die wahrnehmbaren Kosten der Kreditgewährleistungen die der Investitionszuschüsse übersteigen. In diesem Fall werden die Subventionsausgaben bei Investitionszuschüssen höher sein. Ob die Subventionsempfänger dennoch Kredithilfen präferieren werden, ist davon abhängig, ob die möglichen Vorteile aufgrund individuellen Moral-hazard-Verhaltens die Verminderung der direkten Subventionsvorteile überkompensieren können oder nicht.

\section{bb. Fiskalillusion}

Eine andere Konstellation liegt vor, wenn die Individuen im Zusammenhang mit öffentlichen Kredithilfen einer Fiskalillusion im Hinblick auf deren Kosten unterliegen. Wenngleich in der Literatur zwischen rationaler Ignoranz und Fiskalillusion nicht immer eindeutig unterschieden wird $^{3}$, lassen sich doch für beide Phänomene klare Abgren-

1 Allerdings besitzen die Subventionsempfänger einen Anreiz, ihren politischen Druck zu vermindern, sofern ein Rückgang des politischen Drucks der Verlierer das Grenzprodukt des politischen Drucks der Subventionsempfänger reduziert. Dennoch werden letztere ihren politischen Druck nur soweit reduzieren, als sie dennoch ein höheres Einflußnahmeniveau erreichen. Vgl. BECKER, G.S. (1983), S.376, 379.

2 Die Verteilungsvorteile bei Kreditgewährleistungen sind unsicher, weil die dadurch induzierte Verbilligung des Kreditzinssatzes nur dann zu Verteilungsvorteilen führt, wenn ein Schadensfall nicht eintritt.

3 So belegt DiLORENZO (1982), S.244 den Fall der Unterschätzung der Kosten staatlicher Maßnahmen aufgrund positiver Informationskosten mit dem Begriff Fiskalillusion. 
zungsmerkmale finden ${ }^{1}$. Während rationale Ignoranz positive Informationskosten voraussetzt, kann Fiskalillusion auch bei kostenloser Information auftreten. Das entscheidende Merkmal der Fiskalillusion liegt darin, daß die Individuen bei gegebenen Informationskosten weniger Informationen als bei fehlender Illusion nachfragen. Dies beruht darauf, da $ß$ die Individuen bei bestimmten fiskalischen Institutionen den Ertrag zusätzlicher Informationen subjektiv zu gering einschätzen ${ }^{2}$. Im Gegensatz dazu setzt rationale Ignoranz die Kenntnis der tatsächlichen individuellen Informationskosten- und Informationsertragsfunktion voraus. Daher impliziert Fiskalillusion im subjektiven individuellen Informationsoptimum stets eine geringere Informationsmenge als rationale Ignoranz. Daraus resultiert bei den Individuen stets ein Rentenverlust infolge der suboptimalen Informationsnachfrage.

Wesentlich für das Auftreten von Fiskalillusion ist weiterhin, daß die Individuen die Kosten bzw. Nutzen bestimmter staatlicher Maßnahmen in systematischer Weise falsch wahrnehmen ${ }^{3}$. D.h. daß die im Rahmen einer vergleichenden Institutionenanalyse wesentlichen relativen Illusionseffekte bei gegebenem Informationsstand eine systematische Unterschätzung der Kosten bzw. Nutzen der in stärkerem Maß illusionsverursachenden Institution gegenüber der Referenzinstitution ergeben.

Der Unterschied zwischen Fiskalillusion und rationaler Ignoranz kann mit folgendem Beispiel verdeutlicht werden. Betrachtet man einen Wanderer in der Wüste, der wegen Wasserknappheit auf der Suche nach der nächsten Oase ist, so kann er die Kosten der Wahl einer bestimmten Wegrichtung deshalb unterschätzen, weil er nur mit einem Kom$\mathrm{pa} ß$ und unvollständigen geographischen Kenntnissen ausgestattet ist. Dennoch ist es rational, diese Richtung zu wählen, weil die erwarteten Opportunitätskosten vollständiger Information, die durch das Ablaufen sämtlicher Richtungen vom Ausgangspunkt und zurück erreicht werden kann, den erwarteten Ertrag übersteigen. Dagegen wird ein Individuum, das eine Fata Morgana wahrnimmt und Wasser "sieht", in seiner Entscheidung über die zu wählende Richtung auch dann beeinflußt, wenn es vollständiges Kartenmaterial in seinem Gepäck hat ${ }^{4}$. Denn aufgrund der Sinnestäuschung wird es tendenziell darauf verzichten, sich anhand der Landkarten umfassend zu informieren, obwohl die Information für ihn nahezu kostenlos wäre. Übertragen auf den gegebenen Zusammenhang bedeutet dies, daß Fiskalillusion gerade kein Problem falscher Information, hoher Informationskosten oder zu geringer marginaler Informationserträge ist. Vielmehr kann Fiskalillusion auch bei voll-

1 Vgl. BUCHANAN (1967), S.126.

2 Die subjektive Komponente der Fiskalillusion wird insbesondere von BUCHANAN (1967), S.126 f. betont.

3 Vgl. BUCHANAN/WAGNER (1977), S.129; BAUM (1982), S.32.

4 Vgl. BUCHANAN (1967), S.128. 
ständiger Information allein durch die Wahl bestimmter institutioneller Gestaltungsformen erzeugt werden ${ }^{1}$. Gleichwohl können rationale Ignoranz und Fiskalillusion identische Effekte für das individuelle Entscheidungsverhalten bewirken ${ }^{2}$. Eine Unterscheidung dieser beiden Phänomene ist allerdings erforderlich, weil sie die Bandbreite der möglichen Handlungsparameter des Staates zur Beeinflussung der individuellen Wahrnehmung von Kosten und Nutzen staatlicher Aktivitäten umschreiben.

Obwohl allgemeine theoretische Maßstäbe dafür fehlen, unter welchen Bedingungen bei alternativen institutionellen Gestaltungsformen das Auftreten relativer Fiskalillusion erwartet werden kann, lassen sich doch einige Ansatzpunkte finden, nach denen bei Kredithilfen in höherem Maße Fiskalillusion erzeugt wird als bei der analytischen Referenzinstitution der Investitionszuschüsse. Dafür spricht vor allem die geringere relative Transparenz von Kredithilfen gegenüber Investitionszuschüssen. Außerdem werden bei Kredithilfen in der Vergabeperiode durch die verbreitete Verschiebung der Finanzierungskosten in die Zukunft die Opportunitätskosten der Subventionierung in Form eines Verzichts auf alternative Verwendungen gegebener Budgetmittel in stärkerem $\mathrm{Ma}$ verschleiert als bei Investitionszuschüssen ${ }^{3}$. Schließlich ist damit zu rechnen, daß die differentiellen Kosten öffentlicher Kredithilfen insbesondere im Hinblick auf die differentiellen Anreizwirkungen auf die Risikoübernahme regelmäßig kaum wahrgenommen werden, weil die Individuen gegebenen Subventionsausgaben unabhängig von der Subventionsform im wesentlichen äquivalente allokative Wirkungen zuschreiben dürften. D.h. Kredithilfen lassen im Vergleich zu Investitionszuschüssen Kostenillusion ${ }^{4}$ erwarten.

Die Konsequenzen der Fiskalillusion auf die Subventionsausgaben sollen mit Hilfe des Medianwählermodells illustriert werden ${ }^{5}$. Dabei wird angenommen, daß durch die Subventionierung externe Nutzen der Konsumenten beim Einsatz des Faktors Kapital internalisiert werden sollen ${ }^{6}$. Die Nachfrage des Medianwählers nach externen Nutzen hängt nun von seiner Grenzbewertung des Kapitaleinsatzes der Produzenten und dem individuellen Grenzpreis ab. Der Grenzpreis des Medianwählers wird durch die Verteilungsregel bestimmt, nach der die Steuern zur Finanzierung der Subventionsausgaben auf die einzelnen Steuerzahler verteilt werden. Die Höhe der Subventionsausgaben

Vgl. BUCHANAN/WAGNER (1977), S.128 ff.

Vgl. BUCHANAN (1967), S.126.

3 Vgl. IPPOLITO (1984), S.88 in bezug auf Kreditgewährleistungen. Im übrigen lassen sich hier dieselben Argumente anführen, die auch für die Existenz einer Staatsschuldillusion sprechen. Vgl. BUCHANAN (1967), S.132 f.; BUCHANAN/WAGNER (1977), S.134 ff.

4 Zum Begriff der Kostenillusion vgl. WINDISCH (1980), S.615.

5 Vgl. WAGNER (1973), S.231 f.

6 Diese Art externer Effekte wird als Produzenten-Konsumenten-Externalität bezeichnet. Vgl. BOADWAY/WILDASIN (1984), S.111 ff. 
ergibt sich dabei als Produkt des marginalen Subventionssatzes mit der Kapitalmenge. Weiterhin soll angenommen werden, daß der wahngenommene Grenzpreis für die Nachfrage nach externen Nutzen maßgeblich ist.

Unterstellt man nun eine Gleichverteilung der Steuern zur Finanzierung der Subventionsausgaben, so ist der wahrgenommene Grenzpreis der externen Nutzen bei einem identischen tatsächlichen marginalen Subventionssatz im Fall von Kredithilfen geringer als bei Investitionszuschüssen. Dementsprechend wird der Medianwähler bei Kredithilfen die Subventionierung einer höheren Kapitalmenge nachfragen als bei Investitionszuschüssen. Folglich sind auch die Subventionsausgaben bei Kredithilfen höher ${ }^{1}$. Der Medianwähler erleidet bei Kredithilfen gegenüber Investitionszuschüssen wegen der relativen Falschwahrnehmung des Grenzpreises der Subventionierung einen individuellen Wohlfahrtsverlust. Daraus folgt jedoch nicht generell, daß sich auch ein gesamtwirtschaftlicher Wohlfahrtsverlust ergeben mu $B^{2}$. Falls nämlich die Nachfrage des Medianwählers nach subventioniertem Kapital bei Investitionszuschüssen aus allokativer Sicht zu gering ist, kann die Nachfrageausweitung bei Kredithilfen allokativ wünschenswert oder unerwünscht sein. Ist die Nachfrage des Medianwählers dagegen bei Investitionszuschüssen bereits ineffizient hoch, so wird die Ineffizienz durch Kredithilfen in jedem Fall noch verstärkt ${ }^{3}$.

Da die Subventionsempfänger durch die Ausweitung der Subventionierung Nettovorteile erwarten können, werden sie durchzusetzen versuchen, daß Kredithilfen als Subventionsform gewählt werden, bevor über das Subventionsvolumen entschieden wird. Dagegen werden Verlierer bei öffentlichen Kredithilfen, insbesondere die Steuerzahler, verhindern wollen, daß Kredithilfen als Subventionsform bestimmt werden, bevor das Subventionsvolumen festgelegt ist, wenn sie ex ante erkennen, daß diese Subventionsform im laufenden politischen Prozeß Fiskalillusion erzeugt. Unter diesen Bedingungen kommt es auf den relativen politischen Einfluß der Gewinner und Verlierer öffentlicher Kredithilfen an, welche Subventionsform bei der Abstimmung über das Subventionsvolumen zugrundegelegt wird. Da die Gewinner bei Kredithilfen die damit verbundenen Vorteile vergleichsweise gut wahrnehmen werden, während die Kosten dieser Subventionsform relativ breit gestreut sein werden, kann angenommen werden, daß sich die Nachfrage nach Kredithilfen tendenziell durchsetzen wird. Dies gilt um so mehr, wenn die Verlierer auch ex ante nicht erkennen, daß Kredithilfen Fiskalillusion und damit individuelle Nachteile bewirken werden.

1 Vgl. WAGNER (1976), S.53; DiLORENZO (1982), S.245 f.

2 So aber WAGNER (1973), S.232.

3 Dieser Zusammenhang ergibt sich bei Anwendung des Medianwähler-Modells generell, sofern sich durch Veränderung der Restriktionen die vom Medianwähler präferierte Menge erhöht. Vgl. BOADWAY/WILDASIN (1984), S.160. 
Allerdings könnten sich alle Bürger auf Kredithilfen als Subventionsform trotz unterstellter Kenntnis ihrer illusionserzeugenden Wirkungen im laufenden politischen Proze $B$ einigen, wenn sie annehmen, daß bei Investitionszuschüssen ein ineffizient niedriges, bei Kredithilfen aufgrund optimaler Fiskalillusion ${ }^{1}$ dagegen ein effizientes Subventionsvolumen realisiert wird. Die Entscheidung zugunsten öffentlicher Kredithilfen ist dann mit sozialen Nettonutzen verbunden. Eine Einigung auf Kredithilfen setzt aber voraus, daß die bei gegebener Steuerverteilungsregel durch die Ausweitung des Subventionsvolumens Benachteiligten von den Gewinnern kompensiert werden. Unter diesen restriktiven Annahmen können Kredithilfen eine paretooptimale Subventionsform repräsentieren. Allerdings ist es kaum realistisch, daß dieser Fall eintritt, weil eine Kompensation der Verlierer regelmäßig nicht stattfinden wird und Informationen über das effiziente Subventionsvolumen üblicherweise nicht vorhanden sind.

Ein Problem der vorstehenden Modellüberlegungen besteht darin, daß das tatsächliche disponible Einkommen der Steuerzahler bei Subventionierung durch Kredithilfen ex post geringer ist als die Individuen erwarten. Um diesem Umstand Rechnung zu tragen, könnte man erwarten, daß die Subventionierung durch Kredithilfen die Individuen langfristig dazu zwingt, ihre Wahrnehmung der Kosten der Kredithilfen zu ändern. Nur wenn man von irrationalem Verhalten der Individuen ausgeht, wären sie in jeder Vergabeperiode bereit, den Einkommensverlust einfach zu akzeptieren, ohne ihn in ihrer Wahrnehmung zu berücksichtigen ${ }^{2}$. Hält man dagegen an der Annahme rationalen Verhaltens fest, so kann die Fiskalillusion bei Kredithilfen nur dann von Dauer sein, wenn die Individuen bei anderen Ausgabenarten einer gegenläufigen Illusion unterliegen, indem sie deren Preis in systematischer Weise überschätzen. Diese Ausgabenarten werden dann in geringerem Ausmaß als ohne Illusion nachgefragt. Bei einer im Zeitablauf konstanten Ausgabenstruktur kann folglich damit gerechnet werden, daß die Fiskalillusion bei Kredithilfen nur von Dauer sein wird, wenn sich sämtliche Illusionseffekte kompensieren ${ }^{3}$. Da diese Annahme indes kaum realistisch ist, kann davon ausgegangen werden, daß Kredithilfen dauerhaft Kostenillusionen erzeugen.

Zum Konzept optimaler Fiskalillusion vgl. WEST/WINER (1980).

Vgl. LOGAN (1986), S.1311.

3 Vgl. LOGAN (1986), S.1312. So ist kaum zu erwarten, daB der Wanderer in der Wüste, der jedesmal vom selben Ausgangspunkt startet, sich stets aufs Neue von der in derselben Richtung wahrgenommenen Fata Morgana täuschen läßt, es sei denn er verkennt aufgrund seines Allgemeinbefindens immer wieder, da $\mathrm{B}$ er umfassende Informationen über die zu wählende Richtung besitzt. 
d. Erzielung von Verteilungsvorteilen durch öffentliche Kredithilfen bei dynamischer Betrachtung

Bislang wurde implizit unterstellt, daß die Subventionierung eines Empfängers einen einmaligen Vorgang darstellt. Diese Annahme soll jetzt gelockert werden. Damit stellt sich die Frage, ob die Entscheidung über die Subventionsform Konsequenzen für die Chancen der Subventionsempfänger auf eine erneute Subventionierung hat.

Ein wesentliches Merkmal öffentlicher Darlehen und Gewährleistungen besteht darin, daß die Höhe der Netto-Subventionsausgaben im Einzelfall vom Erfolg der damit geförderten Aktivitäten abhängt. Daher handelt es sich aus Sicht des Staates um riskante Subventionsformen. Wird nun ein Investor mit öffentlichen Darlehen oder Gewährleistungen subventioniert, so erhält er dadurch im Hinblick auf künftige Subventionswünsche einen nicht zu unterschätzenden Vorteil: die möglichen Einnahmenausfälle bzw. Ausgaben des Staates dienen dem Subventionsempfänger als Faustpfand zur "Erzwingung" künftiger Subventionsleistungen. Dies soll mit folgenden Überlegungen verdeutlicht werden.

Es wird angenommen, daß einem Unternehmen als "Gegenleistung" für die Schaffung von Arbeitsplätzen eine unentgeltliche öffentliche Gewährleistung für Kreditverbindlichkeiten gewährt wird. Wird dieses Unternehmen zahlungsunfähig, so besteht für den Staat eine Alternative darin, einen Konkurs und damit den Verlust von Arbeitsplätzen hinzunehmen. In diesem Fall hätte der Staat Ausgaben zur Erfüllung der Gewährleistungsverbindlichkeiten zu tragen. Andererseits könnte der Staat zusätzliche Kredite für das Unternehmen verbürgen, um dessen momentane Zahlungsunfähigkeit zu überwinden. Damit bliebe für die Steuerzahler zumindest die vage Hoffnung, daß sich Subventionsausgaben auf Dauer vermeiden lassen.

Während die von einer Fortführung des Unternehmens begünstigten Gruppen unter Hinweis auf die drohenden Arbeitsplatzverluste starken politischen Druck zur erneuten Subventionierung ausüben werden, ist ein massiver Widerstand der Steuerzahler dagegen nicht zu erwarten. Denn sie werden tendenziell in erster Linie wahrnehmen, daß sich durch die zusätzliche Gewährleistungsübernahme zumindest kurzfristig staatliche Ausgaben vermeiden lassen. Die volkswirtschaftlichen Verluste einer erneuten Subventionierung, die regelmäßig darin bestehen, daß ineffiziente Unternehmen am Leben erhalten werden und damit eine effiziente Kapitalallokation beeinträchtigt wird, sind dagegen kaum wahrnehmbar. Wenn die Wahrscheinlichkeit einer Unternehmenssanierung optimistisch eingeschätzt wird, ist daher zu erwarten, daß es zu einer erneuten Subventionierung kommen wird. Dieses Spiel läßt sich theoretisch über mehrere Spielrunden hinweg fortsetzen. Wird jedoch 
nach einigen Perioden festgestellt, da $\mathrm{B}$ das Unternehmen endgültig nicht saniert werden kann, hat die wiederholte Subventionierung außerordentlich hohe Subventionsausgaben zur Folge, die sich dann nicht mehr vermeiden lassen.

Würde die ursprüngliche Subventionierung hingegen in Form von direkten Zuschüssen erfolgen, wären im Falle eines Konkurses keine zusätzlichen Ausgaben fällig. Somit wird der politische Widerstand der Steuerzahler gegen eine erneute Subventionierung unter den genannten Bedingungen größer sein. Dementsprechend wird ihre Durchsetzung bei gegebenem politischen Druck der Koalition der Begünstigten bei einer ürsprünglichen Subventionierung in Form von Zuschüssen auf größere Schwierigkeiten stoßen. D.h. aber, daß sich der erwartete Ertrag eines Einsatzes von Rent-seeking-Ressourcen erhöht, wenn die Subventionierung ursprünglich durch Darlehen oder Gewährleistungen erfolgt ist.

Damit kann angenommen werden, daß die Subventionsnachfrager, die selbst damit rechnen, in mehreren Perioden auf staatliche Subventionen "angewiesen" zu sein, in der Ausgangsperiode tendenziell Darlehen oder Gewährleistungen nachfragen werden, um damit die Durchsetzung von Folgesubventionen zu erleichtern.

\section{Angebotsseitige Erklărungsansătze für öffentliche Kredithilfen}

Bei den nachfrageseitigen Erklärungsansätzen öffentlicher Kredithilfen wurde implizit unterstellt, daß die Entscheidungen über die Subventionsform durch das Verhalten der Nachfrager nach öffentlichen Leistungen determiniert werden. Da die unmittelbare Entscheidung über Subventionsformen jedoch von den staatlichen Akteuren getroffen wird, müssen die Bedingungen für die Umsetzung der Nachfrage in ein entsprechendes staatliches Angebot analysiert werden. Grundlegend hierfür ist die aus Gründen methodologischer Konsistenz getroffene Annahme, daß die staatlichen Akteure wie andere Individuen eigene Interessen verfolgen ${ }^{1}$. "Es werden die gleichen Menschen in privaten und öffentlichen Entscheidungssituationen betrachtet, wobei der Unterschied nicht in den Motivationen, sondern in den Beschränkungen liegt, unter denen individuelle Ziele verfolgt werden."2 Entscheidend ist also, inwieweit die geltenden Restriktionen die staatlichen Akteure an die Nachfrage der Bürger nach der jeweiligen Subventionsform binden bzw. ob die staatlichen Akteure bei der Wahl der Subventionsform einen Handlungsspielraum zur Verfolgung eigener Interessen jenseits der Interessen der Nachfrager besitzen ${ }^{3}$. Die staatlichen

1 Vgl. BRENNAN/BUCHANAN (1980/1988), S.6; BRENNAN/BUCHANAN (1981a), S.156 f.; FOLKERS (1984), S.501; BUCHANAN (1987), S.587.

2 Vgl. FOLKERS (1986d), S.5.

3 Vgl. FOLKERS (1986d), S.17. 
Akteure lassen sich vereinfachend in zwei Gruppen einteilen, die regierenden Politiker und die Bürokraten, die im folgenden getrennt betrachtet werden.

\section{a. Anreize der Politiker zur Vergabe von Kredithilfen}

Politiker werden im Rahmen der ökonomischen Theorie der Politik im allgemeinen als Individuen modelliert, welche ihren Nutzen dadurch zu maximieren suchen, daß sie die zum Wahlgewinn erforderlichen Stimmen anstreben ${ }^{1}$. In diesem Modellrahmen werden die regierenden Politiker aus ihrem Wiederwahlinteresse heraus ihre Entscheidungen so treffen $^{2}$, daß die Differenz zwischen Stimmengewinnen und -verlusten maximiert wird ${ }^{3}$. Läßt sich durch bestimmte politische Maßnahmen ein Stimmenzuwachs erzielen, realisieren die Politiker einen politischen Nettoertrag, der sich für sie in einem Nutzenzuwachs auswirkt. Es soll nun untersucht werden, unter welchen Bedingungen die Vergabe von Kredithilfen dieser Zielsetzung dienen kann.

aa. Kredithilfen als ausgabenminimale Subventionsform

Zunächst sei davon ausgegangen, daß Kredithilfen unter bestimmten Bedingungen ausgabenminimale Subventionsformen zur Erreichung eines gegebenen Subventionszwecks repräsentieren. Weiterhin wird unterstellt, da $\beta$ die Subventionsausgaben unabhängig von der Subventionsform in der Vergabeperiode ausgabenwirksam und die sonstigen Staatsausgaben konstant seien. Außerdem wird angenommen, daß sämtliche Staatsausgaben durch Steuereinnahmen gedeckt sein müssen. Die Bildung von Einnahmenüberschüssen sei verboten. Außerdem wird unterstellt, daß der Kreis der Subventionsempfänger von der Subventionsform unabhängig ist.

Wie gezeigt, bringt die ausgabenminimale Subventionsform den Steuerzahlern Vorteile in Gestalt einer geringeren Steuerlast, während die Subventionsempfänger gegenüber einer ausgabenintensiveren Subventionsform relative Verteilungsnachteile erleiden. Daher können die Politiker bei der Entscheidung für Kredithilfen von den Steuerzahlern Stimmengewinne erwarten, während von seiten der Subventionsempfänger Stimmenverluste drohen. Ist der Kreis der Subventionsempfänger relativ klein, führt ein Abweichen von der

1 Vgl. grundlegend dazu DOWNS (1957/1968).

2 Dabei soll hier unberücksichtigt bleiben, daß die regierenden Politiker Anreize besitzen, bei ihren Entscheidungen die Interessen der jeweiligen Opposition zu berücksichtigen, um sich selbst gegen die Risiken eines Machtverlusts abzusichern. Vgl. dazu SHEPSLE/WEINGAST (1981), S.109; FOLKERS (1990), S.12.

Vgl. PELTZMAN (1976), S.214 ff. 
ausgabenminimalen Subventionsform zu vergleichsweise geringen Mehrausgaben, deren Kosten auf die Gesamtheit der Steuerzahler verteilt und damit breit gestreut werden ${ }^{1}$. Die Subventionsempfänger werden die zusätzlichen Vorteile der ausgabenintensiveren Subventionsform wahrnehmen, während die zusätzliche Steuerbelastung für den einzelnen Steuerzahler kaum spürbar ist. Daher kann erwartet werden, daß die Politiker einen Netto-Stimmenzuwachs und damit individuelle Vorteile erzielen können, wenn sie statt Kredithilfen eine ausgabenintensivere Subventionsform anbieten. Umgekehrt ist ein Angebot an Kredithilfen um so eher zu erwarten, je größer der Kreis der Subventionsempfänger gezogen ist, weil dann die zusätzliche Steuerlast bei der Entscheidung für die ausgabenintensivere Subventionsform um so mehr wahrnehmbar sein wird.

Läßt man eine Variation der sonstigen Staatsausgaben zu, kann die ausgabenintensivere Subventionsform sogar dann gewählt werden, wenn der marginale Stimmenzuwachs für die Politiker daraus geringer ist als der marginale Stimmenverlust infolge höherer staatlicher Steuereinnahmen. Dies gilt dann, wenn der Stimmengewinn der ausgabenintensiveren Subventionsform höher ist als der Stimmenverlust bei einer Reduzierung der staatlichen Ausgaben in anderen Bereichen ${ }^{2}$. D.h. die Politiker besitzen bei der Entscheidung über die Subventionsform mit der Möglichkeit der Erhöhung von Steuereinnahmen und der Senkung sonstiger Staatsausgaben regelmäßig zwei Handlungsparameter. Aus der Interessenlage der Politiker sind ausgabenminimierende Kredithilfen daher zumindest nicht generell erklärbar.

Allerdings wird die Entscheidung für die ausgabenintensivere oder ausgabenminimale Subventionsform bei gegebenem Subventionszweck im Zeitablauf nicht in jedem Fall konstant bleiben. Nimmt man beispielsweise an, daß die Steuerzahler bei ungünstiger wirtschaftlicher Entwicklung die Kosten gegebener Steuerzahlungen in höherem Maß wahrnehmen, werden die marginalen Stimmenverluste bei Realisierung der ausgabenintensiveren Subventionsform zunehmen. Dadurch erhöht sich die Wahrscheinlichkeit, daß die Politiker eine in früheren Perioden getroffene Entscheidung für die ausgabenintensivere Subventionsform revidieren und zur Erreichung des gegebenen Subventionszwecks Kredit-

1 Vgl. FOLKERS (1983b), S.200.

2 Dieses Ergebnis ist durchaus plausibel, wenn die Ausgaben in sonstigen Bereichen für die Bereitstellung öffentlicher Güter vorgesehen sind. Dies trifft insbesondere dann zu, wenn die durch die ausgabenintensivere Subventionsform Begünstigten die daraus resultierenden Vorteile vollständig wahrnehmen, während die Bürger den entgangenen Nutzen aus der verringerten Bereitstellung öffentlicher Güter unterschätzen. Zur Nutzenillusion bei der Bereitstellung öffentlicher Güter vgl. DOWNS (1965). 
hilfen als ausgabenminimierende Subventionsform anbieten ${ }^{1}$. Dementsprechend läßt sich bisweilen beobachten, daß in Zeiten erhöhten politischen Drucks zur sparsamen Haushaltsführung insbesondere Kreditgewährleistungen in verstärktem $\mathrm{Maß}$ vergeben werden ${ }^{2}$. Ein Angebot an Kredithilfen als ausgabenminimale Subventionsform durch die Politiker ist also um so eher zu erwarten, je höher die politischen Opportunitätskosten ausgabenintensiverer Subventionsformen sind.

\section{bb. Begünstigung spezieller Interessengruppen bei gegebenen Subventionsausgaben}

Sind die Subventionsausgaben konstant und bei allen Subventionsformen in der Vergabeperiode vom Staat zu finanzieren, so werden die Politiker Kredithilfen anbieten, wenn sie dadurch im Vergleich zu alternativen Subventionsformen marginale Netto-Stimmengewinne erwarten können.

Vergleicht man Kredithilfen mit Steuervergünstigungen, so werden die Politiker bei Kredithilfen tendenziell eher Netto-Stimmengewinne erzielen können, weil sie von den dadurch Begünstigten eine starke Unterstützung erfahren, während die Nachteile der Gewinner von Steuervergünstigungen relativ breit gestreut und damit weniger wahrnehmbar sein werden ${ }^{3}$. Denn die Gewährung von Steuervergünstigungen führt zu einem Rechtsanspruch eines nur allgemein und abstrakt abgrenzbaren Personenkreises. Demgegenüber werden Kredithilfen meist ohne Rechtsanspruch der Empfänger gewährt. Dadurch wird es bei Kredithilfen eher möglich sein, gegebene Subventionsausgaben auf einen geringeren Personenkreis zu konzentrieren als bei Steuervergünstigungen.

Es wird nun unterstellt, daß der Kreis der Subventionsempfänger, ihre durchschnittliche Begünstigung und die Wirkung auf formal nicht beteiligte Dritte bei allen Subventionsformen identisch ist. Werden durch Kredithilfen im Gegensatz zu alternativen Subventionsformen riskantere Projekte privilegiert, so werden sich für die Politiker um so eher Netto-Stimmengewinne ergeben, wenn die Gruppe der Subventionsempfänger mit überdurchschnittlichem Kreditrisiko relativ klein ist und einen hohen Organisationsgrad aufweist. Denn in diesem Fall werden die Kosten der Kredithilfen für die Subventionsemp-

1 So wurde Anfang der achtziger Jahre die Ausbildungsförderung nach dem BAFöG im Zuge der Bemühungen zu einer Haushaltskonsolidierung von einer gemischten Zuschuß- und Darlehensförderung auf eine reine Darlehensförderung umgestellt.

2 So führt die saarländische Landesregierung in ihrem MITTELSTANDSBERICHT (1984), S.44 aus: "In einer Zeit knapper öffentlicher Mittel, die den Staat zwingt, direkte Subventionen einzuschränken, kommt dem Instrument der Staatsbürgschaft eine wachsende Bedeutung zu." Siehe auch DICKERTMANN (1983), S.366.

Vgl. FOLKERS (1983b), S.200. 
fänger mit unterdurchschnittlichem Kreditrisiko relativ breit gestreut und damit kaum wahrnehmbar sein.

\section{cc. Ausdehnung von Kredithilfen aufgrund der Falschwahrnehmung ihrer Kosten}

Die Politiker werden Kredithilfen weiterhin anbieten, wenn die wahrgenommenen Vorteile der Subventionierung für die Begünstigten verglichen mit anderen Subventionsformen gleich groß, die wahrgenommenen Nachteile für die Benachteiligten dagegen geringer ausfallen, da sich auf diese Weise ihre Wiederwahlchancen erhöhen'1.

Es soll nun angenommen werden, da $B$ sich Kredithilfen von alternativen Subventionsformen, insbesondere Investitionszuschüssen, allein dadurch unterscheiden, daß sie erst in späteren Perioden ausgabenwirksam werden, während Investitionszuschüsse bereits in der Vergabeperiode zu Ausgaben führen. Dabei sollen die den Politikern bekannten abdiskontierten Netto-Subventionsausgaben ${ }^{2}$ bei Kredithilfen mit den Subventionsausgaben bei Investitonszuschüssen übereinstimmen ${ }^{3}$. Besitzen die als identisch angenommenen Steuerzahler in einer Welt ohne Informationskosten vollkommene Voraussicht und sind sie zwischen verschiedenen Zeitpunkten der Steuerzahlung indifferent, so werden die Politiker zwischen den alternativen Subventionsformen ebenfalls indifferent sein.

Geht man dagegen realitätsnäher davon aus, daß Informationen Kosten verursachen, so werden die Steuerzahler die künftigen Steuerbelastungen bei Kredithilfen in der Vergabeperiode aufgrund rationaler Ignoranz nur unvollkommen wahrnehmen. Daher werden sie Kredithilfen für eine billigere Subventionsform halten als alternative Subventionsformen. Folglich werden die marginalen Stimmenverluste der Politiker von seiten der Steuerzahler bei einer Subventionierung durch Kredithilfen in der Gegenwart geringer sein als bei einer Subventionierung durch Investitionszuschüsse. D.h. der in marginalen BruttoStimmenverlusten ausgedrückte relative Preis von Kredithilfen sinkt. Dementsprechend werden die Politiker unter normalen Bedingungen bei gegebenem Subventionsbudget zusätzliche Kredithilfen anbieten. Darüber hinaus läßt sich auf diese Weise das Subventionsbudget steigern, weil durch ein erhöhtes Angebot an Kredithilfen der relative Preis von Subventionen gegenüber anderen Ausgabenkategorien sinkt.

1 Vgl. BENNETT/DILORENZO (1983a), S.312.

2 Zur Vereinfachung wird angenommen, daß bei der Vergabe von Kredithilfen nur unsystematische Risiken auftreten, die aufgrund von Risk-pooling verschwinden.

3 Dabei müssen die in künftigen Perioden anfallenden Subventionsausgaben mit dem risikolosen Marktzinssatz abdiskontiert werden, da der Staat seine in der Vergabeperiode zugesagten Subventionsleistungen mit Sicherheit erfüllen muß. 
Die Politiker besitzen außerdem einen Anreiz, die Informationskosten in bezug auf die Kosten von Kredithilfen zusătzlich zu erhöhen, indem sie beispielsweise über Kredithilfen und die damit verbundenen Subventionsausgaben vergleichsweise unvollständig Bericht erstatten. Ansatzpunkte zur Informationsverschleierung bei Kredithilfen bestehen in der behaupteten mangelnden Quantifizierbarkeit der Subventionsausgaben insbesondere bei Kreditgewährleistungen ${ }^{1}$, in der Hervorhebung der Zins - und Tilgungseinnahmen bei offenlichen Darlehen und der Ausgrenzung bestimmter Kredithilfen vom Subventionsbegriff. Damit kann der relative Preis von Kredithilfen für die Politiker weiter verringert werden, die damit zusätzliche Stimmengewinne realisieren können.

Allerdings muß berücksichtigt werden, daß Kredithilfen in künftigen Perioden mit Ausgaben verbunden sind. D.h. die Politiker müssen in künftigen Perioden im Fall von Kredithilfen ceteris paribus höhere Steuereinnahmen realisieren. Wird auf diese Weise die Wahrnehmung der Finanzierungskosten der Subventionierung bei Kredithilfen nachgeholt, so haben die Politiker folglich in Zukunft bei Kredithilfen relative Stimmenverluste zu erwarten. Insofern werden die Politiker diese künftigen Stimmenverluste in ihrem Kalkül berücksichtigen, falls ihre Zeitpräferenzrate kleiner unendlich ist.

Dennoch sprechen zwei Argumente dafür, daß die Politiker bis zu einem gewissen Ausmaß Kredithilfen präferieren. Zum einen verteilen sich die Netto-Subventionsausgaben bei Kredithilfen regelmäßig über mehrere Perioden. Damit werden die zur Finanzierung der Subventionsausgaben erforderlichen Belastungen zeitlich relativ weit gestreut. Die Finanzierungskosten der Subventionierung werden folglich nicht nur in der Gegenwart, sondern auch über alle Zeitperioden betrachtet bei Kredithilfen in geringerem Ausmaß wahrgenommen werden als bei Investitionszuschüssen. Das andere Argument bezieht sich darauf, daß die Politiker eine hohe Zeitpräferenzrate besitzen und damit die für sie in der Zukunft resultierenden politischen Kosten relativ stark abdiskontieren ${ }^{2}$. Denn sie kalkulieren die Möglichkeit eines Machtverlusts in späteren Perioden ein ${ }^{3}$ und können damit rechnen, die politischen Kosten der in die Zukunft verschobenen Finanzierungskosten auf eventuelle Amtsnachfolger zu überwälzen.

Ist der Kalkül der Politiker dagegen darauf gerichtet, bei gegebenen politischen Kosten die Nutzen aufgrund von Subventionsmaßnahmen zu maximieren, so ist ebenso mit einer Präferenz der Politiker für Kredithilfen zu rechnen. Da bei dieser Subventionsform aufgrund von rationaler Ignoranz und Fiskalillusion die Kosten der Subventionierung in

1 Vgl. SUBVENTIONSBERICHT (1985), S.296.

2 Vgl. GWARTNEY/WAGNER (1988), S.12 ff. Siehe auch PENNER/SILBER (1972), S.662.

3 Vgl. FOLKERS (1990), S.12. 
geringerem Umfang als beispielsweise bei Investitionszuschüssen wahrgenommen werden, sind bei gegebenen Stimmenverlusten durch eine Subventionierung höhere Subventionsausgaben möglich. Unterstellt man, daß die durch die Subventionierung Begünstigten unabhängig von der Subventionsform ihre Subventionsvorteile in vollem Umfang wahrnehmen, läßt das Angebot von Kredithilfen damit ceteris paribus höhere Brutto- und Netto-Stimmengewinne erwarten.

\section{dd. Umgehung fiskalischer Restriktionen}

Reale demokratische Staatsverfassungen sind dadurch gekennzeichnet, daß sie den Politikern eine Vielzahl rechtlicher Restriktionen auferlegen, die deren Handlungsspielraum begrenzen. Solche Restriktionen finden ihre logische Grundlage darin, daß der politische Prozeß ohne solche Restriktionen Unvollkommenheiten aufweist, die für die Politiker einen Anreiz schaffen, ihre individuellen Vorteile zu steigern, auch wenn dies auf Kosten der Allgemeinheit geschieht ${ }^{1}$. Eine der wesentlichen Unvollkommenheiten besteht darin, daß eine vollständige Kontrolle der Politiker durch Wahlen allein schon deshalb ausgeschlossen ist, weil Wahlen stets nur in größeren Zeitabständen stattfinden. Daher soll im folgenden angenommen werden, daß sich die Politiker in gewissem Umfang gegebenen konstitutionellen Regeln gegenübersehen. Die Betrachtung beschränkt sich dabei auf fiskalische Restriktionen, also auf Regeln, die in der Finanzverfassung enthalten sind.

Nimmt man an, daß die Politiker versuchen werden, ihren eigenen Nutzen zu maximieren, werden sie bereit sein, unter Beachtung der Buchstaben fiskalischer Restriktio$\mathrm{nen}^{2}$, diese zu umgehen, wenn sie dadurch ihren Nutzen steigern können ${ }^{3}$. Andererseits werden fiskalische Restriktionen auch in ihrem materiellen Gehalt beachtet, wenn dies den Zielen der Politiker förderlich ist ${ }^{4}$. Stiftet eine Umgehung fiskalischer Restriktionen durch die Vergabe von Kredithilfen den Politikern Nutzen, so werden sie diese Subventionsform auch anbieten, wenn die durch die Subventionierung Begünstigten zwischen allen Subventionsformen indifferent sind. Andererseits nimmt der Anreiz der Politiker zur

$1 \mathrm{Zu}$ den analytischen Grundlagen konstitutioneller Regeln ausführlich vgl. BRENNAN/BUCHANAN (1980/1988),S.3 ff, siehe dazu auch FOLKERS (1984), S.502 und Abschnitt D.II.1.

2 So basiert letztlich die gesamte konstitutionelle Wirtschaftstheorie auf der durch empirische Erfahrungen gestützten Annahme, da $B$ konstitutionelle Beschränkungen von den staatlichen Akteuren beachtet werden. Darüber hinaus sprechen empirische Erfahrungen dafür, da $B$ die Wähler die offenkundige Mißachtung von Regeln durch Politiker mit Stimmentzug sanktionieren, so daß es rational ist, wenn die Politiker solche Regeln zumindest formal beachten. Vgl. BENNETT/DILORENZO (1983b), S.33.

3 In diesem Sinne bereits MILL (1861/1977), S.505.

4 Vgl. FOLKERS (1984), S.501. 
Umgehung fiskalischer Restriktionen durch Kredithilfen mit zunehmendem Widerstand der Nachfrager öffentlicher Leistungen gegen diese Subventionsform ab.

Es sollen nun verschiedene fiskalische Restriktionen ${ }^{1}$ darauf untersucht werden, unter welchen Bedingungen sie gegen einen Einsatz von Kredithilfen als Umgehungsstrategie anfällig sind.

aaa. Umgehung des Gebots eines materiellen Haushaltsausgleichs

Zunächst wird unterstellt, daß die Finanzverfassung einen materiellen Budgetausgleich vorschreibt, wonach der Staat zur Deckung seiner Ausgaben nur Steuereinnahmen einsetzen darf, während Einnahmen aufgrund öffentlicher Verschuldung oder von Geldschöpfung nicht zugelassen sind ${ }^{2}$. Unter diesen Bedingungen werden die Politiker die Subventionsausgaben so weit ausdehnen, bis die politischen Grenzerträge aus zusätzlichen Subventionsausgaben mit den politischen Grenzkosten aufgrund zusätzlicher Steuereinnahmen oder marginaler Ausgabenkürzungen in anderen Bereichen übereinstimmen. Unterstellt man, daß bei staatlicher Kreditaufnahme die Opportunitätskosten der Staatsausgaben unterschätzt werden, so wird das staatliche Budget höher sein als bei einem staatlichen Kreditaufnahmeverbot ${ }^{3}$. Wird die Budgetstruktur von den Politikern so bestimmt, daß der politische Grenznutzen der marginalen Ausgaben der verschiedenen Verwendungsrichtungen jeweils gleich hoch ist, so wird durch die Budgetausgleichsvorschrift indirekt auch der Umfang der Subventionsausgaben beschränkt.

Obwohl zusätzliche Subventionsmaßnahmen positive politische Brutto-Grenzerträge versprechen, werden sie von den Politikern nur dann angeboten, wenn sich ihre politischen Grenzkosten gegenüber dem Fall zusätzlicher Steuereinnahmen senken lassen. Da bei Kredithilfen eine versteckte Verschuldung durch Verschiebung der Subventionsausgaben in die Zukunft möglich ist ${ }^{4}$, lassen sich in der Gegenwart dadurch zusätzliche Subventionsmaßnahmen durchführen, ohne daß bei gegebenen Einnahmen und Ausgaben das staatliche Kreditaufnahmeverbot formal verletzt wird. Materiell entspricht die Vergabe von Kredithilfen bei gegebenem Gegenwartswert der (Netto-) Subventionsausgaben jedoch genau einer verbotenen kreditfinanzierten Ausweitung der Subventionsausgaben entsprechender

$1 \mathrm{Zu}$ den verschiedenen Arten fiskalischer Begrenzungen vgl. BRENNAN/BUCHANAN (1980/1988), S.252 ff.; FOLKERS (1983a), S.27 ff.; FOLKERS (1984), S.503 f.; FOLKERS (1986b).

2 Zum Konzept und den Implikationen eines materiellen Haushaltsausgleichs vgl. ausführlich BAUM (1982). Zur entsprechenden Diskussion in den USA vgl. FOLKERS (1986a).

3 Vgl. BUCHANAN/WAGNER (1977); TOLLISON/WAGNER (1986), S.384 f.

4 Vgl. RICHTER (1970), S.54 ff.; KRAJEWSKI (1975), S.49. 
Höhe. So geht der Staat jeweils Verbindlichkeiten ein, deren Gegenwarts- bzw. Endwert in beiden Fällen gleich hoch ist. Sofern die Vorschrift des materiellen Haushaltsausgleichs lediglich Kreditverbindlichkeiten verbietet, können die Politiker ohne Rechtsverstoß sonstige Verbindlichkeiten eingehen, die erst in späteren Perioden zu Ausgaben führen. Somit kann durch die Vergabe von Kredithilfen die Haushaltsausgleichsvorschrift umgangen werden.

Diese Umgehungsstrategie kann auch so eingesetzt werden, daß sie nicht nur Implikationen für das Ausmaß der Subventionierung, sondern darüber hinaus für sämtliche Staatsausgaben besitzt. Werden im Grenzfall alle sofort ausgabenwirksamen Subventionsmaßnahmen durch die Vergabe von Kredithilfen substituiert, so können die Staatsausgaben in anderen Bereichen ausgedehnt werden. Würden nämlich die Steuereinnahmen auf die Höhe der sonstigen Staatsausgaben reduziert, so wären die politischen Grenzerträge konstanter staatlicher Ausgaben größer als ihre Grenzkosten. Daher können sich die Politiker durch eine Ausweitung der Staatsausgaben zusätzliche politische Nettoerträge sichern.

Allerdings ist nicht zu erwarten, daß sämtliche Subventionsmaßnahmen in Form von Kredithilfen erfolgen. Denn wenn die staatlichen Kredithilfeaktivitäten eine bestimmte Grenze überschreiten, werden die Bürger vermutlich erkennen, daß damit die Budgetausgleichsvorschrift umgangen wird. Außerdem werden die Verlierer der Verschiebung der Subventionsausgaben ihre Opposition dagegen so weit verstärken, daß die Politiker Stimmenverluste zu befürchten haben. Zum anderen werden rational handelnde Politiker, die über mehrere Zeitperioden im Amt bleiben wollen, die Gefahr sehen, daß sich bei einer Erhöhung der Staatsausgaben und einer zeitlichen Verschiebung der Subventionsausgaben der staatliche Ausgabenspielraum in Zukunft verringern kann'1. Dadurch kann in Zukunft die für die Politiker wünschenswerte Allokation der Haushaltsmittel so stark beeinträchtigt werden, daß sie zumindest dann von einer ausschließlichen Subventionierung durch Kredithilfen absehen, wenn ihre Zeitpräferenzrate kleiner unendlich ist.

bbb. Umgehung des Gebots zur Subventionierung mit der ausgabenminimalen Subventionsform

Eine andere Regel der Finanzverfassung möge vorschreiben, da $B$ jeder Subventionszweck nur mit der ausgabenminimalen Subventionsform gefördert werden darf. Soll die

1 Grundlegend zur entsprechenden Problematik bei der Staatsverschuldung vgl. DOMAR (1944). Siehe auch MÜCKI (1983). 
Durchführung liquiditätsbeschränkter Investitionen ermöglicht werden, ist die Gewährung von öffentlichen Darlehen mit geringeren Ausgaben verbunden als eine Zuschußgewährung. Dementsprechend muß der Staat aufgrund der Finanzverfassung in diesem Fall Kredithilfen gewähren, wenn sie ex ante als ausgabenminimale Subventionsform identifiziert werden können. D.h. durch diese Vorschrift wird verhindert, daß sich die Subventionsempfänger Verteilungsvorteile aneignen können, die zur Induzierung der erwünschten Verhaltensreaktionen, also der Durchführung der geförderten Aktivitäten, nicht erforderlich sind.

Nimmt man an, daß eine Zuschußgewährung den Politikern ohne fiskalische Beschränkung einen höheren Nettoertrag verspricht als die Gewährung von Darlehen, so haben die Politiker einen Anreiz, den Subventionsempfängern nachträglich die entsprechenden Verteilungsvorteile zukommen zu lassen. Dies läßt sich einfach erreichen, wenn der Staat die Möglichkeit besitzt, den Darlehensempfängern in späteren Perioden die mit der Darlehensgewährung verbundenen Schulden zu erlassen. Da ein Schuldenerlaß keine Ausgaben verursacht, werden seine Kosten für die Politiker um so geringer sein, je weniger die Steuerzahler den Entgang künftiger Kredithilfeeinnahmen wahrnehmen. Dabei können die Politiker ihren Nettoertrag noch erhöhen, wenn es ihnen gelingt, den Schuldenerlaß als Akt der sozialen Gerechtigkeit oder Maßnahme zur Erhöhung des Gemeinwohls zu rechtfertigen. Auf diese Weise läßt sich die Vorschrift zur Wahl der ausgabenminimalen Subventionsform umgehen.

ccc. Umgehung eines Verbots zur Bildung staatlichen Finanzvermögens

In realen Finanzverfassungen sind bisweilen Regeln enthalten, die es dem Staat verbieten, in einzelnen Haushaltsperioden Finanzvermögen zu marktlichen Konditionen aufgrund von Einnahmenüberschüssen zu akkumulieren ${ }^{1}$. Damit sollen die Politiker gezwungen werden, die Höhe der Steuereinnahmen auf die Höhe der in jeder Periode gewünschten Ausgaben für öffentliche Güter, sonstige öffentliche Leistungen und den Erwerb von Vermögensaktiva, die der Erfüllung öffentlicher Aufgaben dienen, zu begrenzen. Im folgenden soll unterstellt werden, daß sich die Politiker einem derartigen Verbot gegenübersehen.

Bei Beachtung dieses Verbots werden die Politiker die Staatsausgaben und Steuereinnahmen in jeder Periode derart festsetzen, daß die politischen Grenzerträge den

1 So dürfen die Gemeinden in der Bundesrepublik Deutschland Vermögensgegenstände nur erwerben, wenn sie der Erfüllung ihrer Aufgaben dienen; vgl. z.B. $\$ 91 \mathrm{Abs.1}$ GemO/BW. Siehe auch BRENNAN/BUCHANAN (1980/1988), S.127. 
politischen Grenzkosten entsprechen. Sind die politischen Grenzkosten der Steuereinnahmen in der Zukunft höher als in der Gegenwart, so wird das für die Politiker optimale Ausgabenniveau bei Beachtung der Restriktion in der Zukunft geringer sein als in der Gegenwart. Andererseits besitzen die Politiker einen Anreiz zur Erzielung von Einnahmenüberschüssen, wenn sie dadurch ihren Nutzen erhöhen können. Zur analytischen Vereinfachung sei unterstellt, daß der intertemporale Kalkül der Politiker nur zwei Perioden umfaßt. Ohne Restriktion würden die Politiker in der Gegenwart Einnahmenüberschüsse so weit ausdehnen und zu marktlichen Konditionen als staatliches Vermögen akkumulieren, bis das Verhältnis des Grenznutzens der Ausgaben in der Gegenwart und des mit der reinen Zeitpräferenzrate der Politiker gewichteten Grenznutzens der Ausgaben in der Zukunft dem intertemporalen Preisverhältnis entspricht ${ }^{1}$. D.h. die Ausgaben wären ohne die Restriktion in der Gegenwart geringer und in der Zukunft höher als mit der Restriktion. Dabei würde der Einnahmenüberschuß in der Gegenwart um so höher ausfallen, je kleiner die reine Zeitpräferenzrate der Politiker ist.

Da jedoch die Bildung von Einnahmenüberschüssen annahmegemäß verboten ist, werden die Politiker versuchen, in der Gegenwart solche Ausgaben zu tätigen, die sich als Ausgaben für öffentliche Leistungen deklarieren lassen, gleichzeitig aber in der Zukunft zu zusätzlichen Einnahmen führen. Solche versteckten Einnahmenüberschüsse lassen sich erzielen, wenn die Politiker eine Subventionierung in Form öffentlicher Darlehen durchführen und die Darlehenssumme zu Lasten anderer Ausgabearten über Steuereinnahmen finanzieren ${ }^{2}$. Damit kann der Staat eine Vermögensmasse bilden, die in der Zukunft liquidiert wird, so daß die Erlöse zur Finanzierung zusätzlicher Staatsausgaben in der Zukunft verwendet werden können. Folglich können die Politiker durch die Vergabe öffentlicher Darlehen die entsprechende fiskalische Restriktion umgehen. Da öffentliche Darlehen zinsverbilligt vergeben werden müssen, um gegebene Subventionszwecke zu erfüllen, ist der relative Preis der künftigen Ausgaben für die Politiker höher als bei einer marktlichen Anlage der Einnahmenüberschüsse. Folglich werden das Nutzenniveau der Politiker und die Zukunftsausgaben in geringerem Umfang erhöht als bei einer marktlichen Anlage der Einnahmenüberschüsse. Dies folgt unter der Annahme fallender politischer Grenznutzen von Staatsausgaben daraus, daß das Verhältnis des Grenznutzens der Ausgaben der Gegenwart und der Zukunft bei öffentlichen Darlehen im Optimum kleiner ist als bei einer marktlichen Anlage von Überschüssen.

1 Vgl. zu einem entsprechenden Ergebnis in bezug auf die intertemporalen Entscheidungen der Individuen BALTENSBERGER/MILDE (1987), S.88.

2 Insoweit überrascht es nicht, daß der Anteil der Darlehensausgaben des Bundes an seinen Gesamtausgaben in den fünfziger Jahren am höchsten war, wo in mehreren Haushaltsperioden Budgetüberschüsse realisiert wurden. 
ddd. Umgehung von Restriktionen für die maximale Subventionsintensität

Eine andere Form fiskalischer Restriktionen kann darauf abzielen, die Förderintensität von Investitionssubventionen auf einen bestimmten Anteil der Investitionssumme zu begrenzen, um allokative Verzerrungen und/oder unerwünschte Verteilungskonsequenzen zu limitieren ${ }^{1}$. Während die Einhaltung solcher Restriktionen bei sofort ausgabenwirksamen Subventionsformen vergleichsweise mühelos überprüft werden kann, ist insbesondere bei öffentlichen Darlehen und Kreditgewährleistungen die Ermittlung der periodischen und der abdiskontierten gesamten Netto-Subventionsausgaben weit schwieriger. Der Gegenwartswert der Netto-Subventionsausgaben muß jedoch bekannt sein, um ihn zur Investitionssumme in Relation setzen zu können und die tatsächliche Förderintensität zu errechnen.

Beispielsweise ergeben sich bei öffentlichen Darlehen die periodischen Netto-Subventionsausgaben je Krediteinheit aus der Differenz żwischen dem marktlichen Alternativzinssatz und dem Zinssatz des öffentlichen Darlehens. Die periodischen Leistungen müssen mit dem marktlichen Alternativzinssatz abdiskontiert werden. Erlaubt es die Restriktion, daß der marktliche Alternativzinssatz zu niedrig festgesetzt wird, so unterschreitet die ausgewiesene Förderintensität bei öffentlichen Darlehen und Kreditgewährleistungen die tatsächliche Förderintensität. Dies kann für öffentliche Darlehen an einem einfachen Beispiel gezeigt werden. Es wird angenommen, daß für eine Investition in Höhe von I ein zinsverbilligtes Darlehen $\mathbf{K}$ mit unendlicher Laufzeit gewährt wird, bei dem der tatsächliche Alternativzinssatz $r_{\mathfrak{t}}$, der zur Berechnung der Förderintensität veranschlagte Zinssatz dagegen $r_{f}$ beträgt, wobei $r_{t}>r_{f}>0$ gelten soll.

Der Zinssatz für das Darlehen betrage $\mathrm{i}<\mathrm{r}_{\mathrm{f}}$. Der tatsächliche Gegenwartswert der Zinsverbilligungsausgaben beträgt danach $\left(r_{t}-i\right) K / r_{t}$, während der veranschlagte Wert lediglich bei $\left(r_{f}-i\right) K / r_{f}$ liegt. D.h. der tatsächliche Wert liegt um $\left(i / r_{f}-i / r_{t}\right) K>0$ über dem veranschlagten Wert. Ist die Obergrenze der Förderintensität für andere Subventionsformen auf $\left(r_{f}-i\right) K / r_{f} I$ festgelegt, kann somit durch die Vergabe von Darlehen und Kreditgewährleistungen die Restriktion umgangen werden. Dazu wird es wiederum dann kommen, wenn die Politiker dadurch einen Stimmenzuwachs gegenüber der Einhaltung der Restriktion im Fall alternativer Subventionsformen realisieren können.

1 Beispiel hierfür sind die verschiedenen EG-Regelungen über die zulässige Förderintensität von Beihilfeprogrammen. 


\section{b. Anreize der Bürokraten zur Vergabe von Kredithilfen}

Ebenso wie die Politiker beeinflussen auch Bürokraten die Auswahl und Durchführung politischer Vorhaben unmittelbar. Ihre Rolle besteht darin, den Politikern Informationen über alternative politische Maßnahmen zu beschaffen und diese Maßnahmen selbst durchzuführen. Dabei werden die Bürokraten durch drohende Wahlniederlagen in weit geringerem Ausmaß beschränkt als Politiker, da ihre berufliche Stellung bei einem Regierungswechsel vergleichsweise wenig gefährdet ist ${ }^{1}$. Die Beziehungen der Bürokraten zu den Politikern werden in der modernen Bürokratietheorie durch eine Optionsfixierungsmacht der Bürokraten charakterisiert, die es erlaubt, die maximale Zahlungsbereitschaft der Politiker bei den Verhandlungen über die Mittelbereitstellung abzuschöpfen².

aa. Das Angebot von Kredithilfen als ausgabenminimale Subventionsform

Nach dem Bürokratiemodell von NISKANEN ${ }^{3}$ werden die Bürokraten als Individuen modelliert, welche die Höhe des von ihnen verwalteten Budgets zu maximieren suchen, da die entscheidenden persönlichen Handlungsmotive der Bürokraten, wie Einkommen, Macht und Prestige, mit der Budgethöhe positiv korreliert sind ${ }^{4}$. Unterstellt man wiederum, daß Kredithilfen unter bestimmten Bedingungen ausgabenminimale Subventionsformen repräsentieren, so werden die Bürokraten bei Gültigkeit der Budgetmaximierungshypothese alternative, ausgabenintensivere Subventionsformen präferieren, weil sich damit der Budgetumfang erhöhen läßt.

Allerdings kann sich dieses Ergebnis entscheidend ändern, wenn die Annahme über das Verhalten der Bürokraten modifiziert wird. So unterstellen MIGUE/BELANGER ${ }^{5}$, daß die Nutzenfunktion der Bürokraten prinzipiell zwei abhängige Variablen enthält: den Output und das sogenannte diskretionäre Budget. Als diskretionäres Budget wird dabei die Differenz zwischen dem zur Verfügung stehenden Gesamtbudget und den zur Produktion des Outputs erforderlichen minimalen Kosten bezeichnet. Das diskretionäre Budget kann von den Bürokraten für Ausgaben verwendet werden, die ihnen selbst einen Nutzen stiften.

Als Output der Bürokraten werden hier die durchschnittlichen Subventionsausgaben bei gegebener Zahl der Subventionsempfänger und als diskretionäres Budget die Differenz zwischen dem gesamten Subventionsbudget und den bei der ausgabenminimalen Subven-

1 Vgl. BRENNAN/BUCHANAN (1980/1988), S.29.

2 Vgl. NISKANEN (1971), S.24 ff.; siehe auch MIGUE/BELANGER (1974).

3 Vgl. NISKANEN (1971).

4 Vgl. dazu den Überblick bei ROPPEL (1979), S.86 ff.

5 Vgl. MIGUE/BELANGER (1974). 
tionsform anfallenden Subventionsausgaben interpretiert. Ziehen die Bürokraten aus dem Output keinen Nutzen, so werden sie, anders als im Niskanen-Modell, die ausgabenminimale Subventionsform wählen, da sie dann ihr diskretionäres Budget maximieren können. Sind sie dagegen lediglich am Output interessiert, so werden die Bürokraten ebenfalls die ausgabenmaximale Subventionsform wählen ${ }^{1}$. Allerdings dürfte die Vorstellung kaum der Realität entsprechen, daß die Bürokraten von den Politikern ein Subventionsbudget erhalten, das für andere Zwecke als für Subventionsausgaben verwendet werden kann, da eine solche Zweckentfremdung der Haushaltsmittel vergleichsweise einfach zu entdecken wäre ${ }^{2}$.

Darüber hinaus ist aber auch das mit Hilfe des Niskanen-Modells gefundene Ergebnis nicht zwingend. Insbesondere wenn der Wahlmechanismus die Politiker zumindest zu einer partiellen Beachtung der Wählerwünsche nötigt, um sich Wiederwahlchancen zu sichern $^{3}$, werden sie die Entscheidung über die Subventionsform kaum den Bürokraten überlassen, sondern sie selbst entsprechend der eigenen Interessenlage treffen. Dies schließt jedoch nicht aus, daß die Bürokraten eine Interessengruppe bilden, welche politischen Druck ausübt, damit bei gegebener Zahl von Subventionsempfängern statt der Kredithilfen ausgabenintensivere Subventionsformen gewählt werden.

\section{bb. Erhöhung der Subventionsausgaben und Administrationskosten durch Kredithilfen}

Wie gezeigt, lassen sich die Subventionsausgaben aufgrund rationaler Ignoranz bzw. Fiskalillusion der Wähler erhöhen, wenn eine Subventionierung durch Kredithilfen erfolgt. Zumindest dann, wenn die Vergabe von Kredithilfen zu einem erhöhten staatlichen Gesamtbudget führt, werden budgetmaximierende Bürokraten die Vergabe von Kredithilfen befürworten. Insofern ist diesbezüglich tendenziell eine Interessenharmonie zwischen Politikern und Bürokraten gegeben.

Geht man davon aus, daß Kredithilfen ein über einen längeren Zeitraum bestehendes Subventionsverhältnis begründen, dann ergibt sich die Notwendigkeit, die Subventionsempfänger über den gesamten Subventionszeitraum zu überwachen. Dies ist insbesondere bei öffentlichen Darlehen mit einigem Aufwand verbunden, weil regelmäßig die ordnungsgemäße Erfüllung der Darlehensverpflichtungen kontrolliert werden muß. Erfolgt die Subventionierung dagegen durch Investitionszuschüsse, so wird die

1 Vgl. in bezug auf die Bereitstellung öffentlicher Güter ROPPEL (1979), S.155.

2 Vgl. NISKANEN (1974), S.43.

3 Dazu und zu anderen Kritikpunkten an den Annahmen Niskanens vgl. ROPPEL (1979), S.170 ff. 
Überwachung der Subventionsempfänger in erster Linie von den privaten Kreditgebern durchgeführt. D.h. daß im Fall von Kredithilfen vergleichsweise hohe Administrationskosten der Subventionierung zu erwarten sind.

Verfolgen die Bürokraten die Zielsetzung, ihren Zuständigkeitsbereich auszudehnen $^{1}$, haben sie bei Kredithilfen Vorteile, weil sie damit zumindest partiell eine "Privatisierung" von Überwachungsfunktionen bei der Subventionierung verhindern können. Die erhöhten Administrationskosten werden in einer Erhöhung der Zahl der in der Subventionsverwaltung Beschäftigten ihren Niederschlag finden. Wenn das Einkommen der ChefBürokraten von der Zahl der Untergebenen abhängt ${ }^{2}$, können diese ihren Nutzen durch die Vergabe von Kredithilfen erhöhen. Jedoch auch die Bürokraten unterhalb der Chefebene werden unter den getroffenen Annahmen die Vergabe von Kredithilfen präferieren, weil mit der Erhöhung der Beschäftigtenzahl auch die Aufstiegsmöglichkeiten für die einzelnen Bürokraten zunehmen ${ }^{3}$. Damit werden die Bürokraten bei gegebenen Finanzierungskosten der Subventionierung den Druck der an Kredithilfen interessierten Nachfragergruppen verstärken. Dadurch erhöht sich die Wahrscheinlichkeit, daß Kredithilfen als Subventionsform durchgesetzt werden können.

\section{cc. Bestehende Kredithilfe-Einrichtungen}

Betrachtet man die organisatorische Durchführung öffentlicher Kredithilfen, so fällt auf, daß dabei vielfach Sonderkreditinstitute als spezielle Form außerbudgetärer Einrichtungen eingeschaltet werden. Es wird angenommen, daß die Sonderkreditinstitute entsprechend den für sie geltenden Rechtsbestimmungen Subventionen lediglich in Form von Kredithilfen vergeben dürfen. Die Beschäftigten dieser außerbudgetären Einrichtungen, die zu den Bürokraten im weiteren Sinn gerechnet werden können, sind daran interessiert, stets Subventionsmaßnahmen in einem Umfang durchführen zu können, der das Überleben der Einrichtung sichern kann.

"One of their strongest motives is job preservation. For many, the continuation of an agency makes the difference between having a job and being unemployed for a time (...). Most organization members will therefore join the battle for agency survival. For the leaders, the incentives are even greater. Their reputations are tied to their agencies, and the fate of their organizations may profoundly affect their professional

1 Vgl. LEIPOLD (1988), S.265; MÄRTZ (1990), S.200.

2 So führt TULLOCK (1965), S.134, aus: "... a situation has arisen in most American and European governmental bureaucracies in which a politician is rewarded by his sovereigns for simply increasing the number of inferiors that he supervises." Siehe auch WILLIAMSON, O.E. (1964), S.34 f., $40 \mathrm{ff}$.

3 Vgl. ROPPEL (1979), S.91. 
status and perhaps even their employability in government and out. (...) Strong as the material motives are, however, they are probably matched by the mysterious forces of organizational loyalty $(. . .)^{n 1}$

Aufgrund der rechtlichen Restriktionen hat die Subventionierung durch Kredithilfen zu erfolgen, so daß sich das Interesse der Bürokraten nicht nur auf den Umfang der durchzuführenden Subventionsmaßnahmen, sondern gerade auch auf die Wahl von Kredithilfen als Subventionsform richtet. Diesem Interesse dient es, wenn Kredithilfen von Vertretern dieser Einrichtungen gegenüber den Wählern und den Politikern als besonders wirkungsvolle Form der Subventionierung dargestellt werden, die kaum Kosten verursacht, andererseits aber großen Nutzen stiftet ${ }^{2}$. Die bei den Sonderkreditinstituten beschäftigten Bürokraten werden daher versuchen, auf die Politiker Einfluß zu nehmen, daß diese Kredithilfen als Subventionsinstitution anbieten. Da die Politiker regelmäßig selbst am Bestehen außerbudgetärer Einrichtungen interessiert sind ${ }^{3}$, ist es dann vergleichsweise leicht durchzusetzen, daß die Subventionierung in Form von Kredithilfen auch von den Sonderkreditinstituten vergeben wird.

\section{Die Synthese nachfrage- und angebotsseitiger Erklărungsansätze für öffentliche Kredithilfen}

Wie gezeigt, ist eine Entscheidung über die Subventionsform in aller Regel nicht paretooptimal. D.h. daß durch eine solche Entscheidung üblicherweise Verteilungsinteressen verschiedener Gruppen berührt werden. Eine Subventionierung durch Kredithilfen ist danach erklärbar, wenn eine dominante Verteilungskoalition existiert, welche die von ihren Mitgliedern präferierte Subventionsform durchsetzen kann. Eine durch

1 KAUFMAN (1976), S.9.

2 So äußert sich der frühere Präsident der Bayerischen Landesanstalt für Aufbaufinanzierung, $H$. Artmann, zu öffentlichen Bürgschaften folgendermaßen: "Bei einer sachbezogenen, politisch emotionsfreien Handhabung halten sich die Ausfälle in vertretbaren Grenzen. (...) Damit ist die gelegentlich als Steuerverschwendung gescholtene Bürgschaft in Wirklichkeit für den Staat das billigste Förderungsmittel. Gleichzeitig ist es besonders wirksam, weil es private Bankmittel mobilisiert, die sonst wegen mangelnder Sicherheiten nicht verfügbar wären." Siehe ARTMANN (1981), S.400. H. Bäkow, Hauptabteilungsleiter der Kreditanstalt für Wiederaufbau, hält einen Abbau von Zuschüssen zur Haushaltskonsolidierung für unausweichlich, während mit den Kredithilfen der Kreditanstalt für Wiederaufbau der "Anspruchsdruck der Wirtschaft auf die öffentlichen Haushalte" gemildert werde. Er folgert daraus: "Das Instrument Kredit bei den notwendigen Schritten zum Subventionsabbau einzusetzen, scheint demnach geradezu zwangsläufig." Siehe BÄKOW (1984), S.415. Noch einen Schritt weiter geht MüllerKästner, Abteilungsdirektor der Kreditanstalt für Wiederaufbau, der in bezug auf deren Eigenmittel-Darlehen vom "amtlichen Vorurteil (...), eine Subvention zu sein" spricht. Siehe MÚLLER-KÄSTNER (1986), S.17.

Vgl. unten Abschnitt D.III.3. 
Kredithilfen begünstigte Verteilungskoalition hat dabei besonders gute Aussichten, eine dominante Stellung zu erreichen, wenn eine Interessenharmonie zwischen den begünstigten Nachfragern nach offentlichen Leistungen und den staatlichen Akteuren besteht. Dies ist insbesondere dann zu erwarten, wenn vergleichsweise kleine Gruppen durch Kredithilfen gegenüber anderen Subventionsformen spezielle Verteilungsvorteile erzielen können, deren Kosten breit gestreut und damit für die Benachteiligten kaum wahrnehmbar sind. Die regierenden Politiker können dann Netto-Stimmengewinne und damit politische Nettoerträge erwarten. Außerdem können die Bürokraten durch eine Ausweitung ihres Aufgabengebietes gegenüber anderen Subventionsformen Nutzensteigerungen erzielen. Darüber hinaus sind Kredithilfen vergleichsweise gut durchsetzbar, weil damit die Kosten der Subventionierung verschleiert werden können ${ }^{1}$. Schließlich kann mit einer Subventionierung in Form von Kredithilfen auch dann gerechnet werden, wenn nur die staatlichen Akteure eine eindeutige Präferenz für öffentliche Kredithilfen besitzen, weil dadurch fiskalische Restriktionen umgangen werden können, während die Nachfrager nach öffentlichen Leistungen hinsichtlich der Subventionsform indifferent sind.

Erkennt man, daß die Entscheidung für oder gegen Kredithilfen als Subventionsform praktisch ausschließlich durch deren Verteilungsimplikationen bestimmt wird, so stellt sich nahezu zwangsläufig die Frage, unter welchen Bedingungen die Wahl von Kredithilfen als Subventionsform normativ gerechtfertigt werden kann. Dies soll nun im folgenden Abschnitt untersucht werden.

\section{NORMATIVE ANALYSE ÖFFENTLICHER KREDITHILFEN AUS KONSTI- TUTIONELLER PERSPEKTIVE}

Für eine normative Beurteilung von Kredithilfen sind Kriterien erforderlich, an denen die Wünschbarkeit dieser Form der Subventionierung gemessen werden kann. Da die Entscheidung zugunsten von Kredithilfen typischerweise mit Vorteilen für bestimmte Gruppen von Nachfragern öffentlicher Leistungen und von staatlichen Akteuren verbunden ist, denen Nachteile anderer Gruppen gegenüberstehen, müssen die normativen Kriterien Aussagen darüber enthalten, ob die jeweiligen Verteilungskonsequenzen erwünscht oder unerwünscht sind. Man könnte fragen, welche Subventionsform eine vorgegebene soziale Wohlfahrtsfunktion maximiert, und danach die Wünschbarkeit von Kredithilfen beurteilen. Allerdings zeigt das Unmöglichkeitstheorem von ARROW2 ${ }^{2}$ daß soziale Wohl-

1 Vgl. LEONARD (1986), S.105.

2 Vgl. ARROW (1951). 
fahrtsfunktionen im laufenden politischen Prozeß nicht aus den individuellen Präferenzen abgeleitet werden können. Unter diesen Bedingungen kann nur mittels externer Normen spezifiziert werden, wer durch Entscheidungen über die Subventionsform begünstigt werden soll ${ }^{1}$. Die Verwendung solcher externer Normen ist jedoch abzulehnen, weil damit stets die Gefahr willkürlicher Bewertungen verbunden ist.

Die Alternative zur Ermittlung eines normativen Maßstabs für Kredithilfen besteht darin, daß man fragt, auf welche politisch-institutionellen Bedingungen für die Vergabe von Kredithilfen sich die Individuen einigen werden. Eine Einigung im laufenden politischen Prozeß muß jedoch scheitern, weil die Gewinner von Kredithilfen die institutionellen Bedingungen für die Subventionsform-Entscheidung regelmäßig so gestalten wollen, daß ihre identifizierbaren Chancen zur Vorteilserzielung nicht beschränkt werden, während die Verlierer Institutionen präferieren, die eigene Verluste verhindern ${ }^{2}$. Daher ist eine Einigung über entsprechende Institutionen nur auf einer gedanklichen oder tatsächlichen konstitutionellen Ebene vorstellbar, die durch Unsicherheit über die individuelle Position in postkonstitutionellen Perioden gekennzeichnet ist. Denn auf diese Weise bleibt es für die Individuen ungewiß, ob sie durch Kredithilfen begünstigt oder benachteiligt werden. Somit werden sie die politisch-institutionellen Bedingungen für Subventionsform-Entscheidungen auf der Grundlage konsensualer Vorstellungen über das Interesse der Allgemeinheit festlegen.

Im folgenden soll zunächst das analytische Grundkonzept der konstitutionellen Wirtschaftstheorie präzisiert werden. In einem nächsten Schritt wird diskutiert, wie die Individuen auf der konstitutionellen Ebene das kollektive Interesse definieren. Daran anschlieBend werden staatliche Verhaltensmuster analysiert, von denen prognostiziert werden kann, daß sie im konstitutionellen Kalkül der Individuen von Bedeutung sind. Schließlich wird analysiert, welche Gestaltungsformen konstitutioneller Regeln generell denkbar sind und welche speziellen Regeln sich für eine Subventionierung durch Kredithilfen in konstitutioneller Betrachtung ableiten lassen, wenn man unterschiedliche staatliche Verhaltensmuster zugrundelegt.

1 Zum entsprechenden Problem bei der normativen Analyse der Steuerstruktur vgl. BRENNAN/BUCHANAN (1980/1988), S.14, 262 f. (Fn.3).

$2 \mathrm{Zu}$ einer vergleichbaren Problematik bei der Bewertung von Steuerstrukturen vgl. FOLKERS (1986d), S.9; FOLKERS (1987a), S.276. 


\section{Das Grundkonzept der konstitutionellen Wirtschaftstheorie}

Ausgangspunkt der konstitutionellen Wirtschaftstheorie ist "the recognition that government derives its legitimate authority from individuals and that such authority can be limited by constitutional constraints" ${ }^{11}$. Entscheidend für die ökonomischen Ergebnisse der laufenden, postkonstitutionellen Perioden sind danach die Regeln, die den staatlichen Akteuren von den Bürgern in der Verfassung vorgegeben werden. "Constitutional economics directs analytical attention to the choice among constraints"2.

Der Grund für Beschränkungen von finanzwirtschaftlichen Entscheidungen liegt darin, daß die Bürger damit für den Staat Anreize setzen wollen, in postkonstitutionellen Perioden im Interesse der Allgemeinheit zu handeln ${ }^{3}$. Das Interesse der Allgemeinheit läßt sich auf der konstitutionellen Ebene durch Übereinkunft ${ }^{4}$ der Individuen bestimmen, da sie hier ihre individuelle Position in nachkonstitutionellen Perioden nicht kennen ${ }^{5}$. Sie handeln hinter einem "Schleier der Unwissenheit"t. Dadurch sind die Individuen frei von jeder "Versuchung", individuelle Verteilungsinteressen in die persönliche Gemeinwohlvorstellung einfließen zu lassen ${ }^{7}$. Der Schleier der Unwissenheit gibt den Individuen den notwendigen Anreiz, sich entsprechend dem Kantschen kategorischen Imperativ $^{8}$ zu verhalten, was eine Übereinkunft der Individuen im Hinblick auf die Bestimmung des Interesses der Allgemeinheit entscheidend erleichtert.

Ohne Beschränkungen besitzen die staatlichen Akteure Handlungsspielräume, um ihre Eigeninteressen zu verfolgen und damit das auf der konstitutionellen Ebene bestimmbare Interesse der Allgemeinheit zu verletzen. Diese Handlungsspielräume beruhen zum einen auf der staatlichen Gewalt, den Individuen zwangsweise durchsetzbare Steuerforderungen aufzuerlegen, wobei im Fall einer unbeschränkten staatlichen Zwangsgewalt per se

1 BUCHANAN (1988), S.XVIII.

2 BUCHANAN (1990), S. 3 (Hervorhebung im Original)

3 Vgl. FOLKERS (1984), S.502.

4 Diese Übereinkunft erfolgt auf der konstitutionellen Ebene idealtypisch nach der Einstimmigkeitsregel. Vgl. WICKSELL (1896). Denn nur so kann sichergestellt werden, daß niemand durch kollektive Entscheidungen geschädigt wird, weil jeder Bürger ein Vetorecht besitzt. Vgl. BRENNAN/BUCHANAN (1981b), S.116.

5 Da die Individuen in postkonstitutionellen Perioden ihre ökonomische Position kennen, werden sie dann auch die jeweiligen Interessengegensätze wahrnehmen. D.h. eine Übereinkunft ist nur auf der konstitutionellen Ebene möglich.

6 RAWLS (1971), S.136 ff.

7 Umgekehrt muß man davon ausgehen, daß im laufenden politischen Prozeß die Zahl der Definitionen des Interesses der Allgemeinheit genau so hoch ist wie die Zahl der Individuen, die an diesem Prozeß beteiligt sind. Vgl. BUCHANAN (1962), S.346.

8 "Handle so, daß die Maxime deines Willens jederzeit zugleich als Prinzip einer allgemeinen Gesetzgebung gelten könne." 
keine Verpflichtung zu einer bestimmten Verwendung der erhobenen Steuereinnahmen enthalten ist ${ }^{1}$. Zum anderen ergeben sich die Handlungsspielräume der staatlichen Akteure dadurch, daß sie durch die Wähler nicht perfekt kontrolliert werden können ${ }^{2}$.

Um eine Schädigung einzelner Gesellschaftsmitglieder auszuschließen, müssen auch die Regeln zur Beschränkung der staatlichen Akteure auf der konstitutionellen Ebene durch Übereinkunft der Individuen beschlossen werden. Dabei hängt die gewählte Ausgestaltung fiskalischer Restriktionen von den inhaltlichen Merkmalen des Interesses der Allgemeinheit bzw. des kollektiven Interesses, den staatlichen Verhaltensmustern in nachkonstitutionellen Perioden und den Prognosen über die Funktionsweise alternativer Regelsysteme $\mathrm{ab}^{3}$. Darüber hinaus ist bei der konstitutionellen Festlegung von Regeln zu berücksichtigen, inwieweit die Wähler den Staat in postkonstitutionellen Perioden kontrollieren können.

Im folgenden soll daher untersucht werden, welche Ausprägung das Interesse der Allgemeinheit in bezug auf Entscheidungen über die Form von Subventionen erwartet werden kann. Weiterhin sollen im Hinblick auf unterschiedliche staatliche Verhaltensmuster Regeln für die Vergabe von Kredithilfen diskutiert werden, auf die sich die Individuen einigen könnten. Dabei wird die vereinfachende Annahme getroffen, daß die Wähler nur die Einhaltung bestehender Restriktionen kontrollieren können ${ }^{4}$.

Auch wenn mit Hilfe der konstitutionellen Wirtschaftstheorie ein für die Allgemeinheit vorteilhaftes System von Kredithilfe-Regeln abgeleitet wird, ist im voraus die Einschränkung zu machen, daß der entscheidende Test für die Wünschbarkeit konstitutioneller Regeln letztlich nur die Übereinstimmung der Individuen selbst sein kann. Daher besitzen die im folgenden diskutierten normativen Konsequenzen nur vorläufigen Charakter ${ }^{5}$. Dennoch ist der konstitutionelle Ansatz von hoher praktischer Relevanz. Denn damit lassen sich die Gefahren unbeschränkter Entscheidungen des Staates über die Subventionsform und mögliche Vorkehrungen dagegen aufzeigen. Diese Problemfelder werden in den meisten Analysen öffentlicher Kredithilfen kaum beachtet.

1 Vgl. BRENNAN/BUCHANAN (1980/1988), S.10.

2 Andernfalls könnte jeder Versto $B$ des Staates gegen kollektive Interessen sofort aufgedeckt und, Sanktionsmöglichkeiten vorausgesetzt, unterbunden werden.

3 Vgl. BRENNAN/BUCHANAN (1980/1988), S.15.

$4 \mathrm{Zu}$ weniger restriktiven Annahmen über die Kontrollmöglichkeiten der Wähler und den daraus resultierenden Konsequenzen für die zu erwartenden Beschränkungen vgl. COURANT/ RUBINFELD (1981); INMAN (1982); INMAN (1987), S.743 ff.

5 Vgl. BRENNAN/BUCHANAN (1980/1988), S.15. 


\section{Das Interesse der Allgemeinheit bei Entscheidungen über die Subventionsform}

Eine Einigung über das Interesse der Allgemeinheit, die auch implizit erfolgen kann, ist im Hinblich auf Entscheidungen über konstitutionelle Regeln erforderlich, da diese auf eine lange Zeitdauer angelegt sind ${ }^{1}$. Sie betreffen demnach auch Individuen, die an den konstitutionellen Entscheidungen nicht beteiligt sind. D.h. aber, daß das Interesse der Allgemeinheit mehr ist als die Summe der Präferenzen der an den konstitutionellen Entscheidungen beteiligten Individuen.

Sollen die Individuen auf der konstitutionellen Ebene das Interesse der Allgemeinheit in bezug auf Subventionsform-Entscheidungen formulieren, so werden sie sich voraussichtlich darauf einigen, daß durch die Wahl der Subventionsform die Effizienz der Ressourcenallokation möglichst wenig beeinträchtigt werden soll. Denn ein effizienter Ressourceneinsatz gewährleistet, daß der in Nutzeneinheiten gemessene gesamtwirtschaftliche Output maximal wird ${ }^{2}$. Es kann aber unterstellt werden, daß die Individuen auf der konstitutionellen Ebene übereinstimmend davon ausgehen, daß sie sich in postkonstitutionellen Perioden wahrscheinlich in absoluten Größen um so besser stellen, je höher der gesamtwirtschaftliche Output ist.

Danach liegt ein Verstoß gegen das Interesse der Allgemeinheit vor, wenn durch Entscheidungen über die Subventionsform soziale Nutzenverluste verursacht werden. Solche Nutzenverluste können zum einen daraus resultieren, daß die Wahl der Subventionsform zu einer Erhöhung der Subventionsausgaben und damit ceteris paribus zu erhöhten Steuereinnahmen führt. Da praktisch alle Steuermaßnahmen zu Mehrbelastungen führen, liegt es folglich im Interesse der Allgemeinheit, wenn durch die Entscheidungen über die Subventionsform keine erhöhten Subventionsausgaben induziert werden. Allerdings könnte eine Erhöhung von Subventionsausgaben durch Realisierung bestimmter Subventionsformen aus konstitutioneller Perspektive wünschenswert sein, wenn bei alternativen Subventionsformen das Ausmaß der Subventionierung ineffizient niedrig ist. Insoweit könnte es beispielsweise im Interesse der Allgemeinheit liegen, wenn durch Kredithilfen eine optimale Fiskalillusion angestrebt würde. Aufgrund der hohen Informationserfordernisse und der damit verbundenen Risiken ist es jedoch wenig wahrscheinlich, daß sich die Individuen auf konstitutioneller Ebene durch ein derartiges Konzept Nutzensteigerungen versprechen. Deshalb soll hierauf im folgenden nicht weiter eingegangen werden.

Vgl. FOLKERS (1986d).

2 Vgl. BRENNAN/BUCHANAN (1980/1988), S. 41 mit Bezug auf konstitutionelle Steuerentscheidungen. 
Zum anderen können soziale Nutzenverluste entstehen, wenn durch die gewählte Subventionsform das Ausmaß der individuellen Vorteile der Subventionierung erhöht werden kann. Denn dadurch wird ein Anreiz geschaffen, zur Beeinflussung der Subventionsform-Entscheidungen Rent-seeking-Ressourcen einzusetzen. Die Verwendung vorhandener Ressourcen für Rent-seeking-Aktivitäten stellt aus ökonomischer Sicht Verschwendung dar $^{1}$ und widerspricht damit dem Interesse der Allgemeinheit.

Weiterhin kann erwartet werden, daß die Individuen auf der konstitutionellen Ebene gegenüber der Nutzenverteilung in postkonstitutionellen Perioden nicht indifferent sind ${ }^{2}$. Insbesondere ist anzunehmen, daß es als eine Verletzung des kollektiven Interesses betrachtet wird, wenn die als wünschenswert erachteten staatlichen Redistributionsmaßnahmen $^{3}$ durch Subventionsform-Entscheidungen konterkariert werden. Dieser Fall ist immer dann gegeben, wenn sich einzelne Gruppen durch bestimmte Subventionsformen Sondervorteile zu Lasten anderer Gruppen aneignen, ohne daß dies im Einklang mit den konstitutionell gewünschten Verteilungsergebnissen steht ${ }^{4}$.

Haben sich die Individuen auf eine Interpretation des Interesses der Allgemeinheit geeinigt, werden sie in einem nächsten Schritt überlegen, unter welchen Bedingungen seine Durchsetzung aufgrund staatlichen Verhaltens gefährdet sein kann. Dies erfordert Prognosen über das staatliche Verhalten in postkonstitutionellen Perioden.

\section{Staatliche Verhaltensmuster im konstitutionellen Kalkül der Individuen}

Im folgenden ist $\mathrm{zu}$ analysieren, welches positive staatliche Verhaltensmuster die Individuen in ihrem konstitutionellen Kalkül übereinstimmend für möglich halten ${ }^{5}$. Denn davon hängt ab, welche Restriktionen zum Schutz kollektiver Interessen aus konstitutioneller Sicht erforderlich sind.

Es soll angenommen werden, daß die Individuen den Staat auf der konstitutionellen Ebene als "Einzelwesen" modellieren, das bestimmte Interessen verfolgt. Das heißt jedoch

1 Vgl. BRENNAN/BUCHANAN (1980/1988), S.42; siehe auch MÄRTZ (1990).

2 Vgl. BRENNAN/BUCHANAN (1980/1988), S.41.

3 Zur Analyse staatlicher Umverteilungsaktivitäten aus konstitutioneller Perspektive vgl. BRENNAN/BUCHANAN (1980/1988), S.41.

4 "Generell erfordern Transfermaßnahmen eine konstitutionelle Festlegung, denn der innerperiodische Wahlprozeß bringt einfach nicht die konstitutionell gewünschten Ergebnisse hervor und dieses Versagen wird auf der konstitutionellen Ebene der Erkenntnis prognostiziert." BRENNAN/BUCHANAN (1980/1988), S.24. Zur Analyse staatlicher Umverteilungsaktivitäten aus konstitutioneller Perspektive siehe auch BRENNAN/BUCHANAN (1981b).

5 Vgl. unten Abschnitt D.II.3.d. Demgegenüber stellt FOLKERS (1988b), S.XIII auf das erwartete staatliche Verhalten ab. 
nicht, daß nach dieser Annahme jeder einzelne staatliche Akteur die Ziele des Staates als individuelle Zielgrößen zu maximieren sucht. Vielmehr wird unterstellt, daß das Interesse des Staates aus der Interaktion aller staatlichen Entscheidungsträger hervorgeht, so da $B$ danach eine Modellierung des Staates als Einzelwesen möglich erscheint ${ }^{1}$. Diese vereinfachende Konstruktion erlaubt es, die Diskussion über konstitutionelle Regeln für die Vergabe von Kredithilfen in Gang zu setzen. Als alternative staatliche Verhaltensmuster sollen dabei die in der Literatur entwickelten Modelle des wohlwollenden Alleinherrschers, des überschußmaximierenden Leviathan und des Vergünstigungsstaats betrachtet werden. Nach der Beschreibung der Implikationen dieser Verhaltensmuster für die Vergabe von Kredithilfen soll deren Relevanz im konstitutionellen Kalkül der Individuen überprüft werden.

\section{a. Der Staat als wohlwollender Alleinherrscher}

Zunächst soll von der Vorstellung ausgegangen werden, daß die staatlichen Akteure im Interesse der Allgemeinheit handeln und dadurch ihren Nutzen maximieren. Danach verfehlen sie bei jeder Verletzung kollektiver Interessen ihr Nutzenmaximum. Diese Annahme entspricht der in den Ansätzen der traditionellen Finanzwissenschaft implizit enthaltenen Modellierung des Staates als "wohlwollender Alleinherrscher", der sich so verhält, daß die Wohlfahrt der Bürger maximiert wird ${ }^{2}$. Dabei kann angenommen werden, $\mathrm{da}$ ein derartiger Staat Subventionen nur aus allokativen Gründen vergibt, weil für eventuelle Umverteilungsaktivitäten zielgenauere Instrumente zur Verfügung stehen.

Unter diesen Bedingungen wird der Staat stets diejenige Subventionsform anbieten, bei der sich ein bestimmter Subventionszweck mit minimalen Subventionsausgaben erreichen läßt. Sofern sich bei bestimmten Subventionsformen Ausgaben einsparen lassen, ist damit das staatliche Budget kleiner und das verfügbare Einkommen der Individuen höher als bei anderen Subventionsformen. Da die Minimierung der Subventionsausgaben ceteris paribus eine Minimierung der Steuereinnahmen impliziert, läßt die ausgabenminimale Subventionsform bei gegebener Steuerstruktur auch eine Begrenzung der Mehrbelastung durch die Subventionierung erwarten.

Werden Subventionsausgaben durch die Vergabe von Kredithilfen reduziert, bietet ein wohlwollender Alleinherrscher zur Erreichung des Subventionszwecks diese Subventionsform an. Kann ein bestimmter Subventionszweck bei verschiedenen Subventionsfor-

1 Vgl. BRENNAN/BUCHANAN (1980/1988), S.36 ff.

2 Vgl. BRENNAN/BUCHANAN (1980/1988), S.5 f. 
men mit Subventionsausgaben gleicher Höhe erreicht werden, ist der wohlwollende Alleinherrscher zwischen diesen Subventionsformen indifferent, sofern auch die Verteilungskonsequenzen bei jeder Subventionsform identisch sind.

Den Zeitpunkt der Finanzierung der Subventionsausgaben würde ein wohlwollender Alleinherrscher nach intertemporalen Gerechtigkeitskriterien bestimmen. Fallen die sozialen Erträge der Subventionierung erst in der Zukunft an, ist eine Verschiebung der "Last" der Subventionierung in die Zukunft unter bestimmten Bedingungen entsprechend dem Pay-as-you-use-Grundsatz ${ }^{1}$ wünschenswert ${ }^{2}$. Allerdings kann eine solche Lastverschiebung beispielsweise auch durch eine Kreditfinanzierung von Investitionszuschüssen erfolgen. Somit ergibt sich für einen wohlwollenden Alleinherrscher keineswegs die Notwendigkeit, aus Gründen intertemporaler Gerechtigkeit Kredithilfen vorzuziehen. Schließlich wird ein wohlwollender Alleinherrscher illusionserzeugende Kredithilfen anbieten, wenn die Individuen den Nutzen von Subventionen unterschätzen.

Da ein wohlwollender Alleinherrscher definitionsgemäß im Interesse der Allgemeinheit handelt, haben die Individuen auf der konstitutionellen Ebene keine Veranlassung, einen derartigen Staat durch irgendwelche Restriktionen in seinen Handlungen einzuschränken.

\section{b. Der Staat als überschußmaximierender Leviathan}

Das analytische Gegenstück zur Annahme eines wohlwollenden Alleinherrschers ist die Modellierung des Staates als überschußmaximierenden Leviathan ${ }^{3}$. Dabei wird die Annahme des Wohlwollens staatlicher Entscheidungsträger in ihr Gegenteil verkehrt, da unterstellt wird, daß sie sich wie die privaten Wirtschaftssubjekte verhalten und aus der Beachtung kollektiver Interessen keinen unmittelbaren Nutzen ziehen. Die Charakterisierung der staatlichen Akteure als homines oeconimicos wird jedoch weniger als deskriptive Hypothese über deren Verhalten, sondern vielmehr als "the appropriate model for testing whether institutions serve to transform private interest into public" ${ }^{14}$ interpretiert.

Ein Leviathan-Staat wird versuchen, die maximal möglichen Steuereinnahmen zu erzielen, weil dann sein fiskalischer Überschuß maximal wird. Ohne Beschränkung der Einnahmenverwendung kann somit das private Einkommen der staatlichen Entscheidungs-

1 Vgl. MUSGRAVE (1959/1966), S.523 ff.

2 Dies gilt jedoch beispielsweise dann nicht, wenn in jeder Periode dieselben Aktivitäten subventioniert werden. Vgl. MUSGRAVE (1959/1966), S.524.

3 Vgl. BRENNAN/BUCHANAN (1980/1988), insbesondere S.16 ff.

4 Vgl. BRENNAN/BUCHANAN (1981a), S.161. 
träger maximiert werden. Gibt es Beschränkungen, die vorschreiben, daß ein bestimmter Anteil der Einnahmen für genau spezifizierte öffentliche Leistungen zu verwenden ist, so ergibt sich der Überschuß des Staates als Differenz zwischen den gesamten staatlichen Einnahmen und den vorgeschriebenen Ausgaben ${ }^{1}$.

Im folgenden sei unterstellt, daß der Staat verpflichtet ist, durch Subventionen bestimmte Aktivitäten zu fördern, die ohne Subventionierung nicht durchgeführt werden. Die Subventionsausgaben sollen bei allen Subventionsformen in der Vergabeperiode ausgabenwirksam sein. Nimmt man weiterhin an, daß abgesehen von den Subventionsausgaben für einen bestimmten Subventionszweck (S) sämtliche Staatsausgaben (A) sowie die staatlichen Maximaleinnahmen (E) gegeben seien, so ergibt sich als Zielfunktion des Leviathan-Staates

$$
\ddot{U}=\mathbf{E}-\mathbf{A}-\mathbf{S}=\text { Max! }
$$

Dabei bezeichnet Ü den Überschuß des Staates als seine Zielgröße. Aus (D.II.1) ist zu erkennen, daß der Überschuß dann maximal wird, wenn die Subventionsausgaben bei Ausschöpfung der Maximaleinnahmen minimal sind. Dementsprechend wird ein Leviathan-Staat ebenso wie der wohlwollende Alleinherrscher Kredithilfen anbieten, wenn dadurch die Subventionsausgaben minimiert werden können ${ }^{2}$. D.h. der Leviathan wird jede "Verschwendung" staatlicher Einnahmen für nicht erforderliche Subventionsausgaben vermeiden, solange er die "Einsparungen" in eigene Gewinne transformieren kann ${ }^{3}$.

Wird dem Staat vorgeschrieben, in jeder Periode Netto-Subventionsausgaben in bestimmter Höhe zu tätigen, wobei die durchschnittlichen Subventionsausgaben je Subventionsempfänger unabhängig von der Subventionsform gleich hoch und die Subventionsausgaben jeweils in der Vergabeperiode ausgabenwirksam sein sollen, dann wird der Leviathan zwischen sämtlichen Subventionsformen indifferent sein, sofern seine erzielbaren Maximaleinnahmen von der Wahl der Subventionsform unabhängig sind. Dies kann auch erwartet werden, wenn die Differentialwirkungen verschiedener Subventionsformen unsicher sind. Andernfalls wird der Leviathan diejenige Subventionsform wählen, welche die ihm zur Verfügung stehenden Steuerbemessungsgrundlagen bei gegebenen Steuersätzen maximiert. Dabei kommt es auf die Steuern und ihre Tarife an, die der Staat erheben darf. Daher ist eine allgemeine Aussage darüber unmöglich, welche Subventionsform ein Leviathan-Staat erheben wird.

1 Vgl. BRENNAN/BUCHANAN (1980/1988), S.34.

2 Dieses Ergebnis entspricht den Ergebnissen der konstitutionellen Steuertheorie, wonach ein Leviathan-Staat dieselben Steuerregeln wählen wird wie ein wohlwollender Alleinherrscher.

Vgl. BRENNAN/BUCHANAN (1980/1988), S.85; FOLKERS (1986d), S.24.

Vgl. BRENNAN/BUCHANAN (1980/1988), S.40. 
Sind Kredithilfen erst in der Zukunft, alternative Subventionsformen, insbesondere Preissubventionen von Güterkäufen, dagegen bereits in der Vergabeperiode ausgabenwirksam, so kommt es für die Wahl der Subventionsform durch den Staat bei unterstellter gegebener Höhe des Gegenwartswerts der Subventionsausgaben darauf an, ob man von einem ewigen oder einem probabilistischen Leviathan ausgeht ${ }^{1}$. Während im Modell des ewigen Leviathan unterstellt wird, daß sich das Staatsverhalten in allen postkonstitutionellen Perioden durch Überschußmaximierung kennzeichnen läßt, ist bei einem probabilistischen Leviathan der fiskalische Überschuß nur zeitweise die Zielgröße des Staates.

Im Rahmen einer Zweiperioden-Betrachtung wird nun die Entscheidung über die Subventionsform der ersten Periode analysiert. Dabei wird unterstellt, daß der Überschuß eines ewigen Leviathan in beiden Perioden dieselbe Höhe aufweist, wenn die Subventionen in der Gegenwart ausgabenwirksam sind. Ist die der Leviathan bei der Kreditvergabe und Kreditaufnahme nur durch seine seine Vermögensrestriktion ${ }^{2}$ beschränkt, so wird er in der ersten Periode zwischen den alternativen Subventionsformen indifferent sein. Denn er kann dann seinen Überschuß entsprechend seiner Zeitpräferenz auf beide Perioden verteilen $^{3}$. Unterliegt der Staat dagegen einem totalen Kreditaufnahmeverbot, während eine Kreditvergabe zum Marktzinssatz erlaubt ist, kann sich dieses Ergebnis ändern. Ist die reine Zeitpräferenzrate des Leviathan höher als der Marktzinssatz, so wird er die Vergabe von Kredithilfen präferieren, weil er damit seinen Überschuß in der Gegenwart und folglich sein Nutzenniveau steigern kann. Dagegen ist der Leviathan zwischen beiden alternativen Subventionsformen indifferent, wenn seine Zeitpräferenzrate kleiner ist als der Marktzinssatz. Denn er kann durch Kreditgewährung unabhängig von der Subventionsform ein bestimmtes Nutzenniveau erreichen. Allerdings wird die Höhe der marktlichen Kredite des Staates von der realisierten Subventionsform bestimmt. Die umgekehrten Ergebnisse folgen, wenn dem Staat die Kreditgewährung untersagt, die Kreditaufnahme hingegen erlaubt ist.

Geht man im Modell des probabilistischen Leviathan davon aus, daß der Leviathan nur in der ersten Periode in Aktion ist, so wird er durch die Vergabe von Kredithilfen und die damit verbundene Verschiebung der Subventionsausgaben in die Zukunft ceteris paribus seinen Überschuß der ersten Periode maximieren ${ }^{4}$. Denn die Zeitpräferenzrate des probabilistischen Leviathan beträgt in diesem Fall unendlich. D.h. der Leviathan kann die

$1 \mathrm{Zu}$ dieser Unterscheidung vgl. BRENNAN/BUCHANAN (1980/1988), S.106 f.

2 Die Vermögensrestriktion des Leviathan ist durch sein Steueraufkommenspotential gegeben. Vgl. BRENNAN/BUCHANAN (1980/1988), S.131.

3 Vgl. BRENNAN/BUCHANAN (1980/1988), S.125.

4 Zum analogen Fall der Kreditaufnahme eines probabilistischen Leviathan vgl. BRENNAN/ BUCHANAN (1980/1988), S.132. 
Ausbeutung der Bürger über die Erzielung der Maximaleinnahmen hinaus ausdehnen, indem er obligatorische staatliche Ausgaben in die Zukunft verlagert. Der Staat wird demnach in der zweiten Periode höhere Steuereinnahmen erzielen müssen als ohne zeitliche Verschiebung der Subventionsausgaben. Verhält sich der Staat dagegen in der ersten Periode als wohlwollender Alleinherrscher und in der zweiten Periode als Leviathan, so kann der Leviathan im Modellrahmen seinen Überschuß durch die Entscheidung über die Subventionsform nicht erhöhen.

Eine Ausweitung der Subventionsausgaben durch die Vergabe von Kredithilfen ${ }^{1}$ ist dagegen für einen Leviathan-Staat bei gegebenen Einnahmen nicht wünschenswert, da dies seinen Überschuß mindern würde ${ }^{2}$. Dagegen kann eine Vergabe zusätzlicher öffentlicher Darlehen den Überschuß eines probabilistischen Leviathan erhöhen, wenn eine staatliche Nettokreditaufnahme, wie in der Bundesrepublik Deutschland, bis zur Höhe der staatlichen Bruttoinvestitionen erlaubt ist, sofern die Darlehensausgaben als Investitionen erfaßt werden. Übernimmt der probabilistische Leviathan einen Bestand an kreditfinanzierten Darlehensforderungen, so kann er unter diesen Bedingungen bei Reduzierung des Bestandes durch Veräußerung bzw. Tilgung in Höhe der daraus resultierenden Einnahmen erneut Darlehen vergeben, die er durch Umschuldungen finanzieren wird. Obwohl die Nettoinvestitionen Null betragen, wird der probabilistische Leviathan zusätzliche Krediteinnahmen erzielen, die er sich aneignen wird, soweit er diesbezüglich keinen Beschränkungen unterliegt. Zusätzliche Vorteile kann der probabilistische Leviathan realisieren, wenn er die Einnahmen aufgrund von Kredithilfen beliebig verwenden darf. Unter diesen Bedingungen wird er seinen Überschuß maximieren, indem er den gesamten Forderungsbestand liquidiert und sich den Forderungserlös aneignet.

Ist dem Staat lediglich das Horten von Überschüssen erlaubt, ihre Anlage zu Marktkonditionen dagegen untersagt, kann die Ausweitung der Netto-Subventionsausgaben den Nutzen des ewigen Leviathan erhöhen. Dazu kommt es, wenn er in der Gegenwart bei entsprechender Zeitpräferenzrate öffentliche Darlehen mit positivem Zinssatz gewährt. Denn durch die Darlehensgewährung reduziert sich der relative Preis des Zukunftskonsums des Leviathan. Sofern der Zukunftskonsum des Leviathan ein superiores Gut ist, wird er somit

1 Dabei kommt es hier nicht auf die Erzeugung von Fiskalillusion bei den Bürgern an, da der Leviathan annahmegemäß durch Wahlen nicht beschränkt wird.

2 Anders ist es allerdings, wenn sich durch die Erhöhung der Subventionsausgaben der Gegenwartswert der maximalen Steuereinnahmen eines ewigen Leviathan erhöhen läßt. So kann es für einen Leviathan-Staat, der die Befugnis zur Erhebung einer Kapitalsteuer besitzt, unter bestimmten Bedingungen durchaus rational sein, die Kapitalbildung zu subventionieren, um damit die für ihn ausbeutbare Bemessungsgrundlage zu maximieren. Vgl. dazu BRENNAN/ BUCHANAN (1980/1988), S.109 ff. Dies kann jedoch prinzipiell auch mit anderen Subventionsformen erreicht werden. 
einen Teil des Überschusses der Gegenwart in die Zukunft verschieben. Allerdings ist eine mit der Darlehensgewährung verbundene Ausweitung der Netto-Subventionsausgaben für die Bürger vorteilhaft, wenn sich dadurch die Maximaleinnahmen des Leviathan nicht erhöhen, da sich dann ihre Netto-Steuerzahlung (Steuern abzüglich Subventionen) vermindert $^{1}$. Anders ausgedrückt vermindert sich durch die Darlehensgewährung der Gegenwartswert des Überschusses für den ewigen Leviathan.

Da ein Leviathan-Staat durch die Wahl öffentlicher Kredithilfen als Subventionsform unter verschiedenen Bedingungen seinen fiskalischen Überschuß erhöhen kann, impliziert ein entsprechendes staatliches Verhalten stets die Gefahr einer Verletzung kollektiver Interessen. Denn die Erhöhung des Überschusses wird die Nutzenverteilung in postkonstitutionellen Perioden einseitig zugunsten der staatlichen Akteure verändern, was aus konstitutioneller Sicht nicht wünschenswert ist $^{2}$. Daher werden die Individuen Beschränkungen für die Vergabe von Kredithilfen beschließen, wenn die LeviathanAnnahme in ihrem konstitutionellen Kalkül Relevanz besitzt.

\section{c. Der Vergünstigungsstaat}

Als dritte Alternative staatlichen Verhaltens wird ein Vergünstigungsstaat betrachtet, in dem die staatlichen Akteure ebenfalls ihren Nutzen maximieren. Im Gegensatz zur Leviathan-Hypothese wird hier jedoch unterstellt, daß die staatlichen Akteure zwar einen gewissen Handlungsspielraum zur Verfolgung eigener Zielsetzungen besitzen, daß sie andererseits einen erheblichen Teil des fiskalischen Überschusses an die Wähler ausschütten müssen, um bisherige Anhänger zu belohnen und neue zu gewinnen. D.h. Nutzenmaximierung des Vergünstigungsstaates setzt voraus, daß er einen Teil des fiskalischen Überschusses mit bestimmten Wählergruppen teilt bzw. auf einen Teil der Maximaleinnahmen verzichtet ${ }^{3}$.

Das Verhaltensmuster eines Vergünstigungsstaates in bezug auf Kredithilfen entspricht weitgehend dem bei der Analyse positiver Erklärungsansätze von Kredithilfen diskutierten staatlichen Verhalten ${ }^{4}$. Dementsprechend ist im Fall eines Vergünstigungsstaates nicht eindeutig determiniert, ob der Staat ceteris paribus Kredithilfen anbieten wird, wenn

1 Von den zusätzlichen Wirkungen einer Erhöhung des Kapitalangebots in der Gegenwart wird an dieser Stelle abgesehen.

2 Vgl. BRENNAN/BUCHANAN (1980/1988), S.41.

3 Vgl. FOLKERS (1986d), S.25.

4 Vgl. FOLKERS (1986d), S.25 ff. 
dadurch die Subventionsausgaben minimiert werden können ${ }^{1}$. Vielmehr werden die staatlichen Entscheidungsträger einen Kosten-Nutzen-Kalkül anwenden, bei dem der Nutzen der ausgabenintensiveren Subventionsform mit ihren Kosten verglichen wird. Dabei wird die ausgabenintensivere im Vergleich zur ausgabenminimalen Subventionsform Opposition der Steuerzahler und damit höhere Kosten für die staatlichen Akteure verursachen, während sie zusätzliche Vorteile von Seiten der dadurch Begünstigten verspricht. Wenn die zusätzlichen Kosten die zusätzlichen Vorteile übersteigen, wird der Staat die Kredithilfen anbieten.

Es ist jedoch zu erwarten, daß der Vergünstigungsstaat Kredithilfen gewährt, wenn er damit bei gegebenen Subventionsausgaben spezielle Gruppen von Subventionsempfängern begünstigen kann oder wenn sich durch Kredithilfen die Subventionsausgaben in die $\mathrm{Zu}$ kunft verschieben lassen. Ebenso wird er vermutlich das Volumen des Gegenwartswerts der (Netto-)Subventionsausgaben mittels der Vergabe von Kredithilfen erhöhen, weil ihre Kosten in geringerem Umfang wahrnehmbar sind als die bestimmter alternativer Subventionsformen. Berücksichtigt man zusätzlich die Möglichkeit eines probabilistischen Vergünstigungsstaates, so können Kredithilfen für diesen zusätzliche Vorteile implizieren. Unterstellt man, da $\beta$ ein probabilistischer Vergünstigungsstaat einen Bestand an Forderungen bzw. Einnahmeansprüchen aufgrund der Kredithilfevergabe früherer Perioden übernimmt, so kann er unter bestimmten Bedingungen Vorteile realisieren, wenn er diese Forderungen erläßt, also quasi verschenkt, oder sie vollständig liquidiert, um sein Vergünstigungspotential auszuweiten ${ }^{2}$.

Durch einen Vergünstigungsstaat wird also das auf konstitutioneller Ebene definierte Interesse der Allgemeinheit bei der Entscheidung über die Subventionsform auf unterschiedliche Art und Weise verletzt. Denn kann ein Vergünstigungsstaat unbeschränkt agieren, wird er durch die Begünstigung spezieller Gruppen postkonstitutionelle Nutzenverteilungen bewirken, die kaum als erwünscht angesehen werden dürften. $\mathrm{Da}$ ein Vergünstigungsstaat bereit ist, gegen eigene Vorteile bestimmten Gruppen Verteilungsvorteile zu verschaffen, setzt er Anreize, Subventionsform-Entscheidungen durch Rent-seeking zu beeinflussen, was eine Ressourcenverschwendung und damit Effizienzkosten impliziert. Darüber hinaus entstehen Effizienzkosten, wenn die Subventionsform-Entscheidung zugunsten von Kredithilfen zu erhöhten Subventionsausgaben führt. Daher werden die Individuen auf konstitutioneller Ebene Restriktionen für den Vergünstigungsstaat

1 So kann es nicht überraschen, daß die Förderung von Humankapitalinvestitionen, die im gegebenen Zusammenhang als Beispiel dienen kann, in der Bundesrepublik zu verschiedenen Zeiten als Zuschußförderung, als Darlehensförderung oder als Mischung von beidem erfolgt ist.

2 Vgl. dazu ausführlich unten die Abschnitte D.II.5.b.bb. und D.II.5.b.cc. 
beschließen, wenn dieses staatliche Verhaltensmodell in ihrem konstitutionellen Kalkül Beachtung findet.

d. Die Relevanz alternativer staatlicher Verhaltensmuster im konstitutionellen Kalkül der Bürger

In einem nächsten Schritt stellt sich die Frage, welches der genannten staatlichen Verhaltensmodelle im konstitutionellen Kalkül der Individuen im Hinblick auf konstitutionelle Regeln entscheidungsrelevant ist. Denn es ist zu erwarten, daß das unterstellte staatliche Verhaltensmuster den Inhalt konstitutioneller Regeln maßgeblich bestimmt ${ }^{1}$. Dabei geht es sowohl um die konstitutionelle Relevanz der einzelnen Verhaltensmodelle, als auch darum, ob die Individuen Regeln für verschiedene denkmögliche postkonstitutionelle Verhaltensmuster des Staates beschließen werden oder ob sie sich auf das wahrscheinlichste Modell als Grundlage für ihre Entscheidungen über die politisch-institutionellen Bedingungen einigen werden.

$\mathrm{Da}$ der Staat im Modell des wohlwollenden Alleinherrschers sich stets so verhält, daß die soziale Wohlfahrt maximiert wird, gibt es in diesem Fall keine logische Grundlage für konstitutionelle Begrenzungen für die Vergabe von Kredithilfen ${ }^{2}$. Daher werden die Individuen auf der konstitutionellen Entscheidungsebene auf Verfassungsregeln für die Vergabe von Kredithilfen verzichten, wenn sie darin übereinstimmen, daß sich der Staat in den postkonstitutionellen Perioden mit Sicherheit als wohlwollender Alleinherrscher verhält.

Allerdings ist es äußerst unwahrscheinlich, daß die Individuen das Modell des wohlwollenden Alleinherrschers für das einzig denkbare Verhaltensmodell des Staates halten werden. Dies wird plausibel, wenn man konstitutionelle Entscheidungen über fiskalische Restriktionen in Analogie zur Privatrechtsordnung betrachtet. Dort zeigt sich, daß das Zivilrecht als "Verfassung" für private Verträge Schutzregelungen für den Fall enthält, daß vertragliche Verpflichtungen vorsätzlich oder fahrlässig nicht oder schlecht erfüllt werden. Solche Schutzregelungen sind in den entsprechenden Gesetzen enthalten, obwohl erwartet werden kann, daß privatrechtliche Verträge ganz überwiegend nur zwischen Individuen zustande kommen, die sich gegenseitig für zuverlässig und ehrlich halten ${ }^{3}$. Für die Kodifizierung privatrechtlicher Schutzbestimmungen kommt es daher entscheidend darauf an, da $\beta$ Unzuverlässigkeit bzw. Unehrlichkeit des Schuldners einer vertraglichen Leistung möglich erscheint.

1 Vgl. BRENNAN/BUCHANAN (1980/1988), S.38.

2 Vgl. BRENNAN/BUCHANAN (1980/1988), S.6.

3 Vgl. BRENNAN/BUCHANAN (1981a), S.161. 
Wenn aber im privaten Rechtsverkehr Schutzregelungen gegen schädigendes Verhalten von Vertragspartnern, die keine unmittelbare Zwangsgewalt besitzen, für notwendig gehalten werden, dürfte dies im Verhältnis zu einem Staat um so eher gelten, der das Monopol zur Ausübung von Gewalt besitzt. Denn "there is at least a strong presumption that individuals do not undergo character transformation when they shift from roles as buyers or sellers in the market-place to roles as (...) politicians, or bureaucrats in the political process"1. Daher ist davon auszugehen, daß das Modell des wohlwollenden Alleinherrscher im konstitutionellen Kalkül der Individuen als irrelevant betrachtet wird, wenngleich sie hoffen oder glauben mögen, daß dieses Modell der Realität in postkonstitutionellen Perioden sehr nahe kommt.

Die Leviathan-Hypothese ist dagegen kaum geeignet, das staatliche Verhalten positiv zu erklären. Denn die vorliegenden positiven Analysen des staatlichen Verhaltens belegen übereinstimmend, daß die staatlichen Akteure zwar einen gewissen Handlungsspielraum zur Verfolgung eigener Interessen abseits der Wählerpräferenzen besitzen. Andererseits widerspricht es allen empirischen Erfahrungen, daß die Akteure eines demokratischen Staates hoheitliche Maßnahmen ohne jede Rücksicht auf die Reaktionen der Wähler durchführen. Somit beschreibt das Leviathan-Modell lediglich die schlechtest denkbaren Ergebnisse des politischen Prozesses. Regeln, die auf dem Leviathan-Modell basieren, beinhalten danach eine Minimax-Strategie, welche die Individuen bei Eintritt des "worst case" schützen sollen ${ }^{2}$.

Positive Analysen des staatlichen Verhaltens lassen hingegen vermuten, daß die Modellierung des Staates als ein von den Nachfragern nach Sondervorteilen abhängiger Vergünstigungsstaat einen hohen positiven Erklärungsgehalt für reale finanzwirtschaftliche Entscheidungen des Staates besitzt. Dies spricht dafür, daß die Individuen auf der konstitutionellen Ebene einem staatlichen Verhalten, wie es durch das Modell des Vergünstigungsstaates beschrieben wird, die höchste Wahrscheinlichkeit zuschreiben.

Welches staatliche Verhaltensmodell werden nun die Individuen ihrem konstitutionellen Kalkül zugrundelegen? Diese Frage ist dann einfach zu beantworten, wenn sich Regeln zum Schutz vor einem Leviathan-Staat und einem Vergünstigungsstaat nicht widersprechen $^{3}$ und wenn diese Regeln in den postkonstitutionellen Perioden keinerlei Kosten für die Bürger verursachen. Unter diesen Bedingungen werden sich die Bürger gegen jede Form schädlichen Staatsverhaltens absichern wollen. Sie werden demnach zum einen

BUCHANAN (1987), S.587.

Vgl. BRENNAN/BUCHANAN (1980/1988), S.XXI, 260. Siehe auch FOLKERS (1986d), S.25.

3 Zur Ableitung einander widersprechender Steuerregeln in Abhängigkeit vom staatlichen Verhaltensmodell vgl. FOLKERS (1986d), S.29 ff. 
Regeln beschließen, die den Leviathan beschränken, und zum anderen solche, die eine Beschränkung des Vergünstigungsstaates implizieren. Dabei ist es unerheblich, wenn Regeln zur Beschränkung des Leviathan im Fall des Vergünstigungsstaates das staatliche Verhalten unbeeinflußt lassen und umgekehrt. Denn konstitutionelle Regeln werden "zu dem Zweck eingeführt, nur dann in Aktion zu treten, wenn die finanzwirtschaftliche Aktivität des Staates gewisse Grenzen überschreitet"1.

Widersprechen sich dagegen die Regeln, die dem Schutz vor einem Vergünstigungsund einem Leviathan-Staat dienen ${ }^{2}$, so ist ein Schutz vor beiden möglichen Konstellationen nicht möglich. Als Kosten der Regeln für den Vergünstigungsstaat müssen daher auf der konstitutionellen Ebene die entgangenen Nutzen bei einem Verzicht auf Regeln für den Leviathan berücksichtigt werden und umgekehrt. Auf welche Regeln verzichtet wird, hängt vom Wahrscheinlichkeitsurteil der Individuen hinsichtlich des Eintretens der einen oder anderen Konstellation, von den möglichen Nettonutzen bei Gültigkeit der jeweiligen Regeln und der Risikopräferenz der Individuen auf der konstitutionellen Ebene, d.h. den erwarteten Opportunitätskosten der jeweiligen Regeln, ab. Ist eine Einigung über die Wahrscheinlichkeit eines Leviathan- bzw. Vergünstigungsstaates nicht möglich, so kann erwartet werden, daß sich die Individuen tendenziell eher gegen den worst case absichern wollen ${ }^{3}$ und somit im Zweifelsfall auf Regeln für den Vergünstigungsstaat verzichten werden. Dies gilt um so mehr, je höher die Risikoaversion der Individuen und die relativen Kosten eines unbeschränkten Leviathan sind ${ }^{4}$.

Außerdem werden die Individuen nur solche Regeln beschließen, die ex ante einen positiven Nettonutzen erwarten lassen ${ }^{5}$. Dies ist insbesondere dann zweifelhaft, wenn bestimmte Regeln "die notwendige Flexibilität für Anpassungen an geänderte Bedingungen und geänderte Wählerpräferenzen verhindern"6. Würde eine Regel staatliches Verhalten unterbinden, welches im Interesse der Allgemeinheit liegt, wird es aus konstitutioneller

1 Vgl. BRENNAN/BUCHANAN (1980/1988), S.106.

2 So können konstitutionelle Steuerregeln für den Leviathan zur Reduzierung des steuerlichen Maximaleinkommens ein Abweichen von der Forderung der traditionellen Steuertheorie nach einer umfassenden Bemessungsgrundlage enthalten, während die konstitutionelle Regeln für den Vergünstigungsstaat tendenziell eine umfassende Steuerbemessungsgrundlage verlangen werden, um unsystematische Ausnahmeregelungen zu verhindern. Vgl. FOLKERS (1986d), S.30.

3 Vgl. BRENNAN/BUCHANAN (1980/1988), S.260.

4 Vgl. BUCHANAN (1987), S.587. Dasselbe Ergebnis kann folgen, wenn die Mehrzahl der Individuen davon ausgeht, da $B$ ein Vergünstigungsstaat für die Bevölkerungsmehrheit vorteilhaft ist.

5 "Regeln werden im Hinblick auf die erwarteten Kosten ihrer Einhaltung aufgestellt." NORTH (1981/1988), S.209.

6 FOLKERS (1983a), S.31. 
Sicht sinnvoll sein, diese Regel entweder durch Ausnahmebestimmungen zu modifizieren ${ }^{1}$ oder ganz zu verwerfen. Allerdings darf nicht angenommen werden, daß nur solche Regeln beschlossen werden, welche die Realisierung der in den Modellen optimaler Finanzpolitik resultierenden Lösungen erlauben. Denn wenn die Individuen auf konstitutioneller Ebene unterstellen, daß der Staat seine finanzwirtschaftlichen Möglichkeiten eben nicht gemäß der theoretischen Optimalitätsbedingungen einsetzt, werden sie es vermutlich in Kauf nehmen, daß durch fiskalische Restriktionen "einige - ohnehin nicht realisierte - Optimierungsmöglichkeiten ausgeschlossen werden"2. Inwieweit die genannten Kosten-NutzenÜberlegungen die Entscheidung über fiskalische Institutionen dennoch beeinflussen können, soll fallweise diskutiert werden. Zunächst soll jedoch eine Klassifizierung möglicher Arten fiskalischer Restriktionen vorgenommen werden.

\section{Arten fiskalischer Restriktionen}

Fiskalische Restriktionen lassen sich generell nach der Art der zu beeinflussenden ökonomischen Zielgrößen bzw. Wirkungszusammenhänge unterscheiden. Dabei sind zwei grundlegende Ansätze zu nennen: verfahrensmäßige und ergebnisbezogene Beschränkungen ${ }^{3}$.

Verfahrensmäßige Restriktionen sind dadurch gekennzeichnet, daß sie "die finanzwirtschaftlichen Ergebnisse indirekt durch Modifikationen des vorgeschriebenen staatlichen Prozesses der finanzwirtschaftlichen Entscheidungsfindung (...) beschränken"4. Diese Wirkung kann darauf basieren, da $B$ solche Restriktionen zu einer effektiveren Kontrolle der staatlichen Entscheidungsfindung durch Wahlen führen und damit die Unvollkommenheiten des Wahlmechanismus mindern ${ }^{5}$. Der Vorteil der verfahrensmäßigen Beschränkungen ist darin zu sehen, daß sie flexible Anpassungen an geänderte wirtschaftliche Konstellationen und gewandelte Wählerwünsche erlauben ${ }^{6}$.

Demgegenüber sind die ergebnisbezogenen Beschränkungen darauf gerichtet, direkte quantitative Grenzen für die geregelten finanzwirtschaftlichen Aktivitäten zu setzen ${ }^{7}$. Sie können damit unmittelbarer wirken als die verfahrensmäßigen Restriktionen. Der Nachteil

1 So zeigt BAUM (1982), S.179 ff., daß eine strikte Budgetausgleichsvorschrift unter bestimmten Bedingungen die Erreichung allokativer und stabilisatorischer Effizienz verhindern kann.

2 FOLKERS (1984), S.505.

3 Vgl. BUCHANAN (1980), S.83; BRENNAN/BUCHANAN (1980/1988), S.245 ff.; FOLKERS (1983a), S.31.

BRENNAN/BUCHANAN (1980/1988), S.255.

Vgl. BRENNAN/BUCHANAN (1980/1988), S.256 f.

6 Vgl. FOLKERS (1983a), S.43.

7 Vgl. BRENNAN/BUCHANAN (1980/1988), S.254; FOLKERS (1984), S.503. 
besteht allerdings darin, da $ß$ die quantitative Fixierung unerwünschter Ergebnisse durch ergebnisbezogene Beschränkungen bei restriktiver Grenzziehung wegen der damit verbundenen Starrheit die Gefahr enthält, zusätzliche Fehlentwicklungen zu verursachen' ${ }^{1}$. Insbesondere ist zu erwarten, daß ergebnisbezogene Grenzen staatliche Ausweichreaktionen induzieren, die unter Umständen wohlfahrtsmindernd sind ${ }^{2}$. Sind die Grenzen hingegen vergleichsweise weit gezogen, werden ergebnisbezogene Beschränkungen kaum effektiv sein und somit ihr Ziel verfehlen. Daher werden auf unbestimmte Dauer angelegte quasi-permanente konstitutionelle Regeln kaum quantitative Restriktionen enthalten ${ }^{3}$.

Löst man sich jedoch von der idealisierten Vorstellung, daß konstitutionelle Entscheidungen stets getroffen werden, bevor der politische Proze $B$ in Gang gesetzt wird, kann dies zu einer positiveren Einschätzung der ergebnisbezogenen Restriktionen führen. Erweisen sich die bestehenden konstitutionellen Regeln im laufenden politischen Entscheidungsproze $\beta$ als unzureichend, um Staatsversagen zu begrenzen, so können ergebnisbezogene Restriktionen als Übergangskonzept zu einer dauernden Regeländerung verstanden werden ${ }^{4}$. Dies gilt insbesondere dann, wenn das Ergebnis des realen politischen Prozesses in einem eindeutig ineffizient hohen Ausmaß bestimmter staatlicher Aktivitäten besteht und ergebnisbezogene Restriktionen leichter durchschaubar und durchsetzbar sind.

\section{Fiskalische Restriktionen für die Vergabe öffentlicher Kredithilfen}

Im folgenden sollen nun verschiedene fiskalische Restriktionen diskutiert werden, mit denen die Anreize für die staatlichen Akteure so verändert werden, daß bei der Wahl von Kredithilfen als Subventionsform das Interesse der Allgemeinheit weitestmöglich gewahrt wird. Dabei sollen zunächst Regeln für einen Leviathan-Staat, daran anschließend solche für einen Vergünstigungsstaat behandelt werden.

1 Vgl. FOLKERS (1983a), S.134; FOLKERS (1984), S.503.

2 Vgl. FOLKERS (1983a), S.50 ff. Weiterhin belegen die empirischen Erfahrungen mit Proposition 13 in Kalifornien, durch die eine quantitative Steuersatzbegrenzung für die property tax eingeführt wurde, daß damit in wesentlichen Bereichen eher eine höhere Ineffizienz induziert wurde. Vgl. FOLKERS (1983a), S.132. Siehe auch TOMA/TOMA (1980), die anhand bürokratietheoretischer Überlegungen zu dem Schluß kommen, da $\beta$ bei ergebnisbezogenen Beschränkungen Wohlfahrtsminderungen möglich sind, sofern Umgehungsaktivitäten der Bürokraten nicht verhindert werden können.

3 Vgl. FOLKERS (1983a), S.134.

4 Vgl. FOLKERS (1986a), S.389; MÄRTZ (1990), S.213. 


\section{a. Kredithilfe-Regeln für den Leviathan}

Die Regeln, die staatliches Leviathan-Verhalten begrenzen sollen, müssen die Möglichkeiten einschränken, daß der Staat durch die Vergabe von Kredithilfen seinen Überschuß erhöht. In diesem Zusammenhang erscheinen ein Verbot der zeitlichen Verschiebung von Subventionsausgaben durch Kredithilfen und Beschränkungen für die Verwendung von Kredithilfe-Einnahmen besonders bedeutsam.

\section{aa. Verbot der zeitlichen Verschiebung von Subventionsausgaben durch Kredithilfen}

Betrachtet man zunächst den Fall eines ewigen Leviathan, so sind Regeln für die Vergabe öffentlicher Kredithilfen vergleichsweise unbedeutend, da ein überschußmaximierender Leviathan bei der Entscheidung zwischen verschiedenen Subventionsformen stets diejenige Form wählen wird, durch die ein bestimmter Subventionszweck mit minimalen Ausgaben erreicht werden kann ${ }^{1}$. Daher sind zu seiner Beschränkung primär solche Regeln erforderlich, die seine Besteuerungsgewalt begrenzen ${ }^{2}$. Auch die zeitliche Verschiebung der Subventionsausgaben durch Kredithilfen stellt im Fall eines ewigen Leviathan eher ein geringes Problem dar, da hiermit ceteris paribus zwar der Zeitstrom, nicht aber der Gegenwartswert des Überschusses verändert wird ${ }^{3}$.

Eine Verschiebung der Subventionsausgaben ist jedoch ungleich dramatischer, wenn ein überschußmaximierender Leviathan nur in einzelnen Perioden erwartet wird, weil auf diese Weise der Gegenwartswert der Steuereinnahmen des Staates erhöht wird ${ }^{4}$. Um die Möglichkeiten des probabilistischen Leviathan zu beschränken, durch die Vergabe von Kredithilfen seine Überschüsse zu erhöhen, liegt es nahe, daß sich die Individuen auf ein Verbot der zeitlichen Verschiebung der Subventionsausgaben einigen werden. Die entsprechende Regel könnte in etwa lauten:

Öffentliche Kredithilfen (Schuldendiensthilfen, Darlehen und Gewährleistungen), dürfen nur gewährt werden, wenn die Subventionskosten im Vergabejahr in voller Höhe ausgabenwirksam sind.

Als Subventionskosten müßten bei öffentlichen Darlehen die Zinsverbilligungskosten, bei Schuldendiensthilfen die abdiskontierten Zuschußausgaben und bei Gewähr-

1 Diese Aussage gilt allerdings nur unter der Bedingung, daß die Wahl der Subventionsform die Höhe der Maximaleinnahmen unbeeinfluBt läBt.

2 Vgl. dazu ausführlich BRENNAN/BUCHANAN (1980/1988).

3 Vgl. BRENNAN/BUCHANAN (1980/1988), S.131 f. zum analogen Problem staatlicher Kreditaufnahme.

4 Vgl. oben Abschnitt D.II.3.b. 
leistungen der Gegenwartswert der erwarteten Ausgaben-Einnahmen-Salden definiert werden.

Allerdings ist es denkbar, daß die zeitliche Verschiebung der Subventionsausgaben in solchen Perioden wünschenswert ist, in denen sich der Staat nicht als Leviathan verhält. Es sei unterstellt, daß die Individuen auf der konstitutionellen Entscheidungsebene erwarten, daß das Angebot öffentlicher Leistungen in einzelnen Perioden vollkommen nachfragebestimmt ist und die Subventionierung bestimmter ökonomischer Aktivitäten zu einer Verbesserung der allokativen Effizienz führt, wobei der Nutzen der Subventionierung erst in den auf die Vergabeperiode folgenden Zeiträumen realisiert werden soll. Unter diesen Bedingungen kann die gegen den probabilistischen Leviathan gerichtete Regel, welche die sofortige Ausgabenwirksamkeit von Subventionsmaßnahmen vorschreibt, bei unvollkommener Voraussicht aufgrund der Falschwahrnehmung der Nutzen der Subventionierung ${ }^{1}$ eine ineffizient niedrige Nachfrage nach Subventionen implizieren. Dies ist dann der Fall, wenn die Nutzenillusion der Wähler die Nachfrage nach Subventionen in stärkerem Maße reduziert als sie durch die Kostenillusion bei der Vergabe von Kredithilfen erhöht wird ${ }^{2}$. Daher kann es sinnvoll sein, die zeitliche Verschiebung von Subventionsausgaben durch Kredithilfen entsprechend dem Ausmaß der Falschwahrnehmung der Nutzen der Subventionierung zuzulassen. Dabei müßte diese ergänzende Bestimmung jedoch garantieren, daß die Nutzenabgabe der Subventionierung mit der Laufzeitenstruktur der Subventionsausgaben zumindest annähernd übereinstimmt ${ }^{3}$. Solche ergänzenden Vorschriften sind aber um so weniger wünschenswert, je höher die von den Individuen auf der konstitutionellen Ebene erwarteten Mitnahmeeffekte bzw. je geringer die realen Nutzen der Subventionierung und je höher die Kostenillusion bei öffentlichen Kredithilfen sind.

Die Zulässigkeit der zeitlichen Verschiebung von Subventionsausgaben durch Kredithilfen aus stabilisatorischen Gründen ist hingegen generell nicht erforderlich. Einigen sich die Individuen beispielsweise auf ein Kreditaufnahmeverbot für dem Staat ${ }^{4}$, so ist

1 Zum entsprechenden Problem bei einem Verbot der Kreditfinanzierung öffentlicher Investitionen vgl. BAUM (1982), S.179.

2 Zum allgemeinen Problem gleichzeitiger Nutzen- und Kostenillusionen vgl. WEST/WINER (1980). Siehe auch BUCHANAN (1967), S.264 f.

3 Zum analogen Fall der Kreditfinanzierung staatlicher Investitionen vgl. BAUM (1982), S.181 f.

4 BRENNAN/BUCHANAN (1980/1988), S.132 halten auch in Notstandssituationen eine staatliche Kreditaufnahme für sehr bedenklich, weil der Staat dadurch einen Anreiz erhält, "Notstandssituationen mit Blick auf ihre Einnahmenimplikationen zu schaffen". Dieses Argument ist im Hinblick auf einen ewigen Leviathan allerdings nur dann überzeugend, wenn eine staatliche "Notstands-Kreditaufnahme" in späteren Perioden die Erhebung zusätzlicher "Notstands-Steuern" zur Finanzierung des Schuldendienstes ermöglicht. 
nicht zu erwarten, daß sie eine Umgehung dieses Verbots durch eine zeitliche Verschiebung der Subventionsausgaben gestatten wollen. Dies gilt vor allem dann, wenn die Individuen die Gefahr von Kostenillusionen bei Kredithilfen aufgrund der fehlenden budgetmäBigen Erfassung in der Vergabeperiode für größer halten als bei der staatlichen Schuldenaufnahme. Gibt es Ausnahmen vom grundsätzlich geltenden Kreditaufnahmeverbot, um dem Staat die stabilisatorischen Handlungsmöglichkeiten $\mathrm{zu}_{\text {bewahren }}{ }^{1}$, so ist eine zeitliche Verschiebung der Subventionsausgaben durch die Vergabe von Kredithilfen entbehrlich, da dies indirekt auch mittels einer Kreditfinanzierung von in der Gegenwart fälligen Subventionsausgaben geschehen kann.

Geht man davon aus, da $B$ die Individuen sich auf eine Regel einigen werden, die es verbietet, durch die Vergabe von Kredithilfen die Subventionsausgaben in die Zukunft zu verschieben, so stellt sich die Frage, wie dieses Verbot praktisch ausgestaltet werden kann.

Zunächst ist es vorstellbar, daß durch Einbeziehung des privaten Sektors die vollständige Ausgabenwirksamkeit von Kredithilfen in der Vergabeperiode erzeugt wird. So kann dem Staat im Fall von Schuldendiensthilfen vorgeschrieben werden, daß diese nur in kapitalisierter Form vergeben werden dürfen. Erscheint eine Auszahlung der kapitalisierten Schuldendiensthilfen unmittelbar an den Empfänger wegen der damit verbundenen Gefahren einer mißbräuchlichen Verwendung unangemessen, kann vorgeschrieben werden, daß die Auszahlung an Dritte erfolgt, welche den kapitalisierten Zuschuß treuhänderisch verwalten und entsprechend den Vorgaben des Kredithilfegebers an den Subventionsempfänger weiterleiten.

Bei öffentlichen Darlehen könnte vorgeschrieben werden, daß die Darlehensforderungen des Staates noch in der Vergabeperiode an private Anleger veräußert werden müssen. Um unsystematische Risiken auszuschalten und damit die Veräußerungserlöse des Staates zu erhöhen, wäre weiterhin vorzuschreiben, daß nicht einzelne Forderungen, sondern "Forderungs-Portfolios" veräußert werden müssen. Unter den Bedingungen eines vollkommenen Kapitalmarktes wird der Erlös des Staates die Darlehenssumme um den Gegenwartswert der Zinsverbilligung unterschreiten ${ }^{2}$. Damit werden die Subventionsausgaben bei öffentlichen Darlehen in vollem Umfang in der Vergabeperiode ausgabenwirksam. Bei Kreditgewährleistungen könnte der Staat in analoger Weise verpflichtet werden, die übernommenen Eventualverbindlichkeiten an private Versicherer abzutreten, wobei an

1 Vgl. dazu BAUM (1982), S.177 f.; FOLKERS (1983a), S.37 f.

2 Vgl. LEONARD (1986), S.104. 
diese ein Betrag zu entrichten wäre, der aus der Differenz der marktlichen und der vom Staat verlangten Prämie abzuleiten wäre ${ }^{1}$.

Alternativ kann dem Staat bei der Vergabe von Kredithilfen die Bildung von Rücklagen vorgeschrieben werden, durch welche die Subventionierung bereits in der Vergabeperiode in vollem Umfang ausgabenwirksam wird. Dabei müßte im Idealfall der Gewartswert der Netto-Subventionsausgaben künftiger Perioden im Jahr der Kredithilfezusage in kapitalisierter Form der jeweiligen Rücklage zugeführt werden. Die Zuführungsbeträge wären dabei im Budget in voller Höhe als Ausgaben zu veranschlagen ${ }^{2}$. Diese Rücklagen werden dann in den auf die Vergabeperiode folgenden Jahren aufgelöst ${ }^{3}$. Darüber hinaus müßten bei Kreditgewährleistungen die Einnahmenüberschüsse in den jeweiligen Perioden budgetneutral als Einnahmen und Ausgaben veranschlagt werden, wobei die Ausgaben durch Zuführung der Überschußbeträge an die entsprechende Rücklage resultieren.

$\mathrm{Zu}$ den Netto-Subventionsausgaben gehört in jedem Fall der Überschuß der Refinanzierungsausgaben über die Kredithilfeerträge. Außerdem wäre der durch Kredithilfen verursachte künftige Verwaltungsaufwand prinzipiell in voller Höhe bei der Rücklagenbildung zu berücksichtigen. Angesichts praktischer Zurechnungsprobleme erscheint ein Verzicht auf die Erfassung des künttigen Verwaltungsaufwands von Kredithilfen jedoch vertretbar, wenn er vom künftigen Verwaltungsaufwand alternativer Subventionsformen nur unwesentlich abweicht.

Während die Umsetzung der genannten Vorschläge bei Schuldendiensthilfen und Darlehen, die nach der "Methode um" verbilligt werden, vergleichsweise einfach ist ${ }^{4}$, sind andere Kredithilfeformen mit weit gravierenderen Problemen verbunden. Da die Höhe der durch öffentliche Darlehen und Kreditgewährleistungen verursachten Nettoausgaben vom Risiko der geförderten Aktivitäten abhängt, besteht die Schwierigkeit, dieses Risiko richtig abzuschätzen. Entsprechende Probleme existieren hinsichtlich der durch staatliche Kredithilfen induzierten Zinsänderungsrisiken, die Risiken für die Höhe der Subventionsausgaben implizieren.

Wird der private Sektor herangezogen, um die sofortige Ausgabenwirksamkeit öffentlicher Kredithilfen zu erzeugen, werden sich erhöhte Subventionsausgaben ergeben,

1 Zu einem ähnlichen Vorschlag vgl. LEONARD (1986), S.104.

2 Vgl. zu diesem Vorschlag CONRAD (1967), S.63 ff.; DICKERTMANN (1980), S.54, 481.

3 Dabei erfolgt die Auflösung bugetneutral, wenn in der Vergabeperiode für die Kredithilfen keine Steuermittel eingesetzt wurden. Die Budgetneutralität wird dadurch erreicht, daB die Entnahmen aus den Rücklagen als Einnahmen und die Netto-Subventionszahlungen in derselben Höhe als Ausgaben veranschlagt werden.

4 Vgl. DICKERTMANN (1980), S.481 f., der aber "aufgrund der ungezählten unterschiedlichen Einzelverträge" auch mit beträchtlichen praktischen Schwierigkeiten rechnet. 
wenn der private Sektor die entsprechenden Risiken in systematischer Weise zu hoch veranschlagt, d.h. wenn Marktversagen bei der Einschaltung des privaten Sektors in die Subventionierung auftritt. Daher dürfte dieser Weg nicht generell zu ökonomisch sinnvollen Ergebnissen führen ${ }^{1}$. Andererseits ist es wahrscheinlich, daß die durch eine Überschätzung des Risikos durch den privaten Sektor möglichen Arbitragegewinne bei längerfristigen Kredithilfeprogrammen nicht dauerhafter Natur sind.

Außerdem gilt auch in diesem Zusammenhang, daß Marktversagen allein noch keine hinreichende Bedingung für eine staatliche Aufgabenübernahme darstellt. Vielmehr muß man auch in diesem Bereich die Möglichkeit von Staatsversagen berücksichtigen. So ist nicht auszuschließen, daß die Abwicklung von Kredithilfen durch den privaten Sektor einen geringeren Verwaltungsaufwand verursacht als die Abwicklung durch den öffentlichen Sektor, weil der private Sektor diese Aufgabe technisch effizienter erfüllt als der öffentliche Sektor ${ }^{2}$. Dazu kommt, daß die Kredithilfeeinnahmen kaum davon unabhängig sein dürften, ob sie einem öffentlichen oder aufgrund eines der genannten Verfahrens einem privaten Gläubiger geschuldet werden. So kann erwartet werden, daß ein privater Gläubiger tendenziell alle rechtlichen Möglichkeiten ausschöpfen wird, um die Erfüllung der ihm zustehenden Forderungen zu erreichen. Dagegen wird der Staat wegen des zu erwartenden politischen Drucks der davon Betroffenen und den damit verbundenen politischen Kosten tendenziell von einer strikten Durchsetzung seiner Rechte absehen. Damit wird ein perverser Anreiz zur Verringerung der Zahlungswilligkeit der Schuldner von Kredithilfe-Forderungen gesetzt ${ }^{3}$. Es sprechen also erhebliche Argumente dafür, daß die Kosten des Staatsversagens höher sind als die Kosten des Marktversagens. Danach wäre die Abwicklung von Kredithilfen durch den privaten Sektor in vielen Fällen wünschenswert.

Entscheiden sich die Individuen auf der konstitutionellen Ebene dennoch für eine öffentliche Abwicklung von Kredithilfen, hätte ein probabilistischer Leviathan den Anreiz, die Kosten des Staatsversagens zu untertreiben, um durch die damit einhergehende Verminderung der Subventionsausgaben in der Gegenwart seinen Überschuß zu erhöhen.

1 Vgl. LEONARD (1986), S.104.

2 Diese Annahme wird durch eine Reihe empirischer Studien gestützt, in denen ein Kosten- bzw. Produktivitätsvergleich zwischen dem öffentlichen und privaten Sektor angestellt werden. Vgl. vgl. z.B. AHLBRANDT (1973); LINDSAY (1976); POMMEREHNE (1976); SPANN (1977). Einen allgemeinen Überblick zur Diskussion über die relative Ineffizienz des öffentlichen gegenüber dem privaten Sektor gibt HORN (1988), S.87 ff.

3 Beispielsweise bemängelt Bundesrechnungshof in seinem Bericht von 1979, daB die Ausfallquote bei den staatlich verwalteten BAFöG-Darlehen bei $30 \%$ liegt, wobei ein erheblicher Teil der Ausfälle auf eine Verschleierung von Einkommens- und Vermögensverhältnisse sowie die Unauffindbarkeit der Schuldner zurückzuführen ist. Demgegenüber liegt z.B. die durchschnittliche Ausfallquote bei privaten Konsumentenkrediten weit unter $1 \%$. Vgl. VAN LITH/ HEMMERT (1982), S.232. 
Dasselbe Ziel kann er durch Untertreibung der Risikohöhe erreichen, wenn Kredithilfen mit Risiken verbunden sind. Dabei läßt sich der Anreiz zur Untertreibung der Subventionsausgaben insbesondere dann nur schwer verhindern, wenn der probabilistische Leviathan nur in einer Periode in Aktion ist. Denn anders als ein ewiger Leviathan hat er die Kosten der Untertreibung in späteren Perioden nicht zu tragen. Daher sollte dem Staat die Abwicklung von Kredithilfen nur dann überlassen werden, wenn Einigkeit darüber herrscht, daß die Einschaltung des privaten Sektors zu erhöhten Subventionsausgaben führen kann. Aus konstitutioneller Perspektive scheint dies am ehesten wahrscheinlich, wenn bezüglich der einzelnen Kredithilfe-Empfänger und der zu fördernden Aktivitäten keine Ex-ante-Informationen vorliegen. Um die Gefahr zu begrenzen, daß ein probabilistischer Leviathan durch Untertreibung der Kosten des Staatsversagen seinen Überschuß erhöhen kann, wäre in diesen Fällen vorzuschreiben, daß sich der Staat bei der Festlegung des $\mathrm{Zu}$ führungsbetrags für die entsprechenden Rücklagen an durchschnittlichen Ex-post-Daten orientieren muß.

Die durch eine Rücklagenbildung entstehenden Finanzmassen können jedoch von einem probabilistischen Leviathan zu seinem eigenen Vorteil verwendet werden. So ist beispielsweise vorstellbar, daß der Leviathan zwar Forderungen in Höhe des Rücklagenbetrages erwirbt, deren Nominalzinssatz jedoch unter dem Marktzinssatz liegt. Die Schuldner dieser Forderungen werden einen um ein Disagio verringerten Auszahlungsbetrag akzeptieren, dessen Höhe bei gegebenem Marktzinssatz vom Nominalzinssatz abhängt. Kann sich der Leviathan den Disagio-Betrag aneignen, so erhöht sich sein Überschuß. Soweit dem Staat die Möglichkeit der Rücklagenbildung nicht verwehrt wird ${ }^{1}$, müssen daher institutionelle Vorkehrungen gegen eine schädliche Anlage der Rücklagenmittel getroffen werden. In diesem Zusammenhang erscheint eine marktliche Anlage der Rücklagenmittel in der Zuführungsperiode und ihre strikte Zweckbindung für Netto-Subventionszahlungen in späteren Haushaltsperioden erforderlich ${ }^{2}$. Dabei darf die Nominalverzinsung der erworbenen Forderung nur dann kleiner sein als Marktzinssatz, wenn der Rückzahlungsbetrag der Hauptforderung den Zuführungsbetrag an die Rücklage überschreitet.

1 Es fällt auf, daß in den für Bund und Länder geltenden haushaltsrechtlichen Vorschriften eine Rücklagenbildung nicht vorgesehen ist. Dagegen sind für die Gemeinden Rücklagen zum Teil zwingend vorgeschrieben. So sind der allgemeinen Rücklage u.a. "rechtzeitig ausreichende Mittel zuzuführen, wenn (...) die Inanspruchnahme aus Bürgschaften (...) die laufende Aufgabenerfüllung erheblich beeinträchtigen würde". Dabei sind die Mittel der Rücklagen "sicher und ertragbringend anzulegen". Vgl. z.B. \$\$ 20, 21 GemHVO/BW.

2 Vgl. DICKERTMANN (1980), S.483. 
bb. Zweckbindung von Kredithilfeeinnahmen

Ein weiteres Problem öffentlicher Kredithilfen besteht darin, daß sie Einnahmenüberschüsse verursachen können. Dabei soll zwischen echten und unechten Einnahmenüberschüssen unterschieden werden. Echte Einnahmenüberschüsse liegen vor, wenn sie die durch Kredithilfen verursachten Ausgaben übersteigen und somit Nettoüberschüsse darstellen. Unechte Einnahmenüberschüsse dagegen sind Bruttoüberschüsse, denen Ausgaben entsprechender Höhe gegenüberstehen, die durch Kredithilfen verursacht sind.

Echte Einnahmenüberschüsse entstehen immer dann, wenn der Staat bei der Vergabe von Kredithilfen Steuern einsetzt, um die künftigen Einnahmenansprüche zu erwerben. Typisches Beispiel hierfür ist die Finanzierung der Darlehenssumme bei öffentlichen Darlehen aus Steuermitteln. In dieselbe Kategorie gehören steuerfinanzierte Rücklagen für Kreditgewährleistungen, deren Höhe einschließlich des Gegenwartswerts der Prämien- und sonstigen Einnahmen aufgrund einer Überschätzung des Risikos den ex post feststellbaren Gegenwartswert der tatsächlichen Netto-Schadensleistungen übersteigt. Unechte Einnahmenüberschüsse kommen zustande, wenn der Erwerb von Einnahmenansprüchen aus Kredithilfen vom Staat kreditfinanziert wird, so daß in den auf das Vergabejahr folgenden Perioden Schuldendienstausgaben für die zurechenbare Staatsschuld entstehen. Bei vollständiger Erfassung der Subventionsausgaben im Vergabejahr reduzieren diese Ausgaben die Netto-Einnahmenüberschüsse in späteren Perioden auf Null ${ }^{1}$. Allerdings wird die Unterscheidung zwischen echten und unechten Einnahmenüberschüssen bei Geltung des Gesamtdeckungsgrundsatzes nahezu unmöglich, weil dann eine direkte Zuordnung der einzelnen Einnahmearten zu den einzelnen Ausgabenposten nicht erfolgt.

Ein Leviathan, der nicht in allen Perioden in Aktion ist, wird sich sämtliche Einnahmenüberschüsse aneignen, wenn es im Hinblick auf ihre Verwendung keine Restriktionen gibt. Dabei kann ein nur in einer Periode agierender Leviathan das gesamte aufgrund von Kredithilfen akkumulierte staatliche Vermögen konsumieren, wenn seine Liquidation zugelassen ist.

Soll die Aneignung von Einnahmenüberschüssen verhindert werden, müssen die Individuen auf der konstitutionellen Ebene Regeln beschließen, welche eine freie Verwendung dieser Überschüsse verbieten. Dieses Ziel kann bei unechten Einnahmenüberschüssen erreicht werden, wenn die gesamten Bruttoeinnahmen aufgrund öffentlicher Kredithilfen zweckgebunden für den Schuldendienst der zu ihrer Finanzierung eingesetzten Kredite zu verwenden sind. Gilt der Grundsatz der Gesamtdeckung, wäre dabei zu fingieren, daß je-

1 D.h. unechte Einnahmenüberschüsse sind in Wirklichkeit budgetneutral. 
der Forderungserwerb als kreditfinanziert gilt, sofern die Nettokreditaufnahme des Staates in der betreffenden Periode die Ausgaben für den Forderungserwerb übersteigt. Damit wird ceteris paribus eine Reduzierung des staatlichen Nettovermögens zugunsten eines probabilistischen Leviathan verhindert. Um eine Umgehung dieser Regel zu vermeiden, muß allerdings sichergestellt sein, daß der Verschuldungsspielraum des Staates um die mit den Einnahmenüberschüssen verbundene Reduzierung der staatlichen Aktiva reduziert wird. D.h. daß eine ergänzende Regel erforderlich ist, die eine staatliche Nettokreditaufnahme maximal bis zur Höhe der staatlichen Nettoinvestitionen erlaubt.

Ist der Forderungserwerb steuerfinanziert, kann die Aneignung echter Einnahmenüberschüsse auf zweierlei Arten restringiert werden. Einmal kann vorgeschrieben werden, $\mathrm{da} ß$ die Einnahmenüberschüsse zweckgebunden für Steuersenkungen einzusetzen sind, damit die Steuerzahler einen Ausgleich für die in früheren Perioden entrichteten "überschüssigen" Steuern erhalten. D.h. die steuerlichen Maximaleinnahmen wären in Perioden mit echten Einnahmenüberschüssen aus Kredithilfen in deren Umfang zu kürzen.

Die andere Alternative besteht in dem Gebot, echte Einnahmenüberschüsse nur für die mit der Kredithilfegewährung verfolgten Zwecke zu verwenden. Bei Darlehen wären danach Zins- und Tilgungseinnahmen sowie die Erlöse einer entgeltlichen Abtretung von Darlehensforderungen, wie es in der Bundesrepublik Deutschland z.B. für Rückflüsse der Wohnungsbaudarlehen vorgesehen ist ${ }^{1}$, erneut zur Vergabe von Darlehen für den entsprechenden Zweck einzusetzen. Wird die Zweckbindungsvorschrift auf die Entnahmen aus einer vorgeschriebenen Rücklage für Zinsverbilligungen ausgedehnt, deren Zuführungen ebenfalls steuerfinanziert sind, erhöht sich der Nominalbestand der Darlehensforderungen bei als unverändert angenommenen Konditionen nur relativ geringfügig ${ }^{2}$. Im Fall von Überschüssen bei der Rücklagenbildung für Kreditgewährleistungen könnte vorgeschrieben werden, daß die Überschußbeträge für die Verbilligung von weiteren Kreditgewährleistungen zu verwenden $\operatorname{sind}^{3}$.

1 Allerdings gilt hier die Zweckbindungsvorschrift unabhängig von der Art der Finanzierung des Forderungserwerbs.

2 Geht man vereinfachend davon aus, daß in der Ausgangsperiode bei einem Marktzinssatz von $\mathbf{r}$ einperiodige, unverzinsliche öffentliche Darlehen in Höhe von $\mathrm{K}_{1}$ gewährt werden, sind Rücklagen $R_{1}$ für Zinsverbilligungen in Höhe von $r K_{1} /(1+r)$ zu bilden. Durch die Darlehensvergabe entstehen also in der ersten Periode Ausgaben in Höhe von $K_{1}+R_{1}$. Der Einnahmenüberschuß nach einer Periode beträgt $(1+r) K_{1}$. Bei einer zweckgebundenen Verwendung dieser Einnahmen läßt sich die Darlehenshöhe der zweiten Periode $K_{2}$ folgendermaßen bestimmen: $K_{2}=K_{1}(1+r)^{2} /(1+2 r)$. Da der Zähler des Terms auf der rechten Seite um $r^{2}$ größer ist als der Nenner, gilt $K_{2}>K_{1}$ bzw. $K_{2}-K_{1}=r^{2} K_{1} /(1+r)$.

3 Demgegenüber will DICKERTMANN (1980), S.482 derartige Überschußbeträge dem Budget als allgemeine Deckungsmittel zuführen, weil er, ohne dies näher zu begründen, eine Zweckbindung hier nicht für zweckmäßig hält. 
Wenngleich eine Zweckbindung staatlicher Einnahmen geeignet erscheint, einen Leviathan-Staat zu begrenzen ${ }^{1}$, so ist eine Zweckbindung für eine fortgesetzte Subventionierung dann problematisch, wenn sich der Staat in einzelnen postkonstitutionellen Perioden als wohlwollender Alleinherrscher verhält. Das Problem der Zweckbindung von Einnahmen besteht darin, daß hierdurch "einzelne Ausgabenzwecke (...) gewissermaßen privilegiert werden, während sich die anderen Aufgabengebiete der Staatstätigkeit nach der Decke der sonstigen Einkünfte strecken müssen" und somit "die Gleichwertigkeit der Staatszwecke durchbrochen"2 wird. Da die zweckgebundenen Einnahmen den Mindestumfang der betreffenden Kredithilfeausgaben markieren ${ }^{3}$, wird der Staat an einer optimalen Allokation der Ressourcen gehindert, wenn die zweckgebundenen Einnahmen das effiziente Ausma $B$ der Ausgaben übersteigt. Da das Modell des wohlwollenden Alleinherrschers kaum Ähnlichkeiten mit der Realität aufweist, ist dies jedoch kaum als wesentliches Argument gegen eine Zweckbindungsvorschrift anzusehen ${ }^{4}$.

Agiert der Staat in den Perioden ohne Leviathan-Verhalten dagegen entsprechend dem Modell des Vergünstigungsstaates, ist für ihn eine Zweckbindung der Einnahmenüberschüsse für eine fortgesetzte Subventionierung regelmäßig vorteilhaft. Während zweckgebundene Steuern eine präferenzgerechtere Bereitstellung öffentlicher Leistungen bewirken können ${ }^{5}$, lassen sich aus der Höhe der Einnahmenüberschüsse aufgrund von Kredithilfen früherer Perioden kaum Rückschlüsse auf die Präferenzen der in den Einnahmenperioden lebenden Individuen für eine Fortdauer der Subventionierung ziehen. Eine entsprechende Zweckbindung für die Einnahmenüberschüsse stellt aber eine Barriere gegen einen Subventionsabbau dar. Dies ist besonders problematisch, wenn die Subventionierung bestimmter Aktivitäten innerhalb eines bestimmten Zeitraums allokativ wünschenswert ist, in späteren Perioden jedoch zu einer allokativ schädlichen Subventionierung oder einer reinen Umverteilungsmaßnahme degeneriert. Unter diesen Bedingungen kann der Staat Sondervorteile ausschütten, für die er von den Begünstigten in irgendeiner Form belohnt wird, während seine Kosten für die Gewährung dieser Vergünstigungen gering sein werden. Denn zum einen kann der Staat darauf verweisen, daß ihm durch die Zweckbindungsvorschrift die alternative Verwendung der Mittel verwehrt ist. Damit kann der Widerstand der Verlierer der fortgesetzten Subventionierung gering gehalten werden. Zum anderen werden die Individuen der späteren Perioden den Nutzenent-

1 Zur Frage zweckgebundener Steuereinnahmen vgl. BRENNAN/BUCHANAN (1980/1988), $\mathrm{S} .170 \mathrm{ff}$.

2 SCHMÖLDERS (1970), S.74.

3 Vgl. FECHER (1963), S.42.

4 Vgl. BRENNAN/BUCHANAN (1980/1988), S.191.

5 Vgl. BUCHANAN (1963). Siehe auch FOLKERS (1983a), S.34. 
gang, der bei früheren Generationen unter der Annahme unvollkommener Voraussicht durch die zur Finanzierung der Kredithilfen verwendeten Steuerzahlungen entstanden ist, tendenziell als "sunk costs" ${ }^{1}$ betrachten. Damit sind die Steuerzahlungen der früheren Generationen für den in späteren Perioden agierenden Vergünstigungsstaat politische sunk costs. D.h. die Subventionierung mit Hilfe der zweckgebundenen Einnahmen impliziert für den Vergünstigungsstaat (nahezu) keine Opportunitätskosten und wird für ihn somit zum "free lunch".

Erkennen die Individuen auf der konstitutionellen Ebene die genannten Zusammenhänge, so ist die fortgesetzte Subventionierung bestimmter Aktivitäten aufgrund vorhandener zweckgebundener Einnahmen ex ante nicht kostenlos, da die unbeschränkte Zweckbindung eine alternative Mittelverwendung verhindert. Einigen sich die Individuen dennoch auf eine Zweckbindung der echten Einnahmenüberschüsse aus Kredithilfen für eine fortgesetzte Subventionierung, dann kann erwartet werden, daß sie zusätzliche Regeln beschließen, durch die den staatlichen Akteuren in postkonstitutionellen Perioden trotz der Zweckbindung Opportunitätskosten bei der Subventionierung mittels zweckgebundener Einnahmen erwachsen. So könnte vorgeschrieben werden, daß der Staat in jeder Periode bei der Verwendung der Einnahmenüberschüsse zwischen den Alternativen Steuersenkung versus fortgesetzte Subventionierung zu entscheiden hat. Während ein Leviathan zwischen beiden Alternativen indifferent wäre, hätte ein Vergünstigungsstaat stets die politischen Nutzen der einen Alternative mit den politischen Kosten des Verzichts auf die andere Alternative abzuwägen, so daß eine fortgesetzte Subventionierung aufgrund des Zweckbindungsgebots nicht determiniert wäre. In dieselbe Richtung geht das Konzept der sogenannten sunset legislation ${ }^{2}$, das verhindern soll, daß bestimmte Ausgabenprogramme für unbegrenzte Zeit beschlossen werden. Danach wäre nach Ablauf eines gewissen Zeitraums, der länger als eine Periode sein könnte, die Entscheidung zwischen den genannten Zweckbindungsalternativen zu treffen. Damit läßt sich vermeiden, daß eine Subventionierung durch Kredithilfen, die mit echten Einnahmenüberschüssen finanziert werden, für einen Vergünstigungsstaat auf unbegrenzte Dauer kostenlos ist. Wollen Individuen die Risiken einer fortgesetzten Subventionierung generell vermeiden, werden sie sich jedoch wahrscheinlich auf eine Zweckbindung echter Einnahmenüberschüsse für Steuersenkungen einigen.

1 "Sunk costs (...) are costs that (...) cannot be eliminated (...). As such, once committed, sunk costs are no longer a portion of the opportunity cost (...)." Siehe BAUMOL/PANZAR/ WILLIG (1982), S.280.

2 Vgl. dazu z.B. FOLKERS (1983a), S.39 f. 


\section{b. Regeln für den Vergünstigungsstaat}

Während durch Regeln für den Leviathan verhindert werden soll, daß sich der Staat durch die Vergabe von Kredithilfen zusätzliche Überschüsse aneignen kann, sind Regeln für den Vergünstigungsstaat primär darauf gerichtet, kollektiven Interessen widersprechende Begünstigungsmaßnahmen für einzelne Gruppen zu reduzieren, die bei unbeschränkter Vergabe von Kredithilfen möglich sind ${ }^{1}$. Dabei ist es das Ziel von solcher Regeln, die Opportunitätskosten der Kredithilfevergabe weitestmöglich offenzulegen, um damit die natürlichen Neigungen des Staates zur Gewährung von Sondervorteilen durch den Wahlprozeß effektiver beschränken zu können ${ }^{2}$. Darüber hinaus ist sicherzustellen, $\mathrm{da}$ sonstige konstitutionelle Regeln, die den Staat beschränken sollen, nicht durch die Entscheidung für Kredithilfen als Subventionsform umgangen werden können.

Das Verbot, die Subventionsausgaben durch die Vergabe von Kredithilfen in die Zukunft zu verschieben, ist nicht nur zur Beschränkung eines probabilistischen Leviathan, sondern auch eines Vergünstigungsstaates geeignet. Denn dadurch wird es dem Vergünstigungsstaat erschwert, rationale Ignoranz hinsichtlich der Kosten einer Subventionierung durch Kredithilfen zu erzeugen, die zu einer Erhöhung der Subventionsausgaben führt. Darüber hinaus sind jedoch auch mehrere Regeln denkbar, die primär auf eine Beschränkung eines Vergünstigungsstaates gerichtet sind.

Im folgenden werden verschiedene verfahrensmäßige Restriktionen für Kredithilfen diskutiert, die den Vergünstigungsstaat beschränken können. Dabei handelt es sich um das Gebot der Wahl der ausgabenminimalen Subventionsform, Grundsätze für die Abfolge von Subventionsentscheidungen, Beschränkungen für den Erlaß und die entgeltliche Veräußerung von durch Kredithilfen erworbenen staatlichen Forderungen, Anreizmechanismen zur korrekten Abschätzung von Kredithilfe-Risiken, das Verbot einer Zinsverbilligung nach der "Methode auf", die umfassende Publizitätspflicht für Kredithilfen, die Vorschrift, daß maximale Subventionsintensitäten anhand der Subventionsausgaben zu bemessen sind, und das Verbot einer Festlegung außerbudgetärer Subventionseinrichtungen auf Kredithilfen. Darüber hinaus sind bestimmte ergebnisbezogene Restriktionen zur Beschränkung des Vergünstigungsstaates denkbar, wie die Begrenzung der Ausgaben für Kredithilfen auf einen bestimmten Anteil an den gesamten Subventionsausgaben oder die Festsetzung einer Obergrenze für die Relation des Haftungsvolumens aufgrund von Kreditgewährleistungen zur Budgethöhe.

1 Zur allgemeinen Zielsetzung von Regeln für den Vergünstigungsstaat vgl. FOLKERS (1986d), S.30.

2 Vgl. BRENNAN/BUCHANAN (1980/1988), S.18 f. 
aa. Gebot der ausgabenminimalen Subventionsform

Wie gezeigt, können Kredithilfen unter bestimmten Bedingungen zu einer Minimierung von Subventionsausgaben führen. Dagegen wird ein Vergünstigungsstaat unter Umständen ausgabenintensivere Subventionsformen bevorzugen, obwohl der die minimalen Ausgaben übersteigende Betrag keine positiven allokativen Effekte erzeugen kann.

Einigen sich die Individuen auf der konstitutionellen Ebene darauf, daß Subventionen nur dann gewährt werden dürfen, wenn allokative Verbesserungen zumindest möglich sind, werden sie dem Staat zwingend vorschreiben, daß er sich bei jedem einzelnen Subventionsprogramm der ausgabenminimalen Subventionsform zu bedienen hat. D.h. der Staat muß zuerst prüfen, ob der Subventionszweck durch Kreditgewährleistungen bzw. Darlehen, bei denen erwartete Einnahmen und Ausgaben übereinstimmen, erreicht werden kann. Andernfalls können verschiedene Subventionsformen in Betracht gezogen werden, die positive Nettoausgaben verursachen, die aber in ihrer Höhe auf einen Anteil an den Ausgaben des Subventionsempfängers für die geförderten Aktivitäten begrenzt sind. Nur im Extremfall dürfen diese Aktivitäten vollständig durch verlorene Zuschüsse des Staates finanziert werden.

Das Problem liegt hier jedoch weniger in der Vorschrift selbst als in ihrer praktischen Durchsetzung. Denn es ist offenkundig, daß ein Vergünstigungsstaat, der aus einer ausgabenintensiveren Subventionsform Vorteile ziehen kann, stets behaupten wird, die jeweils ausgabenminimale Subventionsform anzubieten. Daher kann erwartet werden, daß die Individuen das Gebot der ausgabenminimalen Subventionsform durch weitere Vorschriften ergänzen werden, deren Verletzung die Rechtswidrigkeit des ganzen Subventionsprogramms zur Folge hat. So könnte vorgeschrieben werden, daß der Staat für jedes geplante Subventionsprogramm den Subventionszweck zu konkretisieren sowie explizit darzulegen hat, warum der Subventionszweck mit einer "billigeren" Subventionsform nicht zu erreichen ist. Dabei müßten die angeführten Gründe für den Verzicht auf eine billigere Subventionsform zumindest vertretbar und nachvollziehbar sein ${ }^{1}$. Wenngleich diese Vorschriften nicht sehr restriktiv wären, würden sie die Rechtskontrolle der staatlichen Subventionsformentscheidung erleichtern und dadurch begrenzende Wirkungen hervorrufen.

$1 \mathrm{Zu}$ einer vergleichbaren Darlegungslast des Haushaltsgesetzgebers bei Überschreitung der Verschuldungsgrenze des Art. 115 Abs.1 S.2 GG vgl. BUNDESVERFASSUNGSGERICHT (1989), S.344 f. Diese Darlegungslast wird von GANDENBERGER (1990), S.39 f., insbesondere Fn.18 ebenfalls als verfahrensmäßige konstitutionelle Restriktion interpretiert. 
bb. Grundsätze für die Abfolge von Subventionsentscheidungen

Jede Subventionsentscheidung läßt sich gedanklich in mehrere Teilentscheidungen aufspalten. So muß entschieden werden, welcher Subventionszweck verfolgt werden soll, wie hoch die Subventionsausgaben sein sollen und welche Subventionsform gewählt werden soll. Sind die Subventionsausgaben festgelegt und werden sie gleichmäßig an die Subventionsempfänger verteilt, so wird deren Anzahl durch die Wahl des bestimmt.

Es sei angenommen, daß die Entscheidung über den Subventionszweck zuerst zu treffen ist. Liegt die Abfolge der weiteren Entscheidungen im Ermessen des Staates, so wird ein Vergünstigungsstaat im nächsten Schritt regelmäßig über die Subventionsform entscheiden. Denn auf diese Weise kann bei gegebenem Empfängerkreis eher verschleiert werden, welche Subventionsform im konkreten Fall ausgabenminimal ist. Andererseits kann der Vergünstigungsstaat durch die Wahl von Kredithilfen Fiskalillusion erzeugen und damit das Subventionsvolumen erhöhen. Daher wäre eine Regel sinnvoll, nach der die Entscheidung über die Höhe der Subventionsausgaben vor der Subventionsformentscheidung zu treffen ist.

Bei Geltung dieser Regel hätte ein Abweichen von der ausgabenminimalen Subventionsform zur Folge, daß die Zahl der Subventionsempfänger sinken würde. Unterstellt man einen fallenden Grenznutzen des Einkommens, dürfte die Entscheidung für die ausgabenintensivere Subventionsform bei gegebenen Subventionsausgaben die Opposition gegen die Subventionierung verstärken und den Nettoertrag der staatlichen Akteure vermindern. Daher wird der Staat tendenziell dazu veranlaßt, Kredithilfen anzubieten ${ }^{1}$ und die Subventionsausgaben auf eine größere Zahl von Subventionsempfängern zu verteilen. Wenngleich damit nur eine Reduzierung der Subventionsausgaben je Subventionsempfänger erreicht werden kann, ist dieses Ergebnis dennoch wünschenswert, wenn die Individuen auf der konstitutionellen Ebene darüber einig sind, daß Mitnahmeeffekte bei der Subventionierung dem Interesse der Allgemeinheit widersprechen. Außerdem entfällt durch diese Regel für einen Vergünstigungsstaat der Anreiz, Kredithilfen nur deshalb anzubieten, um die Subventionsausgaben erhöhen zu können.

1 Dieses Ergebnis weist Ähnlichkeiten zum budgetbeschränkten Angebot öffentlicher Güter durch die Bürokraten im Modell von NISKANEN auf, wonach der Output der Bürokraten durch eine Begrenzung des bereitgestellten Budgets reduziert werden kann. Vgl. NISKANEN (1971), S.46 f. 
cc. Beschränkungen für den Erlaß von Kredithilfe-Forderungen

Ist der Erlaß von Forderungen, die durch die Kredithilfevergabe erworben wurden, uneingeschränkt möglich, wird ein Vergünstigungsstaat einen Schuldenerlaß immer dann durchführen, wenn er dadurch für sich Nettovorteile erzielen kann. Dies ist insbesondere dann möglich, wenn ein Vergünstigungsstaat nur in einzelnen Perioden in Aktion ist, so daß er die politischen Kosten der entgangenen Zukunftseinnahmen nicht tragen muß.

Erkennen die Individuen auf der konstitutionellen Ebene, daß durch einen ungebundenen Schuldenerlaß regelmäßig keine allokativen Verbesserungen möglich sind, werden sie sich auf ein Verbot eines Schuldenerlasses einigen. Damit soll verhindert werden, daß die Schuldner solcher Forderungen einseitige Verteilungsvorteile realisieren können, die in der Periode des Erlasses für die Steuerzahler weitgehend im Verborgenen bleiben. Das Verbot des Schuldenerlasses ist insoweit unproblematisch, als dadurch die Möglichkeit von Transferzahlungen an die Schuldner von Kredithilfe-Forderungen aus distributiven Gründen nicht berührt wird.

Ein Schuldenerlaß könnte jedoch unter der Bedingung zugelassen werden, daß im Budget Ausgaben in Höhe des Gegenwartswerts der erlassenen Forderungen als Zuführung zu einer Rücklage für entgangene Einnahmen veranschlagt werden. Formal müssen die Rücklagenbeträge in den Folgeperioden vereinnahmt werden. Da diese Einnahmen jedoch nur fiktiv sind, sind in den jeweiligen Perioden Ausgaben derselben Höhe zu veranschlagen, so da $\beta$ der Schuldenerla $\beta$ in den Folgeperioden budgetneutral wirkt. Um einem willkürlichen Schuldenerlaß eines Vergünstigungsstaates vorzubeugen, kann zusätzlich vorgesehen werden, daß er nur unter speziellen Bedingungen, wie z.B. einer extremen wirtschaftlichen Notlage des Schuldners ${ }^{1}$, vorgenommen werden darf, die auch eine Transferzahlung an den Schuldner rechtfertigen würde.

\section{dd. Beschränkungen für die entgeltliche Veräußerung von Kredithilfe-Forderungen}

Für einen Vergünstigungsstaat kann jedoch auch die entgeltliche Veräußerung von Kredithilfe-Forderungen vorteilhaft sein. Es sei unterstellt, daß die Nettovorteile eines Vergünstigungsstaats vom Bestand der Forderungen aus öffentlichen Darlehen abhängen. D.h. daß durch Tilgung dieser Darlehensforderungen der Nutzen für den Vergünstigungsstaat abnimmt. Dabei wird aus Vereinfachungsgründen angenommen, daß die Schuldner der Darlehensforderungen gegenüber alternativen Gläubigern indifferent sind. Der An-

1 Vgl. hierzu $\$ 59$ BHO und seine Kommentierung in PIDUCH (1990), Anm.5. 
fangsbestand der Darlehensforderungen sei steuerfinanziert, wobei für die gewährten Zinsverbilligungen Rücklagen zu bilden seien, die ebenfalls steuerfinanziert sein sollen. Weiterhin sei für sämtliche Darlehenseinnahmen eine Zweckbindung für öffentliche Darlehen vorgesehen.

Unter diesen Bedingungen besitzt ein Vergünstigungsstaat den Anreiz, durch Veräußerung dieser Darlehensforderungen den Bestand an zinsverbilligten Darlehensforderungen zu erhöhen. Im folgenden wird unterstellt, daß der Staat unverzinsliche öffentliche Darlehen mit einer Laufzeit von einer Periode vergibt. Unter den unrealistischen Annahmen eines vollkommen elastischen Kapitalangebots und unendlicher Transaktionsgeschwindigkeit wird der Vergünstigungsstaat die im Zeitpunkt $t_{0}$ durch die anfängliche Darlehensgewährung erworbenen Forderungen $K_{1}$ sofort wieder veräußern. Bei einem Marktzinssatz von $r$ kann der Staat damit einen Veräußerungserlös von $K_{1} /(1+r)$ sowie Einnahmen aus der Auflösung der Rücklage in Höhe von $\mathrm{rK}_{1} /(1+r)$ liquidieren. D.h. die gesamten Einnahmen betragen $K_{1}$. Diese Einnahmen kann der Staat in einer zweiten Runde erneut zur Vergabe öffentlicher Darlehen verwenden. Die Darlehenssumme $\mathrm{K}_{2}$ der zweiten Runde beträgt $K_{1}[(1+r) /(1+2 r)] .{ }^{1}$ Der Staat kann die dadurch erworbenen Forderungen wiederum veräußern, um die daraus resultierenden Einnahmen zur erneuten Darlehensvergabe zu verwenden. Wiederholt sich der ganze Proze $\beta \mathrm{n}$ mal und strebt $\mathrm{n}$ gegen unendlich, dann gilt $K_{n}=0$, da $[(1+r) /(1+2 r)]<1$ ist. D.h. die gesamten ursprünglich eingesetzten finanziellen Mittel bzw. das durch die erste Darlehensvergabe erworbene staatliche Vermögen werden aufgrund der wiederholten Veräußerung der Forderungen restlos aufgezehrt. Andererseits ergibt sich ein maximaler Bestand an zinsverbilligten Darlehensforderungen von $\mathrm{K}_{1}(1+2 \mathrm{r}) / \mathrm{r}^{2}$

Nehmen die Individuen die Vorteile des staatlichen Vermögens als Potential für künftige private oder öffentliche Konsumausgaben nicht wahr und existiert der Vergünstigungsstaat nur in $\mathrm{t}_{0}$, dann wird er Darlehensforderungen so oft veräußern, bis das gesamte staatliche Vermögen aufgezehrt und der Darlehensbestand maximiert wird. Dagegen wird er die Wiederholung der Veräußerung der Forderungen um so früher abbrechen, je besser die Individuen die Opportunitätskosten der entgangenen Zukunftseinnahmen aufgrund der Darlehensforderungen wahrnehmen. Dasselbe gilt, wenn das Kapitalangebot nicht vollkommen elastisch ist, weil dann die wiederholte Veräußerung der Darlehensforderungen zu einem Anstieg des Marktzinssatzes führen wird, wodurch zunehmend die Anbieter sonstiger Vermögenstitel bzw. die jeweils marginalen Kapitalnachfrager verdrängt werden und

1 Es gilt: $K_{2}+r K_{2} /(1+r)=K_{1}$ :

2 Die Zinsverbilligungskosten dieses Bestandes belaufen sich auf $K_{1}(1+2 r) /(1+r)$, was genau der Höhe der ursprünglich für die Darlehensvergabe eingesetzten finanziellen Mitteln entspricht. 
die inframarginalen Kapitalnachfrager Rentenverluste erleiden. Außerdem wird ein in allen Perioden agierender Vergünstigungsstaat, dessen Zeitpräferenzrate kleiner unendlich ist, einen höheren Nutzen realisieren können, wenn er einen Teil der Darlehensforderungen behält, da er dann in späteren Perioden über zusätzliche Einnahmen verfügt, die er in einer für ihn vorteilhaften Art und Weise verausgaben kann.

Dieses Beispiel belegt dennoch, daß ein Vergünstigungsstaat aus allokativer Sicht ungleich gefährlicher sein kann als ein Leviathan-Staat. Denn ein Leviathan wäre an der entgeltlichen Veräußerung von Darlehensforderungen nicht interessiert, weil er dadurch unter den genannten Bedingungen seinen Überschuß nicht erhöhen könnte. Dagegen wird ein Vergünstigungsstaat den Individuen in der gegebenen Situation außerordentlich hohe Wohlfahrtskosten auferlegen. Denn die Ausweitung der Subventionen durch die wiederholten Forderungsabtretungen wird regelmäßig Mehrbelastungen hervorrufen und außerdem zusätzliche Rent-seeking-Aktivitäten induzieren ${ }^{1}$. Dementsprechend wäre ohne Zweckbindung die Aneignung des Anfangsbestandes der Darlehensforderungen durch einen probabilistischen Leviathan nach seiner einmaligen Veräußerung gegenüber dem Fall des probabilistischen Vergünstigungsstaates allokativ vorteilhafter, weil der Leviathan den Forderungserlös tendenziell eher in allokativ neutraler Weise verwenden würde.

Daher werden die Individuen auf der konstitutionellen Ebene auch gerade dann die entgeltliche Veräußerung von Darlehensforderungen beschränken, wenn die Erlöse zweckgebunden für eine erneute Subventionierung zu verwenden sind. Dabei ist denkbar, daß sich die Individuen zu einem generellen Verbot der entgeltlichen Veräußerung von Forderungen aus öffentlichen Darlehen entschließen. Damit würde zugleich das Potential des Staates zur Ausweitung der Subventionierung begrenzt.

Sieht man von möglichen intertemporalen Verteilungseffekten bei unvollkommener Voraussicht der Individuen ab, ist dieses Verbot allerdings nicht erforderlich, wenn eine Zweckbindung der Kredithilfe-Einnahmen für Steuersenkungen bzw. Tilgungen der Staatsschuld besteht. Denn dann wird eine Veräußerung der Forderungen lediglich zu einer Vorverlagerung von Steuersenkungen bzw. Schuldentilgungen führen. D.h. daß eine entsprechende Zweckbindung für Kredithilfe-Einnahmen tendenziell eine hinreichende Beschränkung für die Veräußerung von Darlehensforderungen wäre. Allerdings ist kaum zu erwarten, daß die Individuen auf der konstitutionellen Ebene gegenüber jeder Form von Steuersenkungen indifferent sind. Bleibt diese konstitutionell unbestimmt, besitzt der Ver-

1 "Der Umfang der Rent-Seeking-Aktivitäten hängt vom Ausmaß der potentiellen Renten einer gruppenspezifisch vorteilhaften Veränderung der Fiskalstruktur ab (...)." Siehe MÄRTZ (1990), S.173. 
günstigungsstaat dadurch wiederum einen Spielraum zur Vergabe spezieller Vergünstigungen. Darauf soll hier jedoch nicht näher eingegangen werden.

ee. Anreizmechanismen zur korrekten Abschätzung von Kredithilfe-Risiken

Im folgenden wird unterstellt, daß der Staat die Höhe des Gegenwartswerts der zu erwartenden Subventionsausgaben für Kredithilfen selbst festlegen kann, indem er eine Rücklage für künftige Zahlungen zu bilden hat. Hängen die Subventionsausgaben für eine Kredithilfe von unsicheren künftigen Umweltzuständen ab, wird ein Vergünstigungsstaat die in der Gegenwart zu veranschlagenden Subventionsausgaben stets relativ gering veranschlagen wollen, da die "hidden costs" der Risikountertreibung von ihm stark abdiskontiert werden ${ }^{1}$.

Um dieser Tendenz entgegenzuwirken, wurde als Vorkehrung gegen einen Leviathan eine Vorschrift diskutiert, wonach die erwarteten Subventionsausgaben unter Berücksichtigung von Ex-post-Daten festzulegen sind. Dies genügt jedoch im Hinblick auf einen Vergünstigungsstaat nicht, weil er, anders als ein von der Begünstigung spezieller Gruppen unabhängiger Leviathan, gegebenenfalls Vorteile realisieren kann, wenn er in der Gegenwart mit Kredithilfen bewußt ein höheres Risiko übernimmt als in der Vergangenheit. Demzufolge müssen zusätzliche Regeln vorgesehen werden, um einen Vergünstigungsstaat zu begrenzen. Als ergänzender Mechanismus könnte daher vorgeschrieben werden, daß nachträgliche Subventionsausgaben aufgrund einer Untertreibung des Risikos in der Vergabeperiode in späteren Perioden durch automatische, proportionale Ausgabenkürzungen bei anderen Ausgabenpositionen des Budgets zu decken sind ${ }^{2}$. Durch einen solchen Kürzungsautomatismus sieht sich der Vergünstigungsstaat der Gefahr ausgesetzt, daß in $\mathrm{Zu}$ kunft gerade auch in solchen Bereichen Ausgabenkürzungen erfolgen, die einen besonders hohen politischen Ertrag versprechen. D.h. daß sich durch einen solchen Kürzungsautomatismus die Kosten einer Untertreibung von Risiken für den Vergünstigungsstaat erhöhen. Dies gilt allerdings nur in den Fällen, in denen sich der Staat in mehreren aufeinanderfolgenden Perioden als Vergünstigungsstaat verhält.

Vielfach wird ein Vergünstigungsstaat unter Hinweis auf eine mangelnde Abschätzbarkeit der Risiken die Veranschlagung von Subventionsausgaben gänzlich zu umgehen su-

1 Vgl. PENNER/SILBER (1972), S.662.

2 Einen vergleichbaren Mechanismus enthält das Gramm-Rudman-Hollings-Gesetz in den USA, das auf einen Abbau des US-amerikanischen Haushaltsdefizits abzielt. Dabei sind Ausgabenkürzungen vorgesehen, wenn bestimmte, vorab festgelegte Zielgrößen für die Höhe des Budgetdefizits in den einzelnen Haushaltsjahren verfehlt werden. Vgl. dazu FOLKERS (1986a). 
chen. Damit lassen sich unter Umständen Subventionsausgaben größeren Ausmaßes in spätere Perioden verschieben. Außerdem lassen fehlende Vorstellungen über die Risikohöhe keinerlei Rückschlüsse über die allokative Wünschbarkeit staatlicher Risikoübernahme zu. Daher sollten sich die Individuen auf eine Regel einigen, daß der Staat Risiken nur übernehmen darf, wenn er den möglichen Schadensfällen Wahrscheinlichkeiten zuordnet.

\section{ff. Beschränkungen für Zinsverbilligungen nach der "Methode auf"}

Im Falle einer Zinsverbilligung ${ }^{1}$ nach der "Methode auf" durch Kredithilfen besteht für einen Vergünstigungsstaat die Möglichkeit, bei gegebenen Subventionsausgaben den Kredithilfe-Empfängern, deren Kreditrisiken überdurchschnittlich hoch sind, Sondervorteile zukommen zu lassen. Diese Sondervorteile sind für die dadurch benachteiligten Individuen kaum sichtbar, sofern die "Methode auf" für alle KredithilfeEmpfänger dieselben Konditionen, z.B. denselben Zinssatz für öffentliche Darlehen, vorsieht. Dadurch wird der falsche Eindruck vermittelt, daß der Vorteil aus den Kredithilfen für alle Empfänger gleich hoch ist.

Geht man davon aus, daß solche Sondervorteile allokativ nicht zu rechtfertigen sind, werden die Individuen auf der konstitutionellen Ebene den Spielraum dafür zu begrenzen suchen. Demnach ist es vorstellbar, da $\beta$ sich die Individuen auf eine Regel einigen, wonach eine Zinsverbilligung nach der "Methode auf" nur zugelassen ist, wenn der fixierte Zinssatz entsprechend dem Risiko des jeweiligen Empfängers variiert. Damit wird ausgeschlossen, daß einzelne Empfänger erhöhte Vorteile realisieren können.

Allerdings besteht dann für den Staat der Anreiz zu behaupten, daß Einzelrisiken nicht identifizierbar seien und deshalb einheitliche Konditionen festzulegen seien. Um dies zu verhindern, könnten sich die Individuen auch auf ein generelles Verbot der Zinsverbilligung nach der "Methode auf" einigen. Danach können Zinsverbilligungen allein nach der "Methode um" erfolgen. Auf diese Weise wird sichergestellt, daß die effektive Zinsverbilligung bei einheitlichen Konditionen für alle Kredithilfe-Empfänger gleich hoch ist. Will der Staat die Empfänger mit höherem Risiko in stärkerem $M a ß$ begünstigen, muß er für sie einen höheren Zinsverbilligungssatz festlegen. D.h. er muß offen dokumentieren, da $\beta$ er zwischen den Empfängern mit unterschiedlichem Risiko diskriminieren möchte. Eine solche sichtbar diskriminierende Behandlung der verschiedenen Empfänger wird die Opposi-

1 Die Ausführungen gelten für Prämiensatzverbilligungen im Fall von Kreditgewährleistungen entsprechend. 
tion der dadurch Benachteiligten und damit die politischen Kosten der Gewährung von Sondervorteilen erhð̌hen. Deshalb enthält die Regel, welche eine Zinsverbilligung nach der "Methode um" vorschreibt, eine Begrenzung des Vergünstigungsstaates.

Diese Regeln würden jedoch auf ein Verbot der Vergabe öffentlicher Darlehen und Kreditgewährleistungen hinauslaufen, sofern zwischen den Empfängern tatsächlich nicht differenziert werden kann. Da unter bestimmten Bedingungen mit diesen Kredithilfeformen Wohlfahrtssteigerungen möglich werden, können Ausnahmeregeln vorgesehen werden, wenn der Staat mangels Information tatsächlich daran gehindert ist, zwischen verschiedenen (Gruppen von) Kredithilfe-Empfängern zu unterscheiden. In diesen Fällen könnte eine Zinsverbilligung auf einen bestimmten Zinssatz zugelassen werden. Allerdings wäre es sinnvoll, die Einführung solcher Ausnahmetatbestände an qualifizierte Mehrheiten zu knüpfen, "um die Schwelle für die Einführung gruppenspezifischer Sondervorteile höher"1 zu setzen.

\section{gg. Umfassende Publizitätspflicht für Kredithilfen}

Die Gewährung von Sondervorteilen durch Kredithilfen wird für den Vergünstigungsstaat erleichtert, wenn er über Kredithilfen in geringerem Maß Informationen bereitzustellen hat als über anderen Formen der Subventionierung. Denn aufgrund der höheren Informationskosten bei Kredithilfen werden die Individuen ihre Opportunitätskosten weniger wahrnehmen als bei Subventionsformen, bei denen eine umfassende Publizitätspflicht für den Staat vorgeschrieben ist.

Daher kann erwartet werden, daß auf der konstitutionellen Ebene beschlossen wird, daß der Staat über sämtliche Subventionsformen dieselbe Informationsmenge bereitzustellen hat. Dadurch kann ein informationsbedingter Bias zugunsten von Kredithilfen verhindert werden, der ansonsten dem Vergünstigungsstaat die Ausweitung seiner Subventionsaktivitäten erlaubt.

Wird für alternative Subventionsformen vorgeschrieben, daß ihre Opportunitätskosten im Rahmen einer Subventionsberichterstattung vollständig darzustellen sind ${ }^{2}$, müssen auch sämtliche Kredithilfen und deren Opportunitätskosten veröffentlicht werden. D.h. daß anders als im Subventionsbericht der Bundesrepublik auch Kreditgewährleistungen zu erfassen sind ${ }^{3}$. Außerdem sind bei öffentlichen Darlehen in der Vergabeperiode

FOLKERS (1985), S.299.

2 D.h. daB z.B. bei Investitionszuschüssen die in der Vergabeperiode entstehenden Ausgaben und bei Steuervergünstigungen die entgangenen Einnahmen aufzuführen sind.

Vgl. DICKERTMANN (1980), S.487. 
nicht die Darlehensausgaben, sondern die abdiskontierten Zinsverbilligungsausgaben, bei Schuldendiensthilfen nicht die periodischen Zuschußzahlungen sondern ebenfalls die abdiskontierten Ausgaben aufzuführen. Bei Kreditgewăhrleistungen müssen danach die erwarteten Nettoausgaben aufgeführt werden. Dabei muß sichergestellt werden, da $B$ die Ermittlung der Subventionsausgaben nach einem überprüfbaren Verfahren erfolgt, das den Manipulationsspielraum des Staates so weit als möglich beschneidet ${ }^{1}$.

Die Erfüllung dieser Publizitätspflichten ist bei öffentlichen Kredithilfen nicht mit höheren Administrationskosten verbunden als bei anderen Subventionsformen, sofern die Subventionsausgaben von Kredithilfen im Vergabejahr ebenfalls in vollem Umfang veranschlagt werden. Daher kann erwartet werden, daß die Individuen eine "Ausdünnung" der Publizitătspflichten für Kredithilfen aufgrund behaupteter unverhältnismäßig hoher Administrationskosten nicht zulassen.

Die Bedeutung solcher Publizitătspflichten kann allerdings relativiert werden, wenn durch geeignete Regeln sichergestellt werden kann, daß Subventionsformentscheidungen erst nach Festlegung der Subventionsausgaben getroffen werden.

hh. Bemessung maximaler Subventionsintensitäten an den Subventionsausgaben

Ein steigender Subventionssatz verursacht zunehmende relative Wohlfahrtsverluste ${ }^{2}$ und erhöht unter bestimmten Bedingungen die Wahrscheinlichkeit von Mitnahmeeffek$\operatorname{ten}^{3}$. Daher werden die Individuen bestimmen, daB die Subventionsintensität, d.h. das Verhältnis des Gegenwartswerts der Netto-Subventionsleistungen zu den Ausgaben für die geförderten Aktivitäten, auf einen bestimmten Wert zu begrenzen ist ${ }^{4}$.

Es wurde bereits darauf hingewiesen, daß bei Kredithilfen sowohl die Ermittlung der periodischen Netto-Subventionsleistungen als auch des Gegenwartswerts dieser periodischen Leistungen mit Schwierigkeiten verbunden sein kann. Würde bei riskanten Kredithil-

1 Vgl. DICKERTMANN (1980), S.489.

2 Verursacht beispielsweise die Standortverlagerung eines Unternehmens bestimmte private Kosten, wird sie nur durchgeführt werden, wenn der daraus resultierende Nutzen einschließlich dem Nutzen aus der Subventionierung diese Kosten übersteigt. Unterstellt man, daß diese durch Subventionen induzierte Standortverlagerung allokativ schädlich ist und die entsprechenden privaten Kosten fix sind, wird die Verlagerung um so eher durchgeführt, je höher der Vorteil aus der Subventionierung ist.

3 Im Fall unteilbarer Projekte genügt eine Subventionierung bestimmter Höhe, um ihnen über die Rentabilitätsschwelle zu verhelfen. Wird die Subventionierung über das erforderliche MaB hinaus ausgedehnt, werden dadurch nur noch Mitnahmeeffekte hervorgerufen.

4 Auf diese Weise werden die Beihilferegeln der EG erklärbar, welche die zulässige Subventionshöhe auf bestimmte Nettosubventionsäquivalente begrenzen. 
fen zur Bestimmung der Subventionsintensität der risikolose Marktzinssatz als Alternativzinssatz bzw. Diskontrate zugelassen, so würde die Subventionsintensität von Kredithilfen zu gering ausgewiesen ${ }^{1}$. Ein Vergünstigungsstaat, der durch die Überschreitung der maximal zulässigen Subventionsintensităt Vorteile realisieren könnte, hätte daher einen Anreiz, Kredithilfen als Subventionsform zu wählen, um diese Begrenzung zu umgehen.

Daher müssen die Individuen eine Regel beschließen, die den Anreiz zur Umgehung maximal erwünschter Subventionsintensitäten durch Kredithilfen vermeidet oder zumindest verringert. In diesem Zusammenhang kann vorgeschrieben werden, daß die Subventionsintensität von Kredithilfen mittels der im Vergabejahr zu veranschlagenden Subventionsausgaben für Kredithilfen zu bestimmen ist. Alternativ dazu könnte festgelegt werden, daß zur Ermittlung der Subventionsintensität bei der Förderung riskanter Aktivitäten ein Zinssatz als Bezugssatz bzw. Diskontierungsrate zu wählen ist, der den risikolosen Marktzinssatz um einen gewissen Prozentsatz überschreitet. Dieser Zuschlagssatz sollte sich dabei an Ex-post-Daten desselben oder vergleichbarer Kredithilfeprogramme orientieren. Auf diese Weise läßt sich zumindest sicherstellen, daß der Anreiz zu solchen Umgehungsaktivitäten gemindert wird, wenngleich sie damit nicht restlos verhindert werden können.

ii. Verbot einer Festlegung außerbudgetärer Subventionseinrichtungen auf Kredithilfen

Unterstellt man, daß sich die durch außerbudgetäre Einrichtungen vergebenen Subventionen tendenziell eher der Kontrolle der Wähler bzw. Steuerzahler entziehen, wird ein Vergünstigungsstaat versuchen, Subventionsaktivitäten auf solche Einrichtungen zu verlagern, da er auf diese Weise ihre Kosten verschleiern und das Ausmaß der Subventionierung ausweiten $\mathrm{kann}^{2}$. Ist für die relevanten außerbudgetären Einrichtungen festgelegt, da $B$ sie ausschließlich Kredithilfen vergeben dürfen, wird ein Vergünstigungsstaat durch Einbeziehung außerbudgetärer Einrichtungen also auch den an den Subventionsausgaben bemessenen relativen Anteil der Kredithilfen an den gesamten Subventionsausgaben erhöhen.

Sind außerbudgetäre Subventionseinrichtungen zugelassen, so werden die Individuen auf der konstitutionellen Ebene vorschreiben, daß diese Einrichtungen nicht auf Kredithilfen als Subventionsform festgelegt werden dürfen. Dies gilt um so eher, wenn Kredithilfen als Subventionsinstitution z.B. aufgrund der Unsicherheit über die ex post tatsächlich anfallenden Subventionsausgaben tendenziell zu Kostenillusionen führen.

1 Vgl. oben Abschnitt B.IV. und D.II.2.a.dd.ddd.

2 Siehe dazu ausführlich unten Abschnitt D.III. Vgl. auch WILDAVSKY (1986), S.261 f. 


\section{ij. Ergebnisbezogene Restriktionen}

Im Verlauf der Diskussion haben sich vielfältige Argumente dafür ergeben, daß die unrestringierte Vergabe offentlicher Kredithilfen zu einer unerwünschten Ausdehnung der Subventionierung führen kann. Lassen sich die daran ansetzenden verfahrensmäßigen Restriktionen kurzfristig politisch nicht umsetzen, können als Übergangskonzepte zur Beschneidung der Vergabe offentlicher Kredithilfen ergebnisbezogene Restriktionen in Betracht gezogen werden.

Berücksichtigt man, daß sich gerade bei Kreditgewăhrleistungen die erwarteten Subventionsausgaben leicht verschleiern lassen und sie andererseits, wie immer wieder deutlich wird, immense Haushaltsrisiken implizieren, könnte eine quantitative Begrenzung für die Übernahme von Kreditgewăhrleistungen sinnvoll sein. Solange die Risiken der Haftungsübernahmen der jeweiligen Perioden nicht spezifiziert werden, scheint die gesamte Haftungssumme als Indikator für die bestehenden Risiken aus Gewährleistungen am ehesten geeignet. Danach läßt die Haftungssumme Rückschlüsse auf mögliche budgetäre Belastungen zu. Da jedoch weniger das absolute Ausmaß der Haftungssumme als vielmehr ihre Relation zur Budgethöhe problematisch ist, bietet es sich an, die Relation zwischen der Haftungssumme aus Gewährleistungen und der Budgethöhe auf einen maximalen Prozentsatz zu beschränken. Diese Obergrenze könnte beispielsweise durch das arithmetische Mittel dieser Relation für einen längeren Zeitraum bestimmt werden. Zur Erreichung dieser Obergrenze könnte für eine Übergangsperiode vorgeschrieben werden, daß die Summe der Haftungszusagen in jedem Haushaltsjahr beispielsweise die Hälfte der Summe der Enthaftungen nicht überschreiten darf.

Eine alternative ergebnisbezogene Restriktion könnte den Anteil der Ausgaben für öffentliche Kredithilfen an den gesamten Subventionsausgaben im Budget auf einen bestimmten Prozentsatz beschränken. Abgesehen von der Bestimmung dieses Prozentsatzes besteht hierbei die Schwierigkeit, die Gesamtheit der Subventionsausgaben in geeigneter Weise abzugrenzen. Außerdem werden die Ausgaben für Kredithilfen nach den geltenden Budgetierungsverfahren durch das Ausma $B$ der Kredithilfevergabe der Vorperioden determiniert. Daher müßte die Restriktion in der Weise ausgedehnt werden, daß neue Kredithilfen nur gewährt werden dürfen, sofern sie in den Folgeperioden nicht zu einer Überschreitung dieser Obergrenze führen.

Beide genannten Restriktionen weisen das für ergebnisbezogene Restriktionen typische Problem auf, daß sie gegen staatliche Umgehungsaktivitäten keinen Schutz bieten. Insbesondere wäre es möglich, durch eine Verlagerung von Kredithilfemaßnahmen auf 
außerbudgetäre Einrichtungen die formale Erfüllung dieser Restriktionen sicherzustellen, ohne daß die damit verfolgte Zielsetzung, die Einschränkung von Kredithilfeaktivitäten, erreicht wäre. Hieraus wird bereits deutlich, daß die politisch-institutionelle Analyse öffentlicher Kredithilfen ohne eine Analyse außerbudgetärer Einheiten unvollständig bleibt.

\section{POSITIVE ERKLĀRUNGSANSÄTZE FÜR AUSSERBUDGETÄRE EINHEITEN}

Während bei der positiven Analyse öffentlicher Kredithilfen untersucht wurde, wie Entscheidungen zugunsten von Kredithilfen als einer von mehreren möglichen Subventionsformen erklärt werden können, sollen in diesem Abschnitt positive Erklärungsansätze für außerbudgetäre Einheiten als alternative Organisationsformen der Subventionierung gegenüber der budgetären Vergabe öffentlicher Kredithilfen analysiert werden. Da die auBerbudgetären Einheiten zum Untersuchungsgegenstand der sogenannten Gemeinwirtschaftslehre gehören, soll zuerst deren Sichtweise dieser Organisationsformen im Rahmen eines knappen Exkurses diskutiert werden. In einem nächsten Schritt werden die theoretischen Grundlagen für eine politisch-ökonomische Analyse außerbudgetärer Einheiten dargestellt. Danach wird untersucht, inwieweit die Errichtung außerbudgetärer Einheiten als Strategie einer Koalition aus Nachfragern nach öffentlichen Kredithilfen und staatlichen Akteuren zur Erlangung spezieller Vorteile dienen kann. Daran anschließend werden Bedingungen herausgearbeitet, unter denen die Errichtung außerbudgetärer Einheiten aus konstitutioneller Perspektive wünschenswert sein kann. Dabei sollen Sondervermögen und Sonderkreditinstitute als Varianten außerbudgetärer Einheiten, soweit möglich, getrennt betrachtet werden.

\section{Exkurs: Außerbudgetăre Einheiten aus der Sicht der Gemeinwirtschaftslehre}

Die Gemeinwirtschaftslehre ist eine Forschungsrichtung, deren dogmenhistorische Wurzeln in der älteren kameralistischen Finanzwissenschaft zu sehen sind ${ }^{1}$. Sie beschäftigt sich mit allen gemeinwirtschaftlichen Organisationseinheiten, zu denen insbesondere die öffentlichen Unternehmen gezählt werden ${ }^{2}$. Neben den hier zu untersuchenden Sonderkreditinstituten werden von der Gemeinwirtschaftslehre auch Sondervermögen analysiert ${ }^{3}$.

\footnotetext{
Vgl. THIEMEYER (1975), S.15.

Vgl. THIEMEYER (1975), S.33 f.

Vgl. THIEMEYER (1975), S.79.
} 
Die vorrangige Fragestellung der Gemeinwirtschaftslehre bezieht sich darauf, unter welchen Bedingungen eine bestimmte Leistungserstellung durch öffentliche statt durch private Unternehmen erfolgen soll. Öffentliche Unternehmen sollen dabei "nur dann und insoweit tätig werden (...), als privatwirtschaftliche Wirtschaften die Zwecke (der öffentlichen Unternehmen, der Verf.) nach politisch vorherrschender Auffassung nicht ebensogut verwirklichen können" ${ }^{\text {"1 }}$ Insoweit ist die Gemeinwirtschaftslehre als normativer Theorieansatz zu verstehen ${ }^{2}$.

Andererseits läßt sich die Gemeinwirtschaftslehre auch als positiver Erklärungsansatz interpretieren. Denn bei öffentlichen bzw. gemeinwirtschaftlichen Wirtschaftseinheiten wird regelmäßig angenommen, daß sie im öffentlichen Interesse tätig sind ${ }^{3}$ und dem $\mathrm{Ge}$ meinwohl dienen ${ }^{4}$. Weiterhin wird unterstellt, daß z.B. die Errichtung von Sonderkreditinstituten "in historisch aktuellen Notwendigkeiten der politischen Umstände ${ }^{n 5}$ begründet ist und demzufolge im öffentlichen Interesse liegt. D.h. die Errichtung von Sonderkreditinstituten wird implizit damit erklärt, daß sie aus normativer Sicht wünschenswert sind.

In diesem Zusammenhang stellt sich die Frage, was die Gemeinwirtschaftslehre unter öffentlichem Interesse versteht. Dazu wird ausgeführt, daß die Bestimmung des öffentlichen Interesses in einer parlamentarischen Demokratie "eine Angelegenheit der persönlichen Entscheidung möglichst vieler natürlicher Personen sein muß. Die Personengesamtheit stellt einen Katalog von individuellen Artikulationen auf, was sie als im öffentlichen Interesse liegend versteht (...)." Danach liegt die Errichtung von Sonderkreditinstituten immer dann im öffentlichen Interesse, wenn der Gesetzgeber dies bejaht. Da außerbudgetäre Einheiten auf der Grundlage spezieller Gesetze errichtet werden, ist danach zu folgern, da $B$ zum Errichtungszeitpunkt stets ein öffentliches Interesse vorhanden gewesen sein $\mathrm{muB}^{7}$, weil der Staat ansonsten auf die Errichtung verzichtet hätte. Auf diese Weise gerät die Argumentation jedoch zum bloßen tautologischen Gedankenspiel ${ }^{8}$.

Weit gravierender ist jedoch die Annahme, daß laufende politische Entscheidungen das jeweils geltende öffentliche Interesse bestimmen. Damit wird nämlich die Erkenntnis

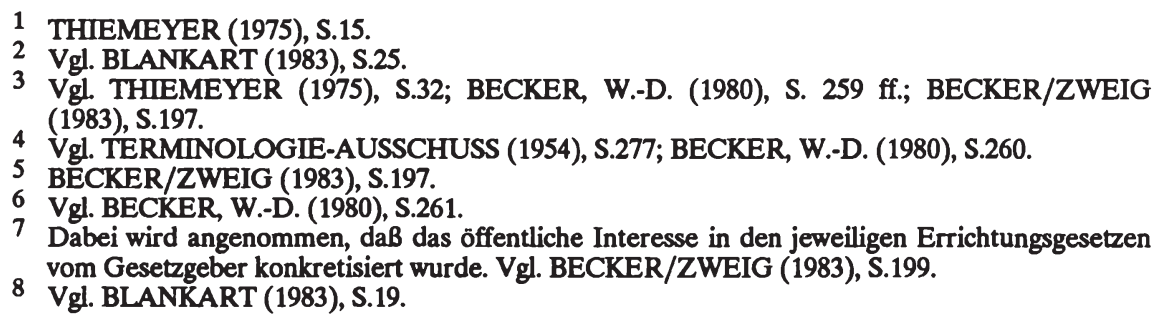

THIEMEYER (1975), S.15.

Vgl. BLANKART (1983), S.25.

3 Vgl. THIEMEYER (1975), S.32; BECKER, W.-D. (1980), S. 259 ff.; BECKER/ZWEIG (1983), S.197.

4 Vgl. TERMINOLOGIE-AUSSCHUSS (1954), S.277; BECKER, W.-D. (1980), S.260.

5 BECKER/ZWEIG (1983), S.197.

6 Vgl. BECKER, W.-D. (1980), S.261.

7 Dabei wird angenommen, daB das öffentliche Interesse in den jeweiligen Errichtungsgesetzen vom Gesetzgeber konkretisiert wurde. Vgl. BECKER/ZWEIG (1983), S.199.

Vgl. BLANKART (1983), S.19. 8 
der modernen politischen Ökonomie ignoriert, daß aus dem laufenden demokratischen Willensbildungsprozeß keinesfalls zwingend stabile soziale Präferenzen resultieren, die sich auf individuelle Präferenzen zurückführen lassen ${ }^{1}$. Dies bedeutet in der logischen Konsequenz, daß die Gemeinwirtschaftslehre bei der Bestimmung sozialer Präferenzen der normativen Kraft des Faktischen Vorrang vor den individuellen Präferenzen eingeräumt wird. D.h. daß jedes beliebige, "demokratisch legitimierte" staatliche Verhalten ex post als normativ wünschenswert erscheint. Danach ist jedoch der Spielraum für eine alternative Erklärung außerbudgetärer Einheiten weitgehend verbaut.

Diese Einschätzung ändert sich nur partiell, wenn man den zweiten wesentlichen Baustein der Gemeinwirtschaftslehre, die sogenannte Instrumentalthese, betrachtet. Sie besagt, da $B$ öffentliche Wirtschaftseinheiten Instrumente der Wirtschaftspolitik ihrer Träger sind ${ }^{2}$. Die Instrumentalfunktion öffentlicher Wirtschaftseinheiten setzt voraus, da $B$ bestimmte Ziele formuliert sind, denen sie dienen sollen ${ }^{3}$. Im Zusammenhang mit den hier behandelten außerbudgetären Einheiten werden in erster Linie strukturpolitische Zielsetzungen ${ }^{4}$ und damit wirtschaftspolitische Lenkungsaufgaben genannt, die mit Hilfe dieser Einrichtungen verfolgt werden sollen ${ }^{5}$. Dazu gehören regionalpolitische Ziele ebenso wie betriebsgrößenbezogene und branchenstrukturelle Ziele. Darüber hinaus werden auch sozialpolitische Ziele genannt, die beispielsweise im Bereich der Wohnungsbauförderung maßgeblich sein sollen ${ }^{6}$.

Gleichzeitig wird in bezug auf die Sonderkreditinstitute anerkannt, daß sie "neben der indirekten Durchsetzung öffentlicher Interessen durch gesetzliche Auflagen, Gebote und Verbote, sowie durch Anreize und Transfers und neben der direkten Aufgabenwahrnehmung durch Verwaltungen ${ }^{\text {7 }}$ nur eines von mehreren möglichen Instrumenten zur staatlichen Aufgabenbewältigung darstellen. Sie sollen immer dann als Instrument gewählt werden, wenn die Vorteile selbständiger Wirtschaftsführung, Eigenverantwortlichkeit und Flexibilität bei der Lösung anstehender Probleme die entscheidende Rolle spielen 8 . Allerdings bleibt unklar, unter welchen Bedingungen diese Vorteile entscheidend sein

1 Vgl. BLANKART (1983), S.21.

Vgl. THIEMEYER (1975), S.28; KIRCHHOFF (1987), S.27.

3 Vgl. PÜTTNER (1983), S.698; THIEMEYER (1975), S.28.

4 Zur entsprechenden Begründung für das ERP-Sondervermögen vgl. z.B. THIEMEYER (1975), S.86.

5 Vgl. KIRCHHOFF (1987), S.30.

6 Vgl. THIEMEYER (1975), S.83 ff., 101; KIRCHHOFF (1987), S.32 f., 87 ff.

7 KIRCHHOFF (1987), S.28.

8 Vgl. LAUX (1976); MÜLLER-KÄSTNER (1986), S.8 
sollen ${ }^{1}$. Außerdem wird in der Regel kaum diskutiert, inwieweit diesen Vorteilen auch Nachteile bzw. Kosten gegenüberstehen können ${ }^{2}$ und welche Gruppen durch außerbudgetäre Einheiten Vorteile bzw. Nachteile zu erwarten haben. Dadurch wird die Frage umgangen, wie gegebenenfalls die Errichtung außerbudgetärer Einheiten erklärt werden kann, die Netto-Wohlfahrtsverluste erwarten lassen.

Nach alledem erscheint die Gemeinwirtschaftslehre als wenig geeignet, um die Errichtung von außerbudgetären Kredithilfe-Einheiten ökonomisch zu erklären. Daher ist es erforderlich, die Fragestellung mit einem leistungsfähigeren theoretischen Instrumentarium zu analysieren.

\section{Analytische Grundlagen politisch-ökonomischer Erklărungsansătze für außerbudge- tăre Einheiten}

Ausgangspunkt der politisch-ökonomischen Analyse ist die Feststellung, daß unterschiedliche Organisationsformen zugleich unterschiedliche institutionelle Bedingungen für die staatlichen Akteure und die privaten Wirtschaftssubjekte implizieren. Danach ist zu erwarten, daß die individuellen ökonomischen Entscheidungen durch die Wahl außerbudgetärer Einheiten als Organisationsform beeinflußt werden ${ }^{3}$. Für die Erklärung außerbudgetärer Einheiten kommt somit den differentiellen Wirkungen der Vergabe von Kredithilfen durch budgetäre und außerbudgetäre Organisationseinheiten entscheidende Bedeutung zu. Denn auf diese Weise lassen sich die Interessen spezifizieren, die zur Errichtung außerbudgetärer Einheiten führen können.

Allerdings geht es hierbei weniger um die differentiellen Wirkungen bei der Anpassung an gegebene Kredithilfemaßnahmen. Denn wie bei budgetären Kredithilfen werden durch außerbudgetäre Kredithilfen bestimmte ökonomische Aktivitäten, insbesondere Investitionen, gefördert. Sieht man von Mitnahmeeffekten ab, wird beispielsweise durch außerbudgetäre wie durch budgetäre Investitionskredithilfen in dem Ausmaß eine Reallokation der Ressourcen in Richtung des geförderten Sektors induziert, bis sich die Nettoertragsraten im geförderten und nichtgeförderten Sektor ausgleichen. D.h. daß die Bruttoertragsrate des Kapitals in den geförderten Sektoren geringer ist als in den anderen Sektoren. Sofern die Förderung nicht zu einer Internalisierung externer Effekte führt, verursa-

1 So bedarf es nach KAGE (1978), S.48 "keiner besonderen Begründung, solange der Staat eigene verwaltungsnahe Aufgaben aus Zweckmäßigkeitsgründen durch ein Bankinstitut erledigen läßt." Siehe auch KIRCHHOFF (1987), S.194.

2 Vgl. BLANKART (1983), S.27.

3 Vgl. BUCHANAN (1967), S.7 f. 
chen auch außerbudgetäre Kredithilfen Mehrbelastungen und damit soziale Wohlfahrtsverluste ${ }^{1}$.

Wesentlich sind vielmehr die differentiellen Wirkungen außerbudgetärer Einheiten im Hinblick auf den politischen Prozeß und die damit gegebenenfalls verbundenen Rückwirkungen auf private Entscheidungen. Dabei kommt es darauf an, ob die Errichtung außerbudgetärer Einheiten aus Entscheidungen des laufenden politischen Prozesses resultiert oder auf einem konstitutionellen Kalkül der Individuen beruht ${ }^{2}$. Der Unterschied wird deutlich, wenn man den ökonomischen Prozeß als Spiel interpretiert. Im ersten Fall erscheint die Errichtung außerbudgetärer Einheiten lediglich als Fixierung einer Strategie $^{3}$ für eine Koalition von Spielern ${ }^{4}$ im Rahmen gegebener Spielregeln. Dabei unterscheidet sich die Strategie von einem Spielzug dadurch, daß sie eine Reihe von Spielzügen im Rahmen des politisch-ökonomischen Spiels determiniert ${ }^{5}$. Erfolgt die Errichtung einer außerbudgetären Einheit hingegen durch konstitutionelle Entscheidung, so werden die Regeln des Spiels verändert und damit die möglichen Strategien der Spieler begrenzt. So macht es einen erheblichen Unterschied, ob eine Eishockey-Mannschaft die Strategie festlegt, im Fall eines knappen Rückstands eine Minute vor dem Spielende den Torwart vom Eis zu nehmen, oder ob diese Verhaltensweise von den Eishockey-Regeln zwingend vorgeschrieben wird. Denn während eine Strategie von den einzelnen Spielern bzw. der Koalition von Spielern einseitig festgelegt und prinzipiell jederzeit abgeändert werden kann, erfordert die Abänderung von Regeln ein weitgehend konsensuales Vorgehen aller Spieler. Daraus folgt, daß die Errichtung außerbudgetärer Einheiten dann als konstitutionelle Entscheidung interpretiert werden kann, wenn sie von allen Individuen zumindest annähernd einstimmig beschlossen worden ist. Somit ist es im gegebenen Zusammenhang vergleichsweise unbedeutend, ob die Errichtungsentscheidung formalrechtlich eine Verfassungsentscheidung darstellt oder nicht.

1 Vgl. WAGNER (1983), S.351; BUCHANAN/FLOWERS (1987), S.168.

2 Die Notwendigkeit einer strikten Abgrenzung zwischen konstitutionellen Entscheidungen und Entscheidungen des laufenden Prozesses betont BUCHANAN (1975/1984).

3 A strategy is defined as a complete plan of action-specifying behavior for any player to follow conditional on any contingency he might find himself in." SCHOTTER/SCHWÖDIAUER (1980), S.485 (Hervorhebung im Original).

4 "In the formal theory a coalition can be any subset of players (...), considered in the context of their possible collaboration." SHUBIK (1982), S.19.

5 Eine vollständige Strategie zeichnet sich dabei dadurch aus, daß sie Spielanweisungen für alle denkmöglichen Spielsituationen enthält, "so that a secretary or agent or programmed computer could play the game on behalf of the original player without ever having to return for further instructions." SHUBIK (1982), S.34. Bei unvollkommener Information ist es jedoch regelmäßig sinnvoll, wenn der Spieler seine Verhaltensstrategien an die sich im Spielablauf ändernde Informationslage anpaBt. 
Unabhängig davon, welchem Kalkül die Errichtung außerbudgetärer Einheiten entspringt, gilt stets, daß außerbudgetäre Einheiten für einen längeren Zeitraum errichtet werden. Daraus folgt, daß außerbudgetäre Einheiten mit Ressourcen ausgestattet werden, für die es verschiedene mögliche Verwendungsrichtungen gibt. Es ist unmittelbar einsichtig, daß nicht alle betroffenen Individuen dieselbe Verwendungsrichtung präferieren werden. Somit impliziert die Errichtung einer außerbudgetären Einheit ein Konfliktpotential für die Dauer ihres Bestehens. Um zu verhindern, daß die Austragung der möglichen Konflikte zu einer weitgehenden Ressourcenverschwendung führt, werden für jede außerbudgetäre Einheit Regeln beschlossen, welche die verfügbaren Optionen der Individuen für den Zeitraum nach ihrer Errichtung beschränken ${ }^{1}$ und dadurch den Prozeß der Verteilung der Vorteile aus der Errichtung außerbudgetärer Einheiten steuern.

Die Unterscheidung zwischen außerbudgetären Einheiten, die als Ergebnis des laufenden politischen Prozesses zu sehen sind, und solchen, die einem konstitutionellen Kalkül entspringen, ist dennoch unverzichtbar. Denn die "innerperiodischen" Präferenzen der am politischen Prozeß beteiligten Individuen und ihre "konstitutionellen" Präferenzen werden regelmäßig in systematischer Weise voneinander abweichen ${ }^{2}$. Daher werden die für außerbudgetäre Einheiten geltenden Regeln davon abhängen, ob ihre Errichtung auf einem innerperiodischen oder einem konstitutionellen Kalkül beruht. $\mathrm{Da}$ aber unterschiedliche institutionelle Bedingungen regelmäßig unterschiedliche individuelle Verhaltensreaktionen nach sich ziehen, ist nicht zu erwarten, daß die differentiellen Wirkungen der Vergabe von Kredithilfen durch außerbudgetäre statt durch budgetäre Einheiten in allen Fällen identisch sind.

Erfolgt die Errichtung außerbudgetärer Einheiten aufgrund "innerperiodischer" Entscheidungen, so lassen sich die außerbudgetären Einheiten als Institutionen interpretieren, die durchgesetzt werden, um einer Verteilungskoalititon aus verschiedenen Individuen die Aneignung nichtmarktlicher Verteilungsvorteile und den staatlichen Akteuren die Realisierung politischer Vorteile zu erleichtern ${ }^{3}$. Dagegen können außerbudgetäre Einheiten aus konstitutioneller Perspektive darauf abzielen, den Handlungsspielraum der staatlichen Akteure zu begrenzen, sich selbst oder Dritten spezielle Vorteile zu verschaffen.

1 Eine Einigung auf Regeln ist immer dann zu erwarten, wenn sich die Situation ohne Regeln als Gefangenen-Dilemma abbilden läBt. Vgl. BRENNAN/BUCHANAN (1985), S.3 ff. Allerdings können auch andere spieltheoretische Situationen zur Entstehung von Regeln führen. Vgl. dazu das "Verkehrsspiel" in SCHOTTER (1981), S.8 f.

2 Vgl. BRENNAN/BUCHANAN (1980/1988), S.23 ff.

3 "Agencies come into existence in response to demands for service from politically mobilized segments of society, both inside and outside the government." KAUFMAN (1976), S.66. Siehe auch BENNETT/DILORENZO (1983b), S.45 f.; BENNETT/DILORENZO (1984), S.222 f.; MÄRTZ (1990), S.217. 
3. Die Errichtung außerbudgetărer Einheiten als Strategie zur Erzielung nichtmarktlicher Verteilungsvorteile

Im folgenden soll analysiert werden, unter welchen Bedingungen Politiker, Bürokraten und spezielle Interessengruppen Vorteile gegenüber einer budgetären Lösung realisieren können, wenn die Vergabe öffentlicher Kredithilfen aus Mitteln spezieller Sondervermögen, durch Sonderkreditinstitute oder durch andere offfentliche Sonderhaushalte erfolgt $^{1}$. Dabei ist mit der Errichtung außerbudgetärer Einheiten im laufenden politischen Prozeß immer dann zu rechnen, wenn die Verteilungsverluste derjenigen, die durch außerbudgetäre Einheiten Nachteile zu erwarten haben, relativ gering, breit gestreut und daher kaum wahrnehmbar sind.

a. Erzielung von Verteilungsvorteilen durch die Errichtung von Sondervermögen

Die Errichtung von Sondervermögen zur Vergabe von Kredithilfen erfordert regelmäßig die Bereitstellung finanzieller Ressourcen durch den Staat. Die dadurch aus dem budgetären Bereich abgesonderten Mittel müssen dann entsprechend dem deklarierten Zweck des Sondervermögens teilweise oder vollständig für Kredithilfen verwendet werden. Die Errichtung von Sondervermögen ist für die Mitglieder der Verteilungskoalition und die staatlichen Akteure vorteilhaft, wenn die für sie dadurch realisierbaren Nutzen langfristig die ihnen entstehenden Kosten übersteigen. Da aus den entsprechenden Sondervermögen vorwiegend öffentliche Darlehen finanziert werden, wird die Analyse auf diese Kredithilfeform beschränkt.

aa. Beeinflussung der Wahrnehmung der Kosten beim Aufbau eines staatlichen Forderungsvermögens

Betrachtet man die in der Bundesrepublik für die Vergabe von Kredithilfen zur Verfügung stehenden Sondervermögen, so fällt auf, daß sie in einigen Fällen aus dem Aufkommen spezieller Abgaben aufgebaut wurden ${ }^{2}$. Dies läßt die Vermutung zu, daß die Erhebung solcher Sonderabgaben eher durchsetzbar ist, wenn ihr Aufkommen ausschließlich zur Finanzierung eines Sondervermögens bestimmt ist. weil dann der Abgabenwiderstand

1 Zur Interessenkonstellation bei außerbudgetären Einheiten allgemein vgl. WALSH (1980), S.169 ff.; BENNETT/DILORENZO (1983b), S.45 ff.

2 Dies gilt z.B. für den Lastenausgleichsfonds und den Ausgleichsfonds für überregionale Maßnahmen zur Eingliederung Schwerbehinderter in Arbeit, Beruf und Gesellschaft. Vgl. oben Abschnitt B.III. 
geringer ist als bei einer Steuererhebung zur Finanzierung budgetärer Kredithilfen ${ }^{1}$. D.h. die politischen Grenzkosten der Steuererhebung können bei Errichtung von Sondervermögen reduziert werden. Unter diesen Bedingungen läßt sich durch die Errichtung von Sondervermögen ein größeres Forderungsvermögen akkumulieren als bei budgetärer Darlehensvergabe.

Sind die Darlehensrückflüsse zweckgebunden für erneute Darlehen zu verwenden, läßt sich folglich bei gegebenen Konditionen das Darlehensvolumen gegenüber der budgetären Lösung dauerhaft ausdehnen. Damit liegt die Errichtung von Sondervermögen im Interesse der Individuen, die daraus in Zukunft zusätzliche Verteilungsvorteile erwarten. Demgegenüber dürften die Verteilungsverluste der dadurch Benachteiligten infolge der erhöhten Steuerzahlung im Errichtungszeitraum und aufgrund des erhöhten Darlehensvolumens in der Zukunft relativ gering ausfallen und weit gestreut sein, so daß die Opposition gegen die Sondervermögen nicht erheblich sein wird. Damit können auch die staatlichen Akteure durch Sondervermögen in späteren Perioden zusätzliche Vorteile erwarten, wenn man unterstellt, daß ihr Nutzen in jeder Periode mit der Höhe der Darlehensausgaben positiv korreliert ist und die Darlehensempfänger zwischen unterschiedlichen Finanzierungsquellen indifferent sind.

bb. Beeinflussung der Wahrnehmung der Bruttoausgaben für öffentliche Kredithilfen

Stehen für den Aufbau eines Sondervermögens bzw. eines alternativen budgetären Forderungsvermögens lediglich dieselben Steuereinnahmen bereit, so können die Politiker durch die Realisierung des Sondervermögens dennoch zusätzliche politische Vorteile in Form höherer politischer Renten erzielen. Um dies zu zeigen, sollen Darlehen aus den Einnahmen eines Sondervermögens mit Darlehen aus den ebenfalls zweckgebundenen Einnahmen eines budgetären Forderungsvermögens verglichen werden. Dabei sollen die Konditionen budgetärer Darlehen und der Darlehen aus Sondervermögen identisch sein. Sondervermögen führen unter diesen Bedingungen zu Vorteilen für die Politiker, wenn die aus den Zins- und Tilgungseinnahmen des Sondervermögens finanzierten Darlehensausgaben von den Steuerzahlern in relativ geringem Umfang wahrgenommen werden. Dazu kommt es, wenn die vorgeschriebene Publizität von budgetären Darlehen umfassender ist als diejenige von Darlehen aus dem Sondervermögen, weil auf diese Weise die Informationen über die Darlehen des Sondervermögens für die Steuerzahler mit relativ hohen Kosten verbunden sind.

1 Vgl. HEINIG (1948), S.461; DICKERTMANN (1971), S.168; HEDTKAMP (1977), S.83. 


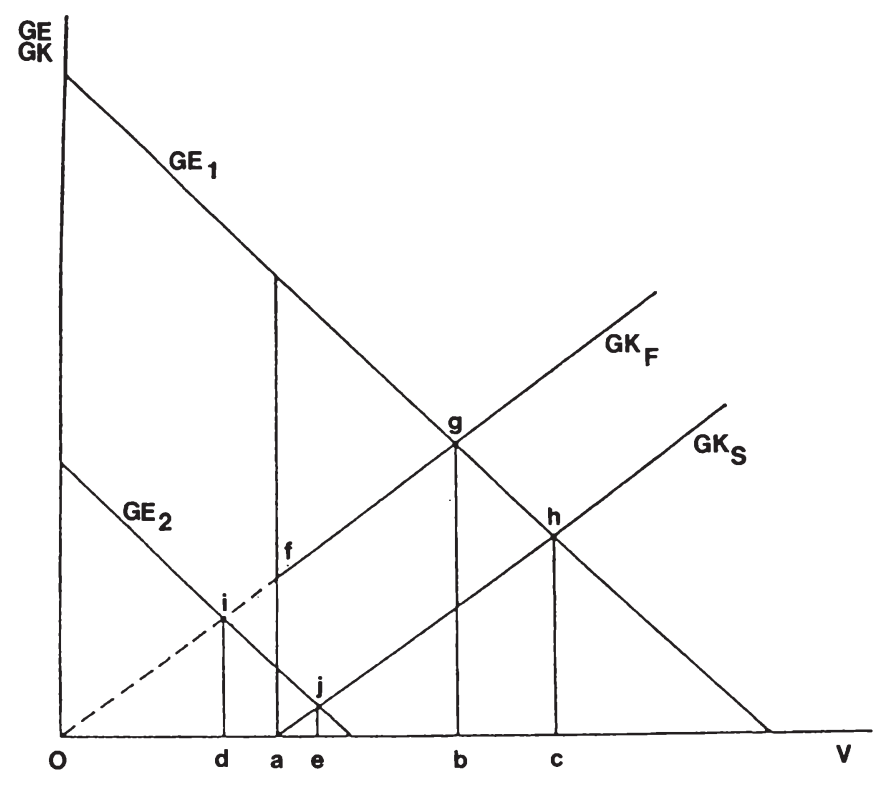

Abb. 12

Dieser Zusammenhang soll anhand von Abb. 12 dargestellt werden. Dabei wird aus Vereinfachungsgründen angenommen, daß der Staat Subventionen ausschließlich in Form öffentlicher Darlehen zu konstanten Konditionen vergibt. Während auf der Abszisse die Höhe des Darlehensvolumens V in einer beliebigen Periode nach Errichtung des budgetären bzw. außerbudgetären Forderungsvermögens abgetragen ist, werden an der Ordinate die politischen Grenzerträge GE und Grenzkosten GK gemessen, welche den Umfang der Darlehensvergabe bestimmen. Weiterhin sei $\mathrm{GE}_{1}$ die politische Grenzertragsfunktion. Der Linienzug Oafg bezeichnet die Grenzkostenfunktion $\mathrm{GK}_{\mathrm{F}}$ im Fall eines budgetären Forderungsvermögens. Die politischen Grenzkosten entsprechen den entgangenen Nutzen der staatlichen Akteure bei einem Verzicht auf die nächstbeste Verwendungsart der staatlichen Einnahmen. Die Strecke Oa entspricht der Höhe der zweckgebundenen Einnahmen des Forderungsvermögens. Ihr horizontaler Verlauf läßt sich damit erklären, daß im Fall 
einer Zweckbindung der Einnahmen des Forderungsvermögens ihre Verwendung keine politischen Opportunitätskosten verursacht, weil alternative Verwendungsarten rechtlich nicht zugelassen sind. In Punkt a weist $\mathbf{G K}_{\mathrm{F}}$ eine Sprungstelle auf, da unterstellt wird, daß die aus dem budgetären Forderungsvermögen finanzierten Darlehen vollständig wahrgenommen werden. Die Grenzkosten für eine infinitesimal kleine Darlehenseinheit rechts von Punkt a betragen af. Thre Höhe bestimmt sich danach, wie hoch die Grenzkosten der Subventionierung im hypothetischen Fall wären, wenn die gesamten staatlichen Einnahmen ungebunden zu verwenden wären. Das politische Gleichgewicht ist bei einem Darlehensvolumen von $0 \mathrm{~b}$ erreicht.

Unterstellt man zusätzlich, daß das alternativ mögliche Sondervermögen gleich hoch ist wie das budgetäre Forderungsvermögen und da $\beta$ die Darlehen des Sondervermögens im Grenzfall beim Budgetierungsprozeß überhaupt nicht wahrgenommen werden, so ergibt sich der Linienzug 0ah als Grenzkostenfunktion $\mathrm{GK}_{\mathrm{S}}$ bei Existenz des Sondervermögens. Die Strecke 0a läßt sich in derselben Weise erklären wie bei dem budgetären Forderungsvermögen. Nach den Annahmen betragen die politischen Grenzkosten für die infinitesimale Einheit links von Punkt a Null. D.h. der rechte Ast von $\mathrm{GK}_{\mathrm{S}}$ ergibt sich durch Parallelverschiebung von $\mathrm{GK}_{\mathrm{F}}$ nach unten mit der Nullstelle in Punkt a. Das gleichgewichtige Darlehensvolumen steigt demnach auf $0 c^{1}$. Dadurch können die Politiker ihre Rente zum einen durch die Ausweitung des Darlehensvolumens und zum anderen durch die Reduzierung der Grenzkosten für die inframarginalen Darlehenseinheiten erhöhen. Daher werden die Politiker die Errichtung von Sondervermögen präferieren, sofern ihre Zeitpräferenzrate kleiner als unendlich ist ${ }^{2}$. Dasselbe gilt für die durch eine Subventionierung Begünstigten, da sie durch die Ausweitung des Darlehensvolumens zusätzliche Verteilungsvorteile erwarten können.

Tendenziell dasselbe Ergebnis folgt, wenn die Alternative zum Sondervermögen in einem budgetären Forderungsvermögen besteht, dessen Einnahmen nicht zweckgebunden sind. Allerdings entsprechen dann die Grenzkosten der Subventionierung bei einem budgetären Forderungsvermögen der Geraden 0g. Schneidet die Grenzertragsfunktion $\mathrm{GK}_{\mathrm{F}}$ rechts von Punkt a, hängt das gleichgewichtige Darlehensvolumen im Fall eines budgetären Forderungsvermögens nicht davon ab, ob die daraus fließenden Einnahmen

1 Eine Erhöhung des Ausmaßes der Subventionierung für bestimmte Subventionszwecke ist auch zu erwarten, wenn diese sowohl aus Mitteln von Sondervermögen als auch durch budgetäre Subventionen gefördert werden. Vgl. DICKERTMANN (1980), S.474.

2 Beträgt die Zeitpräferenzrate unendlich, werden künftige Nutzen von den Politikern in der Gegenwart auf Null abdiskontiert, so daß sie bereits auf die Akkumulation von staatlichen Forderungsvermögen verzichten werden, sofern die zu ihrer Finanzierung erforderlichen Steuereinnahmen positive Grenzkosten verursachen. 
zweckgebunden oder ungebunden verwendet werden. Dementsprechend ist die differentielle Wirkung von Sondervermögen im Hinblick auf die Gesamthöhe der Subventionierung in beiden Fällen ebenfalls identisch. Verlăuft die Grenzertragsfunktion dagegen wie $\mathrm{GE}_{2}$, läßt sich das gleichgewichtige Darlehensvolumen durch die Errichtung des Sondervermögens gegenüber dem budgetären Forderungsvermögen zusätzlich erhöhen. So erhöht sich das Darlehensvolumen bei Realisierung des Sondervermögens gegenüber dem zweckgebundenen budgetären Forderungsvermögen lediglich um ae, während es gegenüber dem ungebundenen Forderungsvermögen um de steigt. Der Grund ist darin zu sehen, da $B$ die Verwendung ungebundener Einnahmen des budgetären Forderungsvermögens für die Vergabe von Darlehen von der ersten Geldeinheit an mit alternativen Verwendungsarten konkurriert. D.h. daß der Anreiz zur Errichtung von Sondervermögen um so stärker ist, je strikter das Non-Affektionsprinzip bzw. Zweckbindungsverbot ${ }^{1}$ hinsichtlich sämtlicher budgetärer Einnahmen anzuwenden ist.

cc. Beeinflussung der Wahrnehmung der Förderintensität öffentlicher Darlehen

Sondervermögen sind aber nicht nur deshalb politisch attraktiv, weil sich damit das Darlehensvolumen bei gegebenen Subventionskonditionen ausweiten läßt. Vielmehr können durch Sondervermögen auch politische Vorteile erzielt werden, wenn bei gegebenem Darlehensvolumen die Netto-Subventionsausgaben budgetärer Darlehen von den Steuerzahlern besser wahrgenommen werden.

Unter der Annahme, daß budgetäre Darlehen in der Vergabeperiode ausgabenwirksam sein müssen ${ }^{2}$, können sie von den Steuerzahlern relativ gut wahrgenommen werden, weil sie insoweit den Einnahmenbedarf des Staates ceteris paribus erhöhen. Ist bei Sondervermögen lediglich Rechenschaft über seinen Nominalbestand abzulegen, so ist eine Erhöhung der Zinsverbilligungskosten für vergebene Darlehen durch Senkung des Zinssatzes und/oder Verlängerung der Darlehenslaufzeit und damit die durchschnittliche Förderintensität für die Steuerzahler nicht wahrnehmbar. Denn aus dem nominalen Bestand an Darlehensforderungen ist die Höhe der damit verbundenen Zinsverbilligungskosten nicht ersichtlich. Damit erhalten die Politiker durch Sondervermögen einen erhöhten Handlungsspielraum zur Verbesserung der Darlehenskonditionen für die Empfänger, den sie entsprechend ihrem politischen Nutzenmaximierungskalkül ausschöpfen können.

1 Vgl. hierzu HEDTKAMP (1977), S.82 ff.

2 Vgl. oben Abschnitt D.II.5.a.aa. 
dd. Umgehung staatlicher Verschuldungsvorschriften

Die Errichtung von Sondervermögen ist für Politiker schließlich auch dann vorteilhaft, wenn sich dadurch bestehende Restriktionen für die staatliche Kreditaufnahme umgehen lassen. Denn auf diese Weise können sich nutzenmaximierende Politiker zumindest teilweise Handlungsspielräume zur Verfolgung eigener Ziele verschaffen, die ihnen durch diese Restriktionen entzogen werden sollen ${ }^{1}$.

Unterstellt man, daß für das staatliche Budget ein vollständiges Kreditaufnahmeverbot gilt, so haben die Politiker einen Anreiz, Sondervermögen zur Vergabe von öffentlichen Darlehen zu errichten, anstatt Darlehen budgetär zu vergeben und damit ein budgetäres Forderungsvermögen aufzubauen. Denn ein steuerfinanziertes Sondervermögen "erwirtschaftet" regelmäßig positive Bruttoerträge, ohne daß es die Kapitalkosten zu decken hat. Es ergeben sich folglich periodische Einnahmenüberschüsse. Wenngleich diese Überschüsse ökonomisch Verluste repräsentieren, entsteht auf diese Weise die Illusion, $\mathrm{da} B$ das Sondervermögen eine ertragbringende staatliche Organisationseinheit darstellt. $\mathrm{Da}$ aber eine Schuldenfinanzierung ertragbringender Projekte klassischerweise als wenig problematisch gilt ${ }^{2}$, ist es nicht überraschend, wenn Sondervermögen die Kreditaufnahme gestattet ist. Auf diese Weise können die Politiker den Umfang der durch ein Sondervermögen vergebenen Darlehen ausweiten, ohne sonstige staatliche Ausgaben kürzen zu müssen. D.h. daß die staatlichen Gesamtausgaben verglichen mit der Situation eines budgetären Forderungsvermögens steigen werden, sofern die Politiker durch die Kreditfinanzierung öffentlicher Darlehen Nettovorteile realisieren können. Aus diesem Zusammenhang wird ersichtlich, $\mathrm{da} B$ die Errichtung von Sondervermögen auch im Interesse budgetmaximierender Bürokraten und der durch öffentliche Darlehen Begünstigten liegt.

Allerdings ist es nicht zwingend, da $B$ die Krediteinnahmen des Sondervermögens zu einer Erhöhung der gesamten Ausgaben des Staates für öffentliche Darlehen in entsprechendem Ausmaß führen. Dies wäre nur dann der Fall, wenn der Grenzertrag der Politiker bei vollständiger Verwendung der Krediteinnahmen für die Vergabe von Darlehen gleich oder höher wäre als bei alternativen Verwendungsarten. Im Normalfall werden die Politiker einen Teil der Krediteinnahmen jedoch auch zur Erhöhung sonstiger Ausgaben verwenden wollen. Dies läßt sich realisieren, wenn budgetäre Darlehen im Umfang der zu-

1 Vgl. BENNETT/DILORENZO (1982), S.334; BENNETT/DILORENZO (1983b), S.46; BENNETT/DILORENZO (1984), S.220 f.

2 "Public debt issue may be chosen as an appropriate part of the over-all "constitution" of a fiscal structure, provided that limitations are imposed to insure debt financing be restricted to projects that yield benefits over time." BUCHANAN (1967), S.265. 
sätzlichen Darlehen des Sondervermögens gekürzt werden und die damit freigewordenen budgetären Mittel für die gewünschten alternativen Ausgabearten zur Verfügung stehen.

Sind budgetäre und außerbudgetäre Darlehen aus der Sicht ihrer Empfänger vollkommene Substitute, dann können die Politiker das Kreditaufnahmeverbot für das Budget perfekt umgehen, solange die maximal zulässige Höhe der Kreditaufnahme des Sondervermögens nicht überschritten wird und substituierbare budgetäre Darlehen vorhanden $\operatorname{sind}^{1}$. Eine Erhöhung sonstiger budgetärer Ausgaben durch eine Kreditaufnahme von Sondervermögen ist auch dann möglich, wenn budgetäre Darlehen für die staatlichen Akteure nicht vorteilhaft sind. Dies gilt in dem Ausmaß, in dem budgetäre Subventionen anderer Art durch Darlehen von Sondervermögen ersetzt werden können.

ee. Schaffung allgemeiner politischer Handlungsspielräume

Generell werden die Politiker daran interessiert sein, daß die für ihr Verhalten maßgeblichen institutionellen Bedingungen ihnen möglichst umfangreiche politische Handlungsspielräume einräumen. Denn das Nutzenniveau der Politiker wird um so höher, je weniger sie durch institutionelle Restriktionen eingeschränkt sind. Dabei wirken sich erhöhte Handlungsspielräume in der Weise aus, daß mit gegebenen politischen Kosten höhere politische Erträge oder daß gegebene politische Erträge mit geringeren politischen Kosten erzielt werden können. Es soll im folgenden untersucht werden, inwieweit die politischen Handlungsspielräume durch Sondervermögen erhöht werden. Dabei wird berücksichtigt, daß Politiker in der Demokratie keine homogene Gruppe darstellen ${ }^{2}$, sondern daß sie bei vereinfachender Betrachtung den Gruppen der Regierungs- und der Oppositionspolitiker zugeordnet werden können. Dabei widersprechen sich die Interessen dieser beiden Gruppen insoweit, als die Regierung ihre politische Macht bewahren will, während die Opposition die Macht zu erlangen sucht ${ }^{3}$.

Da die Aufgaben von Sondervermögen bei ihrer Errichtung regelmäßig eingegrenzt werden, ist anzunehmen, da $\beta$ das Ausgabenverhalten parlamentarisch vergleichsweise wenig umstritten ist, weil die Ausgabenzwecke naturgemäß nur in engem Umfang variiert werden können. Damit sind die politischen Kosten der parlamentarischen Entscheidungs-

1 D.h. das Volumen der budgetär veranschlagten Darlehen müßte ohne Kreditaufnahme des betrachteten Sondervermögens gleich hoch oder höher sein als die kreditfinanzierten Darlehensausgaben des Sondervermögen.

2 Siehe dazu ausführlich FOLKERS (1990).

3 Vgl. DOWNS (1957/1968), S.50 ff. 
findung in bezug auf Ausgabenprogramme der Sondervermögen für die regierenden Politiker bei Sondervermögen geringer als bei vergleichbaren budgetären Programmen, die stets mit alternativen Verwendungsrichtungen konkurrieren müssen.

Außerdem ist die öffentliche Kontrolle bei Sondervermögen vergleichsweise gering, weil die allgemeine politische Auseinandersetzung üblicherweise schwerpunktmäßig im Rahmen der Budgetberatungen stattfindet und sich das Interesse der Öffentlichkeit demgemäß auf diese Ebene der staatlichen Ausgabenplanung konzentriert. Da die Sondervermögen insoweit geringere öffentliche Aufmerksamkeit erfahren, sind die politischen Kosten ihrer Ausgaben fast zwangsläufig geringer als bei einer budgetären Veranschlagung derselben Ausgaben. Anders ausgedrückt lassen Sondervermögen eine geringe Ausgabenmerklichkeit und damit geringe Verwendungswiderstände erwarten ${ }^{1}$. Damit erhöhen sich die politischen Nettoerträge gegebener Ausgaben für die regierenden Politiker bei einer Finanzierung durch Sondervermögen gegenüber einer budgetären Finanzierung.

Schließlich wird auch die jeweilige parlamentarische Opposition gegen die Ausgabenprogramme von Sondervermögen in aller Regel keinen nennenswerten Widerstand leisten. Vielmehr wird sie diese Programme häufig sogar unterstützen, weil sie damit verhindern kann, daß die Begünstigten dieser Programme die daraus resultierenden Vorteile allein der Regierung zuschreiben. Folglich werden die durch die Ausgaben der Sondervermögen Begünstigten zumindest partiell auch der Opposition Unterstützung zukommen lassen. Andererseits hat die Opposition aufgrund der geringen Merklichkeit der Ausgaben von Sondervermögen für die nichtbegünstigten Wähler durch deren Billigung nur vergleichsweise geringe politische Kosten zu erwarten. Dagegen riskieren die Oppositionspolitiker die Unterstützung durch ihre Stammwähler, wenn sie die Haushaltspolitik der Regierung öffentlich billigen. Denn diese Stammwählerschaft wird aus ideologischen oder taktischen Gründen regelmäßig verlangen, daß sich die Opposition als politische Alternative profiliert, indem sie die Regierung in den als wesentlich betrachteten Fragen, wie der staatlichen Haushaltspolitik, mit demokratischen Mitteln bekämpft. Somit können auch die Oppositionspolitiker durch eine Verlagerung bestimmter Ausgaben auf Sondervermögen gegebene politische Erträge mit geringeren politischen Kosten verwirklichen.

Wenngleich Sondervermögen insoweit für alle Politiker Vorteile erwarten lassen, gibt es dennoch keine vollkommene Interessenharmonie zwischen Regierungs- und Oppositionspolitikern im jeweiligen Errichtungszeitpunkt. Dies liegt insbesondere daran, daß zum

1 Die Frage der Merklichkeit von Ausgaben ist das Gegenstück zum vieldiskutierten Problem der Merklichkeit von Steuern. Vgl. dazu SCHMÖLDERS (1959). Dabei gilt, daß eine geringe Merklichkeit von Steuern mit geringen Steuerwiderständen einhergeht. Vgl. FOLKERS (1987a), S.280. 
Aufbau von Sondervermögen in der Errichtungsperiode finanzielle Ressourcen notwendig sind, die alternativen Verwendungszwecken entzogen werden müssen ${ }^{1}$. Daher kann unterstellt werden, daß Sondervermögen in der Aufbauphase für die regierenden Politiker politische Nettokosten verursachen, denen politische Nettoerträge künftiger Perioden gegenüberstehen. Nimmt man an, daß die politischen Kosten in der Aufbauphase primär von den jeweiligen Regierungspolitikern zu tragen sind, wird deren Nutzen-Kosten-Kalkül um so eher zuungunsten von Sondervermögen ausfallen, je höher die politischen Kosten in der Gegenwart ausfallen $^{2}$ und je höher ihre Zeitpräferenzrate ist, mit der die künftigen Nettoerträge abdiskontiert werden. Dagegen werden die Oppositionspolitiker unter den getroffenen Annahmen durch die Errichtung von Sondervermögen in aller Regel politische Nettoerträge erwarten können. Dies gilt unabhängig davon, ob sie für die Zukunft mit einer Regierungsübernahme rechnen oder nicht. Damit wird erklärbar, weshalb sich gerade Oppositionspolitiker immer wieder für die Errichtung von zusätzlichen Sondervermögen aussprechen ${ }^{3}$.

Allerdings darf aus der vorstehenden Analyse nicht der Schluß gezogen werden, daß sich die politischen Handlungsspielräume durch Sondervermögen generell erhöhen. So ist zum einen zu erwarten, daß es von den jeweiligen geplanten Aufgaben und damit den Ausgabezwecken abhängt, ob sich beide Gruppen von Sondervermögen politische Nettoerträge versprechen. Zum anderen engen Sondervermögen die politischen Handlungsspielräume ein, wenn die Politiker damit rechnen, daß die politischen Nettoerträge der Ausgaben für die jeweiligen Zwecke im Zeitablauf stark schwanken. Während bei budgetären Ausgaben die Ausgabenhöhe relativ einfach variiert werden kann, steigt sie bei Sondervermögen aufgrund der Zweckbindung der Einnahmen kontinuierlich. Unter diesen Bedingungen sind Sondervermögen politisch weniger erstrebenswert.

b. Erzielung von Verteilungsvorteilen durch die Errichtung von Sonderkreditinstituten

Die Sonderkreditinstitute haben mit den Sondervermögnen gemein, daß der Staat in der Errichtungsphase und gegebenenfalls auch in späteren Perioden budgetäre Mittel in den außerbudgetären Bereich transferiert, um die Vergabe öffentlicher Kredithilfen zu

1 Die folgenden Ergebnisse ändern sich nur unwesentlich, wenn sich die Aufbauphase bei Sondervermögen über mehrere Perioden erstreckt.

2 Sie werden dann besonders hoch sein, wenn das Sondervermögen vollständig in der Errichtungsperiode finanziert werden muß. Andererseits kann mit geringeren politischen Kosten

3 gerechnet werden, wenn der Vermögensaufbau zeitlich gestreckt wird.

3 Beispielsweise fordert die SPD seit einigen Jahren die Errichtung eines Sondervermögen "Arbeit und Umwelt". Vgl. dazu DICKERTMANN/HANSMEYER (1987), S.136. 
ermöglichen. Allerdings unterscheiden sich diese beiden Formen außerbudgetärer Einheiten dadurch, daß die Sonderkreditinstitute aufgrund ihrer Ausstattung mit Personal selbst handlungsfăhig sind. Außerdem umfaßt ihr Tătigkeitsbereich regelmäßig Aktivităten, die eine Gewinnerzielung erlauben. Somit kann einerseits erwartet werden, daß mit Sonderkreditinstituten teilweise vergleichbare Effekte wie mit Sondervermögen erreicht werden können, wobei die Beeinflussung der Wahrnehmung der Kosten offentlicher Kredithilfen im Vordergrund steht. Andererseits erweitern Sonderkreditinstitute aber auch den Handlungsspielraum der Politiker. Dies ist zu berücksichtigen, wenn die Errichtung von Sonderkreditinstituten als strategisches Verhalten erklärt werden soll.

In der folgenden Betrachtung soll dabei besonders auf die empirisch beobachtbaren Funktionen der Sonderkreditinstitute bei der Vergabe öffentlicher Kredithilfen Bezug genommen werden, wie sie in Abschnitt B.III.2. herausgearbeitet wurden. Weiterhin wird versucht, die Vorteilhaftigkeit außerbudgetärer Einrichtungen für die staatlichen Akteure unabhängig von ihrem speziellen Aufgabengebiet in allgemeiner Form zu erklären.

\section{aa. Vorteile aufgrund der Durchführung budgetärer Kredithilfen}

Im folgenden wird unterstellt, daß Sonderkreditinstitute die aus Budgetmitteln finanzierten Kredithilfeprogramme kostengünstiger als budgetäre Einheiten durchführen können $^{1}$, weil bei der Vergabe bankmäßige Kreditvergabegrundsätze beachtet werden müssen. Weiterhin wird angenommen, daß eine Durchführung der Programme durch private Kreditinstitute möglich wäre, wobei die Einhaltung der erforderlichen öffentlichrechtlichen Grundsätze durch das Rechtsinstitut des Beliehenen ${ }^{2}$ sichergestellt werden könnte ${ }^{3}$. Unter diesen Annahmen gibt es also eine dritte organisatorische Alternative für die Durchführung budgetärer Kredithilfen.

Es gibt einige Argumente dafür, daß private Kreditinstitute Kredithilfeprogramme kostengünstiger durchführen können als Sonderkreditinstitute. Dafür spricht zum einen, daß die Hausbanken der Kredithilfe-Empfänger trotz der Existenz von Sonderkreditinstituten regelmäßig bei der Durchführung von Kredithilfen beteiligt werden und bankmäßige Überprüfungen vornehmen sowie Kreditrisiken tragen. Dabei kann man davon ausgehen, daß die Einschaltung der Hausbanken zu einer stärkeren Besicherung von

1 Vgl. dazu unten Abschnitt D.III.4.b.

2 Beliehene sind natürliche oder juristische Personen des Privatrechts, denen die Zuständigkeit eingeräumt ist, bestimmte Staatsaufgaben mit hoheitlichen Mitteln unter staatlicher Aufsicht in eigenem Namen wahrzunehmen. Vgl. HUISMANS (1971), S.36 ff.; WOLFF/BACHOF (1976), $\S 104$.

Vgl. HUISMANS (1971), S.68 ff. 
Förderdarlehen führt' ${ }^{1}$. Außerdem dürften die Kosten der Überwachung der KredithilfeEmpfänger während der Kreditlaufzeit bei den Hausbanken wegen der größeren Kundennähe geringer sein als bei Sonderkreditinstituten ${ }^{2}$. Außerdem kann angenommen werden, $\mathrm{da} B$ private Kreditinstitute trotz öffentlichrechtlicher Bindungen in geringerem Maß politischen Pressionen ausgesetzt sind als die von den Politikern unmittelbar kontrollierten Sonderkreditinstitute. So werden private Kreditinstitute ihre Entscheidungen im vorgegebenen rechtlichen Rahmen tendenziell nach ökonomischen Kriterien treffen und ihre Forderungen im Rahmen des rechtlich Möglichen vollständig durchzusetzen suchen. Demgegenüber ist es bei den Sonderkreditinstituten wahrscheinlicher, daß sie bei ihren Entscheidungen politische Erwägungen einfließen lassen. Somit kann vermutet werden, daß private Institute die Vergabe und Abwicklung öffentlicher Kredithilfen in effizienterer Weise vornehmen können als Sonderkreditinstitute.

Ist die Durchführung von Kredithilfeprogrammen durch budgetäre Einheiten aus Kostengründen keine politisch durchsetzbare Alternative, so können Politiker, Bürokraten und Kredithilfe-Empfänger durch die Errichtung von Sonderkreditinstituten Vorteile realisieren, obwohl die Vergabe staatlicher Kredithilfen durch private Kreditinstitute mit geringeren Kosten möglich wäre.

So ist es für die Politiker vorteilhaft, wenn ihnen ein möglichst umfassender Spielraum für politische Interventionen verbleibt, um Subventionsentscheidungen gegebenenfalls entsprechend ihrem politischen Kalkül steuern zu können. Andererseits erlaubt die Durchführung staatlicher Kredithilfeprogramme durch die Sonderkreditinstitute den Politikern, "to distance themselves from public sector activities that create popular discontent $^{n 3}$. Dies dürfte auch der Grund dafür sein, weshalb in der Öffentlichkeit regelmäßig die Eigenständigkeit der Sonderkreditinstitute betont wird ${ }^{4}$. Die Bürokraten sind an den Sonderkreditinstituten unter den genannten Bedingungen interessiert, weil sie damit verhindern können, daß bestimmte Aufgaben, wie die Überwachung der Kredithilfe-Empfänger, dem öffentlichen Sektor entzogen werden, wodurch zugleich die Beschäftigungsmöglichkeiten im öffentlichen Sektor vermindert würden. Schließlich sind die Kredithilfe-Empfänger daran interessiert, daß die Vergabe und Abwicklung von Kredithilfen so organisiert ist, daß die Produktivität des Ressourceneinsatzes zur Erzeugung politischen Drucks maximal ist. Kann auf die Sonderkreditinstitute mit gegebenem Ressourceneinsatz ein höherer politischer Druck ausgeübt werden als auf private Kreditinstitute, können die

\footnotetext{
Vgl. MENZEL (1960), S.76; GOLDSCHMIDT (1987), S.205.

Vgl. GOLDSCHMIDT (1987), S.205 f.

HORN (1988), S.56.

4 HORN (1988), S.56, Fn.3.
} 
erfolgreichen "Produzenten" politischen Drucks durch die Errichtung von Sonderkreditinstituten zusätzliche politische Renten erwarten.

bb. Vorteile aufgrund der Finanzierung der Darlehensausgaben staatlicher Kredithilfen durch Sonderkreditinstitute

Sonderkreditinstitute übernehmen vielfach die Finanzierung der Darlehensausgaben für staatliche Darlehensprogramme, während die Finanzierung der Zinsverbilligungskosten aus dem staatlichen Budget erfolgt. Auf diese Weise ist es möglich, die Höhe des staatlichen Budgetdefizits zu senken, ohne auf Zinszuschüsse als Kredithilfeform ausweichen zu müssen. Werden die Darlehensausgaben von den Sonderkreditinstituten fremdfinanziert, so ändert sich die Höhe der "konsolidierten" Verschuldung des gesamten öffentlichen Sektors ceteris paribus nicht. Daher wird in diesem Zusammenhang auch von einer versteckten öffentlichen Verschuldung gesprochen ${ }^{1}$.

Unterstellt man, daß die Zinsverbilligungskosten in der Vergabeperiode ausgabenwirksam sind, dann ist die Finanzierung der Darlehensausgaben durch Sonderkreditinstitute für die Politiker stets attraktiv, wenn die Bürger die künftige Belastung durch die staatliche Verschuldung besser wahrnehmen als die Entlastung durch die künftigen Darlehenseinnahmen gleicher Höhe ${ }^{2}$, d.h. wenn sie die künftige Belastung durch die staatliche Verschuldung relativ überschätzen. Dies gilt allerdings nur dann, wenn die Bürger die Verbindlichkeiten der Sonderkreditinstitute aus der Finanzierung der Darlehensausgaben nicht als Belastung empfinden, soweit ihnen Forderungen derselben Höhe gegenüberstehen. Da man davon realistischerweise ausgehen kann, lassen sich durch die Finanzierungsbeteiligung von Sonderkreditinstituten die politischen Grenzkosten der Gewährung öffentlicher Darlehen senken. Damit können die Politiker durch Ausweitung des Volumens öffentlicher Darlehen marginale politische Nettoerträge erzielen. Außerdem können auf diese Weise die durch zusätzliche Darlehen Begünstigten ihre politischen Renten erhöhen.

Allerdings ist darauf hinzuweisen, daß eine Ausweitung des Darlehensvolumens auch wünschenswert sein kann, wenn durch die zusätzliche Darlehenssubventionierung Wohlfahrtssteigerungen möglich sind. Unter diesen Bedingungen würde nämlich eine Überschätzung der Kosten öffentlicher Darlehen zu einem ineffizient niedrigen Angebot an öffentlichen Darlehen führen.

1 Vgl. DICKERTMANN (1985), S.170.

2 Vgl. BENNETT/DILORENZO (1983a), S.313. 
cc. Vorteile aufgrund von Eigenprogrammen der Sonderkreditinstitute

Ist der zulässige Tätigkeitsbereich der Sonderkreditinstitute nicht auf die Vergabe von Kredithilfen beschränkt, sondern ist ihnen zusätzlich die Erledigung gewöhnlicher Bankgeschäfte gestattet, so können diese außerbudgetären Einrichtungen bilanzielle Ertragsüberschüsse $^{1}$ realisieren. Diese Ertragsüberschüsse erhöhen ceteris paribus die "konsolidierten" Einnahmen des Staates und damit seinen Ausgabenspielraum². Besonders reizvoll ist es dabei für die Politiker, daß der Geschäftsbetrieb der Sonderkreditinstitute praktisch ohne jeden Kapitaleinsatz bzw. ohne Einsatz budgetärer Mittel in Gang gesetzt werden kann, da die Gebietskörperschaften und damit letztlich die Steuerzahler mit ihrem gesamten Steueraufkommenspotential für die Verbindlichkeiten der Mehrzahl der Sonderkreditinstitute haften ${ }^{3}$. Unter diesen Bedingungen können die Politiker durch die Errichtung von Sonderkreditinstituten praktisch ohne politische Opportunitätskosten zusätzliche Einnahmen erzielen, welche bei einem positiven politischen Grenzertrag zusätzlicher Ausgaben höhere staatliche Ausgaben implizieren. Dieses Ergebnis ändert sich allerdings partiell, wenn durch die Geschäftsbankentätigkeit der Sonderkreditinstitute aufgrund verschiedener Privilegien ${ }^{4}$ und spezieller Anreizstrukturen Verzerrungen der Ressourcenallokation und damit Wohlfahrtsverluste verursacht werden ${ }^{5}$. Solche Verzerrungen können überdies bei gegebenen Steuersätzen zu einem verringerten Steueraufkommen des Staates führen, so daß die saldierten Zusatzeinnahmen durch die Ertragsüberschüsse verringert werden. Auf diesen Zusammenhang soll jedoch im Verlauf der weiteren Diskussion nicht näher eingegangen werden, zumal unterstellt werden kann, daß die Politiker die entsprechenden ökonomischen Konsequenzen im Zeitpunkt der Errichtungsentscheidung nicht wahrnehmen oder für unerheblich halten.

1 Diese Überschüsse entsprechen jedoch keinesfalls dem ökonomischen Gewinn, da die Eigenkapitalkosten bilanzmäßig als Überschußanteile erfaßt werden.

2 Überschüsse der Sonderkreditinstitute entstehen außerdem dadurch, daß sie für die Vergabe staatlicher Kredithilfeprogramme ein Entgelt erhalten. Unter der Annahme, daB durch Sonderkreditinstitute keine Kosteneinsparungen möglich sind, führen die aufgrund der Entgelte erzielten Überschüsse nicht zu einer Erhöhung des "konsolidierten" Ausgabenspielraums des Staates. Denn diesen Überschüssen stehen dann zusätzliche Staatsausgaben zur Finanzierung der Entgelte gegenüber.

3 Dieser Umstand wurde bei der Kreditanstalt für Wiederaufbau in extremer Weise ausgenutzt, wo bis Anfang der achtziger Jahre von den Eigentümer-Gebietskörperschaften lediglich 0,5 Promille des Nennkapitals eingezahlt wurden. Vgl. MÜLLER-KÄSTNER (1986), S.10.

4 Dazu gehören sowohl steuerliche Vergünstigungen als auch die letztlich unbegrenzte Haftung für die Verbindlichkeiten der Sonderkreditinstitute.

5 Vgl. CONRAD (1967), S.68 ff.; KIRCHHOFF (1987), S.194; DAVIES (1981). Zu den möglichen allokativen Vorteilen öffentlicher Banken vgl. SHEPARD (1976); HAHN (1978); KIRCHHOFF (1987), S.85 ff. 
Nimmt man also an, daß sich durch die Sonderkreditinstitute zusätzliche Einnahmen erzielen lassen, so werden insbesondere die Politiker befürworten, daß die Sonderkreditinstitute keine Gewinnausschüttungen vornehmen, um die Gewinnverwendung weitgehend der öffentlichen Kontrolle zu entziehen und damit die politischen Grenzkosten der Verwendung dieser Zusatzeinnahmen zu reduzieren. Gelingt es, die "Förderung der Wirtschaft" als Unternehmenszweck festzulegen, ist damit die Grundlage dafür geschaffen, daß die Sonderkreditinstitute zumindest Teile ihrer Erträge zur Finanzierung der Verbilligungskosten von Kredithilfen verwenden können. Sofern als alternative Gewinnverwendung lediglich die Erhöhung des Eigenkapitals erlaubt ist, können die für die Sonderkreditinstitute verantwortlichen Politiker nämlich unter Hinweis auf den Unternehmenszweck dieses Vorgehen rechtfertigen. Dabei können sie darauf setzen, daß die Steuerzahler die Finanzierungskosten der mit Ertragsteilen verbilligten Kredithilfen kaum wahrnehmen, weil sie einer Fiskalillusion unterliegen. Dies ist darauf zurückzuführen, daß sich die Bürger in der Mehrzahl nicht darüber klar sind, daß sie letztlich Eigentümer der im öffentlichen Eigentum stehenden Sonderkreditinstitute sind, und damit ihnen die mit diesem Eigentum erwirtschafteten Erträge zustehen. So stellt bereits PUVIANI fest:

"Viele Grundbesitzer, viele Kapitalisten, viele Berufstätige haben wahrscheinlich noch nie daran gedacht, daß sie den Staat auch insofern zu finanzieren helfen, als sie Miteigentümer staatlicher Ländereien, Eisenbahnen oder Banken sind. Andere Bürger der modernen Staaten haben zwar eine vage Kenntnis von der Existenz der Domänen, glauben aber, da $\beta$ deren Kapitalwert oder Erträge geringer seien, als sie in Wirklichkeit sind. Aufgrund dieser Umstände kann der Bürger den Umfang des Teils der Güter, die er dem Staat abtritt, entweder gar nicht oder nur sehr unvollkommen abschätzen."1

Weil die aus den Erträgen der Sonderkreditinstitute verbilligten Kredithilfen keine unmittelbaren budgetären Konsequenzen haben, werden die Steuerzahler glauben, da $B$ diese Kredithilfen für sie gratis sind ${ }^{2}$. Daher werden sie es hinnehmen, wenn die Erträge durch die Vergabe von Kredithilfen aufgezehrt werden, ohne dabei eine Belastung zu empfinden. Sofern sich die Steuerzahler aus den entsprechenden Kredithilfen einen gewissen sozialen Nutzen versprechen, werden sie sogar die weitestmögliche Verwendung dieser Erträge für Kredithilfen fordern, da dann der wahrgenommene soziale Nettonutzen der Kredithilfen bei wahrgenommenen Opportunitätskosten von (nahezu) Null stets positiv sein wird. Aber selbst wenn sie annehmen, daß Kredithilfen lediglich für einen kleinen

1 PUVIANI (1903/1960), S.41.

2 Vgl. PUVIANI (1903/1960), S.40; BENNETT/DILORENZO (1986), S.281; HORN (1988), S.57. 
Kreis von Begünstigten private Vorteile bewirken, werden sie aus demselben Grund nicht dagegen opponieren ${ }^{1}$.

Dieser Effekt wird verstärkt, wenn die Berichterstattung über diese Aktivitäten nur unvollkommen ist. So werden die aus Erträgen der Sonderkreditinstitute verbilligten Kredithilfen üblicherweise nicht in den Subventionsberichten der jeweiligen Gebietskörperschaften dokumentiert. Außerdem ist die durch solche Eigenprogramme verursachte Ertragsbelastung vielfach nicht einmal aus den Geschäftsberichten der einzelnen Institute zu erkennen ${ }^{2}$.

Aufgrund der unvollkommenen Wahrnehmung der Verbilligungskosten von Kredithilfen der Sonderkreditinstitute können die Politiker durch deren Errichtung zusätzliche politische Nettoerträge erwarten. Dasselbe gilt für budgetmaximierende Bürokraten, weil die zusätzlichen Einnahmen eine Ausweitung des staatlichen Gesamtbudgets erlauben. Schließlich sind auch die Kredithilfe-Empfänger an diesen Sonderkreditinstituten interessiert, weil dadurch wie im Fall der Sondervermögen höhere Kredithilfe-Leistungen des öffentlichen Sektors erwartet werden können.

dd. Vorteile aus der Abtretung von budgetären Darlehensforderungen an die Sonderkreditinstitute

Durch die Möglichkeit zur Abtretung von budgetären Forderungen an die Sonderkreditinstitute erhalten die Politiker zusätzliche Handlungsspielräume. So kann durch eine Forderungsabtretung die Höhe des Schuldenstandes der Gebietskörperschaften gesenkt werden, sofern die Erlöse von den Politikern zur Schuldentilgung verwendet werden. Dies liegt insbesondere dann im Interesse der Politiker, wenn die Staatsverschuldung eine Höhe erreicht hat, welche hohe politische Kosten verursacht, und wenn die budgetären Forderungen aufgrund des politischen Kosten-Nutzen-Kalküls anderweitig nicht liquidierbar sind. Da in der Realität solche Forderungserlöse jedoch regelmäßig für die erneute Vergabe von Kredithilfen verwendet werden, ist allerdings eher anzunehmen, daß der Staat auf diese Weise zusätzliche Ausgaben mit Einnahmen finanzieren will, deren Kosten kaum wahrgenommen werden. Dies ist insofern plausibel, weil die mit der Forderungsabtretung verbundene Reduzierung des realen staatlichen Nettovermögens bzw. des künftigen

1 Insoweit überrascht es kaum, wenn sich ein Vertreter der Kreditanstalt für Wiederaufbau "ungestraft" in der Öffentlichkeit dazu bekennt, daß der größere Teil der Aktivitäten, die mit von der Kreditanstalt für Wiederaufbau verbilligten Darlehen gefördert werden, auch ohne Förderung durchgeführt würde, d.h. also überwiegend Mitnahmeeffekte bewirkt werden. Vgl. MÜLLER-KÄSTNER (1986), S.15.

2 Vgl. DICKERTMANN (1980), S.474 sowie oben Abschnitt B.IV.5.b. und c. 
Steuerentlastungspotentials für die große Mehrzahl der Steuerzahler nicht nachvollziehbar sein dürfte.

Allerdings ist dies für sich genommen noch kein Argument für die Errichtung von Sonderkreditinstituten, da budgetäre Forderungen prinzipiell auch an private Wirtschaftssubjekte veräußert werden können. Ein Argument für die Einschaltung von Sonderkreditinstituten in solche Transaktionen ergibt sich jedoch dann, wenn die Schuldner dieser Forderungen öffentliche gegenüber privaten Forderungsgläubigern präferieren. Sind die budgetären Einheiten und die Sonderkreditinstitute beispielsweise bei der Durchsetzung abgetretener Forderungen weniger rigoros als private Forderungsgläubiger, so würden die Schuldner versuchen, durch Ausübung politischen Drucks gegen die Veräußerung der budgetären Forderungen zu opponieren. Damit würden die Kosten der Liquidation dieser Forderungen für die Politiker steigen und die dadurch möglichen politischen Erträge fallen. Dieser für die Politiker nachteilige Effekt läßt sich vermeiden, wenn die Schuldner zwischen budgetären und außerbudgetären öffentlichen Gläubigern indifferent sind.

ee. Vorteile aus der Schaffung politischer Handlungsspielräume

Wie durch Sondervermögen gewinnen die Politiker durch Sonderkreditinstitute politische Handlungsspielräume, indem diese Einrichtungen nach "Bedarf" in die Vergabe von Kredithilfen eingeschaltet werden können. Dabei sind die Sonderkreditinstitute noch erheblich variabler einsetzbar als die Sondervermögen, weil bei den Sonderkreditinstituten eine formale parlamentarische Ex-ante-Kontrolle regelmäßig nicht vorgesehen ist und durch deren Gewinnerzielung zusätzliche politische Handlungsmöglichkeiten entstehen.

Ein weiterer Vorzug sämtlicher außerbudgetärer Einrichtungen, und damit auch der Sonderkreditinstitute, ist aus der Interessenlage der Politiker darin zu sehen, daß ihre personalpolitischen Handlungsspielräume durch diese Einrichtungen ausgeweitet werden. Denn "all politicians are interested in having patronage jobs or plum positions for their supporters and contributors" ${ }^{n}$. Dabei üben die Politiker bei der Besetzung der Spitzenpositionen außerbudgetärer Einrichtungen regelmäßig entscheidenden Einfluß aus. Andererseits sind die außerbudgetären Einrichtungen nicht an die vergleichsweise strikten beamtenrechtlichen Vorschriften gebunden, die bei der Besetzung leitender Positionen im budgetären Bereich zu beachten sind. Zusätzlich übersteigen die bei außerbudgetären Einrichtungen möglichen Gehälter zum Teil erheblich den beamtenrechtlichen Besoldungs-

1 BENNETT/DILORENZO (1983b), S.46. 
spielraum ${ }^{1}$. Schließlich können Positionen in den Kontrollorganen vergeben werden, die finanziell honoriert werden.

Sind außerbudgetäre Einrichtungen vorhanden, wird es damit für die Politiker einfacher, "verdiente" Parteigänger mit komfortabel ausgestatteten Arbeitsplätzen zu belohnen bzw. solche Personen auf lukrative Posten abzuschieben, die der eigenen Karriere hinderlich sind. So gibt es bei den Sonderkreditinstituten des Bundes und der Länder eine lange Tradition, Vorstandsposten mit ehemaligen Ministern, Staatssekretären oder Abgeordneten zu besetzen ${ }^{2}$. Da außerdem die Zahl der Arbeitsplätze bei den Sonderkreditinstituten weiterhin wesentlich von der Aufgabenzuweisung durch die Politiker abhängt, können die Politiker die relativ ausgeprägte formelle Unabhängigkeit der Sonderkreditinstitute von den Eigentümer-Gebietskörperschaften ${ }^{3}$ durch informelle Abhängigkeiten begrenzen. Sie stellen weitgehend sicher, daß die Aktivitäten der Sonderkreditinstitute entsprechend der politischen Zielvorstellungen erfolgen. So ist zu erwarten, daß die Manager der außerbudgetären Einrichtungen ihren diskretionären Handlungsspielraum, den sie aufgrund unvollständiger Kontrolle durch die Steuerzahler und ihrer formellen Unabhängigkeit vom Staat besitzen, in vergleichsweise geringem Umfang gegen die Politiker ausnutzen werden ${ }^{4}$.

c. Erzielung von Verteilungsvorteilen durch die Verwendung der Mittel sonstiger außerbudgetärer Einrichtungen zur Finanzierung öffentlicher Kredithilfen

Im ersten Teil der Arbeit wurde gezeigt, daß in der Bundesrepublik Deutschland auch die Träger der Sozialversicherung, und hierbei insbesondere die Bundesanstalt für Arbeit, in gewissem Umfang öffentliche Kredithilfen vergeben. Es soll hier nicht untersucht werden, wie sich die Organisation der Sozialversicherungen als außerbudgetäre

1 Beispielsweise ist die Höhe der Gesamtbezüge für die fünf Vorstandsmitglieder der Kreditanstalt für Wiederaufbau für das Geschäftsjahr 1988 mit 2,35 Mio. DM ausgewiesen. Vgl. BUNDESMINISTERIUM DER FINANZEN (1989), S.81. Das durchschnittliche Gehaltsniveau der Vorstandsmitglieder bewegt sich damit in Größenordnungen, wie sie allenfalls bei den politischen Spitzenämtern annähernd erreicht werden.

2 Beispielsweise waren 1977 in den größten Banken, bei denen der Bund eine Mehrheitsbeteiligung besitzt, ehemalige Minister oder Staatssekretäre im Vorstand vertreten. Vgl. o.V. (1977), S.42, 44. Im Jahr 1988 waren in den Vorständen der Kreditanstalt für Wiederaufbau und der Deutschen Ausgleichsbank ein ehemaliger Staatssekretär bzw. ein ehemaliger Bundestagsabgeordneter vertreten. Vgl. BUNDESMINISTERIUM DER FINANZEN (1989), S.81, 87. Entsprechende Beispiele lassen sich bei den Sonderkreditinstituten der Länder finden.

3 Vgl. DICKERTMANN (1980), S.474 f.

4 Vgl. BENNETT/DILORENZO (1983b), S.49 ff. So nimmt auch die Kreditanstalt für Wiederaufbau für sich in Anspruch, ihre Mittel "immer in Absprache mit der Bundesregierung und entsprechend ihren Vorgaben" eingesetzt zu haben. MÜLLER-KÄSTNER (1986), S.10. 
Einheiten erklären läßt. Weiterhin soll nicht erklärt werden, weshalb die Sozialversicherungsträger im Rahmen ihrer Aufgabenerfüllung teilweise öffentliche Darlehen vergeben ${ }^{1}$. Vielmehr beschränken sich die folgenden Ausführungen auf die Frage, weshalb die Sozialversicherungen Fördermaßnahmen in Form von öffentlichen Darlehen durchführen, die mit ihrem gesetzlichen Auftrag nicht unmittelbar übereinstimmen ${ }^{2}$.

Für Sozialversicherungen ist wie für jede andere Versicherung typisch, daß sich Perioden mit Einnnahmen- und Ausgabenüberschüssen abwechseln. Aufgrund empirischer Beobachtungen läßt sich feststellen, daß solche zweckfremden oder zweckwidrigen Darlehen dann vergeben werden, wenn die Sozialversicherungen relativ hohe Einnahmenüberschüsse aufweisen ${ }^{3}$. Dies läßt sich einfach damit erklären, daß die staatlichen Akteure die Neigung besitzen, vorhandene Finanzmassen für eigene Zwecke zu verwenden ${ }^{4}$. Würden die Einnahmenüberschüsse lediglich dazu eingesetzt, um marktliche Rücklagen für die künftigen Perioden zu bilden, könnten die Beiträge für die Versicherungsleistungen intertemporal in versicherungsmathematisch korrekter Höhe festgelegt werden. Erfolgt die Rücklagenbildung dagegen durch die Vergabe minderverzinslicher öffentlicher Darlehen, müssen die künftigen Beiträge im Vergleich zur Referenzsituation höher sein, um die entgangenen Zinseinnahmen auszugleichen. Da diese zusätzlich erforderlichen Beiträge auf die Gesamtheit der Beitragszahler verteilt und zeitlich breit gestreut werden können, werden die Nachteile solcher zweckwidriger Darlehen kaum wahrnehmbar sein, während die Begünstigten ihre Vorteile relativ gut erkennen können. Aufgrund dieses Zusammenhangs können die Politiker erwarten, daß die politischen Erträge einer zweckwidrigen Verwendung eines gewissen Teils eventueller Einnahmenüberschüsse die politischen Kosten übersteigen. Folglich ist es aus ihrem Kalkül heraus rational, wenn sie aufgrund der zweckwidrigen Darlehensvergabe in Zukunft höhere Beiträge in Kauf nehmen. Daher werden die Politiker bestrebt sein, institutionelle Regeln für diese außerbudgetären Einrichtungen durchzusetzen, die ihnen eine Darlehenssubventionierung aus Mitteln periodischer Ein-

1 Die Darlehensvergabe erfolgt überwiegend als Alternative zu einer Zuschußfinanzierung für bestimmte Aktivitäten, z.B. Umschulungsmaßnahmen. Daher scheinen Darlehen als kostenreduzierende Subventionsform gerechtfertigt.

2 So gehört die Förderung des sozialen Wohnungsbaus durch verbilligte Darlehen der Bundesanstalt für Arbeit kaum zu deren unmittelbarem Aufgabengebiet, da die Vorteile daraus allenfalls mittelbar den Versicherten zugute kommen, die mit ihren Beiträgen den größten Teil der Ausgaben der Bundesanstalt finanzieren. Dennoch besaßen solche Darlehen in früheren Jahren erhebliche finanzielle Bedeutung. Vgl. QUELLMALZ (1963).

3 Vgl. HEDTKAMP (1977), S.262.
Diese Verhalten der Politiker ist im wesentlichen dafür verantwortlich, daß eine antizyklische Finanzpolitik unter den gegebenen politisch-institutionellen Bedingungen in Boomphasen regelmäßig scheitert. Vgl. dazu ausführlich BUCHANAN/WAGNER (1977). 
nahmenüberschüsse erlauben. Allerdings muß eine solche Subventionierung aus verfassungsrechtlichen Gründen mit dem gesetzlichen Zweck der Einrichtung übereinstimmen. Folglich werden die Politiker daran interessiert sein, daß ihnen bei der Bestimmung einer zweckentsprechende "Anlage" von Einnahmenüberschüssen ein möglichst weiter "Ermessensspielraum" eingeräumt wird.

\section{Die Errichtung außerbudgetărer Einheiten als konstitutionelle Entscheidung}

Die Errichtung außerbudgetärer Kredithilfe-Einheiten kann als konstitutionelle Entscheidung interpretiert werden, wenn die Vergabe von Kredithilfen durch außerbudgetäre Einheiten im Interesse der Allgemeinheit liegt, wie es durch Übereinkunft der Individuen definiert ist ${ }^{1}$. Geht man davon aus, daß die Durchführung gegebener staatlicher Maßnahmen mit minimalen Kosten im Interesse der Allgemeinheit liegt, sind außerbudgetäre Einheiten dann wünschenswert, wenn sie eine effizientere staatliche Aufgabenerfüllung, insbesondere eine effizientere Durchführung staatlicher Subventionen, erlauben². Zum anderen ist es denkbar, daß außerbudgetäre Einheiten aus einem konstitutionellen Kalkül heraus errichtet werden, um unerwünschtes Verhalten der staatlichen Akteure zu restringieren und damit die kollektiven Interessen zu schützen. Es soll nun untersucht werden, inwiefern die Vergabe von Kredithilfen aus Mitteln von Sondervermögen bzw. durch Sonderkreditinstitute im Interesse der Allgemeinheit liegt und deren Errichtung somit als konstitutionelle Entscheidung erklärbar ist.

a. Die Errichtung von Sondervermögen als konstitutionelle Entscheidung

aa. Effizientere Erfüllung staatlicher Aufgaben durch Sondervermögen

Ein wesentlicher Vorteil von Sondervermögen wird darin gesehen, daß sie auf lange Sicht zu einer Entlastung des Budgets und damit der Steuerzahler führen können. Dies gilt dann, wenn ein Sondervermögen einen Umfang erreicht hat, bei dem die Finanzierung von

1 Vgl. dazu oben Abschnitt D.II.2.

2 Diese möglichen Vorteile außerbudgetärer Einheiten werden von der älteren finanzwissenschaftlichen Literatur hervorgehoben. Zu einem Überblick dazu vgl. SCHEMMEL (1990), S.8 ff. In diesem Sinn argumentiert auch die BUNDESREGIERUNG (1988), S.1, wenn sie im Hinblick auf die Vorteilhaftigkeit außerbudgetärer Einheiten ausführt: "Angesichts der Vielgestaltigkeit der staatlichen Aktivitäten ist es weder verfassungsrechtlich noch haushaltsrechtlich noch ordnungspolitisch bedenklich, wenn (...) die Kreditanstalten des Bundes wesentliche Aufgaben der Wirtschaftsförderung als eigene Aufgaben erfüllen. Sie handeln dabei in dem vom Parlament vorgegebenen gesetzlichen Rahmen. Das stellt keine unzulässige 'Flucht aus dem Budget' dar, sondern dient einer wirkungsvollen Aufgabenerledigung." 
Kredithilfen aus den Rückflüssen der Kredithilfen früherer Perioden geleistet werden kann. Allerdings ist stets zu beachten, da $\mathrm{B}$ in den Perioden des Aufbaus des Kapitalstocks von Sondervermögen das staatliche Budget belastet wird, sofern dazu allgemeine Haushaltsmittel verwendet werden und zusätzliche zweckgebundene Einnahmen nicht zur Verfügung stehen ${ }^{1}$. Mit diesem Argument läßt sich jedoch nicht belegen, daß die Sondervermögen im Vergleich zu einer budgetären Vergabe von Kredithilfen zu Effizienzsteigerungen führen. Denn in späteren Perioden sind nur dann budgetäre Entlastungen zu verzeichnen, wenn die Finanzierung des Kapitalstocks von Sondervermögen allenfalls zu einem geringen Teil durch staatliche Kreditaufnahme erfolgt.

Stehen zum Aufbau von Sondervermögen Steuereinnahmen zur Verfügung, so ergeben sich aus der Bildung von Sondervermögen keine Vorteile, wenn diese Steuereinnahmen auch zur Akkumulation eines staatlichen Forderungsvermögens im Rahmen des Budgets eingesetzt werden können. Ein solches budgetäres Forderungsvermögen würde nämlich in späteren Perioden ebenfalls eine budgetäre Entlastung nach sich ziehen. Auch wenn sich hingegen zur Finanzierung von Sondervermögen im Vergleich zu einer budgetären Verwendung von Einnahmen aufgrund eines verringerten Steuerwiderstands zusätzliche Steuerquellen erschließen lassen ${ }^{2}$, sind Wohlfahrtsgewinne im Sinn einer Paretoverbesserung nur unter restriktiven Bedingungen denkbar. Denn selbst wenn die durch zusätzliche Steuereinnahmen finanzierten zusätzlichen Kredithilfen einen positiven Nettogegenwartswert aufweisen, erleiden die Individuen, die den Aufbau des Sondervermögens finanzieren, bei unvollkommener Voraussicht Verteilungsverluste gegenüber einer Finanzierung des Sondervermögens durch Kreditaufnahme, während die späteren Generationen Wohlfahrtsgewinne realisieren können. Es ist jedoch unwahrscheinlich, daß sich die Individuen auf der konstitutionellen Ebene darauf einigen werden, daß eine derartige intertemporale Umverteilung im Interesse der Allgemeinheit liegt.

Nach einem anderen Argument ist der Vorteil von Sondervermögen darin zu sehen, daß sie eine weniger strikte Handhabung der im Haushaltsrecht verankerten Budgetgrundsätze der Spezialität erlauben. Die bei Sondervermögen resultierende Umgehung dieser Grundsätze führt danach zu einer "Erleichterung der Bewirtschaftung"3 ${ }^{3}$ und einer erhöhten organisatorischen Flexibilität bei der Subventionierung bestimmter Aktivitäten ${ }^{4}$. So erlaube die "budgetpolitische Unabhängigkeit" von Sondervermögen, "unter Beachtung der vorgegebenen Zielsetzung, die Mittel kurzfristig in Richtung bestimmter regionaler oder

1 Vgl. DICKERTMANN (1971), S.175.

2 Vgl. DICKERTMANN (1971), S.176.

3 VIALON (1951), S.115.

4 Vgl. NEUMARK (1952), S.598; DICKERTMANN (1971), S.172, 179. 
struktureller Schwerpunkte umzudisponieren, wobei auf die ökonomische Dringlichkeit und größtmögliche Effizienz beim Mitteleinsatz Rücksicht genommen werden" könne ${ }^{\mathbf{1}}$. Dies kann unter Effizienzaspekten wünschenswert sein, weil dadurch die Anpassungszeiten der Subventionsstruktur an geänderte ökonomische Bedingungen verkürzt werden können ${ }^{2}$. Flexible Anpassungsstrategien bei der Subventionspolitik können in bestimmten Situtationen für ihren Erfolg von wesentlicher Bedeutung $\operatorname{sein}^{3}$.

Andererseits liegt die Vermutung nahe, daß die Zielrichtung der Spezialitätsgrundsätze gerade darin besteht, solche auf den ersten Blick als vorteilhaft erscheinenden flexiblen Anpassungsstrategien des Staates zu verhindern. So verschafft die relativ kurzfristige Änderbarkeit der Ausgabenzwecke bei Sondervermögen gerade der Exekutive einen erheblichen diskretionären Handlungsspielraum, um die Mittel für Ausgaben zu verwenden, die primär ihren eigenen Nutzen erhöhen ${ }^{4}$. Somit stehen den Nutzen in Form erhöhter Flexibilität höhere Kontrollkosten gegenüber, um mißbräuchliche Verwendungen der Mittel zu beschränken ${ }^{5}$. Je geringer die potentiellen Erträge der erhöhten Flexibilität und je höher die Kosten der Kontrolle der staatlichen Akteure sind bzw. je weniger Ressourcen zu ihrer Kontrolle im politischen Prozeß bereitgestellt werden, desto eher erscheint die Flexibilität der Sondervermögen durch Umgehung der Spezialitätsgrundsätze als Laster denn als Tugend ${ }^{6}$. Dies gilt insbesondere dann, wenn die erhöhte Flexibilität der Sondervermögen darauf beruht, daß sich durch sie außer den budgetären Spezialitätsgrundsätzen weitere Restriktionen, wie z.B. staatliche Verschuldungsregeln, umgehen lassen, welche den diskretionären Handlungsspielraum staatlicher Akteure begrenzen sollen. Gleichwohl sind allgemeingültige Aussagen über die Kosten-Nutzen-Relation der höheren Flexibilität von Sondervermögen nicht ohne weiteres möglich.

Schließlich werden Sondervermögen als Instrument zur Effizienzsteigerung betrachtet, weil dadurch eine Bündelung verschiedener Ausgabenpositionen möglich werde, "denen zwar eine gleiche Zielrichtung vorgegeben ist, die aber wegen der Kompetenzüberschreitungen bei mehreren Ressorts oftmals unkoordiniert nebeneinander stehen." Mit einer Konzentration des Mitteleinsatzes bei einem Sondervermögen ist danach "die Vermeidung von Parallelprogrammen oder sogar gegenläufiger Maßnahmen und ein verbes-

1 DICKERTMANN (1971), S.172.

2 Vgl. SENF (1977), S.409 f. Beispielsweise konnten Mittel des ERP-Sondervermögens im Zuge der deutschen Vereinigung relativ kurzfristig in das Gebiet der früheren DDR gelenkt werden.

$3 \mathrm{Zu}$ der vergleichbaren Problematik bei der staatlichen Stabilisierungspolitik vgl. z.B. MUSGRAVE (1959/1966), S.465 ff.

4 Vgl. NEUMARK (1952), S.578, 587; DICKERTMANN (1971), S.180; SENF (1977), S.409.

5 Vgl. SENF (1977), S.410.

6 Vgl. BENNETT/DILORENZO (1983b), S.53. 
serter Informationsfluß verbunden, so daß Mittel eingespart, rationeller verwendet und ihre gesamtwirtschaftliche Bedeutung klarer herausgestellt werden könnte. ${ }^{n 1}$ Diese idealisierte Vorstellung deckt sich jedoch kaum mit den empirischen Tatsachen. So trifft es in der Bundesrepublik Deutschland nicht zu, daß beispielsweise die Wirtschaftsförderung auf Sondervermögen konzentriert ist. Somit läßt sich vermuten, daß durch die Errichtung von Sondervermögen die Gefahr der Mittelverschwendung durch Parallelprogramme eher erhöht als reduziert wird.

Bei entsprechender Dimensionierung steht einer Effizienzsteigerung durch Sondervermögen die Zweckbindung ihrer Einnahmen entgegen. Durch diese Zweckbindung werden die Ausgaben für die entsprechenden Zwecke in sachlicher und zeitlicher Hinsicht zementiert, da eine Überprüfung der Dringlichkeit der Ausgaben regelmäßig nur einmalig bei der Festlegung der Zweckbindung erfolgt. D.h. daß den Sondervermögen die Tendenz zur Selbsterhaltung innewohnt ${ }^{2}$, die sich darin äußert, daß bestimmte ökonomische Aktivitäten auch dann durch Sondervermögen weitergefördert werden, wenn die ökonomische Rechtfertigung dafür aufgrund der wirtschaftlichen Entwicklung längst entfallen ist.

Damit sprechen gewichtige Argumente dagegen, da $B$ mit Hilfe von Sondervermögen eine effizientere staatliche Subventionierung möglich ist. So kann es nicht verwundern, daß Sondervermögen auch in der älteren finanzwissenschaftlichen Literatur nur in Ausnahmefällen als ökonomisch wünschenswerte Einrichtungen betrachtet werden ${ }^{3}$. Dementsprechend dürften konstitutionelle Entscheidungen zugunsten von Sondervermögen kaum auf der Erwartung von Effizienzsteigerungen bei der Subventionierung beruhen.

\section{bb. Sondervermögen als fiskalische Restriktionen}

Sollen Sondervermögen als fiskalische Restriktionen wirken, so setzt dies voraus, daß unter bestimmten Bedingungen die kollektiven Interessen besser geschützt sind, wenn zur Finanzierung bestimmter Ausgaben Sondervermögen eingerichtet werden, als wenn diese Ausgaben budgetär finanziert werden. Es soll unterstellt werden, daß der Staat in einer bestimmten historischen Periode zweckgebundene Einnahmen erzielt, die nach der Vorstellung der Finanziers dieser Einnahmen zur Akkumulation staatlicher Vermögensaktiva verwendet werden und für einen bestimmten Zeitraum oder dauerhaft der Förderung bestimmter Aktivitäten dienen sollen. Dies impliziert im Regelfall eine Förderung

1 DICKERTMANN (1971), S.175 f.

2 Vgl. HEINIG (1948), S.451; DICKERTMANN (1971), S.179 f.

3 Vgl. DICKERTMANN (1971), S.181. 
durch öffentliche Darlehen ${ }^{1}$. Mögliche Finanziers sind dabei sowohl dritte Staaten, wie beim ERP-Sondervermögen, als auch die Steuerzahler.

Ist im budgetären Bereich die obligatorische Bestandserhaltung bestimmter Teile des staatlichen Vermögens bzw. eine Zweckbindung von Vermögenseinnahmen rechtlich nicht zugelassen, so besteht aus konstitutioneller Sicht die Gefahr, daß ein probabilistischer Vergünstigungsstaat, der nur zeitweise in Aktion ist ${ }^{2}$, bei budgetärer Verwendung der ursprünglichen Einnahmen die späteren Vermögenseinnahmen so verausgabt, daß die Höhe der Vorteile für die aus der Subventionierung Begünstigten und damit die Vorteile der staatlichen Akteure maximiert werden. Dies läßt sich dadurch erreichen, daß die staatlichen Akteure die Vermögenseinnahmen anstelle öffentlicher Darlehen vollständig zur Gewährung verlorener Zuschüsse einsetzen. Dabei kann entweder der Subventionssatz für die geförderten Aktivitäten oder die Zahl der Subventionsempfänger erhöht werden. Darüber hinaus besitzt ein Vergünstigungsstaat einen Anreiz zur Zweckentfremdung der Vermögenseinnahmen, wenn sich dadurch die politischen Erträge steigern lassen. Ein probabilistischer Leviathan ${ }^{3}$ würde sich unter den genannten Bedingungen den maximal möglichen Teil der Vermögenseinnahmen aneignen und für eigene Zwecke verwenden.

Werden die zweckgebundenen Einnahmen zur Finanzierung eines budgetären Forderungsvermögens verwendet, so besteht also die Gefahr, daß dieses Vermögen von einem unrestringierten Staat in seinem Nominalbestand reduziert wird, was zugleich eine Einschränkung des künftigen Förderungspotentials impliziert. Wollen die Individuen auf der konstitutionellen Ebene einem derartigen staatlichen Verhalten vorbeugen, um einseitige Nutzenverteilungen zu vermeiden, so erscheint es möglich, daß sie sich auf eine Regel einigen, nach der zweckgebundene Einnahmen zum Aufbau von Sondervermögens zu verwenden sind. Dabei muß allerdings zwingend vorgeschrieben sein, daß Sondervermögen in ihrem Bestand zu erhalten ${ }^{4}$ und die Vermögenseinnahmen zweckgebunden einzusetzen sind. Unter diesen Bedingungen läßt sich verhindern, daß eine mit Hilfe zweckgebundener Einnahmen aufgebaute Vermögensmasse durch eine zweckwidrige Verwendung der Vermögenseinnahmen aufgezehrt wird ${ }^{5}$.

1 Allerdings ist auch vorstellbar, daß ein Teil der Einnahmen zur Gewährung von Zuschüssen verwendet wird, während mit dem anderen Teil der Erwerb marktlicher Vermögenstitel finanziert wird. Von dieser Möglichkeit soll jedoch im folgenden abgesehen werden.

2 Vgl. dazu oben Abschnitt D.II.3.c.

3 Zum Begriff des probabilistischen Leviathan vgl. oben Abschnitt D.II.3.b.

4 Zielt die Zweckbestimmung der Finanziers der ursprünglichen Einnahmen auf eine zeitliche Befristung der Förderaktivitäten ab, wäre in entsprechender Weise eine maximale periodische Vermögensminderung als Restriktion vorzusehen.

Vgl. HEDTKAMP (1977), S.83. 


\section{b. Die Errichtung von Sonderkreditinstituten als konstitutionelle Entscheidung}

Die Errichtung von Sonderkreditinstituten wird aus konstitutioneller Sicht wünschenswert sein, wenn damit die Funktionsfăhigkeit der Kreditmärkte einer Volkswirtschaft verbessert oder wiederhergestellt werden kann $^{1}$. Dieser Aspekt wird im allgemeinen im Hinblick auf die Gründung der Kreditanstalt für Wiederaufbau hervorgehoben ${ }^{2}$. Denn zweifellos war die Kreditversorgung zahlreicher Wirtschaftszweige in der damaligen Zeit mangelhaft. In dieser Situation erreichte die Kreditanstalt für Wiederaufbau rasch eine bedeutende Stellung als Kreditanbieter ${ }^{3}$. Dieser Umstand ist jedoch nicht darauf zurückzuführen, daß die Kreditanstalt für Wiederaufbau bei der Mobilisierung eines marktlichen Kapitalangebots besonders erfolgreich war. Vielmehr hatte sie von Beginn ihrer Tätigkeit an die Aufgabe, Kredithilfen zu vergeben, die sie mit Mitteln aus dem Marshall-Plan refinanzierte. Daher bleibt zu untersuchen, unter welchen Bedingungen die Vergabe von Kredithilfen durch Sonderkreditinstitute anstelle andere Organisationseinheiten aus konstitutioneller Sicht wünschenswert sein kann. Dabei soll auch hier analysiert werden, ob durch Sonderkreditinstitute eine effizientere Erfüllung staatlicher Aufgaben möglich ist bzw. ob die Errichtung von Sonderkreditinstituten als spezielle Form fiskalischer Restriktionen interpretiert werden kann.

aa. Effizientere Erfüllung staatlicher Aufgaben durch Sonderkreditinstitute

Es sei unterstellt, daß die Vergabe öffentlicher Kredithilfen aus tatsächlichen oder rechtlichen Gründen nicht durch private Kreditinstitute erfolgen kann. Ein tatsächliches Hindernis für die Vergabe von Kredithilfen durch das private Bankensystem liegt vor, wenn es nicht hinreichend entwickelt ist, um die flächendeckende Distribution von Kredithilfen zu gewährleisten. Ein rechtliches Hindernis liegt vor, wenn es aus verfassungsrechtlichen Gründen verboten ist, Aufgaben der staatlichen Leistungsverwaltung als Teil der hoheitlichen Tätigkeit des Staates in größerem Umfang durch Private wahrnehmen zu lassen. Dies ist in bezug auf Kredithilfen insbesondere dann anzunehmen, wenn private Kreditinstitute bei nicht-kompetitiver Struktur des Kreditmarkts und informationsbedingten Unvollkommenheiten aufgrund ihres Gewinnmaximierungskalküls einen Anreiz zu einer will-

1 HAHN (1978), S.296 spricht in diesem Zusammenhang von einer MarkterschlieBungsfunktion öffenticher Banken.

2 Vgl. KIRCHHOFF (1987), S.64; SCHLESINGER (1987), S.31; ZIMMERMANN-TRAPP (1987), S.203.

3 So entfielen 1950 rund $20 \%$ der gesamten Kreditzusagen im damaligen Gebiet der Bundesrepublik Deutschland auf die Kreditanstalt für Wiederaufbau. Vgl. BÄKOW (1984), S.413. 
kürlichen Ungleichbehandlung der Antragsteller besitzen und damit den angestrebten Subventionserfolg gefährden.

Sind aus diesen Gründen nur budgetäre und außerbudgetäre Einrichtungen mögliche alternative Organisationsformen zur Durchführung von staatlichen Kredithilfeprogrammen, so sind Sonderkreditinstitute als Organisationsform vorzuziehen, wenn bei einem als konstant angenommenen staatlichen Kredithilfeangebot und einer von der Organisationsform unabhängigen Verteilung der Kredithilfen durch Sonderkreditinstitute die Kosten der Subventionierung gesenkt werden können ${ }^{1}$. Als Kostenkategorien sind in diesem Zusammenhang die Administrationskosten, die "Erzielungskosten"2 der Kredithilfe-Empfänger sowie die sozialen Zeitkosten der Programmdurchführung zu berücksichtigen.

Die Administrationskosten umfassen dabei sämtliche Kosten, die mit dem durch die Kredithilfevergabe vorgenommenen Ressourceneinsatz verbunden sind. Dazu gehören insbesondere Personal- und Kapitalkosten sowie die Kosten des laufenden Geschäftsbetriebs $^{3}$. Die Erzielungskosten der Kredithilfe-Empfänger umfassen die Kosten aller Ressourcen, welche die Empfänger der Kredithilfen zu ihrer Erlangung einsetzen müssen. Analog zu den compliance costs der Besteuerung lassen sich hierbei monetäre, psychische und Zeitkosten unterscheiden ${ }^{4}$, die im Zusammenhang mit der Informationsbeschaffung, Antragstellung und Antragsbearbeitung entstehen. Unter sozialen Zeitkosten werden die entgangenen sozialen Nutzen verstanden, die dadurch verursacht werden, daß die Subventionierung nicht mit unendlicher Geschwindigkeit durchgeführt werden kann.

Es ist nun zu analysieren, unter welchen Bedingungen die Durchführung von Kredithilfeprogrammen durch Sonderkreditinstitute unter den gegebenen Annahmen kostengünstiger erfolgt als durch budgetäre Einheiten. Dabei stellt sich zunächst die Frage, welche Argumente dafür sprechen, daß Sonderkreditinstitute die Vergabe von Kredithilfen mit geringeren Administrationskosten durchführen können als budgetäre Einheiten.

Im folgenden sei unterstellt, daß die mit der Vergabe von Kredithilfen betrauten Organisationseinheiten jeweils die im Rahmen der gegebenen Restriktionen mögliche Minimalkostenkombination verwirklichen. Ist die Kredithilfevergabe primär mit der Erfüllung bankmäßiger Aufgaben verbunden, so können sich komparative Vorteile der Sonderkreditinstitute bei den Administrationskosten daraus ergeben, daß sie gegenüber budgetären Einheiten Vorteile bei der Rekrutierung entsprechend qualifizierter Arbeits-

1 Vgl. ZIMMERMANN-TRAPP (1987), S.203.

2 Diese Erzielungskosten entsprechen den sogenannten compliance costs bei der Steuererhebung. Vgl. dazu SANDFORD/GODWIN/HARDWICK (1989).

3 Vgl. SANDFORD/GODWIN/HARDWICK (1989), S.6.

$4 \mathrm{Vgl}$. SANDFORD/GODWIN/HARDWICK (1989), S.10 ff. 
kräfte besitzen. Dies gilt insbesondere dann, wenn es segmentierte Arbeitsmärkte für den öffentlichen Dienst und den Bankenbereich gibt, die nur unvollkommen interagieren ${ }^{1}$, weil die budgetären Einheiten aufgrund bestehender Laufbahnvorschriften und des starren Lohngefüges für die Anbieter auf dem "Banken-Arbeitsmarkt" vergleichsweise unattraktiv sind. Ist die Grenzproduktivität der Arbeit aufgrund des bankspezifischen Humankapitals bei den Sonderkreditinstituten höher, so können letztere Kredithilfeprogramme kostengünstiger durchführen als budgetăre Einheiten. Dieses Argument gilt primär für solche Kredithilfeprogramme, auf die kein Rechtsanspruch besteht und für welche die Bonität des Empfängers von Bedeutung ist. Umgekehrt kann angenommen werden, daß budgetäre Einheiten komparative Vorteile bei der Vergabe von Kredithilfen besitzen, deren Gewährung primär oder ausschließlich von rechtlichen Kriterien abhängt ${ }^{2}$.

Darüber hinaus können die Administrationskosten bei einer Kredithilfevergabe durch Sonderkreditinstitute geringer sein, wenn sie gegenüber budgetären Einheiten höhere Innovationsanreize besitzen. Erhalten die Sonderkreditinstitute beispielsweise je Kredithilfe-Einheit einen Pauschalbetrag als "Kostenersatz" und richtet sich die Entlohnung ihrer Manager nach der Höhe des Gewinns der Sonderkreditinstitute, so werden sie tendenziell mehr Innovationsaktivitäten entfalten als budgetäre Einheiten, deren Chefbürokraten nicht erfolgsorientiert entlohnt werden. Höhere Innovationsaktivitäten erhöhen jedoch die Produktivität der eingesetzten Produktionsfaktoren, so daß eine gegebene Kredithilfemenge mit geringeren Inputmengen vergeben werden $\mathrm{kann}^{3}$. Allerdings wird die Erfolgsmessung bezüglich der Durchführung staatlicher Kredithilfeprogramme bei Sonderkreditinstituten äußerst schwierig, wenn sie teilweise auch marktliche Bankaktivitäten durchführen und Ertragsanteile zur Verbilligung eigener Kredithilfeprogramme einsetzen.

Läßt man Abweichungen von der Minimalkostenkombination zu, so können Unterschiede in den Administrationskosten auch daraus resultieren, daß die Differenz zwischen den tatsächlichen und den minimalen Kosten bei gegebener Kredithilfemenge, die sogenannte X-Ineffizienz ${ }^{4}$, bei Sonderkreditinstituten geringer ist als bei budgetären Einheiten. Solche X-Ineffizienzen werden zum einen dadurch verursacht, daß die in den jeweiligen Bereichen tätigen Akteure aufgrund hoher Kontrollkosten einen Anreiz besitzen, bei der Leistungserstellung Spielräume zur Einschränkung der möglichen Arbeitsanstrengungen

1 Zu einem Überblick hierzu vgl. BUTTLER/GERLACH (1982), S.692 ff.; TARLING (1987), S.87.

2 Insoweit ist es kaum überraschend, daß beispielsweise BAFöG-Darlehen von budgetären Einheiten vergeben werden.

3 Vgl. HERB (1988), S.7 f.

4 Vgl. LEIBENSTEIN (1966). 
auszunutzen. Ein derartiges Verhalten wird als Shirking bezeichnet ${ }^{1}$. Andererseits können $\mathrm{X}$-Ineffizienzen darin bestehen, daß bei der Leistungserstellung auch Ausgaben für unproduktive Inputs getätigt werden, welche für die Beschäftigten nicht-monetäre Einkommensbestandteile repräsentieren ${ }^{2}$. Das differentielle Ausmaß solcher X-Ineffizienzen im budgetären und außerbudgetären Sektor wird maßgeblich durch Unterschiede in den Anreizsystemen beider Sektoren bestimmt ${ }^{3}$.

Die differentiellen Wirkungen von alternativen institutionellen Bedingungen werden insbesondere im Rahmen der Property-Rights- ${ }^{4}$ und der Principal-Agent-Theorie ${ }^{5}$ diskutiert. Mit dem Instrumentarium der Principal-Agent-Theorie wird untersucht, wie sogenannte anreizkompatible Verträge zwischen einem Auftraggeber, dem Prinzipal, und einem Beauftragten, dem Agenten, unter den Annahmen von Unsicherheit und asymmetrischer Information ausgestaltet sein müssen, um die Anreize der Agenten zu Shirking-Verhalten zu begrenzen ${ }^{6}$. Demgegenüber werden von der Property-Rights-Theorie die differentiellen Wirkungen unterschiedlicher Systeme von Verfügungsrechten, die sich in unterschiedlichen Organisationsformen ausdrücken, in den Vordergrund gestellt ${ }^{7}$. Dabei wird allerdings ebenfalls die Bedeutung von Informationsunvollkommenheiten und von daraus resultierenden Kontrollproblemen betont, so daß beide Ansätze miteinander verknüpft werden können ${ }^{8}$.

Allerdings werden im Rahmen des Property-Rights-Ansatzes meist nur öffentliche Organisationsformen, vor allem öffentliche Unternehmen, einerseits und private Unternehmen andererseits, nicht aber unterschiedliche öffentliche Organisationsformen vergleichend analysiert. Dabei wird argumentiert, daß bei privaten Unternehmen selbst dann, wenn die wesentlichen Entscheidungskompetenzen an Manager delegiert sind, Kontrollmechanismen, wie der Kapitalmarkt, der Arbeitsmarkt für Führungskräfte und die Möglichkeit von Take-overs mit der Gefahr der Auswechslung des Managements, wirksam sind, die ein Managerverhalten im Interesse der Eigentümer induzieren ${ }^{9}$. Dagegen wird bei öffentlichen Unternehmen das Problem gesehen, daß solche wirksamen Kontrollmechanismen kaum vorhanden sind. So entfällt eine Kapitalmarktkontrolle, weil die Anteilseigner,

Vgl. dazu grundlegend ALCHIAN/DEMSETZ (1972); DEALESSI (1983).

2 Vgl. WAHL (1987), S.21 f.

3 "Study of efficiency (...) necessarily involves understanding of the institutional background and

the conditions under which transactions take place." FURUBOTN/PEJOVICH (1972), S.1141.

4 Vgl. DEMSETZ (1967); ALCHIAN/DEMSETZ (1972); FURUBOTN/PEJOVICH (1972).

5 Vgl. ROSS (1973); GROSSMAN/HART (1983); REES (1985).

6 Vgl. STIGLITZ (1987), S.968.

7 Vgl. FURUBOTN/PEJOVICH (1972), S.1148 f.

8 Vgl. WAHL (1987), S.21.

9 Vgl. ALCHIAN/DEMSETZ (1972), S.788; HANKE (1987), S.976. 
nämlich die Steuerzahler, ihre Anteile nicht veräußern können. Damit wird jedoch eine Kapitalisierung der Konsequenzen des Managerverhaltens unmöglich und der Anreiz zur Managerkontrolle ist gering. Dies gilt um so mehr, als die Kontrolle öffentlicher Unternehmen ein öffentliches Gut darstellt und somit das bekannte Free-rider-Problem auftritt. Weiterhin ist das Bankrottrisiko für öffentliche Unternehmen extrem gering ${ }^{1}$. Danach ist der diskretionäre Handlungsspielraum für die Manager öffentlicher Unternehmen erheblich größer als für Manager privater Unternehmen ${ }^{2}$. Somit kann erwartet werden, daß die $\mathrm{X}$-Ineffizienz bei privaten Unternehmen tendenziell geringer ist als bei öffentlichen Organisationseinheiten.

Für die hier interessierende vergleichende Analyse unterschiedlicher öffentlicher Organisationsformen erscheint der Property-Rights-Ansatz relativ wenig geeignet, da die Anreizprobleme im Hinblick auf eine effektive Kontrolle öffentlicher Organisationseinheiten bei öffentlichen Unternehmen, wie den Sonderkreditinstituten, und bei budgetären Einheiten überwiegend ähnlich gelagert sind. Allenfalls könnte man argumentieren, daß die Manager von Sonderkreditinstituten stärkere Anreize zu einer effizienten Leistungserstellung besitzen als die Chefbürokraten budgetärer Einheiten, weil bei Sonderkreditinstituten die Möglichkeit der Privatisierung besteht ${ }^{3}$, wodurch sich das Beschäftigungsrisiko der Manager erhöht. Allerdings werden die dadurch vermittelten Anreize nicht sehr stark sein, da die Privatisierungs-Wahrscheinlichkeit bei einer effizienten Leistungserstellung eher steigen als fallen dürfte. Außerdem lassen sich Privatisierungen öffentlichrechtlicher Organisationseinheiten nicht zuletzt wegen der damit verbundenen rechtlichen Probleme selten kurzfristig durchführen. Je länger aber eine "Privatisierungsoperation" dauert, desto geringer werden die Anreizeffekte aufgrund der "Privatisierungsgefahr" sein, solange diese nicht akut ist.

Eine höhere Produktionseffizienz der Sonderkreditinstitute läßt sich jedoch insoweit vermuten, als die hier üblichen privatrechtlichen Beschäftigungsverhältnisse in stärkerem Umfang Sanktionsmöglichkeiten zulassen als die für budgetäre Einheiten typischen beamtenrechtlichen Beschäftigungsverhältnisse. So läßt sich durch einfache Principal-AgentModelle zeigen, daß fehlende Kündigungsmöglichkeiten als Sanktionsinstrument bei Shirking-Verhalten den Anreiz zu einer ineffizienten Leistungserstellung in extremer Weise verstärken können ${ }^{4}$. Insofern dürften die Sonderkreditinstitute über ein wirksa-

1 Vgl. HANKE (1987), S.977.

2 Vgl. DE ALESSI (1980), S.27 f.

3 So wurden verschiedentlich auch die Kreditanstalt für Wiederaufbau und die Deutsche Ausgleichsbank als mögliche Privatisierungsobjekte genannt. Vgl. KIRCHHOFF (1987), S.197 m.w.N.

4 Vgl. WAHL (1987), S.33 f. 
meres Sanktionsinstrumentarium verfügen als budgetäre Einheiten. Allerdings muß berücksichtigt werden, daß auch das Beamtenrecht eine Reihe von Regeln enthält, die für den einzelnen Beamten Leistungsanreize vermitteln ${ }^{1}$. Daher dürfte die X-Ineffizienz im budgetären Bereich zumindest nicht wesentlich höher sein als bei außerbudgetären Einrichtungen ${ }^{2}$. Dennoch erscheint es unter den getroffenen Annahmen nicht unplausibel, wenn man erwartet, da $B$ Sonderkreditinstitute Kredithilfeprogramme mit geringeren Administrationskosten durchführen können als budgetäre Einheiten.

Werden Kredithilfeprogramme alternativ von budgetären Einheiten oder Sonderkreditinstituten durchgeführt, so können sich Unterschiede in den Erzielungskosten der Kredithilfe-Empfänger zum einen daraus ergeben, da $B$ die Informationsbeschaffungskosten bei beiden Alternativen nicht gleich hoch sind. Allerdings spricht wenig dafür, da $B$ die bisweilen beklagte Transparenz von Subventionsprogrammen ein Problem budgetärer oder außerbudgetärer Durchführung von Kredithilfen darstellt ${ }^{3}$. Deshalb soll dieser Aspekt nicht weiter vertieft werden. Zum anderen werden sich die Erzielungskosten unterscheiden, wenn die Bearbeitungszeiten der Kredithilfeanträge von der organisatorischen Durchführung der Programme abhängen. Da mit der Realisierung der durch Kredithilfen geförderten Maßnahmen regelmäßig erst nach einer Entscheidung über den Kredithilfeantrag begonnen werden darf, impliziert die Dauer der Antragsbearbeitung reale Zeitkosten. Da die Ausgaberegeln für die Sonderkreditinstitute im allgemeinen weniger restriktiv sein werden als für budgetäre Einheiten, kann angenommen werden, daß die Bearbeitungsdauer bei Sonderkreditinstituten aufgrund der damit verbundenen erhöhten Flexibilität kürzer ist als bei budgetären Einheiten ${ }^{4}$. Darüber hinaus ist zu erwarten, daß Sanktionen für Rechtsverstöße bei der Vergabe von Kredithilfen im budgetären Bereich härter sind als bei den Sonderkreditinstituten. Damit wird hier die Intensität der rechtlichen Prüfung von Anträgen aufgrund höherer individueller Grenzerträge der Beschäftigten höher sein als bei Sonderkreditinstituten ${ }^{5}$. Da die Bearbeitungsdauer von Anträgen mit

1 Vgl. dazu ausführlich WAHL (1987), S.97 ff.

2 In diesem Zusammenhang sei auch nochmals darauf hingewiesen, daß in der moderne Bürokratietheorie bisweilen die Auffassung vertreten wird, daB X-Ineffizienzen bei der bürokratischen Leistungserstellung eine vergleichsweise geringe Rolle spielen. Dies gilt insbesondere dann, wenn die Bürokraten eine hohe Präferenz für ihren Output besitzen. Vgl. PETHIG (1988), S.688 f.

3 Vgl. MÜLLER-KÄSTNER (1986), S.19.

4 Vgl. MÜLLER-KÄSTNER (1986), S.17. Diese Überlegung wird tendenziell durch Befragungen gestützt, wonach die Antragstellung für die von Sonderkreditinstituten vergebenen ERP-Darlehen von der Mehrheit der Darlehensempfänger als nicht aufwendiger empfunden wird als bei einem normalen Bankkredit. Vgl. MÜLLER-KÄSTNER (1986), S.9.

5 Daraus kann jedoch nicht ohne weiteres geschlossen werden, daß die Prüfungsintensität im budgetären Bereich ineffizient hoch ist. 
zunehmender Prüfungsintensität steigen wird, spricht auch dieses Argument dafür, daß die Erzielungskosten bei einer Programmdurchführung von Sonderkreditinstituten geringer sind.

Allerdings implizieren die verringerten Zeitkosten für die Antragsteller im Fall von Sonderkreditinstituten noch nicht, daß sich damit auch die sozialen Zeitkosten der Vergabe von Kredithilfen verringern lassen. Dies trifft nur unter der Bedingung zu, daß die betreffenden Kredithilfeprogramme Nettowohlfahrtseffekte erzeugen. Andernfalls wäre es allokativ wünschenswert, daß die Vergabe von Kredithilfen möglichst viel Zeit in Anspruch nimmt.

Unter der Annahme positiver Nettowohlfahrtseffekte eines zusätzlichen Kredithilfeprogramms kann seine Abwicklung durch Sonderkreditinstitute auch insofern zu einer Senkung sozialer Zeitkosten führen, als diese ohne Rücksicht auf budgetäre Vorgaben relativ kurzfristig zusätzliche Inputs beschaffen und damit die Programmdurchführung beschleunigen können.

Als Zwischenergebnis kann somit festgehalten werden, daß unter den getroffenen Annahmen eine Reihe von Argumenten dafür spricht, daß durch Sonderkreditinstitute tatsächlich Effizienzsteigerungen in Form von Kosteneinsparungen bei der Subventionsverwaltung realisiert werden können. Allerdings wird sich diese positive Einschätzung der Sonderkreditinstitute umkehren, wenn man realistischerweise berücksichtigt, daß sich die Zusammmensetzung des Kreises der Subventionsempfänger in Abhängigkeit von der Organisationsform der Subventionsverwaltung ändern kann. Dies soll anhand der folgenden Überlegungen gezeigt werden.

Es sei angenommen, daß Kredithilfen in Form öffentlicher Darlehen vergeben werden, wobei für alle Darlehensempfänger ein einheitlicher Darlehenszinssatz festgelegt sei. Nach der Zielsetzung des Darlehensprogramms sollen damit Investitionen ermöglicht werden, deren Finanzierung über den Kapitalmarkt aufgrund der gegebenen Investitionsrisiken gefährdet ist. Weiterhin sei das Darlehensvolumen rationiert, so daß nicht die gesamte Nachfrage nach zinsverbilligten Darlehen befriedigt werden kann. Die potentiellen Darlehensempfänger sollen sich durch ihr Kreditrisiko unterscheiden. Das individuelle Risiko soll durch den Einsatz bankspezifischer Ressourcen erkennbar sein. Außerdem wird aus Vereinfachungsgründen angenommen, daß über die Höhe der direkten Subventionsausgaben vollständige Information gegeben sei. Die Entlohnung des Managements der Sonderkreditinstitute soll sich mangels alternativer Erfolgsmaßstäbe nach der Höhe des Gegenwartswerts der Netto-Subventionsausgaben bemessen, während die Entlohnung im budgetären Bereich erfolgsunabhängig sein soll. 
Unter diesen Bedingungen werden Sonderkreditinstitute, die über bankspezifische Ressourcen verfügen, die Auswahl der Darlehensempfänger in der Weise vornehmen, daß sie vorrangig die Darlehensnachfrager mit dem geringsten Risiko bedienen. Damit ist das Risiko des Portfolios an Darlehensforderungen sowie die Höhe der Netto-Subventionsausgaben geringer, wenn die Darlehensvergabe durch Sonderkreditinstitute anstelle von budgetären Einheiten erfolgt. Diese auf den ersten Blick wünschenswerte Konsequenz erweist sich bei genauerem Hinsehen als nicht unproblematisch. Unterstellt man nämlich, daß die Darlehensnachfrager mit dem geringsten Risiko ihre Investitionen mit marktlichen Kapitalmarktmitteln finanzieren könnten, dann führt die Darlehensvergabe durch Sonderkreditinstitute zu einer Erhöhung der Mitnahmeeffekte und damit zu einer Verfehlung des angestrebten Subventionserfolgs ${ }^{1}$. Da die Höhe der Mitnahmeeffekte für die Politiker nicht meßbar ist, handeln die in den Sonderkreditinstituten tätigen Akteure jedoch rational, wenn sie die Darlehensempfänger in der Weise auswählen, daß nicht die Mitnahmeeffekte, sondern die Subventionsausgaben minimiert werden, weil damit der für die Politiker wahrnehmbare Erfolg der Sonderkreditinstitute maximal wird ${ }^{2}$.

Damit ist freilich nicht gesagt, daß die Verringerung der Mitnahmeeffekte bei einer Darlehensvergabe durch budgetäre Einheiten stets wohlfahrtssteigernd wäre. Entsprechen beispielsweise die Durchschnittsrisiken der potentiellen und der tatsächlichen Darlehensempfänger einander, so werden wahrscheinlich auch solche Darlehensnachfrager bedient werden, deren Investitionen ineffizient sind, weil der erwartete Investitionsertrag aufgrund des hohen Risikos die Kapitalkosten nicht deckt. Insofern hängen die differentiellen Wohlfahrtseffekte von Sonderkreditinstituten und budgetären Einheiten davon ab, ob der soziale Nutzen aus der Verringerung von Mitnahmeeffekten bei budgetären Einheiten durch die Förderung ineffizienter Investitionen überkompensiert wird oder nicht.

Diese Überlegungen zeigen, daß die komparativen Vorteile der Sonderkreditinstitute bei der Erstellung bankmäßiger Leistungen keinesfalls zwangsläufig zu Effizienzsteigerungen führen. Nimmt man an, daß dies auf der konstitutionellen Entscheidungsebene erkannt wird, dann dürften diese Vorteile von Sonderkreditinstituten allein kaum hinreichen, um ihre Errichtung als konstitutionelle Entscheidung erklären zu können.

1 Insofern kann es nicht überraschen, daß zumindest bei den aus eigenen Erträgen verbilligten Darlehen der Kreditanstalt für Wiederaufbau von hohen Mitnahmeeffekten auszugehen ist. Vgl. MÜLLER-KÄSTNER (1986), S.15; SCHLESINGER (1987), S.32.

2 "As production of attributes not expected to be observed by Congress will not increase a manager's perceived productivity it will not pay for agencies to devote resources to their production." LINDSAY (1976), S.1065. 
bb. Sonderkreditinstitute als fiskalische Restriktionen

Es bleibt somit zu untersuchen, ob durch solche Einrichtungen der Spielraum der staatlichen Akteure für Handlungen bei der Vergabe von Kredithilfen, die dem Interesse der Allgemeinheit widersprechen, begrenzt werden kann, so daß die Errichtung von Sonderkreditinstituten als konstitutionelle Entscheidung interpretiert werden kann. Dabei wird wiederum unterstellt, daß auf der konstitutionellen Ebene nur budgetäre Einheiten und Sonderkreditinstitute als alternative Organisationseinheiten für die Vergabe von Kredithilfen betrachtet werden. Weiterhin wird angenommen, daß die Individuen auf der konstitutionellen Entscheidungsebene davon ausgehen, daß bei Kredithilfen, auf die kein Rechtsanspruch besteht, die Nachfrage das Angebot regelmäßig übersteigt, so daß eine mengenmäßige Rationierung der Kredithilfen erforderlich wird. Dies kann damit erklärt werden, daß sich der Staat in den postkonstitutionellen Perioden mit hoher Wahrscheinlichkeit als Vergünstigungsstaat verhält, der gegebene Netto-Subventionsausgaben bei Kredithilfen tendenziell auf vergleichsweise wenige Empfänger verteilt, indem er den $\mathrm{Zu}$ schuß- bzw. Zinsverbilligungssatz relativ hoch festsetzt, weil die Empfänger dann hohe Vorteile realisieren können. Auf diese Weise lassen sich die politischen Renten gegenüber einer Verteilung erhöhen, bei welcher der Subventionssatz so niedrig festgesetzt wird, daß alle Subventionsnachfrager bedient werden können.

Typische Begleiterscheinung von Mengenrationierungen sind diskriminierende Zuteilungsverfahren, die durch Ausspielung "guter Beziehungen", Korruption usw. gesteuert werden ${ }^{1}$. Dies trifft insbesondere dann zu, wenn das rationierte Gut nicht handelbar ist und somit die Bildung schwarzer Märkte nicht möglich ist. Da nicht die gesamte Kredithilfe-Nachfrage erfüllt werden kann, ist daher zu erwarten, daß die Politiker im Vergünstigungsstaat laufend Pressionen ausgesetzt sind, damit sie bei der Vergabe von Kredithilfen die Mitglieder bestimmter Interessengruppen bevorzugt behandeln. Es entspricht dabei dem Nutzenmaximierungskalkül der Politiker, solchen Pressionen nachzugeben, wenn die erzielbaren Vorteile die damit einhergehenden politischen Kosten übersteigen. Allerdings ist das Ausmaß der dadurch verursachten Diskriminierung bei der Verteilung der rationierten Kredithilfen wiederum von den gegebenen institutionellen Bedingungen und damit von der Organisation der Kredithilfevergabe abhängig.

Sonderkreditinstitute sind dadurch gekennzeichnet, da $B$ sie bei ihren Vergabeentscheidungen über ein relativ hohes $\mathrm{Ma}$ an Eigenständigkeit verfügen, während die budgetären Einheiten gegenüber den Politikern weisungsabhängig sind. Kommen die Politiker

1 Vgl. SCHUMANN (1987), S.67. 
aufgrund politischer Pressionen zu der Überzeugung, daß für sie durch eine bestimmte Verteilung der Kredithilfen zusätzliche Vorteile erreichbar sind, können sie diese Verteilung im Fall budgetärer Einheiten mit entsprechenden Weisungen vergleichsweise einfach durchsetzen, ohne daß solche Weisungen mit besonderen zusätzlichen Kosten verbunden sind. Dagegen ist die Durchsetzung einer durch Interessengruppen beeinflußten Verteilung der Mittel bei Sonderkreditinstituten nur auf informellem Weg möglich. Dies impliziert für die Politiker jedoch ein erhöhtes Risiko und damit erhöhte politische Kosten, weil sie nicht ausschließen können, daß sich die Verantwortlichen in den Sonderkreditinstituten gegen ein "Hineinregieren" in ihre Angelegenheiten widersetzen werden ${ }^{1}$. Darüber hinaus können sich die Wiederwahlchancen der Politiker verschlechtern, wenn die Überschreitung ihrer formellen Kompetenzen publik wird. Auf diese Weise kann durch Pressionen, die von Kredithilfe-Nachfragern auf die Politiker ausgeübt werden, die Vergabeentscheidung budgetärer Einheiten in stärkerem $\mathrm{Maß}$ beeinflußt werden als von Sonderkreditinstituten.

Zum einen werden die Individuen auf der konstitutionellen Ebene die Kredithilfevergabe durch Sonderkreditinstitute allein schon deshalb präferieren, weil sie die Realisierung von Sondervorteilen aufgrund politischer Einflußnahme kaum als fair empfinden werden. Über diesen Gerechtigkeitsaspekt hinaus werden sie die Sonderkreditinstitute auch aus allokativen Gründen bevorzugen.

Zwar wurde oben für den Fall risikobehafteter öffentlicher Darlehen gezeigt, daß sich bei einer Kredithilfevergabe durch Sonderkreditinstitute das Ausmaß der Mitnahmeeffekte erhöhen und damit der angestrebte Subventionserfolg reduzieren kann. Allerdings wurde dabei implizit angenommen, daß die budgetären Einheiten ihre Vergabeentscheidungen nach dem Zufallsprinzip vornehmen. Berücksichtigt man nun hingegen die Möglichkeit politischer Einflußnahme auf die Vergabeentscheidungen, so ergibt sich, daß der Anreiz zur Ausübung politischen Drucks bzw. zur Entfaltung von Rent-seeking-Aktivitäten mit der Höhe der erzielbaren Rente steigt ${ }^{2}$. Demnach werden unter den getroffenen Annahmen diejenigen Kredithilfe-Nachfrager die stärksten Pressionen auf die Politiker ausüben, die aus den Darlehen den höchsten Verteilungsvorteil erwarten können. Zun einen steigen die Verteilungsvorteile der Darlehensnachfrager mit zunehmendem Kreditrisiko, sofern die Darlehen zu einem einheitlichen Zinssatz vergeben werden. Unterstellt man, daß der erwartete Ertrag der geförderten Aktivitäten mit steigendem Kreditrisiko der

1 Diese Möglichkeit wird auch von BAUM (1982), S.115 in bezug auf die führenden Mitglieder der formal unabhängigen Notenbanken berücksichtigt.

2 Vgl. MÄRTZ (1990), S.27. 
Darlehensnachfrager im Durchschnitt fällt ${ }^{1}$, so wird der erwartete Durchschnittsertrag der geförderten Aktivitäten bei budgetärer Darlehensvergabe tendenziell geringer ausfallen als bei einer Vergabe durch Sonderkreditinstitute.

Darüber hinaus sind die Verteilungsvorteile aus der Subventionierung für diejenigen Darlehensempfänger besonders hoch, welche die Förderung weitgehend nur "mitnehmen". Sollen durch die Kredithilfen beispielsweise Kapitalgüterkäufe gefördert werden, die eine Internalisierung externer Effekte ermöglichen, so werden diejenigen Kredithilfe-Nachfrager den stärksten politischen Druck ausüben, deren Preiselastizität der Güternachfrage am geringsten ist. Folglich werden durch budgetäre Einheiten tendenziell diejenigen Nachfrager bedient, welche die geringsten Mengeneffekte und damit einen vergleichsweise geringen Internalisierungserfolg erwarten lassen. Demgegenüber werden Mengen- und Internalisierungseffekte bei einer Kredithilfevergabe durch Sonderkreditinstitute relativ höher ausfallen, weil diese geringerem politischen Druck ausgesetzt sind und somit die Vergabeentscheidung tendenziell eher nach ökonomischen Kriterien treffen, solange dadurch ihr Geschäftserfolg nicht geschmälert wird.

Da budgetäre Einheiten bei der Vergabe von öffentlichen Kredithilfen einem vergleichsweise hohen politischen Druck ausgesetzt sind, der regelmäßig zu speziellen Verteilungsvorteilen für einzelne Gruppen auf Kosten der allokativen Effizienz führt, können Sonderkreditinstitute als fiskalische Restriktion dienen, durch welche die politische Beeinflußbarkeit von Vergabeentscheidungen begrenzt wird. Unter diesem Gesichtspunkt erscheint es möglich, Sonderkreditinstitute als Ergebnis konstitutioneller Entscheidungen zu betrachten. Dies setzt allerdings voraus, daß die Vorteile der Sonderkreditinstitute bei konstitutioneller Betrachtung in der Abwägung mit den aufgezeigten Nachteile stärker gewichtet werden.

\section{Bestehende außerbudgetăre Einheiten - Ergebnis strategischen Verhaltens oder konstitutionellen Kalküls?}

Nach der vorstehenden Analyse scheint sich im Hinblick auf eventuelle normative Konsequenzen nahezu zwangsläufig die Frage zu stellen, ob bestehende außerbudgetäre Einheiten als Ergebnis strategischen Verhaltens bestimmter Verteilungskoalitionen oder eines konstitutionellen Kalküls zu erklären sind. Eine Antwort darauf fällt insofern schwer,

1 Diese Annahme erscheint, Rationalverhalten privater Kapitalgeber unterstellt, nicht völlig unplausibel, wenn man berücksichtigt, daB Subventionsnachfrager mit besonders hohem Risiko häufig eine marktliche Finanzierung für ihre geplanten Aktivitäten nicht erhalten können. 
als die Errichtung der außerbudgetären Einheiten regelmäßig durch einfache Gesetze beschlossen wurde, so daß nicht festgestellt werden kann, ob diese Entscheidungen die Unterstützung der ganz überwiegenden Mehrheit der Bürger hatte. Daher ist man darauf angewiesen, aus den für die außerbudgetären Einheiten ursprünglich beschlossenen institutionellen Regeln Rückschlüsse zu ziehen.

Bei der Betrachtung der jeweiligen Errichtungsgesetze fällt auf, daß zahlreiche Aktivitäten außerbudgetärer Einheiten und ihre Behandlung im laufenden politischen Prozeß, welche die Realisierung von Sondervorteilen erwarten lassen, ursprünglich nicht explizit vorgesehen waren. Dies gilt beispielsweise für die festgestellte mangelhafte Berichterstattung über außerbudgetäre Kredithilfen genauso wie für die Vergabe von Kredithilfen durch Sonderkreditinstitute, die aus ihren Erträgen zinsverbilligt werden. Vielmehr sind die meisten Sondervermögen aus zweckgebundenen Einnahmen aufgebaut worden, um aus den Vermögensrückflüssen längerfristig bestimmte, im voraus festgelegte Fördermaßnahmen, nicht aber andere staatliche Ausgaben zu finanzieren. Bei der Mehrzahl der Sonderkreditinstitute besteht die wesentliche gesetzliche Aufgabe in der eigenständigen Durchführung von bestimmten Kredithilfeprogrammen. Da gezeigt wurde, daß solche Aktivitäten aus konstitutioneller Sicht wünschenswert sein können, kann nicht ausgeschlossen werden, daß die Errichtung außerbudgetärer Einheiten zumindest in manchen Fällen als konstitutionelle Entscheidung zu erklären ist. Andererseits fällt auf, daß die in den Errichtungsgesetzen enthaltenen Regeln den staatlichen Akteuren weite Gestaltungsspielräume belassen, um auch solche Maßnahmen treffen zu können, die ihnen selbst nützlich sind. Insoweit erscheint eine Erklärung außerbudgetärer Einheiten durch strategisches Verhalten wahrscheinlicher. Daher läßt sich aus den für die außerbudgetären Einheiten beschlossenen Regeln im Einzelfall kaum deduzieren, wie ihre Errichtung positiv erklärt werden kann.

Betrachtet man die Aktivitäten außerbudgetärer Einheiten im laufenden politischen Prozeß, so kann daraus geschlossen werden, daß diese regelmäßig in einer Weise eingesetzt werden, die gegenüber der Kredithilfevergabe budgetärer Einheiten die Erzielung von Sondervorteilen erwarten läßt. Jedoch ist auch dies noch kein Indiz dafür, daß die Errichtung außerbudgetärer Einheiten als strategisches Verhalten zu erklären ist. Denn auch bei den außerbudgetären Einheiten, die auf einer konstitutionellen Entscheidung beruhen, besitzen die staatlichen Akteure einen Anreiz, durch deren Einsatz den eigenen Nutzen zu steigern, sofern dies mit den Buchstaben der geltenden Regeln vereinbar ist.

Wenn nun die Errichtung außerbudgetärer Einheiten im Einzelfall ex post regelmäßig nicht erklärt werden kann, erscheint die obige Diskussion im Hinblick auf normative 
Erwägungen kaum relevant. Dies ist so jedoch nicht zutreffend. Denn damit würde man die Bedeutung historischer Entscheidungen für eine spätere konstitutionelle Betrachtung überschätzen. Ausgangspunkt jedweder konstitutionellen Entscheidung ist nämlich der verfassungsmäßige Status quo, der die Gesamtheit aller Regeln und Institutionen einschließlich der vorhandenen staatlichen Einrichtungen umfaßt ${ }^{1}$. Dies gilt gegebenenfalls auch dann, wenn der vorhandene Status quo zum Teil damit zu erklären ist, daß die staatlichen Akteure in früheren Perioden primär ihr Eigeninteresse verfolgt haben. Jedoch erhöht schädigendes Verhalten des Staates in früheren Perioden die Wahrscheinlichkeit, daß sein Spielraum dafür bei einer Neuverhandlung über konstitutionelle Regeln eingeengt wird ${ }^{2}$.

Die Bedeutung des Status quo läßt sich im gegebenen Zusammenhang einfach illustrieren. Es sei unterstellt, daß ein Vergünstigungsstaat in einer früheren Periode allein deshalb ein Sondervermögen aufgebaut hat, um sich selbst zusätzliche Vorteile zu verschaffen. Wäre es sinnvoll, wenn die Bürger in einer späteren Periode die frühere Entscheidung des Vergünstigungsstaates einfach umkehren wollten, indem sie die Liquidation des Sondervermögens beschließen? Wohl kaum, sofern beispielsweise die Möglichkeit eines überschußmaximierenden Leviathan besteht, der sich den Liquidationserlös einfach aneignen könnte. Auch ein Sonderkreditinstitut, das zur Erzielung spezieller Vorteile errichtet wurde, kann in späteren Perioden nicht einfach aufgelöst werden, wenn erkannt wird, da $\beta$ es unter veränderten institutionellen Bedingungen bei konstitutioneller Betrachtungsweise wünschenswert sein kann. Denn damit würde man unnötigerweise die Errichtungskosten für ein neues Sonderkreditinstitut auf sich nehmen. Letztlich ergibt sich die Bedeutung des Status quo daraus, daß er die Opportunitätskosten der Änderung gegebener Institutionen bestimmt, während die Opportunitätskosten früherer Entscheidungen in vergangenen Perioden angefallen sind ${ }^{3}$.

Mit der vorstehenden Analyse konnte jedoch gezeigt werden, daß außerbudgetäre Einheiten bei konstitutioneller Betrachtungsweise für die Individuen wünschenswert sein können. Andererseits eröffnen sie den staatlichen Akteuren unter bestimmten institutionellen Bedingungen Handlungsspielräume zur Erzielung spezieller Vorteile auf Kosten der Allgemeinheit. Unterstellt man, daß die Individuen bei einer konstitutionellen Neuverhandlung über die Zulässigkeit bzw. die institutionellen Bedingungen für das Tätigsein außerbudgetärer Einheiten beide Aspekte berücksichtigen, so werden sie sich mit hoher Wahrscheinlichkeit auf ein generelles Verbot außerbudgetärer Einheiten zur Kredithilfevergabe ebensowenig einigen wie auf die Zulässigkeit ihres unrestringierten Einsatzes

1 Vgl. BUCHANAN (1975/1984), S.111; BUCHANAN (1977a), S.278 f.

2 Vgl. BUCHANAN (1975/1984), S.121.

3 Vgl. BUCHANAN (1977a), S.278. 
durch die staatlichen Akteure. Denn es ist nicht einsichtig, weshalb die Individuen auf einer konstitutionellen Ebene auf die möglichen Vorteile außerbudgetärer Einheiten verzichten sollten, indem sie diese verbieten, sofern sie Chancen sehen, daß diese Vorteile bei einer geeigneten Gestaltung der politisch-institutionellen Bedingungen realisiert werden können ${ }^{1}$. Da durch außerbudgetäre Einheiten andererseits Nachteile zu befürchten sind, erscheinen aus konstitutioneller Perspektive Regeln erforderlich, die verhindern sollen, $\mathrm{da} ß$ solche staatlichen Organisationseinheiten auf Kosten der Allgemeinheit eingesetzt werden können.

\section{NORMATIVE ANALYSE AUSSERBUDGETÄRER EINHEITEN AUS KONSTI- TUTIONELLER PERSPEKTIVE}

Nach der vorstehenden Analyse läßt sich der Status quo im Hinblick auf außerbudgetäre Einheiten dadurch kennzeichnen, daß die Politiker bei deren Einsatz im Rahmen der Vergabe von Kredithilfen weitgehende Handlungsspielräume zur Verfolgung eigener Interessen besitzen. Mit Bezug auf diesen Status quo werden im folgenden Regeln für außerbudgetäre Einheiten entworfen, auf die sich die Individuen auf einer gedanklichen konstitutionellen Ebene wahrscheinlich einigen werden. Damit soll gewährleistet werden, daß außerbudgetäre Einheiten nur dann zur Vergabe von Kredithilfen eingestzt werden, wenn dies im Interesse der Allgemeinheit liegt und diese Organisationsformen insoweit normativ wünschenswert erscheinen. Im folgenden wird auf dabei die in Abschnitt D.II. dargestellten Grundlagen der konstitutionellen Analyse zurückgegriffen.

Die Regeln sollen die Handlungsspielräume der staatlichen Akteure zur Instrumentalisierung außerbudgetärer Einheiten für eigene Ziele beschränken, ohne die Realisierung ihrer potentiellen Vorteile für die Allgemeinheit zu verhindern. Dabei sollen die Restriktionen einerseits im Hinblick auf bereits bestehende außerbudgetäre Einheiten wirksam sein. Außerdem sollen sie den Anreiz vermindern, daß für die Vergabe von öffentlichen Kredithilfen zusätzliche außerbudgetäre Einheiten errichtet werden, die allein der Erzielung zusätzlicher politischer Vorteile dienen. Im folgenden werden mögliche Beschränkungen für Sondervermögen, Sonderkreditinstitute und sonstige außerbudgetäre Einrichtungen getrennt betrachtet.

1 So wird auch von Kritikern außerbudgetärer Einheiten eingeräumt, daß sie bei Vorliegen besonderer sachlicher Erfordernisse gerechtfertigt sein können. Vgl. FOLKERS (1986b), S.243. 


\section{Restriktionen für Sondervermögen}

Wie gezeigt, sind Sondervermögen insbesondere dann politisch attraktiv, wenn sie eine relative Unterschätzung der Kosten staatlicher Ausgaben für Kredithilfen gegenüber budgetär finanzierten Kredithilfen bewirken. $\mathrm{Da}$ auf diese Weise Effizienzkosten und Verteilungskonsequenzen resultieren, die aus konstitutioneller Sicht unerwünscht sind, müssen die Beschränkungen für Sondervermögen Vorkehrungen gegen solche Kostenunterschätzungen treffen. Dabei erscheinen Beschränkungen für die Kreditaufnahme der Sondervermögen, zeitliche Beschränkungen für die "Lebensdauer" von Sondervermögen, Beschränkungen für die Förderintensität der von ihnen gewährten Kredithilfen und das Gebot einer umfassenden Information über die Kredithilfeaktivitäten von Sondervermögen besonders wichtig. Außerdem muß im Hinblick auf neu zu errichtende Sondervermögen sichergestellt werden, da $B$ ihre intertemporalen Verteilungsimplikationen im Errichtungszeitpunkt wahrgenommen werden. Da Sondervermögen Kredithilfen hauptsächlich als öffentliche Darlehen gewähren, soll sich die folgende Betrachtung nur auf diese Kredithilfeform beziehen.

\section{a. Beschränkungen für die Kreditaufnahme von Sondervermögen}

Politiker können durch die Kreditaufnahme der Sondervermögen zusätzliche politische Nettoerträge erzielen, wenn eine budgetäre Kreditfinanzierung von öffentlichen Darlehen verboten oder mit vergleichsweise hohen politischen Kosten verbunden ist. Denn durch eine Kreditaufnahme der Sondervermögen läßt sich kurzfristig das Volumen öffentlicher Darlehen ausweiten, wenngleich andererseits das ohne Kreditaufnahme langfristig realisierbare Volumen verringert wird.

Eine mögliche Restriktion für die Kreditaufnahme von Sondervermögen könnte nun in einer Vorschrift bestehen, wie sie für das ERP-Sondervermögen gilt, wonach ihr nominaler Netto-Vermögensbestand im Zeitablauf zu erhalten ist. Nimmt man an, daß der anfängliche Kapitalstock des betrachteten Sondervermögens steuerfinanziert ist und die aufgenommenen Kredite sowie eventuelle Darlehensrückflüsse ebenfalls zur Finanzierung öffentlicher Darlehen eingesetzt werden, dann läßt sich mit dieser Vorschrift die Höhe der Kreditaufnahme begrenzen. Denn bei gegebenem Marktzinssatz r, gegebenem Zinssatz für die öffentlichen Darlehen r' und gegebenem Netto-Vermögensbestand $\mathbf{N}$ wird der maximal zulässige Schuldenstand S dadurch determiniert, daß die Zinsaufwendungen für die Schulden des Sondervermögens seine Zinserträge nicht übersteigen dürfen, da andernfalls der Nominalbestand des Nettovermögens reduziert wird. Im Grenzfall gilt also: 
(D.IV.1) $\quad(\mathrm{N}+\mathrm{S}) \mathrm{r}^{\prime}=\mathrm{rS}$

bzw.

(D.IV.1a) $\quad S /(N+S)=r^{\prime} / r$.

Aus (D.IV.1a) folgt, daß der maximale Anteil der Verbindlichkeiten am BruttoVermögensbestand und damit der maximale Schuldenstand um so höher sein kann, je höher r' in Relation zu r ist. D.h. daß um so mehr Forderungen kreditfinanziert werden können, je geringer die durchschnittlichen Zinsverbilligungskosten der vergebenen Darlehen sind.

Wenngleich durch den Grundsatz der Bestandserhaltung eine quantitative Beschränkung der Kreditaufnahme von Sondervermögen erreichbar ist, kann damit bei Gültigkeit eines staatlichen Kreditaufnahmeverbots dessen Umgehung durch die Kreditaufnahme eines Sondervermögens nur unvollkommen vermieden werden, da budgetäre steuerfinanzierte öffentliche Darlehen unterhalb der Verschuldungsobergrenze des Sondervermögens ohne weiteres durch kreditfinanzierte Darlehen dieses Sondervermögens substituiert werden können. Außerdem kann dieser Bestandserhaltungsgrundsatz nicht verhindern, daß die Höhe der aus Sondervermögen finanzierten öffentlichen Darlehen mittels Kreditaufnahme in unerwünschter Weise ausgedehnt wird. Nimmt man beispielsweise an, da $B$ der Staat zunächst für eine gewisse Anzahl von Perioden das Recht zur Kreditaufnahme durch das Sondervermögen nicht ausübt, so wird sich der Nominalbestand des Sondervermögens in diesem Zeitraum erhöhen. Tritt dann ein probabilistischer Vergünstigungsstaat in Aktion, so kann er in einer Periode in erheblichem Umfang zusätzliche öffentliche Darlehen vergeben. Unterstellt man, daß die politischen Grenzerträge eines Vergünstigungsstaates aus der Erhöhung des Forderungsbestands von Sondervermögen aufgrund der zusätzlich vergebenen Darlehen stets ihre politischen Grenzkosten übersteigen, so wird er in der Periode, in der er in Aktion ist, den gesamten Verschuldungsspielraum ausschöpfen ${ }^{1}$. Damit kann er durch die Verschuldung ein zusätzliches Darlehensvolumen von $r^{\prime} N /\left(r-r^{\prime}\right)$ finanzieren ${ }^{2}$. Gilt $r=8 \%$ und $r^{\prime}=6 \%$, könnten danach bei einem NettoVermögensbestand von $20 \mathrm{Mrd}$. DM in einer Periode Kredite von $60 \mathrm{Mrd}$. DM zur Finanzierung öffentlicher Darlehen aufgenommen werden, ohne daß sich der Netto-Vermögensbestand verringert.

1 Diese Annahme ist allerdings kaum realistisch, wenn die Kreditaufnahme des Sondervermögens quantitativ bedeutsam ist, weil das Kreditangebot auf dem Kapitalmarkt üblicherweise nicht vollkommen elastisch ist. Dadurch werden diejenigen, die durch induzierte Zinssteigerungen Verluste zu erwarten haben, politischen Widerstand gegen eine maximale Kreditaufnahme leisten.

2 Dieses Ergebnis folgt durch Umformung von Gleichung (D.IV.1). 
Bei gegebenen Zinssătzen ist das Volumen der zusătzlich finanzierbaren Darlehensforderungen um so größer, je später der probabilistische Vergünstigungsstaat in Aktion tritt, wenn man unterstellt, daß der Staat bei anderen Verhaltensmustern auf eine Kreditaufnahme von Sondervermögen verzichtet. Denn der Nominalbestand wăchst bei Verzicht auf eine Kreditaufnahme entsprechend der durchschnittlichen Verzinsung des Bestandes der Darlehensforderungen. Die Konsequenz der Vergabe zusätzlicher kreditfinanzierter öffentlicher Darlehen besteht darin, daß innerhalb einer Periode die gesamten Zukunftserträge des Sondervermögens aufgezehrt werden können, so daß in künftigen Perioden die Höhe der Neu-Darlehen auf die Höhe der Tilgungseinnahmen von Darlehen früherer Perioden beschränkt ist. D.h. die kurzfristige Ausdehnung des Darlehensvolumens durch eine Kreditaufnahme von Sondervermögen stellt lediglich die "Spitze des Eisbergs" dar. Langfristig muß dafür der Preis in Form verringerter Ausgabenspielräume der Sondervermögen entrichtet werden ${ }^{1}$. Da eine solche, zeitlich ungleiche Verteilung der aus Sondervermögen finanzierten Kredithilfen den kollektiven Interessen widersprechen dürfte, kann der Bestandserhaltungsgrundsatz kaum als hinreichende Restriktion betrachtet werden.

Um die Umgehung budgetärer Kreditaufnahmevorschriften sowie eine Aufzehrung des Kredithilfe-Potentials von Sondervermögen in einzelnen Perioden zu verhindern, erscheint daher nur ein generelles Kreditaufnahmeverbot sinnvoll. Dabei müßten allerdings für Sondervermögen, denen bislang eine Schuldenaufnahme gestattet ist, Ausnahmen zugelassen werden. Ihnen wäre für eine Übergangszeit das Recht einzuräumen, in bestimmtem Umfang Kredite zur Umschuldung bestehender Kreditverbindlichkeiten aufzunehmen. Andernfalls würde nämlich die Tilgung bestehender Schulden den Ausgabenspielraum für neue öffentliche Darlehen in einzelnen Perioden auf Kosten der in der Übergangszeit lebenden Generation einengen, sofern die Laufzeit der öffentlichen Darlehen die Laufzeit der Kreditverbindlichkeiten übersteigt. Eine solche Kreditaufnahme zu Umschuldungszwecken würde den Abbau des Schuldenstandes des Sondervermögens verlangsamen und somit die Kosten der Anpassung an geänderte Verschuldungsregeln mindern.

\section{b. Zeitliche Befristung von Sondervermögen}

Übersteigen die Einnahmen eines Sondervermögens aufgrund vergebener Darlehen die entsprechenden Ausgaben und werden diese Einnahmenüberschüsse aufgrund bestehender Zweckbindungsvorschriften zur Finanzierung zusätzlicher öffentlicher Darlehen

1 Solche "Eisbergeffekte" sind typisch für jede staatliche Kreditaufnahme. Vgl. FOLKERS (1986b), S.232. 
verwendet, so wächst der nominale Vermögensbestand des Sondervermögens im Zeitablauf. Dies ist zwar für einen Vergünstigungsstaat vorteilhaft, weil sich für ihn dadurch aufgrund der Zweckbindung der Einnahmen praktisch keine politischen Kosten, sehr wohl aber politische Erträge ergeben. Aus konstitutioneller Sicht ist die stetige Ausweitung der Darlehensausgaben dagegen nur wünschenswert, wenn erwartet wird, daß damit dauerhaft marginale Wohlfahrtsgewinne möglich sind. Davon kann im allgemeinen jedoch kaum ausgegangen werden. Demnach sind in diesem Zusammenhang Restriktionen erforderlich.

Um eine unbefristete, automatische Ausweitung der öffentlichen Darlehen zu unterbinden, scheint es wünschenswert, Sondervermögen nicht auf unbefristete Zeit zu errichten. Zur Unterbrechung dieser Automatik könnte entsprechend dem Konzept der sunset legislation ${ }^{1}$ vorgeschrieben werden, da $B$ ein Sondervermögen nach Ablauf einer im voraus zu bestimmenden Frist zwingend aufgelöst werden muß, wenn das Fortbestehen des Sondervermögens nicht explizit beschlossen wird. Auf diese Weise werden die staatlichen Akteure tendenziell gezwungen, die ökonomischen Opportunitätskosten von Sondervermögen in bestimmten Zeitabständen offenzulegen. Damit wird die Aneignung spezieller Vorteile durch Interessengruppen und staatliche Akteure erschwert.

Sollte sich für die Weiterführung eines Sondervermögens nicht die erforderliche Mehrheit finden, so sind im wesentlichen zwei Varianten denkbar, wie seine Auflösung durchgeführt werden könnte. Eine Variante kann so aussehen, daß die Vergabe neuer Darlehen aus den Einnahmen des Sondervermögens untersagt wird und diese Einnahmen dem Budget zugeführt werden müssen. Damit besteht das Sondervermögen solange fort, bis seine Aktiva planmäßig liquidiert sind, d.h. bis die gesamten Darlehensforderungen entsprechend den Vergabebestimmungen getilgt sind. Danach würde sich die Auflösung des Sondervermögens regelmäßig über einen längeren Zeitraum erstrecken. Die andere Variante besteht darin, daß das Sondervermögen sofort liquidiert wird, indem seine gesamten Forderungen entgeltlich an Dritte abgetreten werden. Damit stünden dem Staat kurzfristig die Veräußerungserlöse zur Verfügung.

Allerdings birgt die Auflösung eines Sondervermögens auch Risiken. Denn sie verschafft dem Staat zusätzliche staatliche Einnahmen, ohne daß er dafür zusätzliche Steuern erheben oder Kredite aufnehmen muß. Neue Steuern oder die verstärkte Anspannung bestehender Steuern wie auch eine öffentliche Kreditaufnahme werden im allgemeinen je-

1 Vgl. oben Abschnitt D.II.5.a.bb. 
doch im Gegensatz zur Erzielung von Einnahmen durch Liquidation staatlichen Vermögens Widerstände der Steuerzahler hervorrufen ${ }^{1}$.

Damit ergibt sich bei der Auflösung von Sondervermögen ein Anreiz zu einer Verschwendung der daraus resultierenden Einnahmen für Ausgaben, die primär den staatlichen Akteuren oder ihrer Klientel nutzen. Um dem zu begegnen, müßte ergänzend vorgeschrieben werden, daß die Verschuldungsgrenze für den Staat um die Höhe der Liquidationserlöse gesenkt wird ${ }^{2}$ bzw. daß sie vom Staat in Überschußjahren für Steuersenkungen verwendet werden müssen.

Ist bei Fristablauf ein probabilistischer Vergünstigungsstaat in Aktion, dann könnte sich dieser durch die vollständige Liquidation und die Ausschüttung des Liquidationserlöses im Auflösungszeitpunkt an die dann lebende Generation zusätzliche Vorteile verschaffen. Er hätte insoweit einen perversen Anreiz, die Fortführung eines Sondervermögens abzulehnen, selbst wenn dies im Vergleich zu seiner Auflösung wohlfahrtssteigernd wäre. Daher erscheint die zeitlich gestreckte Auflösung von Sondervermögen aus konstitutioneller Sicht überlegen.

\section{c. Beschränkungen für die Förderintensität von Darlehen der Sondervermögen}

Ein weiteres Problem von Sondervermögen besteht darin, daß der Staat unter bestimmten Bedingungen einen Anreiz besitzt, sich zusätzliche Vorteile zu verschaffen, indem er bei gegebenem Darlehensvolumen der Sondervermögen die Förderintensität und damit die Zinsverbilligungskosten der Darlehen erhöht. Die Erhöhung der Förderintensität kann dabei durch eine Reduzierung des Zinssatzes oder eine Verlängerung der Darlehenslaufzeit erfolgen.

Um zu verhindern, daß ein probabilistischer Vergünstigungsstaat auf diese Weise das Kreditvergabe-Potential künftiger Perioden verringert, können zum einen quantitative Unter- bzw. Obergrenzen für Darlehenszinssatz und -laufzeit durch eine konstitutionelle

1 "Steuern und Anleihen verlangten von der öffentlichen Autorität das Bekenntnis, daß sie sich in einer schlechten finanziellen Lage befand, und mußten zudem Diskussionen anregen über die Verwendung der dem Fiskus bereits zugeflossenen Summen, über den tatsächlichen Bedarf, über die Zinsen der Anleihen usw. Eine Reihe von Veräußerungen von Domänen ermöglichte es, außerordentliche Bedürfnisse zu befriedigen, ohne etwas sagen, erklären oder fordern zu müssen, und indem man Unzufriedenheit und Sorgen in die Zukunft verschob." PUVIANI (1903/1960), S.42 f.

2 Dies würde sich zwangsläufig ergeben, wenn die Kreditobergrenze strikt an die Höhe der staatlichen Nettoinvestitionen gebunden wäre, weil die Liquidationserlöse Desinvestitionen darstellen. 
Regel festgelegt werden ${ }^{1}$. Mit solchen quantitativen Beschränkungen wird untersagt, daß die Förderintensität über die festgelegten Grenzen hinaus erhöht werden kann, auch wenn dies aufgrund geänderter Konstellationen wünschenswert sein sollte. Daher erscheinen auch in diesem Zusammenhang verfahrensmäßige Restriktionen sinnvoller.

Eine verfahrensmäßige Restriktion könnte vorsehen, daß die Zinsverbilligungskosten der in einer Periode vergebenen Darlehen durch Rücklagenbildung ausgabenwirksam gemacht werden müssen ${ }^{2}$. Diese Rücklagen wären dann über die Laufzeit der verbilligten Darlehen aufzulösen und würden damit in späteren Perioden einnahmenwirksam. Die Höhe der Darlehensausgaben, deren Obergrenze durch die Einnahmen des Sondervermögens bestimmt wird, würde danach mit zunehmenden Zinsverbilligungskosten der in der Betrachtungsperiode vergebenen Darlehen fallen. D.h. es würde auf diese Weise ein Trade-off zwischen der Vergünstigungshöhe für den einzelnen Darlehensempfänger und der Zahl der Darlehensempfänger hergestellt. Damit wäre eine Erhöhung der Zinsverbilligungskosten für den Vergünstigungsstaat mit zusätzlichen Kosten verbunden.

\section{d. Gebot einer umfassenden Information über Kredithilfen der Sondervermögen}

Da die Wahrnehmung von Kredithilfen der Sondervermögen durch ihre Herauslösung aus dem staatlichen Budget tendenziell beeinträchtigt ist, sind zusätzliche Informationsregeln sinnvoll, um zu verhindern, daß sich der Staat auf diese Weise zusätzliche Vorteile verschaffen kann. Dabei ist es in jedem Fall wünschenswert, daß über die Kredithilfeaktivitäten der Sondervermögen im Rahmen einer Subventionsberichterstattung zumindest in derselben Weise Rechenschaft abgelegt wird wie bei budgetären Kredithilfen ${ }^{3}$. Darüber hinaus könnte die Wahrnehmung der Aktivitäten der Sondervermögen durch die Bürger erhöht werden, wenn Einnahmen und Ausgaben von Sondervermögen zumindest als durchlaufende Posten in den staatlichen Haushalten veranschlagt werden müßten ${ }^{4}$. Es kann erwartet werden, daß auf diese Weise die Kredithilfen der Sondervermögen bei der Bestimmung des Umfangs zusätzlicher budgetärer Kredithilfen in stärkerem Maß berücksichtigt werden.

1 Entsprechende Bestimmungen gelten beispielsweise für den Ausgleichsfonds nach $\S 12$ Schwerbehindertengesetz. Vgl. dazu Abschnitt B.II.2.a.cc.

2 Vgl. zu einer entsprechenden Regel für budgetäre Kredithilfen Abschnitt D.II.5.a.aa.

3 In den Subventionsberichten des Bundes wird auf freiwilliger Basis lediglich über die Kredithilfen des ERP-Sondervermögens berichtet. Vgl. DICKERTMANN (1980), S.486.

4 Vgl. FOLKERS (1986b), S.244. 


\section{e. Darlegungslast bei der Errichtung von Sondervermögen}

Da der Aufbau von Sondervermögen, die aus Steuermitteln finanziert werden, regelmäßig zu einer Belastung von früheren Generationen zugunsten künftiger Generationen führt, werden die Individuen aus konstitutioneller Sicht Restriktionen gegen die Errichtung neuer Sondervermögen wünschen. Dabei kann unterstellt werden, da $\beta$ die Individuen auf der konstitutionellen Ebene im Hinblick auf neu zu errichtende Sondervermögen nicht wissen, ob sie bzw. ihre Nachkommen zu der belasteten oder begünstigten Generation gehören werden.

Um die Wahrnehmung der Belastung der gegenwärtigen Generation durch die Errichtung von Sondervermögen zu erhöhen, muß der Staat verpflichtet werden, diesen Zusammenhang darzulegen und zu begründen, weshalb er die Belastung der gegenwärtigen Generation für gerechtfertigt hält. Aufgrund der verbesserten Informationslage erhöht sich die Wahrscheinlichkeit, daß sich der politische Widerstand gegen eine Belastung der gegenwärtigen Generation durch die Errichtung des Sondervermögens formieren kann ${ }^{1}$. D.h. durch derartige Offenlegungspflichten des Staates wird ein funktionsfähiger Wettbewerb von Interessengruppen begünstigt, der effizientere Ergebnisse erwarten läßt, als der Fall eines Informationsmonopols der begünstigten Interessengruppen gegenüber der Gruppe der Verlierer ${ }^{2}$.

\section{Restriktionen für Sonderkreditinstitute}

Wie bei Sondervermögen können die staatlichen Akteure auch im Fall von Sonderkreditinstituten insbesondere dann die Realisierung politischer Vorteile erwarten, wenn durch ihre Einschaltung in die Vergabe von Kredithilfen deren Kosten in geringerem Umfang wahrgenommen werden. Daher müssen Beschränkungen für Sonderkreditinstitute darauf ausgerichtet werden, derartige Wahrnehmungsverzerrungen zu unterbinden. Darüber hinaus müssen Regeln eingeführt werden, welche Anreize vermitteln, daß Sonderkreditinstitute ihre Aufgaben bei der Durchführung öffentlicher Kredithilfeprogramme möglichst effizient erfüllen. Dagegen soll hier nicht untersucht werden, welche Regeln den Sonderkreditinstituten bei der Durchführung gewöhnlicher Bankgeschäfte auferlegt werden sollen, da die Frage nach der ökonomischen Rechtfertigung öffentlicher Banken nicht zum Gegenstand dieser Arbeit gehört.

1 Zu den Wirkungschancen von staatlichen Darlegungsobliegenheiten hinsichtlich der Staatsverschuldung vgl. GANDENBERGER (1990), S.44 f.

2 Vgl. MÄRTZ (1990), S.129 ff. 
Im folgenden sollen Restriktionen für die Verbilligung von Kredithilfen aus Erträgen der Sonderkreditinstitute, Informations-, Darlegungs- und Begründungspflichten für die Aktivitäten der Sonderkreditinstitute und Vorschriften zur Stärkung ihrer Eigenständigkeit diskutiert werden.

a. Verbot der Verbilligung von Kredithilfen aus Erträgen der Sonderkreditinstitute

Die Verbilligung von Kredithilfen aus den Erträgen der Sonderkreditinstitute führt dazu, daß die zu diesem Zweck eingesetzten Ressourcen für alternative Verwendungsmöglichkeiten nicht mehr zur Verfügung stehen. Dabei entzieht sich der Vorgang weitgehend der Kontrolle des Parlaments und der Öffentlichkeit ${ }^{1}$, da die Höhe der Verbilligungskosten nicht im Budget und bei den meisten Instituten auch nicht in den Geschäftsberichten dokumentiert ist. Auf diese Weise kann ein Vergünstigungsstaat nahezu ohne politische Kosten Sondervorteile an spezielle Gruppen verteilen.

Der Anreiz für die staatlichen Akteure, auf diese Weise zusätzliche politische Erträge zu erzielen, kann vermindert werden, wenn es den Sonderkreditinstituten rechtlich untersagt wird, Teile ihrer Überschüsse zur Finanzierung der Netto-Subventionsausgaben von Kredithilfen zu verwenden. Danach wäre nur die Durchführung solcher Kredithilfeprogramme gestattet, für die den Sonderkreditinstituten von den Gebietskörperschaften die Zinsverbilligungskosten ersetzt werden.

Allerdings verursacht das Verbot von Eigenprogrammen unter bestimmten Bedingungen soziale Kosten in Form einer ineffizienteren Leistungserstellung der Sonderkreditinstitute. Dies gilt insbesondere dann, wenn eine Gewinnabführung der Sonderkreditinstitute an die Haushalte der Eigentümer-Gebietskörperschaften nicht vorgesehen ist. Dies soll anhand der folgenden vereinfachenden Überlegungen gezeigt werden.

Es wird zunächst der Fall betrachtet, daß den Sonderkreditinstituten die Durchführung von Eigenprogrammen erlaubt ist. Dabei wird unterstellt, daß der Nutzen der Manager der Sonderkreditinstitute von ihrem Gesamteinkommen abhängt. Dieses Gesamteinkommen $Y$ soll sich aus einem monetären und einem nichtmonetären Teil zusammensetzen, wobei beide Arten von Einkommensbestandteilen vollkommene Substitute seien. Das monetäre Einkommen soll aus einem fixen Betrag $L$, einem fixen Anteil a $(<1)$ des Kredithilfevolumens $\mathrm{V}^{2}$ und einem fixen Anteil des b $(<1)$ des realisierten

1 Vgl. SCHLESINGER (1987), S.32.

2 Diese Annahme erscheint nicht unplausibel, da die Manager der Sonderkreditinstitute andernfalls nur vergleichsweise geringe Anreize zur Durchführung staatlicher Kredithilfeprogramme 
Gewinns bestehen. Das Kredithilfevolumen sei eine Funktion des realisierten Gewinns, da höhere realisierte Gewinne bei gegebenem Zinsverbilligungssatz die Vergabe zusätzlicher Kredithilfen erlauben. Der realisierte Gewinn ergibt sich als Differenz des als konstant angenommenen Gewinns $\mathrm{G}$ bei produktionseffizienter Leistungserstellung und den Ausgaben A für Annehmlichkeiten der Manager ${ }^{1}$, die gleichzeitig die Höhe ihres nichtmonetären Einkommens bestimmen. Die Obergrenze für $\mathrm{A}$ sei durch $\mathrm{G}$ bestimmt. Die Subventionsausgaben für die Eigenprogramme seien als Gewinnverwendung des Staates für die Einkommenshöhe der Manager unbeachtlich. Danach gilt:

$$
\begin{aligned}
& \mathrm{V}=\mathrm{f}(\mathrm{G}-\mathrm{A}) \\
& \text { mit } \mathrm{f}^{\prime}>0 ; \mathrm{f}^{\prime \prime}<0
\end{aligned}
$$

und

(D.IV.3) $\quad \mathrm{Y}=\mathrm{L}+\mathrm{af}(\mathrm{G}-\mathrm{A})+\mathrm{b}(\mathrm{G}-\mathrm{A})+\mathrm{A}$.

Unter diesen Annahmen folgt als Optimalbedingung für ein Einkommensmaximum:

$$
a f^{\prime}+b=1 \text {. }
$$

D.h. die Ausgaben für Annehmlichkeiten werden solange ausgedehnt, bis Grenzertrag und Grenzkosten dieser Ausdehnung übereinstimmen, wobei die Grenzkosten in Form entgangenen monetären Einkommens auftreten. Ist die Durchführung von Eigenprogrammen bei gleichzeitigem Gewinnabführungsverbot unter sonst gleichen Bedingungen untersagt, gilt $\mathrm{f}^{\prime}=0$. Damit übersteigt der Grenzertrag einer Erhöhung der Ausgaben für Annehmlichkeiten bis zum maximal möglichen Betrag stets die Grenzkosten. Somit wird im Optimum der gesamte erzielbare Gewinn für Annehmlichkeiten der Manager ausgegeben. Die Leistungserstellung erfolgt $\mathrm{x}$-ineffizient.

Deshalb könnte ergänzend vorgeschrieben werden, daß die Sonderkreditinstitute den realisierten Gewinn an die Haushalte der Gebietskörperschaften abführen müssen. Werden diese Gewinne teilweise wieder an die Sonderkreditinstitute zurücktransferiert, um zusätzliche Kredithilfen zu verbilligen, so wird der Anreiz zur Erhöhung des nichtmonetären Einkommens verringert, weil $f^{\prime}$ dann wieder einen positiven Wert annimmt. Allerdings ist zu erwarten, daß bei freier Verwendbarkeit nur ein Teil der Gewinne der Sonderkreditinstitute wieder an diese Einrichtungen zurücktransferiert wird, so daß $\mathrm{f}^{\prime}$ bei jeder Gewinnhöhe einen geringeren Wert und folglich A einen höheren Wert annimmt als im

besitzen und demgegenüber tendenziell die Ausdehnung sonstiger erlaubter Aktivitäten präferieren würden.

$1 \mathrm{Zu}$ den Ausgaben für Annehmlichkeiten werden dabei sämtliche Ausgaben für unproduktive Zwecke gerechnet. 
Ausgangsfall. Damit stehen den gegebenenfalls realisierbaren sozialen Erträgen bei alternativer Gewinnverwendung soziale Kosten in Form höherer X-Ineffizienz gegenüber.

Obwohl dieses Ergebnis unter stark vereinfachenden Annahmen abgeleitet wurde, ist zu erwarten, daß das Verbot der Verbilligung von Kredithilfen aus den Erträgen der Sonderkreditinstitute kaum kostenlos sein wird, wenn man die daraus resultierenden Anreizeffekte für ihre Manager in die Betrachtung einbezieht. Andererseits dürften die Individuen aus konstitutioneller Sicht eine entsprechende Regel bei gleichzeitiger Gewinnabführungspflicht befürworten, wenn alternative Gewinnverwendungsmöglichkeiten soziale Wohlfahrtsgewinne erwarten lassen und Anreizsysteme für die Manager so ausgestaltet werden können, daß ihre Entlohnung vom Kredithilfevolumen unabhängig ist.

b. Informationspflichten bezüglich der Kredithilfeaktivitäten der Sonderkreditinstitute

Subventionsaktivitäten sind für einen Vergünstigungsstaat vorteilhaft, weil sie die Gewährung von Sondervorteilen erlauben, die in der Öffentlichkeit regelmäßig als wohlfahrtssteigernd gerechtfertigt werden. Andererseits sind ihre wohlfahrtssteigernden Wirkungen regelmäßig zweifelhaft, so daß ein Vergünstigungsstaat den Anreiz besitzt, das Ausma $B$ der Subventionierung zu verschleiern, um den politischen Widerstand dagegen zu reduzieren und damit die bei gegebenen Subventionsaktivitäten erzielbaren politischen Nettoerträge zu steigern ${ }^{1}$.

Um einer solchen Informationsverschleierungen vorzubeugen, ist vorzuschreiben, daß über die Subventionsaktivitäten der Sonderkreditinstitute in derselben Weise im Rahmen von Subventionsberichten öffentlich Rechenschaft abzulegen ist wie über budgetäre Subventionen. Solange die Sonderkreditinstitute aus eigenen Erträgen verbilligte Kredithilfeprogramme durchführen, ist eine Regel erforderlich, wonach die NettoSubventionsausgaben dieser Programme in kapitalisierter Form erfaßt werden müssen². Außerdem muß sichergestellt sein, daß das ausgewiesene Subventionsvolumen nicht durch eine Verlagerung gegebener budgetärer Maßnahmen auf die Sonderkreditinstitute verändert werden darf. Daher ist es beispielsweise sinnvoll, wenn bei öffentlichen Darlehen die Brutto-Subventionsausgaben unabhängig davon erfaßt werden, ob die

1 The successful politician must bestow benefits on his constituents while limiting perceived costs if he is to maximize the probability of reelection (...) BENNETT/DILORENZO (1983a), S.312 (Hervorhebung im Original).

2 Vgl. DICKERTMANN (1980) $S .487 \mathrm{ff}$. 
Darlehensvergabe mit budgetären Mitteln oder durch Sonderkreditinstitute finanziert wird ${ }^{1}$.

Darüber hinaus sollte vorgeschrieben werden, daß die Sonderkreditinstitute ihre Kredithilfeaktivitäten in ihren Geschäftsberichten ausführlich dokumentieren müssen, um jeden Anreiz zu ihrer Verschleierung auszuschalten ${ }^{2}$. Danach sollte aus den Geschäftsberichten die Höhe der Ausgaben für zinsverbilligte Darlehen ebenso erkennbar sein wie die Höhe des Bestandes an zinsverbilligten Darlehensforderungen. Außerdem sollten, entsprechend der Praxis der LKB Baden-Württemberg, Rückstellungen für Zinsverbilligungen bzw. Wertberichtigungen zwingend vorgeschrieben werden. Wenn den Sonderkreditinstituten in der Vergabeperiode kapitalisierte Netto-Subventionsausgaben durch die staatlichen Haushalte ersetzt werden, sind die Zuführungen zu diesen Rückstellungsposten für die Sonderkreditinstitute erfolgsneutral.

Schließlich sollten die Sonderkreditinstitute dazu verpflichtet werden, regelmäßig eine Erfolgsbeurteilung der von ihnen durchgeführten Kredithilfeprogramme durchzuführen. Dabei ist insbesondere auch auf die sozialen Kosten und die geschätzten Mitnahmeeffekte einzugehen. Um eine wirksame Erfolgskontrolle zu erleichtern, ist eine Explizierung der gewählten Erfolgsmaßstäbe unerläßlich ${ }^{3}$.

c. Darlegungs- und Begründungspflichten bei Durchführung staatlicher Kredithilfeprogramme durch Sonderkreditinstitute

Wie gezeigt wurde, können Sonderkreditinstitute auch zur Vergabe staatlicher Kredithilfen herangezogen werden, um eine Programmabwicklung durch private Kreditinstitute zu verhindern. Daher wäre eine Regel sinnvoll, wonach für jedes Kredithilfeprogramm darzulegen und zu begründen ist, weshalb die Programmabwicklung nicht von privaten Kreditinstituten vorgenommen werden kann. Dabei müßte privaten Instituten die Möglichkeit zur Stellungnahme eingeräumt werden.

1 Dabei muß allerdings der Eindruck vermieden werden, daß die Belastung des Kapitalmarktes bei öffentlichen Darlehen zwangsläufig höher ist als bei anderen Subventionsformen.

2 Vgl. KIRCHHOFF (1987), S.238 f.

3 Zur Forderung nach einer allgemeinen Subventionskontrolle vgl. ALBRECHT/THORMÄLEN (1985), S.101 ff. 


\section{d. Regeln zur Stärkung der Eigenständigkeit von Sonderkreditinstituten}

Aus konstitutioneller Sicht ist es regelmäBig vorteilhaft ist, wenn die einzelnen Vergabeentscheidungen über Kredithilfen auf allgemeinen $\operatorname{Regeln}^{1}$ basieren und durch Politiker möglichst wenig beeinflußt werden können. Danach ist es wünschenswert, wenn die Sonderkreditinstitute eine möglichst hohe Eigenständigkeit gegenüber den Politikern aufweisen. Daher muß den Politikern verboten werden, die laufenden Vergabeentscheidungen positiv mitzubestimmen. Insbesondere ist ein Weisungsrecht der Exekutive über die jeweiligen Aufsichtsgremien gegenüber den Sonderkreditinstituten auszuschließen². Vielmehr sollten die Politiker allein auf ihre Rechtsaufsichtsfunktion beschränkt werden.

Um eine informelle Einflußnahme der Politiker auf die Sonderkreditinstitute zu erschweren, müßte darüber hinaus das Verfahren zur Besetzung der Spitzenpositionen dieser Einrichtungen objektiviert werden. Dabei könnte vorgesehen werden, daß ein unabhängiges Gremium bei einer Neubesetzung von Spitzenpositionen ein alleiniges Vorschlagsrecht besitzt, das die Politiker bindet. Dabei sollten in einem solchen Gremium neben Mitgliedern der Exekutive, der Legislative und der betroffenen Interessengruppen auch Mitglieder der rechtsprechenden Gewalt vertreten sein. Durch eine derartige $\mathrm{Zu}$ sammensetzung wird die Wahrscheinlichkeit verringert, daß persönliche oder politische Abhängigkeiten die Vergabe solcher Spitzenpositionen entscheidend beeinflussen. Damit reduziert sich auch die Gefahr, daß Vergabeentscheidungen der Sonderkreditinstitute durch die Politiker manipuliert werden.

\section{e. Sonstige Beschränkungen}

Durch die Errichtung von Sonderkreditinstituten wird stets der Grundstein dafür gelegt, da $B$ sich Interessengruppen bilden, welche das Fortbestehen dieser Einrichtungen dauerhaft sichern wollen ${ }^{3}$. Dazu gehören die Leistungsempfänger, die in der Existenz "ihres" Instituts einen Besitzstand sehen, ebenso wie die Beschäftigten dieser Einrichtungen und die Politiker, die auf diese Weise personalpolitische Handlungsspielräume behaupten können ${ }^{4}$. Wenn die ursprünglichen Aufgaben der Sonderkreditinstitute weggefallen sind,

1 Zur generellen Bedeutung allgemeiner Regeln aus konstitutioneller Perspektive vgl. HAYEK (1960).

2 Insofern ist die Bestimmung für die KfW äußerst problematisch, daß über alle Kredite über 30 Mio. DM im Verwaltungsrat entschieden wird, der maßgeblich von den Politikern beherrscht wird. Zu den Vergabebestimmungen der KfW vgl. MÜLLER-KÄSTNER (1986), S.13.

3 Vgl. KAUFMAN (1976).

4 Vgl. DICKERTMANN (1980), S.496. 
werden diese Interessengruppen daher Druck ausüben, um neue Aufgaben zu erhalten', unabhängig davon, ob die Erfüllung solcher neuer Aufgaben mit Wohlfahrtsverlusten verbunden ist oder von anderen Organisationseinheiten effizienter geleistet werden kann. Um zu verhindern, daß Sonderkreditinstitute nur beibehalten werden, um bestimmte Gruppeninteressen zu befriedigen, kann in den Errichtungsgesetzen zwingend vorgeschrieben werden, daß die Sonderkreditinstitute nach einem bestimmten Zeitraum aufzulösen oder zu privatisieren sind. Damit würde man jedoch in Kauf nehmen, daß gegebenenfalls hohe Errichtungskosten für ein neues Institut anfallen, wenn bei Fristablauf die Existenz eines entsprechenden Sonderkreditinstituts für wünschenswert gehalten wird ${ }^{2}$. Folglich erscheint es sinnvoll, wenn die Möglichkeit zum Fortbestehen des betreffenden Sonderkreditinstituts eingeräumt wird, sofern dies durch explizite Entscheidung beschlossen wird. Allerdings dürfte eine solche modifizierte Befristungsregel allein selbst dann wenig effektiv sein, wenn für einen Fortsetzungsbeschlu $ß$ qualifizierte Mehrheiten vorgeschrieben wären. Denn es ist regelmäßig zu erwarten, daß tendenziell alle politischen Gruppierungen das Fortbestehen der Sonderkreditinstitute präferieren werden, da die jeweilige Regierungspartei auf diese Weise der jeweiligen Oppositionspartei Vorteile zukommen lassen kann, indem lukrative Jobs zwischen Regierung und Opposition aufgeteilt werden $^{3}$. Daher erscheinen die zuvor diskutierten Regeln bedeutsamer, weil sie den Spielraum zur Erzielung von Sondervorteilen mit Hilfe von Sonderkreditinstituten einengen.

\section{Beschrănkungen für die Verwendung der Mittel sonstiger außerbudgetărer Einrichtungen}

Im Hinblick auf sonstige außerbudgetäre Einrichtungen, wie die Sozialversicherungen, sind Vorkehrungen dagegen erforderlich, daß sie ihre Einnahmen nicht für Zwecke verwenden werden, die nicht zum speziellen Aufgabengebiet dieser Einrichtungen gehören, sondern allenfalls allgemeine Staatsaufgaben betreffen. Als Beispiel soll hier wiederum die Bundesanstalt für Arbeit betrachtet werden.

1 Ein Wegfall eines wesentlichen Teils der ursprünglichen Aufgaben führte beispielsweise bei der Kreditanstalt für Wiederaufbau und der Deutschen Ausgleichsbank dazu, daB ihnen andere Aufgaben übertragen wurden. Vgl. KIRCHHOFF (1987), S.203.

2 Vgl. BECKER/ZWEIG (1983), S.199 f.; KIRCHHOFF (1987), S.203.

3 Zur Problematik der Rententeilung zwischen Politikern verschiedener Richtungen, die als Mutualismus-Strategie bezeichnet wird, vgl. FOLKERS (1990). 


\section{a. Definition von Eigentumsrechten der Versichertengemeinschaft}

Um zu vermeiden, daß die Einnahmen der Arbeitslosenversicherung von der Bundesanstalt für Arbeit zweckentfremdet verausgabt werden, könnte eine konstitutionelle Regel eingeführt werden, welche die verfassungsmäßige Eigentumsgarantie auf die Gemeinschaft der Versicherten ausdehnt. Danach wäre eine Verwendung der Versicherungsbeiträge zur Finanzierung versicherungsfremder Leistungen verboten. Als versicherungsfremd wären dabei alle Leistungen einzustufen, die auf außergewöhnlichen Risiken beruhen, welche nicht durch die Gemeinschaft der Versicherten verursacht sind ${ }^{1}$. Die im Zusammenhang mit solchen außergewöhnlichen Risiken entstehenden Ausgaben wären der Bundesanstalt daher aus allgemeinen Haushaltsmitteln zu ersetzen. Darüber hinaus wären alle Leistungen als enteignungsgleicher Eingriff verboten, die nicht unmittelbar dem Zweck der Arbeitslosenversicherung entsprechen. Dadurch wäre es der Bundesanstalt beispielsweise rechtlich untersagt, Aktivitäten wie den sozialen Wohnungsbau aus Beitragseinnahmen mit Kredithilfen zu fördern.

\section{b. Verbot der nichtmarktlichen Anlage von Rücklagemitteln}

Da die zweckfremde Verwendung von Beitragseinnahmen auch bei Ausdehnung der Eigentumsgarantie auf die Gemeinschaft der Versicherten in Grenzfällen rechtlich unterhalb der Schwelle der Verfassungswidrigkeit bleiben kann, ist eine Ergänzungsregel sinnvoll, welche die Verwendung von periodischen Einnahmenüberschüssen für Maßnahmen verbietet, die nicht zum gesetzlichen Maßnahmenkatalog der Bundesanstalt gehören. D.h. daß sämtliche Überschußbeträge, die zur Sicherung der Liquidität der Bundesanstalt notwendig sind, zu marktlichen Konditionen anzulegen wären. Die zur Liquiditätssicherung nicht erforderlichen Beträge könnten alternativ in eine Konjunkturrücklage eingestellt werden, um die Schwankungsbreite der notwendigen Beitragssätze zu begrenzen ${ }^{2}$, oder zur "Finanzierung" von Beitragssenkungen vorwendet werden. Die bisher von $\$ 220$

1 Danach wäre es bedenklich, die Kosten des durch die deutsche Vereinigung verursachten Arbeitsplatzrisikos der Beschäftigten im Gebiet der früheren DDR in formaler Hinsicht allein den versicherungspflichtig Beschäftigten mittels erhöhter Versicherungsbeiträge aufzubürden.

2 Diese Vorgehensweise würde der Forderung nach einer "Konstanz der Wirtschaftspolitik" entsprechen, welche durch Verringerung der Unsicherheit die gesamtwirtschaftliche Investitionstätigkeit anregt. Vgl. EUCKEN (1975), S.287 f. 
AFG $^{1}$ zugelassene Verwendung von Beitragseinnahmen für Kredithilfen mit einem mehr oder weniger losen arbeitsmarktpolitischen Bezug ${ }^{2}$ wäre danach zu untersagen.

Auf diese Weise wird dem Staat keinesfalls verwehrt, bestimmte Aktivitäten mit Kredithilfen zu fördern, die er, aus welchen Gründen auch immer, für förderungswürdig hält. Vielmehr wird ihm lediglich untersagt, daß er die vergleichsweise geringe Kontrollintensität in Überschußperioden ausnützt, um Zwangsbeiträge einer bestimmter Gruppen von Individuen für die Vergabe von Kredithilfen zu verwenden, die einzelnen Interessengruppen oder der Allgemeinheit zugute kommen.

\section{ZUSAMMENFASSUNG}

Gegenstand dieses Kapitels war die Frage, unter welchen Voraussetzungen die Wahl von Kredithilfen als spezifischen Subventionsinstitutionen und von außerbudgetären Einheiten als organisatorischen Institutionen bei gegebenen politisch-institutionellen Bedingungen erwartet werden kann. Darüber hinaus wurde untersucht, wie diese politischinstitutionellen Bedingungen geändert werden sollten, um mögliche Verstöße des auf konstitutioneller Ebene definierten Interesses der Allgemeinheit bei den Entscheidungen zugunsten von Kredithilfen und außerbudgetären Einheiten zu begrenzen.

Bei der Analyse positiver Erklärungsansätze öffentlicher Kredithilfen wird angenommen, daß sich Entscheidungen über die Subventionierung bestimmter Aktivitäten und Entscheidungen über die Subventionsform analytisch trennen lassen. Die positive Erklärung öffentlicher Kredithilfen beruht darauf, daß bestimmte Gruppen mit dieser Subventionsform Vorteile realisieren können. Dabei kann danach unterschieden werden, ob diese Vorteile für Nachfrager oder Anbieter öffentlicher Leistungen auftreten.

Als potentielle Nachfrager von Kredithilfen sind die Subventionsempfänger und die sonstigen durch eine Subventionierung Begünstigten sowie die Steuerzahler zu berücksichtigen. Dabei wurde herausgearbeitet, daß Subventionsform-Entscheidungen in aller Regel nicht dem Paretokriterium entsprechen. Vielmehr stehen den Vorteilen einer Gruppe stets Nachteile einer anderen Gruppe gegenüber. Demnach kommt es darauf an, welche Gruppen unter verschiedenen Bedingungskonstellationen Präferenzen für die Wahl von Kredithilfen als Subventionsform besitzen und daher Kredithilfen nachfragen werden. Die Grup-

1 Vgl. dazu oben Abschnitt B.III.3.

2 Vgl. QUELLMALZ (1963), S.79 ff., der sich kritisch zu den arbeitsmarktpolitischen Wirkungen der aus Überschüssen der Arbeitslosenversicherung finanzierten zinsverbilligten Darlehen äußert. 
pen, welche durch Kredithilfen Nachteile erleiden, werden dagegen alternative Subventionsformen präferieren. Welche Subventionsform im laufenden politischen Prozeß nachfragewirksam wird, hängt von dem Verfahren ab, in dem die Nachfrage nach Kredithilfen artikuliert werden kann.

Es wurde gezeigt, daß durch Kredithilfen Subventionsempfänger mit hohem Risiko zu Lasten derjenigen mit geringem Risiko, die gegenwärtige Generation zu Lasten der künftigen Generation und die Subventionsbegünstigten zu Lasten der Steuerzahler Vorteile erzielen können. Allerdings können die Steuerzahler Kredithilfen präferieren, wenn sich bestimmte Subventionserfolge bei dieser Subventionsform mit geringeren Ausgaben erreichen lassen als bei anderen Subventionsformen.

Unterstellt man, daß Subventionsform-Entscheidungen durch Mehrheitswahl getroffen werden, so kommt es auf das zahlenmäßige Verhältnis der Gewinner und Verlierer von Kredithilfen an, ob die Nachfrage nach dieser Subventionsform wirksam wird. Allerdings können in diesem Fall zyklische Präferenzen auftreten, wenn über mehr als zwei alternative Subventionsformen abgestimmt wird. Realistischerweise ist jedoch anzunehmen, daß sich die Nachfrage nach Kredithilfen als Subventionsform im Rahmen des Wettbewerbs von Interessengruppen durch Ausübung politischen Drucks artikuliert. Dabei ist der Druck auf die Subventionsanbieter zur Bereitstellung von Kredithilfen dann besonders stark, wenn die dadurch Begünstigten hohe Vorteile realisieren können, während die Nachteile breit gestreut und wegen ihrer geringen Höhe für die Verlierer kaum wahrnehmbar sind.

Als Anbieter von Kredithilfen sind die staatlichen Akteure, also die regierenden Politiker und Bürokraten, zu betrachten. Die Politiker treffen im Normalfall die Entscheidungen über die Subventionsform. Dabei werden sie Kredithilfen anbieten, wenn sie dadurch Netto-Stimmengewinne und folglich politische Nettoerträge erzielen können. Netto-Stimmengewinne erscheinen dann wahrscheinlich, wenn die Vorteile der Gewinner dieser Subventionsform relativ hoch und die Nachteile der Verlierer breit gestreut sind. Damit lassen die Konstellationen, die zu einer wirksamen Nachfrage nach Kredithilfen führen, auch ein entsprechendes Angebot durch die Politiker erwarten. Darüber hinaus besitzen die Politiker einen Anreiz, Kredithilfen bereitzustellen, wenn sich damit bestimmte fiskalische Restriktionen, wie z.B. das Gebot eines materiellen Haushaltsausgleichs, umgehen lassen, die der Begrenzung politischer Handlungsspielräume dienen sollen.

Ist der individuelle Nutzen der Bürokraten mit der Budgethöhe positiv korreliert, werden sie Kredithilfen als Subventionsform präferieren, wenn sie dadurch ein größeres Budget realisieren oder ihren Zuständigkeitsbereich ausweiten können. Unter diesen 
Bedingungen werden sie auf die Politiker Druck ausüben, daß Kredithilfen als Subventionsform gewählt werden.

In einem nächsten Schritt wurde analysiert, wie der politisch-institutionelle Rahmen gestaltet werden sollte, um zu verhindern, daß Entscheidungen über die Subventionsform im Widerspruch zum kollektiven Interesse getroffen werden. Dabei ist das kollektive Interesse auf einer konstitutionellen Ebene zu bestimmen, weil hier die Individuen hinter dem "Schleier der Unwissenheit" unabhängig von ihrer postkonstitutionellen ökonomischen Position und damit unabhängig von ihrem individuellen Verteilungsinteresse entscheiden. Es kann vermutet werden, daß die Individuen auf der konstitutionellen Ebene sicherstellen wollen, da $B$ bestimmte Subventionserfolge mit minimalen Subventionsausgaben erreicht werden. Außerdem werden sie verhindern wollen, daß durch die Entscheidungen über die Subventionsform spezielle Verteilungsvorteile auf Kosten einer optimalen Ressourcenallokation erzielt werden können.

Nach Auffassung der konstitutionellen Wirtschaftstheorie erfordern diese Zielsetzungen konstitutionelle Regeln, die Anreize dafür schaffen, daß das kollektive Interesse im laufenden politischen Prozeß beachtet wird. Beruhen die Regeln für die Vergabe von Kredithilfen auf einer Einigung der Individuen, so können sie als paretooptimal betrachtet werden, da andernfalls die durch solche Regeln Geschädigten die Zustimmung verweigern würden. Konstitutionelle Entscheidungen über Regeln setzen voraus, da $B$ die Individuen eine Vorstellung über das staatliche Verhaltensmuster in postkonstitutionellen Perioden besitzen. Es kann angenommen werden, daß sich die Individuen gegen den "worst case" eines ausbeuterischen Leviathan-Staates ebenso absichern wollen wie gegen einen Vergünstigungsstaat, bei dem sich die staatlichen Akteure durch Teilung politischer Renten mit bestimmten Interessengruppen eigene Vorteile verschaffen.

Es wurden sodann einige mögliche Regeln diskutiert, die allerdings strikt vorläufigen Charakter besitzen, da alleiniger Maßstab für die normative Wünschbarkeit von Regeln in der tatsächlichen Einigung der Individuen zu sehen ist. Besonders bedeutsam erscheinen in diesem Zusammenhang Regeln, welche die ausgabenminimale Subventionsform vorschreiben, die sofortige Ausgabenwirksamkeit der Subventionsausgaben in der Vergabeperiode sicherstellen, den Erlaß und die entgeltliche Veräußerung von Kredithilfeforderungen untersagen und eine umfassende Informationspflicht über staatliche Kredithilfeaktivitäten bestimmen.

Danach wurde untersucht, wie sich die Einschaltung außerbudgetärer Einheiten in die Kredithilfevergabe erklären läßt. Es wird gezeigt, daß die Errichtung außerbudgetärer Einheiten als Strategie zur Erzielung von Verteilungsvorteilen interpretiert werden kann. 
Dies gilt insbesondere dann, wenn die Kosten der staatlichen Kredithilfeaktivitäten mit Hilfe außerbudgetärer Einheiten verschleiert oder fiskalische Restriktionen umgangen werden können. Andererseits kann die Errichtung außerbudgetärer Einheiten auch als konstitutionelle Entscheidung gewertet werden, wenn diese dem kollektiven Interesse dienen. So kann die Errichtung von Sondervermögen aus konstitutioneller Sicht wünschenswert sein, wenn damit die zweckwidrige Verwendung spezieller staatlicher Vermögenseinnahmen verhindert werden kann. Sonderkreditinstitute können insoweit vorteilhaft sein, als sie Kosteneinsparungen bei der Subventionsverwaltung erlauben und Manipulationsmöglichkeiten bei der Kredithilfevergabe reduzieren.

Aufgrund der positiven Erklärung außerbudgetärer Einheiten wurde gefolgert, daß auch in diesem Zusammenhang konstitutionelle Regeln erforderlich sind. Damit soll der Spielraum des Staates begrenzt werden, sich durch entsprechende Organisationsformen auf Kosten der Allgemeinheit zusätzliche Vorteile zu verschaffen, ohne die möglichen wünschenswerten Effekte außerbudgetärer Einheiten zu unterbinden. Demnach ist ein generelles Verbot außerbudgetärer Einheiten kaum wünschenswert. Als mögliche Regeln werden unter anderem ein Verschuldungsverbot für Sondervermögen, ein Verbot von Eigenprogrammen der Sonderkreditinstitute und spezielle Informationspflichten über die Kredithilfen außerbudgetärer Einheiten vorgeschlagen. Darüber hinaus werden Vorkehrungen für sinnvoll erachtet, die eine zweckfremde Verausgabung von Einnahmen sonstiger außerbudgetärer Einrichtungen verhindern. 


\section{E. SCHLUSSBEMERKUNGEN}

Die Analyse $8 f f e n t l i c h e r$ Kredithilfen hat gezeigt, daß diese Subventionsformen aus ökonomischer Sicht keinesfalls weniger problematisch sind als andere Arten von Subventionen. Denn Kredithilfen verursachen, ebenso wie andere Subventionsformen, regelmäßig Wohlfahrtsverluste und führen zu Verteilungskonsequenzen, die aus konstitutioneller Sicht kaum wünschenswert sind. Dies gilt auch dann, wenn sie lediglich zu Mitnahmeeffekten führen, wobei in diesem Fall außerdem der angestrebte Subventionserfolg verfehlt wird. Darüber hinaus hat die politisch-institutionelle Analyse gezeigt, daß die Subventionierung in Form offentlicher Kredithilfen insofern politisch attraktiv ist, als sich damit im Vergleich zu anderen Subventionsformen für Subventionsempfänger und staatliche Akteure zusätzliche Vorteile realisieren lassen. Diesem Ziel dienen unter bestimmten Bedingungen auch außerbudgetäre Einheiten, die bei der Vergabe von Kredithilfen eingesetzt werden. Demnach konnte mit der vorstehenden Analyse gezeigt werden, daß die vielbeklagte Subventionsproblematik ${ }^{1}$ wesentlich dadurch bestimmt wird, ob es dem Staat erlaubt ist, Subventionsinstitutionen beliebig zu wählen oder nicht.

Als zwingende normative Konsequenz der positiven Analyse öffentlicher Kredithilfen und außerbudgetärer Einheiten ist die Notwendigkeit fiskalischer Restriktionen zu betrachten, die im Hinblick auf die Entscheidungen über die Subventionsform und die Organisationsform der Kredithilfevergabe Anreize zu Verhaltensweisen geben sollen, die im Einklang mit dem kollektiven Interesse stehen. Gleichwohl kann die Realisierung der Gesamtheit der entwickelten Regeln nicht als endgültige normative Forderung erhoben werden, da sich ihre Wünschbarkeit letztlich nur im Rahmen eines konstitutionellen Prozesses erweisen kann.

Abgesehen von ihrer Ausgestaltung im Detail sind fiskalische Restriktionen in bezug auf öffentliche Kredithilfen und die zu ihrer Vergabe eingesetzten außerbudgetären Einheiten als wesentlicher Baustein eines Ordnungsrahmens für die staatliche Subventionspolitik zu betrachten. Sie sind damit zugleich Bestandteil einer Ordnungspolitik für den öffentlichen Sektor, die zunehmend für dringend erforderlich gehalten wird ${ }^{2}$.

Bei der Implementierung der in dieser Arbeit diskutierten fiskalischen Restriktionen ist zunächst ein rechtstechnisches Problem zu lösen. Es stellt sich nämlich die Frage, inwieweit es sinnvoll ist, die zum Teil sehr speziellen Regeln in den Text der geschriebenen

1 "Die Subventionswirtschaft ist seit langem ein Ärgernis." SACHVERSTÄNDIGENRAT (1982), S.156.

2 Vgl. z.B. FOLKERS (1984), S.504; CASSEL (1988); TIETZEL (1988); MÄRTZ (1990), S.208. 
Verfassung aufzunehmen. Geht man davon aus, da $B$ der Verfassungstext aus Praktikabilitätsgründen nur ganz elementare Regeln enthalten sollte, müssen die Regeln für budgetäre und außerbudgetäre Kredithilfen auf ihren Wesensgehalt verdichtet werden, der Bestandteil der Verfassung sein sollte. Diese unmittelbaren Verfassungsbestimmungen müßten hinreichend eindeutig sein, damit der Gesetzgeber sein Ermessen bei der Formulierung der Detailregelungen in Form einfacher Gesetzes nicht mißbräuchlich verwenden kann.

Als mögliche Verfassungsbestimmungen zur Beschränkung der staatlichen Subventionsform-Entscheidungen kommen eine Konkretisierung des Gleichheitssatzes und allgemeine Ausgabenbestimmungen in Betracht. Der Gleichheitssatz müßte im Sinn einer allgemeinen Ausgabengerechtigkeit erweitert werden. Danach wäre durch geeignete Vorschriften sicherzustellen, daß eine Privilegierung bestimmter Gruppen durch die Wahl von Kredithilfen als Subventionsform nur dann rechtmäßig ist, wenn dies durch besondere sachliche Gründe gerechtfertigt ist. Zu den allgemeinen Ausgabenbestimmungen, die Verfassungsrang erhalten sollten, gehört eine Regel, die vorschreibt, daß öffentliche Aufgaben mit den geringstmöglichen Ausgaben erfüllt werden müssen. Außerdem sollte die Verfassung die Vorschrift enthalten, daß Subventionen nur dann zugelassen sind, wenn sie in der Vergabeperiode ausgabenwirksam sind. Um einer fiskalischen Schattenwirtschaft ${ }^{1}$ entgegenzuwirken, wäre in der Verfassung im Hinblick auf außerbudgetäre Einheiten vorzuschreiben, daß sie zur Subventionierung privater Aktivitäten nur berechtigt sind, wenn zur Deckung der Subventionskosten Mittel der staatlichen Haushalte zur Verfügung stehen.

Die Konkretisierung dieser grundlegenden Verfassungsbestimmungen könnte in der Bundesrepublik Deutschland im Rahmen der Grundsatzgesetzgebungskompetenz des Bundes für das Haushaltswesen ${ }^{2}$ erfolgen. Dies hätte den Vorteil, daß der Fortbestand dieser konkretisierenden Regeln bei sich ändernden politischen Machtverhältnissen aufgrund der Besonderheiten in dem für die Grundsatzgesetzgebung vorgeschriebenen Verfahren nicht unmittelbar gefährdet wäre. Vor allem aber können gesetzlich geregelte Haushaltsgrundsätze nicht durch einfache Haushaltsgesetze derogiert werden, so da $B$ ihnen bereits insoweit eine erhöhte Bestandskraft zukommt.

Weit bedeutsamer als dieses rechtstechnische Problem erscheint die Frage nach den Implementierungschancen der in dieser Arbeit diskutierten Regeln. Denn der "Schleier der Unwissenheit", der aus theoretischer Sicht die Rahmenbedingung für die erforderlichen konstitutionellen Entscheidungen darstellen muß, ist stets durchsichtig, verbirgt also nicht den Blick auf die individuelle postkonstitutionelle Position, wenn konstitutionelle Refor-

1 Vgl. BENNETT/DILORENZO (1983b).

2 Vgl. Art. 109 Abs.3 GG. 
men angestrebt werden. "Wenn die abgeleiteten institutionellen Änderungen in Restriktionen politischen Handelns bestehen, welche den gegebenen Interessen der Politiker zuwiderlaufen, fragt sich nämlich, wie derartige Konzepte im politischen ProzeB durchgesetzt werden sollen."1 Außerdem kann erwartet werden, daß auch diejenigen Interessengruppen, die ohne Beschrănkungen Verteilungsvorteile realisieren kőnnen, gegen Restriktionen für die Vergabe von Kredithilfen und den Einsatz außerbudgetärer Einheiten opponieren werden. Daher sind die Chancen zur Implementierung entsprechender Restriktionen nicht besonders günstig, wenngleich sich solche "konstitutionellen Subventionsreformen" gesamtwirtschaftlich als Positivsummenspiel beschreiben lassen ${ }^{2}$. Denn paretosuperiore institutionelle Änderungen liegen nicht bereits dann vor, wenn sich bei hypothetischer Betrachtung bestimmte Individuen verbessern können, ohne daß sich andere Individuen verschlechtern, sondern erst wenn diese Situation tatsächlich eintritt. Daher ist mit einem Erfolg angestrebter konstitutioneller Reformen generell in erster Linie dann zu rechnen, wenn sie durch ein Netz aus kompensierenden Maßnahmen abgesichert werden ${ }^{3}$. Wie solche kompensierenden Maßnahmen im gegebenen Zusammenhang aussehen können, muß in dieser Arbeit offen bleiben.

Die Realisierungschancen konstitutioneller Reformen für die staatliche Subventionspolitik hängen schließlich entscheidend davon ab, ob es gelingt, die öffentliche Diskussion darüber in Gang zu setzen. In Zeiten erhöhter staatlicher Finanznöte sind die Chancen dafür als relativ gut zu beurteilen, da unter diesen Bedingungen in der Bevölkerung regelmäßig eine erhöhte Sensibilisierung im Hinblick auf finanzwirtschaftliche Fehlentwicklungen zu beobachten ist. So ist es nicht überraschend, daß sich die Subventionspolitik in jüngster Zeit verstärkter Kritik ausgesetzt sieht, da die Bürger zur Finanzierung der deutschen Einheit offenkundig Ausgabeneinsparungen für notwendig erachten. Es wäre allerdings bedauerlich, wenn in der aktuellen Situation lediglich das Ziel kurzfristiger Kürzungen von staatlichen Subventionsausgaben verfolgt werden würde. Denn damit würde übersehen, $\mathrm{da} ß$ auf diese Weise unter den geltenden politisch-institutionellen Bedingungen künftige Fehlentwicklungen bei der Subventionspolitik nicht verhindert werden können. Denn bloße Ausgabenkürzungen schaffen keine dauerhaften Anreize für die staatlichen Akteure, Subventionen nur dann zu vergeben, wenn dies im Interesse der Allgemeinheit liegt. Erst wenn sich die Erkenntnis durchsetzt, daß institutionelle Reformen erforderlich sind, die dem Staat gerade auch in bezug auf die zulässigen Formen der Subventionierung und ihre

1 Vgl. FOLKERS (1986d), S.32.

$2 \mathrm{Zu}$ einer entsprechenden Einordnung konstitutioneller Steuerreformen vgl. BUCHANAN/ BRENNAN (1980), S.35.

3 Vgl. BRENNAN/BUCHANAN (1985), S.140. 
organisatorische Durchführung Begrenzungen auferlegen, bestehen Aussichten, daß in diesem Bereich staatlicher Aktivitäten langfristig Effizienzsteigerungen erreicht werden können. Wenn die vorliegende Arbeit einen kleinen Beitrag zur Verbreitung dieser Erkenntnis zu leisten vermag, hat sie ihren Zweck erreicht. 
Peter Mendler - 978-3-631-75549-5

Downloaded from PubFactory at 01/11/2019 03:40:17AM

via free access 


\section{A N H A N G}

Peter Mendler - 978-3-631-75549-5

Downloaded from PubFactory at 01/11/2019 03:40:17AM

via free access 
Tabelle 1 : Schuldendiensthilfen der öffentlichen Haushalte (in Mio. DM)

\begin{tabular}{|c|c|c|c|c|c|c|}
\hline \multirow[t]{2}{*}{ Jahr } & \multicolumn{2}{|c|}{ Bund } & \multicolumn{2}{|c|}{ Länder } & \multicolumn{2}{|c|}{ Gemeinden } \\
\hline & insgesamt & $\begin{array}{l}\text { ohne öffentlichen } \\
\text { Bereich }\end{array}$ & insgesamt & $\begin{array}{l}\text { ohne öffentlichen } \\
\text { Bereich }\end{array}$ & insgesamt & $\begin{array}{l}\text { ohne öffentlichen } \\
\text { Bereich }\end{array}$ \\
\hline 1960 & 101 & 86 & 154 & 71 & 1) & 1) \\
\hline 1961 & 153 & 124 & 285 & 124 & 1) & 1) \\
\hline 1962 & 226 & 174 & 365 & 180 & 1) & 1) \\
\hline 1963 & 316 & 201 & 478 & 215 & 1) & 1) \\
\hline 1964 & 459 & 274 & 560 & 357 & 1) & 1) \\
\hline 1965 & 534 & 365 & 661 & 431 & 1) & 1) \\
\hline 1966 & 597 & 369 & 785 & 505 & 1) & 1) \\
\hline 1967 & 958 & 573 & 967 & 616 & 1) & 1) \\
\hline 1968 & 1.079 & 624 & 1.080 & 700 & 1) & 1) \\
\hline 1969 & 1.160 & 1.060 & 1.066 & 669 & 1) & 1) \\
\hline 1970 & 1.157 & 1.027 & 1.285 & 1.024 & 1) & 1) \\
\hline 1971 & 1.388 & 1.232 & 1.297 & 994 & 1) & 1) \\
\hline 1972 & 1.406 & 1.164 & 1.740 & 1.329 & 1) & 1) \\
\hline 1973 & 1.564 & 1.279 & 1.660 & 1.193 & 1) & 1) \\
\hline 1974 & 1.410 & 1.143 & 2.128 & 1.520 & 130 & 95 \\
\hline 1975 & 1.252 & 1.007 & 2.401 & 1.759 & 167 & 116 \\
\hline 1976 & 1.281 & 1.020 & 2.685 & 2.056 & 176 & 124 \\
\hline 1977 & 1.228 & 951 & 3.025 & 2.385 & 190 & 131 \\
\hline 1978 & 1.348 & 1.033 & 3.084 & 2.447 & 172 & 127 \\
\hline 1979 & 1.334 & 964 & 2.672 & 2.080 & 181 & 133 \\
\hline 1980 & 1.468 & 1.091 & 2.744 & 2.217 & 206 & 152 \\
\hline 1981 & 1.482 & 1.093 & 2.879 & 2.369 & 202 & 150 \\
\hline 1982 & 1.512 & 1.276 & 2.600 & 2.230 & 213 & 153 \\
\hline 1983 & 1.644 & 1.385 & 2.691 & 2.128 & 205 & 148 \\
\hline 1984 & 1.744 & 1.408 & 2.835 & 2.274 & 232 & 175 \\
\hline 1985 & 1.630 & 1.284 & 3.370 & 2.894 & 231 & 174 \\
\hline 1986 & 1.688 & 1.326 & 3.131 & 2.684 & 230 & 168 \\
\hline
\end{tabular}

1) - keine Angaben

Quelle: Finanzberichte des Bundes 
Tabelle 2: Zinszuschüsse des Bundes an die KfW (in Mio. DM)

\begin{tabular}{|c|c|c|c|c|c|c|c|c|c|c|c|}
\hline $\begin{array}{l}\text { Verwendungs- } \\
\text { zweck }\end{array}$ & 1978 & 1979 & 1980 & 1981 & $\begin{array}{l}\text { Jah } \\
1982\end{array}$ & 1983 & 1984 & 1985 & 1986 & 1987 & $1988^{1}$ \\
\hline $\mathrm{FZ}^{2}$ & 59 & 54 & 45 & 36 & 29 & 24 & 19 & 15 & 12 & 9 & 7 \\
\hline $\begin{array}{l}\text { Krankenhaus- } \\
\text { finanzierung }\end{array}$ & 28 & 27 & 20 & 14 & 13 & 13 & 1 & 0 & 0 & 0 & 0 \\
\hline Wohnungsbau & 94 & 124 & 98 & 214 & 257 & 279 & 280 & 272 & 258 & 223 & 194 \\
\hline Polen-Kredit & 50 & 50 & 50 & 49 & 51 & 50 & 48 & 44 & 42 & 33 & 32 \\
\hline $\begin{array}{l}\text { 6,3 Mrd.DM- } \\
\text { Programm }\end{array}$ & - & - & - & - & -40 & 115 & 92 & 76 & 40 & 28 & 11 \\
\hline $\begin{array}{l}\text { US-Devisen- } \\
\text { ausgleich }\end{array}$ & 118 & 123 & 11 & 12 & 5 & 4 & 7 & 2 & - & - & - \\
\hline $\begin{array}{l}\text { Airbus- } \\
\text { Absatz- } \\
\text { finanzierung }\end{array}$ & 32 & 27 & 34 & 63 & 95 & 41 & 57 & 41 & 19 & 15 & 17 \\
\hline Werfthilfe & 58 & 57 & 60 & 66 & 85 & 119 & 137 & 148 & 141 & 135 & 150 \\
\hline Summe & 439 & 461 & 319 & 453 & 575 & 644 & 640 & 599 & 513 & 444 & 412 \\
\hline
\end{tabular}

1 Geschätzte Zahlen

2 Finanzielle Zusammenarbeit mit Entwicklungsländern

Quelle: BUNDESREGIERUNG (1988), S.21

Tabelle 3: Zinserträge von LKB und LfA in Form von Zinszuschüssen ${ }^{1}$

\begin{tabular}{|l|c|c|c|c|}
\hline Jahr & \multicolumn{2}{|c|}{ LKB: Zinszuschüsse } & \multicolumn{2}{|c|}{ LfA: Zinszuschüsse } \\
& in Mio.DM & $\begin{array}{c}\text { in.H.der } \\
\text { Zinserträge }\end{array}$ & in Mio. DM & $\begin{array}{l}\text { in v.H. der } \\
\text { Zinserträge }\end{array}$ \\
\hline 1973 & 158,7 & 36,4 & $1)$ & \\
1974 & 203,2 & 38,3 & $1)$ & \\
1975 & 247,6 & 37,7 & $1)$ & \\
1976 & 298,7 & 37,2 & $1)$ & \\
1977 & 325,8 & 36,4 & $1)$ & \\
1978 & 344,7 & 35,1 & $1)$ & \\
1979 & 370,6 & 33,5 & $1)$ & \\
1980 & 422,2 & 33,6 & $1)$ & \\
1981 & 462,3 & 31,7 & $1)$ & 26,2 \\
1982 & 469,8 & 28,3 & $1)$ & 25,0 \\
1983 & 474,7 & 25,8 & $1)$ & 24,0 \\
1984 & 470,1 & 23,8 & 241,1 & \\
1985 & 446,8 & 22,3 & 234,8 & \\
1986 & 425,9 & 21,1 & 227,5 & \\
1987 & $1)$ & & 218,3 & \\
1988 & $1)$ & & 211,5 & \\
\hline
\end{tabular}

1) Keine Angaben

Quellen: Geschäftsberichte der LKB; Schriftliche Auskunft der LfA vom 21.11.1989 an den Verf. 
Tabelle 4: Schuldendiensthilfen des Bundes und der Länder an Dritte nach Förderzwecken von 1960 bis 1974

\begin{tabular}{|c|c|c|c|c|c|c|c|c|}
\hline Jahr & $\begin{array}{l}\text { Gesamt } \\
\text { in Mio. } \\
\text { DM (1) }\end{array}$ & Wohnungsbau & $\begin{array}{l}\quad \text { Bund } \\
\text { davon in v.H. vo } \\
\text { Ernährung, } \\
\text { Land- und } \\
\text { Forstwirtschaft }\end{array}$ & $\begin{array}{l}\text { für } \\
\text { Wirtschafts- } \\
\text { förderung }\end{array}$ & $\begin{array}{l}\text { Gesamt } \\
\text { in Mio. } \\
\text { DM (2) }\end{array}$ & Wohnungsbau & $\begin{array}{l}\text { Lände } \\
\text { von in v.H. von } \\
\text { Ernährung, } \\
\text { Land- und } \\
\text { Forstwirtschaft }\end{array}$ & $\begin{array}{l}\text { Wirtschafts- } \\
\text { förderung }\end{array}$ \\
\hline 1960 & 86 & 6,0 & 87,6 & 6,4 & 71 & 67,5 & 20,8 & 5,2 \\
\hline 1961 & 124 & 13,6 & 79,4 & 6,8 & 124 & 82,5 & 11,4 & 5,7 \\
\hline 1962 & 174 & 18,6 & 76,9 & 4,4 & 180 & 90,1 & 4,5 & 5,3 \\
\hline 1963 & 201 & - & 96,8 & 2,9 & 215 & 89,5 & 3,6 & 6,6 \\
\hline 1964 & 274 & 0,4 & 88,0 & 9,2 & 357 & 90,2 & 3,1 & 5,8 \\
\hline 1965 & 365 & 12,5 & 78,6 & 6,2 & 431 & 91,2 & 1,7 & 6,5 \\
\hline 1966 & 369 & 0,4 & 96,0 & 0,8 & 505 & 91,3 & 1,5 & 6,2 \\
\hline 1967 & 573 & 1,2 & 57,4 & 38,7 & 616 & 91,5 & 1,6 & 6,0 \\
\hline 1968 & 624 & 2,0 & 54,6 & 40,4 & 700 & 87,1 & 1,8 & 10,3 \\
\hline 1969 & 1.060 & 12,2 & 38,5 & 18,3 & 669 & 74,8 & 1,9 & 22,5 \\
\hline 1970 & 1.027 & 12,7 & 37,0 & 16,4 & 1.024 & 69,3 & 3,0 & 20,8 \\
\hline 1971 & 1.232 & 9,6 & 38,9 & 21,0 & 994 & 65,3 & 2,9 & 19,2 \\
\hline 1973 & 1.279 & 5,7 & 31,4 & 27,7 & 1.193 & 61,2 & 3,2 & 24,7 \\
\hline 1974 & 1.143 & 7,2 & 32,6 & 12,0 & 1.520 & 59,1 & 2,8 & 20,8 \\
\hline
\end{tabular}

Quelle: Eigene Berechnungen aufgrund der Angaben in DICKERTMANN (1980), S.569 f., Tabelle 15. 
Tabelle 5: Schuldendiensthilfen des Bundes im Sinne des $\S 12$ StabWG nach Förderzwecken

\begin{tabular}{|c|c|c|c|c|}
\hline Jahr & $\begin{array}{l}\text { Insgesamt } \\
\text { in Mio.DM } \\
\text { (1) }\end{array}$ & $\begin{array}{l}\text { Ernährung, } \\
\text { Landwirtschaft } \\
\text { und Forsten } \\
\text { in v.H. von (1) }\end{array}$ & $\begin{array}{l}\text { Gewerbliche } \\
\text { Wirtschaft } \\
\text { in v.H. } \\
\text { von (1) }\end{array}$ & $\begin{array}{l}\text { Wohnungsbau } \\
\text { in v.H. } \\
\text { von (1) }\end{array}$ \\
\hline 1981 & 1.167 & 22,7 & 12,0 & 65,2 \\
1982 & 1.272 & 19,4 & 18,6 & 62,0 \\
1983 & 1.405 & 16,1 & 21,2 & 62,7 \\
1984 & 1.581 & 13,0 & 21,5 & 65,5 \\
1985 & 1.450 & 12,3 & 23,9 & 63,8 \\
1986 & 1.528 & 11,1 & 19,9 & 69,0 \\
\hline
\end{tabular}

Quellen: Subventionsberichte des Bundes

Tabelle 6: Ausgaben der öffentlichen Haushalte für Darlehen an den öfientlichen Bereich (in Mio. DM)

\begin{tabular}{|l|c|c|c|c|r|}
\hline $\begin{array}{l}\text { Jahr } \\
\text { en }\end{array}$ & Insgesamt & Bund & $\begin{array}{c}\text { ERP-Sonder- } \\
\text { vermögen }\end{array}$ & Länder & Gemeind \\
\hline 1974 & 1.506 & 1.056 & 140 & 157 & 153 \\
1975 & 4.233 & 3.592 & 262 & 193 & 187 \\
1976 & 2.344 & 1.216 & 663 & 268 & 197 \\
1977 & 1.551 & 865 & 269 & 295 & 122 \\
1978 & 1.412 & 812 & 226 & 259 & 115 \\
1979 & 2.213 & 1.453 & 409 & 256 & 95 \\
1980 & 2.361 & 1.399 & 545 & 279 & 137 \\
1981 & 2.406 & 1.422 & 504 & 343 & 138 \\
1982 & 2.280 & 1.358 & 524 & 270 & 127 \\
1983 & 2.142 & 1.268 & 570 & 221 & 914 \\
1984 & 2.493 & 1.472 & 747 & 184 & 103 \\
1985 & 2.726 & 1.602 & 705 & 315 & 94 \\
1986 & 2.679 & 1.578 & 542 & 465 & \\
\hline
\end{tabular}

Quellen: Finanzberichte des Bundes 
Tabelle 7: Ausgaben der öffentlichen Haushalte für Darlehen an Dritte absolut (in Mio. DM) und in \% der Gesamtausgaben der jeweiligen Haushalte

\begin{tabular}{|c|c|c|c|c|c|c|c|c|c|c|c|c|c|}
\hline \multirow[t]{2}{*}{ Jahr } & \multirow{2}{*}{$\begin{array}{l}\text { Insgesamt } \\
\text { abs. }\end{array}$} & \multicolumn{2}{|c|}{ Bund } & \multicolumn{2}{|c|}{$\begin{array}{l}\text { ERP-Sonder- } \\
\text { vermögen }\end{array}$} & \multicolumn{2}{|c|}{$\begin{array}{l}\text { Lastenaus- } \\
\text { gleichs- } \\
\text { fonds }\end{array}$} & \multicolumn{2}{|c|}{$\begin{array}{l}\text { Sozialver- } \\
\text { sicherung }\end{array}$} & \multicolumn{2}{|c|}{ Länder } & \multicolumn{2}{|c|}{$\begin{array}{l}\text { Gemeinden, } \\
\text { Gemeinde- } \\
\text { und Zweck- } \\
\text { verbände }\end{array}$} \\
\hline & & abs. & in \% & abs. & in \% & abs. & in \% & abs. & in $\%$ & abs. & in \% & abs. & in $\%$ \\
\hline 1950 & 2.161 & 132 & 1,0 & a & & 345 & 17,1 & a & & 1.490 & 13,8 & 194 & 2,6 \\
\hline 1951 & 3.065 & 301 & 1,6 & a & & 426 & 17,6 & a & & 2.091 & 15,6 & 248 & 2,9 \\
\hline 1952 & 3.943 & 586 & 2,8 & $\mathbf{a}$ & & 242 & 11,9 & a & & 2.729 & 17,9 & 386 & 4,0 \\
\hline 1953 & 4.327 & 663 & 3,3 & a & & 563 & 16,3 & a & & 2.635 & 15,7 & 466 & 4,2 \\
\hline 1954 & 5.373 & 1.084 & 5,2 & a & & 1.124 & 26,3 & a & & 2.594 & 14,7 & 572 & 4,7 \\
\hline 1955 & 5.216 & 961 & 4,2 & a & & 1.040 & 26,5 & a & & 2.537 & 13,0 & 678 & 4,9 \\
\hline 1956 & 6.182 & 1.164 & 4,2 & a & & 948 & 26,4 & a & & 3.399 & 14,6 & 671 & 4,3 \\
\hline 1957 & 6.892 & 1.930 & 6,0 & a & & 790 & 20,8 & a & & 3.176 & 12,4 & 996 & 6,1 \\
\hline 1958 & 6.739 & 2.174 & 5,5 & a & & 784 & 18,8 & a & & 3.047 & 11,0 & 734 & 4,2 \\
\hline 1959 & 6.987 & 2.059 & 5,5 & a & & 764 & 17,1 & a & & 3.416 & 11,8 & 748 & 3,9 \\
\hline 1960 & 5.223 & 1.181 & 3,8 & a & & 564 & 17,4 & a & & 2.806 & 11,1 & 672 & 4,1 \\
\hline 1961 & 8.096 & 2.537 & 5,5 & a & & 678 & 17,1 & a & & 3.881 & 10,5 & 1.000 & 4,1 \\
\hline 1962 & 8.477 & 1.666 & 3,3 & 593 & 89,8 & 525 & 11,9 & a & & 4.465 & 10,5 & 1.228 & 4,4 \\
\hline 1963 & 9.570 & 2.184 & 4,0 & 1.409 & 90,0 & 432 & 12,0 & a & & 4.231 & 9,2 & 1.315 & 4,2 \\
\hline 1964 & 8.987 & 1.854 & 3,2 & 792 & 89,4 & 372 & 9,2 & a & & 4.520 & 9,0 & 1.449 & 4,0 \\
\hline 1965 & 9.456 & 1.999 & 3,1 & 1.253 & 93,3 & 337 & 9,2 & a & & 4.403 & 8,1 & 1.464 & 3,8 \\
\hline 1966 & 8.613 & 2.372 & 3,5 & 895 & 89,9 & 247 & 7,9 & a & & 3.789 & 6,5 & 1.310 & 3,2 \\
\hline 1967 & 9.530 & 3.790 & 3,1 & 994 & 82,8 & 159 & 4,8 & a & & 3.401 & 5,7 & 1.186 & 2,9 \\
\hline 1968 & 7.532 & 2.659 & 3,5 & 902 & 63,7 & 119 & 3,4 & a & & 2.775 & 4,4 & 1.041 & 2,4 \\
\hline 1969 & 7.077 & 2.780 & 3,4 & 1.067 & 75,9 & 131 & 3,7 & a & & 2153 & 3,2 & 945 & 2,0 \\
\hline
\end{tabular}


Fortsetzung von Tabelle 7:

\begin{tabular}{|c|c|c|c|c|c|c|c|c|c|c|c|c|c|}
\hline \multirow[t]{2}{*}{$\mathrm{Jahr}$} & \multirow{2}{*}{$\begin{array}{c}\text { Insgesamt } \\
\text { abs. }\end{array}$} & \multicolumn{2}{|c|}{ Bund } & \multicolumn{2}{|c|}{$\begin{array}{l}\text { ERP-Sonder- } \\
\text { vermögen }\end{array}$} & \multicolumn{2}{|c|}{$\begin{array}{l}\text { Lastenaus- } \\
\text { gleichs- } \\
\text { fonds }\end{array}$} & \multicolumn{2}{|c|}{$\begin{array}{l}\text { Sozialver- } \\
\text { sicherung }\end{array}$} & \multicolumn{2}{|c|}{ Länder } & \multicolumn{2}{|c|}{$\begin{array}{l}\text { Gemeinden, } \\
\text { Gemeinde- } \\
\text { und Zweck- } \\
\text { verbände }\end{array}$} \\
\hline & & abs. & in $\%$ & abs. & in $\%$ & abs. & in \% & abs. & in \% & abs. & in $\%$ & abs. & in $\%$ \\
\hline 1970 & 6.755 & 2.149 & 2,5 & 1.246 & 79,7 & 133 & 4,0 & a & & 2.041 & 2,7 & 1.186 & 2,1 \\
\hline 1971 & 7.459 & 2.494 & 2,5 & 1.270 & 87,1 & 146 & 4,4 & a & & 1.868 & 2,1 & 1.681 & 2,5 \\
\hline 1972 & 7.691 & 2.634 & 2,3 & 1.277 & 80,9 & 132 & 4,2 & a & & 2.032 & 2,0 & 1.617 & 2,2 \\
\hline 1973 & 7.550 & 3.152 & 2,6 & 1.050 & 79,0 & 145 & 4,9 & a & & 1.701 & 1,5 & 1.502 & 1,8 \\
\hline $1974^{1}$ & 7.311 & 2.931 & 2,2 & 1.436 & 82,2 & 122 & 4,2 & a & & 2.093 & 1,6 & 729 & 0,8 \\
\hline 1975 & 7.518 & 2.884 & 1,8 & 1.559 & 75,6 & 88 & 2,8 & a & & 2.357 & 1,6 & 629 & 0,6 \\
\hline 1976 & 8.854 & 2.972 & 1,8 & 1.315 & 59,2 & 48 & 1,5 & a & & 3.783 & 2,5 & 736 & 0,7 \\
\hline 1977 & 8.167 & 2.669 & 1,5 & 1.515 & 76,0 & 34 & 1,2 & a & & 3.336 & 2,1 & 613 & 0,6 \\
\hline 1978 & 9.233 & 3.292 & 1,7 & 1.833 & 76,2 & 22 & 0,8 & a & & 3.505 & 2,0 & 583 & 0,7 \\
\hline $1979_{3}$ & 10.771 & 3.800 & 1,9 & 2.185 & 77,3 & 26 & 1,0 & a & & 4.091 & 2,1 & 669 & 0,5 \\
\hline $1980^{3}$ & 12.033 & 3.846 & 1,8 & 2.641 & 75,7 & 29 & $0,2^{4}$ & $\mathbf{a}$ & & 4.658 & 2,2 & 859 & 0,6 \\
\hline 1981 & 13.212 & 4.271 & 1,8 & 3.047 & 78,8 & 32 & 0,2 & $\mathbf{a}$ & & 4.721 & 2,2 & 1.139 & 0,7 \\
\hline 1982 & 13.195 & 4.575 & 1,9 & 2.462 & $.70,9$ & 35 & 0,2 & 256 & 0,08 & 4.783 & 2,1 & 1.083 & 0,7 \\
\hline 1983 & 15.003 & 4.930 & 2,0 & 3.164 & 74,3 & 30 & 0,2 & 376 & 0,11 & 5.351 & 2,3 & 1.152 & 0,8 \\
\hline 1984 & 17.611 & 6.347 & 2,5 & 3.231 & 72,1 & 34 & 0,2 & 406 & 0,12 & 6.399 & 2,7 & 1.194 & 0,8 \\
\hline 1985 & 16.765 & 5.751 & 2,2 & 3.083 & 70,7 & 32 & 0,2 & 390 & 0,11 & 6.434 & 2,6 & 1.075 & 0,7 \\
\hline $1986^{2}$ & 16.555 & 5.252 & 2,0 & 3.317 & 75,7 & 32 & 0,2 & 506 & 0,14 & 6.366 & 2,5 & 1.082 & 0,6 \\
\hline
\end{tabular}

a keine Angaben

1 Änderung der Berechnungsmethode

2 Vorläufiges Ergebnis

4 Ab 1980 in v.H. der bereinigten Ausgaben

4 Lastenausgleichsfonds/EG-Anteile

Quelle: Statistische Bundesamt, Lange Reihen zur Wirtschaftsentwicklung (verschiedene Jahrgänge) 
Tabelle 8: $\quad$ Zinseinnahmen der öffentlichen Haushalte (in Mio. DM)

\begin{tabular}{|l|c|c|c|c|c|c|}
\hline Jahr & Bund & LAF & $\begin{array}{c}\text { ERP-Sonder- } \\
\text { vermögen }\end{array}$ & Länder & Gemeinden & Insgesamt \\
\hline 1974 & 541 & 7 & 334 & 625 & 1.375 & 2.882 \\
1975 & 582 & 9 & 429 & 561 & 883 & 2.463 \\
1976 & 616 & 6 & 358 & 549 & 724 & 2.252 \\
1977 & 638 & 5 & 432 & 556 & 792 & 2.423 \\
1978 & 656 & 4 & 437 & 528 & 728 & 2.352 \\
1979 & 802 & 4 & 421 & 597 & 979 & 2.803 \\
1980 & 664 & 4 & 472 & 683 & 1.403 & 3.226 \\
1981 & 775 & 4 & 607 & 692 & 1.527 & 3.605 \\
1982 & 738 & 3 & 764 & 730 & 1.299 & 3.533 \\
1983 & 855 & 3 & 857 & 763 & 1.033 & 3.721 \\
1984 & 741 & 3 & 933 & 908 & 1.135 & 4.176 \\
1985 & 1.051 & 2 & 999 & 923 & 1.202 & 4.032 \\
1986 & 991 & 2 & 993 & 927 & 1.119 & 2.576 \\
1987 & 811 & 2 & 970 & 793 & - & 2.584 \\
1988 & 872 & 2 & 925 & 785 & - & \\
\hline
\end{tabular}

${ }^{1}$ Ohne Gemeinden

Quelle: Finanzberichte des Bundes

Tabelle 9: Tilgungseinnahmen der öffentlichen Haushalte von anderen Bereichen (in Mio. DM)

\begin{tabular}{|l|c|c|c|c|c|c|}
\hline Jahr & Bund & LAF & $\begin{array}{c}\text { ERP-Sonder- } \\
\text { vermögen }\end{array}$ & Länder & Gemeinden & Insgesamt \\
\hline 1974 & 730 & 293 & 1.164 & 1.239 & 412 & 3.838 \\
1975 & 688 & 287 & 1.327 & 1.256 & 605 & 4.163 \\
1976 & 700 & 286 & 1.097 & 1.412 & 420 & 3.914 \\
1977 & 1.063 & 315 & 1.236 & 1.398 & 369 & 4.382 \\
1978 & 979 & 300 & 1.876 & 1.397 & 450 & 5.001 \\
1979 & 1.264 & 285 & 1.453 & 1.450 & 463 & 4.914 \\
1980 & 1.490 & 267 & 1.382 & 1.507 & 585 & 5.230 \\
1981 & 1.689 & 259 & 1.524 & 1.781 & 508 & 5.760 \\
1982 & 1.564 & 256 & 2.010 & 2.686 & 579 & 7.096 \\
1983 & 1.211 & 247 & 2.330 & 2.461 & 558 & 6.806 \\
1984 & 1.150 & 233 & 2.425 & 1.974 & 602 & 6.384 \\
1985 & 1.597 & 219 & 2.896 & 2.386 & 662 & 7.760 \\
1986 & 1.994 & 202 & 3.479 & 2.185 & 689 & 8.548 \\
1987 & 1.767 & 171 & 3.784 & 2.184 & 820,1 & 8.690 \\
1988 & 2.329 & 171 & 3.620 & 2.482 & 834,1 & 9.436 \\
\hline
\end{tabular}

${ }^{1}$ Einschließlich Darlehensrückflüsse vom öffentlichen Bereich Quelle: Finanzberichte des Bundes 
Tabelle 10: Deckungsrelation zwischen Darlehenseinnahmen und Darlehensausgaben beim Bund und beim offentlichen Gesamthaushalt (ohne Sozialversicherung)

\begin{tabular}{|l|c|l|l|l|l|l|}
\hline Jahr & \multicolumn{3}{|c|}{ Bund ${ }^{1}$} & \multicolumn{3}{c|}{ Offentlicher Gesamthaushalt ${ }^{2}$} \\
\hline & $\begin{array}{l}\text { Einnahmen } \\
\text { in Mio. DM } \\
\text { (1) }\end{array}$ & $\begin{array}{l}\text { Ausgaben } \\
\text { in Mio. DM } \\
(2)\end{array}$ & $\begin{array}{l}\text { Relation } \\
(1):(2) \\
\text { in v.H. }\end{array}$ & $\begin{array}{l}\text { Einnahmen } \\
\text { in Mio. DM } \\
(3)\end{array}$ & $\begin{array}{l}\text { Ausgaben } \\
\text { in Mio. DM } \\
(4)\end{array}$ & $\begin{array}{l}\text { Relation } \\
(3):(4) \\
\text { in v.H. }\end{array}$ \\
\hline 1974 & 1.806 & 3.987 & 45,3 & 6.720 & 7.311 & 91,9 \\
1975 & 1.808 & 6.476 & 27,9 & 6.626 & 7.518 & 88,1 \\
1976 & 1.866 & 4.188 & 44,6 & 6.166 & 8.854 & 69,6 \\
1977 & 2.310 & 3.534 & 65,4 & 6.805 & 8.167 & 83,3 \\
1978 & 2.208 & 4.104 & 53,8 & 7.353 & 9.233 & 79,6 \\
1979 & 3.142 & 5.253 & 59,8 & 7.717 & 10.771 & 71,6 \\
1980 & 3.094 & 5.245 & 59,0 & 8.456 & 12.033 & 70,3 \\
1981 & 3.115 & 5.693 & 54,7 & 9.365 & 13.212 & 70,9 \\
1982 & 3.063 & 5.933 & 51,6 & 10.629 & 12.939 & 82,1 \\
1983 & 2.888 & 6.198 & 46,6 & 10.317 & 14.627 & 70,5 \\
1984 & 3.124 & 7.819 & 40,0 & 10.105 & 17.205 & 58,7 \\
1985 & 3.638 & 7.353 & 49,5 & 11.936 & 16.375 & 72,9 \\
1986 & 3.992 & 6.830 & 58,4 & 12.580 & 16.049 & 78,4 \\
1987 & 3.553 & 8.193 & 43,4 & $11.266,3$ & 15.718 & 71,7 \\
1988 & 4.066 & 8.666 & 46,9 & $12.020,3$ & 16.505 & 72,8 \\
\hline
\end{tabular}

1 Einschließlich Einnahmen vom und Ausgaben an den öffentlichen Bereich

2 Nur Einnahmen vom und Ausgaben an den nichtöffentlichen Bereich

3 Ohne Zinseinnahmen der Gemeinden; mit Tilgungseinnahmen der Gemeinden vom öffentlichen Bereich

Quelle: Finanzberichte des Bundes 
Tabelle 11: Jăhrliche Zinsverbilligungskosten für den Forderungsbestand aus Finanzhilfe-Darlehen des Bundes

\begin{tabular}{|c|l|c|c|}
\hline Jahr & $\begin{array}{l}\text { Bestände an Finanzhilfe- } \\
\text { Darlehen am Endes des } \\
\text { Haushaltshaltsjahres } \\
\text { (in Mrd. DM) } \\
\text { (1) }\end{array}$ & $\begin{array}{l}\text { Zinsverbilligungs- } \\
\text { kosten (in Mio. DM) } \\
\text { (2) }\end{array}$ & $\begin{array}{l}\text { Zinsverbilligungs- } \\
\text { satz [(1):(2)] }\end{array}$ \\
\hline 1977 & 33,8 & 1.280 & 3,79 \\
1978 & 34,1 & 1.290 & 3,78 \\
1979 & 38,5 & 1.400 & 3,64 \\
1980 & 39,1 & 1.430 & 3,66 \\
1981 & 39,6 & 1.450 & 3,66 \\
1982 & 40,2 & 1.470 & 3,66 \\
1983 & 40,9 & 1.500 & 3,67 \\
1984 & 41,8 & 1.530 & 3,66 \\
\hline
\end{tabular}

Quellen: Subventionsberichte des Bundes; eigene Berechnungen.

Tabelle 12: Jăhrliche Zinsverbilligungskosten für den gesamten Forderungsbestand aus Darlehen des Bundes

\begin{tabular}{|l|l|l|l|l|l|}
\hline Jahr & $\begin{array}{l}\text { Durchschnitt- } \\
\text { licher Zins- } \\
\text { satz für } \\
\text { offentliche } \\
\text { Darlehen } \\
\text { in v.H. (1) }\end{array}$ & $\begin{array}{l}\text { Durchschnitt- } \\
\text { licher Zins- } \\
\text { satz für } \\
\text { Schulden } \\
\text { in v.H. (2) }\end{array}$ & $\begin{array}{l}\text { Durchschnitt- } \\
\text { licher Zins- } \\
\text { verbilligungs- } \\
\text { satz in v.H. } \\
(3)=(2)-(1)\end{array}$ & $\begin{array}{l}\text { Darlehens- } \\
\text { bestand zu } \\
\text { Beginn des } \\
\text { Haushalts- } \\
\text { jahres } \\
\text { (in Mrd. DM) } \\
(4)\end{array}$ & $\begin{array}{l}\text { Zinsver- } \\
\text { billigungs- } \\
\text { kosten in } \\
\text { Mio. DM } \\
(3) *(4)\end{array}$ \\
\hline 1974 & 1,54 & 7,42 & 5,88 & 45.808 & 2.689 \\
1975 & 1,52 & 7,51 & 5,99 & 49.005 & 2.935 \\
1976 & 1,46 & 6,42 & 5,96 & 54.200 & 2.688 \\
1977 & 1,51 & 6,81 & 5,30 & 56.890 & 3.015 \\
1978 & 1,43 & 6,46 & 5,03 & 59.534 & 2.995 \\
1979 & 1,63 & 6,39 & 4,76 & 61.666 & 2.935 \\
1980 & 1,36 & 6,93 & 5,57 & 63.589 & 3.542 \\
1981 & 1,52 & 7,82 & 6,30 & 63.965 & 4.030 \\
1982 & 1,47 & 8,22 & 6,75 & 65.515 & 4.422 \\
1983 & 1,74 & 8,63 & 6,89 & 64.819 & 4.466 \\
1984 & 1,68 & 8,12 & 6,44 & 68.893 & 4.437 \\
1985 & 2,02 & 7,98 & 5,96 & 71.257 & 4.247 \\
1986 & 1,83 & 7,71 & 5,88 & 74.315 & 4.370 \\
\hline
\end{tabular}

Quelle: Finanzberichte des Bundes; eigene Berechnungen 
Tabelle 13: Darlehensforderungen des Bundes (Stand am Ende des Haushaltsjahres) ${ }^{1}$

\begin{tabular}{|c|c|c|c|c|}
\hline Jahr & $\begin{array}{l}\text { Darlehens- } \\
\text { bestand } \\
\text { insgesamt } \\
\text { in Mio. DM }\end{array}$ & $\begin{array}{l}\text { darunter: } \\
\text { Darlehen für } \\
\text { Wohnungsbau } \\
\text { und Siedlungs- } \\
\text { wesen } \\
\text { in Mio. DM }\end{array}$ & $\begin{array}{l}\text { nachrichtlich: } \\
\text { Schulden- } \\
\text { stand } \\
\text { in Mio. DM }\end{array}$ & $\begin{array}{l}\text { Darlehens- } \\
\text { bestand zu } \\
\text { Schulden- } \\
\text { stand in v.H. }\end{array}$ \\
\hline $\begin{array}{l}1952 \\
1953 \\
1954 \\
1955 \\
1956 \\
1957 \\
1958 \\
1959 \\
1960 \\
1961 \\
1962 \\
1963 \\
1964 \\
1965 \\
1966 \\
1967 \\
1968 \\
1969 \\
1970 \\
1971 \\
1972 \\
1973 \\
1974 \\
1975 \\
1976 \\
1977 \\
1978 \\
1979 \\
1980 \\
1981 \\
1982 \\
1983 \\
1984 \\
1985 \\
1986 \\
1987 \\
1988\end{array}$ & $\begin{array}{r}3.025 \\
4.568 \\
6.158 \\
6.158 \\
10.716 \\
13.419 \\
15.855 \\
19.141 \\
21.095 \\
24.364 \\
23.067 \\
25.844 \\
28.777 \\
32.363 \\
31.945 \\
36.034 \\
36.582 \\
37.879 \\
39.657 \\
41.889 \\
43.583 \\
45.808 \\
49.005 \\
54.200 \\
56.890 \\
59.534 \\
61.666 \\
63.589 \\
63.965 \\
65.515 \\
64.819 \\
68.893 \\
71.257 \\
74.315 \\
72.843 \\
79.420 \\
78.371 \\
\end{array}$ & $\begin{array}{r}1.440 \\
2.441 \\
3.236 \\
4.012 \\
5.036 \\
6.676 \\
8.445 \\
10.590 \\
12.118 \\
13.811 \\
15.655 \\
17.222 \\
18.634 \\
19.997 \\
18.312 \\
19.278 \\
20.081 \\
20.477 \\
20.835 \\
21.350 \\
22.056 \\
22.929 \\
23.799 \\
24.629 \\
25.291 \\
25.698 \\
25.839 \\
26.311 \\
27.083 \\
27.706 \\
28.050 \\
28.929 \\
29.561 \\
29.831 \\
30.449 \\
36.191 \\
\text { k.A. }\end{array}$ & $\begin{array}{r}11.745 \\
21.595 \\
25.882 \\
25.421 \\
25.333 \\
25.660 \\
24.610 \\
25.851 \\
28.470 \\
31.188 \\
31.199 \\
34.426 \\
35.458 \\
36.842 \\
41.012 \\
48.848 \\
52.333 \\
50.615 \\
47.670 \\
48.726 \\
52.012 \\
57.780 \\
69.317 \\
98.172 \\
125.412 \\
146.424 \\
173.207 \\
198.487 \\
226.016 \\
263.717 \\
301.432 \\
332.792 \\
361.217 \\
384.267 \\
411.733 \\
439.624 \\
472.825\end{array}$ & $\begin{array}{l}25,8 \\
21,2 \\
23,8 \\
24,2 \\
42,3 \\
52,2 \\
64,4 \\
74,0 \\
74,1 \\
78,1 \\
73,9 \\
75,1 \\
81,2 \\
87,8 \\
77,9 \\
73,8 \\
70,0 \\
74,8 \\
83,2 \\
86,0 \\
83,8 \\
79,3 \\
70,7 \\
55,2 \\
45,4 \\
40,7 \\
35,6 \\
32,0 \\
28,3 \\
24,8 \\
21,5 \\
20,7 \\
19,7 \\
19,3 \\
17,7 \\
18,1 \\
16,6\end{array}$ \\
\hline
\end{tabular}

k.A. keine Angaben

1 1952-1959: 31.03. des folgenden Kalenderjahres; 1960-1987: Bestand jeweils am 31.12. eines

Kalenderjahres.

2 ab 1967 einschließlich Exportkredit-Forderungen des Bundes an die KfW

Quellen: Finanzberichte des Bundes; Haushaltsrechnung und Vermögensrechnung des Bundes (1950-1956: Haushaltsrechnung, Anlage V: Das Vermögen des Bundes; 1957-1987:

Vermögensrechnung, Vermögen des Bundes). 
Tabelle 14: Entwicklung des ERP-Sondervermögens (Bestånde am Ende des Rechnungsjahres in Mio. DM)

\begin{tabular}{|c|c|c|c|c|}
\hline Jahr & $\begin{array}{l}\text { Netto- } \\
\text { Vermögens- } \\
\text { bestand }\end{array}$ & $\begin{array}{l}\text { Verbindlich- } \\
\text { keiten }\end{array}$ & $\begin{array}{l}\text { Passiva } \\
\text { gesamt }\end{array}$ & $\begin{array}{l}\text { Verpflichtungen } \\
\text { aus } \\
\text { Gewährleistungen }\end{array}$ \\
\hline $\begin{array}{l}1954^{1} \\
1955^{1} \\
1956^{1} \\
1957^{1} \\
1958^{1} \\
19591 \\
1960^{1} \\
1960^{2} \\
1961 \\
1962 \\
1963 \\
1964 \\
1965 \\
1966 \\
1967 \\
1968 \\
1969 \\
1970 \\
1971 \\
1972 \\
1973 \\
1974 \\
1975 \\
1976 \\
1977 \\
1978 \\
1979 \\
1980 \\
1981 \\
1982 \\
1983 \\
1984 \\
1985 \\
1986 \\
1987 \\
1988\end{array}$ & $\begin{array}{r}6.111 \\
6.492 \\
6.660 \\
6.926 \\
7.165 \\
7.372 \\
7.522 \\
7.455 \\
7.678 \\
7.922 \\
8.127 \\
8.365 \\
8.610 \\
8.825 \\
9.068 \\
9.296 \\
9.538 \\
9.793 \\
10.070 \\
10.311 \\
10.598 \\
10.855 \\
11.117 \\
11.438 \\
11.798 \\
11.824 \\
12.156 \\
12.550 \\
13.031 \\
13.479 \\
13.942 \\
14.458 \\
14.961 \\
15.474 \\
16.000 \\
16.550\end{array}$ & $\begin{array}{r}- \\
- \\
- \\
- \\
- \\
75 \\
75 \\
75 \\
75 \\
575 \\
567 \\
565 \\
560 \\
706 \\
1.075 \\
1.227 \\
1.296 \\
1.364 \\
1.474 \\
1.151 \\
1.158 \\
1.304 \\
1.790 \\
1.659 \\
1.518 \\
2.313 \\
3.446 \\
4.829 \\
5.338 \\
5.796 \\
6.564 \\
6.690 \\
6.415 \\
5.931 \\
5.970\end{array}$ & $\begin{array}{r}6.111 \\
6.492 \\
6.660 \\
6.926 \\
7.165 \\
7.372 \\
7.522 \\
7.530 \\
7.752 \\
7.997 \\
8.701 \\
8.932 \\
9.174 \\
9.385 \\
9.773 \\
10.371 \\
10.765 \\
11.089 \\
11.434 \\
11.786 \\
11.748 \\
12.013 \\
12.421 \\
13.228 \\
13.458 \\
13.342 \\
14.470 \\
15.997 \\
17.860 \\
18.817 \\
19.738 \\
21.022 \\
21.651 \\
21.890 \\
21.913 \\
22.520\end{array}$ & $\begin{array}{r}- \\
- \\
- \\
- \\
- \\
- \\
- \\
- \\
- \\
- \\
569 \\
470 \\
462 \\
375 \\
382 \\
415 \\
506 \\
532 \\
544 \\
501 \\
473 \\
456 \\
433 \\
403 \\
333 \\
290 \\
277 \\
682 \\
680 \\
677 \\
613 \\
610 \\
610\end{array}$ \\
\hline
\end{tabular}

1 Das Rechnungsjahr endete jeweils am 31.3. des betreffenden Kalenderjahres.

21960 erfolgte eine Umstellung des Rechnungsjahres auf das Kalenderjahr, so daß das Rechnungsjahr 1960 lediglich neun Monate umfaßte.

Quelle: Haushalts- und Vermögensrechnung des Bundes. Übersicht zur Haushaltsrechnung, Abschnitt 4.2.2.1 
Tabelle 15: Ōfientliche Gewăhrleistungen (Haftungssumme am Ende des Haushaltsjahres in Mio. DM)

\begin{tabular}{|c|c|c|c|c|c|}
\hline Jahr & Insgesamt & Bund & $\begin{array}{l}\text { ERP-Sonder- } \\
\text { vermögen }\end{array}$ & $\begin{array}{l}\text { Lander } \\
\text { Gemeinden }\end{array}$ & $\begin{array}{l}\text { Gemd } \\
\text { Zweck- } \\
\text { verbände }\end{array}$ \\
\hline 1960 & 27.753 & 18.534 & - & 7.066 & 2.133 \\
1961 & 32.139 & 21.824 & - & 7.914 & 2.379 \\
1962 & 35.612 & 24.250 & - & 8.467 & 2.772 \\
1963 & 39.733 & 26.946 & - & 9.446 & 3.319 \\
1964 & 44.433 & 30.072 & - & 10.627 & 3.713 \\
1965 & 49.196 & 32.779 & - & 12.265 & 4.134 \\
1966 & 51.872 & 32.865 & 569 & 13.675 & 4.746 \\
1967 & 58.566 & 38.294 & 470 & 14.671 & 5.114 \\
1968 & 65.360 & 43.615 & 462 & 15.911 & 5.357 \\
1969 & 74.804 & 50.457 & 375 & 18.375 & 5.584 \\
1970 & 82.019 & 55.385 & 382 & 20.451 & 5.787 \\
1971 & 91.491 & 60.739 & 415 & 23.897 & 6.428 \\
1972 & 94.383 & 63.659 & 506 & 22.629 & 7.572 \\
1973 & 101.466 & 67.158 & 532 & 25.005 & 8.762 \\
1974 & 111.857 & 72.837 & 544 & 29.147 & 9.321 \\
1975 & 125.651 & 84.312 & 501 & 31.409 & 9.422 \\
1976 & 155.198 & 111.964 & 473 & 32.373 & 10.382 \\
1977 & 175.769 & 131.710 & 456 & 33.008 & 10.590 \\
1978 & 187.349 & 144.029 & 433 & 32.630 & 10.253 \\
1979 & 198.835 & 156.986 & 403 & 30.735 & 10.709 \\
1980 & 211.183 & 170.602 & 333 & 29.801 & 10.447 \\
1981 & 229.911 & 186.403 & 290 & 31.996 & 11.222 \\
1982 & 257.181 & 212.869 & 277 & 32.549 & 11.486 \\
1983 & 271.785 & 225.984 & 682 & 32.454 & 12.665 \\
1984 & 276.510 & 229.854 & 680 & 34.116 & 11.860 \\
1985 & 273.736 & 225.852 & 677 & 35.053 & 12.154 \\
1986 & 270.631 & 221.464 & 613 & 34.824 & 13.730 \\
1987 & 264.059 & 213.306 & 610 & 35.051 & 15.092 \\
1988 & 255.540 & 206.144 & 610 & 35.080 & 13.707 \\
\hline
\end{tabular}

Quelle: Finanzberichte des Bundes 
Tabelle 16: Gewăhrleistungen des Bundes

\begin{tabular}{|c|c|c|c|c|c|c|c|}
\hline Jahr & $\begin{array}{l}\text { Haftungs- } \\
\text { volumen } \\
\text { am Ende des } \\
\text { Haushalts- } \\
\text { jahres } \\
\text { in Mrd. DM } \\
\text { (1) }\end{array}$ & $\begin{array}{l}\text { nachricht- } \\
\text { lich: } \\
\text { Gesamt- } \\
\text { ausgaben } \\
\text { in Mrd. } \\
\text { DM } \\
\quad \text { (2) }\end{array}$ & $\begin{array}{l}\text { Relation } \\
\text { (1) : (2) } \\
\text { in } \mathbf{v} . \mathrm{H} .\end{array}$ & $\begin{array}{l}\text { Ausgaben } \\
\text { aufgrund von } \\
\text { Gewăhr- } \\
\text { leistungen } \\
\text { in Mio. DM }\end{array}$ & $\begin{array}{l}\text { Einnahmen } \\
\text { aufgrund von } \\
\text { Gewahr- } \\
\text { leistungen } \\
\text { in Mio. DM }\end{array}$ & $\begin{array}{l}\text { Ausgaben- } \\
\text { überschuB } \\
\text { in Mio. DM } \\
\text { (3) }\end{array}$ & $\begin{array}{l}\text { Relation } \\
\text { (3) : (1) } \\
\text { in v.T. }\end{array}$ \\
\hline 1960 & 18.5 & 31,1 & 59,9 & k.A. & k.A. & 81 & 4,4 \\
\hline 1961 & 21,8 & 46,2 & 47,2 & k.A. & k.A. & -70 & $-3,2$ \\
\hline 1962 & 24,3 & 50,9 & 47,7 & k.A. & k.A. & -47 & $-1,9$ \\
\hline 1963 & 26,9 & 55,2 & 48,7 & k.A. & k.A. & -9 & $-0,3$ \\
\hline 1964 & 30,1 & 58,9 & 51,1 & k.A. & k.A. & -34 & $-1,1$ \\
\hline 1965 & 32,8 & 65,5 & 50,1 & k.A. & $\mathbf{k} \mathbf{A}$. & -183 & $-5,6$ \\
\hline 1966 & 32,9 & 68,5 & 48,0 & k.A. & k.A. & -54 & $-1,6$ \\
\hline 1967 & 38,3 & 76,5 & 50,1 & k.A. & k.A. & -52 & $-1,4$ \\
\hline 1968 & 43,6 & 76,1 & 57,3 & k.A. & k.A. & -166 & $-3,8$ \\
\hline 1969 & 50,5 & 81,9 & 61,7 & k.A. & k.A. & .72 & $-1,4$ \\
\hline 1970 & 55,4 & 88,2 & 62,8 & k.A. & k.A. & -100 & $-1,8$ \\
\hline 1971 & 60,7 & 98,4 & 61,7 & k.A. & k.A. & 64 & 1,1 \\
\hline 1972 & 63,7 & 112,6 & 56,6 & k.A. & k.A. & 58 & 0,9 \\
\hline 1973 & 67,2 & 122,1 & 55,0 & k.A. & k.A. & 47 & 0,7 \\
\hline 1974 & 72,8 & 134,9 & 54,0 & k.A. & k.A. & -208 & $-2,9$ \\
\hline 1975 & 84,3 & 160,1 & 52,7 & k.A. & k.A. & -406 & $-4,8$ \\
\hline 1976 & 112,6 & 166,7 & 67,5 & k.A. & k.A. & -480 & $-4,3$ \\
\hline 1977 & 131,7 & 174,2 & 75,6 & k.A. & k.A. & -592 & $-4,5$ \\
\hline 1978 & 144,0 & 191,2 & 75,3 & 711 & 675 & 36 & 0,3 \\
\hline 1979 & 157,0 & 205,1 & 76,5 & 606 & 801 & -195 & $-1,2$ \\
\hline 1980 & 170,6 & 217,6 & 78,4 & 945 & 863 & 82 & 0,5 \\
\hline 1981 & 186,4 & 234,9 & 79,4 & 931 & 981 & -50 & $-0,3$ \\
\hline 1982 & 212,9 & 246,6 & 86,3 & 1.310 & 1.327 & -17 & $-0,1$ \\
\hline 1983 & 226,0 & 248,7 & 90,9 & 1.900 & 1.160 & 740 & 3,3 \\
\hline 1984 & 229,9 & 253,9 & 90,3 & 2.737 & 1.160 & 1.577 & 6,9 \\
\hline 1985 & 225,9 & 259,4 & 87,1 & 2.706 & 1.645 & 1.061 & 4,7 \\
\hline 1986 & 221,5 & 263,2 & 84,2 & 2.431 & 1.459 & 972 & 4,4 \\
\hline 1987 & 213,3 & 270,9 & 78,7 & 2.800 & 1.220 & 1.580 & 7,4 \\
\hline 1988 & 206,1 & 277,8 & 74,2 & 2.897 & 1.311 & 1.586 & 7,7 \\
\hline
\end{tabular}

k.A. keine Angaben

* Negative Vorzeichen kennzeichnen Einnahmenüberschüsse

Quellen: Bundeshaushaltsrechnungen; Statistisches Bundesamt, Lange Reihen zur Wirtschaftsentwicklung; dass., Statistisches Jahrbuch 1989, S.428; eigene Berechnungen. 
Tabelle 17: Geldforderungen des Bundes aus Gewăhrleistungen (Stand am Jahresende in Mio. DM)

\begin{tabular}{|c|c|c|c|}
\hline Jahr & Umschuldungen & $\begin{array}{l}\text { Forderungen aus Bürgschaften } \\
\text { und Garantien im Ausfuhrgeschäft }\end{array}$ & Summe \\
\hline 1974 & 1.085 & 122 & 1.207 \\
1975 & 1.032 & 120 & 1.152 \\
1976 & 1.362 & 146 & 1.508 \\
1977 & 1.076 & 273 & 1.349 \\
1978 & 968 & 478 & 1.446 \\
1979 & 1.080 & 631 & 1.711 \\
1980 & 946 & 1.055 & 2.001 \\
1981 & 1.441 & 1.152 & 2.593 \\
1982 & 1.538 & 1.152 & 2.690 \\
1983 & 1.655 & 1.482 & 3.137 \\
1984 & 1.778 & 194 & 1.972 \\
1985 & 2.361 & 4.215 & 6.576 \\
1986 & 6.037 & 3.309 & 9.346 \\
1987 & 6.886 & 3.122 & 10.008 \\
1988 & 8.219 & 4.218 & 12.437 \\
\hline
\end{tabular}

Quelle: Finanzberichte des Bundes

Tabelle 18: Gewăhrleistungen der öffentlichen Haushalte nach Förderzwecken (Haftungsvolumen am Ende des Haushaltsjahres in Mio DM)

\begin{tabular}{|c|c|c|c|c|c|}
\hline \multirow[t]{2}{*}{ Jahr } & \multirow[t]{2}{*}{ Insgesamt } & \multicolumn{4}{|c|}{ davon: } \\
\hline & & $\begin{array}{l}\text { Außenwirt- } \\
\text { schaftliche } \\
\text { Gewähr- } \\
\text { leistungen } 1,2\end{array}$ & $\begin{array}{l}\text { Wohnungs- } \\
\text { bau }\end{array}$ & $\begin{array}{l}\text { Allgemeine } \\
\text { Wirtschafts- } \\
\text { förderung }\end{array}$ & $\begin{array}{l}\text { Wirtschafts- } \\
\text { unternehmen }\end{array}$ \\
\hline 1974 & 111.857 & 38.908 & 19.575 & 67.973 & 4.403 \\
\hline 1975 & 125.651 & 47.521 & 21.185 & 78.029 & 4.617 \\
\hline 1976 & 155.198 & 61.494 & 22.503 & 99.601 & 5.229 \\
\hline 1977 & 175.769 & 79.901 & 24.053 & 124.525 & 5.567 \\
\hline 1978 & 187.349 & 87.551 & 24.340 & 136.376 & 5.528 \\
\hline 1979 & 198.835 & 99.172 & 23.488 & 145.524 & 5.650 \\
\hline 1980 & 211.183 & 120.863 & 22.363 & 23.810 & 5.641 \\
\hline 1981 & 229.911 & 137.548 & 23.703 & 24.605 & 6.492 \\
\hline 1982 & 257.181 & 158.806 & 27.458 & 27.028 & k.A. \\
\hline 1983 & 271.785 & 170.819 & 24.680 & 26.769 & 7.045 \\
\hline 1984 & 276.510 & 169.943 & 25.510 & 27.291 & 7.140 \\
\hline 1985 & 273.736 & 169.110 & 26.245 & 27.516 & 7.382 \\
\hline 1986 & 270.521 & 164.329 & 26.972 & 26.754 & 7.746 \\
\hline 1987 & 264.059 & 153.498 & 27.450 & 26.659 & 8.779 \\
\hline 1988 & 255.540 & 148.955 & 26.779 & 27.259 & 7.799 \\
\hline
\end{tabular}

1 Stand am 30.06. des Haushaltsjahres

2 nur Bund

Quellen: Finanzberichte des Bundes 
Tabelle 19: Zusagen für aus eigenen Ertrăgen verbilligte Darlehen der KfW, DAB und LfA

\begin{tabular}{|c|c|c|c|c|c|c|}
\hline Jahr & in Mio.DM & $\begin{array}{l}N \\
\text { en } 1 \\
\text { in v.H. der } \\
\text { gesamten } \\
\text { Kredit- } \\
\text { zusagen }\end{array}$ & in Mio.DM & $\begin{array}{l}\text { B } \\
\text { en }^{3} \\
\text { in v.H. der } \\
\text { gesamten } \\
\text { Kredit- } \\
\text { zusagen }\end{array}$ & in Mio.DM & $\begin{array}{l}\text { A } \\
\text { gen } 5 \\
\text { in v.H. der } \\
\text { gesamten } \\
\text { Kredit- } \\
\text { zusagen }\end{array}$ \\
\hline $\begin{array}{l}1976 \\
1977 \\
1978 \\
1979 \\
1980 \\
1981 \\
1982 \\
1983 \\
1984 \\
1985 \\
1986 \\
1987 \\
1988\end{array}$ & $\begin{array}{l}1613,0 \\
2132,9 \\
4204,1 \\
4148,1 \\
2412,2 \\
4501,5 \\
2847,6 \\
3529,5 \\
3295,8 \\
6632,5 \\
7384,9 \\
4894,2 \\
7064,1\end{array}$ & $\begin{array}{c}6 \\
6 \\
6 \\
6 \\
23,7 \\
37,7 \\
24,6 \\
30,5 \\
25,0 \\
49,5 \\
52,8 \\
39,0 \\
36,0\end{array}$ & $\begin{array}{c}28,6 \\
125,3^{4} \\
82,2 \\
59,1 \\
26,0 \\
15,5 \\
19,5 \\
69,7 \\
181,6 \\
361,5 \\
296,8 \\
323,2 \\
362,6\end{array}$ & $\begin{array}{r}8,1 \\
22,3 \\
9,8 \\
5,3 \\
2,1 \\
1,2 \\
1,4 \\
3,0 \\
8,6 \\
16,2 \\
11,0 \\
11,3 \\
11,7\end{array}$ & $\begin{array}{r}73,0 \\
112,0 \\
90,0 \\
113,0 \\
128,0 \\
117,0 \\
160,0 \\
171,6 \\
276,1 \\
493,2 \\
781,4 \\
735,5 \\
914,3\end{array}$ & $\begin{array}{r}8,7 \\
13,1 \\
7,3 \\
6,5 \\
7,8 \\
8,2 \\
10,8 \\
12,3 \\
20,0 \\
26,1 \\
30,1 \\
30,7 \\
33,4\end{array}$ \\
\hline
\end{tabular}

1 Nur KfW-Programme zur Förderung inländischer Investitionen (ohne Sonderkredite für volkswirtschaftlich bedeutende Investitionsvorhaben).

2 Ohne KfW-Gemeindeprogramm (aus Mitteln des Bundes zinsverbilligt).

3 1976: Ergänzungsdarlehen; 1977-1983: Ergänzungsprogramme I und II; seit 1984: Ergänzungsprogramme I, II und III.

4 Einschließlich der zur Aufstockung der ERP-Mittel im Existenzgründungs- und Standort5 programm verwendeten Beträge.

5 "Aus Mitteln des LfA-Gewinns" verbilligte Darlehen sowie seit 1982 auch Ergänzungsdarlehen.

6 Keine Daten verfügbar.

Quellen: Geschäftsberichte der KfW, DAB (früher LAB) und der LfA; KIRCHHOFF (1987), S.188, Tabelle 16; eigene Berechnungen. 
Tabelle 20: Zuführungen der LKB zu Rückstellungen für Zinsverbilligungszuschüsse

\begin{tabular}{|l|r|c|}
\hline Jahr & \multicolumn{2}{|c|}{ Zuführungen } \\
& in Mio. DM & $\begin{array}{l}\text { in v.H. des } \\
\text { Jahresüberschusses }\end{array}$ \\
\hline 1976 & 101 & 28,0 \\
1977 & 136 & 22,0 \\
1978 & 96 & 62,3 \\
1979 & 43 & 81,1 \\
1980 & 216 & 141,2 \\
1981 & 239 & 121,9 \\
1982 & 238 & 120,8 \\
1983 & 158 & 156,4 \\
1984 & 114 & 156,2 \\
1985 & 187 & 111,3 \\
1986 & 115 & 111,7 \\
1987 & 113 & 151,1 \\
1988 & 190 & 122,6 \\
\hline
\end{tabular}

Quelle: Geschäftsberichte der LKB; eigene Berechnungen.
Tabelle 21: Gewăhrleistungsübernahme der Sonderkreditinstitute mit eigenem Haftungsrisiko (in Mio. DM)

\begin{tabular}{|l|r|l|l|l|}
\hline Jahr & KfW & DAB $^{1}$ & LKB & LfA \\
\hline 1982 & 100 & 89 & 29 & 31 \\
1983 & 2.833 & 74 & 73 & $38^{3}, 3$ \\
1984 & 2.280 & 69 & 85 & $41^{3}$ \\
1985 & 864 & 50 & 57 & 55 \\
1986 & 100 & 48 & 47 & 59 \\
1987 & 124 & 38 & 54 & 61 \\
1988 & 529 & $75^{, 2}$ & 56 & 70 \\
\hline
\end{tabular}

${ }^{1}$ Bürgschaften teilweise durch ERPSondervermögen rückverbürgt.

2 Einschließlich der vom Wiedereingliederungsfonds des Europarates rückverbürgten Bürgschaftsübernahmen.

3 Ohne Garantien für mittelständische Beteiligungen.

Quelle: Geschäftsberichte der genannten Institute.

Tabelle 22: Darlehen der Bundesanstalt für Arbeit für arbeitsmarktpolitische Maßnahmen

\begin{tabular}{|c|c|c|c|c|c|c|c|}
\hline \multirow[t]{3}{*}{ Jahr } & \multirow{3}{*}{$\begin{array}{l}\text { Insgesamt } \\
\text { in Mio. DM } \\
\text { (1) }\end{array}$} & \multicolumn{6}{|c|}{ davon mit Zinssatz } \\
\hline & & & & & & & \\
\hline & & abs. & in v.H. & abs. & in v.H. & abs. & in v.H. \\
\hline 1980 & 187 & 65 & 34,8 & 42 & 22,5 & 80 & 42,8 \\
\hline 1981 & 128 & 51 & 39,8 & 24 & 18,4 & 54 & 42,2 \\
\hline 1982 & 239 & 152 & 63,6 & 31 & 13,0 & 56 & 23,4 \\
\hline 1983 & 343 & 260 & 75,8 & 21 & 6,1 & 61 & 17,8 \\
\hline 1984 & 362 & 282 & 77,9 & 25 & 6,9 & 55 & 15,2 \\
\hline 1985 & 339 & 289 & 85,3 & 16 & 4,7 & 34 & 10,0 \\
\hline 1986 & 384 & 340 & 88,6 & 22 & 5,7 & 23 & 6,0 \\
\hline 1987 & 440 & 396 & 90,0 & 26 & 5,9 & 18 & 4,1 \\
\hline 1988 & 478 & 432 & 90,4 & 29 & 6,1 & 17 & 3,6 \\
\hline 1989 & 472 & 430 & 91,1 & 27 & 5,7 & 15 & 3,2 \\
\hline
\end{tabular}

Quelle: Schriftliche Auskunft der Bundesanstalt für Arbeit vom 9.4.1990 
Tabelle 23: Entwicklung der Glăubigerstruktur der KfW von 1978 - 1988

\begin{tabular}{|c|c|c|c|c|}
\hline Jahr & $\begin{array}{l}\text { Verbindlichkeiten } \\
\text { insgesamt* } \\
\text { in Mio DM }\end{array}$ & $\begin{array}{l}\text { Anteile der } \\
\text { ERP-Sonder- } \\
\text { vermögen }\end{array}$ & $\begin{array}{l}\text { verschiedenen Gläu } \\
\text { Verbindlichkeiten } \\
\text { Bund } \\
\text { (Haushaltsmittel) }\end{array}$ & $\begin{array}{l}\text { pen) an den } \\
\text { Kreditinstitute } \\
\text { und Sonstige }\end{array}$ \\
\hline 1978 & 20.298 & 34 & 20 & 46 \\
\hline 1979 & 27.608 & 26 & 27 & 47 \\
\hline 1980 & 35.686 & 22 & 33 & 45 \\
\hline 1981 & 44.210 & 21 & 36 & 43 \\
\hline 1982 & 52.172 & 18 & 40 & 42 \\
\hline 1983 & 56.273 & 18 & 41 & 41 \\
\hline 1984 & 60.067 & 18 & 42 & 40 \\
\hline 1985 & 64.497 & 17 & 41 & 42 \\
\hline 1986 & 67.679 & 17 & 42 & 41 \\
\hline 1987 & 69.620 & 16 & 43 & 42 \\
\hline 1988 & 75.403 & 15 & 41 & 44 \\
\hline
\end{tabular}

"Ohne Treuhandverbindlichkeiten.

Quellen: $\quad$ BUNDESREGIERUNG (1988), S.17 (Tabelle 3); KREDITANSTALT FÜR WIEDERAUFBAU (1988), S.63

Tabelle 24: Jahresüberschüsse von $\mathrm{KFW}$, DAB, LKB und LAA (in Mio.DM)

\begin{tabular}{|r|r|r|r|r|}
\hline Jahr & KfW $^{1}$ & DAB & LKB & LfA \\
\hline 1976 & 71 & 4 & 28 & 26 \\
1977 & 79 & 5 & 22 & 41 \\
1978 & 82 & 5 & 62 & 45 \\
1979 & 70 & 5 & 81 & 55 \\
1980 & 12 & 5 & 141 & 58 \\
1981 & 22 & 5 & 122 & 58 \\
1982 & 122 & 6 & 121 & 60 \\
1983 & 66 & 7 & 156 & 66 \\
1984 & 109 & 10 & 156 & 66 \\
1985 & 149 & 10 & 112 & 66 \\
1986 & 163 & 10 & 111 & 72 \\
1987 & 132 & 10 & 151 & 72 \\
1988 & 134 & 100,1 & 123 & 72 \\
\hline
\end{tabular}

${ }^{1}$ Die Steigerung gegenüber dem Vorjahr ist mitverursacht durch die Auflösung von Sammelwertberichtungen.

Quelle: Geschäftsberichte dieser Institute 


\section{LITERATURVERZEICHNIS}

AARON, H.Y. (1972a)

Federal Housing Subsidies, in: Shoup, C.S., Jasinowski, J. (Hrsg.), The Economics of Federal Subsidies Programs: A Staff Study, Joint Economic Committee, Washington, D.C., S. 571 - 596

AARON, H.Y. (1972b)

Shelter and Subsidies: Who Benefits from Federal Housing Policies?, Washington, D.C.

AHLBRANDT, R. (1973)

Efficiency in the Provision of Fire Services, in: Public Choice 16, S. 1 - 15

AKERLOF, G.A. (1970)

The Market for "Lemons": Quality Uncertainty and the Market Mechanism, in: Quarterly Journal of Economics 84, S. 488 - 500

ALBRECHT, D./THORMÄHLEN, T. (1985)

Subventionen - Politik und Problematik, Frankfurt a.M. u.a.O.

ALCHIAN, A.A./DEMSETZ, H. (1972)

Production, Information Costs, and Economic Organization, in: American Economic Review 62, S. 777 - 795

ALEWELL, K. (1965)

Subvention als betriebswirtschaftliche Frage, Eine betriebswirtschaftliche Untersuchung ihres Wesens, ihrer Erfassung im betrieblichen Rechnungswesen und ihrer Wirkungen auf die empfangenden Betriebe, Köln

ALTENMÜLLER, R (1981)

Die Wirtschaftsförderung kommunaler Gebietskörperschaften, in: Verwaltungsblätter für Baden-Württemberg 2, S. 201 - 232

ANDEL, N. (1970)

Subventionen als Instrument des finanzwirtschaftlichen Interventionismus, Tübingen

ANDEL, N. (1990)

Finanzwissenschaft, 2. Aufl., Tübingen

V.ARNIM, H.H. (1986)

Subventionen, Von der Schwierigkeit der Subventionskontrolle, in: Finanzarchiv, N.F. 44, S. 81 - 97

ARROW, KJ. (1951)

Social Choice and Individual Values, New York

ARROW, K.J. (1965)

Aspects of the Theory of Risk-Bearing, Helsinki

ARROW, K.J. (1968)

The Economics of Moral Hazard: Further Comment, in: American Economic Review 58, S. 537 - 539 
ARTMANN, H. (1981)

Der Staat als Bürge - Uberlegungen zur Wirtschaftsförderung durch Risikoübernahme, in: Der Langfristige Rredit 32, S. 400 - 402

ASMACHER, C./SCHALK, H.-J./THOSS, R. (1987)

Analyse der Wirkungen regionalpolitischer Instrumente, Münster

ATKINSON, A.B./STIGLITZ, J.E. (1980)

Lectures on Public Economics, London u.a.O.

AUERBACH, A.J. (1979)

Wealth Maximization and the Cost of Capital, in: Quarterly Journal of Economics 93, S. 433 - 446

BADEN-WÜRTTEMBERG (1990)

Staatshaushaltsplan Baden-Württemberg für 1989 und 1990, Stuttgart

BÄKOW, H.J. (1984)

Kreditinstitute mit Sonderaufgaben (III): Kreditanstalt für Wiederaufbau, in: Die Bank 24, S. 413 - 416

\section{BALTENSBERGER, E./DEVINNEY, T.M. (1985)}

Credit Rationing Theory: A Survey and Synthesis, in: Journal of Institutional and Theoretical Economics (Zeitschrift für die gesamte Staatswissenschaft) 141, S. 475 - 502

BALTENSBERGER, E./MILDE, H. (1987)

Theorie des Bankverhaltens, Berlin u.a.O.

BARON, D.P. (1983)

The Export-Import Bank: an Economic Analysis, New York u.a.O.

BARTLETT, R. (1973)

Economic Foundations of Political Power, New York, London

BATRA, R.N./ULLAH, A. (1974)

Competitive firm and the theory of input demand under price uncertainty, in: Journal of Political Economy 82, S. 537 - 548

BAUM, Th.M. (1982)

Staatsverschuldung und Stabilisierungspolitik in der Demokratie, Frankfurt a.M., Bern

BAUMOL, W.J./OATES, W.E. (1988)

The theory of environmental policy, 2. Aufl., Cambridge u.a.O.

BAUMOL, W.J./PANZAR, J.C./WILLIG, R.D. (1982)

Contestable Markets and the Theory of Industry Structure, New York u.a.O.

BAYERISCHE LANDESANSTALT FÜR AUFBAUFINANZIERUNG (1976) Bericht über das Geschäftsjahr 1976, München

BAYERISCHE LANDESANSTALT FÜR AUFBAUFINANZIERUNG (1981)

Bericht über das Geschäftsjahr 1981, Müchen 
BAYERISCHE LANDESANSTALT FÜR AUFBAUFINANZIERUNG (1985)

Bericht über das Geschäftsjahr 1985, München

BAYERISCHE LANDESANSTALT FÜR AUFBAUFINANZIERUNG (1987)

Bericht über das Geschäftsjahr 1987, München

BAYERISCHE LANDESANSTALT FÜR AUFBAUFINANZIERUNG (1988)

Bericht über das Geschäftsjahr 1988, München

BECKER, G.S. (1964)

Human Capital. A Theoretic and Empirical Analysis with Special Reference to Education, New York

BECKER, G.S. (1982)

Der ökonomische Ansatz zur Erklärung menschlichen Verhaltens, Tübingen

BECKER, G.S. (1983)

A Theory of Competition among Pressure Groups for Political Influence, in: Quarterly Journal of Economics 48, S. 371 - 400

BECKER, G.S. (1985)

Public Policies, Pressure Groups, and Dead Weight Costs, in: Journal of Public Economics 28, S. 329 - 347

BECKER, H. (1980)

Die Kreditgarantiegemeinschaften des Handels, in: Kamp, M.E. (Hrsg.), Mittelstandspolitische Akzente 1981, Beiträge zur Mittelstandsforschung 66, Göttingen, S. 23 - 36

BECKER, W.-D. (1980)

Öffentliche Banken als Instrumente der staatlichen Ordnungspolitik, in: Zeitschrift für öffentliche und gemeinwirtschaftliche Unternehmen 3, S. 257 - 270

BECKER, W.-D./ZWEIG, G. (1983)

Aufgabenwandel bei öffentlichen Kreditinstituten, in: Eichhorn, P., Münch, P. (Hrsg.), Aufgaben öffentlicher und gemeinwirtschaftlicher Unternehmen im Wandel, BadenBaden, S. 197 - 205

BENNETT, J.T./DiLORENZO, T.J. (1982)

Off-budget activities of local government: The bane of the tax revolt, in: Public Choice 39, S. 333 - 342

BENNETT, J.T./DILORENZO, T.J. (1983a)

The Ricardian Equivalence Theorem: Evidence from the Off-Budget Public Sector, in: Public Finance/Finances Publiques 38, S. 309 - 316

BENNETT, J.T./DILORENZO, T.J. (1983b)

Underground Government: The Off-Budget Public Sector, Washington, D.C.

BENNETT, J.T./DILORENZO, T.J. (1984)

Political Entrepreneurship and Reform of the Rent-Seeking Society, in: Colander, D.C. (Hrsg.), Neoclassical Political Economy, The Analysis of Rent-Seeking and DUP Activities, Cambridge, Mass., S. 217 - 227 
BENNETT, J.T./DILORENZO, T.J. (1986)

Credit Allocation and Capital Formation: The Political Economy of Indirect Taxation, in: Lee, D.R. (Hrsg.), Taxation and the Deficit Economy, San Francisco, S. 275 - 296

BERNHOLZ, P. (1973)

Logrolling, Arrow Paradox and Cyclical Majorities, in: Public Choice 15, S. 87 - 95

BESTER, H. (1987)

Die Anreizfunktion von Kreditsicherheiten, in: Schneider, D. (Hrsg.), Kapitalmarkt und Finanzierung, Schriften des Vereins für Socialpolitik, N.F. 165, Berlin, S. 225 - 236

BESTER, H./HELLWIG, M. (1989)

Moral Hazard and Equilibrium Credit Rationing: An Overview of the Issues, in: Bamberg, G., Spremann, K. (Hrsg.), Agency Theory, Information, and Incentives, Berlin u.a.O., S. 135 - 166

BITZ, M. (1981)

Entscheidungstheorie, München

BLACK, D. (1948)

On the Rationale of Group Decision Making, in: Journal of Political Economy 56, S. 23 $-34$

BLANKART, Ch.B. (1983)

Öffentliche Unternehmen aus der Sicht der Gemeinwirtschaftslehre und der Neuen Politischen Ökonomie, in: Zeitschrift für öffentliche und gemeinwirtschaftliche Unternehmen 6, S. 18 - 29

BLECKMANN, A. (1984)

Ordnungsrahmen für das Recht der Subventionen, Gutachten D, in: Verhandlungen des 55. Deutschen Juristentages, München, S. D1 - D115

BOADWAY, R.W. (1979)

Public Sector Economics, Cambridge

BOADWAY, R.W./BRUCE, N. (1984)

Welfare Economics, Oxford

BOADWAY, R.W./WILDASIN, D.E. (1984)

Public Sector Economics, 2. Aufl., Boston, Toronto

BOSKIN, M.J./BARHAM, B./CONE, K./OZLER, S. (1987)

The Federal Budget and Federal Insurance Programs, in: Boskin, M.J. (Hrsg.), Modern Developments in Public Finance: Essays in Honor of Arnold Harberger, Oxford, New York, S. 14 - 39

BOSWORTH, B.P./CARRON, A.S./RHYNE, E.H. (1987)

The Economics of Federal Credit Programs, Washington, D.C.

BREAK, G.F. (1961)

The Economic Impact of Federal Loan Insurance, Washington, D.C.

BREAK, G.F. (1965)

Federal Lending and Economic Stability, Washington, D.C. 
BRECKNER, F. (1956)

ERP-Finanzierung, in: Seischab, H, Schwantag, K. (Hrsg.), Handwörterbuch der Betriebswirtschaft 1, 3. Aufl., Stuttgart, Sp. $1674-1686$

BRENNAN, G./BUCHANAN, J.M. (1980/1988)

The Power to Tax. Analytical Foundations of a Fiscal Constitution, New York, deutsch: Besteuerung und Staatsgewalt. Analytische Grundlagen einer Finanzverfassung, herausgegeben und übersetzt von C. Folkers; Hamburg

BRENNAN, G./BUCHANAN, J.M. (1981a)

The Normative Purpose of Economic "Science": Rediscovery of an Eighteenth Century Method, in: International Review of Law and Economics 1, S. 155 - 166

BRENNAN, G./BUCHANAN, J.M. (1981b)

Der verteilende Staat: Ansätze zu einer Theorie der Umverteilung, in: Zeitschrift für Wirtschaftspolitik 30, S. 103 - 128

BRENNAN, G./BUCHANAN, J.M. (1983)

Predictive Power and the Choice among Regimes, in: Economic Journal 93, S. 89 - 105

BRENNAN, G./BUCHANAN, J.M. (1985)

The reason of rules, Constitutional political economy, Cambridge u.a.O.

BRENNAN, G./McGUIRE, TH. (1975)

Optimal Policy Choice under Uncertainty, in: Journal of Public Economics 4, S. 205 - 209

BROWN, C.V./JACKSON, P.M. (1986)

Public Sector Economics, 3. Aufl., Oxford, New York

BROWNING, E.K. (1976)

The Marginal Cost of Public Funds, in: Journal of Political Economy 84, S. 283 - 298

BROWNING, E.K./BROWNING J.M.(1989)

Microeconomic Theory and Applications, 3. Aufl., Glenview u.a.O.

BUCHANAN, J.M. (1958)

Public Principles of Public Debt, Homewood, Ill.

BUCHANAN, J.M. (1962)

The relevance of Pareto optimality, in: Journal of Conflict Resolution, S. 341 - 354

BUCHANAN, J.M. (1963)

The Economics of Earmarked Taxes, in: Journal of Political Economy 71, S. 457 - 469

BUCHANAN, J.M. (1964a)

Concerning Future Generations, in: Ferguson, J.M. (Hrsg.), Public Debt and Future Generations, Chapel Hill, S. 55 - 63

BUCHANAN, J.M. (1964b)

Public Debt, Cost Theory, and the Fiscal Illusion, in: Ferguson, J.M. (Hrsg.), Public Debt and Future Generations, Chapel Hill, S. $150-163$ 
BUCHANAN, J.M. (1967)

Public Finance in Democratic Process, Chapel Hill

BUCHANAN, J.M. (1975/1984)

The Limits of Liberty, Between Anarchy and Leviathan, Chicago, London, deutsch: Die Grenzen der Freiheit, Tübingen

BUCHANAN, J.M. (1977a)

Freedom in Constitutional Contract, College Station

BUCHANAN, J.M. (1977b)

Why does Government Grow?, in: Borcherding, T.E. (Hrsg.), Budgets and Bureaucrats, The Source of Government Growth, Durham, N.C., S. $3-18$

BUCHANAN, J.M. (1980)

Procedural and Quantitative Constitutional Constraints on Fiscal Authority, in: Moore, W.S.; Penner, R.G. (Hrsg.), The Constitution and the Budget, Washington D.C., S. 80 - 84

BUCHANAN, J.M. (1987)

constitutional economics, in: Eatwell, J., Milgate, M., Newman, P. (Hrsg.), The New Palgrave, A Dictionary of Economics 1, London, Basingstoke, S. 585 - 588

BUCHANAN, J.M. (1988)

Preface to the German Translation, in: Brennan, G., Buchanan, J.M., Besteuerung und Staatsgewalt. Analytische Grundlagen einer Finanzverfassung, herausgegeben und übersetzt von C. Folkers, Hamburg, S. XVII - XVIII

BUCHANAN, J.M. (1990)

The Domain of Constitutional Economics, in: Constitutional Political Economy 1, S. 1 - 18

BUCHANAN, J.M./BRENNAN, G. (1980)

Tax Reforms without Tears, in: Aaron, H.J., Boskin, M.J. (Hrsg.), The Economics of Taxation, Washington, D.C., S. 33 - 53

BUCHANAN, J.M./FAITH, R.L. (1981)

Entrepreneurship and the Internalization of Externalities, in: Journal of Law and Economics 24, S. 95 - 111

BUCHANAN, J.M./FLOWERS, M.R. (1987)

The Public Finances, 6. Aufl., Homewood, Ill.

BUCHANAN, J.M./MOES, J.E. (1960)

A Regional Countermeasure to National Wage Standardization, in: American Economic Review 50, S. 434 - 438

BUCHANAN, J.M./ROBACK, J. (1987)

The Incidence and Effects of Public Debt in the Absence of Fiscal Illusion, in: Public Finance Quarterly 15, S. 5 - 25

BUCHANAN, J.M./TOLLISON, R.D./TULLOCK, G. (1980)

Toward a Theory of the Rent-Seeking Society, College Station

BUCHANAN, J.M./TULLOCK, G. (1962)

The Calculus of Consent, Ann Arbor 
BUCHANAN, J.M./WAGNER, R.E. (1977)

Democracy in Deficit, New York

BUND/LÄNDER-ARBEITSAUSSCHUSS (1982)

Bericht des Bund/Länder-Arbeitsausschusses "Haushaltsrecht und Haushaltssystematik" zur Abgrenzung des Begriffs der öffentlichen Investitionen im gemeinsamen Gruppierungsplan vom 15.6.1982, abgedruckt in: Bundesministerium der Finanzen (Hrsg.), Finanzbericht 1983, S. 130 - 132

BUNDESANSTALT FÜR ARBEIT (1988)

Geschäftsbericht 1988, Nürnberg

BUNDESGERICHTSHOF (1959)

Urteil vom 30.04.1959, in: Die öffentliche Verwaltung 12, S. 710

BUNDESHAUSHALTSPLAN (1988)

Bundesministerium der Finanzen (Hrsg.), Bundeshaushaltsjahr 1988, Bonn

BUNDESHAUSHALTSRECHNUNG (1984)

Bundesministerium der Finanzen (Hrsg.), Haushaltsrechnung und Vermögensrechnung des Bundes, Haushaltsjahr 1983, Bonn

BUNDESMINISTER DER FINANZEN (1989)

Beteiligungen des Bundes im Jahre 1988, Bonn

BUNDESMINISTER FÜR WIRTSCHAFT (1989)

Ausfuhrgarantien und Ausfuhrbürgschaften der Bundesrepublik Deutschland, Bericht über das Jahr 1988, BMWi-Dokumentation Nr. 298, Bonn

BUNDESMINISTERIUM FÜR WIRTSCHAFT (1988)

Die ERP-Programme 1988/89, Bonn

BUNDESMINISTERIUM FÜR WIRTSCHAFTLICHE ZUSAMMENARBEIT (1980)

Vierter Bericht zur Entwicklungspolitik der Bundesregierung, Bundestagsdrucksache $8 / 3582$, Bonn

\section{BUNDESREGIERUNG (1988)}

Antwort der Bundesregierung auf die kleine Anfrage der Abgeordneten Dr. Apel u.a. Bundestagsdrucksache 11/2367 -, Verlagerung von Aufgaben und Ausgaben aus dem Bundeshaushalt, Bundestagsdrucksache 11/2710, Bonn

BUNDESREGIERUNG (1990)

Gesetzentwurf der Bundesregierung - Entwurf eines Ersten Gesetzes zur Änderung des Haushaltsgrundsätzegesetzes, Bonn (Sonderdruck)

BUNDESVERFASSUNGSGERICHT (1956)

Urteil vom 25.1.1955, in: Entscheidungen des Bundesverfassungsgerichts, Band 4, S. 144 $-156$

BUNDESVERFASSUNGSGERICHT (1964)

Beschluß vom 7.5.1963, in: Entscheidungen des Bundesverfassungsgerichts, Band 16, S. 95 $-118$ 
BUNDESVERFASSUNGSGERICHT (1972)

Beschluß vom 18.7.1972, in: Entscheidungen des Bundesverfassungsgerichts, Band 33, S. 303 - 355

BUNDESVERFASSUNGSGERICHT (1975)

Beschluß vom 18.12.1974, in: Entscheidungen des Bundesverfassungsgerichts, Band 38, S. 281 - 312

\section{BUNDESVERFASSUNGSGERICHT (1989)}

Urteil vom 18.4.1989, in: Entscheidungen des Bundesverfassungsgerichts, Band 79, S. 311 $-357$

BUTTLER, F./GERLACH, K. (1982)

Arbeitsmarkttheorien, in: Albers, W. u.a. (Hrsg.), Handwörterbuch der Wirtschaftswissenschaft 9, Stuttgart u.a.O., S.686 - 696

CASPARI, M. (1987)

Die Beihilferegeln des EWG-Vertrags und ihre Anwendung, in: Mestmäcker, E.-J., Möller, H., Schwarz, H.-P. (Hrsg.), Eine Ordnungspolitik für Europa, Festschrift für Hans von der Groeben zu seinem 80. Geburtstag, Baden-Baden, S. 69 - 91

CASSEL, D. (1988)

Wirtschaftspolitik als Ordnungspolitik, in: Cassel, D., Ramb, B.-Th., Thieme, H.J. (Hrsg.), Ordnungspolitik, München, S. 313 - 333

CHANEY, P.K./THAKOR, A.V. (1985)

Incentive Effects of Benevolent Intervention, in: Journal of Public Economics 26, S. 169 $-189$

CLEMENZ, G. (1986)

Credit Markets with Asymmetric Information, Berlin u.a.O.

COE, R.D./WILBER, C.K. (1985)

Schumpeter Revisited: An Overview, in: Coe, R.D., Wilber, C.K. (Hrsg.), Capitalism and Democracy: Schumpeter Revisited, Indiana, S. 1 - 59

CONGRESSIONAL BUDGET OFFICE (1981a)

The Benefits and Costs of the Export-Import Bank Loan Subsidy Program, Washington, D.C.

CONGRESSIONAL BUDGET OFFICE (1981b)

Conference on the Economics of Federal Credit Activity, Part II - Papers, Washington, D.C.

CONRAD, E.-A. (1967)

Bürgschaften und Garantien als Mittel der Wirtschaftpolitik, Berlin

COURANT, P.N., RUBINFELD, D.L. (1981)

On the Welfare Effects of Tax Limitation, in: Journal of Public Economics 16, S. 289 - 316

CUNY, R.H. (1987)

Die Bestandspflege rückt in den Vordergrund, in: Wirtschaftsdienst 67, S. 34 - 39 
DAVIE, B.F./DUNCOMBE, B.F. (1972)

Public Finance, New York u.a.O.

DAVIES, D.G. (1981)

Property Rights and Economic Behavior in Private and Government Enterprises: The Case of Australia's Banking System, in: Research in Law and Economics 3, S. 111 - 142

DEALESSI, L. (1980)

The Economics of Property Rights: A Review of the Evidence, in: Research in Law and Economics 2, S. 1 - 47

De ALESSI, L. (1983)

Property rights, transaction costs, and X-efficiency: An essay in economic theory, in: American Economic Review 73, S. 64 - 81

DEAN, J. (1956)

Capital Budgeting, 3. Aufl., New York

DEMSETZ, H. (1967)

Toward a Theory of Property Rights, in: American Economic Review 57, Proceedings, S. 347 - 359

DEUTSCHE AUSGLEICHSBANK (1987)

Jahresbericht 1987, Bonn

DEUTSCHE AUSGLEICHSBANK (1988)

Jahresbericht 1988, Bonn

DEUTSCHE BUNDESBANK (1975)

Ein Vierteljahrhundert Lastenausgleich, in: Monatsberichte der Deutschen Bundesbank, 27. Jahrgang, Nr. 10, S. 21 - 26

DEUTSCHE BUNDESBANK (1985)

Finanzierungsströme und Bestände an Forderungen und Verpflichtungen in der Bundesrepublik Deutschland 1984, in: Monatsberichte der Deutschen Bundesbank 37, Nr.5, S. 13 $-21$

DEUTSCHER BUNDESTAG (1968)

Bericht der Bundesregierung über die Untersuchung der Wettbewerbsverschiebungen im Kreditgewerbe und über eine Einlagensicherung, Bundestagsdrucksache V/3500, Bonn

DIAMOND, P./STIGLITZ. J. (1974)

Increases in Risk and Risk Aversion, in: Journal of Economic Theory 8, S. 337 - 360

DICKERTMANN, D. (1971)

Investitionsbudgetierung durch revolvierende Fonds? in: Hansmeyer, K.-H. (Hrsg.), Das rationale Budget, Köln, S. 163 - 181

DICKERTMANN, D. (1980)

Öffentliche Finanzierungshilfen - Darlehen, Schuldendiensthilfen und Bürgschaften als Instrumente des finanzwirtschaftlichen Interventionismus, Baden-Baden 
DICKERTMANN, D. (1981)

Kreditinstitute des Bundes - Subventionspolitische Schattenhaushalte, in: Archiv für offentliche und freigemeinnützige Unternehmen 13, S. 63 - 96

DICKERTMANN, D. (1983)

Staatliche Bürgschaften in der Kritik, in: Wirtschaftswissenschaftliches Studium 12, S. 366 $-369$

DICKERTMANN, D. (1985)

Die Kreditinstitute der Länder Teil I und II, in: Zeitschrift für öffentliche und gemeinwirtschaftliche Unternehmen 8, S. 38 - 82 und S. 164 - 186

DICKERTMANN, D. (1987)

Haben Kredite in offentlichen Kreditprogrammen auch Schattenseiten?, in: Zeitschrift für das gesamte Kreditwesen, S. 96 - 104

DICKERTMANN, D./DILLER, K.D. (1986a)

Finanzhilfen und Steuervergünstigungen - ein subventionspolitischer Instrumentenvergleich, in: Zeitschrift für Wirtschaftspolitik 35, S. 273 - 300

DICKERTMANN, D./DILLER, K.D. (1986b)

Der Subventionsbericht des Bundes, in: Wirtschaftswissenschaftliches Studium 15, S. 601 $-608$

DICKERTMANN, D./DILLER, K.D. (1989)

Subventionstechnik, Aktionsparameter des subventionspolitischen Instrumentariums, in: Wirtschaftswissenschaftliches Studium 18, S. 166 - 172

DICKERTMANN, D./HANSMEYER, K.-H. (1987)

Der öffentliche Kredit II: Der Staat als Finanzier, Frankfurt a.M.

DILORENZO, T.J. (1982)

Utility Profits, Fiscal Illusion, and Local Public Expenditures, in: Public Choice 38, S. 243 252

DITTES, E. (1989)

Die Finanzierungshilfen des Bundes und der Länder - an die gewerbliche Wirtschaft; - für den Wohnungsbau; - an die Landwirtschaft, Sonderausgaben der Zeitschrift für das gesamte Kreditwesen

DOMAR, E.D. (1944)

The "Burden of Debt" and National Income, in: American Economic Review 34, S. 798 $-827$

DOMAR, E.D./MUSGRAVE, R.A. (1944)

Proportional income taxation and risk taking, in: Quarterly Journal of Economics 58, S. 387 $-422$

DOWNS, A. (1957/1968)

An Economic Theory of Democracy, New York; deutsch: Ökonomische Theorie der Demokratie, Tübingen 
DOWNS, A. (1965)

Why the Government Budget is Too Small in a Democracy, in: Phelps, E.S. (Ed.), Private Wants and Public Needs, 2.Aufl., New York, S. 76 - 95

EHLERS, D. (1983)

Die Handlungsformen bei der Vergabe von Wirtschaftssubventionen, in: Verwaltungsarchiv 74, S. 112 - 132

EHRENFORTH, W. (1965)

Reichssiedlungsgesetz und Grundstücksverkehrsgesetz; Kommentar, Köln u.a.O.

EHRLICH, J./BECKER, G.S. (1972)

Market Insurance, Self Insurance and Self Protection, in: Journal of Political Economy 80, S. 623 - 648

EISEN, R. (1979)

Theorie des Versicherungsgleichgewichts: Unsicherheit und Versicherung in der Theorie des generellen ökonomischen Gleichgewichts, Berlin

ELBRECHT, L. (1976)

Kreditinstitute mit Sonderaufgaben, in: Büschgen, H.E. (Hrsg.), Handwörterbuch der Finanzwirtschaft 6, Stuttgart, Sp. 1178 - 1188

EUCKEN, W. (1975)

Grundsätze der Wirtschaftspolitik, 5. Aufl., Tübingen

FAMA, E.F./MILLER, M.H. (1972)

The Theory of Finance, Hinsdale, Ill.

FECHER, H. (1963)

Probleme der Zweckbindung öffentlicher Einnahmen, Berlin

FEDERAL CREDIT PROGRAMS (1963)

A Series of Research Studies, prepared for the Commission on Money and Credit, Englewood Cliffs, N.J.

FELIX, G. (1976)

Zur ertragsteuerlichen Behandlung öffentlicher Zuschüsse für die Sicherung von Arbeitsplätzen, die an Auffanggesellschaften gewährt werden, in: Der Betrieb 16, S. 740 - 743

FINAG (1985)

Geschäftsbericht 1985 der Finanzierungs-Aktiengesellschaft Rheinland-Pfalz -FINAG-, Mainz

FINANZBERICHT (1989)

Bundesministerium der Finanzen (Hrsg.), Finanzbericht 1990, Bonn

FISHER, I. (1930)

The Theory of Interest, New York

FOLKERS, C. (1974)

Meritorische Güter als Problem der normativen Theorie öffentlicher Ausgaben, in: Jahrbuch für Sozialwissenschaft 25, S. 1 - 29 
FOLKERS, C. (1978)

Der Reformakzelerator, in: Wirtschaftsdienst 58, S. 340 - 345

FOLKERS, C. (1980)

Vermögen I: Struktur und Verteilung, in: Albers, W. (Hrsg.), Handwörterbuch der Wirtschaftswissenschaft 8, Stuttgart u.a.O., S. 265 - 282

FOLKERS, C. (1981)

Vermögensverteilung und staatliche Aktivität, Frankfurt a.M.

FOLKERS, C. (1983a)

Begrenzungen von Steuern und Staatsausgaben in den USA, Eine Untersuchung über Formen, Ursachen und Wirkungen vorgeschlagener und realisierter fiskalischer Restriktionen, Baden-Baden

FOLKERS, C. (1983b)

$\mathrm{Zu}$ einer positiven Theorie der Steuerreform, in: Hansmeyer, K.-H. (Hrsg.), Staatsfinanzierung im Wandel, Berlin, S. 189 - 211

FOLKERS, C. (1984)

Fiskalische Begrenzungen, in: Wirtschaftswissenschaftliches Studium 13, S. 500 - 506

FOLKERS, C. (1985)

Steuerreforminteressen und Steuervergünstigungen in positiver und institutioneller Perspektive, in: Jahrbuch für Sozialwissenschaft 36, S. 274 - 301

FOLKERS, C. (1986a)

Das Dilemma des Defizits, Haushaltsentwicklung und gesetzliches Konsolidierungsverfahren in den USA, in: Finanzarchiv, N.F. 44, S. 365 - 403

FOLKERS, C. (1986b)

Effizienzsteigerung im staatlichen Bereich durch verfassungsmäßige Begrenzung öffentlicher Ausgaben?, in: Wille, E. (Hrsg.), Konkrete Probleme öffentlicher Planung: Grundlegende Aspekte der Zielbildung, Effizienz und Kontrolle, Bern, New York, S. 223 - 261

FOLKERS, C. (1986c)

Die Konsequenzen des Staatsversagens, in: Wirtschaftsdienst 66, S. 208 - 212

FOLKERS, C. (1986d)

Die politische Ökonomie der Besteuerung, Diskussionsbeiträge aus dem Institut für Volkswirtschaftslehre der Universität Hohenheim 30

FOLKERS, C. (1987a)

Konzept und Wirkungen der großen Steuerreform in den USA, in: Wirtschaftswissenschaftliches Studium 16, S. $276-281$

FOLKERS, C. (1987b)

Wandlungen der Verbrauchsbesteuerung, in: Häuser, K. (Hrsg.), Wandlungen der Besteuerung, Berlin, S. 89-212

FOLKERS, C. (1988a)

Steuern und Subventionen als Instrumente zur Beeinflussung des Ernährungsverhaltens, in: Berichte über Landwirtschaft 66, S. 236 - 255 
FOLKERS, C. (1988b)

Vorwort des Herausgebers, in: Brennan, G., Buchanan, J.M., Besteuerung und Staatsgewalt. Analytische Grundlagen einer Finanzverfassung, herausgegeben und übersetzt von C. Folkers, Hamburg, S. XI - XVI

FOLKERS, C. (1988c)

Wer wird durch Steuervergünstigungen eigentlich begünstigt? $\mathrm{Zu}$ einem Problem der materiellen Steuerinzidenz, in: Finanzarchiv, N.F. 46, S. 214 - 235

FOLKERS, C. (1990)

Politische Präferenzen und institutionelle Bedingungen der Interessenpolitik, -Zur Logik der staatlichen Aufgabenübernahme-, erscheint demnächst

FOX, K.-P./ZEITEL, G. (1984)

Subventionsabbau, Bemerkungen zum sinnvollen Kern einer populären Forderung, in: Die öffentliche Verwaltung 37, S. 865 - 872

FRANZ, W./SCHALK, H.J. (1982)

Investitionsfördernde Maßnahmen als Mittel der Regionalpolitik: Eine ökonometrische Analyse, in: Jahrbuch für Regionalwissenschaft 3, S. 5 - 35

FREISTAAT BAYERN (1989)

Haushaltsplan 1989/1990, München

FREUND, U. (1982)

Rolle und Ausmaß des Mitnahmeeffektes in der Gemeinschaftsaufgabe "Verbesserung der regionalen Wirtschaftsstruktur", in: Müller, J.H., Dams, T. (Hrsg.), Planung in der regionalen Strukturpolitik, Berlin, S. 61 - 82

FRIEDMAN, M.S. (1953)

Essays in Positive Economics, Chicago

FRIEDMAN, M.S. (1962)

Capitalism and Freedom, Chicago.

FRIEDMAN, M.S./SAVAGE, L.J. (1948)

The Utility Analysis of Choices Involving Risk, in: Journal of Political Economy 56, S. 279 $-304$

FROTSCHER, W. (1984)

Grundfälle zum Wirtschaftsverfassungs- und Wirtschaftsverwaltungsrecht, in: Juristische Schulung 9, S. 692 - 698

FURUBOTN, E./PEJOVICH, S. (1972)

Property Rights and Economic Theory: A Survey of Recent Literature, in: Journal of Economic Literature 10, S. 1137 - 1162

GALE, D./HELLWIG, M. (1985)

Incentive-Compatible Debt Contracts. The One-Period Problem, in: Review of Economic Studies 52, S. $647-663$

GANDENBERGER, O. (1981)

Theorie der öffentlichen Verschuldung, in: Neumark, F. (Hrsg.), Handbuch der Finanzwissenschaft 3, 3. Aufl., Tübingen, S. 3 - 49 
GANDENBERGER, O. (1990)

Verfassungsgrenzen der Staaatsverschuldung, Eine Auseinandersetzung mit dem Urteil des Bundesverfassungsgerichts vom 18.April 1989, in: Finanzarchiv, N.F. 48, S. 28 - 51

GEIGANT, F. (1984)

Banken, in: Oberender, P. (Hrsg.), Marktstruktur und Wettbewerb in der Bundesrepublik Deutschland, München, S. 537 - 576

GISSER, M. (1981)

Intermediate Price Theory, Auckland u.a.O.

GLAGOW, M./HARTMANN, R./MENNE, U./POLLVOGT, R./SCHIMANK, U. (1985)

Die deutschen Entwicklungsbanken, Saarbrücken, Fort Lauderdale

GOLDSCHMIDT, Th. (1987)

Öffentliche Kredithilfen im Rahmen der Mittelstands- und Regionalpolitik in BadenWürttemberg, Berlin

GRÖBNER, B.F. (1983)

Subventionen - eine kritische Analyse, Göttingen

GROH, M. (1973)

Öffentliche Zuschüsse in der Handels- und Steuerbilanz, in: Der Betriebs-Berater 16, S. $742-746$

GROSSMAN, S.J./HART, O.D. (1983)

An Analysis of the Principal-Agent Problem, in: Econometrica 51, S. 7 - 45

GUBELT, M. (1985)

Kommentierung zu Art. 3, in: v.Münch, I. (Hrsg.), Grundgesetz-Kommentar, Band 1, Präambel bis Art. 20, 3. Aufl., München, S. $163-224$

GÜNDISCH, J. (1984)

Die Entwicklung des Subventionsrechts 1980 bis 1983, in: Neue Zeitschrift für Verwaltungsrecht 8, S. 489 - 498

GUTENBERG, E. (1972)

Grundlagen der Betriebswirtschaftslehre, Dritter Band, Die Finanzen, 5. Aufl., Berlin u.a.O.

GWARTNEY, J.D./WAGNER, R.E. (1988)

Public Choice and the Conduct of Representative Government, in: Gwartney, J.D., Wagner, R.E. (Hrsg.), Public Choice and Constitutional Economics, Greenwich, Conn., London 1988, S. 3 - 28

HAGENMÜLLER, K.F./JAKOB, A.-F. (1987)

Der Bankbetrieb, Kredite und Kreditsurrogate, Dienstleistungsgeschäft, 5. Aufl., Wiesbaden

HAHN, O. (1978)

Probleme der öffentlich-rechtlichen Universalbank, in: Österreichisches Bankarchiv, S. 295 $-306$ 
HAKANSSON, N.H. (1970)

Optimal Investment and Consumption Strategies Under Risk for a Class of Utility Functions, in: Econometrica 38, S. 587 - 607

HALL, R.E./JORGENSON, D.W. (1967)

Tax Policy and Investment Behaviour, in: American Economic Review 57, S. 391 - 414

HANKE, St.H. (1987)

Privatization, in: Eatwell, J., Milgate, M., Newman, P. (Hrsg.), The New Palgrave, A Dictionary of Economics 3, London u.a.O., S. 976 - 977

HANSMEYER, K.-H. (1977)

Transferzahlungen an Unternehmen (Subventionen), in: Neumark, F. (Hrsg.), Handbuch der Finanzwissenschaft 1, 3. Aufl., Tübingen, S. 959 -996

HANSMEYER, K.-H./DICKERTMANN, D. (1971)

Lehren für die Landwirtschaft aus der Erfahrung mit "Revolving Funds", in: Berichte über Landwirtschaft 48, S. 585 - 615

HANSSON, J./STUART, Ch. (1989)

The Marginal Cost of Public Funds: Methods and Prospects, in: Changes in Revenue Structures, Proceedings of the 42nd Congress of the International Institute of Public Finance, Athens 1986, Detroit, S. 231 - 241

HARBERGER, A.C. (1962)

The Incidence of the Corporation Income Tax, in: Journal of Political Economy 70, S. 215 $-240$

HARBERGER, A.C. (1974)

Taxation, Resource Allocation, and Welfare, in: Harberger, A.C., Taxation and Welfare, Chicago, London, S. 25 - 62

HARTLAND-THUNBERG, P./CRAWFORD, M.H. (1982)

Government Support for Exports, A Second-Best Alternative, Lexington, Toronto

HARTMAN, R. (1975)

Competitive Firm and the Theory of Input Demand under Price Uncertainty: Comment, in: Journal of Political Economy 83, S. 1289 - 1290

HARTMAN, R.W. (1971)

Credit for College: Public Policy for Student Loans, New York

HARTWIG, H. (1990)

Wirtschaftlicher Strukturwandel und staatliche Strukturhilfen, Frankfurt a.M. u.a.O.

HAUGEN, R.A./SENBET, L.W. (1978)

The Insignificance of Bankruptcy Costs to the Theory of Optimal Capital Structure, in: Journal of Finance 33, S. 383-393

HAYEK, F.A. (1960)

The Constitution of Liberty, Chicago

HEDTKAMP, G. (1977)

Lehrbuch der Finanzwissenschaft, 2. Aufl., Neuwied 
HEINIG, K. (1948)

Das Budget, Band 1, Tübingen

HENDERSON, J.M./QUANDT, R.E. (1983)

Mikroökonomische Theorie, 5. Aufl., München

HENKE, W. (1979)

Das Recht der Wirtschaftssubventionen als öffentliches Vertragsrecht, Tübingen

HERB, F. (1988)

Marktwirtschaftliche Innovationspolitik, Frankfurt a.M. u.a.O.

HEY, J.D. (1979)

Uncertainty in Microeconomics, Oxford

HICHERT, J. (1986)

Staatliche Exportabsicherung - Die Hermes-Deckung vor dem Hintergrund der internationalen Verschuldungskrise, Köln

HIRSHLEIFER, J. (1970)

Investment, Interest, and Capital, Englewood Cliffs, N.J.

HIRSHLEIFER, J./RILEY, J.G. (1979)

The Analytics of Uncertainty and Information - an Expository Survey, in: Journal of Economic Literature 17, S. 1375 - 1421

HOCHMAN, H.M./ROGERS, J.D. (1969)

Pareto Optimal Redistribution, in: American Economic Review 59, S. 542 - 557

HODGMAN, D.R. (1960)

Credit Risk and Credit Rationing, in: Quarterly Journal of Economics 74, S. 258 - 278

HORN, M.J. (1988)

The Political Economy of Public Administration: Organization, Control and Performance of the Public Sector, Ann Arbor

HUISMANS, R. (1971)

Der öffentliche Kredit - Verwaltungsrechtliche Probleme der Einschaltung von Kreditinstituten bei der Vergabe von Subventionen an die gewerbliche Wirtschaft, Münster

HUNTER, W.C. (1981)

Moral Hazard, Adverse Selection, and SBA Business Loan Guarantees, in: Congressional Budget Office (Hrsg.), Conference on the Economics of Federal Credit Activity, Part II Papers, Washington, D.C., S. 233 - 280

HYMAN, D.N. (1990)

Public Finance, A Contemporary Application of Theory to Polity, 3.Aufl., Chicago u.a.O.

INMAN, R.P. (1982)

The Economic Case for Limits to Government, in: American Economic Review 72, S. 176 $-183$ 
INMAN, R.P. (1987)

Markets, Governments, and the "New" Political Economy, in: Auerbach, A.J., Feldstein, M. (Hrsg.), Handbook of Public Economics 2, S. 647 - 777

INNENMINISTERIUM BADEN-WÜRTTEMBERG (1989)

Wohnungsbau in Baden-Württemberg, Landeswohnungsbauprogramm 1990, Stuttgart

IPPOLITO, D.S. (1984)

Hidden Spending - The Politics of Federal Credit Programs, Chapel Hill, London

IPSEN, H.P. (1967)

Verwaltung durch Subventionen, in: Veröffentlichungen der Vereinigung Deutscher Staatsrechtslehrer 25, Berlin, S. 257 - 445

JAFFEE, D./RUSSELL, T. (1976)

Imperfect Information, Uncertainty, and Credit Rationing, in: Quarterly Journal of Economics 90, S. 651 - 666

JARASS, H.D. (1984a)

Der Vorbehalt des Gesetzes bei Subventionen, in: Neue Zeitschrift für Verwaltungsrecht 3, S. $473-480$

JARASS, H.D. (1984b)

Wirtschaftsverwaltungsrecht und Wirtschaftsverfassungsrecht, 2. Aufl., Frankfurt a.M.

JENSEN, M.C./MECKLING, W.H. (1976)

Theory of the Firm: Managerial Behaviour, Agency Costs and Ownership Structure, in: Journal of Financial Economics 3, S. 305 - 360

JOOSS, G. (1987)

Subventionsrecht, in: Klein, F. (Hrsg.), Lehrbuch des Finanzrechts, Neuwied, Darmstadt, S. 283 - 344

JORGENSON, D.W. (1963)

Capital Theory and Investment Behavior, in: American Economic Review 53, S. 247 - 259

KAGE, K. (1978)

Die Umgliederung der Banken des Bundes, in: Zeitschrift für öffentliche und gemeinwirtschaftliche Unternehmen 1, S. 45 - 60

KARL-BRÄUER-INSTITUT DES BUNDES DER STEUERZAHLER (1990)

Zur Finanzierung von DDR-Hilfen, Einsparmöglichkeiten nutzen! Wiesbaden

KASTROP, C./BERGMANN, E. (1988)

Staatsbürgschaften - Ein Instrument des finanzpolitischen Interventionismus, in: Wirtschaftsdienst 68 , S. $317-324$

KAUFMAN, H. (1976)

Are Government Organizations Immortal?, Washington, D.C.

KAUFMAN, H.M. (1981)

Loan Guarantees and Crowding Out, in: Congressional Budget Office (Hrsg.), Conference on the Economics of Federal Credit Activity, Part II - Papers, Washington, D.C., S. 67 - 110 
KEETON, W.R. (1979)

Equilibrium Credit Rationing, New York, London

KELLY, J.S. (1988)

Social Choice Theory, Berlin u.a.O.

KEYNES, J.M. (1936/1951)

The General Theory of Employment, Interest and Money, London (Reprint 1951)

KIRCHHOFF, U. (1987)

Zielwandel bei öffentlichen Unternehmen, aufgezeigt am Beispiel der Banken des Bundes, Berlin

KLÄSCHEN, K.D. (1990)

Körperschaftsteuergesetz, mit den einschlägigen Vorschriften des EStG, Kommentar (Loseblattsammlung), Bonn

KLEIN, A. (1982)

Aktivitäten der Länder in eigener Verantwortung versus bundesweite Planung in der regionalen Strukturpolitik, in: Müller, J.H., Dams, T. (Hrsg.), Planung in der regionalen Strukturpolitik, Berlin, S. 29 - 47

KLEMP, A.H. (1990)

Öffentliche Finanzhilfen (Subventionen) - Instrumente staatlicher Finanzintervention, Frankfurt a.M. u.a.O.

KLUG, M. (1985)

Zur Ableitung von Kapitalkosten aus dem diskreten Optionspreismodell, Berlin

KNEMEYER, F.-L./ROST-HAIGIS, B. (1981)

Kommunale Wirtschaftsförderung, in: Deutsches Verwaltungsblatt 96, S. 241 - 247

KNIGHT, F. (1921)

Risk, Uncertainty, and Profit, New York

KNIRSCH, H. (1984)

Gestaltungsfreiräume kommunaler Subventionsgewährung, in: Neue Zeitschrift für Verwaltungsrecht 3, S. 495 - 498

KOMMISSION DER EUROPÄISCHEN GEMEINSCHAFTEN (1979)

Mitteilung der Kommission über regionale Beihilferegelungen, Amtsblatt Nr. C 31 vom 3. Februar 1979

KOMMISSION DER EUROPÄISCHEN GEMEINSCHAFTEN (1985)

14. Bericht über die Wettbewerbspolitik, Brüssel

KOMMISSION DER EUROPÄISCHEN GEMEINSCHAFTEN (1987a)

16. Bericht über die Wettbewerbspolitik, Brüssel

KOMMISSION DER EUROPÄISCHEN GEMEINSCHAFTEN (1987b)

Wettbewerbsregeln der EWG und der EGKS für staatliche Beihilfen, Luxemburg 
KOTLIKOFF, L.J./SUMMERS, L.H. (1987)

Tax Incidence, in: Auerbach, A.J., Feldstein, M. (Hrsg.), Handbook of Public Economics 2, Amsterdam u.a.O., S. 1043 - 1092

KOTOWITZ, Y. (1987)

moral hazard, in: Eatwell, J., Milgate, M., Newman, P. (Hrsg.), The New Palgrave, A Dictionary of Economics 3, London u.a.O., S. 549 - 551

KRAHNEN, J.P. (1988)

Zur Wahl der Vertragsdauer bei Kreditarrangements unter asymmetrischer Information, in: Wirtschaftswissenschaftliches Studium 17, S. 343 - 349

KRAJEWSKI, G. (1975)

Schuldendiensthilfen als Finanzierungsinstrument im offentlichen Haushalt, Meisenheim a.G.

KRAUSE-JUNK, G. (1981)

Finanzwirtschaftliche Verteilungspolitik, in: Neumark, F. (Hrsg.), Handbuch der Finanzwissenschaft 3, 3. Aufl., Tübingen, S. 257 - 358

KREDITANSTALT FÜR WIEDERAUFBAU (1988)

Bericht über das Geschäftsjahr 1988, Frankfurt a.M.

KRIST, H./MAAS, G. (1983)

Zur mikroökonomischen Analyse der Wirkungen von Investitionsanreizen - Theoretische Überlegungen, Berlin

KRIST, H./NICOL, W.R. (1982)

Wirkungsanalysen in der Regionalpolitik, in: Raumforschung und Raumordnung 40, S. 133 $-146$

KRUEGER, A.O. (1974)

The Political Economy of the Rent-Seeking Society, in: American Economic Review 64, S. 291 - 303

KRUMING, H. (1955)

Öffentliche Darlehen und Bürgschaften, Freiburg

KRUSCHWITZ, L. (1987)

Das Bernoulliprinzip I und II, in: Wirtschaftswissenschaftliches Studium 16, S. 567 - 570 und S. $618-621$

\section{LANDESKREDITBANK BADEN-WÜRTTEMBERG (1986)}

Geschäftsbericht 1986, Karlsruhe

LANDESKREDITBANK BADEN-WÜRTTEMBERG (1988)

Geschäftsbericht 1988, Karlsruhe

LANDESTREUHANDSTELLE FÜR AGRARFÖRDERUNG (1988)

Tätigkeitsbericht 1988, Hannover

LANDESTREUHANDSTELLE FÜR DEN WOHNUNGS- UND STÄDTEBAU (1988)

Tätigkeitsbericht 1988, Hannover 
LARKINS, D. (1972)

300 Billion Dollars in Loans - An Introduction to Federal Credit Programs, American Enterprise Institute for Public Policy Research, Washington, D.C.

LASTENAUSGLEICHSBANK (1970)

Jahresbericht 1970, Bonn

LASTENAUSGLEICHSBANK (1971)

Jahresbericht 1971, Bonn

LAUX, E. (1976)

Größere Flexibilität der öffentlichen Verwaltung durch Verselbständigung betrieblicher Einrichtungen, WIBERA-Sonderdruck, Nr. 75, Düsseldorf

LAW, W.A. (1963)

The Aggregate Impact of Federal Credit Programs on the Economy, in: Federal Credit Programs, A Series of Research Studies, prepared for the Commission on Money and Credit, Englewood Cliffs, N.J., S. 247 - 316

LEIBENSTEIN, H. (1966)

Allocative Efficiency vs. "X-Efficiency", in: American Economic Review 56, S. 392 - 415

LEIPOLD, H. (1988)

Ordnungspolitische Konsequenzen der ökonomischen Theorie der Verfassung, in: Cassel, D., Ramb, B.-Th., Thieme, H.J. (Hrsg.), Ordnungspolitik, München, S. 257 - 283

LEONARD, H.B. (1986)

Checks Unbalanced, The Quiet Side of Public Spending, New York

LEONARD, H.B./RHYNE, E.H. (1981)

Federal Credit and the "Shadow Budget", in: Public Interest 65, S. 40 - 58

LERNER, A.P. (1948/1964)

The Burden of the National Debt, wiederabgedruckt in: Ferguson, J.M. (Hrsg.), Public Debt and Future Generations, Chapel Hill, S. 16 - 19

LEVHARI, D./MIRMAN, L.J. (1977)

Savings and uncertainty with an uncertain horizon, in: Journal of Political Economy 85, S. $265-281$

LINDSAY, C.M. (1976)

A Theory of Government Enterprise, in: Journal of Political Economy 84, S. 1061 - 1077

LINTNER, J. (1965)

The Valuation of Risk Assets and the Selection of Risky Investments in Stock Portfolios and Capital Budgets, in: Review of Economics and Statistics 47, S. 13 - 37

LIPPMAN, S.A./McCALL, J.J. (1981)

The Economics of Uncertainty: Selected Topics and Probabilistic Methods, in: Arrow, K.J., Intriligator, M.D. (Hrsg.), Handbook of Mathematical Economics 1, Amsterdam u.a.O., S. $211-284$

LIPSEY, R.G./LANCASTER, K. (1956/57))

The General Theory of Second Best, in: Review of Economic Studies 24, S. 11 - 32 
VAN LITH, U./HEMMERT, B. (1982)

Alternativen zur Ausbildungsförderung, in: Wirtschaftsdienst 62, S. 229 - 234

LOGAN, R.R. (1986)

Fiscal Illusion and the Grantor Government, in: Journal of Political Economy 94, S. 1304 $-1318$

LÜDER, K. (1984)

Zum Einfluß staatlicher Investitionsfördermaßnahmen auf unternehmerische Investitionsentscheidungen, in: Zeitschrift für Betriebswirtschaft 54, S. 531 - 547

MÄRTZ, Th. (1990)

Interessengruppen und Gruppeninteressen in der Demokratie, Frankfurt u.a.O.

MALKIEL, B.G. (1962)

Expectations, Bond Prices, and the Term Structure of Interest Rates, in: Quarterly Journal of Economics 76, S. 197 - 218

MANKIW, N.G. (1986)

The Allocation of Credit and Financial Collapse, in: Quarterly Journal of Economics 101, S. 455 - 470

MANN, H. (1987)

Theorie und Politik der Steuerreform in der Demokratie, Frankfurt a.M. u.a.O.

MATTESINI, F. (1986)

Essays on the Loan Market, New York

MAURER, H. (1986)

Allgemeines Verwaltungsrecht, 5. Aufl., München

MAY, E. (1981)

Erfolgreiche Existenzgründungen und öffentliche Förderung, in: Institut für Mittelstandsforschung (Hrsg.), Beiträge zur Mittelstandsforschung 1981, Göttingen, S. 80 - 114

MCCALL, J.J. (1971)

Probabilistic Microeconomics, in: Bell Journal of Economics and Management Science 2, S. 403 - 433

MCCALL, J.J. (1987)

insurance, in: Eatwell, J., Milgate, M., Newman, P. (Hrsg.), The New Palgrave, A Dictionary of Economics 2, London u.a.O., S. $868-870$

McCORMICK, R.E./TOLLISON, R.D. (1981)

Politicians, Legislation, and the Economiy: An Inquiry into the Interest-Group Theory and Government, Boston u.a.O.

MCKELVEY, R.D. (1976)

Intransitivities in Multidimensional Voting Models and Some Implications for Agenda Control, in: Journal of Economic Theory 12, S. 472 - 482 
McKIE, J.W. (1963)

Credit Gaps and Federal Credit Programs, in: Federal Credit Programs, A Series of Research Studies, prepared for the Commission on Money and Credit, Englewood Cliffs, N.J., S. 317 - 353

MCLURE Ch.E. (1971a)

The Design of Regional Tax Incentives for Columbia, in: Gillis, M. (Hrsg.), Fiscal Reform for Columbia, Cambridge, Mass., S. 545 - 556

MCLURE, Ch.E. (1971b)

The theory of tax incidence with imperfect factor mobility, Finanzarchiv, N.F. 30, S. 27 - 48

MCLURE, Ch.E. (1975)

General equilibrium incidence analysis: The Harberger model after ten years, in: Journal of Public Economics 4, S. 125 - 161

MCLURE, Ch.E./THIRSK, W.R. (1975)

A Simplified Expostion of The Harberger Model, I: Tax Incidence, in : National Tax Journal 28, S. 1 - 27

MENZEL, H. (1960)

Die Mitwirkung der Hausbanken bei der Vergabe und Verwaltung öffentlicher Kredite Die Abwicklung zentraler Bereitstellungen durch örtliche Banken und Sparkassen, Berlin

MIESZKOWSKI, P.M. (1967)

On the theory of tax incidence, in: Journal of Political Economy 75, S. $250-262$

MIGUE, J.-L./BELANGER, G. (1974)

Toward a General Theory of Managerial Discretion, in: Public Choice 17, S. 27 - 43

MILBRADT, G.H. (1975)

Ziele und Strategien des debt management. Ein Beitrag zur Theorie der optimalen Schuldenstruktur des Staates unter Einbeziehung der Notenbank, Baden-Baden

MILL, J.St. (1861/1977)

Considerations on Representative Government (erstmals veröffentlicht 1861). Abgedruckt in: Essays on Politics and Society, Vol. XIX of Collected Works of J.S. Mill, Toronto

MITTELSTANDSBERICHT (1982)

Bericht der Landesregierung von Baden-Württemberg über die Entwicklung der mittelständischen Wirtschaft und über die Förderungsmaßnahmen der Landesregierung im Rahmen des Mittelstandsförderungsgesetzes von Baden-Württemberg - § 24 MFG Berichtszeitraum 1979 - 1981, Stuttgart (erschienen als Sonderdruck)

MITTELSTANDSBERICHT (1984)

Bericht der Landesregierung über die Lage der mittelständischen Wirtschaft im Saarland, Dritter Mittelstandsbericht-, Landtag des Saarlandes, 8. Wahlperiode, Drucksache 8/1904

MODIGLIANI, F. (1961)

Long-Run Implications of Alternative Fiscal Policies and the Burden of the National Debt, in: Economic Journal 71, S. 730 - 755 
MODIGLIANI, F./MILLER, M.H. (1958)

The Cost of Capital, Corporation Finance and the Theory of Investment, in: American Economic Review 48, S. 261 - 297

MOLITOR, B. (1980)

Vermögenspolitik, in: Handwörterbuch der Wirtschaftswissenschaft 8, Stuttgart u.a.O., S. $282-299$

MOMBAUR, P.M. (1989)

Europäischer Binnenmarkt: Kommunalpolitik und Wirtschaftsförderung im Wettbewerb der Standorte, in: Die öffentliche Verwaltung 6, S. 243 - 249

MOSSIN, J. (1966)

Equilibrium in a Capital Asset Market, in: Econometrica 34, S. 768 - 783

MOSSIN, J. (1968)

Taxation and Risk-Taking: An Expected Utility Approach, in: Economica 35, S. 74 - 82

MÜCKL, W. (1983)

Öffentliche Kreditaufnahme und budgetärer Ausgabenspielraum, in: Wirtschaftsstudium 12 , S. $519-523$ und $571-575$

MUELLER, D.C. (1979)

Public Choice, London u.a.O

MUELLER, D.C. (1989)

Public choice II, Cambridge u.a.O.

MÜLLER, P. (1987)

Intertemporale Wirkungen der Staatsverschuldung, Frankfurt a.M. u.a.O.

MÜLLER-KÄSTNER, B. (1986)

Außerbudgetäre Finanzierungshilfen, Arbeitspapier Nr. 6 des Schwerpunktes Finanzwissenschaft/Betriebswirtschaftliche Steuerlehre, Universität Trier, Trier

MUSGRAVE, R.A. (1959/1966)

The Theory of Public Finance, New York; deutsch: Finanztheorie, Tübingen

NERLOVE, M. (1972)

On Tuition and the Costs of Higher Education: Prolegomena to a Conceptual Framework, in: Journal of Political Economy 80, S. S178 - S218

NEUMARK, F. (1952)

Theorie und Praxis der Budgetgestaltung, in: Gerloff, W., Neumark, F. (Hrsg.), Handbuch der Finanzwissenschaft 1, 2. Aufl., Tübingen, S. 554 - 605

NEUNDÖRFER, K. (1984)

Die Politik von Kommission und Rat sowie die Judikatur des Gerichtshofs im Bereich der sektoriellen Beihilfen, in: Börner, B., Neundörfer, K. (Hrsg.), Recht und Praxis der Beihilfen im gemeinsamen Markt, Kölner Schriften zum Europarecht 32, Köln u.a.O., S. S. 83 - 110

NG, Y.-K. (1977)

Towards a Theory of Third Best, in: Public Finance 32, S. 1 - 15 
NIEDERSÄCHSISCHE LANDESTREUHANDSTELLE FÜR WIRTSCHAFTSFÖRDERUNG (1988)

Tätigkeitsbericht 1988, Hannover

NISKANEN, W.A. (1971)

Bureaucracy and Representative Government, Chicago

NISKANEN, W.A. (1974)

Comment, in: Public Choice 17, S. 43 - 45

NORDRHEIN-WESTFALEN (1989)

Haushaltsplan 1989, Düsseldorf

NORTH, D.C. (1981/1988)

Structure and Change in Economic History, New York; deutsch: Theorie des institutionellen Wandels, Tübingen

O’DRISCOLL, G.P. (1977)

The Ricardian Nonequivalence Theorem, in: Journal of Political Economy 85, S. 207 - 210

OECD (1987)

The Export Credit Financing Systems in OECD Member Countries, 3. Aufl., Paris

OLDIGES, M (1984)

Richtlinien als Ordnungsrahmen der Subventionsverwaltung, in: Neue Juristische Wochenschrift 35, S. 1927 - 1936

OLSON, M. (1965)

The Logic of Collective Action, Cambridge

o.V. (1977)

Am liebsten bündeln, in: DER SPIEGEL, 31.Jahrgang, Heft 43, S. 42 - 44

o.V. (1987)

Bonn will mit Zinsvorteilen locken, in: Stuttgarter Zeitung, 2. Dezember 1987, Nr.278, S. 11

o.V. (1990)

Unternehmensnachrichten, in: Frankfurter Allgemeine Zeitung, 9.August 1990, Nr.183, S. 13

PAULY, M.V. (1974)

Overinsurance and Public Provision of Insurance: The Roles of Moral Hazard and Adverse Selection, in: Quarterly Journal of Economics 88, S. 44 - 62

PEFFEKOVEN, R. (1988)

Öffentliche Finanzen, in: Vahlens Kompendium der Wirtschaftstheorie und Wirtschaftspolitik 1, 3. Aufl., München, S. 463 - 543

PELTZMAN, S. (1976)

Toward a More General Theory of Regulation, in: Journal of Law and Economics 19, S. $211-240$ 
PENNER, R.G./SILBER, W.L. (1972)

Federal Housing Credit Programs: Costs, Benefits, and Interaction, in: Shoup, C.S., Jasinowski, J., (Hrsg.), The Economics of Federal Subsidies Programs: A Staff Study, Joint Economic Committee, Washington, D.C., S. 660 - 675

PENNER, R.G./SILBER, W.L. (1973)

The Interaction Between Federal Credit Programs and the Impact on the Allocation of Credit, in: American Economic Review 63, S. 838 - 852

PETER, H. (1973)

Finanzierungsfragen bei der regionalen Wirtschaftsförderung, in: Zeitschrift für das gesamte Kreditwesen 21, S. 1044 - 1047

PETHIG, R. (1988)

Bürokratische Produktion im staatlichen und privaten Sektor, in: Wirtschaftsstudium 17, S. $686-691$

PIDUCH, E.A. (1990)

Bundeshaushaltsrecht, Band 1 und 2, Kommentar, Stuttgart u.a.O. (Loseblattsammlung)

PLANTES, M.K./SMALL, D. (1981)

Macroeconomic Consequences of Federal Credit Activity, in: Congressional Budget Office (Hrsg.), Conference on the Economics of Federal Credit Activity, Part II - Papers, Washington, D.C., S.1 - 66

POMMEREHNE, W.W. (1976)

Private versus öffentliche Müllabfuhr: Ein theoretischer versus empirischer Vergleich, in: Finanzarchiv, N.F. 35, S. 272 - 294

POSNER, R.A. (1974)

Theories of Economic Regulation, in: Bell Journal of Economics and Management Science 5, S. $335-357$

POSNER, R.A. (1975)

The Social Costs of Monopoly and Regulation, in: Journal of Political Economy 83, S. 807 $-827$

PRATT, J.W. (1964)

Risk Aversion in the Small and in the Large, in: Econometrica 32, S. 122 - 136

PRATT, J.W./ZECKHAUSER, R.J. (1985)

Principals and Agents: The Structure of Business, Boston

PRUNS, H. (1976)

Finanzierungszuständigkeit des Bundes im Aufgabenbereich des Bundesministers für Ernährung, Landwirtschaft und Forsten, in: Die öffentliche Verwaltung, S. 217 - 227

PÜTTNER, G. (1983)

Öffentliche Unternehmen als Instrument staatlicher Politik, in: Die Öffentliche Verwaltung, S. $697-704$

PUVIANI, A. (1903/1960))

Teoria dell'Illusione Finanziara, Mailand u.a.O.; deutsch: Die Illusion in der öffentlichen Finanzwirtschaft, Berlin 
QUELLMALZ, J. (1963)

Die Kreditgewährung duch parafiskalische Gebilde, dargestellt an den Krediten der Bundesanstalt für Arbeitsvermittlung und Arbeitslosenversicherung, Köln

RAWLS, J. (1971)

A Theory of Justice, Cambridge

REES, R. (1985)

The Theory of Principal and Agent, Part I, in: Bulletin of Economic Research 37, S. 3 - 26

REINERMANN, W. (1976)

Kreditgarantiegemeinschaften, in: Büschgen, H.E. (Hrsg.), Handwörterbuch der Finanzwirtschaft, Stuttgart, Sp. 1157 - 1164

RENGELING, H.-W. (1984)

Das Beihilferecht der Europäischen Gemeinschaften, in: Börner, B., Neundörfer, K. (Hrsg.), Recht und Praxis der Beihilfen im gemeinsamen Markt, Kölner Schriften zum Europarecht 32, Köln u.a.O., S. 23 - 54

RHYNE, E.H. (1988)

Small Business, Banks and SBA Loan Guarantees, Subsidizing the Weak or Bridging a Credit Gap?, New York u.a.O.

RICHTER, J. (1970)

Die Zinssubventionen in der Bundesrepublik Deutschland, Frankfurt a.M.

RIEBSCHLÄGER, K. (1987)

Die Wohnungsbau-Kreditanstalt Berlin, Porträt eines öffentlich-rechtlichen Kreditinstituts, in: Zeitschrift für öffentliche und gemeinwirtschaftliche Unternehmen 10, S. 62 - 68

ROOSA, R. (1951)

Interest Rates and the Central Bank, in: Money, Trade and Economic Growth: Essays in Honour of John H. Williams, New York, S. 270 - 295

ROPPEL, U. (1979)

Ökonomische Theorie der Bürokratie, Freiburg i.Br.

ROSER, T. (1965)

Der staatliche Kredit - Ein Beitrag zur Theorie und Praxis der Leistungsverwaltung, Tübingen

ROSS, S. (1973)

The Economic Theory of Agency: The Principal's Problem, in: American Economic Review 63, S. 134 - 139

ROTHSCHILD, M./STIGLITZ, J.E. (1970)

Increasing Risk I: A Definition, in: Journal of Economic Theory 2, S. 225 - 243

ROTHSCHILD, M./STIGLITZ, J.E. (1976)

Equilibrium in Competitive Insurance Markets: An Essay on the Economics of Imperfect Information, in: Quarterly Journal of Economics 90, S. 629 - 949 
ROWLEY, Ch.K. (1984)

The Relevance of the Median Voter Theorem, in Zeitschrift für die gesamte Staatswissenschaft (Journal of Institutional and Theoretical Economics) 140, S. 104 - 126

SACHVERSTÄNDIGENRAT (1977)

Mehr Wachstum, Mehr Beschäftigung, Jahresgutachten 1977/78 des Sachverständigenrates zur Begutachtung der gesamtwirtschaftlichen Entwicklung, Bundestagsdrucksache 8/1221

SACHVERSTÄNDIGENRAT (1982)

Jahresgutachten 1982/83 des Sachverständigenrates zur Begutachtung der gesamtwirtschaftlichen Entwicklung, Bundestagsdrucksache 9/2118

SANDMO, A. (1969)

Capital Risk, Consumption, and Portfolio Choice, in: Econometrica 37, S. 586 - 599

SANDMO, A. (1970)

The Effect of Uncertainty on Saving Decisions, in: Review of Economic Studies 37, S. 353 $-360$

SANDMO, A. (1974)

Investment Incentives and the Corporate Income Tax, in: Journal of Political Economy 82, S. $287-302$

SANDMO, A. (1985)

The Effects of Taxation on Savings and Risk Taking, in: Auerbach, A.J., Feldstein, M. (Hrsg.), Handbook of Public Economics 1, S. 265 - 311

SANDMO, A. (1990)

Wohlfahrtsstaat: Krise des skandinavischen Modells, Verzerrende Wirkungen, in: Wirtschaftswoche Nr.47 vom 16.11.1990, S. 144 - 150

SANDFORD, C./GODWIN, M./HARDWICK, P. (1989)

Administrative and Compliance Costs of Taxation, Fersfield

SAULNIER, R.J./HALCROW, H.G./JACOBY, N.H. (1958)

Federal Lending and Loan Insurance, Princeton

SCHÄFER, H. (1977)

Kontrolle der öffentlichen Finanzwirtschaft, in: Neumark, F. (Hrsg.), Handbuch der Finanzwissenschaft 1, 3. Aufl., S. 519 - 550

SCHEMMEL, L. (1990)

Unternehmen und Sondervermögen der öffentlichen Hand - Funktionale Ausgliederung oder Flucht aus dem Budget?, Arbeitspapier Nr. 20 des Schwerpunktes Finanzwissenschaft/Betriebswirtschaftliche Steuerlehre der Universität Trier, Trier

SCHERER, J. (1985)

Öffentlich-rechtliche Konkurrentenklagen im Wirtschafts- und Beamtenrecht, in: Jura 1, S. 11 - 19

SCHETTING, G. (1973)

Rechtspraxis der Subventionierung - Eine Untersuchung zur normativen Subventionspraxis in der Bundesrepublik Deutschland, Berlin 
SCHIERENBECK, H. (1987)

Institutionelle Bankbetriebslehre, Eine Einführung in die institutionellen Grundlagen des Geld-, Finanz- und Bankwesens, Stuttgart

SCHINKEL, S./STEINER, J. (1980)

Bedeutung, Problematik und Maßnahmen der Förderung von Existenzgründungen, in: Wirtschaftswissenschaftliches Studium 9, S. 489 - 493

SCHLAUWITZ, W. (1966)

Der Bund als Finanzier - ERP-Sondervermögen, Sondervermögen für berufliche Leistungsförderung, Bad Godesberg

SCHLECHT, O. (1982)

Darf der Staat sanierungsreifen Unternehmen helfen?, in: Wirtschaftsdienst 62, S. 423 428

SCHLESINGER, H. (1987)

Kapitalmarkt, Kapitalbildung und Kapitalallokation, in: Schneider, D. (Hrsg.), Kapitalmarkt und Finanzierung, Berlin, S. 17 - 47

SCHIESWIG-HOLSTEIN (1989)

Landeshaushaltsplan 1989, Kiel

SCHMAH, U. (1967)

Der Einkommensredistributionseffekt der Anleihefinanzierung bei unterschiedlichen Zeitpräferenzen, in: Finanzarchiv, N.F. 26, S. 232 - 237

SCHMIDT, D. (1984)

Das Verfahren zur Gewährung von Mitteln der Gemeinschaftsaufgabe "Verbesserung der regionalen Wirtschaftsstruktur", in: Ebermann, H. (Hrsg.), Handwörterbuch der regionalen Wirtschaftsförderung, Köln, Kap. C1

SCHMIDT, G. (1971)

Das Haushaltsrechtinstitut "Zweckvermögen", in: Der öffentliche Haushalt - Archiv für das öffentliche Haushaltswesen 11, S. 19 - 32

SCHMIDT, R.H. (1981)

Grundformen der Finanzierung - Eine Anwendung des neo-institutionalistischen Ansatzes der Finanzierungstheorie, in: Kredit und Kapital 14, S. 186 - 221

SCHMIDT, R.H. (1986)

Grundzüge der Investitions- und Finanzierungstheorie, 2. Aufl., Wiesbaden

SCHMIDT-BLEIBTREU, B./KLEIN, F. (1983)

Kommentar zum Grundgesetz für die Bundesrepublik Deutschland, 6. Aufl., Neuwied, Darmstadt

SCHMÖLDERS, G. (1959)

"Unmerkliche Steuern", in: Finanzarchiv, N.F. 20, S. 23 - 34

SCHMÖLDERS, G. (1970)

Finanzpolitik, 3. Aufl., Berlin u.a.O. 
SCHNEIDER, D. (1990)

Investition, Finanzierung und Besteuerung, 6. Aufl., Wiesbaden

SCHNEIDER-GÄDICKE, K.H. (1963)

Der öffentliche Kredit an die gewerbliche Wirtschaft, Berlin

SCHOLZ, G. (1984)

Grundgesetz II, Organisationsteil und Allgemeine Staatslehre, 4. Aufl, München

SCHOLZ, G. (1985)

Grundgesetz I, Grundlagen, Die Grundrechte, 5. Aufl., München

SCHOTTER, A. (1981)

The economic theory of social institutions, Cambridge u.a.O.

SCHOTTER, A./SCHWÖDIAUER, G. (1980)

Economics and the Theory of Games: A Survey, in: Journal of Economic Literature 18, S. 479 - 527

SCHRÖDER, G. (1973)

Staatliche Ausfuhrgarantien und Ausfuhrbürgschaften, in: Zeitschrift für das gesamte Kreditwesen 26, S. 664 - 668

SCHULZ, S. (1970)

Die Inanspruchnahme der öffentlichen Hand nach Ausfall eines durch die Kreditgarantiegemeinschaft verbürgten Kredits, in: Der Betrieb 23, S. 336 - 338

SCHUMANN, J. (1987)

Grundzüge der mikroökonomischen Theorie, 5. Aufl., Berlin u.a.O.

SCOTT, I. Jr. (1957)

The Availability Doctrine: Theoretical Underpinnings, in: Review of Economic Studies 25, S. 41 - 48

\section{SEHRBROCK, H. (1981)}

Die Deutsche Siedlungs- und Landesrentenbank - Ein Unternehmensporträt, in: Zeitschrift für öffentliche und gemeinwirtschaftliche Unternehmen 4, S. 108 - 115

SEIDEL, G.W. (1982)

Die Landwirtschaftliche Rentenbank - Porträt eines gemischt-wirtschaftlichen Unternehmens, in: Zeitschrift für öffentliche und gemeinwirtschaftliche Unternehmen 5, S. 396 - 403

SENF, P. (1977)

Kurzfristige Haushaltsplanung, in: Neumark, F. (Hrsg.), Handbuch der Finanzwissenschaft 1, 3. Aufl., S. 371 - 425

SHARPE, W.F. (1964)

Capital Asset Prices: A Theory of Market Equilibrium under Conditions of Risk, in: Journal of Finance 19, S. 425 - 442

SHAVELL (1979)

Risk sharing and incentives in the prinicipal and agent relationship, in : Bell Journal of Economics and Management Science 10, S. 55 - 73 
SHEPARD, W.G. (1976)

Public Enterprise in Financial Sector, in: Shepard, W.G. and Associates, Public Enterprise: Economic Analysis of Theory and Practice, Lexington, S. 185 - 204

SHEPSLE, K.A./WEINGAST, B.R. (1981)

Structure-Induced Equilibrium and Legislative Choice, in: Public Choice 37, S. 503 - 519

SHOUP, C.S. (1972)

The Economic Theory of Subsidy Payments, in: Shoup, C.S., Jasinowski, J., (Hrsg.), The Economics of Federal Subsidies Programs: A Staff Study, Joint Economic Committee, Washington, D.C., S. 55 - 73

SHUBIK, M. (1982)

Game Theory and the Social Sciences, Concepts and Solutions, London, Cambridge, Mass.

SILBER, W.L./BLACK, D.G. (1981)

Subsidies in Government Credit Programs: General Theory with Illustration from the Mortgage Market, in: Congressional Budget Office (Hrsg.), Conference on the Economics of Federal Credit Activity, Part II - Papers, Washington, D.C., S. 111 - 157

SMEKAL, Chr. (1971)

Probleme des öffentlichen Aktivkredits in Österreich, in: Geiger, W. u.a. (Hrsg.), Der wirtschaftende Staat, Festschrift zum 70. Geburtstag von Theo Keller, Bern, Stuttgart, S. 73 $-94$

SPANN, R.M. (1977)

Public versus Private Provision of Governmental Services, in: Borcherding, Th.E. (Hrsg.), Budgets and Bureaucrats: The Sources of Government Growth, Durham, S. 71 - 89

SPENCE, M./ZECKHAUSER, R. (1971)

Insurance, Information, and Individual Action, in: American Economic Review 61, S. 380 $-391$

v.SPIEGEL, H.U. Frhr. (1984)

Die neuen Richtlinien für die Übernahme von Ausfuhrgewährleistungen durch die Bundesrepublik Deutschland, in: Neue Juristische Wochenschrift 36, S. 2005 - 2008

STATISTISCHES BUNDESAMT (1978)

Rechnungsergebnisse des öffentlichen Gesamthaushalts, Fachserie 14, Reihe 3.1, Stuttgart, Mainz

\section{STATISTISCHES BUNDESAMT (1984)}

Rechnungsergebnisse des öffentlichen Gesamthaushalts, Fachserie 14, Reihe 3.1, Stuttgart, Mainz

STATISTISCHES BUNDESAMT (1987)

Rechnungsergebnisse des öffentlichen Gesamthaushalts, Fachserie 14, Reihe 3.1, Stuttgart, Mainz

STATISTISCHES BUNDESAMT (1988)

Lange Reihen zur Wirtschaftsentwicklung, Stuttgart, Mainz 
STIGLER, G.J. (1971)

The Theory of Economic Regulation, in: Bell Journal of Economics and Management Science 2, S. 3 - 21

STIGLITZ, J.E. (1969)

The Effects of Income, Wealth, and Capital Gains Taxation on Risk-Taking, in: Quarterly Journal of Economics 83, S. 263 - 283

STIGLITZ, J.E. (1987)

principal and agent (ii), in: Eatwell, J., Milgate, M., Newman, P. (Hrsg.), The New Palgrave, A Dictionary of Economics 3, London u.a.O., S. 966 - 972

STIGLITZ, J.E./WEISS, A. (1981)

Credit Rationing in Markets with Imperfect Information, in: American Economic Review 71, S. $393-410$

STIGLITZ, J.E./WEISS, A. (1983)

Incentive Effects of Terminations: Applications to the Credit and Labor Markets, in: American Economic Review 73, S. 912 - 927

STOBER, R. (1984)

Zur verfassungsrechtlichen Lage der kommunalen Wirtschaftsverwaltung (Wirtschaftsüberwachung, -förderung und -planung), in: Juristenzeitung 39, S. 105 - 114

STOBER, R. (1987)

Wirtschaftsverwaltungsrecht, 5. Aufl., Stuttgart

STRASSL, W. (1988)

Externe Effekte auf Versicherungsmärkten, Tübingen

SUBVENTIONSBERICHT (1983)

Bericht der Bundesregierung über die Entwicklung der Finanzhilfen des Bundes und der Steuervergünstigungen für die Jahre 1981 bis 1984 gemäß § 12 des Gesetzes zur Förderung der Stabilität und des Wachstums der Wirtschaft (StWG) vom 8. Juni 1967 (Neunter Subventionsbericht), Bundestagsdrucksache 10/352

\section{SUBVENTIONSBERICHT (1985)}

Bericht der Bundesregierung über die Entwicklung der Finanzhilfen des Bundes und der Steuervergünstigungen für die Jahre 1983 bis 1986 gemäß \& 12 des Gesetzes zur Förderung der Stabilität und des Wachstums der Wirtschaft (StWG) vom 8. Juni 1967 (Zehnter Subventionsbericht), Bundestagsdrucksache 10/3821

\section{SUBVENTIONSBERICHT (1987)}

Bericht der Bundesregierung über die Entwicklung der Finanzhilfen des Bundes und der Steuervergünstigungen für die Jahre 1985 bis 1988 gemäß $\S 12$ des Gesetzes zur Förderung der Stabilität und des Wachstums der Wirtschaft (StWG) vom 8. Juni 1967 (Elfter Subventionsbericht), Bundestagsdrucksache 11/1338

\section{SUBVENTIONSBERICHT (1989)}

Bericht der Bundesregierung über die Entwicklung der Finanzhilfen des Bundes und der Steuervergünstigungen gemäß $\S 12$ des Gesetzes zur Förderung der Stabilität und des Wachstums der Wirtschaft (StWG) vom 8. Juni 1967 für die Jahre 1987 bis 1990 (Zwölfter Subventionsbericht), Bundestagsdrucksache 11/5116 
SWOBODA, P. (1989)

The Liquidation Decision as a Principal-Agent Problem, in: Bamberg, G., Spremann, K. (Hrsg.), Agency Theory, Information, and Incentives, Berlin u.a.O., S. 167 - 177

TARLING, R. (1987)

labour markets, in: Eatwell, J., Milgate, M., Newman, P. (Hrsg.), The New Palgrave, A Dictionary of Economics 3, London u.a.O., S.86 - 88

TERBERGER, E. (1987)

Der Kreditvertrag als Instrument zur Lösung von Anreizproblemen, Heidelberg

TERMINOLOGIE-AUSSCHUSS (1954)

Die Definitionen des Terminologie-Ausschusses der Gesellschaft zur Förderung der öffentlichen Wirtschaft, in: Archiv für öffentliche und freigemeinwirtschaftliche Unternehmen 1, S. 276 - 279

THIEMEYER (1975)

Wirtschaftslehre öffentlicher Betriebe, Reinbek bei Hamburg

THIESING, J. (1983)

Kommentar zu Artikel 92 und 93, in: von der Groeben, H., v.Boeckh, H., Thiesing, J., Ehlemann, C.-D. (Hrsg.), Kommentar zum EWG-Vertrag 1, 3. Aufl., Baden-Baden, S. 1568 $-1647$

THOMAS, H. (1989)

Kommentar zu § 765, in: Palandt, Bürgerliches Gesetzbuch, 48. Aufl., München, S. 824 $-827$

TIETZEL, M. (1988)

Ethische und theoretische Probleme interventionistischer Wirtschaftspolitik, in: Cassel, D., Ramb, B.-Th., Thieme, H.J. (Hrsg.), Ordnungspolitik, München, S. 77 - 105

TOBIN, J. (1957/58)

Liquidity Preference as Behavior towards Risk, in: Review of Economic Studies 25, S. 65 $-86$

TOLLISON, R.D./WAGNER, R.E. (1986)

Balanced Budgets and Beyond, in: Buchanan, J.M., Rowley, Ch.K., Tollison, R.D. (Hrsg.), Deficits, New York, S. 374 - 390

TOMA, M./TOMA, E.F. (1980)

Bureaucratic responses to tax limitation amendments, in: Public Choice 35, S. 333 - 348

TRESCH, R.W. (1981)

Public Finance: A Normative Theory, Plano, Georgetown, Ont.

TSCHEBULL, J. (1988)

Sinn und Unsinn der Wirtschaftsförderung, in: Gantner, M., Rinderer, C. (Hrsg.), Staatliche Wirtschaftsförderung: ökonomische Effizienz und politische Rationalität, Frankfurt a.M. u.a.O., S. 19 - 25

TULLOCK, G. (1965)

The Politics of Bureaucracy, Washington, D.C. 
TULLOCK, G. (1972)

Towards a Mathematics of Politics, Ann Arbor

VARIAN, H.R. (1989)

Grundzüge der Mikroökonomik, München, Wien

VAUBEL, R. (1990)

Die Politische Ökonomie des Internationalen Währungsfonds: Eine Public-ChoiceAnalyse, in: Jahrbuch für Neue Politische Ökonomie 9, S. 258 - 281

VIALON, F.K. (1951)

Das Sondervermögen, Eine haushaltsrechtliche Betrachtung, in: Die öffentliche Verwaltung, S. 113 - 117

VICKREY, W. (1983)

Agenda Setting and Social Choice, in: Pfaff, M. (Hrsg.), Public Transfers and Some Private Alternatives during the Recession, Berlin

VOGEL, K. (1977)

Begrenzung von Subventionen durch ihren Zweck, in: Hamburg, Deutschland, Europa, Beiträge zum deutschen und europäischen Verfassungs-, Verwaltungs- und Wirtschaftsrecht, Festschrift für H.P. Ipsen, S. 539 - 554

WAGNER, R.E. (1973)

The Public Economy, Chicago

WAGNER, R.E. (1976)

Revenue Structure, Fiscal Illusion, and Budgetary Choice, in: Public Choice 25, S. 45 - 61

WAGNER, R.E. (1983)

Public Finance, Revenues and Expenditures in a Democratic Society, Boston

WAHL, J. (1987)

Der Einfluß des beamtenrechtlichen Dienstverhältnisses in der Bundesrepublik Deutschland auf das Leistungsverhalten, Regensburg

WALSH, A.H. (1980)

The Public's Business, London, Cambridge, Mass.

WATSON, H. (1984)

Credit Markets and Borrower Effort, in: Southern Economic Journal 50, S. 802 - 813

WEILEPP, M. (1982)

Subventionsabbau tut not - aber wie? in: Wirtschaftsdienst 62, S. 329 - 332

WEST, E.G./WINER, S.L. (1980)

Optimal Fiscal Illusion and the Size of Government, in: Public Choice 35, S. 607 - 622

WESTON, J.F. (1963)

Analysis of the Technical Components of the Federal Credit Programs, in: Federal Credit Programs, A Series of Research Studies, prepared for the Commission on Money and Credit, Englewood Cliffs, N.J., S. 587 - 614 
WHITE, M.M./WHITE, LJ. (1977)

The Tax Subsidy to Owner-Occupied Housing: Who Benefits?, in: Journal of Public Economics 3, S. 111 - 126

WICKSELL, K. (1896)

Finanztheoretische Untersuchungen, Jena

WILDAVSKY, A. (1986)

Budgeting, A Comparative Theory of Budgetary Process, Boston

WILLIAMSON, O.E. (1964)

The Economics of Discretionary Behavior: Managerial Objectives in a Theory of the Firm, London

WILLIAMSON, St.D. (1986)

Costly Monitoring, Financial Intermediation, and Equilibrium Credit Rationing, in: Journal of Monetary Economics 18, S. 159 - 179

WILSON, Ch. (1987)

adverse Selection, in: Eatwell, J., Milgate, M., Newman, P. (Hrsg.), The New Palgrave, A Dictionary of Economics 3, London u.a.O., S. 32 - 34

WINDISCH, R. (1980)

Die Baumolsche Kostenkrankheit öffentlicher Dienste II, in: Wirtschaftsstudium 9, S. 613 $-615$

WIRTSCHAFTSFÖRDERUNGSPROGRAMM BADEN-WÜRTTEMBERG (1985)

Ministerium für Wirtschaft, Mittelstand und Technologie Baden-Württemberg (Hrsg.), Stuttgart

WISSENSCHAFTLICHER BEIRAT (1980)

Gutachten zum Begriff der öffentlichen Investitionen, erstattet vom Wissenschaftlichen Beirat beim Bundesministerium der Finanzen, Schriftenreihe des Bundesministeriums der Finanzen, Heft 29, Bonn

WOLF, C. (1979)

A Theory of Nonmarket Failure: Framework for Implementation Analysis, in: Journal of Law and Economics 22, S. 107 - 139

WOLFF, H.J./BACHOF, O. (1976)

Verwaltungsrecht II, 4.Aufl., München

WONDRAK, B. (1986)

Management von Zinsänderungschancen und -risiken, Heidelberg

WROBEL, B. (1979)

Organisation und Aufgaben kommunaler Wirtschaftsförderungsdienststellen und -gesellschaften, Ergebnisse zweier Umfragen, Berlin

v.WYSOCKI, K. (1961)

Öffentliche Finanzierungshilfen, Köln, Opladen 
ZACHER, F. (1967)

Verwaltung durch Subventionen, in: Veröffentlichungen der Vereinigung Deutscher Staatsrechtslehrer 25, Berlin, S. 308 - 400

ZEITEL, G. (1967)

Staatliche Darlehensgewährung als Mittel der Finanz- und Wirtschaftspolitik, in: Finanzarchiv, N.F. 26, S. 193 - 214

ZEITEL, G. (1977)

Theoretische und technische Aspekte öffentlicher Darlehen und Gewährleistungen, in: Neumark, F. (Hrsg.), Handbuch der Finanzwissenschaft 1, 3. Aufl., Tübingen, S. 997 - 1024

ZEITEL, G. (1982)

Ein ordnungspolitisches Trauerspiel, in: Wirtschaftsdienst 62, S. 428 - 433

ZIMMERMANN, H. (1987)

Der Mitnahmeeffekt, in: Wirtschaftswissenschaftliches Studium 16, S. 339 - 343

ZIMMERMANN-TRAPP, A. (1987)

Kreditanstalt für Wiederaufbau (KfW), in: Wirtschaftswissenschaftliches Studium 16, S. 203 - 205

ZINN, K.G. (1982)

Staatliche Hilfen sind gerechtfertigt, in: Wirtschaftsdienst 62, S. 430 - 433

ZIPPEL, W. (1984)

Die Implikationen der bisherigen und gegenwärtigen Beihilfenpraxis der EG-Kommission für die Zukunft des Gemeinsamen Marktes, in: Börner, B., Neundörfer, K. (Hrsg.), Recht und Praxis der Beihilfen im gemeinsamen Markt, Kölner Schriften zum Europarecht 32, Köln u.a.O., S. 1 - 22 


\section{HOHENHEIMER VOLKSWIRTSCHAFTLICHE SCHRIFTEN}

Band 1 Walter Deffaa: Anonymisierte Befragungen mit zufallsverschlüsselten Antworten. Die Randomized-Response-Technik (RRT). Methodische Grundlagen, Modelle und Anwendungen. 1982.

Band 2 Thomas Michael Baum: Staatsverschuldung und Stabilisierungspolitik in der Demokratie. Zur neoinstitutionalistischen Kritik der keynesianischen Fiskalpolitik. 1982.

Band 3 Klaus Schröter: Die wettbewerbspolitische Behandlung der leitungsgebundenen Energiewirtschaft. Dargestellt am Beispiel der Fernwărmewirtschaft der Bundesrepublik Deutschland. 1986.

Band 4 Hugo Mann: Theorie und Politik der Steuerreform in der Demokratie. 1987.

Band 5 Max Christoph Wewel: Intervallarithmetische Dependenzanalyse in der Okonometrie. Ein konjekturaler Ansatz. 1987.

Band 6 Heinrich Pascher: Die U.S.-amerikanische Deregulation Policy im Luftverkehrs- und Bankenbereich. 1987.

Band 7 Harald Lob: Die Entwicklung der franzősischen Wettbewerbspolitik bis zur Verordnung Nr. 86-1243 vom 01. Dezember 1986. Eine exemplarische Untersuchung der Erfassung der Behinderungsstrategie auf der Grundlage des Konzepts eines wirksamen Wettbewerbs. 1988.

Band 8 Ulrich Kirschner: Die Erfassung der Nachfragemacht von Handelsuntemehmen. Eine Analyse der okonomischen Beurteilungskriterien und der wettbewerbsrechtlichen Instrumente im Bereich der Verhaltenskontrolle.1988.

Band 9 Friedhelm Herb: Marktwirtschaftliche Innovationspolitik. 1988.

Band 10 Claus Schnabel: Zur okonomischen Analyse der Gewerkschaften in der Bundesrepublik Deutschland. Theoretische und empirische Untersuchungen von Mitgliederentwicklung, Verhalten und Einfluß auf wirtschaftliche Größen. 1989.

Band 11 Jan B. Rittaler: Industrial Concentration and the Chicago School of Antitrust Analysis. A Critical Evaluation on the Basis of Effective Competition. 1989.

Band 12 Thomas Märtz: Interessengruppen und Gruppeninteressen in der Demokratie. Zur Theorie des Rent-Seeking. 1990.

Band 13 Andreas Maurer: Statistische Verfahren zur Ermittlung von oligopolistischen Strukturen. 1990.

Band 14 Peter Mendler: Zur okonomischen und politisch-institutionellen Analyse offentlicher Kredithilfen. 1992. 


\section{Alfred H. Klemp}

\section{Öffentliche Finanzhilfen (Subventionen) - Instrumente staatlicher Finanzintervention Eine Untersuchung zum investiven Wirkungspotential und zur Effizienz staatlicher Finanzhilfen}

Frankfurt/M., Bern, New York, Paris, 1990. VII, 205 S., zahlr. Tab. Europäische Hochschulschriften: Reihe 5, Volks- und Betriebswirtschaft. Bd. 1058

ISBN 3-631-41792-6

br. DM 67.--

Eine Politik der Auf- und Ausgabeneinschränkung durch Einnahmeverkürzungen hat die öffentliche Diskussion um Subventionsabbau und -kürzungen wieder belebt. Von daher erschien es sinnvoll, das Thema Subventionen, und zwar in Form der staatlichen (Bund, Länder, ERP) Finanzintervention (Investitionszuschüsse, -zulagen, Schuldendiensthilfen, Darlehensgewährungen) in den privaten Unternehmenssektor, ökonomisch-rational neu anzugehen.

An Fallbeispielen (wirkungsanalytisch) und empirisch wird die Notwendigkeit und Effizienz der an der unternehmerischen Investitionstätigkeit ansetzenden Subventionierung kritisiert: Dauersubventionierung, Subventionswettlauf, Mehrfach- und flächendeckende Förderung, Prestige-Objekt-Förderung (Airbus), etc. sind Symptome, die auch durch wenig konkrete Zielsetzungen der Subventionsgeber mit verursacht werden.

Abschließend werden Maßnahmen und Möglichkeiten (organisatorische Veränderungen, Gesetzesvorbehalt) aufgezeigt, die zu Ausgabenaber nicht zu Aufgabeneinschränkungen führen; sie stehen für eine Neustrukturierung und Umorientierung in der Subventionspolitik: mehr Transparenz und höhere Effizienz bei geringerem Mitteleinsatz.

Aus dem Inhalt: Öffentliche Finanzhilfen zur Stimulierung und Stützung privater Investitionstätigkeit - Wirkungsanalytisch und empirisch feststellbare Effizienzdefizite - Subventionswettlauf, Mitnahme, Mehrfachförderung usw. als sichtbare "Fehlentwicklungen" - Organisatorische Maßnahmen und Gesetzesvorbehalt als Lösungsansatz für eine höhere Subventionseffizienz

Verlag Peter Lang Frankfurt a.M. Bern - New York $\cdot$ Paris Auslieferung: Verlag Peter Lang AG, Jupiterstr. 15, CH-3000 Bern 15 Telefon (004131) 321122, Telex pela ch 912 651, Telefax (004131) 321131

- Preisänderungen vorbehalten - 
Peter Mendler - 978-3-631-75549-5

Downloaded from PubFactory at 01/11/2019 03:40:17AM

via free access 